
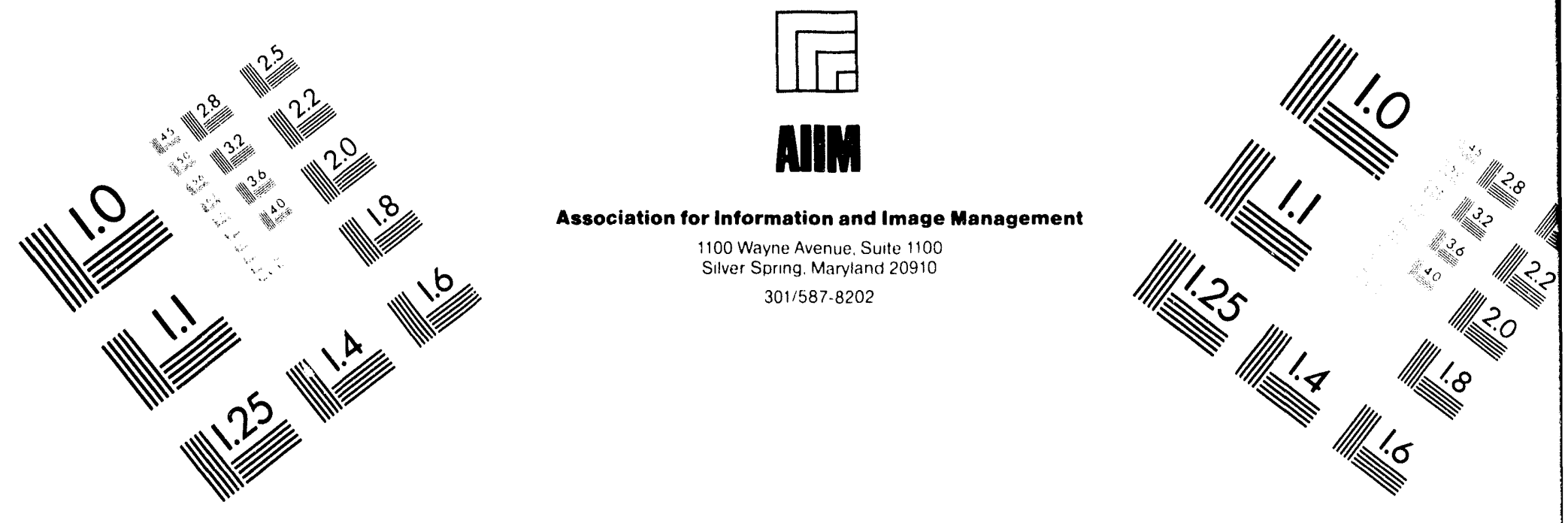

\title{
Centimeter
}

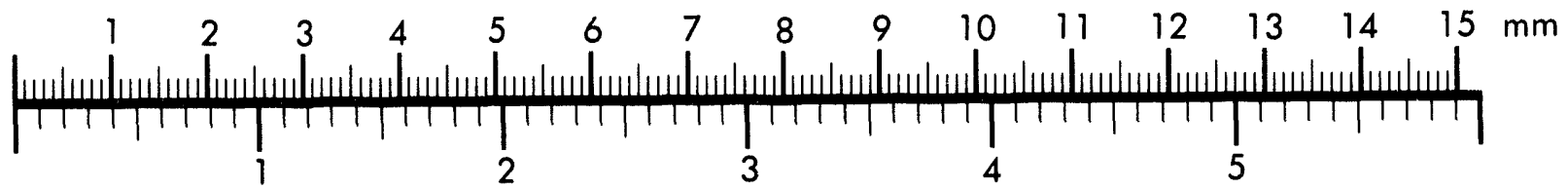
Inches
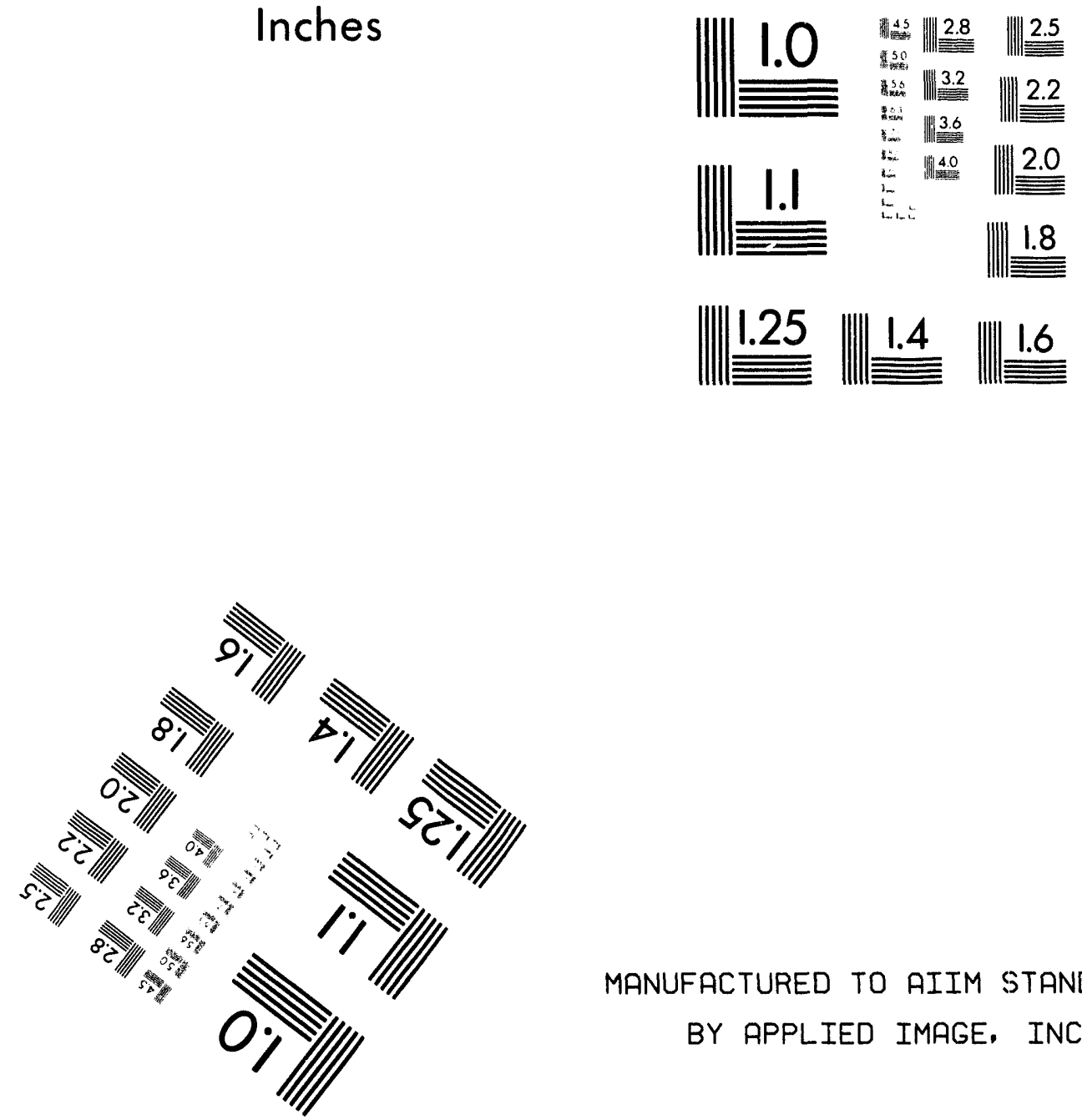

MANUFACTURED TO AIIM STANDARDS

BY APPLIED IMAGE, INC.

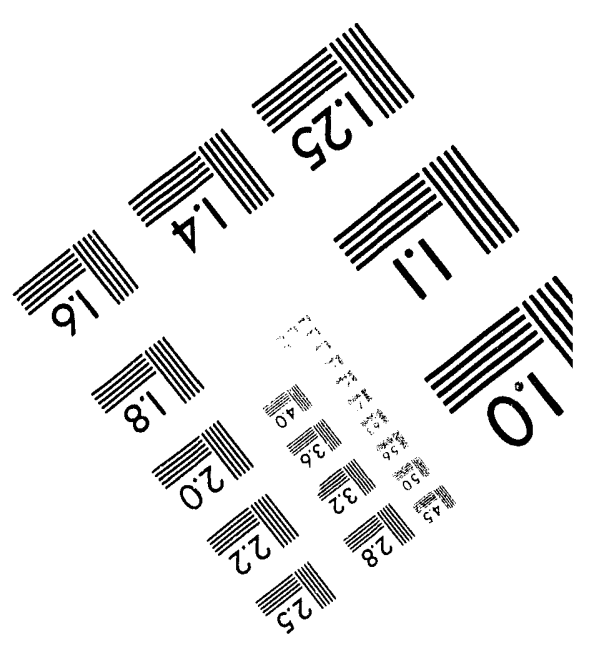



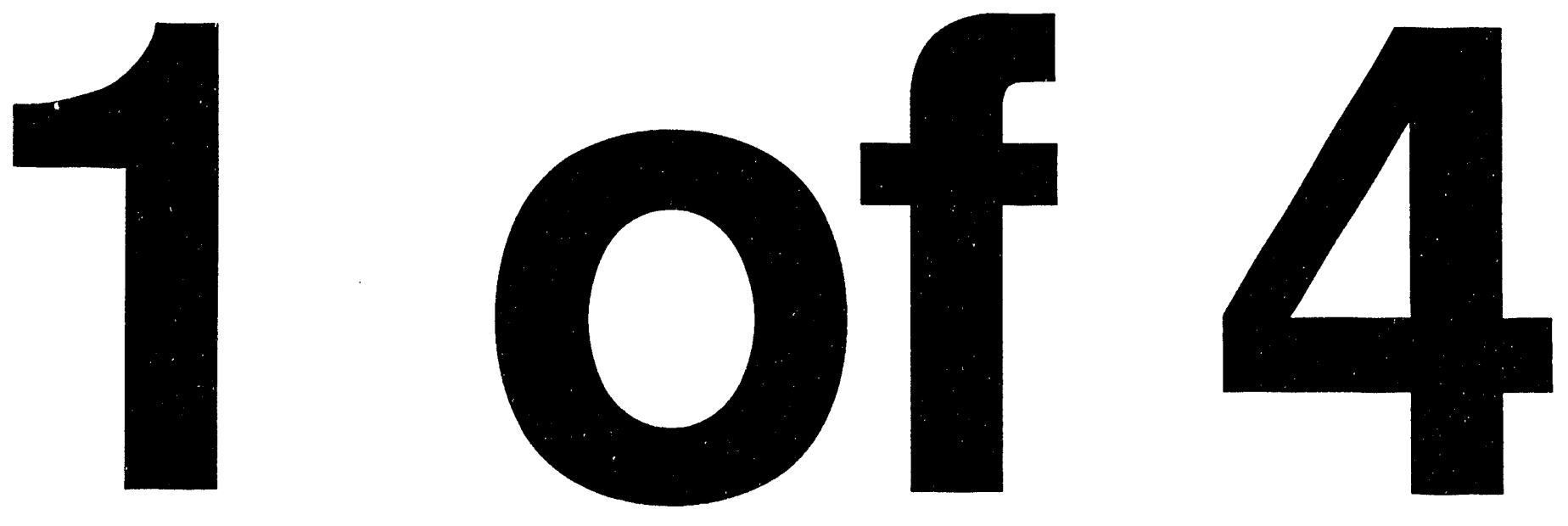


\section{Environmental Sciences Division Annual Progress Report for Period Ending September 30, 1993}

\section{Director}

\section{R. I. Van Hook}

\section{Associate Director}

S. G. Hildebrand

\section{Operations Section Head}

D. E. Fowler

\section{Research Section Heads}

C. W. Gehrs

Environmental Biotechnology

F. E. Sharples

Environmental Analyses

\section{Program Managers}

J. H. Cushman

Biofuels Feedstock

Development Program

Environmental Sciences Division

Publication No. 4211

Date Published: May 1994

Prepared by

Oak Ridge National Laboratory

Cak Ridge, Tennessee 37831-6285

managed by

Martin Marietta Energy Systems, Inc.

for the

U.S. Department of Energy

under contract DE-AC05-84OR21400
D. S. Shriner

Ecosystem Studies

S. H. Stow

Earth and Atmospheric Sciences

P. Kanciruk

Environmental Information

Analysis Program 
List of Technical Summaries

Preface

xvii

Abbreviations and Acronyms

xix

Research Overview

$\mathbf{x x v}$

Significant Accomplishments

$\mathbf{x x x i}$

1 Section Activities 1

Earth and Atmospheric Sciences 3

Introduction 3

Technical Summaries $\quad 10$

Section Staff and Guests $\quad 44$

Ecosystem Studies $\quad 47$

Introduction 47

Technical Summaries $\quad 52$

Section Staff and Guests $\quad 68$

Environmental Analyses $\quad 71$

Introduction 71

Technical Summaries $\quad 74$

Section Staff and Guests $\quad 86$

$\begin{array}{ll}\text { Environmental Biotechnology } & 87\end{array}$

$\begin{array}{ll}\text { Introduction } & 87\end{array}$

Technical Summaries $\quad 92$

Section Staff and Guests 114

$\begin{array}{ll}\text { Division Operations } & 117\end{array}$

Introduction 117

Section Staff and Guests 118 
2 Program Activities $\quad 119$

Biofuels Feedstock Development Program 121 Introduction 121

Technical Summaries $\quad 124$

$\begin{array}{lc}\text { Program Staff and Guests } & 128\end{array}$

Environmental Information Analysis Program $\quad 129$

$\begin{array}{lr}\text { Introduction } & 129\end{array}$

$\begin{array}{ll}\text { Technical Summaries } & 133\end{array}$

Program Staff and Guests 135

$\begin{array}{ll}\text { Environmental Restoration Program } & 137\end{array}$

3 ESD Award Highlights 141

ESD Scientific, Operational, Technical, and Administrative Awards

4 Lists 147

Awards and Honors $\quad 149$

International Activities $\quad 155$

Research and Development Subcontracis and $\begin{array}{ll}\text { Interagency Agreements } & 161\end{array}$

Technology Transfer $\quad 171$

Education Activities $\quad 173$

Affirmative Action $\quad 177$

$\begin{array}{ll}\text { Visitors Hosted } & 181\end{array}$

Conferences Organized or Chaired 183

$\begin{array}{ll}\text { Publications } & 187\end{array}$

$\begin{array}{ll}\text { Presentationis } & 227\end{array}$

Other Professional Ac, jities 255

5 Organization Chart 291

$\begin{array}{ll}\text { Author Index } & 295\end{array}$

$\begin{array}{ll}\text { Photo Index } & 299\end{array}$ 


\section{List of Technical Summaries}

1 New Specifications Are Prepared for Energy

Systems Drilling Services Subcontract

2 Optimization Models Help Site New

Groundwater Monitoring Wells

3 Methodology Is Developed to Validate

Field Data for the Background Soil

Characterization Project

4 Core Analysis Combined with Electromagnetic

Borehole Flowmeter Surveys Is Effective in

Documenting Transmissive Geologic Structures

5 Regional Thrusting Sequence as Evidenced

by the Copper Creek and Whiteoak Mountain

Faults Has Important Implications for

Development of the Southern Appalachian

Thrust Belt

6 Changes in Sedimentary Facies Within the

Basal Maynardville Limestone May Affect

Groundwater Flow Within Bear Creek Valley.

Oak Ridge, Tennessee

7 Porosity Changes and Fractures Are Identified

in Carbonate Rocks by Using Borehole Geophysics

8 Top-of-Rock Topography Was Determined at the

ANS Preferred Site by Using Seismic

Refraction Methods

9 Fracture Mechanics Moreling Indicates That

Folding-Related Extension Fracture Development

Can Vary Across a Thrust Belt

10 Porosity in the Maynardville Limestone Is Dependent

on Lithology and Depth

11 Watershed Sampling Identifies Contaminant

Source Areas 
12 New Method is Demonstrated for Estimating

Exceedance Probabilities of Extreme Floods

13 Second Annual Report of the Environmental

Restoration Monitoring and Assessment

Program Is Published

14 Three-Dimensional Groundwater Flow Model of ORNL

Waste Areas Is Running on the Supercomputer

15 Enriched Deuterium in Oak Ridge Reservation

Groundwaters Results from Natural Processes

16 Chemical Variability of Waters in a Karst Aquifer

Is Used to Detect Quickflow Zones at the

Oak Ridge Y-12 Plant

17 Effectiveness of Three RCRA Caps at the Oak Ridge

Y-12 Plant Is Evaluated

18 Source of Cesium on the Surface of a Sand-Filled

Lysimeter Is Identified

19 Use of Noble Gases as Groundwater Tracers Suggests

That Diffusive Transport Is of Great Importance

in Sandy Aquifers

20 Novel Soil Sampling and Field Screening Techniques

Are Applied at Acid Canyon in Los Alamos, New Mexico

21 Geographic Information System Is Used to Conduct

Hydrological Data Analysis

22 Mass and Volume Balance Constraints Are Used

to Evaluate Water Vapor Behavior During

In Situ Vitrification

23 Thermal History of an Artificial Magma Is Modeled by Using Pseudobinary Thermodynamics C supled with Heat Conduction 
24 Crystallization of an Artificial Magma Created by In Situ Vitrification Is Accurately Simulated

by Thermodynamic Modeling

25 Organic Chelates Alter the Fate and Transport of Inorganic Contaminants Through

Subsurface Environments

26 Field-Scale Tracer Mobility During Storm Events Indicates the Importance of Multiregion Flow and Transport in Natural Subsurface Environments

27 Three-Dimensional Model of Fluid Flow and Multispecies Hydrogeochemical Transport Is Being Developed and Validated

$28{ }^{244} \mathrm{Cm}$ and ${ }^{241}$ Am Activities in Well 516 at SWSA 5 North Are Rlated to Hydrological Conditions in Waste Trenches

$29{ }^{244} \mathrm{Cm}$ and ${ }^{241}$ Am Activities in Well 516 at SWSA 5 North May Be Associated with Low Molecular Weight Organic Material

30 Mercury(II) Adsorption in the Presence of lodide Is Examined

31 Technique Is Developed for Field Analysis of Mercury in Water

32 First National Symposium on Measuring and Interpreting VOCs in Soils Documents Urgent Need for Change

33 In Situ Treatment of Contaminated Soil Uses Physicochemical Processes in a Continuously Mixed Subsurface Soil Reactor

34 Automated pH Control System Saves Transport and Treatment Costs for Waste Management Operations 
35 Cryogenic Immobilization of Tritiated Groundwater Is Studied

36 Subsurface Contaminant Availability Is Measured, and Oxidation and German Recirculation Technologies Are Evaluated

37 Soil Containing ${ }^{137}$ Cs Can Be Decontaminated

38 Background Soil Characterization Project Provides Data for Risk Assessment of Contaminated Sites

39 Microplots and Rainfall Simulators Simultaneously Measure Runoff Losses of Contaminant and Sediment Transport During Storms

40 Grouting of Low-Level Radioactive Waste Disposal Silos Is Completed

41 Interaction Between Vegetation and Soil Is Influenced by Global Change

42 Interhemispheric Ocean Carbon Transport Affects Global Carbon Cycle

43 Terrestrial Biosphere Response to Land-Use Change and Increasing Atmospheric $\mathrm{CO}_{2}$ Is Studied

44 Mercury Emission Rates over Contaminated Soils Are Measured

45 Throughfall Studies in the Smoky Mountains Indicate Significant Effects of Forest Canopy Gaps and Edges on Atmospheric Deposition

46 Partitioning and Removal of Radionuclides in Conventional Wastewater Treatment Plant Are Investigated

47 Data on Water Quality in Upper Bear Creek Support Recommendation to Reduce Monitoring Effort at BCK-12.46 
48 Correlation of the Ellsworth Mountains with

Transantarctic Mountains Helps Explain the Changing Geography of Antarctica

49 Tritium in Groundwater Helps Determine Fluid Mean Residence Times of Valles Caldera Hydrothermal Fluids

50 Coppicing of Yellow-Poplars Does Not Enhance Growth Response to Elevated $\mathrm{CO}_{2}$

51 Nonmethane Organic Compound Emissions from Forest Litter and Soils Represent an Insignificant Carbon Loss from Oak Forests

52 White Oak Responses to Atmospheric $\mathrm{CO}_{2}$ Enrichment Change Over Time

53 Literature Review Provides Information for Data Base on Growth Response of Forests to Atmospheric $\mathrm{CO}_{2}$ Enrichment

54 Thermal Desorption Techniqus Shows Promise for Measuring Trichloroethylene Volatilization Rates and Soil Concentrations

55 Laboratory Studies Show Hardwood Foliage Is a Minor Sink for Metallic Mercury Vapor at Near-Ambient Concentrations

56 Staff Member Provides Fisheries Assistance to DOE's Bonneville Power Administration

57 Optimization Models Help Site New GroundwaterMonitoring Wells

58 Rapid Bioassessment Protocols Help Examine Responses of Benthic Macroinvertebrates to Hydropower

Flow Diversions

59 Chinook Salmon Response to Flow Regulation Is Simulated for Tuolumne River, California 
60 Low Levels of Anthropogenic Radionuclides Are Observed in Alaskan Marine Sediments

61 Atmospheric $\mathrm{CO}_{2}$ Enrichment Increases ${ }^{18} \mathrm{O}$ Content of Leaf Water and Cellulose, Complicates Paleoclimatic and Ecophysiological Studies

62 Hydrologic Model Is Validated for Flood Forecasting

63 Whole-Stream Method to Measure Metabolism Is Developed and Tested in Walker Branch Watershed

64 Whole-Stream Method Evaluates Seasonal Metabolism Changes in Walker Branch

65 Visualization Reveals Data Patterns at Different Scales

66 ORNL Develops Strategic Plan for Water Resources

67 Biomass Energy Technology Could Supply Economical Power to the Tennessee Valley Authority Region

68 OREIS Offers Environmental Restoration Data for Analysis and Planning

69 Beavers Are Active on the Oak Ridge Reservation

70 Case Study of South and Southeast Asia Considers Contribution of Land-Use Change to Atmospheric $\mathrm{CO}_{2}$ Concentrations

71 Individual-Based Model Simulates Growth and Survival in Fish Cohort's First Growing Seisson

72 A Method Is Developed to Analyze Scale-Dependent Changes in Landscape Pattern

73 Life-History Theory and Individual-Based Modeling Provide an Integrated Approach for Cross-Species Comparison of Fish Population Dynamics 
74 Ozone Sensitivity in Northern Red Oak Depends on Growth Stage

75 Environmental Report for the Foothills Parkway Identifies Numerous Rare Species and Sensitive Habitats

76 Effects of Temperature on Growth and Survival of Hydropsyche depravata in East Fork

Poplar Creek Are Determined

77 ESD Helps Prepare Environmental Assessment Sourcebook for EPA

78 Technical Review of Draft CERCLA/NEPA Documentation Enhances Integrity of Remedial Action Decision Process

79 Silvicultural Practices Decrease Carbon Pools in Northern Wetland

80 Level of Environmental Impact from Advanced Oil Recovery Technology Is Similar to That of Current Oil Production

81 ESD Assists DOE in Preparing NEPA Compliance Guide

82 Ecolugical Implications of Geothermal Development in Hawaii Are Studied

83 Visit to Guatemala Lays Groundwork for Increased ORNL Assistance in Environmental Matters

84 Environmental Analyses and Reviews Help the U.S. Antarctic Program Minimize Impacts, Improve Planning, and Comply with Mandates

85 Staff Assist U.S. Army Europe in Environmental Gompliance Activities

86 ESD Aids Air Combat Command in Analyzing Environmental Compliance Deficiencies 
87 Environmental Compliance Group Assists DOE Nevada Field Office in RCRA Compliance

88 Imprint of 1967 Atmospheric Release from Soviet Kyshtym Site is Observed in Analysis of ${ }^{137} \mathrm{Cs}$ Uptake by Terrestrial Biota

89 ESD Helps Prepare ORNL Strategic Plan for Waste Management

90 Aquatic Toxicity Benchmarks Are Developed for Identifying Potential Contaminants

91 Text on Ecological Risk Assessment is Published

92 Characterization of Resources at Six National Laboratories Will Aid Development of Methodology for Ecological Risk Assessment

93 Threatened and Endangered Species Habitats in South Carolina Are Vulnerable to Rise in Sea Level

94 U.S. Southeast Coastlines Are at Risk from Sea-Level Rise

95 Potentially Novel Microorganisms Are Cultured from Deep Subsurface Sediments

96 Source of Groundwater, Not Source of Bacteria, Dominates Assimilation Patterns of Natural Dissolved Organic Matter

97 Movement of PAHs from Soil to Vegetation Is Minimal

98 Innovative Biotreatment System Is Developed to Remove Trichloroethylene from Water

99 Biodegradation of Related Compounds by Bacteria Depends on Chemical Availability 
101 Glutathione S-Transferases from Freshwater Snail Are Purified and Characterized

102 PCB Contamination of Hartwell Lake Adversely Affects

Fish Health and Reproductive Competence

103 Biological Indicators Are Used to Assess Health of Fish Communities Exposed to Pulp Mill Effluents

104 Great Blue Herons Nesting on the Oak Ridge Reservation Are Potentially at Risk from Exposure to Environmental Contaminants

105 Problems Are Noted in Processing Data for Oak Ridge Environmental Information System

106 Advances in Information Technology and Expanded Regulatory Agreements Change Methods of Managing Environmental Restoration Data

107 Transport and Fate of Contaminants in Clinch River and Watts Bar Reservoir System Are Assessed by Using ${ }^{137}$ Cs

108 Technical Review Enhances Integrity of Clinch River Environmental Restoration Data

109 Seasonal Changes in Water Quality Influence Chemical Speciation and Behavior of Arsenic in Freshwater Ecosystems

1:0 Monitoring Provides Results on Contaminant Concentrations and Water Quality

During and After Construction of Sediment-Retention Structure

111 Effluent Dechlorination Does Not Alter Survival or Growth of Clams in East Fork Poplar Creek

112 Total Residual Chlorine Can Affect Mortality Rates of Central Stoneroller and Striped Shiner 
113 Dispersal Study of Dead Fish in Upper East Fork

Poplar Creek Indicates Localized Toxicity

114 Caged Blacknose Dace Are Used to Detect

Mercury in Streams

115 Risk Assessment Methodology Evaluates Likelihood of Adverse Human Health Effects

from Construction Project

116 Raccoons from White Oak Creek Watershed Contain Higher Fur Concentrations of ${ }^{60} \mathrm{Co},{ }^{137} \mathrm{Cs}$. and Mercury

117 Periphyton Communities Sorb Contaminants in Streams

118 Composting Is Assessed as a Method for Ecologically Remediating Soils Contaminated with TNT

119 New Earthworm Soil Toxicity Test Can Improve

Terrestrial Ecological Risk Assessments

120 ESD Assists Four DOE Facilities in Negotiations for NPDES Permits

121 Sediment and Water Toxicity Tests Are Developed to Assess Ecological Risk Off-Site

122 Field-Scale Transport of Natural Organic Matter Is Studied

123 Fish Exposed to High Concentrations of Dissolved Organic Mercury Accumulate Predominantly Methylmercury

124 Biosensors Measure Bioavailability of Sorbed Organic Contaminants

125 Plant-Tissue Culture Systems Can Help Identify Hybrid Poplars Tolerant to Water Stress

126 Osmotic Adjustment to Water Stress in Tolerant Poplar Clones Is Constitured by Potassium, Malic Acid, and Soluble Carbohydrates 
127 Biomass Energy Technology Could Supply Economical Power to the Tennessee Valley Authority Region

128 Environmental Studies of Energy Crops Demonstrate Successful Way to Organize Cooperative Research

129 Atmospheric Radiation Measurement Archive Is Being Developed

130 OREIS Offers Environmental Restoration Data for Analysis and Planning

131 CDIAC Completes Second Volume of Russian-English Climate-Change Bibliographies 


\section{Preface}

This progress report summarizes the research and development activities conducted in the Environmental Sciences Division (ESD) of Oak Ridge National Laboratory during fiscal year (FY) 1993, which extended from October 1, 1992, through September 30, 1993. The report is structured to provide descriptions of current activities and accomplishments in each of the division's major organizational units. Following the sections describing the organizational units are sections highlighting ESD Scientific, Technical, and Administrative Achievement awards and listing information necessary to convey the scope of the work in the division. An organizational chart of staff and long-term guests who were in ESD at the end of FY 1993 is located in the final section of the report. 


\section{Abbreviations and Acronyms}

\begin{tabular}{|c|c|}
\hline $\mathrm{AA}$ & Affirmative Action \\
\hline AAAS & American Association for the Acivancement of Science \\
\hline ACS & American Chemical Society \\
\hline AFS & American Fisheries Society \\
\hline AGU & American Geophysical Union \\
\hline AID & U.S. Agency for International Development \\
\hline ANS & Advanced Neutron Source \\
\hline AOR & advanced oil recovery \\
\hline ARM & Atmospheric Radiation Measurement (Program) \\
\hline ASA & American Society of Agronomy \\
\hline ASCE & American Snciety of Civil Engineers \\
\hline ASEMP & Active Sites Environmental Monitoring Program \\
\hline ASTM & American Snciety for Testing and Materials \\
\hline AWIS & Association for Women in Science \\
\hline AWRA & American Water Resources Association \\
\hline AWU & Associated Western Universities \\
\hline $\mathrm{BCK}$ & Bear Creek kilometer \\
\hline $\mathrm{BCV}$ & Bear Creek Valley \\
\hline BFDP & Biofuels Feedstock Development Program \\
\hline BMAP & Biological Monitoring and Abatement Program \\
\hline BOREAS & Boreal Ecosystem-Atmısphere Study \\
\hline BPA & Bonneville Power Administration \\
\hline BSCP & Background Soil Characterization Project \\
\hline $\mathrm{CAA}$ & Clean Air Act \\
\hline CDIAC & Carbon Dioxide Information Analysis Center \\
\hline CD-ROM & compact disk, read-only memory \\
\hline CEQ & Council on Environmental Quality \\
\hline CERCLA & $\begin{array}{l}\text { Comprehensive Environmental Response, Compensation, and } \\
\text { Liability Act }\end{array}$ \\
\hline CMDL & Climate Monitoring and Diagnostics Laboratory \\
\hline CMS & Clay Minerals Society \\
\hline $\mathrm{CO}_{2}$ & carbon dioxide \\
\hline COMPMECH & compensatory mechanisms in fish populations \\
\hline CRADA & Cooperative Research and Development Agreement \\
\hline CRRI & Clinch River Remedial Investigation \\
\hline CR/WBR & Clinch River/Watts Bar Reservoir \\
\hline CSCE & Canadian Society of Civil Engineering \\
\hline CSSA & Crop Science Society of America \\
\hline CT & critical time \\
\hline CY & calendar year \\
\hline DAAC & Distributed Active Archive Center \\
\hline DEIS & draft environmental impact statement \\
\hline DIM & dissolved inorganic mercury \\
\hline DNA & deoxyribonucleic acid \\
\hline DNAPL & dense nonaqueous phase liquid \\
\hline DOD & U.S. Department of Defense \\
\hline
\end{tabular}




\begin{tabular}{|c|c|}
\hline DOE & U.S. Department of Energy \\
\hline DOE-HQ & DOE Headquarters \\
\hline EA & environmental assessment \\
\hline ECAMP & Environmental Compliance Assessment and Management Program \\
\hline ECG & Environmental Compliance Group \\
\hline $\mathrm{ECO}$ & Environmental Careers Organization \\
\hline EDTA & ethylenediaminetetraacetate \\
\hline EEO & Equal Employment Opportunity \\
\hline EFK & East Fork kilometer \\
\hline EFPC & East Fork Poplar Creek \\
\hline EIS & environmental impact statement \\
\hline $\mathrm{EM}$ & Ellsworth Mountains \\
\hline EMAP & Environmental Monitoring and Assessment Program \\
\hline EMCOM & Environmental Management Career Opportunities for Minorities \\
\hline EOSDIS & Earth Observing System Data and Information System \\
\hline EPA & U.S. Environmental Protection Agency \\
\hline EPRI & Electric Power Research Institute \\
\hline EPSCOR & Experimental Program to Stimulate Competitive Research \\
\hline EPT & Ephemeroptera-Plecoptera-Trichoptera \\
\hline ER & environmental restoration \\
\hline ESA & Ecological Society of America \\
\hline ESL & Environmental Sciences Division \\
\hline FERC & Federal Energy Regulatory Commission \\
\hline FFA & Federal Facilities Agreement \\
\hline FRP & Faculty Research Program \\
\hline FS & feasibility study \\
\hline FY & fiscal year \\
\hline GIS & geographic information system \\
\hline GLCA & Great Lakes Colleges Association \\
\hline GSA & Geological Society of America \\
\hline GSMNP & Great Smoky Mountains National Park \\
\hline GSRP & Graduate Student Research Participation Program \\
\hline GST & glutathione S-transferase \\
\hline GWPO & Groundwater Program Office \\
\hline HAZWRAP & Hazardous Waste Remedial Action Program \\
\hline HBCU & historically black colleges and universities \\
\hline HMCRI & Hazardous Niterials Control Research Institute \\
\hline HQ ACC & Headquarte $;$ of the Air Combat Command \\
\hline HQ USAREUR & Headquarters of U.S. Army Europe \\
\hline IAEA & International Atomic Energy Agency \\
\hline IAWQ & International Association on Water Quality \\
\hline ID & integrated demonstration \\
\hline IGBP & International Geosphere-Biosphere Programme \\
\hline INEL & Idaho National Engineering Laboratory \\
\hline IPCC & Intergovernmental Panel on Climate Change \\
\hline ISV & in situ vitrification \\
\hline IUFRO & International Union of Forest Research Organizations \\
\hline
\end{tabular}




\begin{tabular}{|c|c|}
\hline JGOFS & Joint Global Ocean Flux Studies \\
\hline LANL & Los Alamos National Laboratory \\
\hline LIP & Legal Internship Program \\
\hline LLLW & liquid low-level waste \\
\hline LLW & low-level (radioactive) wacte \\
\hline $\mathrm{MCB}$ & Miscellaneous Chemical Basin \\
\hline MEI & Minority Educational Institution \\
\hline MOU & memorandum of understanding \\
\hline NAACP & National Association for the Advancement of Colored People \\
\hline NADP & National Atmospheric Deposition Program \\
\hline NAEP & National Association of Environmental Professionals \\
\hline NAPAP & National Acid Precipitation Assessment Program \\
\hline NAS & National Academy of Sciences \\
\hline NASA & National Aeronautics and Space Administration \\
\hline NDP & numeric data package \\
\hline NEPA & National Environmental Policy Act \\
\hline NFO & Nevada Field Office \\
\hline NMOC & nonmethane organic compound \\
\hline NOAA & National Oceanic and Atmospheric Administration \\
\hline NOM & natural organic matter \\
\hline NOV & notice of violation \\
\hline NPDES & National Pollutant Discharge Elimination System \\
\hline NPP & net primary production \\
\hline NPS & National Park Service \\
\hline NSF & National Science Foundation \\
\hline NTN & National Trends Network \\
\hline NTS & Nevada Test Site \\
\hline OECD & Organisation for Economic Co-Operation and Development \\
\hline OFA & Office of Federal Activities \\
\hline OHER & Office of Health and Environmental Research (DOE) \\
\hline OPA & Office of Program Assessment \\
\hline ORAU & Oak Ridge Associated Universities \\
\hline OREIS & Oak Ridge Environmental Information System \\
\hline ORISE & Oak Ridge Institute for Science and Education \\
\hline ORNL & Oak Ridge National Laboratory \\
\hline ORP & Oil Research Program \\
\hline ORR & Oak Ridge Reservation \\
\hline ORRHAGS & Oak Ridge Reservation Hydrology and Geology Study \\
\hline OTD & Office of Technology Development \\
\hline P\&A & plugging and abandonment \\
\hline PAH & polycyclic aromatic hydrocarbon \\
\hline PCB & polychlorinated biphenyl \\
\hline PIP & Professional Internship Program \\
\hline PMF & probable maximum flood \\
\hline PNL & Pacific Northwest Laboratory \\
\hline PRC & People's Republic of China \\
\hline PVC & polyvinyl chloride \\
\hline
\end{tabular}




\begin{tabular}{|c|c|}
\hline QA & quality assurance \\
\hline R\&D & research and development \\
\hline RCRA & Resource Conservation and Recovery Act \\
\hline RDS & Reservation Data Systems \\
\hline RFP & request for proposals \\
\hline RI & remedial investigation \\
\hline RIHMI-WDC & $\begin{array}{l}\text { All-Russian Research Institute of Hydrometeorological } \\
\text { Information-World Data Center }\end{array}$ \\
\hline RME & reasonable maximum exposure \\
\hline RNA & ribonucleic acid \\
\hline ROW & Restoring Our Waters (Institute) \\
\hline SAMAB & Southern Appalachian Man and the Biosphere \\
\hline SBIR & Small Business Innovation Research \\
\hline SEED & Summer Education Experience for the Disadvantaged \\
\hline SERDP & Strategic Environmental Research Defense Program \\
\hline SERS & Science and Engineering Research Semester \\
\hline SETAC & Society of Environmental Toxicology and Chemistry \\
\hline SI & Site Investigations \\
\hline SRL & Savannah River Laboratory \\
\hline SRP & Summer Research Program \\
\hline SRS & Savannah River Site \\
\hline SRWC & short-rotation woody crop \\
\hline SSSA & Soil Science Society of America \\
\hline SWSA & solid waste storage area \\
\hline TCE & trichloroethylene \\
\hline TIE & Technology Information Exchange \\
\hline TM & Transarctic Mountains \\
\hline TRAC & Teacher Research Associates \\
\hline TRC & total residual chlorine \\
\hline TTD & time-to-death \\
\hline TTU & Tennessee Technological University \\
\hline TVA & Tennessee Valley Authority \\
\hline USAF & U.S. Air Force \\
\hline USCOLD & U.S. Committee on Large Dams \\
\hline USDA & U.S. Department of Agriculture \\
\hline USFS & U.S. Forest Service \\
\hline USFWS & U.S. Fish and Wildlife Service \\
\hline USGS & U.S. Geological Survey \\
\hline US-IALE & International Association of Landscape Ecology (U.S. chapter) \\
\hline UV-B & ultraviolet-B \\
\hline VAMP & Validation of Assessment Model Predictions \\
\hline VOC & volatile organic compound \\
\hline WAG & waste area grouping \\
\hline WDC-A & World Data Center-A \\
\hline WM & waste management \\
\hline WMO & Waste Management Operations \\
\hline WMO & World Meteorological Organization \\
\hline
\end{tabular}




$\begin{array}{ll}\text { WMRAD } & \text { Waste Management and Remedial Action Division } \\ \text { WMWL } & \text { World Meteoric Water Line } \\ \text { WOC } & \text { White Oak Creek } \\ \text { WOCE } & \text { White Oak Creek Embayment } \\ \text { WOD } & \text { White Oak Dam } \\ \text { WREMCON } & \text { Water Resources and Environmental Management Consortium } \\ \text { WTH } & \text { whole-tree harvesting }\end{array}$




\section{Research Overview}

The mission of the Environmental Sciences Division (ESD) at Oak Ridge National Laboratory (ORNL) is to understand and evaluate how the development and use of energy affect the environment. ESD conducts environmental research and analyses associated with both energy technology development and the interactions between people and the environment.

The division engages in basic and applied research for a diverse list of sponsors. While the U.S. Department of Energy (DOE) is the primary sponsor, ESD staff also perform research for other federal agencies, state agencies, and private industry. The division collaborates with federal agencies, universities, and private organizations in achieving its research objectives and hosts numerous visiting investigators from these organizations.

ESD also has an extensive education program, providing opportunities for research participation and other educational activities in environmental sciences while meeting division programmatic objectives. These activities range from precollege offerings to undergraduate, graduate, and postgraduate opportunities.

Given the diverse interdisciplinary specialization of its staff, ESD provides technical expertise on complex environmental problems and renders technical leadership for major environmental issues of local, national, and global concern. This progress report highlights many of ESD's accomplishments in these and other areas during fiscal year (FY) 1993.

\section{Earth and Atmospheric Sciences Section}

Staff of the Earth and Atmospheric Sciences Section engage in basic and applied research and conduct demonstration projects directed toward understanding and controlling the physical and chemical mechanisms that influence the movement of material through the lithosphere, hydrosphere, and atmosphere. The major areas of emphasis involve geochemistry, geology, geophysics, environmental chemistry, mathematical modeling, soil science, hydrology, atmospheric chemistry, oceanography, and environmental engineering. The scope of the studies includes field characterization, testing and demonstration, laboratory experiments, and mathematical and computer modeling.

The section strives to maintain a balance between basic and applied studies. The staff address issues that are necessary to understand the impact of energy technologies on the environment.

The common theme of most section activities is the study of waste materials and by-proaucts from energy production, and activities span major portions of the energy cycle. Staff of the Earth and Atmospheric Sciences Section are heavily committed to investigating many of the critical issues that are essential in dealing with the cleanup of DOE facilities in order to bring them into environmental compliance. Innovative waste treatment technologies have been developed, including bioremediation of organic contaminants and mercury, as well as oxidation and venting of organic contaminants that occur in soils and 
groundwater. Other major areas of emphasis are modeling of the global carbon cycle, atmospheric chemistry of trace metals, and application of high-performance computing to earth science problems.

\section{Ecosystem Studies Section}

Research in the Ecosystem Studies Section focuses on characterizing the structure and functional relationships of regional landscapes and terrestrial and aquatic ecosystems, communities, and populations. This information is then used to predict the responses of these regions and ecosystems to both natural and human-induced disturbances. Major research areas include theoretical ecology, biogeochemical cycling, hydrosystems, resource analysis, and the physiological ecology of terrestrial plants.

The development of ecological theory is an important underpinning of research in ESD. Staff of the Ecosystem Studies Section develop simulation and mathematical models to describe and predict the behavior of ecological systems. Currently, research in landscape ecolngy and individual-based population modeling is emphasized.

Research on biogeochemical cycling centers on Walker Branch Watershed, where investigations are conducted on the relative importance of hydrogeochemical transport and biogeochemical cycling in the regulation of productivity in forests and streams. Other research investigates the effects of atmospheric deposition in high-elevation red spruce forests. In addition, a project funded by the National Science Foundation focuses on nutrient cycling and stability in stream ecosystems. Important to such research on biogeochemical cycling is the use of light stabie isotopes to study ecological processes.

Research on the physiology of terrestrial plants focuses on the effects that such pollutants as ozone, acid deposition, and nitroge: oxides have on terrestrial systems. A current research emphasis is on investigations into the effects of increased atmospheric $\mathrm{CO}_{2}$ on forests. Researchers in the Ecosystem Studies Section are also tracing the fate of nuclear waste that is disposed of in arctic seas.

Hydrosystems researchers in the section analyze environmental issues associated with hydropower development and assess the compatibility of water allocation strategies with the maintenance of fisheries resources and other important water uses within river basins. Researchers doing resource analysis develop and improve methodologies for evaluating a broad range of issues related to the sustainable development of natural resources, including such alternatives as the large-scale implementation of biofuels technologies.

In addition, researchers in the section are involved in important interactions with thc Tennessee Valley Authority, the Great Smcky Mountains National Park, the Southern Appalachian Man and the Biosphere Program, The University of Tennessee, and many other universities. Major research sponsors include the DOE Environmental Sciences Division, Office of Health and Environmental Research, and the Biofuels Feedstock Development Program; the U.S. Department of Agriculture Forest Service; the U.S. Environmental Protection Agency; the Electric Power Research Institute; the National Science Foundation; the 
Federal Energy Regulatory Commission; and the Martin Marietta Energy Systems, Inc., Environmental Restoration (ER) Division.

\section{Environmental Analyses Section}

The Environmental Analyses Section focuses on interdisciplinary analysis and assessment of environmental problems. In this context, the section develops problemsolving tools, such as methodologies, data bases, and information and policy analyses. The environmental issues addressed cover a range of spatial scales, from individual sites and regional landscapes to the continent and the globe. Various sponsors obtain technical assistance for the development of environmental management and regulatory policies, and technical information and analyses produced by the section also serve as a broader resource for the scientific and technical community.

Researchers in the section prepare impact analyses for DOE, the Federal Energy Regulatory Commission, the Nuclear Regulatory Commission, and the U.S. Department of Defense as part of the agencies' cor spliance with the National Environmental Policy Act (NEPA). Section staff also conduct regulatory analysis and environmental compliance activities in support of such sponsors as the DOE Office of Environmental Guidance, the DOE Office of Environmental Audit, the DOE Office of NEPA Oversight, the Hazardous Waste Remedial Actions Program, and the U.S. Air Force. Other members of the section develop methods for quantitative assessment of environmental risks; apply these methods to local, regional, and national environmental problems; and guide regulatory agencies on the uses of environmental risk assessment.
For the DOE Office of Energy Research, members of the Environmental Analyses Section provide information, data, and analytical capabilities essential to performing comprehensive, resourceintensive regional- and global-scale evaluations of increases in radiatively active trace gases in the atmosphere

("greenhouse" gases) and the potential effects of such increases on environmental and societal resources. The single largest function in this area is to operate the Carbon Dicxide Information Analysis Center in support of the DOE Global Change Research Program, and the World Data Center-A for Atmospheric Trace Gases, a component of the International Council of Scientific Unions' World Data Center System.

\section{Environmental Biotechnology Section}

The Environmental Biotechnology Section performs basic and applied research on the mechanisms that influence the response of biological systems to contaminants, the effects that the receiving systems have on the availability and distribution of materials to which they are exposed, and the modification of biological systems to enhance degradation or immobilization of contaminants. Research is conducted at different levels of biological organization, from the subcellular and biochemical to the ecosystem level, using experimental, observational, and simulation studies. Researchers investigate the roles of molecular, biochemical, and physiological processes in regulating the bioaccumulation of contaminants and assess the adverse environmental effects of these contaminants.

Section activities center on the ecological response of Oak Ridge Reservation (ORR) streams to waste management and 
cleanup activities and on the development of capabilities for predicting the direct and indirect effects of contaminants released into the environment. Research addresses the sources of acute and chronic toxicity in wastewaters and on ORR streams and includes the development of innovative in situ and laboratory tests to quantify and assess toxicity.

Other areas of research include the transport, fate, and biogeochemistry of contaminants in the aquatic environment, particularly in the off-site environs. In addition, section staff fulfill data management responsibilities for ER projects conducted at Energy Systems facilities and participate in a major effort to combine molecular biology and traditional microbiological tools to investigate the degradation of soil and groundwater contaminants.

\section{Biofuels Feedstock Development Program}

The Biofuels Feedstock Development Program's goal is to develop and demonstrate environmentally acceptable and commercially viable biomass supply systems based on energy crops. The program emphasizes perennial energy crops, both woody and herbaceous, suitable for use in the major cropproducing regions of the United States. A national program supported by DOE's Office of Transportation Technologies, the Biofuels Feedstock Development Program includes cooperators in the private sector, universities, other DOE laboratories, and other government agencies.

Resource assessment, environmental analysis, economic studies, and basic physiology and genetic research are performed largely within ESD and
ORNL. Research on specific crops, including scale-up plantings and regional or site-specific environmental research, is primarily conducted by cooperators and subcontractors including universities and the U.S. Department of Agriculture. The Biofucls Feedstock Development Program's energy crop development efforts are closely coordinated with the National Renewable Energy Laboratory's research on advanced biomass conversion technologies.

In FY 1993, the Biofuels Feedstock Development Program had five major research and analysis components-Model Wood Energy Species, Model Herbaceous Energy Species, Environmental Research and Analysis, Economic Analysis and Integration, and Energy Crop Data and Information Management. The Tennessee Valley Authority sponsored the development of energy crop supply curves for the Tennessee Valley and related regions. Other program efforts included participation in the International Energy Agency's biomass production activities, cooperation with the U.S. Congress's Office of Technology Assessment on biomass energy assessments, and participation in the National Biofuels Roundtable sponsored by the Electric Power Research Institute and the National Audubon Society.

\section{Environmental Information Analysis Program}

The Environmental Information Analysis Program supports large, integrated environmental data base projects with extensive data analysis components. The management of research data has become a vital component of modern observational and theoretical science. The significant global change projects of the 1990s-such as the DOE Atmospheric Radiation 
Measurement (ARM) project; the DOE Computer Hardware, Advanced Mathematics and Model Physics project; and the National Acronautics and Space Administration's (NASA's) comprehensive Earth Observing System Program-have large data management components that are vital to their success. The ability to intelligently manage and analyze substantial environmental data sets is one of the division's historically unique capabilities.

The program currently consists of the Carbon Dioxide Information Analysis Center, which supports DOE's Global Change Research Program and operates the World Data Center-A for Atmospheric Trace Gases as part of the International Council of Scientific Unions' World Data Center System; the ARM Archive, which supports the DOE ARM project; the NASA Distributed Active Archive Center, which supports NASA's Earth Observing System Program; and the Oak Ridge Environmental Information System, which supports the data needs of local restoration efforts at DOE facilities in Oak Ridge.

\section{Environmental Restoration Program}

ESD's ER Program is a multidisciplinary effort that draws on staff from all the research sections. Nationwide, DOE has initiated a massive undertaking to assess the nature and extent of contamination resulting from its past operations and to clean up, or remediate, the contaminated soils, bedrocks, and waters that pose risks to human health and the environment.
ESD staff play key roles in addressing the ER needs at all five sites managed by Martin Marietta Energy Systems, Inc. (ORNL, the Oak Ridge Y-12 Plant the Oak Ridge K-25 Site, the Portsmouth Gaseous Diffusion Plant, and the Paducah Gaseous Diffusion Plant), as well as in the surface-water system downstream from the Oak Ridge facilities.

ESD staff are involved in diverse ER activities. Many tasks are field oriented, requiring geologic, hydrologic, and aquatic ecologic staff; others are laboratory-based or use ORNL's high-speed computational systems.

The challenges associated with the ER Program at Oak Ridge are immense, perhaps greater than those at any other DOE facility in the country. Not only have myriad types of materials (e.g., radionuclides, organic compounds, and hazardous metals) been released to the environment over the past 50 years, but virtually all disposal methods were used. Furthermore, the underlying geologic and groundwater systems at Oak Ridge are the most complex of all the DOE sites, and rainfall is abundant here: thus, the ER needs at Oak Ridge are great.

Fortunately, the ER efforts can draw on the long history of basic environmental research that resides in ESD, for the technical questions that must be answered to effectively remediate the environment are not ones that can simply be answered by conventional technologies. Largely because of ESD's coupling of basic and applied research, the ER effort in ESD has grown significantly in recent years. 


\section{Significant Accomplishments}

During FY 1993, ESD reported numerous technical accomplishments, the most significant of which are listed here.

- Researchers measured mercury emission rates over contaminated soils by using the modified Bowen ratio method of micrometeorology.

- The background soils project provided data for the risk assessment of contaminated sites.

- Researchers showed that in situ treatment of contaminated soil can be achieved by using physicochemical processes in a continuously mixed subsurface soil reactor.

- Scientisis accurately simulated the crystallization of an artificial magma from in situ vitrification through the use of thermodynamic modeling.

- The first definitive reports on the geology and the hydrology of the Oak Ridge Reservation (ORR) were issued.

- Researchers initiated a stand-level experiment at Walker Branch Watershed whereby soil moisture is manipulated to study how organisms and ecosystems adapt to changes in climate. The study is evaluating the effects of the changes on the plant, pest/pathogen, and microbial processes that drive carbon-, water-, and nutrientcycling budgets.

- Scientists found that increase in growth efficiency is a reliable indicator of the degree to which forests sequester carbon in response to elevated levels of $\mathrm{CO}_{2}$. Reliance on plant dry mass as a predictor of the long-term response obscures basic similarities across species and sites.

- A multidisciplinary team from ESD and ORNL's Energy Division revised a draft environmental impact statement studying the effects of nine hydroelectric projects proposed for the Skagit River Basin in Washington.

- At the Eighth Annual U.S. Landscape Ecology Symposium, staff presented a paper on the probable environmental impacts of growing energy crops in the Tennessee Valley Authority (TVA) region. Their preliminary modeling work suggests that erosion, evapotranspiration, and nitrate loss through runoff will decrease as switchgrass increasingly replaces other crops.

- For the fifth consecutive year, staff members studied postfire vegetation dynamics in Yellowstone National Park, measuring species richness, percent cover, and the density of selected species at nearly 700 sampling points distributed in 9 study areas (1-3600 ha in size) across the subalpine plateau. In addition, researchers conducted pilot studies on the broad-scale distribution of aspen seedlings and plant reestablishments in "double burns" (sites previously burned within 15 years).

- The U.S. National Academy of Sciences established World Data Center-A for Atmospheric Trace Gases at ORNL. The new center will be integrated into the Carbon Dioxide Information Analysis Center to manage critical data related to the cycling of trace gases. 
- Staff members assisted the U.S. Air Force's Air Combat Command by identifying serious recurring environmental compliance deficiencies as part of the Air Force's Environmental Compliance Assessment and Management Program. Future activities will focus on developing tools to solve recurring problems throughout the command.

- Staff directed an expert peer review of models of northwest salmon populations to evaluate their strengths and weaknesses. Impartial evaluation is important because competing models are used as references in legal actions and in developing strategies for protecting and enhancing endangered salmon of the Columbia River Basin.

- ESD staff developed an environmental assessment sourcebook for the U.S. Environmental Protection Agency (EPA) Office of Federal Activities to satisfy the office's increasing need to answer requests for information. The sourcebook emphasizes generic elements of the environmental assessment process and will be useful to decision makers at all levels of government, both nationally and internationally.

- Staff assisted the DOE Office of NEPA Oversight in revising its NEPA Compliance Guide. The guide allows DOE staff and contractors to understand and comply with the letter and spirit of the National Environmental Policy Act.

- Scientists studied the field-scale transport of natural organic matter (NOM) at a site in Georgetown, South Carolina. Results confirmed that the macroscopic transport of NOM is consistent with mechanistic studies of NOM adsorption and desorption. The results have implications for contaminant transport because the components of NOM have different affinities for binding and thus potentially for cotransporting organic and inorganic contaminants.

- Researchers examined subsurface environments at DOE installations and in Taylorsville Triassic Basin sediments $>2500 \mathrm{~m}$ beneath the land surface. The investigation resulted in the culturing of microorganisms that appear to be distinct from known taxa. Knowledge of the survival and transport of microb/es and the utility of subsurface microorganisms for contaminant remediation provides an important base on which to evaluate a site's potential for bioremediation.

- Scientists developed a rapid and efficient method for assessing bacterial growth and used it to determine the bioavailability of NOM from groundwater sources. Researchers discovered that the source of groundwater, not the source of bacteria, dominates the assimilation patterns of dissolved NOM. The experiments yield information on factors controlling microbial populations in the subsurface and will yield insights into how to increase microbial growth as part of the bioremediation of hazardous waste sites.

- The cause of a fish kill at the Oak Ridge Y-12 Plant in December 1993 was determined with assistance from Y-12 Plant personnel.

Researchers identified a small spring as 
the most probable source of ammonia from an upgradient urea storage area, and measures were promptly implemented to minimize or eliminate area runoff into the stream.

- As part of a Cooperative Research and Development Agreement (CRADA) between Martin Marietta Energy Systems, Inc., and Envirogen, researchers demonstrated an innovative system for the biological remediation of groundwater containing trichloroethylene.

- The Biofuels Feedstock Development Program (BFDP) joined TVA and The University of Tennessee in a biomass resource assessment for the Tennessie Valley and related regions. BFDP staff developed supply curves on shortrotation woody crops and estimates of associated changes in regional erosion and pesticide and fertilizer use.

- In studies for BFDP, researchers identified metabolites and inorganic ions that constitute osmotic adjustment to water stress in clones of black cottonwood, eastern cottonwood, and their hybrid progeny. The findings led to a proposed CRADA for FY 1994 with an industrial partner to validate the results in a large-scale field trial, including a wide variety of clones of diverse origin.

- ESD initiated the development of the Distributed Active Archive Center for Biogeochemical Dynamics at ORNL for the National Aeronautics and Space Administration's Earth Observing System Data and Information System. Key staff were hired for populating the data base, developing the user interface, and interacting with the scientific research community.
- Staff with the Oak Ridge Environmental Information System (OREIS) revised the OREIS model and data dictionary, developed software that integrates commercial software (Oracle, SAS, and ARC/INFO) to meet user specifications, and provided regulators with data packages based on environmental restoration reports for the Clinch River, East Fork Poplar Creek, and ORNL Was: Area Grouping 1.

- The Groundwater Program Office continued to provide all five Energy Systems facilities with technical guidance and support during the year. As part of the activity, two benchmark documents were issued dealing with the very complex geology and hydrology of ORR.

- Two in situ field remediation demonstrations were completed during FY 1993: the X-231B soil remediation experiments at the Portsmouth Gaseous Diffusion Plant, in which volatile organic compounds were successfully removed by a variety of techniques, and the in situ vitrification test at ORNL, where a full field-scale application is planned for the pits and trench area.

- Staff completed a data summary report and a screening-level risk assessment for the first phase of the Clinch River/Watts Bar Reservoir Remedial Investigation. In addition, staff devised a sampling and analysis plan for the final phase of the investigation. The plan was approved by the State of Tennessee and EPA. Sampling of sediment, water, and fish began in August 1993.

- Researchers analyzed the movement of radionuclides from seeps along White 
Oak Creek and identified ${ }^{90} \mathrm{Sr}$ and ${ }^{3} \mathrm{H}$ fluxes from the southern boundary of Waste Area Grouping 5 as the single most significant contributor to the total radionuclide flux at White Oak Dam under baseflow conditions. This finding led the Environmental Restoration

Program to initiate an interim corrective action to reduce potential off-site risk by intercepting and treating the seep fluxes before they enter the creek. 


\section{Earth and Atmospheric Sciences}

\section{Introduction}

Staff in the Earth and Atmospheric Sciences Section of the Environmental Sciences Division (ESD) at Oak Ridge National Laboratory (ORNL) conduct basic and applied research on interdisciplinary problems related to the broad field of earth sciences. Most of the section's research focuses on managing energy-related waste materials. Field, laboratory, and computer-based investigations support these efforts.

Research is directed toward understanding the factors that control the movement of materials through the solid earth, the hydrosphere, and the atmosphere. Major sponsors include the U.S. Department of Energy (DOE) [the Office of Health and Environmental Research, the Office of Technology Development, Environmental Restoration (ER), Defense Waste and Environmental Restoration, the Oak Ridge Y-12 Plant, the Paducah and Portsmouth gaseous diffusion plants, and other national laboratories]; the Tennessee Valley Authority; the U.S. Geological Survey; the Elcctric Power Research Institute; and the U.S. Environmental Protection Agency (EPA).

\section{Atmospheric and Geochemical Processes}

The Atmospheric and Geochemical Processes Group performs basic research designed to quantify and to understand the processes that influence the transport, transformation, deposition, and fate of materials released into the environment. This research encompasses the fields of atmospheric, marine, freshwater, and soil sciences. Primary areas include the atmospheric chemistry and deposition of trace metals, air-surface exchange and its role in biogeochemical cycling, and processes controlling the transformation and mobility of radionuclides and other contaminants in aquatic and soil systems.

During FY 1993, staff of the Atmospheric and Geochemical Processes Group performed the first-ever direct flux measurements of mercu $y$ from contaminated soils under field conditions. Staff designed a unique mass-flow controlled sampling system and combined it with a newly developed micrometeorological method for trace gas fluxes that uses concentration gradients. The work was reported at an international conference, several university seminars, and a program review and is in press in open literature.

\section{Earth Svstems Modeling}

The Earth Systems Modeling Group develops, applies, and evaluates mathematical models used in addressing local-, regional-, and global-scale environmental issues. Current research emphasizes the development of new models and the examination and integration of disparately scaled existing models to comprehensively address global carbon dynamics. This work is designed to increase understanding of the global carbon cycle and to forecast the effects of changes in atmospheric carbon emissions on global climate and ecological resources during the next century. Group interests also include quantification of the implicatic s of model uncertainties on model performance. Sensitivity and uncertainty analyses are used to evaluate performance and to place model forecasts in the context of global risks. Earth 
systems modelers use an innovative synthesis of techniques to address problems in mesoscale, regional, and global modeling.

The Earth Systems Modeling Group seeks to improve our understanding of the earth's major dynamic systems, climate, and the global biogeochemical cycles through the development and analysis of comprehensive earth systeins models. The group's research objectives address major issues within the U.S. Global Change Research Program. These objectives include clarifying the relationship between fossil fuel emissions and changes in atmospheric greenhouse gas concentrations, analyzing means of decreasing greenhouse gas emissions or compensating for emissions by increased elimination from the atmosphere, and assessing ways in which climatic change resulting from greenhouse gas increases can affect the carbon cycle and its control of atmospheric $\mathrm{CO}_{2}$ concentration. The group also addresses interactions between the global biogeochemical cycles and the potential impacts of global environmental change on terrestrial and marine ecosystems. DOE, EPA, and the National Aeronautics and Space Administration fund group projects. Group members participate in activities of the International Geosphere-Biosphere Program and assessments of the Intergovernmental Panel on Climate Change.

During FY 1993, the Earth Systems Modeling Group completed a number of major tasks, including estimation of the latitudinal distribution of fossil fuel emissions and their isotopic content, analysis of the influence of plant growth response to increases of atmospheric $\mathrm{CO}_{2}$ on estimates of carbon releases into the atmosphere because of land use, development of an oceanic radiocarbon inventory for model testing, and implementation of an oceanic general circulation model for carbon cycle analysis.

\section{Energy Systems Groundwater Program}

The Groundwater Program Office (GWPO) provides coordination for all groundwater activities at the five DOE facilities managed by Martin Marietta Energy Systems, Inc. The program's primary objective is to develop a consistent approach to ensure that applicable state or federal environmental laws and relevant DOE orders are satisfied and that the environment and the health of the public are protected. GWPO, working through Groundwater Coordinators at each of the sites, provides management support to achieve these goals.

The Oak Ridge Hydrology Support Program offers technical expertise to the five Energy Systems plants in the broad areas of hydrology and geology. Two principal groups make up this program. The first consists of hydrologists who advise the groundwater programs on groundwater and surface water issues related to ER and regulatory compliance. The second group is directed toward understanding fundamental hydrogeologic principles related to groundwater flow and remediation in fractured rock systems such as those that dominate the Oak Ridge Reservation (ORR).

During FY 1993, the Energy Systems Groundwater Program continued to supply technical oversight and direction to the groundwater programs at the five facilities operated by Energy Systems for DOE. This included daily interactions by our Technical Support staff, as well as participation in a variety of ad hoc 
activities (e.g., evaluation of a proposed pilot pump-and-treat project at Paducah). In June 1993 our Technical Support staff member for Portsmouth was appointed Acting Groundwater Program Manager at that site until a permanent replacement is found.

Several additional activities of Groundwater Program staff are worthy of note. For example, we issued an update to the ORR conceptual groundwater flow model, a report on ORR geology that includes a new geologic map of the reservation, and a series of reports concerning groundwater geochemistry at the Oak Ridge Y-12 Plant. Furthermore, many staff members participated, either as presenters or session chairs, in the technical program of the Fourth Environmental Restoration Technical Information Exchange meeting held in Knoxville in May 1993. Research staff associated with the program also sponsored a brine workshop in September 1993. This workshop brought together recognized experts on brines to consider the origin of brines underlying ORR and their potential importance to contaminant migration.

\section{Environmental Engineering}

The Environmental Engineering Group performs basic and applied research related to ER and waste management (WM). This research involves process modeling, benchand pilot-scale experimentation, and fullscale field experimentation and demonstration activities. Current emphasis includes research of processes controlling the measurement, behavior, and treatment of contaminants in waste deposits and in contaminated soil and groundwater systems. Staff conduct research on environmental monitoring technologies and assessment strategies, spatial modeling of contaminant distributions, process modeling of physicochemical treatment systems, and in situ treatment by physicochemical and biological processes. Research is also directed toward the development of critical enabling technologies, including in situ recirculation systems, fracture emplacement methods, and mixed-region subsurface reactors. Increasing efforts are placed on field-scale research and on the demonstration of emerging ER technologies at sites across the United States and abroad.

During FY 1993, the group continued work on proposals to DOE and EPA, provided support to DOE Headquarters for the Integrated Program for In Situ Remediation, continued documentation of the successful X-231B Technology Demonstration, and supported the next phase involving full-scale implementation at the DOE Portsmouth site. The group also completed a project studying in situ recirculation technologies for treatment of volatile organic compounds in groundwater under sponsorship of the DOE International Technology Exchange Program, completed the first phase of an EPA-sponsored project studying the development and implementation of nationally consistent cleanup goals for contaminated sites, and continued studies in colloid transport and fate in groundwater systems and chemical oxidation of contaminated soils-including those contaminated by polycyclic aromatic hydrocarbons from an old coal gasification site. Some major initiatives were the study of stability of organic compounds in contaminated soil and groundwater, a collaborative study with the American Petroleum Institute, a project to study the cryogenic immobilization of ${ }^{3} \mathrm{H}$ in seepage, and studies of in situ treatment of groundwater by using peat and peat mixtures in reactive barriers. 
The group also continued to give ad hoc support to ER and WM at ORNL, Y-12, Portsmouth, and Paducah sites, establish laboratory research facilities to further research and development in areas of ER and WM, organize and chair several symposiums, make presentations, and publish several articles. One group member was awarded the Rocha Medal for research in fracture mechanics after an international competition.

\section{Geology and Geophysics}

The Geology and Geophysics Group deals with field-based geologic and geophysical aspects of WM. Principal emphasis is on the elucidation of geologic principles that are important in quantifying groundwater flow, the characterization and evaluation of waste disposal sites, and geologic mapping. Specific topics include analysis of structural and lithologic controls on groundwater flow paths, development and application of nonintrusive surface and borehole geophysical techniques to geologic problems in WM areas, and geologic characterization of ORR and other DOE sites.

This year the Geology and Geophysics Group began several new research initiatives directed toward two broad-based goals: (1) to develop noninvasive geophysical techniques for investigating WM areas and (2) to evaluate geologic properties of fractured sedimentary rocks that control groundwater flow and contaminant transport. Moreover, the group is providing support on ongoing sitespecific investigations and thereby expanding the geologic and geophysical data base. As part of that effort, geophysical logging evaluation techniques are being developed to research the integrity of well casings.
Noninvasive geophysical studies include a helicopter-based aerial survey of ORR that was conducted to assess techniques for reconnaissance and detailed characterization of WM areas. The survey results are used to evaluate the presence and extent of contaminants, as well as to integrate the geophysical signature of ORR with geologic mapping data. An instrumented model airplane is being used to develop additional airborne geophysical reconnaissance techniques. Surface seismic investigations are being conducted to define large-scale geologic structures that influence local and regional groundwater flow systems.

Geologic property investigations seek to understand rock matrix properties that control contaminant storage and to define hydrologically important fracture parameters and spatial changes in fracture networks. These studies are both laboratory and field-based and take advantage of a growing ORR data base of core borehole geophysical and hydrologic data. Matrix porosities are being evaluated and calibrated through a combination of laboratory, geophysical, and petrographic measurements. Fracture network studies identify lateral and vertical changes in the system and evaluate the origin of the networks in terms of rock properties and geologic history. Results of these studies are being integrated into conceptual and numerical groundwater flow models. The results aiso provide the framework for developing conceptual and analytical models for the transport of dense, nonaqueous phase liquids in sedimentary rocks.

\section{Groundwater Hydrology}

The Groundwater Hydrology Group addresses technical problems related to the preservation and restoration of 
groundwater quality. Staff activities include application of complex numerical models to simulate multiphase flow of fluids in porous and fractured systems, design and operation of groundwater monitoring systems, characterization of large-area hydrologic properties, use of artificial tracers and natural groundwater chemistry to study transport processes, and studies of interactions with surface water and groundwater. The primary strength of the group lies at the interface between modeling and field activities. Field work is directed at understanding flow mechanisms in complex subsurface systems. Research topics include the effects of fracture flow systems on the dynamic storage and release of pollutants, development of innovative drilling and sampling methods, and disect measurement of rates of recharge by means of groundwater dating with ${ }^{3} \mathrm{H}$ and ${ }^{3} \mathrm{He}$. Modelers within the group are adapting the extensive ensemble of ORNL groundwater models to massively parallel computers and exploring new modeling techniques on these computers.

\section{Soil Science}

The Soil Science Group conducts applied and basic research in the characterization and management of soils and sediments.

Much of the research centers on understanding how contaminants interact with soils and wastes in a subsurface environment. Because many of the pollutants released from past DOE WM practices are contained in the soils and sediments, considerable effort is expended in developing methods to characterize, decontaminate, and control the fate of these contaminants. Soils scientists interact with environmental engineers, hydrologists, and aquatic and terrestrial ecologists in defining the magnitude of the problems with respect to the transport and fate of a large spectrum of inorganic and organic pollutants in the environment.

Recent projects include the development of a large data base characterizing the concentrations of potential anthropogenic constituents in natural soils surrounding the Oak Ridge DOE facility. The purpose of this study is to determine background levels of these constituents in soils so that contaminating events can be properly identified. Other projects involve the development of methods to remove uranium from contaminated soils through the use of selective leaching processes and the containment of contaminants in soils through the use of in situ vitrification (ISV) processes.

Efforts in FY 1993 by the Soil Science Group focused on soil remediation. These involved (1) development of baseline data for concentrations of potential contaminants in undisturbed soils surrounding ORR, (2) characterization of uranium contaminated soils, (3) development of soil-leaching protocols to remove uranium from soils, and (4) develorment of ISV processes to remediate contaminated soils.

During the past 2 years, members of the Soil Science Group directed a DOE project to provide background concentration data on potential contaminants (radionuclides and inorganic and organic compounds) in undisturbed soils on ORR. A final report has been issued which contains the technical interpretaticn of the field data integrated with analytical data to determine the meaning and implications of the results. The information presented in this document should be used to differentiate between unavoidable (background) and avoidable risks and to ensure that risk 
management decisions are based on excess cancer risk associated with actual site contamination.

Other members of the Soil Science Group are actively involved in the "Uranium in Soils" Integrated Demonstration sponsored by DOE's Office of Technology Development at Fernald, Ohio. Their efforts to identify the mineralogical components of uranium and their distribution among particle sizes of soil in these soils have been very valuable. Using density gradient techniques and X-ray diffraction analyses, they have observed uranium to be associated with uranite and uranium phosphate minerals. The soils decontamination group has evaluated a variety of extracting media for selectively removing uranium from soils. The leading candidate, one that selectively removes $U$ without removing copious quantities of $\mathrm{Fe}$ and $\mathrm{Al}$, is an extraction of

$\mathrm{NaHCO}_{3}-\mathrm{Na}_{2} \mathrm{CO}_{3} / \mathrm{KMnO}_{4}$ in combination with attrition scrubbing.

\section{Subsurface and Surficial Geochemistry}

Research in geochemistry emphasizes the understanding of processes that control the transport, fate, and transformation of elements in subsurface and surficial geological environments. This understanding is used in developing and applying interpretive models of element behavior to solve energy-related problems. Complementary field, laboratory, and computational research efforts are undertaken to evaluate strategies for the effective use of energy resources, the future disposal of wastes, and ER at existing contaminated sites.

This research incorporates principles from the disciplines of aqueous geochemistry, biogeochemistry, computer science, geology, hydrology, isotope geochemistry, limnology, radiogeochemistry, and soil chemistry. Research efforts focus on biotic and abiotic transformations of contaminants in natural waters, soils, and sediments; characterization of contaminants in active and inactive waste disposal areas; colloid mobility; contaminant transport in unsaturated, heterogeneous soils; hydrogeochemical aspects of the local groundwater system; ISV for the stabilization of contaminated soils; sorption of trace metals onto natural materials; and trace element transport and cycling in river, lake, and coastal zone environments.

The Subsurface and Surficial Geochemistry Group addresses challenges in geochemistry that are related to the safe management of hazardous and radioactive wastes. Results from complementary field, laboratory, and computational research efforts are used in evaluating strategies for disposal options for future wastes and for remedial actions on existing waste sites.

Accomplishments during FY 1993 included (1) development of new techniques for the rapid field analysis of mercury in water, sediment, and soil samples; (2) determination of the importance of varying water tables and the presence of low-molecular-weight organics in controlling the release and transport of actinides from existing waste sites at ORNL; (3) collection of field-scale data on the transport of contaminants in heterogeneous cubsurface media that will be used to validate three-dimensional multiregion flow and transport models and in the design of stormflow-monitoring schemes for complex hydrogeologic sites; (4) experimentation illustrating that iodide enhances the adsorption of mercury onto clays such as kaclinite and illite and reduces the volatile loss of mercury by 
strongly binding it in the aqueous phase as $\mathrm{HgI}_{2}$; and (5) elucidation of heat and mass transfer processes in melt-crystal-volatile systems to help understand the behavior of ISV melts and natural magmatic systems.

\section{Surface Water Hydrology}

The Surface Water Hydrology Group addresses problems related to flow and water quality in natural and impacted surface water systems. The group characterizes and quantifies contaminant transport in contaminated drainages on ORR by investigating mechanisms of flow, sediment production, sediment transport, and contaminant movement. Group members study interactions between groundwater and surface water by analyzing the occurrence and chemical signature of seeps and springs and their roles in surface water production. Investigations include developing and implementing models of water budgets and watershed hydrology, with an emphasis on flow in fractured-rock terrain. New projects include the evaluation of methodologies for estimating extreme floods with return periods $>100$ years and the development of empirical models to assess the effectiveness of remedial actions.
During FY 1993, the work performed by the Surface Water Hydrology Group mainly focused on ER issues at ORNL. The group conducted surveys of springs and seeps on the ORNL site to determine the distribution and quantity of contaminant inputs to the White Oak Creek drainage system that have leaked from closed low-level radioactive disposal facilities. A flood-monitoring system was implemented to determine the movement and fate of contaminated sediments under extreme hydrologic conditions. The group relied on diverse surface and groundwater data to develop an innovative risk-based methodology used to formulate a long-term monitoring system for Waste Area Grouping 6. The monitoring system emphasizes the measurement of major contaminant releases, identifies contaminants that exceed risk-based concentration levels, and proves to be cost-effective.

New initiatives include modeling work for the U.S. Nuclear Regulatory Commission that will generate guidelines for evaluating potential releases of contaminants to surface waters by ower generators. 


\section{Technical Summaries}

\section{New Specifications Are Prepared for Energy Systems Drilling Services Subcontract}

\section{S. L. Winters and T. O. Early}

Technical staff of the Groundwater Program Office of Martin Marietta Energy Systems, Inc. (Energy Systems), in conjunction with the five Energy Systems Groundwater Protection Program coordinators, have prepared specifications for the new Energy Systems drilling services subcontract. Following a final technical review of the specifications, the drilling services bid package was released for competitive bidding in March 1993. The subcontrart should be implemented in April 1994 and will expire in 1997.

Several additions or enhancements beyond the existing Energy Systems drilling services subcontract have been included in the revision: (1) dual-tube reverse circulation rotary drilling, which allows drilling-fluid circulation to be maintained while drilling through vugs, fractures, and cavities-a feature particularly useful for investigators working in karst terrains; (2) angle drilling and coring, a technique useful in sampling soils and groundwater at locations otherwise inaccessible to a drill rig (e.g., under buildings or tanks); (3) soil sampling for volatile organics using 6-in.-long brass sleeves that minimize volatile losses incurred during sampling; and (4) well plugging and abandonment (P\&A) procedures to destroy and seal well casings and well construction materials in place, thus minimizing worker exposure during well
P\&A and greatly reducing the amount of hazardous waste generated.

\section{Optimization Models Help Site Now Groundwater Monitoring Wells}

\author{
H. E. Cardwell, J. W. Douthitt, D. D. Huff, \\ and $M . J$. Sale
}

Optimization models were used to identify potential locations for groundwater monitoring wells for two contamination sites at the Paducah, Kentucky, DOE site. To develop trade-offs between competing coverage and cost-based objectives, optimization models runs varied the number of additional monitoring wells and the appropriate objective functions. The optimization model modified a simple location modeling approach, which required dividing the area of interest into a grid. The model assigns a weight to each point in the grid on the basis of contaminant concentration and water table elevation. The solution maximizes the sum of the weights of those grid points within a specified distance of a potential monitoring well site. Although the model is structured as an integer program, it can usually be solved by simple linear programming methods.

The optimization results provided a range of possible solutions that were compared with solutions based on professional judgment. As a result, groundwater specialists selected a revised design that involved fewer wells than originally planned. New work is under way to adapt these techniques so that existing monitoring well networks can be evaluated; the goal is to eliminate redundant or unneeded wells. A quantitative analysis is also in progress to improve the rule for assigning grid weights. 


\section{Methodology is Developed to Validate Field Data for the Background Soil Characterization Project}

\section{J. Switek}

Extensive effort in quality assurance and quality control is under way to satisfy the data quality objectives of the Environ-

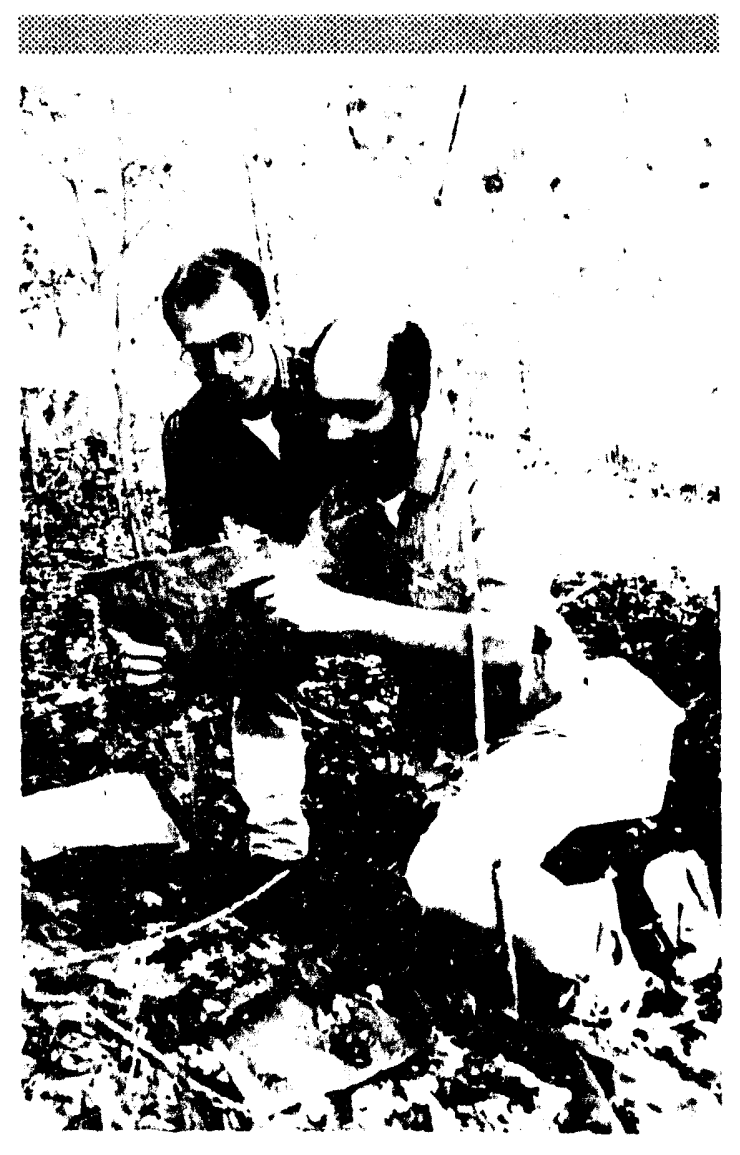

Researcher Mac Post (right) and Mark Wittenberger, a graduate intern, collect bags of leaf litter. Information about changes in the amount of litter is used in models of the relationship between leaf decomposition, environmental conditions, and plant productivity. mental Restoration (ER) Program's Background Soil Characterization Project (BSCP). Validation of the project field data is vital to ensure that the field data set is complete with respect to procedure ESP-500, ESH/Sub/87-21706/1, as specified in the project plan. A validation worksheet listing the ESP-500 elements was prepared for each site sampled in Phase I of the project, and the elements were checked off as they were found.

The validation effort revealed that project field records are essentially complete but are scattered among several notebooks, so a general index of records and their content is needed. The primary data omissions are a lack of information on sample preservation and a lack of landowner contact information for sites off the Oak Ridge Reservation.

A report about the Phase I validation has been sent to key project staff. Validation on Phase II field data has also been completed. The validated field and laboratory data for the BSCP will be transmitted to the ER Document Management Center for distribution and archiving. Data sets generated in the project will be vital tools in the ongoing ER process.

\section{Core Analysis Combined with Electromagnetic Borehole Flowmeter Surveys Is Effective in Documenting Transmissive Geologic Structures}

\section{P. J. Lemiszki, ${ }^{1}$ P. S. Neuhoff, ${ }^{2}$ and R. B. Dreier}

To better characterize the geological factors that control the distribution of permeable and impermeable groundwater intervals on the Oak Ridge Reservation, an electromagnetic borehole flowmeter, 
developed by the Tennessee Valley Authority, was used to survey 60 piezometer wells and 12 coreholes in the Rome Formation, Conasauga Group, and Chickamauga Group. Previously, the results were used to develop a model for groundwater flow paths by assuming that permeable intervals consist of a single fracture intersecting the borehole.

Our purpose was to determine the geologic characteristics of flowmeterdefined permeable and impermeable intervais by direct examination of core. Occasionally, pin-pointing the exact feature responsible for flow within a permeable interval was hampered by a relatively large sampling interval $(>1 \mathrm{ft}$ ) of the flowmeter surveys. Regardless, potential transmissive features were identified by the presence of iron staining, euhedral calcite and gypsum crystallization, partial infilling of fractures, and dissolution features.

Within carbonates, permeable intervals are associated with (1) open fractures normal and oblique to bedding that are parallel, oblique, and perpendicular to bedrock strike; (2) vuggy veins and solution cavities that are not vein related; and (3) open bed-parallel clay seams and shear fractures. Within primarily noncarbonate units, however, permeable intervals did not consist of individual fractures, but rather highly fractured zones.

The highly fractured zones are associated with changes in bedding dip and the development of shear fractures that are related to the development of faults and folds that appear to provide laterally extensive permeable pathways.

\footnotetext{
${ }^{1}$ The University of Tennessee, Knoxville.

${ }^{2}$ Oak Ridge Associated Universities, Oak Ridge, Tennessee.
}

\section{Regional Thrusting Sequence as Evidenced by the Copper Creek and Whiteoak Mountain Faults Has Important Implications for Development of the Southern Appalachian Thrust Belt}

\section{P. J. Lemiszki ${ }^{1}$ and R. D. Hatcher, Jr. ${ }^{1}$}

In the southern Appalachian foreland fold-thrust belt, a number of criteria have been developed to indirectly determine the regional sequence of thrusting. These criteria include folded thrust faults, thrust sheet rotation, fault intersection patterns, stratigraphic position of the basal fault, and stratigraphic cutoff-line patterns.

In the past, these criteria have been applied to geologic structures in East Tennessee, but interpretations differ, leading to contrasting views on the regional thrusting sequence (e.g., foreland-to-hinterland vs hinterland-to-foreland). Therefore, validating the applicability of the criteria is necessary because information pertaining to the regional and local thrusting sequence is needed to constrain models of thrust belt evolution.

Furthermore, documenting the regional sequence of thrusting is needed to constrain interpretations pertaining to the development of local and regional fracture sets that can control the movement of subsurface fluids.

For the first time, results from detailed geologic mapping, structural analysis, seismic reflection profiling, and drilling across the Whiteoak Mountain-Clinchport fault system and Copper Creek fault in East Tennessee have been incorporated for a better understanding of their regional structural style and emplacement history. 
Application of the thrusting sequence criteria to these faults indicates that (1) the faults formed in a hinterlandto-foreland progression of thrusting; (2) minor faults formed in both a breakforward and break-back sequence; and (3) the Whiteoak Mountain fault system may have been reactivated out of sequence after passage of the thrust front.

Combining these results with previously documented regional relationships supports the idea of a hinterland-toforeland thrusting progression and the existence of structures that may have developed to produce internal thickening of the thrust belt. As a consequence, critical-taper mechanical models may be only partially applicable to the growth of the southern Appalachian foreland fold-thrust belt.

In addition, these results can be used to assess the interaction between local and regional fracture sets and the development of regions of enhanced fracture permeability.

${ }^{1}$ The University of Tennessee, Knoxville.

6 Changes in Sedimentary Facies Within the Basal Maynardville Limestone May Affect Groundwater Flow Within Bear Creek Valley. Oak Ridge, Tennessee

\section{P. M. Goldstrand, ${ }^{1}$ R. B. Dreier, and L. A. Shevenell}

Recent drilling data from Bear Creek Valley (BCV) indicate that the basal Maynardville Limestone (lower Low Hollow member) is one of the most transmissive members of this formation and that water-bearing zones are, in part, lithologically controlled. Analysis of core, well-cutting data, and gamma-ray logs from 17 wells has allowed for the construction of three-dimensional sedimentary facies maps of the lower Low Hollow member to better predict water-bearing zones beneath $\mathrm{BCV}$.

The lower Low Hollow member consists mostly of medium- to thick-bedded thrombolitic limestone (biothermal calcareous algae, which developed in shallow subtidal environments during the Lower Paleozoic age).

Porosity within the thrombolitic limestones appears to be related to dissolution of carbonate mud originally trapped between the algal structures (forming small vugs) and dissolution along fractures and along the interface of thin shale stringers (forming larger elongate voids).

Throughout BCV, the thrombolitic limestones generally thicken to the southeast and interfinger with less transmissive limestones to the northwest.

Southeast of the Burial Grounds Waste Management Area, at least two areas occur where the lower Low Hollow thins and the upper Low Hollow member directly overlies a thickened section of upper Nolichucky Shale.

These two areas probably represent subtidal channels of lower relief than the adjacent thrombolitic mounds and were filled in with less transmissive limestones and shales. Along strike, groundwater movement could be impeded in this area; however, the velocity of downdip flow (to the southeast) could decrease as water enters the thicker thrombolitic units.

${ }^{1}$ The University of Tennessee, Knoxville. 


\section{Porosity Changes and Fractures Are Identified in Carbonate Rocks by Using Borehole Geophysics}

\section{R. B. Dreier}

On the Oak Ridge Reservation (ORR), diffusion into the rock matrix and rapid flow through fractures are common processes for contaminant transport. As a result, characterization of fractures and matrix porosity plays an important role in understanding contaminant migration. These parameters can be determined, in part, through the use of borehole geophysics.

Changes in natural gamma and neutron logs are commonly related to relative changes in clay mineral content. The natural gamma log responds to gamma emitters such as K-40, and the neutron log responds to bound hydrogen in clay minerals. Thus, cross-plots of these logs show linear trends as a function of the amount of clay minerals.

Deviations from the trends on the neutron log result from excess hydrogen and are attributed to an increase in matrix porosity.

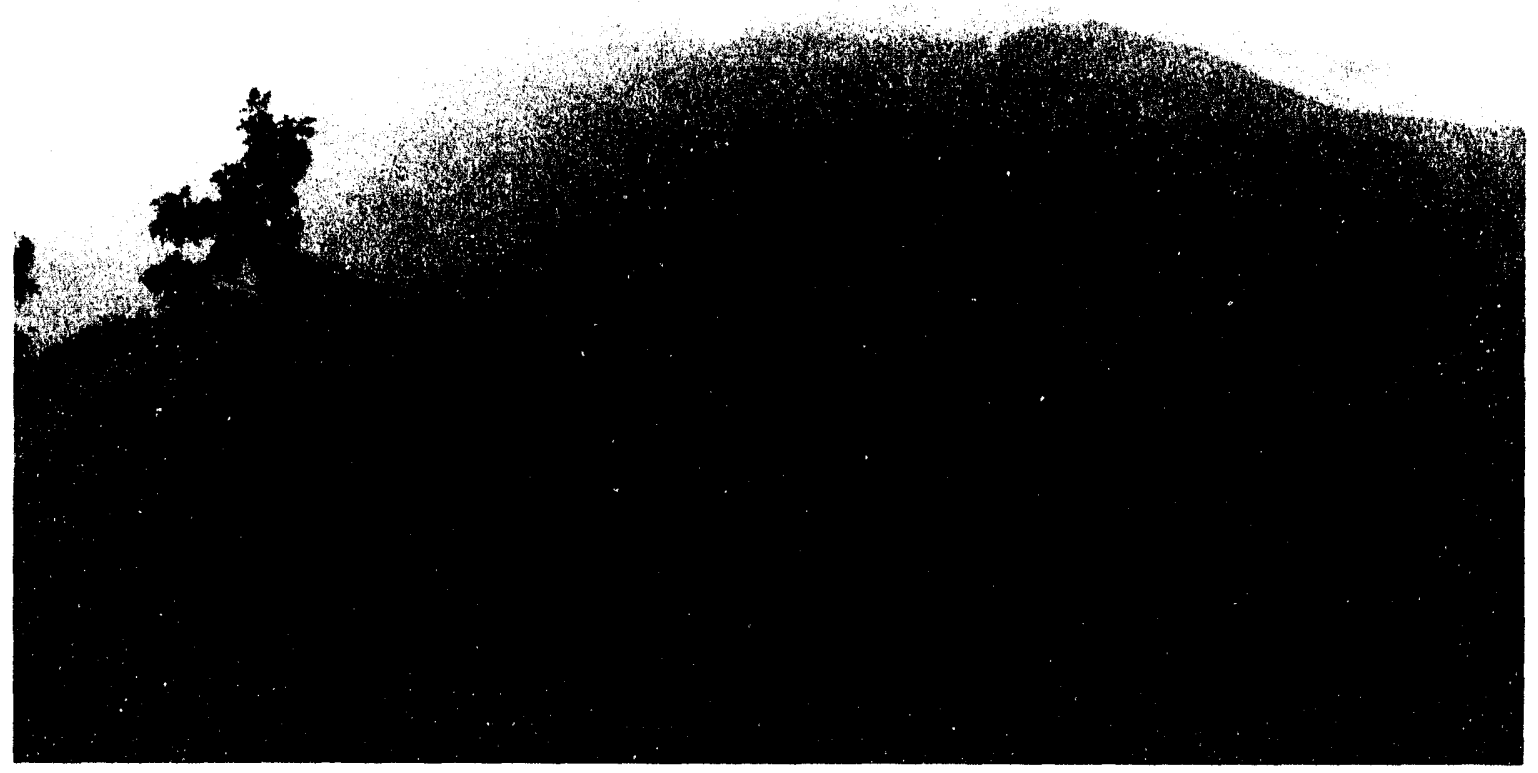

A cloud cap forming over a research site in the Great Smoky Mountains National Park. Throughfall studies indicate that cloudwater deposition is much enhanced by winds into the edges of forest stands in mountainous terrain. 
These deviations have been used to investigate changes in matrix porosity within the Maynardville Limestone on ORR and show a strong correlation with preliminary petrographic studies. Abrupt changes in the neutron direction on the natural gamma-neutron cross-plots indicate individual fractures.

Fractures identified with this method correspond well with fractures determined from core, temperature, and flowmeter logging. This type of cross-plot will be very useful at sites where core or an extensive suite of geophysical logs are not available for fracture identification.

\section{Top-of-Rock Topography Was Determined at the ANS Preferred Site by Using Seismic Refraction Methods}

\author{
R. K. Davis, ${ }^{1}$ R. A. Hopkins, ${ }^{2}$ and \\ W. E. Doll
}

A seismic refraction study was conducted at the Advanced Neutron Source (ANS) preferred site to provide estimates of topof-rock topography, based on seismic velocities, and to delineate variations in rock and soil velocities.

Data were acquired digitally with an EG\&G ES-2401 seismograph. The output from $14-\mathrm{Hz}$ geophones was recorded with $250-\mathrm{Hz}$, high-frequency cutoff filters to reduce unwanted transient high-frequency noise. To ensure precise first-break information, data were sampled at $0.10 \mathrm{~ms}$.

Forty-four seismic refraction spreads were shot to determine top-of-rock depths at 42 locations on a $200-\mathrm{ft}$ grid. Four top-of-rock profiles were produced from nine seismic spreads shot with long offsets to provide 216 top-of-rock depths on 10-ft centers. The refraction spread locations were based on the grid for the ANS Phase I drilling program.

Results from the seismic refraction methods used in this survey indicate that the top-of-rock depth is shallow (9 to $42 \mathrm{ft}$ ) across the site. The seismic refraction interpretations are generally consistent from spread to spread and support the assumption that the top-of-rock surface correlates well with surface topography.

Seismic refraction methods average the velocities of subsurface materials to obtain an average velocity for each seismic layer. The results are inferential and therefore require confirmation from limited drilling. A comparison of the available cored boring information from the site shows a close correlation with the results from this survey.

'Automated Sciences Group, Oak Ridge,
Tennessee.
${ }^{2}$ Marrich, Inc., Knoxville, Tennessee.

9 Fracture Mechanics Modeling Indicates That Folding-Related Extension Fracture Development Can Vary Across a Thrust Belt

\author{
P. J. Lemiszki, ${ }^{1}$ J. D. Landes, ${ }^{1}$ and \\ R. D. Hatcher, Jr.
}

The location of the most productive hydrocarbon and groundwater wells has long been recognized as commonly related to the greater frequency of fracturing associated with fold hinges. Geologic mapping and outcrop analysis in the Oak Ridge area have documented the various fracture sets that can form within folded layers and have related their geometry to position in the fold and the stress history during folding. 
The most common fracture sets observed in folds in the area are hinge-parallel extension fractures oriented perpendicular to bedding that results from tangentiallongitudinal strain. Tangential-longitudinal strain folding of layers in foreland foldthrust belts can occur as a result of buckling and bending of stratigraphic units during the development of decollement folds, fault-bend folds, and fault-propagation folds. Hinge-parallel extension fractures propagate as a result of local tensile stresses that develop during the stretching of layers in the outer arc of fold hinges.

Our purpose is to use the results of a previously published finite-element model for folding of a viscous layer in a less viscous matrix as input to a fracture mechanics analysis of hinge-parallel extension fracturing in a tangential-longitudinal strain fold. Available estimates of sandstone and limestone fracture toughness measured under triaxial stress conditions were used to examine the relationship between strain rate, confining stress, and the amount of fold shortening required for the propagation of a bed-perpendicular Mode I crack (extension fracture). The results indicate that the development of extension fractures is related to the rate and depth of folding and can range from minor shortening by folding before cracks propagate to the development of a tight fold with no crack growth. These results suggest that development of hinge-parallel extension fractures can vary across a thrust belt as a function of strain (thrusting) rate, the amount of bending at thrust ramps, and the depth of folding. An understanding of the factors affecting hinge-parallel fracture development within a thrust belt is needed to better predict zones of enhanced fracture permeability.

${ }^{1}$ The University of Tennessee, Knoxville.

\section{Porosity in the Maynardville Limestone Is Dependent on Lithology and Depth}

\section{P. M. Goldstrand ${ }^{l}$ and P. J. Lemiszki ${ }^{1}$}

Groundwater data from Bear Creek Valley $(B C V)$ in East Tennessee suggest that the Maynardville Limestone ( $\mathrm{Cmn}$ ) contains contaminants from adjacent waste disposal facilities and acts as a hydraulic drain with flow in the valley generally northeast to southwest, parallel to bedrock strike. To evaluate the factors affecting porosity in the Cmn, petrographic $(n=27)$ and volumetric porosity $(n=261)$ analyses have been completed on two cores from the $\mathrm{Cmn}$ in BCV. All primary porosity has been filled in by calcite cement; secondary porosity, which has developed through localized dissolution of the carbonate, accounts for all the present porosity.

The two cored intervals of the Cmn occur between $400-1000 \mathrm{ft}(122-303 \mathrm{~m})$ and $600-1200 \mathrm{ft}(182-364 \mathrm{~m})$ below ground surface. The upper part of the Cmn is the most porous and hydrologically active, with mean matrix porosities of $3.8 \%$ (shallower core) and $1.1 \%$ (deeper core). Solution cavities and vugs increase total porosities up to $15 \%$. These high porosities in the upper $\mathrm{Cmn}$ are related to dissolution of stromatolitic dolostone and dolomitic limestone.

Petrographic analysis indicates that dedolomitization and dissolution of gypsum produce vuggy and moldic porosities. The lower Cmn is the next most porous unit, consisting of thrombolitic limestone with mean matrix porosities between $0.7 \%$ (shallower core) and $0.4 \%$ (deeper core). Dissolution of fine-grained carbonate beds and local oxidation of pyrite produce vuggy 
and moldic porosities up to $3 \%$. The highest porosities in the lower Cmn appear to occur near (but not at) the contact with the Nolichucky Shale. The middle Cmn consists of oolitic, peloidal, and oncolitic limestone and generally has lower porosities (mean matrix porosity of $0.5 \%$ ). Lithologies within the middle Cmn with a high probability of porosity enhancement are spatially restricted; hence, most of the middle Cmn is unlikely to transmit large volumes of groundwater.

${ }^{1}$ The University of Tennessee, Knoxville.

\section{Watershed Sampling Identifies Contaminant Source Areas}

\section{S. Hicks}

The major pathways for water movement and associated contaminants in the subsurface are through the shallow water table and the stormflow zone. Water that infiltrates the soil surface moves through these shallow pathways, intercepting and leaching contaminants from buried wastes, and then emerges at seeps where it discharges to the surface water system. Because seeps represent connections between subsurface and surface flow regimes and because tributaries can be used as spatial integrators of contaminant releases, a seep and tributary monitoring task was initiated as part of the Waste Area Grouping (WAG) 2 surface water program. The objective is to identify tributaries and seeps that are responsible for contaminant fluxes in the White Oak Creek (WOC) watershed.

During FY 1992, two extensive screening sampling rounds were conducted. Samples were collected from $\sim 30$ seep locations and 100 tributary and stream locations once during a wet-season baseflow condition and once during a dry season baseflow condition. Besides visible seeps, areas of contaminated groundwater se $>p$ age directly into stream channels were identified by significant increases in contaminant concentrations along a stream reach.

Results from the two sampling rounds identify key seeps and areas that contribute significantly to the total contaminant flux in the WOC watershed. Four relatively discrete seepage areas near WAG 5 contribute $\sim 25-50 \%$ of the ${ }^{3} \mathrm{H}$ and $\sim 20-35 \%$ of the ${ }^{90} \mathrm{Sr}$ within the watershed. The results are being used to guide focused investigations in these four areas to identify contaminant sources (e.g., trenches) and to direct remedial efforts. Additional sampling rounds during different hydrological conditions were completed in FY 1993 to help clarify the distribution of contaminant fluxes and sources in the WOC watershed and to guide future remedial efforts.

\section{New Method Is Demonstrated for Estimating Exceedance Probabilities of Extreme Floods}

\section{T. A. Fontaine and W. C. Stoddart}

Estimates of the exceedance probabilities of extreme floods [e.g., flood magnitudes between the 100-year event and the probable maximum flood (PMF)] are needed for risk analysis of nuclear energy facilities and high-hazard dams. A new approach using a joint probability distribution of extreme rainfalls and antecedent soil moisture conditions, along with a rainfall runoff model, provides estimates of probabilities for floods approaching the PMF. A demonstration of this approach on a $570-\mathrm{km}^{2}$ catchment indicated that 
the exceedance probability of the 0.65 PMF event is $2.2 \times 10^{-6}$ (i.e., the recurrence interval is 454,000 years). An additional demonstration is being conducted in the Oak Ridge area.

Estimates of the probabilities of floods between the 100-year event and the PMF at specific sites will provide an important alternative to the current criterion used to reduce flood hazards at existing facilities, a criterion that is controversial and very conservative. A regional or national risk assessment is possible using flood exceedance probabilities at existing structures. Such an assessment could help maximize risk reduction per dollar spent on flood protection and greatly reduce flood hazard more quickly. In addition to use at existing high-hazard sites, exceedance probabilities of extreme floods would also be useful in designing new facilities at moderate-hazard sites.

${ }^{1}$ Engineering Division, ORNL.

\section{Second Annual Report of the Environmental Restoration Monitoring and Assessment Program Is Published}

\section{R. B. Clapp and J. A. Watts}

The Second Annual Report of the Environmental Monitoring and Assessment Program at the Oak Ridge National Laboratory summarizes the investigation and monitoring activities conducted to support the Environmental Restoration (ER) Program during FY 1993. This summary primarily reflects the comprehensive efforts of the Waste Area Grouping (WAG) 2 and Site Investigations (SI) Program.

WAG 2, which includes the lower portion of White Oak Creek (WOC), the floodplain, and White Oak Lake, is the drainage area that receives most of the contaminants released from the waste disposal sites and the discharges from the main plant at ORNL. Surface water from WAG 2 discharges to the Clinch River.

As a part of the remedial investigation for WAG 2, a long-term multimedia environmental monitoring effort takes advantage of the role WAG 2 serves as an integrator and conduit for contaminants. These monitoring efforts rely heavily on the expertise and diversity of staff from ESD and other ORNL divisions.

Research activities are divided into four major tasks-Surface Water, Groundwater, Soil and Sediment, and Biota-and include support activities such as risk assessment and remedial assessment. In recent years radionuclides (especially ${ }^{3} \mathrm{H}$, and ${ }^{90} \mathrm{Sr}$ ) have contributed the majority of the off-site risk from the ORNL WAGs; the most significant on-site risk is from gamma exposure to ${ }^{137} \mathrm{Cs}$ in the soils and sediments.

Interrelated contaminant transport pathways (e.g., groundwater to surface water, surface water to sediment and soils, and surface water and sediment to biota) have led to an integrated and comprehensive approach to providing information that supports ER efforts at ORNL. The results of this integrated effort are used to develop a conceptual understanding of the key contaminants and the sources, fluxes, and processes affecting their distribution and movement within the WOC watershed. The WAG 2/SI Program exemplifies the incorporation of applied and basic research to form a basis for prioritizing sites and for selecting, implementing, and evaluating remedial actions within the WOC watershed. The program can serve as a model for future remedial investigations. 


\section{Three-Dimensional Groundwater Flow Model of ORNL Waste Areas Is Running on the Supercomputer}

\section{E. Toran and O. R. West}

A three-dimensional, 40,000-node groundwater flow model of Melton Valley was constructed to gain an understanding of the role groundwater plays in contaminant discharge. PFEM, a parallel version of 3DFEMWATER, was used in runs made on the ORNL supercomputer. The model area includes Waste Area Groupings (WAGs) 4, 6, and 7 and part of WAG 2. WAGs 5,8 , and 10 are currently being incorporated. The model is calibrated to about 150 measurements of groundwater levels at various depths and baseflow fluxes obtained from five surface water measuring stations.

Model calibration has provided new information about the hydraulic conductivity and flow system boundaries not available from existing field data. A 1:5 ratio of vertical:horizontal hydraulic conductivity indicates a better match to the deep system. Ridges in the model may act as groundwater divides, or water may underflow the ridge. A better match was achieved when underflow was used, but the model also indicated that the source of this water was not shallow contaminated areas.

The model also is being used to calculate groundwater fluxes to streams where gages are not available, thus improving estimates of off-site contaminant migration. An earlier version of the model predicted lowering of the water table of less than $10 \mathrm{ft}$ if the trenches in WAG 6 were capped and very little change in stream fluxes. Thus, capping would not have reduced flow through waste trenches in some portions of the model area. Through a better definition of groundwater flow boundaries, the calibrated model will help to identify contaminant pathways and construct smaller-scale models of individual watersheds or waste areas.

\section{Enriched Deuterium in Oak Ridge Reservation Ground- waters Results from Natural Processes}

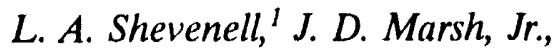
L. E. Toran, and L. W. Cooper

Between 1987 and 1992, 71 samples for deuterium $(\delta \mathrm{D})$ and oxygen-18 $\left(\delta^{18} \mathrm{O}\right)$ were collected on the Oak Ridge Reservation (ORR) from both rain and groundwaters up to depths of $1200 \mathrm{ft}$. Most samples $(79 \%)$ are either enriched in $\delta \mathrm{D}$ or depleted in $\delta^{18} \mathrm{O}$ relative to the World Meteoric Water Line (WMWL). The stable isotope data most likely reflect source areas of the precipitation recharging the groundwaters.

Air masses moving from the Gulf of Mexico northward to the continental United States are isotopically enriched compared with arctic air masses moving southward. Data compiled and contoured by previous workers show that an average $\delta \mathrm{D}$ value in Tennessee is $-30 \%$, similar to the average value of $-33.3 \%$ obtained from the 71 ORR samples. The $-30 \%$ contour extends up the eastern coast of the United States and down the Gulf coast into Mexico and Central America.

The International Atomic Energy Agency (IAEA) reports $\delta^{18} \mathrm{O}$ and $\delta \mathrm{D}$ for three stations (Veracruz, Mexico; Hatteras, North Carolina; and Waco, Texas) within the $-30 \%$ contour that have stable isotope contents similar to those found in 
Tennessee. Many of the 322 data points from these stations are also shifted in relation to the WMWL. Recharge to the ORR aquifers occurs predominantly during the wetter, winter months; hence, the IAEA data are evaluated on the basis of season.

The number of data points from each station that have enriched $\delta \mathrm{D}$ by $>1 \%$ in relation to the WMWL were summed for the winter and summer months. Approximately $70 \%$ of the precipitation in the October to March season has had enriched $\delta \mathrm{D}$ at the three stations between 1953 and 1987 , whereas $\sim 75 \%$ of the precipitation during the summer months is depleted relative to the WMWL. Because most of the recharge on ORR occurs during the winter, it is reasonable to expect that groundwaters would exhibit isotopic enrichment relative to the WMWL. Hence, the shifted isotopic compositions of the ORR waters reflect natural, regional isotopic compositions rather than local effects.

${ }^{1}$ The University of Tennessee, Knoxville.

\section{Chemical Variability of Waters in a Karst Aquifer Is Used to Detect Quickflow Zones at the Oak Ridge Y-12 Plant}

\section{A. Shevenell}

Low concentrations of contaminants enter the Maynardville Limestone (Cmn), a dolomitic limestone that occurs adjacent to several waste disposal sites at the Oak Ridge Y-12 Plant. Within the Cmn, cavities filled with water and mud range in size from $<1$ to $\sim 40 \mathrm{ft}$. Sixty-seven percent of all wells drilled in the Cmn have encountered cavernous zones, most commonly at depths $\leq 100 \mathrm{ft}$ and elevations $\geq 770 \mathrm{ft}$. Portions of the aquifer are subject to a quickflow component in which recharge to the system is rapid and water levels and water quality change rapidly in response to precipitation events. Of 70 water zones, water samples from 16 are

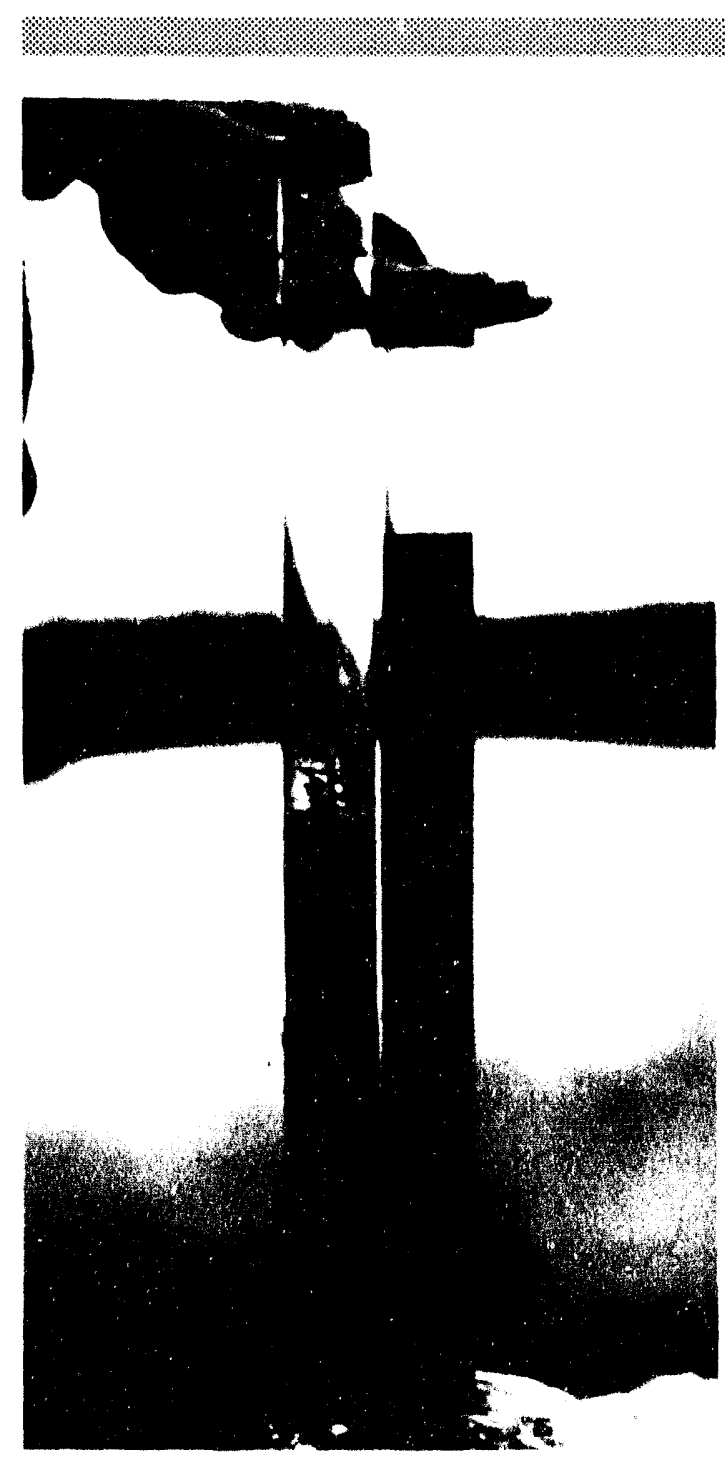

Two undisturbed sediment cores, before sectioning. The cores were collected from Toolik Lake, on the Alaskan arctic North Slope, in July 1991. ESD researchers analyze the contents of such cores to learn more about the cycling of organic matter. 
consistently undersaturated with respect to calcite, which suggests active solution enlargement.

Repeat sampling of water zones shows that both supersaturation and undersaturation with respect to dolomite occurs in each of 27 water zones; this indicates that relatively old waters diffusing from the rock matrix into conduits during baseflow experience periodic flushing by rapidly recharged waters. Nine of the zones have partial pressures of $\mathrm{CO}_{2}$ near atmospheric values. This finding suggests limited interaction between recharge waters and aquifer soils and rocks and, hence, relatively short residence times. Other water zones show no geochemical evidence for quickflow.

Generalized maps, based on the locations of identified cavities and chemical characteristics of the waters, are a first approximation to the distribution of quickflow zones and suggest that active groundwater flow in the Cmn occurs through a complicated network of interconnected, perhaps anastomosing, cavities. The degree of interconnection between cavities has yet to be determined, but significant vertical and lateral interconnection is expected throughout the study area.

${ }^{1}$ The University of Tennessee, Knoxville.

\section{Effectiveness of Three RCRA Caps at the Oak Ridge Y-12 Plant Is Evaluated}

\section{A. Shevenell ${ }^{l}$ and P. M. Goldstrand}

The objective of Resource Conscrvation and Recovery Act (RCRA) caps at the Oak Ridge Y-12 Plant was to control interaction between wastes and water moving through the site by reducing direct infiltration into waste areas and contaminant migration from the sites. Based on the available data (water levels and chemical analyses in wells) at the three Y-12 sites investigated (Chestnut Ridge Security Pits, Oil Landfarm Waste Management Area, and New Hope Pond), installed caps appear to have had a minimal effect on contaminant migration.

No changes in the configuration of the water table were observed at the sites following cap construction. Migration of contaminant plumes occurred at all sites, apparently without regard to the timing of cap installation. This migration may be related to shallow groundwater and stormflow beneath the caps.

However, evaluation of RCRA cap effectiveness was difficult and conclusions tentative because the frequency and type (water level vs chemical) of monitoring were different before and after capping; also, numerous wells monitored after capping were located at relatively large distances from the capped areas.

Wells at large distances from caps will respond to natural recharge, flushing, and dispersion processes that mask the effectiveness of the caps. When quarterly monitoring is conducted at these wells, it is difficult to determine which processes are dominant at the time of sample collection. Monitoring of wells in and very near capped areas, both before and after capping, may provide less ambiguous data.

One type of monitoring, which has thus far been underutilized, is frequent monitoring before and after capping in first-order streams draining a waste site, where the changes in contaminant concentrations and fluxes during and between storm events can be quantified. This type of monitoring should be considered at other sites at 
which performance assessment of remediation efforts will be required. In the future, performance criteria and the methods by which the criteria are to be evaluated should be more clearly defined before RCRA capping begins.

${ }^{1}$ The University of Tennessee, Knorville.

\section{Source of Cesium on the Surface of a Sand-Filled Lysimeter Is Identified}

\section{W. E. Sanford and I. L. Larsen}

During routine site monitoring, increased radioactivity was found on the surface of a sand-filled lysimeter at the EPICOR-II Resin Leaching Experiment site in Waste Area Grouping 6. The EPICOR-II project is examining the degradation of various cements used to solidify an ion exchange resin that is contaminated as a result of filtering the reactor water spilled at the Three Mile Island Nuclear Power Plant.

The lysimeter is a self-contained stainless steel tank $90 \mathrm{~cm}$ in diameter and $300 \mathrm{~cm}$ in length. The upper two-thirds is filled with a fine- to medium-grained silica sand (with a very low cation exchange capacity), and the lower third is a reservoir to collect the leachate. Waste is buried $100 \mathrm{~cm}$ below the surface.

Surface samples of the sand located near the center of the lysimeter (where most of the activity is concentrated) were collected at two depths, $0-2.5 \mathrm{~cm}$ and $2.5-5 \mathrm{~cm}$, on August 7,1992 . By using the initial ratio of ${ }^{137} \mathrm{Cs}:{ }^{134} \mathrm{Cs}$ of the waste, the measured ratio of the sand samples, and the known date of burial, researchers attributed the surface cesium activity to migration from below and not from an alternative source. This determination has important implications in regards to subsurface disposal of cesium-contaminated nuclear waste.

Conventional wisdom suggests that cesium will be relatively immobile because it is easily sorbed to soil particles and that any movement would be downward because rainfall infiltration significantly exceeds evaporation in our area. Upward migration, if significant, could lead to direct gamma exposures and off-site transport by erosion. Work is currently anticipated to determine both the mechanism of cesium transport and the form of cesium during migration.

\section{Use of Noble Gases as Groundwater Tracers Suggests That Diffusive Transport is of Great Importance in Sandy Aquifers}

\section{W. E. Sanford, D. K. Solomon, and J. F. McCarthy}

The influence of diffusive exchange between regions of high and low permeability in a saturated granular porous medium was investigated using noble gases as tracers. Helium and neon were used as tracers in a two-well forced-gradient tracer experiment in an unconfined, sandy, coastal plain aquifer near Georgetown, South Carolina. The field site is $5 \mathrm{~m}$ square and is underlain by an impermeable clay layer at $3 \mathrm{~m}$ depth. The site is the location of 33 monitoring wells used in an ongoing study to examine the transport of natural organic matter and colloids.

Hydraulic conductivity, measured at over 300 locations through slug tests, was found to increase with depth from $10^{-5} \mathrm{~cm} / \mathrm{s}$ at the top of the saturated zone to $10^{-1} \mathrm{~cm} / \mathrm{s}$ just above the clay layer. Breakthrough 
curves from single-tracer experiments do not sufficiently quantify the effects of diffusion between these layers; however, multiple tracers with differing aqueous diffusion coefficients can provide additional information.

A suite of noble gases as groundwater tracers has several advantages: (1) the gases can be dissolved in the injection water several orders of magnitude above background levels without affecting the physical properties of the water, (2) samples can be accurately analyzed for concentrations at least five orders of magnitude below the iniection concentration, and (3) the primary difference in the chemical behavior of the dissolved gases is due to their different diffusion coefficients.

The field experiment was designed to inject the gases into the groundwater for 21 days in order to saturate the subsurface with tracers. Breakthrough and elution curves of the two gases were recorded at two depths in a monitoring well $3 \mathrm{~m}$ from the injection well along the centerline between the two pumping wells. The sample depths correspond to the layers of highest hydraulic conductivity at the base of the aquifer and the lowest conductivity at the top of the saturated zone.

Variations in the He: $\mathrm{Ne}$ ratio result from the differing rates of diffusion of the gases between zones of high and low permeability. The initial results indicate that in a small system with relatively high flow rates, significant separation of helium and neon can occur, indicating the importance of diffusive transport. Although more samples have yet to be analyzed, these findings may have important ramifications on the design and implementation of remediation activities of contaminated groundwater.

\section{Novel Soil Sampling and Field Screening Techniques Are Applied at Acid Canyon in Los Alamos, New Mexico}

\author{
N. E. Korte, K. S. Dickerson, ' and \\ S. E. Wagner ${ }^{2}$
}

A surface soil sampling and screening program was conducted at Acid Canyon in Los Alamos, New Mexico, the site of the first radioactive liquid waste treatment plant at Los Alamos National Laboratory (LANL). This project was conducted in response to concerns that activities at LANL might have affected an area that is now county property and open to the public. There is also public concern that the incidence of brain cancer was higher than expected in Los Alamos and that contamination in Acid Canyon was partially responsible.

The field screening and surface soil sampling program was designed to determine the extent of surface residual contamination and the possible exposure to those members of the public using the canyon for recreation. Screening and sampling locations focused on the former locations of five solid waste management units, including the canyon cliff face where effluents were discharged.

Unique field techniques were required based on a number of factors. Because of the extreme terrain, rappeling was required for cliff-face sample collection.

Researchers also had to backpack equipment more than 1 mile to several remote sampling locations. A unique combination of field screening techniques and quality assurance/quality control methods was also required because of the possibility of mixed waste. Finally, because of intense public interest, field 
investigations were covered by both national and local media. Field screening results did not detect any radioactive or organic compounds above background levels. Results from the field screening indicate that the site is not contributing to excess public exposure.

${ }^{1}$ Health and Safety Research Division, ORNL. ${ }^{2}$ Los Alamos National Laboratory, Los Alamos, New Mexico.

\section{Geographic Information System Is Used to Conduct Hydrological Data Analysis}

\section{B. K. Harrington'}

The Oak Ridge Reservation Hydrology and Geology Study (ORRHAGS) uses a Geographic Information System (GIS) together with information stored in the ORRHAGS groundwater data base to help reach a conceptual understanding of groundwater flow for the Oak Ridge Reservation (ORR). A GIS can link data to map features, thereby allowing the spatial relationship of data to be explored that would be difficult to observe in a list of tabular data.

ORRHAGS has developed a groundwater data base that contains information on groundwater chemistry and monitoring well construction from the Oak Ridge K-25 Site, ORNL, and the Oak Ridge Y-12 Plant. Well coordinates were used to create a well-location coverage in ARC/INFO, a commonly used GIS. ARC/INFO was then used to link well locations on ORR with concentrations of groundwater constituents for spatial analysis.

In the well-location coverage, each well has a unique numeric identifier. This numeric identifier was used to link water chemistry data to well locations. For example, when looking at the concentration of volatile organic compounds (VOCs) in groundwater, all wells with different concentration ranges can be displayed in different colors to illustrate spatial variations in concentrations.

A file containing the unique $\mathrm{ARC} / \mathrm{INFO}$ well identifier and a sum of the averages for petroleum VOCs, chlorinated VOCs, and total VOCs for each well was created and loaded into ARC/INFO. ARCPLOT, an ARC/INFO subsystem, was used to create map compositions for total VOCs at the Y-12 Plant.

These maps were used to examine the general shape of the total VOC contaminant plume, the variability of VOC concentrations from the chlorinated and petroleum VOC groups, the different VOC contaminant sources, and the type of VOCs released from each source. Several VOC concentration maxima were found, and the general shapes of the VOC plumes were shown.

${ }^{1}$ The University of Tennessee, Knoxville.

\section{Mass and Volume Balance Constraints Are Used to Evaluate Water Vapor Behavior During In Situ Vitrification}

\author{
G. K. Jacobs, V. Alexiades, ' and \\ N.W. Dunbar ${ }^{2}$
}

In situ vitrification (ISV) is an environmental remediation technology used to stabilize contaminated soil sites. The behavior of water and other volatile constituents in the soil-melt system is important to the overall performance of ISV technology. 
Mass and volume balance constraints were used to derive a method to indirectly estimate the volume of (1) soil that dehydrates and releases water vapor to the off-gas and (2) outside air pulled to the off-gas treatment system. These constraints allow an analysis of whether some water may remain in the soil rather than being completely transported to the off-gas system.

The method is tested with data from the 1991 field-scale ISV test conducted at ORNL. Results suggest that, contrary to previous conceptual models, not all water that is vaporized reaches the surface and becomes captured by the off-gas treatment system. Some percentage most likely remains within the soil beneath and around the molten ISV mass.

${ }^{1}$ Engineering Physics and Mathematics Division, ORNL.

${ }^{2}$ New Mexico Bureau of Mines and Mineral Resources, Socorro.

\section{Thermal History of an Artificial Magma Is Modeled by Using Pseudobinary Thermo- dynamics Coupled with Heat Conduction}

\author{
G. K. Jacobs, V. Alexiades, ${ }^{\prime} M . T$. Naney, \\ and N.W. Dunbar ${ }^{2}$
}

Cooling rate and the degree of undercooling in crystallizing magmas control the textures of mineral assemblages. It is difficult to quantify such parameters in natural systems because active magmas are unavailable for detailed characterization at the surface. Crystallization processes can be investigated in laboratory experiments, but convection and thermal processes such as conduction cannot be addressed. This problem can be partially circumvented by investigating artificial magmas produced by in situ vitrification (ISV). During an ISV test in 1991, a thermal arrest was observed in the cooling history of a small melt $\left(5 \mathrm{~m}^{3}\right)$, indicating large-scale crystallization and the concomitant release of heat. Large crystals with equilibrium growth textures (slow cooling and small undercooling) were found in the center of the rock body, whereas small crystals with dendritic and spherulitic textures (rapid cooling and large undercooling) occurred at the edges of the mass.

A two-dimensional axisymmetric model of melt solidification based on binary thermodynamics coupled with heat conduction was used to model the thermal history of the melt. Pseudobinary thermodynamic parameters were derived using output from a multicomponent melt model developed by Mark Ghiorso (University of Washington). The multicomponent model was necessary to accurately represent the liquidus temperatures of the system and the fraction of melt as a function of temperature.

Estimated values for key model parameters were obtained by matching model simulations with observed thermal trends from several thermocouples. The model was then run for a variety of positions within the melt. Even for this small melt, the calculated cooling rates are dramatically faster close to the edge and top of the melt body. These calculated cooling rates and, by inference, degrees of undercooling are consistent with variations in cooling rates and degrees of undercooling necessary to form the textural zonation observed from the center to the edge of the rock body.

\footnotetext{
${ }^{1}$ Engineering Physics and Mathematics Division, ORNL.

${ }^{2}$ New Mexico Bureau of Mines and Mineral Resources, Socorro.
} 


\section{Crystallization of an Artificial Magma Created by In Situ Vitrification Is Accurately Simulated by Thermodynamic Modeling}

\section{T. Naney, G. K. Jacobs, M. S. Ghiorso, ${ }^{1}$ and N.W. Dunbar ${ }^{2}$}

Models for accurately describing the physical and chemical properties of chemically complex silicate melts and their solidification products are needed to advance understanding of natural geologic processes (e.g., volcanism, ore formation, and geothermal fluid evolution) and industrial processes that generate silicate melts.

The thermodynamic model MELTS, developed for analysis of natural magma systems, has been used to simulate crystallization of the silicate melt created by the 1991 in situ vitrification (ISV) test conducted at ORNL. This research has provided an opportunity to test a thermodynamic model developed and calibrated for natural magmas with observations from a well-monitored and well-characterized ISV-generated artificial magma, which has a composition outside the normal range of natural magmas. This application of the MELTS model has successfully demonstrated the use of a thermodynamic model to evaluate and understand products of ISV piocessing

Modeling results are compared with petrological observations of the naturally cooled, solidification products of the artificial high-calcium basaltic melt. MELTS calculations predict that diopsidic pyroxene and anorthitic plagioclase feldspar are the only minerals to crystallize during the first $60^{\circ} \mathrm{C}$ of cooling to $1142^{\circ} \mathrm{C}$, producing solidification of $56 \mathrm{wt} \%$ of the system. This is consistent with inferences about widespread crystallization of the large artificial melt as inferred from the observed thermal arrest over the $1147-1137^{\circ} \mathrm{C}$ range. The model also predicts precipitation of sanidine feldspar beginning at $1022^{\circ} \mathrm{C}$ (following resorption of leucite) from liquids having silica contents of $62 \mathrm{wt} \%$; this prediction is in agreement with the observed presence of sanidine in silicaterich interstitial glass.

Equilibrium phase relations calculated with the thermodynamic model MELTS are in good agreement with observations from the field-scale crystallization experiment. The phase assemblage and proportions predicted by MELTS at $1002^{\circ} \mathrm{C}$ (Pyroxene $_{48}+$ Plagioclase feldspar $_{27}+$ Sanidine feldspar ${ }_{14}+$ Glass $_{11}$ ) are consistent with the observed mineralogy and phase proportions calculated from the observed bulk and mineral chemistries (Pyroxene $_{50}+$ Plagioclase feldspar $_{28}+$ Sanidine feldspar $_{10}+$ Glass $_{12}$ ).

This study illustrates the usefulness of the generalized model MELTS for quantifying petrologic observations and the unique opportunities that artificial magmas generated by ISV provide for investigating petrologic processes.

${ }^{1}$ University of Washington, Seattle.

${ }^{2}$ New Mexico Bureau of Mines and Mineral Resources, Socorro.

\section{Organic Chelates Alter the Fate and Transport of Inorganic Contaminants Through Subsurface Environments}

\section{P. M. Jardine and G. K. Jacobs}

DOE facilities involved in defense-related activities have generated huge quantities 
of low-level radioactive mixed waste over the past several decades. The waste is composed of organically complexed contaminants, also known as cocontaminants, that are typically disposed of in shallow land burial sites.

Some of the most common cocontaminant mixtures involve ${ }^{60} \mathrm{Co},{ }^{90} \mathrm{Sr}$, and ethylenediaminetetra-acetate (EDTA).

The objeciive of this study was to provide an improved understanding of the geochemical processes controlling cocontaminant transport in heterogeneous, unsaturated subsurface media.

Large undisturbed columns $(14 \times 40 \mathrm{~cm})$ were isolated from a proposed waste site consisting of fractured saprolitic shale, and the steady-state unsaturated transport of Co(II)EDTA ${ }^{2-}, \operatorname{Co}$ (III)EDTA; and SrEDTA $^{2-}$ was investigated at $-10 \mathrm{~cm}$ pressure-head. This condition closely mimics the natural flow characteristics of the soil during storm events where most unsaturated flow occurs through mesopores and micropores.

The displacement studies indicated that the cocontaminants and the subsurface media were significantly modified by sorption, surface complexation, and redox reactions during transport. Subsurface $\mathrm{Fe}$ and $\mathrm{Al}$ sources effectively dissociated the SrEDTA $^{2-}$ cocontaminant, and $\mathrm{Sr}$ was transported as a reactive, uncomplexed species. The EDTA readily complexed with $\mathrm{Fe}$ and $\mathrm{Al}$; this resulted in significant solid-phase modification of the porous media through chelate-enhanced dissolution and redox alterations.

Displacement of Co(II)EDTA ${ }^{2-}$ through the subsurface media was characterized by a $\mathrm{MnO}_{2}$-mediated oxidation of the cocontaminant with subsequent formation of Co(III)EDTA: The latter cocontaminant was an extremely stable complex that was transported through the subsurface as a single, reactive entity. Although Co(III)EDTA ${ }^{-}$exhibited an overall retardation that was similar to the uncomplexed contaminant $\mathrm{Co}^{2+}$, sorption kinetics of the former were more sluggish in relation to $\mathrm{Co}$, and contaminant transport was accelerated in the presence of EDTA.

\section{Field-Scale Tracer Mobility During Storm Events Indicates the Importance of Multiregion Flow and Transport in Natural Subsurface Environments}

\author{
P. M. Jardine, G. V. Wilson, ${ }^{1}$ J. P. Gwo, ${ }^{2}$ \\ J. D. O'Dell, ${ }^{1}$ G. T. Yeh, ${ }^{2}$ and \\ R. J. Luxmoore
}

This research contributes to an improved understanding and predictive capability of in situ subsurface contaminant transport processes at DOE facilities. The objective of the project was to develop a field-scale experimental data base that will enable the validation of a novel three-dimensional transport model incorporating the transport processes of various pore scales (macro-, meso-, and micropores). Using the Melton Branch subsurface weir facility (Solid Waste Storage Area 7), we initiated a $\mathrm{Br}^{-}$ tracer release from a ridgetop buried line source during a storm event in order to simulate a leaky contaminated trench. The spatial and temporal variabilities of solute concentration and tracer fluxes were monitored for 10 storm events over a period of 7 months.

Tracer migration predominantly followed lateral stormflow in the upper 2-3 $\mathrm{m}$ of the soil and experienced little interaction with the groundwater system. The tracer plume was partially refracted in the direction of 
subsurface clay and fractured saprolite bedding planes that are perpendicular to the surface topography.

Macropores and mesopores were very significant in producing rapid tracer fluxes during storm events, and micropores served as a source/sink. Fifty percent of the nonreactive tracer still remained within this small pore region at the termination of the study ( 7 months). A cascading process of $\mathrm{Br}^{-}$transfer from small to large pores near the source was reversed at greater distances during sequences of drainage and redistribution.

A novel three-dimensional, multiregion flow and transport model was used to simulate the measured subsurface tracer fluxes exiting the subwatershed boundary. The model simulated flow and transport in the three distinct pore regions with interregion exchange treated $r$, means of a diffusion-type approximat..n.

Numerical simulations were in fair agreement with observed $\mathrm{Br}^{-}$transport data, and the results stressed the important contribution of pore-scale heterogeneities during flow and transport in natural subsurface environments.

${ }^{1}$ The University of Tennessee, Knoxville.

${ }^{2}$ Pennsylvania State University, University Park.

\section{Three-Dimensional Model of Fluid Flow and Multispecies Hydrogeochemical Transport Is Being Developed and Validated}

\author{
P. M. Jardine, G. T. Yeh, ${ }^{1}$ Z. S. Kooner, ${ }^{2}$ \\ and R. S. Turner
}

The purpose of this research is to develop, verify, and validate a generic three-dimensional fluid flow and multi- species hydrogeochemical transport model for assessing field-scale multispecies contaminant transport problems.

The specific objectives of the project are to (1) spatially characterize the key subsurface chemical and physical properties controlling contaminant mobility at a field facility on the Melton Branch watershed (Solid Waste Storage Area 7), (2) develop a three-dimensional fluid flow and hydrogeochemical transport model (3D HYDROGEOCHEM) equipped with an efficient and accurate numerical algorithm, and (3) validate the generic three-dimensional model in step 2 with measured fluxes and chemical distributions from the field facility by using input parameters obtained in step 1.

Experimental research has focused on the spatial characterization of surface and subsurface hydraulic properties, competitive electrostatic interactions, soil surface complexation reactions, soil indigenous cations and anions, soil $\mathrm{pH}$, soil cation and anion exchange capacities, soil organic matter content, and mineralogy of the clay fraction. The spatially characterized experimental data will then be used as input parameters for a newly developed three-dimensional fluid flow and multispecies hydrogeochemical transport model.

Successful field-scale modeling will require an efficient and accurate numerical algorithm, which will be obtained by modifying the Lagrangian-Eulerian approach with a new adaptive val grid refinement. The refinement gl. 'y reduces the number of nodes that rieed to be numerically zoomed and improves the accuracy of the computations.

The predictive capabilities of the model will be compared with those of stormdriven multi-species solute transport 
studies conducted at the field facility from 1990 to 1992 . Once validated, the model will allow engineers to develop remediation strategies to alleviate specific problems at complex waste sites with a higher probability of success.

${ }^{1}$ Pennsylvania State University, University Park. ${ }^{2}$ The University of Tennessee, Knoxville.

\section{$28{ }^{244} \mathrm{Cm}$ and ${ }^{241}$ Am Activities in Well 516 at SWSA 5 North Are Related to Hydrological Conditions in Waste Trenches}

\section{J. D. Marsh, Jr., T. L. Ashwood, and D. S. Hicks}

Well 516 at Solid Waste Storage Area 5 (North) has been monitored quarterly for the last 2.5 years due to its high alpha activity. The data obtained from these samples indicate that $95 \%$ of the gross alpha activity is due to ${ }^{244} \mathrm{Cm}$ and the remaining 5\% to ${ }^{241} \mathrm{Am}$. The ${ }^{244} \mathrm{Cm}$ correlates so well with the gross alpha activity $\left(r^{2}=97 \%\right)$ that the gross alpha activity could be used as an economical means for monitoring ${ }^{244} \mathrm{Cm}$ in this well.

The activities ranged from 7.1-220 Bq/L for ${ }^{244} \mathrm{Cm}$ and $0.057-7.0 \mathrm{~Bq} / \mathrm{L}$ for ${ }^{241} \mathrm{Am}$. Both the ${ }^{244} \mathrm{Cm}$ and ${ }^{241} \mathrm{Am}$ activities were lognormally distributed; thus the geometric mean is a better estimate of the "average" activities of these radionuclides. For the 2.5-year sampling period, the geometric mean for ${ }^{244} \mathrm{Cm}$ is $36.3 \mathrm{~Bq} / \mathrm{L}$ in comparison with its arithmetic average, 63.2. The geometric mean for ${ }^{241} \mathrm{Am}$ is $0.78 \mathrm{~Bq} / \mathrm{L}$ in comparison with its arithmetic average, $1.81 \mathrm{~Bq} / \mathrm{L}$.

A simple hydrological model can explain the observed levels of activity found during the wet and dry seasons. During the dry season, the water table is low; the number of waste trenches it intersects is limited to the deepest trenches. During the wet season, the water table rises above a threshold elevation (about $790 \mathrm{ft}$ above mean sea level), and the shallower trenches are below the water table. The ${ }^{244} \mathrm{Cm}$ and especially ${ }^{241} \mathrm{Am}$ activities increase at this level, as evidenced by the lower ${ }^{244} \mathrm{Cm}:{ }^{241} \mathrm{Am}$ ratios during the wet season. The lower ratios indicate an increased leaching of ${ }^{241} \mathrm{Am}$ from the trenches saturated only at high water levels.

\section{$29{ }^{244} \mathrm{Cm}$ and ${ }^{241}$ Am Activities in Well 516 at SWSA 5 North May Be Associated with Low Molecular Weight Organic Material}

\section{J. D. Marsh, Jr., J. F. McCarthy, and T. L. Ashwood}

Routine monitoring of Well 516 at Solid Waste Storage Area 5 (North) reveals activities of ${ }^{244} \mathrm{Cm}$ and ${ }^{241} \mathrm{Am}$ as high as $220 \mathrm{~Bq} / \mathrm{L}$ and $7.0 \mathrm{~Bq} / \mathrm{L}$, respectively. $\mathrm{A}$ field investigation was initiated to determine the mode and rate of transport of these radionuclides from the waste trench area.

Because adsorption of actinides onto colloidal particles is a well-known means of transport from waste burial sites, a series of filtration steps was used to isolate different particle sizes to identify the size range associated with the alpha activity. Particle sizes of $0.45 \mu \mathrm{m}, 0.1 \mu \mathrm{m}, 100,000$ $(100 \mathrm{~K})$ daltons, and 3000$)(3 \mathrm{~K})$ daltons were sampled by in-line milli-Q filters ( $0.45 \mu \mathrm{m}$ only) and hollow-fiber filtration systems.

The results show no alpha activity in the size fractions above $100 \mathrm{~K}$ daltons, and only 
$5 \%$ of the ${ }^{244} \mathrm{Cm}$ activity was found between the $3 \mathrm{~K}$ and $100 \mathrm{~K}$ fractions; thus, $95 \%$ of the ${ }^{244} \mathrm{Cm}$ and $100 \%$ of the ${ }^{241} \mathrm{Am}$ are in the $<3 \mathrm{~K}$ fraction. Therefore, most of the alpha activity appears in the dissolved state (defined as $<3 \mathrm{~K}$ daltons) and is not being transported by colloidal particles. Also, about $95 \%$ of the dissolved organic matter was found in the $<3 \mathrm{~K}$ fraction, and the remaining $5 \%$ was in the $3 \mathrm{~K}$ to $100 \mathrm{~K}$ region.

Finding both the alpha activity and the organic matter in the dissolved fraction suggests that the ${ }^{244} \mathrm{Cm}$ and ${ }^{241} \mathrm{Am}$ are forming complexes with organic matter that has low molecular weight ( $<3 \mathrm{~K}$ daltons) and that they are staying in solution. This conclusion is consistent with a moderate migration rate for ${ }^{244} \mathrm{Cm}$, whose migration rate is calculated to be $2 \mathrm{~m} /$ year on the basis of the ${ }^{240} \mathrm{Pu}:{ }^{244} \mathrm{Cm}$ ratio.

This work has important implications for the hydrogeochemical modeling of contaminant transport as well as for any type of remediation technique to be applied to this site.

\section{Mercury(II) Adsorption in the Presence of lodide Is Examined}

\section{W. P. Hamilton ${ }^{l}$ and R. R. Turner}

Recent developments in soil decontamination technology have stimulated further investigation into the soil chemistry of mercury and halides. Mercury forms strong complexes with halides, with solubilities and complex formation constants varying over several orders of magnitude.

Because of excess chluride in natural systems, chloride-mercury interactions have been thoroughly investigated; however, information on the interactions of mercury with other less abundant halides is lacking. Due to a new soil-washing technique (patented by General Electric) that employs the use of an $\mathrm{I} / \mathrm{I}_{2}$ lixiviant, the consequences of residual $\mathrm{I}^{-}$on the mobility of mercury in the environment are of interest.

Research has begun in ESD to investigate the effects of trace concentrations $(\mu \mathrm{g} / \mathrm{L})$ of $I-$ on the adsorption of mercury to clays. Work by others indicates that $\mathrm{Cl}^{-}$reduces mercury adsorption to clays and that $\mathrm{pH}$ is an important parameter, affecting both the surface charge of the adsorbent (clay) and the speciation of the adsorbate (mercury complexes).

In addition, studies show that organic matter may affect the mobility of mercury, even in the presence of strong inorganic complexors such as chloride, either by forming strong complexes with the soluble organic fraction or by adsorbing , particulates.

Results from studies incorporating the radiotracer ${ }^{203} \mathrm{Hg}$ show, in contrast to the chloride system, that iodide enhances adsorption of mercury to clays such as kaolinite and illite. Additionally, the presence of iodide appears to reduce the volatile loss of mercury by strongly binding it in the aqueous phase as $\mathrm{HgI}_{2}$.

This complex is a potentially important part of the adsorption reaction, either because it enables a surface reaction to proceed or because iodide has its own affinity for the clay. Further experiments will examine the effects of $\mathrm{pH}$ and organic matter on the sorptive behavior of mercury in iodide-enriched media.

\footnotetext{
${ }^{\prime}$ The University of Tennessee, Knoxville.
} 


\section{Technique Is Developed for Field Analysis of Mercury in Water}

\section{A. A. Krigerl and R. R. Turner}

Techniques for rapid field analysis of mercury in water, sediment, and soil samples are needed to permit immediate screening of these environmental media. Such a screening capability could be costeffective because it would improve guidance in selecting sites for sampling for laboratory analysis and it could be used to more accurately and efficiently direct cleanup activities.

We developed a method for water analysis that involves chemical pretreatment and an analysis of the headspace mercury vapor through the use of a portable, commercially available analyzer. Samples are collected and analyzed in ordinary polypropylene bottles. A reductant (stannous chloride) is added to the sample, and the sample is shaken manually for $1 \mathrm{~min}$.

Aided by vigorous agitation, the $\mathrm{Hg}^{0}$ partitions between the solution and the headspace according to Henry's Law. The headspace vapor is analyzed through the use of a Jerome Model 411 Gold Film mercury analyzer. Preliminary experiments with mercury-dosed water samples indicate that a linear response is obtained for $\mathrm{Hg}^{0}$ over the range of $0.1 \mu \mathrm{g} / \mathrm{L}$ to $30 \mu \mathrm{g} / \mathrm{L}$, with excellent agreement between theoretical and experimental values.

Additional analytical figures of merit include high sensitivity, selectivity, a low limit of detection $(0.1 \mu \mathrm{g} / \mathrm{L})$, and a linear response over almost three orders of magnitude. The method is rapid (10 s per measurement after extraction/reduction), inexpensive, and free of matrix interferences encountered using other methodologies. Furthermore, the method requires only a small amount of sample (10-100 $\mathrm{mL}$ of water), and generates less hazardous waste than existing techniques. Ongoing effort is directed toward soil and sediment extraction.

'Oak Ridge Institute for Science and Education, Oak Ridge, Tennessee.

\section{First National Symposium on Measuring and Interpreting VOCs in Soils Documents Urgent Need for Change}

\section{R. L. Siegrist}

Volatile organic compounds (VOCs) are the most prevalent contaminants at sites across the United States and abroad. However, the conventional measurement and interpretation process may hamper the overall effectiveness of site assessment and remedial action at VOCcontaminated sites. To address this issue, a national symposium was convened on January 12-14, 1993, in Las Vegas. The symposium was sponsored by the U.S. Environmental Protection Agency and coordinated by ORNL.

Attended by over 300 people, the symposium explored the foundation of the conventional VOC measurement and interpretation process and examined results from research and practice that have advanced the understanding of this process. The results of the symposium are now being documented in a proceedings white paper. VOC properties and behavior in soil were shown to exacerbate the measurement process. Sound decision making remains an elusive task, in terms of determining both the critical questions and the data required to support effective 
decisions. On-site screening and analytical techniques can enhance data sufficiency for decision making; however, their use has been hindered by lack of standard procedures and performance data.

A critical examination of current approved methods for characterizing soil regions revealed serious deficiencies. VOCs measured in bulk soil samples containerized and preserved at $4^{\circ} \mathrm{C}$ and analyzed after being held a few days consistently yielded results that were several orders of magnitude lower than results obtained from samples more rigorously preserved (e.g., through in-field immersion in inethanol). This was true for organic solvents and petroleum hydrocarbons. Moreover, prediction of VOCs at unobserved locations by spatial modeling techniques often deviated by one to two orders of magnitude from the subsequent measured values. These findings suggested that many VOC-contaminated sites have been and are being improperly characterized. Changes in current practice were deemed critical and included use of sample screening and compositing methods, better preservation techniques, and greater use of in-field analytical techniques.

\section{In Situ Treatment of Contaminated Soil Uses Physicochemical Processes in a Continuously Mixed Subsurface Soil Reactor}

\section{R. L. Siegrist, M. I. Morris, O. R. West, D. A. Pickering, D. T. Davenpori, D. D. Gates, R. A. Jenkins, and T. J. Mitchell}

Fine-textured soils contaminated by trichloroethylene and other chlorinated solvents present a serious environmental restoration challenge at DOE sites. The
X-231B Solid Waste Management Unit at the Portsmouth Gaseous Diffusion Plant (POR'TS) presented such a challenge. Formerly used as a land disposal site for waste oils and solvents, the soil and groundwater beneath the X-231B Unit were contaminated by volatile organic compounds (VOCs) and radioactive substances. Conventional treatment approaches were judged either technically infeasible or too costly.

The X-231B Technology Demonstration project was initiated by DOE and Energy Systems at ORNL in July 1991. During the past year, numerical analysis and modeling, laboratory experimentation, and full-scale field testing have been completed.

Directed by ESD, the project has integrated contributions of research and technical staff from six divisions at ORNL and principal collaborators from The University of Tennessee and Michigan Technological University, along with support from several private industries. As a result of this effort, we have demonstrated an in situ treatment approach that couples selected physicochemical processes in continuously mixed subsurface soil reactors to either vaporize, oxidize, or immobilize contaminants in situ.

Treatment processes can be combined or used individually. Treatment of soil VOCs can be effectively and rapidly accomplished (e.g., $>85 \%$ efficiency at $>20$ tons $/ \mathrm{h}$ ) while limiting worker exposure and controlling the fate of VOCs and radioactive substances. Moreover, in situ treatment costs appear to be substantially lower than available ex situ technologies. The Portsmouth plant is using the demonstrated processes for effective closure and remediation of solid waste management units, saving several million dollars. 
This project clearly demonstrates the benefits gained from fast-track, focused research and demonstration activities, by which technical resources at a DOE national laboratory are coupled with those of academia and private industry to solve pressing environmental problems at a $\mathrm{DOE}$ site.

\section{Automated pH Control System Saves Transport and Treatment Costs for Waste Management Operations}

\section{M. Morrissey and D. F. Hall}

The Waste Management Operations (WMO) Group and ESD at ORNL instituted the Active Sites Environmental Monitoring Program (ASEMP) in 1989 to comply with the environmental monitoring requirements of DOE Order 5820.2A, which governs radioactive waste disposal. One aspect of the ASEMP involves monitoring effluent from the tumulus-type concrete low-level (radioactive) waste (LLW) disposal facilities in Solid Waste Storage Area 6 (SWSA 6). The objectives of the monitoring activities are twofold-early detection of contaminant release and assessment of long-term performance. Samples of the effluent from the tumulus facilities are routinely collected and assayed for radiological parameters as well as field parameters such as $\mathrm{pH}$. Sample analyses revealed that the effluent $\mathrm{pH}$ frequently exceeded the National Pollutant Discharge Elimination System (NPDES) limit of 9.0. The possibility of a permit violation forced WMO to contain and transport the effluent to the Process Waste Treatment Plant. The costs of containing, pumping, transporting, and treating the runoff increased the expense of solid LLW disposal at SWSA 6 considerably.
As a result, WMO asked ASEMP to design, install, and operate a $\mathrm{pH}$ control system at the newest of the tumulus-type facilities, the Interim Waste Management Facility. This $\mathrm{pH}$ control system involves bubbling $\mathrm{CO}_{2}$ through the effluent water before discharge through the NPDES outfall. The remote location and quantity of effluent released required that the system be automatically controlled and designed to minimize the amount of $\mathrm{CO}_{2}$ used.

The system uses a pressure transducer and a $\mathrm{pH}$ probe to monitor flow and $\mathrm{pH}$, respectively. The transducer and probe are electronically connected to a data logging system. The data logger is also connected to a pair of solenoid valves that control the flow of $\mathrm{CO}_{2}$. The logger supplies digital signals to the valves that instruct one valve to open when there is flow from the disposal units and the other valve to open when the effluent $\mathrm{pH}$ exceeds a setpoint.

The system has proven to be a very lowcost, effective means of controlling $\mathrm{pH}$. The WMO group has saved thousands of dollars in transport and treatment costs while eliminating the possibility of violating the NPDES permit. Such a system is applicable to other concrete-based waste disposal facilities that must meet permitted $\mathrm{pH}$ limits in their discharge waters.

\footnotetext{
${ }^{1}$ Waste Management and Remedial Action Division, ORNL.
}

\section{Cryogenic Immobilization of Tritiated Groundwater Is Studied}

\section{D. Gates}

Preliminary investigations have been initiated to determine the feasibility of 
employing cryogenic immobilization as an environmental restoration technique at an ORNL solid waste storage area.

This technology can be used to form a subsurface frozen barrier with multiple treatment and containment capabilities. The application being considered for ORNL Solid Waste Storage Area 5 (SWSA 5) includes completely surrounding a tritium-contaminated waste disposal trench with a frozen barrier 5-10 ft thick.

The objective of this activity would be twofold: (1) to contain tritium-contaminated groundwater within the frozen barrier and (2) to prevent the migration of nontritium-contaminated groundwater into the tritium source trench.

Successful demonstration of this technology will require the coordination of several ORNL divisions and many outside agencies such as the U.S. Army Corps of Engineer's Cold Regions Research and Engineering Laboratory and other private vendors. This activity includes a feasibility study, pilot-scale treatability study, and a full-scale field demonstration.

Areas requiring further research and investigation, prior to the initiation of the full-scale demonstration, include the suitability of the soils at SWSA 5 for ground freezing, the structural and remedial integrity of the frozen soil barrier formed, the characteristics of the soils once ground freezing has ceased, the extent of soil heaving (expansion) during ground freezing, and the effect of heaving on trench contents.

The experience and information obtained from this study and field demonstration could be used extensively in the restoration of contaminated waste sites.
36 Subsurface Contaminant Availability Is Measured, and Oxidation and German Recirculation Technologies Are Evaluated

\section{O. F. Webb}

Research during the previous year centered on improving subsurface remediation methods and on improving techniques for scale-up and implementation. We evaluated different German environmental restoration technologies for DOE use. Several countries, in particular Germany, have significant research and development programs in environmental restoration. Germany has a significant environmental legacy from the world wars and industrialization.

A German vertical well recirculation technology shows promise. The well produces recirculation in the aquifer by withdrawing groundwater at the base of the well and reinjecting it at the top of the aquifer. Treatment occurs as the groundwater passes through the well.

The technology has a number of advantages over present technologies. Further investigation identified modifications to improve the treatment efficiency of this technology by up to two orders of magnitude. In an unrelated study, we investigated oxidation processes for destroying subsurface contaminants in place.

Hydrogen peroxide shows promise for destruction of hydrocarbon and polycyclic aromatic hydrocarbon contamination at the Wilsonville, Alabama, gasification site. This work is in its initial stages. New methods also are being studied to better measure contaminant transport, mass transfer, and adsorption in soil. These properties control the availability of 
contaminants in soil; however, natural soil heterogeneities make them difficult to measure.

Contaminants must be available in the liquid phase for destruction or removal. Appropriate measurement of these properties reduces scale-up costs and improves our ability to implement treatment in a cost-effective and timely manner. Measurement methods include frequency response analysis and moments analysis by use of adsorbed and nonadsorbed pulse and square waves. Bioluminescent reporter strains also are being investigated for use as remote sensors for measuring contaminant availability.

${ }^{1}$ Oak Ridge Institute for Science and Education, Oak Ridge, Tennessee.

\section{Soil Containing ${ }^{137} \mathrm{Cs}$ Can Be Decontaminated}

\section{B. P. Spalding}

The strong adsorption or fixation of ${ }^{137} \mathrm{Cs}$ to soil and sediment is essentially irreversible because of the ubiquitous presence of the causative illitic minerals. This characteristic results in contaminated soil within and around radioactive waste disposal sites and in sediment of streams and rivers that have received discharges from nuclear facilities, including DOE operations and nuclear-powered electricity generating plants. Because of the 30-year half-life of ${ }^{137} \mathrm{Cs}$, untreated soil and sediment will remain contaminated for hundreds of years before radioactive decay eliminates the hazard.

Efforts to decontaminate or restore soil and sediment to an uncontaminated state or to some de minimis activity level have not been attempted, because no effective decontamination process or technique has been developed. However, researchers have recently found that ${ }^{137} \mathrm{Cs}$ can be removed from soil (or soil plus crushed limestone) by thermal treatment between 800 and $1000^{\circ} \mathrm{C}$ in the presence of chloride-containing materials. Effective sources of chloride include sodium chloride, calcium chloride, hydrochloric acid, and polyvinyl chloride. The thermal treatment breaks down the illitic mineral structure that is responsible for the strong fixation of ${ }^{137} \mathrm{Cs}$ by most contaminated soils. Chloride is then available to complex with ${ }^{137} \mathrm{Cs}$; the complex, carrying $>99 \%$ of the ${ }^{137} \mathrm{Cs}$ present, is subsequently or concurrently distilled from the soil, leaving dehydrated soil solids in the residuum.

\section{Background Soil Characterization Project Provides Data for Risk Assessment of Contaminated Sites}

\author{
D. R. Watkins, J. T. Ammons, ${ }^{\prime}$ \\ J. L. Branson, ' B. B. Bungoa,' \\ P. L. Goddard, ${ }^{2}$ T. L. Hatmaker, ${ }^{3}$ \\ L. A. Hook, B. L. Jackson, \\ C. W. Kimbrough, ${ }^{4}$ S. Y. Lee, \\ D. A. Lietzke, ${ }^{5}$ C. W. McGinn, ${ }^{3}$ \\ B. D. Nourse, ${ }^{3}$ R. L. Schmoyer, ${ }^{6}$ \\ R. A. Shaw, ${ }^{3}$ S. E. Stinnette, \\ J. Switek, and J. C. Wright
}

The Background Soil Characterization Project (BSCP) provides background concentration data on potential contaminants (organic compounds, metals, and radionuclides) in natural soils that are key to Environmental Restoration (ER) projects on the Oak Ridge Reservation (ORR).

The objectives are to provide fully validated and defensible baseline data for contaminated-site assessment and to provide estimates of background risk 
associated with concentrations of potentially hazardous substances and other constituents in native soils. The BSCP addresses variability of concentration levels in terms of major soil types occurring in different geologic formations, soil sampling depths (horizons) within a specific soil profile, and natural variations in soils developed in the same geologic formations.

Soils from the Conasauga Group were sampled in Phase I of the project. ESD is involved in this 2-year field project for the ER Program. To date, all field sampling work and subsequent analytical laboratory analyses have been completed, and Phase I and Phase II data, validated.

Analysis and interpretation of Phase I data indicate consistency in most constituents of interest and in the levels of risk associated with background concentrations of soil constituents in sampling sites on ORR and in sites in remote areas of Roane and Anderson counties.

${ }^{1}$ The University of Tennessee, Knoxville.

${ }^{2} \mathrm{~K}-25$ Site Program Office, ORNL.

${ }^{3}$ Health Sciences Research Division, ORNL. ${ }^{4}$ Analytical Projects Office, Martin Marietta Energy Systems, Inc.

${ }^{5}$ Consultant, Rutledge, Tennessee.

${ }^{6}$ Engineering Physics and Mathematics Division, ORNL.

39 Microplots and Rainfall Simulators Simultaneously Measure Runoff Losses of Contaminant and Sediment Transport During Storms

\section{B. B. Burgoa' and R. D. Wauchope ${ }^{2}$}

Quantifying soluble contaminant losses in runoff and leaching solutions is an important step in understanding and preventing surface and groundwater pollution from nonpoint sources. Contaminants lost in runoff are associated also with eroded soil particles (i.e., sediment) and erosion processes.

The advantages of laboratory studies that use microplots include reduced cost and time, as well as precise control over variables that affect soil erosion and chemical transport (e.g., soil type, slope, initial soil water content, leaching rate, and intensity and length of rainfall).

Such advantages are almost impossible to achieve in field studies. Extrapolation of microplot results to larger-scale studies (e.g., field or watershed) may be a limitation.

To examine plot-scale effect, 300 tests conducted after the first event following pesticide application were compared for plot sizes ranging from $1 \mathrm{~m}^{2}$ to 5 ha.

The observed difference between the chemical losses of microplots and those of larger-scale experiments was a result of rainfall intensity and timing after pesticide application. However, plot size did not correlate with losses when the data were normalized by the volume and timing of runoff.

Microplots and rainfall simulators are useful tools in studying the physical and chemical factors that may control sediment and contaminant transport. Microplot data should provide an excellent test for a watershed integrated model that attempts to simultaneously analyze runoff and leaching losses of soluble contaminants.

\footnotetext{
${ }^{1}$ The University of Tennessee, Knoxville.

${ }^{2}$ U.S. Department of Agriculture, Tipton, Georgia.
} 


\section{Grouting of Low-Level Radioactive Waste Disposal Silos Is Completed}

\author{
C. W. Francis, C. D. Farmer, and \\ R. G. Stansfield
}

At ORNL, one method of solid low-level radioactive waste disposal is the use of below-grade cylindrical concrete silos. Located in Solid Waste Storage Area 6 (SWSA 6), each silo measures $8 \mathrm{ft}$ in diameter and $20 \mathrm{ft}$ deep. Water had accumulated in the bottom of $-75 \%$ of the silos. The silo water (leachate) contained a wide range of types and concentrations of radionuclides. To remediate potential migration of contaminated leachate out of the silo into adjoining soil and groundwater, the silos were injected with a particulate-based grout.

Grouting involved three steps: (1) silo preparation, (2) formulation and preparation of the grout mixture, and (3) injection of the grout into the silos. Thirty-five of the 54 silos grouted were equipped with a 3 -in.-diam polyvinyl chloride (PVC) pipe used to monitor water levels in the silos.

A method for rupturing the bottom section of these PVC wells was developed so that grout could be pumped to the bottom of those silos. Holes (2 in. diam) were drilled through the $\sim 18$-in.-thick concrete to fill the remaining 19 wells without the PVC monitoring wells.

The formulation of grout injected into the silos was based on a Portland Type I cement, flyash, sand, and silica fume admixture. Compressive strength of grout delivered to SWSA 6 during grouting operations averaged $1808 \mathrm{lb} / \mathrm{in}^{2}{ }^{2}$ with a bulk density of $3549 \mathrm{lb} / \mathrm{yd}^{3}$.
Injection of grout into the 19 silos without the PVC monitoring wells was very poor (average of $2.5 \mathrm{yd}^{3}$ per silo). However, for the silos with monitoring wells, an average of $11.4 \mathrm{yd}^{3}$ of grout was injected per silo. Considerably less grout could be injected into the silos that contained contaminated soil.

For example, for those silos equipped with PVC monitoring wells, only $7.9 \mathrm{yd}^{3}$ of grout could be injected into silos that contained contaminated soil, as compared to $12.7 \mathrm{yd}^{3}$ in those silos that did not contain contaminated soil.

'Geotechnical consultant.

\section{Interaction Between Vegetation and Soil Is Influenced by Global Change}

\author{
W. M. Post, J. Pastor,' A. W. King, and \\ W. R. Emanuel
}

The terrestrial biosphere is an important component in determining the concentration of $\mathrm{CO}_{2}$ in the earth's atmosphere. Changes in atmospheric $\mathrm{CO}_{2}$ since 1860 have possibly changed the balance between global net primary productivity and decomposition. To evaluate this possibility, we needed to determine whether the experimental observations on plant growth affect carbon storage in ecosystems.

Experimental results for forest ecosystems currently were not available, so we used a forest gap model to evaluate several potential effects of elevated atmospheric $\mathrm{CO}_{2}$ on organic matter storage in ecosystems. These analyses focused on some aspects of ecosystem carbon dynamics; however, they ignored many processes and interactions that must be considered to give accurate estimates of changes in 
carbon storage within forest ecosystems as a result of global changes in climate and atmospheric $\mathrm{CO}_{2}$ concentration.

Contrary to previous $\mathrm{CO}_{2}$ fertilization experiments using forest gap models, we showed that considerable potential exists for increasing carbon storage in forest ecosystems because of plant responses to elevated $\mathrm{CO}_{2}$ levels. All potential plant responses examined (increased annual basal area increment, decreased water use, and increased allocation of carbon and nitrogen to roots) have the potential to increase organic matter in forest ecosystems.

The amount of increased organic matter storage depends on species composition, water holding capacity in soil, and resultant nitrogen dynamics. Most changes in storage occur in aboveground biomass. The litter and soil organic matter pools change very little between model experiments.

The enhancement of net ecosystem production is relatively short lived, however. The difference in ecosystem carbon storage between nominal plant response and potential $\mathrm{CO}_{2}$-enhanced responses does not increase after 100 years.

Carbon storage over long periods of time on soils with good water holding capacity can be increased on average by $25 \%$, with $50 \%$ increases in basal area increment. Increases in carbon storage can be even greater in water-limited forest ecosystems.

The indirect effect of reduced transpiration can have even greater effects than the direct $\mathrm{CO}_{2}$ growth effects on carbon storage in water-limited forest ecosystems.

\footnotetext{
${ }^{1}$ University of Minnesota, Duluth.
}

\section{Interhemispheric Ocean Carbon Transport Affects Global Carbon Cycle}

\author{
T.-H. Peng
}

During the $1980 \mathrm{~s}$, observed partial pressures of atmospheric $\mathrm{CO}_{2}$ at high latitudes in the Northern Hemisphere were an average $3 \mu \mathrm{atm}$ higher than those over Antarctica. By contrast, Tans et al. predicated a pole-to-pole meridional $\mathrm{pCO}_{2}$ gradient of 5.7 to $7.3 \mu \mathrm{atm}$. $^{1}$

Furthermore, the researchers concluded that the growth rate of the terrestrial biota may have been enhanced, presumably, by $\mathrm{CO}_{2}$ fertilization in the northern temperate region. They suggested that such terrestrial sinks could be as large as 2.0 to $3.4 \mathrm{Pg}$ of carbon per year. The unexpected lower $\mathrm{pCO}_{2}$ gradient observed in the atmosphere could also be explained, however, by a reverse atmospheric $\mathrm{CO}_{2}$ gradient prior to the industrial revolution.

Keeling and Heimann proposed a south-tonorth interhemispheric transport of $\sim 1 \mathrm{Pg}$ of carbon through the atmosphere during preindustrial times. ${ }^{2}$ If such transport existed, it would have been compensated by a southward transport of carbon through the ocean; thus, to evaluate the proposed mechanism for carbon transport through the atmosphere, we can examine the interhemispheric transport of carbon through the ocean.

Carbonate chemistry and nutrient data obtained during several global ocean survey programs were analyzed to evaluate the potential latitudinal gradient of total dissolved inorganic carbon in seawater. Results of this analysis give an estimate of a difference of $\sim 80 \mu \mathrm{mol} / \mathrm{kg}$ of $\mathrm{\Sigma CO}_{2}$ between southward-flowing deep water 
and the northward-flowing waters, which, assuming a dcep flow of 20 sverdrups, is equivalent to $\sim 0.6 \mathrm{Pg}$ of carbon each year that would be transported from north to south through the Atlantic conveyor circulation in preindustrial times. The excess carbon transported to the Southern Hemisphere in this way would eventually increase the partial pressure of atmospheric $\mathrm{CO}_{2}$ in the Southern Hemisphere. This would create a reverse atmospheric $\mathrm{CO}_{2}$ gradient of $\sim 1.2 \mu \mathrm{atm}$ before the industrial revolution. The results of this study support the idea that a natural reverse atmospheric gradient may have played an important role in affecting the current north-south distribution of atmospheric $\mathrm{CO}_{2}$.

${ }^{1}$ P. P. Tans, I. Y. Fung, and T. Takahashi, "Observational Constraints on the Global Atmospheric $\mathrm{CO}_{2}$ Budget, " Science 247, 1431-38 (1990).

${ }^{2} C$. D. Keeling and M. Heimann, "Meridional Eddy Diffusion Model of the Transport of Atmospheric Carbon Dioxide. Part 2. Mean Annual Carbon Cycle," J. Geophys. Res. 91, 7782-96 (1986).

\section{Terrestrial Biosphere} Response to Land-Use Change and Increasing Atmospheric $\mathrm{CO}_{2}$ Is Studied

\section{A. W. King, W. R. Emanuel, and W. M. Post}

In models that simulate land-use change, the fate of carbon in affected ecosystems and the consequent exchange of $\mathrm{CO}_{2}$ with the atmosphere appear to be high because the models do not allow for enhanced carbon assimilation by the biosphere in response to increasing atmospheric $\mathrm{CO}_{2}$. We examined this hypothesis with a model of biosphere response to changes in land use.
Model inputs specify the areas affected by land-use change from 1700 to the present by geographical region and ecosystem type. The dynamics of the affected areas are described by a compartment model of carbon in vegetation, litter, and soil.

As forests recover from harvest and agricultural lands are abandoned and recover, vegetation growth is modeled as the difference between net primary production (NPP, which is the net flux of carbon from atmosphere to vegetation) and mortality. The response of NPP to atmospheric $\mathrm{CO}_{2}$ is proportional to the logarithm of the ratio of current to preindustrial $\mathrm{CO}_{2}$.

Published values of the proportionality constant $\beta$ range between 0.25 and 0.5 . When $\beta=0$ (no response to $\mathrm{CO}_{2}$ ), our estimate of land-use emissions is virtually identical to that of other models that use the same history of land-use change, and our global carbon cycle simulations that use these emissions overestimate recent changes in atmospheric $\mathrm{CO}_{2}$. With $\beta=0.5$, our estimate of land-use emissions is reduced, but the reduction is not sufficient for satisfactory agreement between simulated and observed atmospheric $\mathrm{CO}_{2}$. Even an extreme $\beta$ value of 1.0 does not provide satisfactory agreement.

The insensitivity of our model to increasing $\mathrm{CO}_{2}$ is contrary to results from other models that achieve reasonable agreement with $\beta$ near 0.3 . The difference is attributable to our more detailed treatment of land-use change and our choice of a nonlinear logistic function to describe NPP instead of the linear formulation more commonly used.

The logistic function is more defensible on ecological grounds. Thus, our model 
results do not support the hypothesis that land-use emission estimates are high because they do not include $\mathrm{CO}_{2}$ fertilization of ecosystem carbon storage.

\section{Mercury Emission Rates Over Contaminated Soils Are Measured}

K.-H. Kim, S. E. Lindberg, P. J. Hanson, T. P. Meyers, ${ }^{1}$ and J. G. Owens

To elucidate the factors and processes controlling the biogeochemical cycle of mercury in the forest environment, we are working with the Atmospheric Turbulence and Diffusion Division of the National Oceanic and Atmospheric Administration in developing and testing various field and laboratory methods (micrometeorological, dynamic enclosure chamber, and controlled laboratory chambers) for estimating the atmosphere-surface exchange of vaporphase $\mathrm{Hg}\left(\mathrm{Hg}^{\circ}\right)$.

To test the applicability of micrometeorological methods, we measured $\mathrm{Hg}^{\circ}$ emissions over contami-nated soils, using the modified Bowen ratio method (March to April 1993). The soils are on the forested floodplain of East Fork Poplar Creek (EFPC) near Oak Ridge, Tennessee, which was contaminated by $\mathrm{Hg}$ from the Oak Ridge Y-12 Plant.

Our measurements of $\mathrm{Hg}^{\circ}$ emission rates of the EFPC soils indicate that (1) in all cases, the contaminated soils acted as a source of $\mathrm{Hg}^{\circ}$ to the atmosphere (source strengths ranged from 17 to $160 \mathrm{ng} \cdot \mathrm{m}^{-2} \cdot \mathrm{h}^{-1}$, so the emissions were orders of magnitude higher than the emissions from background soils) and (2) the strengths of $\mathrm{Hg}^{\circ}$ emissions can be greatly influenced by the combined effects of surface soil temperature, residence time of air masses over the source area, and turbulence conditions.

A laboratory-controlled flow chamber system was also used at $30^{\circ} \mathrm{C}$ to assess the potential role of contaminated soils as sources of $\mathrm{Hg}^{\circ}$ during midsummer conditions. These results suggest that contaminated soils can exhibit emission rates of $\mathrm{Hg}$ that are up to an order of magnitude higher under more favorable conditions (e.g., elevated soil temperature, soil structure disturbance, and high turbulence).

The contaminated EFPC soils, unlike clean background soils that act as both sources and sinks of $\mathrm{Hg}^{\circ}$ to the atmosphere, can clearly serve as a significant repository of airborne $\mathrm{Hg}^{\circ}$ within the given locality.

${ }^{1}$ Atmospheric Turbulence and Diffusion Division, National Oceanic and Atmospheric Adminis. tration, Oak Ridge, Tennessee.

\section{Throughfall Studies in the Smoky Mountains Indicate Significant Effect.; of Forest Canopy Gaps and Edges on Atmospheric Deposition}

\section{S. E. Lindberg and J. G. Owens}

The health and functioning of forest ecosystems in mountain terrain are recognized as important indicators of environmental stress. High-elevation forests are exposed to unusually high rates of atmospheric deposition. Mountain forests are often characterized by extremes in canopy density and topographical features that influence deposition rates.

The resultant fluxes in highly complex terrain are impossible to quantify by 
conventional micrometeorological methods. We established an extensive network for collection of precipitation events to measure hydrologic and sulfate fluxes in rain and in throughfall beneath the canopies of several high-elevation forest stands in the Great Smoky Mountains National Park during the summers of 1989 and 1990.

The throughfall data were used as deposition surrogates to quantify trends in atmospheric deposition as influenced by cloudwater and by canopy structure (as represented by sapling trees growing in forest gaps and forest trees surrounding each gap). The paired gap/edge stands were located above $(1940 \mathrm{~m})$ and below $(1720 \mathrm{~m})$ the base of the clouds typically impacting this mountain.

As expected, clouds exerted a strong effect on inputs; both water and sulfate fluxes were up to two times greater beneath the forest edge at the cloud-prone 1940-m site than at $1720 \mathrm{~m}$. However, the presence of a forest edge showed an even stronger influence; total hydrologic and sulfate fluxes beneath the edge trees exceeded fluxes beneath the adjacent gap saplings by as much as a factor of 3 at both elevations.

Estimates of sulfate deposition from cloud impaction were consistent with net throughfall (throughfall flux minus rain flux) sulfate fluxes at the $1940-\mathrm{m}$ forest edge; however, estimates greatly exceeded net throughfall sulfate flux at the 1940-m gap, suggesting differences in ion concentrations in cloud droplets impacting mature, edge trees vs sapling trees in forest gaps. This observation has important implications for cloud water deposition modeling based on typical measurements of cloud water chemistry.

\section{Partitioning and Removal of Radionuclides in Conventional Wastewater Treatment Plant Are Investigated}

\author{
I. L. Larsen, H. L. Boston, E. H. Stetar, ${ }^{1}$ \\ and M. H. Mobley ${ }^{2}$
}

The Oak Ridge Wastewater Treatment Plant receives radionuclides from a variety of sources, including industry and hospitals, as well as naturally occurring radionuclides associated with storm runoff.

Depending on their chemical form and partitioning behavior, these radionuclides either remain in solution or become associated with particulate material and accumulate in the digested sludge.

Radionuclides associated with the sludge are disposed of by land application, whereas the soluble radionuclides are discharged with the effluent into a nearby stream.

To determine the degree to which certain radionuclides are partitioned during processing, tracer solutions of radiocobalt, radiocesium, and radioiodine were introduced into the plant influent as a pulse source. Samples were collected over time at the various processing stages and analyzed for radioactivity.

Results of the investigation indicate that $3-5 \%$ of radioactive iodine, approximately $31 \%$ of radiocobalt, and about $12 \%$ of radiocesium are removed from the influent. The remaining fractions of the radiotracers remained with the soluble phase of the wastewater and were discharged with the treatment plant effluent.

These investigations are providing information needed to establish radionuclide 
limits for inputs to municipal wastewater systems and to safely manage treatment plant discharges and sludge disposal.

${ }^{1}$ Performance Technology Group, Inc., Nashville, Tennessee.

${ }^{2}$ Director, Tennessee Division of Radiology and Health, Nashville, Tennessee.

\section{Data on Water Quality in Upper Bear Creek Support Recommendation to Reduce Monitoring Effort at BCK-12.46}

\section{A. Bogle and R. R. Turner}

To evaluate a recommendation for consolidating monitoring efforts on upper Bear Creek by discontinuing the weekly monitoring at Bear Creek kilometer (BCK) 12.46 in favor of the downstream BCK 11.97, ESD staff statistically analyzed the available water quality data.

Water quality at BCK 11.97 was expected to be more inclusive and representative of groundwater and surface water contamination from the S-3 Ponds because this site receives flow from two sources (a tributary, NT-1, and a spring, SS-1) known to be contaminated by the plume from the S-3 Ponds. Statistical analysis (paired $t$-tests) of water quality data showed significant differences between the two sites for most of the constituents whose concentrations exceeded minimum detection limits. Concentrations were usually higher and more variable for the downstream site, BCK 11.97.

In addition, examination of limited water quality data for NT-1 and SS-1 indicated that neither source was likely to dilute contaminant concentrations in Bear Creek and that NT-1 was likely to contribute significant quantities of certain constituents (e.g., $\mathrm{NO}_{3}, \mathrm{Ca}, \mathrm{Sr}, \mathrm{Ba}, \mathrm{Mg}, \mathrm{Mn}$, and gross Beta). Regression analysis, directed at predicting BCK 12.46 constituent concentrations from water quality data taken at BCK 11.97, showed poor predictability. The results of the water quality comparison, the nature of the hydrologic system in upper Bear Creek, and the need to consolidate monitoring efforts support the reduction of water quality monitoring at BCK 12.46 from weekly to quarterly, the addition of monitoring of NT-1 on a quarterly basis, and the continuance of weekly monitoring at BCK 11.97.

\section{Correlation of the Ellsworth Mountains with Transantarctic Mountains Helps Explain the Changing Geography of Antarctica}

\section{P. M. Goldstrand}

The Ellsworth Mountains (EM) are stratigraphically and structurally anomalous to their present geographic location with respect to adjacent regions in West Antarctica. Several researchers have noted that the stratigraphy of EM is similar to the Transantarctic Mountains (TM) of East Antarctica. However, a major tectonic event (the Ross orogeny), present as an angular unconformity throughout TM, had not been recognized in EM.

During the 1992-1993 Antarctic field season, evidence of the Ross orogeny was found in the southern part of EM, thus linking EM to East Antarctica during the Early Paleozoic.

In EM, no angular discordance between sedimentary sequences is present; however, sharp changes occur in the depositional sequences. These changes indicate the 
presence of the Ross orogeny. In the northern Heritage Range of EM, shallow marine carbonate rocks are directly overlain by outer shelf siliciclastic rocks. In the southern part of EM, a previously unrecognized braided fluvial conglomerate and sandstone unit unconformably overlies shallow marine carbonate rocks. Granitic clasts within this conglomerate suggest a source from the Precambrian basement rocks of East Antarctica. During the Ross orogeny, deformation and uplift occurred in the eastern part of East Antarctica, whereas, in the western part of East Antarctica, subsidence occurred without folding of Cambrian strata. EM were connected to the western part of TM and have since been rotated a maximum of $60^{\circ}$ and translated northward a minimum of $500 \mathrm{~km}$, probably during the Jurassic breakup of Gondwana and the Cretaceous opening of the Weddell Sea.

${ }^{1}$ The University of Tennessee, Knoxville.

\section{Tritium in Groundwater Helps Determine Fluid Mean Residence Times of Valles Caldera Hydrothermal Fluids}

\section{A. Shevenell and F. Goff ${ }^{1}$}

Naturally and artificially produced tritium $\left({ }^{3} \mathrm{H}\right)$ in precipitation allows researchers to place limits on mean residence times of fluids associated with the Valles caldera geothermal reservoir, located in New Mexico. Values for ${ }^{3} \mathrm{H}$ concentrations in precipitation are used to calculate fluid mean residence times based on two end-member cases: piston-flow and well-mixed models. The very low levels of ${ }^{3} \mathrm{H}(\sim 0.01$ T.U.) produced in situ by neutron interaction with ${ }^{6} \mathrm{Li}$ are taken into account.

Calculations with the end-member models at Valles caldera indicate that mean residence times of geothermal waters in the reservoir are between $\sim 3000$ and 10,000 years. The results also show that the two geochemically distinct subsystems of the main reservoir are associated with different fluid mean residence times.

Waters in the Redondo Creek subsystem are older $(\simeq 4300$ to $>10,000$ years old) than waters in the Sulphur Springs subsystem ( $\approx 2000$ to 4400 years old). Comparison of the results of the endmember cases with those obtained from more sophisticated methods indicates that the two end-member cases using ${ }^{3} \mathrm{H}$ values can provide acceptable limits (within an order of magnitude) on fluid mean residence times and volumes within a reservoir.

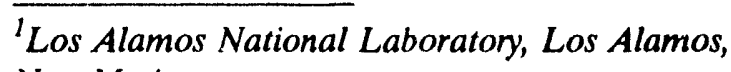
New Mexico. 


\section{Section Staff and Guests}

\section{S. H. Stow}

\begin{tabular}{|c|c|c|c|}
\hline J. T. Ammons ${ }^{1}$ & B. J. Frederick ${ }^{1}$ & I. L. Larsen & C. T. Rightmire \\
\hline R. J. Andres ${ }^{2}$ & D. D. Gates & S. Y. Lee & P. A. Rubin \\
\hline T. Barkay ${ }^{3}$ & M. A. Gillman ${ }^{3}$ & P. J. Lemiszki ${ }^{1}$ & W. E. Sanford ${ }^{2}$ \\
\hline F. P. Baxter ${ }^{4}$ & P. M. Goldstrand ${ }^{2}$ & V. L. Lewis ${ }^{12}$ & E. G. Sauter ${ }^{3}$ \\
\hline M. A. Bogle & J. M. Grebmeier ${ }^{1}$ & L. Liang & L. A. Shevenell ${ }^{1}$ \\
\hline D. M. Borders ${ }^{1}$ & S. M. Gregory & C. A. Liebert ${ }^{3}$ & J. L. Shular \\
\hline J. L. Branson' & B. C. Grigg & D. A. Lietzke ${ }^{13}$ & R. L. Siegrist \\
\hline T. J. Brown & J. P. Gwo ${ }^{2}$ & S. E. Lindberg & P. T. Singley \\
\hline B. B. Burgoa ${ }^{1}$ & J. A. Hanson ${ }^{1}$ & J. A. Little & A. D. Solomon ${ }^{19}$ \\
\hline J. Burnham ${ }^{2}$ & V. L. Harless ${ }^{1}$ & R. L. Livingston ${ }^{1}$ & D. K. Solomon \\
\hline A. J. Caldanaro ${ }^{1}$ & B. K. Harrington ${ }^{1}$ & R. J. Luxmoore & B. P. Spalding \\
\hline R. B. Clapp & R. D. Hatcher ${ }^{1}$ & M. Mamo' & D. Stair ${ }^{1}$ \\
\hline S. R. Cline & R. R. Held ${ }^{8}$ & G. H. Marland & R. G. Stansfield ${ }^{13}$ \\
\hline B. A. Couzens ${ }^{1}$ & D. S. Hicks & J. D. Marsh & K. L. Stewart \\
\hline J. S. Cox & C. M. Hill ${ }^{9}$ & D. S. Marshall & W. J. Stratton ${ }^{20}$ \\
\hline Y. S. Cox & F. M. Hoffman ${ }^{1}$ & D. H. McKamey ${ }^{14}$ & J. Switek \\
\hline M. W. Craig ${ }^{5}$ & D. D. Huff & T. P. McKenzie & D. L. Taylor \\
\hline P. F. Daugherty & R. E. Huffman ${ }^{8}$ & B. W. McMaster ${ }^{1}$ & A. L. Thomas \\
\hline R. K. Davis ${ }^{6}$ & A. E. Hunley & G. K. Moore ${ }^{1}$ & M. E. Timpson ${ }^{1}$ \\
\hline L. K. Demaree ${ }^{5}$ & A. G. Hunt ${ }^{2}$ & T. D. Moore ${ }^{1}$ & L. E. Toran \\
\hline W. E. Doll & L. K. Hyder & C. M. Morrissey & K. M. Turnage ${ }^{1}$ \\
\hline R. B. Dreier & G. K. Jacobs & M. T. Naney ${ }^{15}$ & R. R. Turner \\
\hline N. W. Dunbar ${ }^{1}$ & P. M. Jardine & R. Nativ ${ }^{16}$ & T. D. Turner ${ }^{10}$ \\
\hline J. T. Dunning ${ }^{7}$ & M. J. Jenkins & P. S. Neuhoff ${ }^{2}$ & D. S. Walker ${ }^{1}$ \\
\hline T. O. Early & P. D. Jenssen & J. E. Nyquist & A. D. Walzel ${ }^{21}$ \\
\hline M. K. Edwards & G. C. Johnson ${ }^{10}$ & C. D. Olson ${ }^{7}$ & D. M. Wasserman 8 \\
\hline M. P. Elless ${ }^{2}$ & P. M. Kearl & J. G. Owens & D. R. Watkins \\
\hline W. R. Emanuel & R. O. Kennard & H. S. Pearson & O. F. Webb ${ }^{2}$ \\
\hline M. A. Evans & K. H. Kim ${ }^{1}$ & A. J. Pendergrass & O. R. West \\
\hline C. D. Farmer & A. W. King & T.-H. Peng & R. T. Williams ${ }^{1}$ \\
\hline N. D. Farrow & S. M. Koerber ${ }^{2}$ & M. E. Peterson ${ }^{17}$ & G. V. Wilson ${ }^{1}$ \\
\hline Y. Feng ${ }^{1}$ & Z. S. Kooner ${ }^{1}$ & W. M. Post & S. L. Winters \\
\hline T. A. Fontaine & N. E. Korte & D. J. Pridmore & S. C. Young ${ }^{7}$ \\
\hline J. L. Foreman ${ }^{1}$ & N. D. Kosier & B. R. Primm & T. F. Zondlo \\
\hline J. E. Foss ${ }^{1}$ & A. D. Laase & D. K. Reece ${ }^{18}$ & \\
\hline C. W. Francis & P. A. Labieniec ${ }^{11}$ & W. A. Rice & \\
\hline
\end{tabular}

${ }^{1}$ The University of Tennessee, Knoxville.

${ }^{2}$ Oak Ridge Institute for Science and Education,

Oak Ridge, Tennessee.

${ }^{3}$ U.S. Environmental Protection Agency, Florida. 
'Office of Environmental Compliance and Documentation, ORNL.

${ }^{S}$ ECE, Knoxville, Tennessee.

'Automated Sciences Group, Inc., Oak Ridge, Tennessee.

${ }^{7}$ Tennessee Valley Authority, Knoxville, Tennessee.

${ }^{8}$ Knarville Recycling Coalition, Knoxville, Tennessee.

${ }^{9}$ Vinginia State University, Richmond.

${ }^{10}$ U.S. Geological Survey, Knoxville, Tennessee.

${ }^{11}$ Camegie Mellon University, Pittsburgh.

${ }^{12}$ Temp Systems, Inc., Knoxville, Tennessee.
${ }^{13}$ Self-employed.

${ }^{14}$ H\&R Technical Services, Knoxville, Tennessee.

${ }^{15}$ Office of Operational Readiness and Facility Safety, ORNL.

${ }^{16}$ Hebrew University of Jerusalem,

Rehovot, Israel.

${ }^{17}$ Battelle Pacific Northwest Laboratory, Richland, Washington.

${ }^{18}$ Analysas Corp., Oak Ridge, Tennessee.

${ }^{19}$ Self-employed, Omer, Israel.

${ }^{20}$ Earlham College, Richmond, Indiana.

${ }^{21}$ Texas A\&I University, Kingsville. 


\section{Ecosystem Studies}

\section{Introduction}

Research in the Ecosystem Studies Section of the Environmental Sciences Division (ESD) at Oak Ridge National Laboratory (ORNL) is directed toward quantitatively characterizing the structure and functional relationships of regional landscapes and terrestrial and aquatic ecosystems, communities, and populations. This information is used to predict the responses of the regions and ecosystems to both natural and human-induced disturbances. The section focuses on complemeritary areas of research, including theoretical ecology, biogeochemical cycling of materials, physiological ecology of terrestrial plants, resource analysis, biofuels, and hydrosystems. Major sponsors of the section's research are the U.S. Department of Energy (DOE) Environmental Sciences Division of the Office of Health and Environmental Research, the DOE Carbon Dioxide Research Program, the DOE Biofuels Feedstock Development Program, the DOE Hydropower Program, the U.S. Forest Service (USFS), the Federal Energy Regulatory Commission (FERC), the U.S. Environmental Protection Agency (EPA), the Electric Power Research Institute (EPRI), the National Science Foundation (NSF), and the National Park Service (NPS).

\section{Biogeochemical Cycling}

Staff in the Biogeochemical Cycling Group study elemental cycling within environmental systems; the spatial and temporal patterns of storage and fluxes of nutrients and pollutants; the role of the biogeochemical cycling of chemicals in regulating the productivity, diversity, and sustainability of natural and human-dominated ecosystems; and the development of innovative methods to measure, analyze, model, and interpret biogeochemical cycles at site-specific, regional, and global scales.

The group is currently involved in research in several areas: (1) the DOE Walker Branch Watershed, which includes longterm studies of basic biogeochemical processes in a mixed deciduous forest; (2) an NSF-funded project investigating spatial gradients in nutrient cycling in streams; (3) a DOE study to evaluate hydrologic processes and the fate of precipitation-borne contaminants in Arctic watersheds; (4) studies on nitrogen and carbon dynamics and storage/export in high- and low-elevation watersheds in the region; and (5) projects monitoring, predicting, and assessing water resources and water quality at local and regional scales.

During FY 1993, staf: of the Biogeochemical Cycling Group successfully competed for a major new experimental manipulation of the water balance of a portion of the Walker Branch Watershed. This experiment will evaluate the response of the forest ecosystem to shifts in moisture similar to those expected as a result of long-term climate change. With Walker Branch streamflow data, staff have additionally demonstrated the application of a hydrologic model to predict the spatial extent of overland flow during both normal and flood conditions. New methods for measuring air-water gas exchange rates have significantly improved a whole-stream 
method for measurement of stream metabolism, leading to improved understanding of seasonal dynamics of nutrient cycling and metabolic processes.

\section{Biomass Systems and International Studies}

The Biomass Systems and International Studies Group develops and applies methodologies that assess the feasibility and implications of the development of biomass energy systems in a national and international framework. Through this group's efforts, ORNL is recognized as an international force in transforming concepts of integrated, sustainable, biomass energy systems into reality. Staff members from ESD, the Energy Division, and the Health Sciences Research Division contribute expertise in resource analysis, economic analysis, forestry, ecology, and information management. Activities include managing and maintaining biomass data bases, evaluating the global role of biomass energy systems in reducing carbon emissions from fossil fuels, characterizing the systems of energy crop production and analyzing their economics, conducting analyses of the total fuel cycle, evaluating and documenting the environmental risks and benefits of biomass energy systems, evaluating integrated biomass energy systems in developing countries, participating in International Energy Agency and biomass energy activities, and developing strategies for the commercialization of biomass energy.

The Biomass Systems and International Studies Group works to resolve in advance potential confrontations between energy crop production and environmental issues. One aspect of this effort has concentrated on biodiversity effects of energy crops in a variety of landscape patterns. Shortrotation hardwood plantations in the northern great plains and lakes states were surveyed along with their surrounding land uses for the presence and movement of birds and small mammals. Results reveal the introduction of unique habitats and unanticipated landscape-level dynamics related to edge effects. Short-rotation plantations, for example, can functionally increase woodlot interior area without changing the sizes of woodlots by reducing edge effect. Such benefits as managing landscapes for improved biodiversity while meeting energy needs may be necessary for energy crops to successfully compete in the agricultural and energy arena.

\section{Hydrosystems}

The Hydrosystems Group conducts applied and basic research required for the management and analysis of water resources and related natural systems (e.g., fish populations affected by water allocation or land-use practices as they interact with water quality). The research focuses specifically on hydroelectric energy production and its environmental effects. The group specializes in the development and application of quantitative assessment techniques to solve environmental problems over a range of spatial scales up to large river basins or national levels. In addition, the group addresses such issues as instream flow needs, fish population modeling, multiple-use trade-off analyses, cumulative impact assessment, contaminant transport, surface water and groundwater monitoring, acidic deposition, and climate change. Capabilities of the group include simulation and optimization modeling, sensitivity and uncertainty analysis, geostatistical applications, geographic information systems (GISs), and scientific data base management. The three major sponsors of the Hydrosystems Group are DOE, FERC, and EPRI. 
A draft environmental impact statement (DEIS) on the Lower Mokelumne River Project, California, was completed and distributed for public comment. This DEIS, prepared for FERC, is typical of several river basin-level analyses in which the Hydrosystems Group has been involvel. These analyses involve challenging issues related to multiple water-resource uses that are frequently in conflict. Major issues at the river basin scale typically include the conservation of anadromous fisheries, water supply for domestic and agricultural use, and other water uses and rights. Innovative analytical methods the Hydrosystems Group developed help to ensure that the results of research in the DOE Hydropower Environmental Mitigation program are effectively integrated into the evaluation of alternative actions in the National Environmental Policy Act process.

\section{Physiological Ecology}

The Physiological Ecology Group evaluates the effects of environmental stress on plant growth and vigor and examines the role of physiological processes in biogeochemical cycling of pollutants within terrestrial ecosystems. The group examines specific atmospheric pollutants such as ozone, acid deposition, and nitrogen oxides are examined, as well as the effects of other changes in the chemical and physical atmospheric environment. Staff members are studying increases in atmospheric $\mathrm{CO}_{2}$, temperature, and high-energy ultraviolet radiation in relation to global environmental pollution. Researchers are also investigating the use of physiological indicators in intensive biomass production from silviculture and herbaceous crops is being investigated as part of the search for nonfossil energy sources. In addition, the role of interactive stresses on physiological indicators of whole-plant resource utilization has received research attention. DOE, EPRI, USFS, and EPA are the primary sponsors of the work.

During FY 1993, research focused on the growth response of forest tree species to atmospheric $\mathrm{CO}_{2}$ enrichment. Studies were completed with white oak saplings grown in elevated concentrations of $\mathrm{CO}_{2}$ for 4 years-the longest that any forest tree species has been exposed to $\mathrm{CO}_{2}$ enrichment. The data set on root and shoot responses to $\mathrm{CO}_{2}$ under field conditions is a critical component of assessment of forest responses to global change.

\section{Resource Analysis}

Staff of the Resource Analysis Group characterize environmental resources and evaluate their development and sustainability, especially at large spatial scales, and devise and improve methodologies for making such evaluations. Efforts of the group can be divided into those activities focused on the Oak Ridge Reservation and other DOE facilities and those activities not related to specific DOE facilities. The Resource Analysis Group characterizes and reports on environmental measurements taken at DOE facilities, develops environmental data bases for the DOE Environmental Restoration Program, manages the Oak Ridge National Environmental Research Park, and provides on-site and off-site environmental programs with GIS support. Members of the group are also involved in broader resource issues, including the sustainability of protected areas, the environmental implications of large-scale development of biomass energy, and the analysis and reporting of national environmental trends. DOE is the primary sponsor of this group.

Environmental and economic simulation models are set up to study the potential 
environmental and socioeconomic impact of using biomass energy crops on a regional and national scale. A new development is the use of network transportation models to optimize the siting of biomass energy conversion facilities and explicitly account for locational constraints to biomass supply. The value of this approach is being tested by developing a biomass resource network model for the Tennessee Valley Authority (TVA) region (23 million acres) using a transportation network model

parameterized with GIS-based information on road networks and cost and location of biomass supplies. The transportation model is linked to geographically specific economic and environmental data derived from ecological and economic simulation models. Such features as regional changes in erosion, fertilizer and pesticide use, and labor demand will be linked to projected energy crop demands. The model framework is adaptable to other regions and can be expanded to include multiple siting and environmental constraints.

\section{Theoretical Ecology}

The Theoretical Ecology Group develops simulation and mathematical methods to describe and predict the behavior of ecological systems. The tools developed within the group are applied to a spectrum of problems, including environmental assessments, theoretical questions in population and ecosystem dynamics, and analyses of phenomena that span scales from the landscape to the globe. Research focuses on landscape ecology, development of individual-based models of animal populations, development of landscape indicators and models for environmental monitoring and assessment, integration of socioeconomic and ecological models of land-use change, and development of analytical techniques that can be used to manage ecosystems. DOE, EPRI, NSF,
NPS, EPA, and USFS are among the groups supporting this work.

An individual-based population model has been developed for smallmouth bass as part of the Program on Compensatory Mechanisms in Fish Populations. The model is being tested by using empirical data from different lakes and is being applied to specific management questions concerning this species. The model can provide acceptably accurate simulations of size-frequency distributions of young-ofyear in different lakes. An example of an application based on this process-oriented representation of growth and survival of the early life stages is the evaluation of alternative scenarios for the opening date of the fishing season.

NOYELP is a landscape simulation model of winter foraging by large ungulates in the northern range of Yellowstone National Park developed to study the effects of burning patterns and winter severity on the survival of ungulates. NOYELP is a spatially explicit model of a 78,000-ha winter range and simulates individual elk and bison foraging in heterogeneous landscapes. A basic feature of the model is a linkage of the core simulation program written in FORTRAN to a visualization environment, PV-WAVE, through the use of a procedure written in $\mathrm{C}$.

\section{TVA Cooperative Forest Studies Program}

As a consequence of a common interest in the environmental impacts of energy development and utilization, TVA and Oak Ridge Operations have developed an agreement to pursue joint research activities specifically involving ESD staff and members of the TVA Resources Group. Under this arrangement, TVA personnel are assigned to ORNL to develop programs investigating the impacts 
that air and water emissions have on terrestrial and aquatic resources. This working relationship combines the experience gained from TVA's powerproducing and resource management activities with the unique research-support facilities of ESD to produce timely and relevant research findings. A number of major collaborative projects have been undertaken. Whereas initial research projects centered on water quality and nutrient-cycling issues in the context of acid rain, more recent and proposed activities focus on (1) ozone and other chemical and physical changes in the environment that are associated with global change, (2) environmental monitoring, and (3) water resources.

Recent research has found that foliage from mature trees is more sensitive to external ozone concentrations than seedling foliage, but the difference in sensitivity can be explained by the differential uptake of ozone by the two leaf classes. The mature tree foliage has greater stomatal conductance, which allows larger internal ozone doses. 


\section{Technical Summaries}

\section{Coppicing of Yellow- Poplars Does Not Enhance Growth Response to Elevated $\mathrm{CO}_{2}$}

\author{
C. A. Gunderson, R. J. Norby, \\ T. J. Tschaplinski, and S. D. Wullschleger
}

Augmentation of forest growth by elevated concentrations of atmospheric $\mathrm{CO}_{2}$ can increase carbon sequestration and ultimately reduce the impact of global change. One factor that may limit growth response is a tree's inability to obtain enough nutrients or water to take advantage of the increased $\mathrm{CO}_{2}$. Such limitations may be alleviated during coppice growth after decapitation because the resprouting shoots have a large established root system.

To investigate the mechanisms limiting $\mathrm{CO}_{2}$-stimulated growth, yellow-poplar saplings that had grown for 2 years in open-top field chambers and been exposed continuously to ambient or elevated $\mathrm{CO}_{2}$ concentrations were cut near ground level and allowed to coppice. Other saplings remained intact for comparison.

Coppice plants exhibited a typical physiological reinvigoration; their leaves were higher in pigment concentration and photosynthetic rate, and they were lower in mass-per-unit leaf area than the leaves of intact plants. The relative effect of $\mathrm{CO}_{2}$ enrichment on these parameters, however, was similar in coppice and intact trees; photosynthetic rates and mass-perunit leaf area were higher and pigment concentrations were lower in leaves exposed to higher $\mathrm{CO}_{2}$ concentrations.
Most importantly, the $\mathrm{CO}_{2}$-induced increase in growth efficiency was not accompanied by significant aboveground growth in either coppice trees or intact trees.

These results suggest that the mechanisms restricting increases in growth and carbon sequestration in this species are not related to nutrient or water limitations or to limitations in sink strength.

\section{Nonmeth ne Organic Compound Emissions from Forest Litter and Soils Represent an Insignificant Carbon Loss from Oak Forests}

\section{P. J. Hanson and W. A. Hoffman ${ }^{l}$}

Forest floor emissions of $\mathrm{CO}_{2}$ and volatile nonmethane organic compounds (NMOCs) were measured to determine their contribution to carbon losses from forests. Forest floor cores $19 \mathrm{~cm}$ in diameter and approximately $10 \mathrm{~cm}$ deep were obtained from beneath loblolly pine (Pinus taeda L.), oak-maple (Quercus/Acer), and yellowpoplar (Liriodendron tulipifera L.) trees on the Walker Branch Watershed. The cores were enclosed in an open-system gasexchange instrument from which inlet and outlet concentrations of NMOC emissions were sampled. NMOCs were quantified by using a carbon trap-cryofocus-gas chromatography approach.

Total NMOC emissions of carbon from the forest floor cores ranged from 15 to $90 \mathrm{nmol} \mathrm{m}{ }^{-2} \mathrm{~s}^{-1}$ and showed a speciesspecific level of emissions. Cores from beneath Liriodendron trees had nearly 1 order of magnitude greater carbon equivalent efflux than either the Pinus or 
Quercus/Acer cores. Monoterpenes made up virtually all of the NMOC emissions from the cores. The carbon equivalent efflux of NMOCs from the forest floor cores was 1 to 2 orders of magnitude lower than rates of $\mathrm{CO}_{2}$ efflux (4-8 $\mu \mathrm{mol} \mathrm{m}^{-2}$ $\left.\mathrm{s}^{-1}\right)$. This low rate indicates that NMOC emissions from litter and soil play a very minor role in carbon cycling within the forest stand.

${ }^{1}$ Denison University, Granville, Ohio.

\section{White Oak Responses to Atmospheric $\mathrm{CO}_{2}$ Enrichment Change Over Time}

\section{R. J. Norby, S. D. Wullschleger, and C. A. Gunderson}

Carbon sequestration in forests is an important component of the global carbon cycle and the relationship between fossil fuel emissions of $\mathrm{CO}_{2}$ and atmospheric concentrations of $\mathrm{CO}_{2}$. An important uncertainty in this analysis is whether tree growth and carbon sequestration increase as the atmospheric $\mathrm{CO}_{2}$ concentration rises. To address this question, white oak (Quercus alba L.) trees were grown in soil under field conditions in open-top chambers on the Oak Ridge National Environmental Research Park. The air circulating through the chambers was continuously enriched with 0,150 , or $300 \mu \mathrm{mol} / \mathrm{mol}$ of $\mathrm{CO}_{2}$ in addition to the $\mathrm{CO}_{2}$ in ambient air.

After four growing seasons, the trees were significantly larger in elevated $\mathrm{CO}_{2}$ : wholetree mass (including woody roots) was 59\% greater in trees grown in +150 and $142 \%$ greater in trees grown in +300 in comparison with the whole-tree mass of ambientgrown trees. The stimulatory effect of $\mathrm{CO}_{2}$ occurred during seedling establishment; $\mathrm{CO}_{2}$ had no effect on relative growth rate after the first field season. However, photosynthesis remained consistently higher in elevated $\mathrm{CO}_{2}$, foliar respiration was reduced, and fine-root density and $\mathrm{CO}_{2}$ efflux from the soil were higher.

The lack of a sustained response in the relative growth rate after the first year in the field suggests that the large effect of $\mathrm{CO}_{2}$ enrichment on tree mass would not persist in a developing forest after canopy closure. Nevertheless, a smaller effect on growth efficiency should be sustained, and the apparent increase in carbon cycling in elevated concentrations of $\mathrm{CO}_{2}$ may have positive secondary effects on forest productivity and carbon storage.

\section{Literature Review Provides Information for Data Base on Growth Response of Forests to Atmospheric $\mathrm{CO}_{2}$ Enrichment}

\section{S. D. Wullschleger}

The capacity of long-lived woody perennials to sequester carbon in a world with higher levels of $\mathrm{CO}_{2}$ is a key component in understanding how forests interact with the global carbon cycle. Although several extensive data bases have been compiled to address a similar concern within the agricultural research community, no such data base exists for forests. Therefore, literature published over the past 25 years is being used to compile a data base describing the growth response of forest species to elevated $\mathrm{CO}_{2}$.

Although the data base is not yet complete, the information collected to date indicates that in short-term studies the total biomass of young seedlings increases 
by approximatcly one-third in response to a doubling of atmospheric $\mathrm{CO}_{2}$ concentration. Averaged across species, this increase in biomass is evenly allocated to leaves, stems, and roots. Within roots, however, preferred allocation of carbon is to fine roots.

Once completed, the data base will allow researchers to determine whether growth responses to $\mathrm{CO}_{2}$ enrichment are different for boreal, temperate, and tropical forest trees and whether $\mathrm{CO}_{2}$-induced increases in aboveground or belowground biomass are likely to be limited by availability of nutrients and water. Information derived from this data base will be used in global carbon models to assess future global change scenarios.

\section{Thermal Desorption} Technique Shows Promise for Measuring Trichloroethylene Volatilization Rates and Soil Concentrations

\section{N. T. Edwards and W. A. Hoffman}

A field study was planned that evaluated the role vegetation plays in the degradation of trichloroethylene (TCE) within the Miscellaneous Chemical Basin (MCB) at Savannah River Laboratory. Such an evaluation required accurate measurements of TCE volatilization rates and TCE concentrations in the soil, water, and vegetation. Soil collected from the MCB was analyzed for TCE concentrations by means of traditional (headspace) analysis techniques and a thermal desorption technique developed at ORNL. Traditional techniques involve enclosure of soil in a sealed container and subsequent analysis of the headspace for TCE. This technique assumes that, because TCE is very volatile, an equilibrium will be reached between the soil atmosphere and the headspace after a short time.

A thermal desorption technique was developed because TCE might possibly be bound in the soil matrix; volatilization might therefore proceed at a very slow rate if TCE concentrations are extremely low. Using the thermal desorption technique, TCE is desorbed from the soil with heat $\left(\sim 130^{\circ} \mathrm{C}\right)$ while purging with helium and is trapped on activated charcoal. The TCE is then thermally desorbed from the carbon trap into a liquid nitrogen cryotrap at the head of a gas chromatograph column and then released into the column for analysis.

Soil samples were collected from the MCB, and each was split into two portions. One portion was sent to Savannah River for headspace analysis, and the other portion was analyzed by thermal desorption. No TCE was detected by using the headspace technique, whereas TCE concentrations measured after thermal desorption varied with soil depth, ranging from 420 to $7000 \mathrm{ng} / \mathrm{g}$ of soil.

Activated carbon traps were also used to collect air samples from confined soil surfaces at the MCB for determination of TCE volatilization rates. Thermal desorption of these traps revealed that TCE volatilization rates ranged from $10 \mathrm{mg}$ $\cdot \mathrm{m}^{-2} \cdot \mathrm{d}^{-1}$ (from a previously identified TCE "hot spot") to zero (from soil surfaces adjacent to the MCB). Volatilization rates decreased with increasing soil moisture (decreasing by 200 times immediately after relatively dry soil received 1 in. of rainfall); these results demonstrate the importance of taking measurements over a range of environmental conditions.

\footnotetext{
${ }^{1}$ Denison University, Granville, Ohio.
} 


\section{Laboratory Studies Show Hardwood Foliage Is a Minor Sink for Metallic Mercury Vapor at Near-Ambient Concentrations}

\author{
P. J. Hanson, S. E. Lindberg, K.-H. Kim, \\ and J. G. Owens
}

Mercury emissions from combustion of fossil fuel have been identified as a potential source of mercury accumulating in natural food chains, and mercury has been characterized as an important toxic element for emission control and possible ambient-air regulation. Thus, researchers need a complete understanding of the fate and cycling of mercury in the environment. We are studying the deposition of mercury vapor from the atmosphere to forest landscape surfaces.

Previous data for crop and weed species have suggested that deposition of metallic mercury vapor to forest landscapes may represent a significant sink within the biogeochemical cycle of mercury. However, those measurements used concentrations that were 2 to 4 orders of magnitude higher than levels expected for current conditions, and it is not clear that the mechanisms responsible for mercury vapor uptake at high concentrations would remain active near ambient levels $\left(0.5-3 \mathrm{ng} / \mathrm{m}^{3}\right)$.

Measurements of mercury vapor deposition near ambient concentrations are being conducted in an open gas-exchange system that allows for simultaneous measurements of $\mathrm{CO}_{2}, \mathrm{H}_{2} \mathrm{O}$, and $\mathrm{Hg}$ exchange under controlled conditions of temperature, light, and relative humidity.

Mercury vapor at $14-18 \mathrm{ng} / \mathrm{m}^{3}$ has shown no tendency for deposition to external or internal surfaces of Norway spruce and red maple foliage. However, measurements conducted at substantially higher concentrations (e.g., $300 \mathrm{ng} / \mathrm{m}^{3}$ ) show that mercury vapor can be deposited on hardwood foliage. These observations suggest the existence of a "compensation point" within foliage below which foliar surfaces in the forested landscape would not act as a sink for atmospheric mercury vapor.

Our data are being compared with micrometeorological measurements of mercury deposition to entire forest stands and will ultimately be scaled to the landscape level by using models of mercury deposition.

\section{Staff Member Provides Fisheries Assistance to DOE's Bonneville Power Administration}

\section{C. Coutant}

ESD staff member C. C. Coutant is serving on a Scientific Review Group to oversee the scientific quality of fisheries research and management under the federal Columbia River Fish and Wildlife Program. DOE's Bonneville Power Administration (BPA) in Portland, Oregon, allocates a portion of its revenues from the distribution and sale of electricity generated in the federal hydropower system on the Columbia River (Washington, Oregon, Idaho, and Montana) to mitigate the effects of this hydropower development on the basin's fish and wildlife resources, especially the Pacific salmon.

The main goal is to stem the rapid decline in the basin's salmon resources, a decline attributed largely to detrimental effects of the nearly continuous series of hydropower dams. The program and BPA's participation were mandated by Congress in the Northwest Power Act of 1980. The 
Columbia River Fish and Wildlife Program annually funds $\sim \$ 100 \mathrm{M}$ of research and mitigation efforts by federal fisheries agencies, state and tribal agencies, and universities.

The Scientific Review Group of technical fisheries experts, collaborating with a parallel Policy Review Group of agency representatives, establishes critical uncertainties in the program, reviews annual implementation plans, evaluates major components of the program (e.g.,

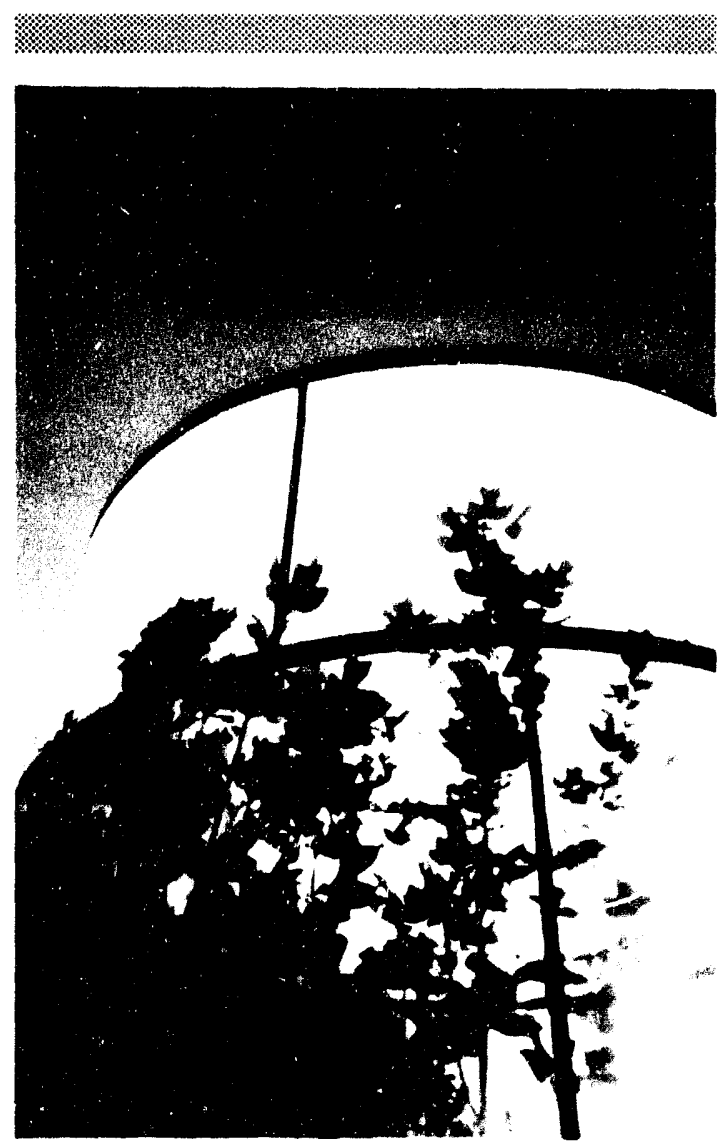

Yellow-poplar saplings growing in an opentop chamber at the Global Change Research Site. ESD researchers investigate how changes in levels of atmospheric $\mathrm{CO}_{2}$ can affect tree growth. supplementation of wild stocks with fish reared in hatcheries), provides guidance to BPA for the evaluation of proposals and projects, and provides technical critiques of some individual proposals.

\section{Optimization Models Help Site New Groundwater- Monitoring Wells}

\author{
H. E. Cardwell, J. W. Douthitt, D. D. Huff, \\ and $M$. J. Sale
}

Optimization models were used to identify potential locations for groundwatermonitoring wells for two contaminated sites at the DOE facility in Paducah, Kentucky. To develop trade-offs between competing coverage and cost-based objectives, optimization model runs varied the number of additional monitoring wells and the appropriate objective functions. The optimization model modified a simple locationmodeling approach, which required dividing the area of interest into a grid. The model assigns a weight to each point in the grid on the basis of contaminant concentration and water table elevation. The solution maximizes the sum of the weights of those grid points within a specified distance of a potential monitoring-well site. Although the model is structured as an integer program, it can usually be solved by simple linear programming methods.

The optimization results provided a range of possible solutions that were compared with solutioni based on professional judgment. As a result, groundwater specialists selected a revised design that involved fewer wells than originally planned. New work is under way to adapt these techniques so that existing monitoring-well networks can be evaluated; the goal is to eliminate redundant or unneeded wells. A 
quantitative analysis is also in progress to improve the rule for assigning grid weights.

\section{Rapid Bioassessment Protocols Help Examine Responses of Benthic Macroinvertebrates to Hydropower Flop Diversions}

\section{G. F. Cada}

Hydropower projects that divert water usually alter natural flow regimes within the bypassed stream reaches. These diversions often lead to reduced aquatic habitat, decreased flushing of fine sediments, and altered water temperatures, which can in turn alter the benthic invertebrate communities. Because water diversions are part of the operating scheme of many hydroelectric power plants, researchers must determine not only the impacts of flow diversions but also the benefits created when mitigating impacts by requiring instream flow releases.

The benthic macroinvertebrate community in the bypassed reach of an old hydropower diversion project in western North Carolina was compared with the communities upstream from the reservoir and downstream from tributary input. The hydropower project had no required instream flow releases, so the only flow into the bypassed reach was from seepage and occasional spillway releases. Benthic communities at the sites were compared on the basis of density, biomass, and several metrics associated with the U.S. Environmental Protection Agency's Rapid Bioassay Protocols.

Benthic invertebrates were less abundant in the bypassed reach than at the other sites but had significantly greater biomass. Taxonomic richness and the Index of Dominant Family indicated no clear impacts within the bypassed reach in relation to the reference site. On the other hand, the EphemeropteraPlecoptera-Trichoptera (EPT) Index, the EPT:Chironomidae ratio, and the Family Biotic Index indicated moderate to severe impairment of sensitive biota in the bypassed reach. The habitat-mediated impacts of this streamflow diversion were best reflected in metrics that focused on resence of pollution-intolerant (EPT) taxa.

\section{Chinook Salmon Response to Flow Regulation Is Simulated for Tuolumne River, California}

\author{
H. I. Jager, M. J. Sale, D. L. DeAngelis, \\ M. S. Bevelhimer, and C. C. Coutant
}

Water resource development of many rivers in California's Central Valley, including the Tuolumne River, has degraded the spawning and rearing habitat of chinook salmon. Flow regulations for rivers influenced by nonfederal hydropower projects fall under the jurisdiction of the Federal Energy Regulatory Commission (FERC). We are developing tools needed by FERC to identify flow recommendations that balance the protection and enhancement of natural resources (e.g., chinook stocks) with the economic feasibility of hydropower operation.

We have developed a spatially explicit, individual-based model of chinook spawning and rearing in the Tuolumne River to predict the response of chinook salmon to alternative flow regimes. In the model, both streamflow and temperature influence (1) the ability of adults in spawning 
condition to migrate upstream, (2) availability of spawning gravels, (3) incubation mortality of eggs and larvae, (4) growth and early displacement of fry as they emerge from the redd, (5) exposure to predation mortality, and (6) development to the smolt stage in time for successful migration to sea. We are presently validating the model against available data from the Tuolumne River. Linking this model of fish response with a model of reservoir operations will allow us to identify economically feasible flow regimes that optimize instream production of chinook.

\section{Low Levels of} Anthropogenic Radionuclides Are Observed in Alaskan Marine Sediments

\section{W. Cooper, J. M. Grebmeier, and I. L. Larsen}

Recently, concern has been generated in Alaska by reports of radionuclide contamination resulting from the disposal of radioactive waste in the Russian arctic and the discovery of radioactive materials left at Point Thompson, Alaska, in the mid-1960s. Despite these reports, radionuclide sampling during an AugustSeptember 1992 oceanographic cruise along the northwest coast of Alaska from near Nome to east of Point Barrow revealed no unexpected amounts of anthropogenic radionuclides in surface sediments $(0-3 \mathrm{~cm}$ depth).

Gamma radioactivity attributable to ${ }^{137} \mathrm{Cs}$, largely a bomb-testing product with a 30-year half-life, ranged from 2.9 to $12.2 \mathrm{mBq} / \mathrm{cm}^{2}$ for the top $3 \mathrm{~cm}$, or 2.8 to $12.5 \mathrm{Mbq} /$ dry gram $(1 \mathrm{Mbq}=1$ decay per $1000 \mathrm{~s})$.
Cores of sediment from depths to $220 \mathrm{~cm}$ are currently being analyzed as part of our ongoing work. Sampling in 1990 south of St. Lawrence Island in the Bering Sea indicated that ${ }^{137} \mathrm{Cs}$ concentrations reach a maximum at sediment depths of 6 to 10 $\mathrm{cm}$. Total inventories in 1990 ranged from 13.7 Mbq/cm ${ }^{2}$ to $56.6 \mathrm{Mbq} / \mathrm{cm}^{2}$. Highest ${ }^{137} \mathrm{Cs}$ activity in 1992 was observed in shallow (10-20 m), near-shore sediments influenced by river inflows and in the deep-water (400 m) Barrow Canyon, which is an apparent sediment-accumulation zone.

Alaskan arctic tundra inventories of ${ }^{137} \mathrm{Cs}$ remaining from fallout from nuclear weapons testing are higher than amounts of ${ }^{137} \mathrm{Cs}$ in the marine sediment samples, ranging from 102.1 to $162.1 \mathrm{Mbq} / \mathrm{cm}^{2}$ in 1991, but are within the range expected from bomb fallout. Relatively higher levels of ${ }^{137} \mathrm{Cs}$ have also been observed in arctic lake sediments near stream inflows. Together, these patterns are consistent with a terrestrial origin of much of Alaska's near-shore marine ${ }^{137} \mathrm{Cs}$, which physically adheres to tundra and peat vegetation that in turn flows into lakes, deltas, and nearshore waters during snowmelt.

\section{Atmospheric $\mathrm{CO}_{2}$ Enrichment Increases ${ }^{18} \mathrm{O}$ Content of Leaf Water and Cellulose, Complicates Paleoclimatic and Ecophysiological Studies}

\section{W. Cooper and R. J. Norby}

The $\delta^{18} \mathrm{O}$ values of daytime total leaf water and leaf cellulose in yellow-poplar, Liriodendron tulipifera (L.), were elevated approximately $2 \%$ when exposed to ambient $+300 \mu \mathrm{mol} / \mathrm{mol}$ of $\mathrm{CO}_{2}$ in outdoor open-top chambers in relation to ambient 
$\mathrm{CO}_{2}$ concentrations. We observed a similar pattern for drought-stressed plants grown under elevated levels of $\mathrm{CO}_{2}$ in an indoor growth chamber in which humidity variation was limited.

In both experiments, there were no significant differences between treatments in $\delta \mathrm{D}$ values of leaf water in ambient or elevated levels of $\mathrm{CO}_{2}$. The lack of difference suggests that elevated $\mathrm{CO}_{2}$ treatments can affect the kinetics of leafwater evapotranspiration, for which $\mathrm{H}_{2}{ }^{18} \mathrm{O}$ evaporation is more sensitive than $\mathrm{DH}^{16} \mathrm{O}$.

Simultaneous measurements made of white oak, Quercus alba (L.), indicate that this elevation in ${ }^{18} \mathrm{O}$ content is not a universal response and may be related to apparently longer water-turnover times in L. tulipifera that were inferred from measurements of conductance and leaf water content.

The apparent long-term incorporation of this increase in $\delta^{18} \mathrm{O}$ values of daytime total leaf water into leaf cellulose of $L$. tulipifera introduces a new complication when using stable isotopes of fossilized plant fibers as paleoclimatic indicators because of the long-term variation in atmospheric $\mathrm{CO}_{2}$ content.

\section{Hydrologic Model Is Validated for Flood Forecasting}

\section{A. Huston, S. P. Timmins, ${ }^{1}$ and T. A. Fontaine}

Because floods are unplanned events that represent a rare combination of extreme hydrologic conditions, their effects are difficult to predict by means of standard models. Models that are calibrated for normal hydrologic conditions generally do not make accurate predictions about extreme conditions. A large flood on Walker Branch Watershed in December 1990 allowed us to evaluate a hydrologic model outside its normal range of parameter conditions.

The hydrologic model, TOPMODEL, uses information on topography as well as soil properties and rainfall to predict streamflow volume. In addition, the model can be used to predict the spatial extent of surface water (overland flow) during both normal and flood conditions.

Data collected after the December 1990 storm allowed us to determine the spatial pattern of overland flow during the flood, thus providing a unique opportunity to test. model predictions for both spatial and temporal patterns of stormflow.

A comparison of model predictions for the 1990 flood (maximum flow rates twice the maximum rate during a typical year) demonstrated that TOPMODEL's predictions for the flood (total flow, maximum flow rate, and upper limit of overland flow) were just as accurate (within $7 \%$ of observed) for parameters obtained over 1983 flow conditions as for parameters obtained over the 1990 flood itself.

Therefore, TOPMODEL can be used to make accurate predictions of flood properties well outside the range of hydrologic conditions for which it was parameterized.

TOPMODEL has been rewritten from its original FORTRAN code into a vectorized form with graphical displays in PV-WAVE on a UNIX workstation for use in ecological and hydrological modeling on the Walker Branch Watershed Project.

'Analysas Corporation, Oak Ridge, Tennessee. 


\section{Whole-Stream Method to Measure Metabolism Is Developed and Tested in Walker Branch Watershed}

\section{P. J. Mulholland and E. R. Marzolf}

Most measurements of stream metabolism (e.g., primary production and respiration) have been made by incubating streambottom materials in closed chambers in which stream water is recirculated. This technique may not provide a realistic measure of metabolism in streams because sediments are disturbed when placed in chambers and because not all streambottom organisms can be quantitatively sampled (e.g., algae and bryophytes that are distributed in patches; microbes and macroinvertebrates within subsurface sediments).

Although a whole-stream method based on repeated measurements of dissolved oxygen concentration in stream water over a $24-\mathrm{h}$ period was proposed nearly 40 years ago, its use has been limited because of problems with measuring air-water gas exchange rates and limited precision of dissolved oxygen sensors.

Recently, ESD scientists have improved this whole-stream method and adapted it for use in small streams. High-precision dissolved-oxygen sensors and a data logger were used to measure and record dissolved oxygen concentrations in stream water at two stations at 5-min intervals over a 40-h period. A gas exchange rate was determined by measuring the evasion rate of propane injected into stream water at the upstream station; the gas exchange rate was then used to correct the changes in dissolved oxygen concentration between stations for air-water exchange. A conservative tracer (chloride or tritium) was also injected into stream water to accurately determine stream-water velocity and groundwater inflow.

Used in Walker Branch, this whole-stream metabolism method indicated significantly higher rates of metabolism than previously measured with chamber methods. The whole-stream method also showed a distinct seasonality in metabolism, with highest rates of primary production in early spring and highest respiration rates in autumn following peak leaffall.

This method is particularly promising for studies of organic matter dynamics and nutrient cycling that require accurate measurements of primary production and respiration for the entire stream ecosystem. The method should also be useful for assessing effects of stream pollutants or other disturbances at the ecosystem level.

\section{Whole-Stream Method Evaluates Seasonal Metabolism Changes in Walker Branch}

\author{
E. R. Marzolf, P. J. Mulholland, \\ A. D. Steinman, A. V. Palumbo, \\ and $D$. L. DeAngelis
}

ESD researchers have developed a combination of techniques to directly measure the metabolic activity (primary productivity and respiration) of entire stream reaches. Periodic measurements were made on a relatively pristine portion of Walker Branch during 1992. Gross primary production was highest in late winter and early spring, before development of the forest leaf canopy that reduced the light levels reaching the stream. As the forest trees began to leaf out, the light levels quickly dropped, and primary production subsey. ently dropped. 
In contrast, previous studies using chamber techniques showed that the highest rates of primary production occurred in late summer, when our whole-stream measurements showed lowest rates of primary production. The higher whole-stream production is most likely the result of patchily distributed macroalgae, which occur primarily during the spring, and bryophytes, which cover about $15 \%$ of the stream bottom. Neither of these plant groups was included in chamber studies. In contrast to primary production, respiration was highest in November and corresponded with the autumn leaffall.

We are comparing the whole-stream metabolism measurements with nutrient uptake and recycling measurements on the same stream reach. During periods when whole-stream metabolism is highest, there appears to be a measurable downstream decline in nutrient concentrations, likely as a result of biological nutrient uptake. During times of the year when metabolism is low, the resulting lower nutrient uptake is insufficient to create a downstream decline in nutrient concentrations.

The new measurement technique could prove useful in a variety of other studies, including evaluating pollutant impacts to streams and studying carbon flow in the stream food web.

\section{Visualization Reveals Data Patterns at Different Scales}

\section{S. P. Timmins, ${ }^{1}$ M. A. Huston, and \\ C. T. Hunsaker}

We applied visualization to modeling surface hydrology on the Walker Branch Watershed to produce an animation showing the varying extent of surface flow produced by storm rain. In a similar manner, patch analysis algorithms were applied to images of gridded land-cover data for a large land area to reveal the landscape pattern. For landscape pattern analysis, efficient methods had to be devised to store and process very large grid data sets (typically $2000 \times 2000$ cells).

Without efficiency, a spatial data project can be mired in the process of data reduction. A first step is to choose a simple model for adjacency relationshipsa simple grid of cells where adjacency can occur only along shared edges. For analysis of satellite images of land-cover patches (e.g., fields and forests), a second step is to measure all the patch areas and perimeters. To do this without excessive cost, the TURTLE program was written with the use of the familiar maze-exit algorithm. The techniques devised to produce these visualizations share common goals of computer efficiency, data compactness, and ease of use.

${ }^{1}$ Analysas Corporation, Oak Ridge, Tennessee.

\section{ORNL Develops Strategic Plan for Water Resources}

\section{R. S. Turner and D. S. Shriner}

Many pressing water resource issues, if not resolved, will limit energy and economic development in the United States and many other countries. ESD researchers undertook a strategic planning effort to develop a vision and plan for how ORNL capabilities could be used to address water resource problems of national significance. A situation analysis showed that research, assessment, and technology development needs related to water resources are variec and many. ORNL has broad 
capabilities for addressing many water resource issues, as well as a long history of water resource-related projects at local to global scales. ORNL will strengthen existing internal and external partnerships to help address the basinwide, comprehensive water resource assessment needs of this and other countries.

The produced planning document reflects a snapshot vision of ORNL interests and capabilities in water resource issues as expressed by a cross-section of ORNL staff in several strategic planning workshops, subsequent discussions, and written comments.

The planning document is intended for use by ORNL researchers and managers for (1) promoting our cross-cutting ideas and multidisciplinary and interdisciplinary capabilities with potential customers and collaborators and (2) continuing the strategic planning process by further developing our ideas and capabilities for addressing water resource issues.

\section{Biomass Energy Technology Could Supply Economical Power to the Tennessee Valley Authority Region}

\section{R. L. Graham and M. E. Downing}

Biomass is becoming an increasingly attractive fuel to the Tennessee Valley Authority (TVA) because of (1) the Clean Air Act (CAA), which calls for reductions in sulfur emissions; (2) federal energy legislation, which gives contained biomass power plants (those fueled by biomass grown specifically for the particular power plant) a 1.5-cent $\mathrm{kWh}$ tax credit; and (3) the proposed Btu tax, which would a.fect coal but not biomass energy. For the same amount of electricity production, a coal-fired power plant will release 26,000 times more $\mathrm{SO}_{x}$ and 20 times more $\mathrm{NO}_{x}$ than a wood-fired plant, even if the coal power plant has scrubbers sufficient to meet current CAA emission standards.

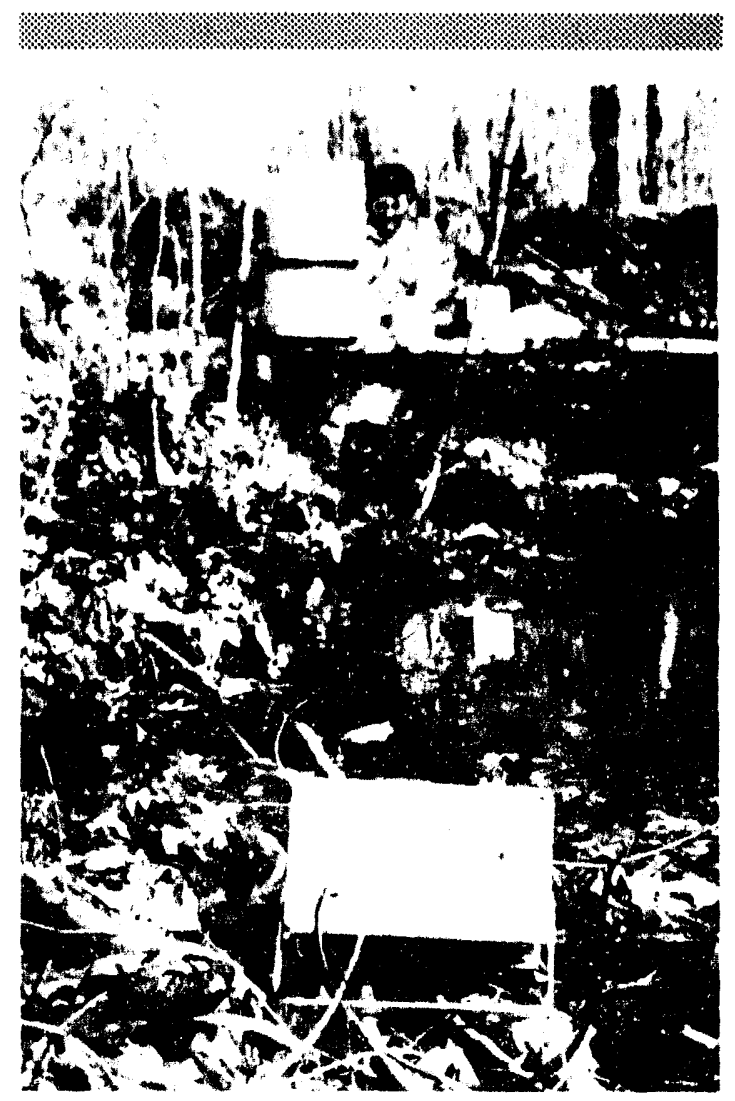

Pat Mulholland prepares to conduct field injections of a hydrologic tracer and propane gas into Walker Branch, a forest stream in the Oak Ridge National Environmental Research Park. The instrument in the foreground provides highprecision measurements of dissolved axygen concentration, which are used in computing rates of metabolism at the whole-stream scale. 
For a price to the farmer of $<\$ 50 /$ dry ton ( $<\$ 3 / \mathrm{MBtu}$ ), over 40 million dry tons of wood could be grown annually on a sustainable basis on agricultural land in the TVA region. This amount of wood could supply $8000 \mathrm{MW}$ of base-load power. If modest increases (25\%) in energy crop yields occurred, the price for the same supply would drop to $<\$ 2.25 / \mathrm{Mbtu}$. Most of this wood would be grown in the western portion of the TVA region. Regional water quality would be improved because land erosion would be reduced significantly, as would the regional use of fertilizers and pesticides.

'Oak Ridge Institute for Science and Education, Oak Ridge, Tennessee.

\section{OREIS Offers}

\section{Environmental Restoration Data for Analysis and Planning}

\section{R. J. Olson and R. A. McCord}

Environmental restoration (ER) is a major focus at DOE facilities. The Oak Ridge Environmental Information System (OREIS) provides consolidated, consistent, and well-documented environmental data and products to support ER activities at the DOE facilities managed by the Oak Ridge Field Office. OREIS brings together data from a variety of sites and projects to provide regulators with data in electronic formats and to provide longterm data storage and retrieval as specified in the Federal Facility Agreement between DOE, the U.S. Environmental Protection Agency, and the state of Tennessee.

The OREIS system will enter an initial operational phase in late 1993. The OREIS data base contains data associated with remedial investigation reports produced by six ER projects. These data have also been given to regulators. Metadata, information about the stored data, can help users understand how to analyze and interpret the material on the basis of the original context of the data. As more data and associated metadata are entered into OREIS, the data base will become an increasingly valuable tool for planning and monitoring future ER activities.

\section{Beavers Are Active on the Oak Ridge Reservation}

P. D. Parr, J. W. Evans, ${ }^{1}$ and A. M. Story ${ }^{2}$

A survey of water areas in Oak Ridge Reservation during the summer of 1993 to determine the extent of beaver presence indicated that the beaver population is becoming widespread. Signs of beavers were found along Bear Creek (three dams), Bearden Creek (bark stripped from trees), and the Gallaher Bend area (a couple of trees were cut down; many were stripped of bark). Prior reports indicated beaver activity at the 0800 Site across from Jones Island, along Poplar Creek and White Oak Creek, and around the Oak Ridge K-25 Site.

Positive impacts of the beaver are the creation or restoration of important wetland areas providing flood control, sediment trapping, and unique habitats. Challenges include removal (or management) of beaver from areas where flooding could result in mobility of contaminants or otherwise affect environmental remediation or monitoring.

Beaver trapping has already been initiated at the $901 \mathrm{~A}$ pond on the K-25 Site because water flow was stopped and water backec up across the road. On Bear Creek, a wire 
mesh culvert was installed in June 1993 within a beaver dam to keep down the water level on the creek. We will continue to monitor the beavers and respond to situations on a case-by-case basis to ensure environmental integrity.

${ }^{1}$ Tennessee Wildlife Resources Agency, Oak Ridge.

${ }^{2}$ Tennessee Technological University, Cookeville.

\section{Case Study of South and Southeast Asia Considers Contribution of Land-Use Change to Atmospheric $\mathrm{CO}_{2}$ Concentrations}

\section{H. Dale}

Land-use change is a major contributor to increases in atmospheric $\mathrm{CO}_{2}$ concentrations. An interdisciplinary approach to addressing the carbon flux issue is presented in a volume published in 1993 by Springer-Verlag.

The approach combines historical analysis, biomass estimates as provided by a geographic information systems model, bookkeeping models that track factors affecting the carbon flux, and an evaluation of the effects economic factors have on tropical deforestation.

Land-use change has historically been the most important source of atmospheric carbon. The most important changes in the amount of carbon in terrestrial ecosystems are caused by shifts in forest mass that result from agricultural expansion and forest harvesting.

South and Southeast Asia are important for consideration of land-use change because (1) the massive deforestation and degradation of these forests during past centuries released large amounts of carbon from the soil and plants to the atmosphere (16-36\% of the total biotic flux from 1850 to 1990), (2) extensive records of land-use changes were kept for tax collection purposes, and (3) the spatially explicit approach developed for estimating atmospheric release of carbon due to land-use change may be useful for other key regions (if not the entire world) and for other broad-scale environmental problems (e.g., regional air pollution and ozone depletion).

\section{Individual-Based Model Simulates Growth and Survival in Fish Cohort's First Growing Season}

\section{L. DeAngelis}

The objective of this research on compensatory mechanisms in fish populations, funded by the Electric Power Research Institute, was to determine if a mechanistically based model can make good qualitative predictions of stock-recruitment relationships during the first growing season of a fish population. In particular, we wanted to know if the models could predict whether density-dependent effects are likely to occur.

An individual-based model was set up to simulate the growth and survivorship of a cohort of smallmouth bass (Micropterus dolomieu) through their first growing season. Individual-based models exhibit the growth and survival rates of many individual organisms simultaneously.

In the model, smallmouth bass were exposed to size-dependent predation, size-independent mortality, and starvation mortality resulting from depletion of their 
prey supply. Model simulations produced survivorship curves. The results showed the following trends: (1) a strong density dependence of the mortality rate early in the growing season and density independence late in the growing season, (2) a distinct critical time (CT) at which the slope of the survivorship curve changes from a steep decline to a shallow one, and (3) a decrease in CT as a function of the initial egg density.

During the early growing season, the fish competed for and overexploited zooplankton prey, thereby producing these results. The results of this model simulation strongly resemble patterns of some empirical data. These data comparisons indicate that individual-based models complex enough to be applied to different data should be useful tools in future fish-population studies.

These models will enable researchers to understand the year-to-year fluctuations of fish populations in terms of such specific factors as weather, fishing, and possible intrinsic oscillatory behavior.

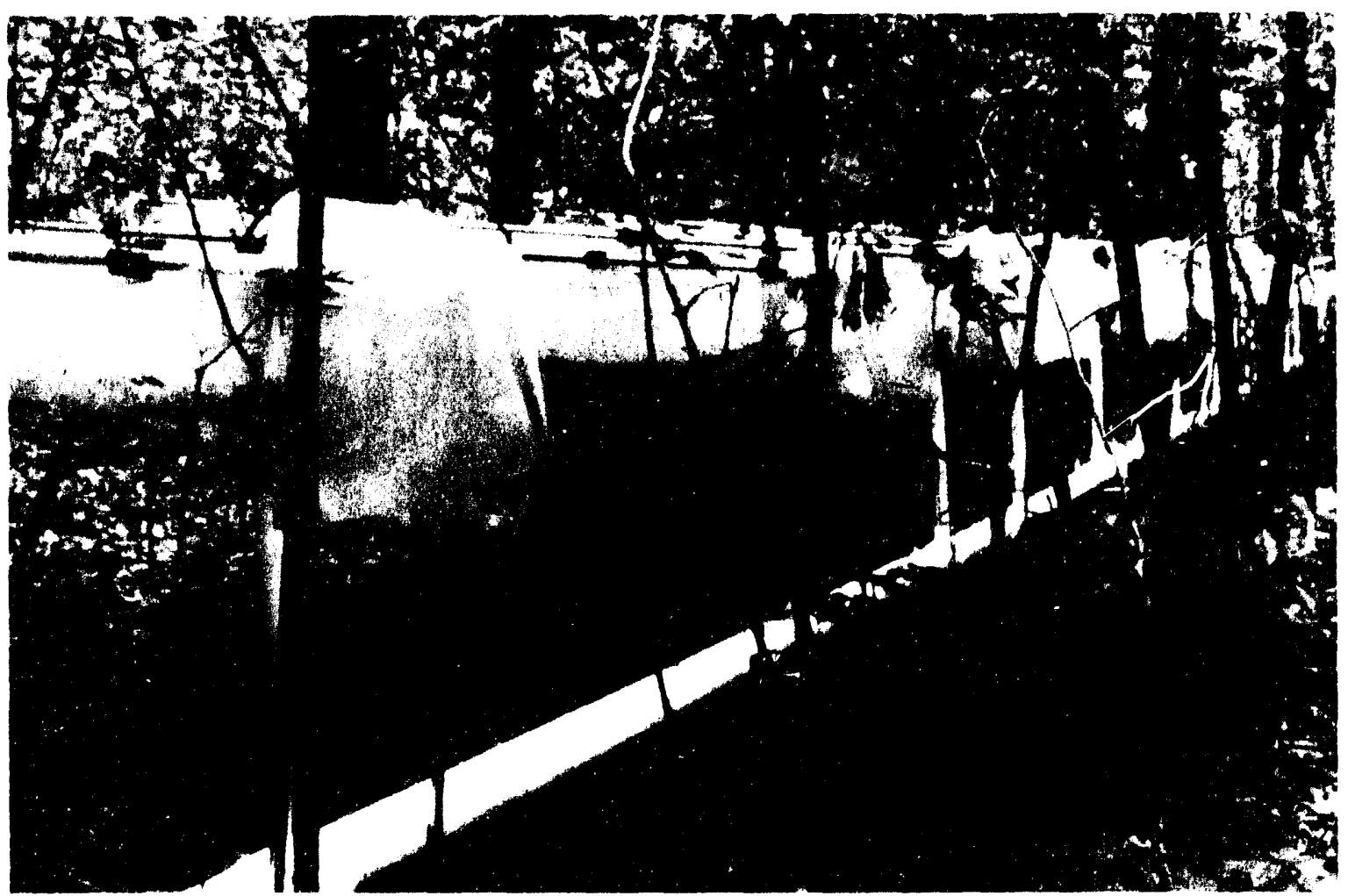

Troughs intercepting rainfall at a site in Walker Branch Watershed as part of a climate change experiment. Through a system of troughs and pipeline, researchers divert rainfall from one plot and transfer it to another so they can study the effects of drought and increased precipitation on the forest ecosystem. 
Such knowledge will help in the management and protection of fish populations.

\section{A Method Is Developed to Analyze Scale-Dependent Changes in Landscape Pattern}

\section{R. H. Gardner, R. E. Plotnick, ${ }^{l}$ and R. V. O'Neill}

Natural disturbances and human impacts affect both the grain and extent of spatial landscape patterns, requiring analysis methods that can reveal scale-dependent changes in pattern. A general measure of spatial pattern, referred to as "lacunarity," has been adapted from principles of fractal geometry to measure (1) the overall fraction of the map containing the resource of interest, (2) the scale-dependent changes in patterns of resources, and (3) the range of spatial scales over which a landscape exhibits self-similarity. Calculations begin with a landscape map of size $L$ (a total of $L^{2}$ sites) that is subsampled by a quadrate of size $r$. The number of sites with the attribute of interest within the quadrate is counted and recorded. The quadrate is moved and the process is repeated until all $(L-r-1)^{2}$ samples of the map have been taken. The mean $(\zeta)$ and variance $\left(S^{2}\right)$ of these counts are calculated, and the ratio, $\Lambda(r)=S^{2} /(\breve{S})^{2}+1$, provides an estimate of lacunarity at scale $r$. The process is iterated at successively larger quadrate sizes until $r=L / 2$. The distribution of $\Lambda$ is then plotted against $r$, providing a graphical measure of the change in aggregation with change in scale.

The overall fraction of sites $P$ of the resource type of interest is equal to $1 / \Lambda$ when $r=1(P=1 / 2=0.5)$. The flat trajectory of the structured map at values of $r<10$ indicates a region of selfsimilarity, and the slope of this line is an estimate of the fractal dimension. A comparison of the structured map with simple random maps indicates that the structured map differs from random until $r>60$.

Lacunarity is simple to calculate and provides readily interpretable graphical results. The method is extremely sensitive and can discriminate differences in pattern even when the resource is very sparse. Estimates of lacunarity provide a new tool for theoretical and practical investigations of the scale-dependent relationship between pattern and process within heterogeneous landscapes.

${ }^{1}$ University of Illinois, Chicago.

\section{Life-History Theory and Individual-Based Modeling Provide an Integrated Approach for Cross- Species Comparison of Fish Population Dynamics}

W. Van Winkle, K. A. Rose, K. O. Winemiller,' D. L. DeAngelis, S. W. Christensen, and R. G. Otto ${ }^{2}$

Life-history theory provides the framework for selecting representative fish species with contrasting life cycles and mechanisms for population regulation. Individual-based modeling is a promising tool for integrating our understanding of the mechanisms that affect the development, growth, survival, and reproduction at the individual level and for extrapolating that understanding to gain insight into population responses such as abundance and size distributions. 
We have demonstrated the linking of these two tools by comparing the effects of changes in larval mortality on the subsequent growth and survival of juvenile smallmouth bass and striped bass.

The life-history characteristics of these two species differ markedly with respect to parental investment per progeny. Results from the two individual-based models are consistent with our a priori expectations. Changes in final growth and survival of juveniles tended to compensate for the effects of changes in larval mortality to a greater extent for smallmouth bass than for striped bass. Our demonstration of this research approach represents an initial attempt to integrate the use of these two tools for comparing fish species with respect to responses to disturbance and capacity for self-regulation.

${ }^{1}$ Texas A\&M University, College Station.

${ }^{2}$ R. G. Otto and Associates, Vienna, Maryland.

\section{Ozone Sensitivity in Northern Red Oak Depends on Growth Stage}

\section{J. Samuelson, ${ }^{1}$ G. S. Edwards, ${ }^{1}$ J. M. Kelly, ${ }^{1}$ P. J. Hanson, and S. D. Wullschleger}

Controlled-fumigation studies of seedlings have shown that some tree species are detrimentally affected by ozone. How accurately seedling responses will reflect responses of mature trees and forest ecosystems to air pollution is unknown. The Tennessee Valley Authority, with the cooperation of ESD scientists, is conducting a study in which seedlings and reproductively mature northern red oak trees located on the TVA Reservation at Norris, Tennessee, are fumigated with subambient, ambient, and twice-ambient levels of ozone.

Thirty-year-old northern red oak trees were more sensitive to ozone in terms of leaf photosynthetic health and leaf growth than seedlings. Trees exposed to twiceambient ozone had lower leaf photosynthetic rates throughout the growing season and less canopy leaf biomass than trees exposed to subambient and ambient ozone. However, reductions in leaf biomass of trees that were treated with twice-ambient ozone did not result in less bole, branch, or bud growth. Observed reductions in carbon efflux from the soil surrounding trees that were treated with twice-ambient ozone suggest potential changes in root or soil microbial processes in response to ozone stress.

In contrast, ozone treatment had no influence on the physiological and growth characteristics of seedlings. Greater ozone sensitivity in trees may be explained, in part, by greater internal ozone uptake through greater stomatal conductance, leaf area, and leaf longevity in trees than in seedlings. Differences that the growth stages exhibit in recurrent patterns of flushing and in the allocation of carbon and nutrients may also influence ozone sensitivity.

Information derived from this study is also being used to address issues of scaling from a seedling to mature tree level in mechanistic plant-response models such as TREGRO, as well as to understand responses of trees and forest ecosystems to air pollution.

\footnotetext{
${ }^{1}$ Tennessee Valley Authority, Norris, Tennessee.
} 


\section{Section Staff and Guests}

\section{S. Shriner}
A. Baybayan' J. J. Beauchamp ${ }^{2}$
G. M. Berntson ${ }^{3}$
C. T. Uarten
C. M. Geil ${ }^{1}$
C. C. Brandt ${ }^{2}$
D. B. Gibbs ${ }^{4}$
A. L. Brenkert
M. A. Brewer ${ }^{1}$
D. Gordon ${ }^{4}$
G. Buckner ${ }^{4}$
R. L. Graham
C. A. Gunderson
D. A. Buehler ${ }^{4}$
B. T. Haie
T. P. Burns 5
A. L. Halleran ${ }^{4}$
G. F. Cada
H. E. Cardwell ${ }^{1}$
M. L. S. Chambers ${ }^{4}$
T. G. Hannah ${ }^{4}$
P. J. Hanson
W. W. Hargrove ${ }^{14}$
S. T. Chancey ${ }^{1}$
J. W. Chason ${ }^{6}$
M. J. Hayes ${ }^{1}$
S. P. Hendricks ${ }^{1}$
B. D. Holcomb ${ }^{15}$
T. A. Chatfield?
M. Holmgren ${ }^{4}$
E. A. Childs ${ }^{8}$
S. E. Childs ${ }^{8}$
M. E. Clark ${ }^{4}$
E. R. Hunt, Jr.'
M. A. Huston
B. L. Jackson ${ }^{16}$
P. J. Clark ${ }^{4}$
M. F. Cochran ${ }^{9}$
R. A. $\mathrm{Cook}^{4}$
H. I. Jager
M. G. Jager ${ }^{4}$
E. A. Jay ${ }^{1}$
L. S. Cooper
L. W. Cooper
J. D. Joslin"1
C. A. Kappelmann
C. C. Coutant
S. C. Crooks ${ }^{8}$
V. H. Dale
J. M. Kelly ${ }^{11}$
J. H. Kenley ${ }^{4}$
C. Lafon ${ }^{4}$
S. L. Davis ${ }^{4}$
P. Lay ${ }^{4}$
D. L. DeAngelis
M. Loreau ${ }^{17}$
Q. Dong ${ }^{10}$
F. Loureiro ${ }^{4}$
D. C. Downing ${ }^{1}$
M. E. Downing ${ }^{1}$
G. L. Edwards ${ }^{1 \mathrm{i}}$
N. T. Edwards
A. R. Ehrenshaft ${ }^{12}$
J. W. Evans ${ }^{13}$
R. O. Flamm ${ }^{1}$
A. J. Fuentes ${ }^{1}$
D. Fugate ${ }^{4}$
R. H. Gardner
B. Lu
H.-K. Luh ${ }^{4}$
R. J. Luxmoore
H. K. Marotto $\mathrm{II}^{18}$
E. A. Marschall ${ }^{15}$
N. McLetchie ${ }^{19}$
B. H. McRae ${ }^{1}$
M. E. Mitch'
P. J. Mulholland
D. A. Neergaard ${ }^{4}$
R. J. Norby
H. L. Offerman ${ }^{20}$
R. J. Olson
E. G. O'Neill
R. V. O'Neill
P. D. Parr
S. M. Pearson 5
B. S. Pedersen 4
R. B. Perlack ${ }^{21}$
C. B. Phillips
P. A. Pier ${ }^{11}$
M. Plaza'
M. R. Poland
W. T. Pope ${ }^{1}$
K. L. Popham
L. R. Pounds ${ }^{4}$
P. M. Presley
J. W. Ranney
B. L. Rashleigh ${ }^{1}$
F. R. Reeves
A. W. Renshaw
N. H. Rice ${ }^{22}$
K. H. Riitters ${ }^{23}$
D. M. Roberson ${ }^{1}$
J. A. Shaakir-Ali ${ }^{16}$
A. B. Sharp ${ }^{24}$
T. L. Shirshac ${ }^{1}$
D. J. Shure ${ }^{25}$
E. P. Smith ${ }^{1}$
I. M. Smith ${ }^{1}$
C. Solis ${ }^{26}$
A. D. Steinman ${ }^{4}$
A. T. Stone ${ }^{4}$
R. T. Strong ${ }^{4}$
T. A. Tabberer ${ }^{1}$
S. P. Timmins ${ }^{27}$
D. E. Todd
T. Tschaplinski
A. F. Turhollow 21
M. G. Turner
R. S. Turner
G. A. Tuskan
J. A. Tyler ${ }^{1}$
H. Van Miegroet
W. Van Winkle
R. O. Wadlington
A. E. Wechsler ${ }^{1}$
D. C. West
S. L. West ${ }^{4}$
J. T. Whitehead, Jr. ${ }^{28}$
W. R. Wiley ${ }^{29}$
R. V. Wilkerson
R. S. Williams ${ }^{30}$
G. T. Roberts ${ }^{8}$
K. A. Rose
A. D. Rosemond ${ }^{15}$
A. D. Wilson ${ }^{25}$
R. Wimmer ${ }^{31}$
B. A. Rosensteel ${ }^{15}$
P. F. Ryan ${ }^{6}$
E. R. Marzolf ${ }^{1}$
M. J. Sale
Y. Matsinos ${ }^{4}$
L. J. Samuelson ${ }^{1}$
P. A. Scarbrough
P. A. Mays:1
D. M. McDermot ${ }^{4}$
A. B. Schwab ${ }^{1}$
M. D. Self ${ }^{23}$
J. D. Wise ${ }^{4}$
M. H. Wolfe"
M. A. Wood
L. L. Wright
S. G. Wright
Y. $\mathrm{Wu}^{4}$
S. B. McLaughlin
S. D. Wullschleger
C. L. Wylie ${ }^{11}$ 

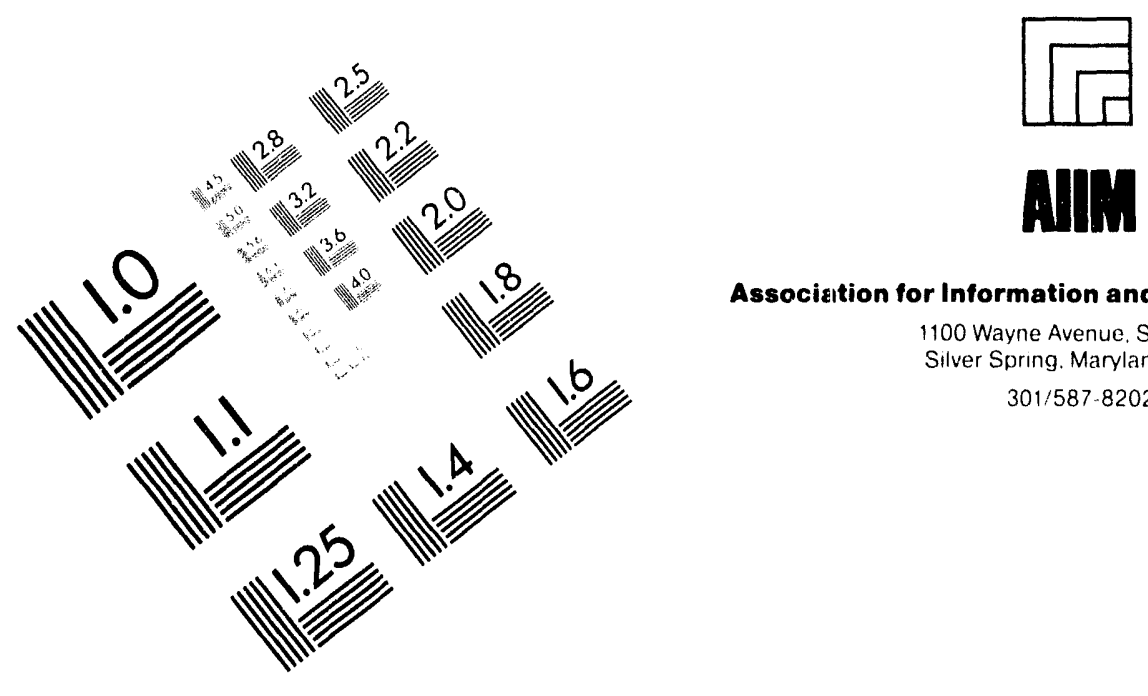

Associztion for Information and Image Management

1100 Wayne Avenue. Sulte 1100

Silver Spring. Maryland 20910

$301 / 587.8202$

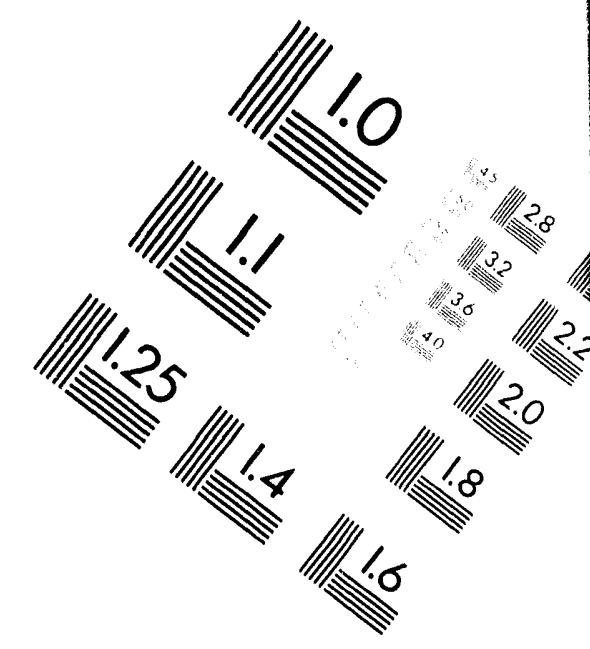

Centimeter

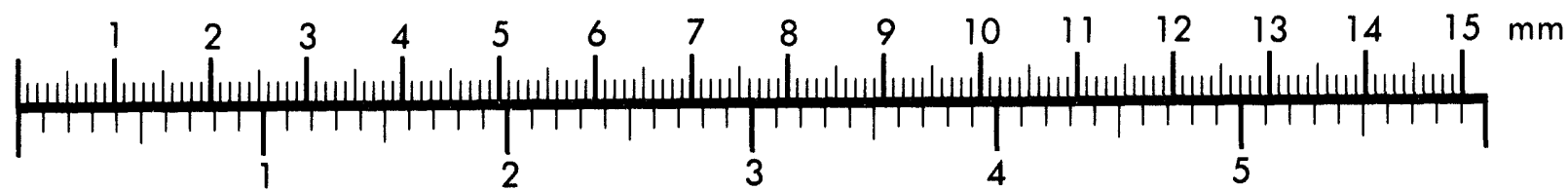
Inches
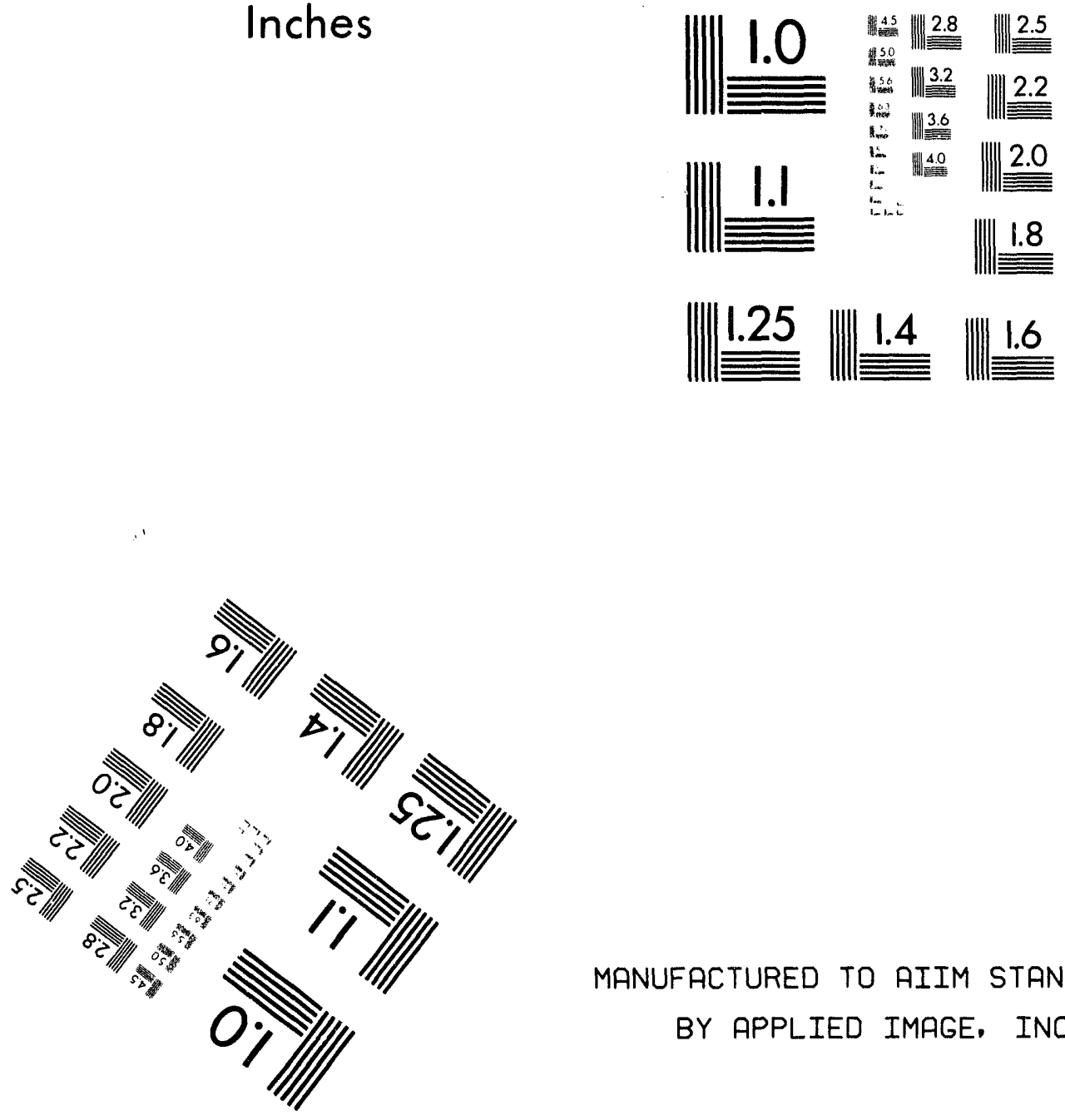

MANUFACTURED TO AIIM STANDARDS BY APPLIED IMAGE, INC.

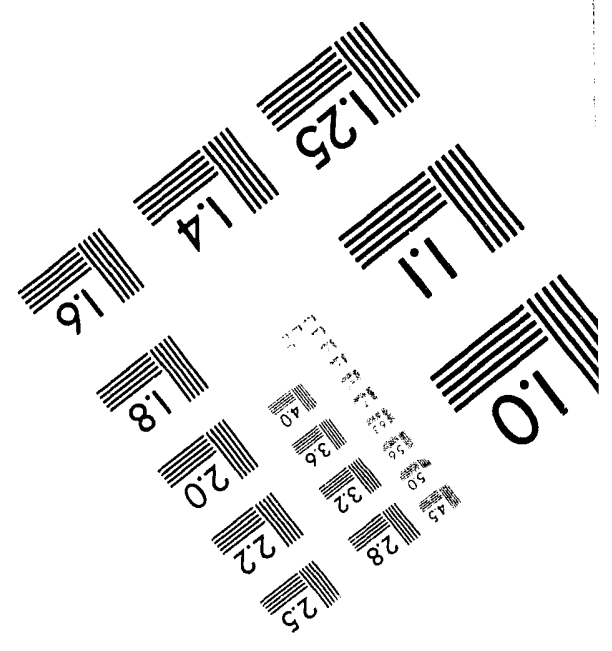



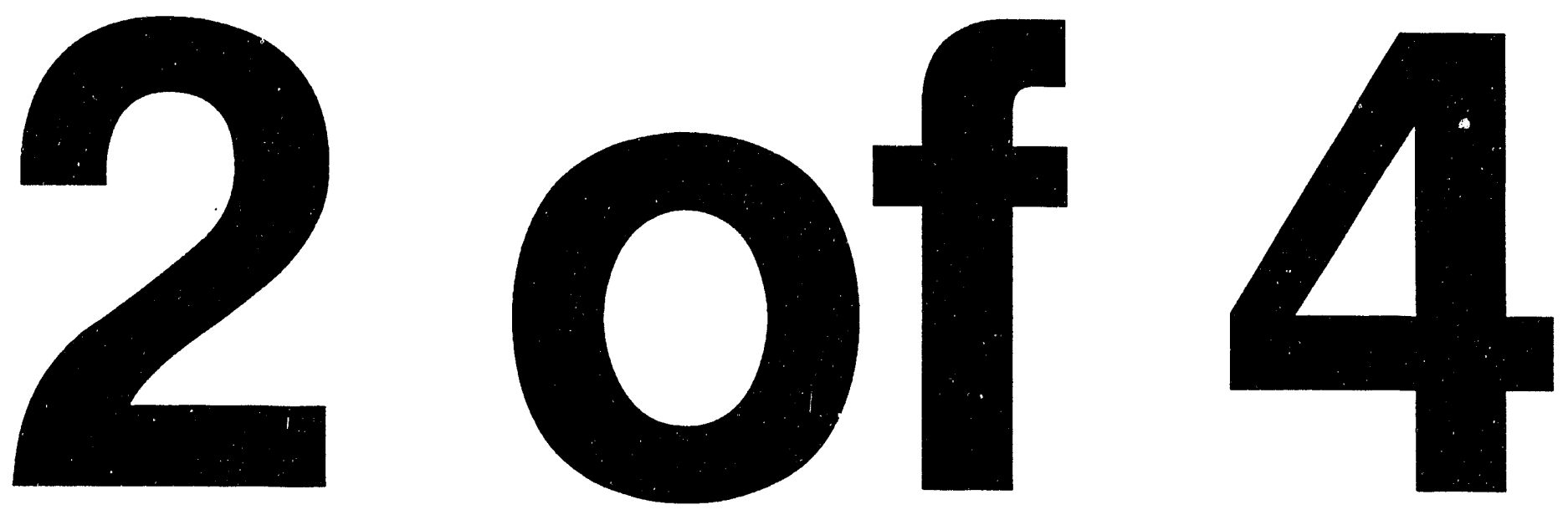
'Oak Ridge Institute for Science and Education, Oak Ridge, Tennessee.

${ }^{2}$ Engineering Physics and Mathematics Division, ORNL.

${ }^{3}$ Harvard University, Cambridge, Massachusetts.

${ }^{4}$ The University of Tennessee, Knoxville.

${ }_{5}^{5}$ Alexander Hollaender Postdoctoral Fellow.

${ }^{6}$ Science Applications International

Corporation, Oak Ridge, Tennessee.

${ }^{7}$ Miami University, Oxford, Ohio.

${ }^{8}$ Roane State Community College,

Harriman, Tennessee.

${ }^{9}$ Yale University, New Haven, Connecticut.

${ }^{10}$ Vanderbilt University, Nashville, Tennessee.

${ }^{11}$ Tennessee Valley Authority, Norris, Tennessee.

${ }^{12}$ Health Sciences Research Division, ORNL.

${ }^{13}$ Tennessee Wildife Resources Agency,

Oak Ridge, Tennessee.

${ }^{14}$ Fort Lewis College, Durango, Colorado.

${ }^{15}$ Self-employed.
${ }^{16}$ Computing Applications Division, ORNL.

${ }^{17}$ University of Brussels, Belgium.

${ }^{18}$ Ohio Wesleyan University, Delaware, Ohio.

${ }^{19}$ University of Kentucky, Lexington.

${ }^{20}$ University of Richmond, Richmond, Virginia.

${ }^{21}$ Energy Division, ORNL.

${ }^{22}$ University of Wisconsin, Madison.

${ }^{23}$ Tennessee Valley Authority, Knoxville, Tennessee.

${ }^{24}$ Realty Executives, Farragut, Tennessee.

${ }^{25}$ Emory University, Atlanta.

${ }^{26}$ Universidad Nacional Autonoma de Mexico, Mexico.

${ }^{27}$ Analysas Corporation, Oak Ridge, Tennessee.

${ }^{28}$ Tennessee Water Resources Agency, Talbott, Tennessee.

${ }^{29}$ Fort Valley College, Boston.

${ }^{30}$ University of South Carolina, Columbia.

${ }^{31}$ Austrian National Science Foundation, Vienna. 


\section{Environmental Analyses}

\section{Introduction}

The Environmental Analyses Section of the Environmental Sciences Division (ESD) at Oak Ridge National Laboratory (ORNL) focuses on interdisciplinary analysis and assessme nt of environmental problems. In this context, the section develops problem-solving tools, such as methodologies, data bases, and information and policy analyses. The environmental issues range widely from those at individual sites and regional landscapes to those of national and global concern. A variety of sponsors are provided with technical assistance for the development of environmental management and regulatory policies. Technical information and analyses produced by the section also serve as a broader resource for the scientific and technical communities. Section sponsors include the U.S. Department of Energy (DOE) Assistant Secretary for Environment, Safety and Health; the DOE Assistant Secretary for Environmental Restoration and Waste Management; the DOE Office of Health and Environmental F.esearch; the U.S Environnental Protection Agency (EPA); the U.S. Air Force; the National Oceanic and Atmospheric Administration; the Martin Marietta Energy Systems, Inc., Environmental Restoration (ER)

Division; and the Bonneville Power Administration.

\section{Environmental Assessment}

The goal of the Environmental Assessment Group is to apply state-of-the-art assessment tools to complex issues at individual plants and at sites that are large geographically and to issues that are programmatic in scope. The group prepares impact analyses for DOE, the Federal Energy Regulatory Commission, the Nuclear Regulatory Commission, and the U.S. Department of Defense as part of agency compliance with the National Environmental Policy Act (NEPA). Impacts on terrestrial and aquatic ecological resources, land and water use, and water quality are assessed for environmental impact statements (EISs) and related documents. Staff members also provide technical reviews and analyses of NEPA documents for the DOE Office of NEPA Oversight and the DOE Environmental Compliance Division, as well as technical support for the EPA Office of Federal Activities. As members of audit teams, staff in the group also help assess NEPA compliance at DOE facilities. In addition, the group provides NEPA training for DOE managers. Recently, staff completed an environmental impact assessment sourcebook for EPA

During FY 1993, the Environmental Assessment Group participated in the preparation of 7 EISs and 16 environmental assessments (EAs), and contributed to the preparation of materials produced by others, including biological surveys, ecological risk assessments, and environmental reports for use in NEPA documents. NEPA training was given at two DOE facilities, and NEPA audits were conducted at two others. Staff are also active in the areas of wetlands and benthic organisms research. During FY 1993, 15 manuscripts were published in the open literature 
or society proceedings, and EPA published an EA sourcebook, prepared by staff.

\section{Environmental Compliance}

The Environmental Compliance Group provides information resources and regulatory expertise to assist various sponsors in their efforts to comply with federal and state environmental laws and regulations. The group tracks, monitors, and reports new environmental laws and regulatory initiatives; provides up-to-date reference materials on all major federal environmental laws; and uses scientific, engineering, legal, and regulatory expertise to analyze regulatory issues, develop environmental compliance methodologies, and assist DOE in creating and implementing environmental policy and guidance. Other important activities include developing and conducting training courses on environmental laws and regulations for DOE; Martin Marietta Energy Systems, Inc.; and other sponsors. The group also conducts environmental compliance audits at U.S. Air Force bases and other federal facilities as well as generates guidance documents that discuss new regulatory developments for the DOE Office of Environmental Guidance. In addition to these services, the Environmental Compliance Group serves as a resource for regulatory technical assistance to ORNL and the Energy Syste ns ER Division.

In FY 1993, the Environmental Compiiance Group developed a Resource Conservation and Recovery Act overview training course, which is currently being offered by EH-23 to DOE field elements. Members of the group also initiated a unique guidance implementation project to assist the Savannah River Site in integrating its remedial investigation/feasibility study activities with natural resource damage assessment concerns.

\section{Environmental Risk}

The Environmental Risk Group devises methods for the quantitative assessment of environmental risks; applies these methods to local-, regional-, and national-scale environmental problems; and provides regulatory agencies with guidance on the uses of environmental risk assessment. The group defines and measures the health of ecological resources, extrapolates test data from laboratory to field and from individuals to populations and ecosystems, quantifies ecological risks at the watershed and landscape levels, and predicts the movement of contaminants through food chains. The research, conducted jointly with other ESD groups and ORNL divisions, supports the ORNL Center for Risk Management. Sponsors include EPA, DOE, and the Energy Systems ER Division.

During FY 1993, the group (1) designed and implemented ecological risk assessment plans for contaminated sites on the Oak Ridge Reservation and the Portsmouth Gaseous Diffusion Plant, (2) conducted research and research planning activities for EPA's Environmental Monitoring and Assessment Program, (3) completed a survey of ecological risk assessment capabilities at DOE facilities nationwide, (4) developed and implemented ecological risk assessment methodologies for a programmatic EIS for the DOE Integrated Environmental Restoration and Waste Management Program, and (5) coordinated a review of fish population models intended for use in managing endangered salmon stocks in the Columbia River Basin. 


\section{Global Trace Gas and Climate Information Systems}

The Global Trace Gas and Climate Information Systems Group provides the information, data, and analytical capabilities essential to performing comprehensive, resource-intensive regional and global evaluations of increases in radiatively active trace gases ("greenhouse" gases) in the atmosphere and the potential effects of such changes on environmental and societal resources. The group employs state-of-the-art information, data management, and analytical techniques to ensure proper exchange of information and data among researchers and a diverse user community of scientists, policymakers, educators, students, and corporate officials. To achieve the careful balance of information and data support needed to meet project requirements, the group relies on information theory, computer science, geographic information systems, library science, telecommunications, scientific visualization, statistical science, and data management.

The group produces journal articles, newsletters, brochures, ORNL and DOE reports, and fully documented numeric data packages (NDPs) and computer model packages. The single largest function of the group is to operate the Carbon Dioxide Information Analysis Center (CDIAC) (in support of the DOE Global Change Research Program) and the World Data Center-A (WDC-A) for Atmospheric
Trace Gases (part of the World Data Center System, coordinated by the International Council of Scientific Unions). The Global Trace Gas and Climate Information Systems Group also analyzes the potential effects that changes in climate and sea level would have on environmental and societal resources.

In FY 1993, the group began to operate the newly established WDC-A for Atmospheric Trace Gases. The group also published several important global-change data and information products, including the NDP Surface Water and Atmospheric Carbon Dioxide and Nitrous Oxide Observations by Shipboard Automated Gas Chromatography: Results From Expeditions Between 1977 and 1990 (in collaboration with the Scripps Institution of Oceanography); the report Climatic Data Bases of the People's Republic of China, 1841-1988 (in collaboration with the Institute of Atmospheric Physics, Beijing; the State University of New York, Albany; and the National Climatic Data Center, Asheville, North Carolina); the duallanguage bibliography Selected Translated Abstracts of Russian-Language ClimateChange Publications: I. Surface Energy Budget (in collaboration with the AllRussian Research Institute of Hydrometeorological Information-World Data Center, Obninsk, Russia); and the two-disk CD-ROM (compact disk, readonly memory) CDLAC's Numeric Data Package Collection. 


\section{Technical Summaries}

\section{Environmental Report for the Foothills Parkway Identifies Numerous Rare Species and Sensitive Habitats}

\author{
L. K. Mann, L. R. Pounds, M. Harvey, ${ }^{1}$ \\ D. K. Smith, ${ }^{2}$ and D. Etnier ${ }^{2}$
}

As with any project on federally owned land, construction of Section 8D of the National Park Service's Foothills Parkway will require close coordination with field biologists to ensure compliance with appropriate requirements for protection of sensitive species, air and water quality, and wetland areas. Because the Foothills Parkway is part of the Great Smoky Mountains National Park (GSMNP), protection of biodiversity, especially biotic components unique to GSMNP, is of special concern.

Terrestrial species surveys of the site identified four federal candidate species, 12 state-listed species, more than 47 species rare in GSMNP, and one invertebrate species endemic to GSMNP that could potentially be affected by construction. None of the vegetation on the right-of-way is old-growth forest; however, sinkholes, a cave, two unusual rocky outcrops, a cobble bar in the Little Pigeon River, and rich, moist, sheltered slopes and ravines all contribute to the biotic richness of this foothills area.

Although not usually included in most environmental surveys, bryophytes were surveyed because of the global significance of the diverse bryophyte flora within the GSMNP. Of the bryophytes found on the right-of-way, 20 were reported for the first time in either the GSMNP or the state of Tennessee, and 79 are regarded as rare in the GSMNP, Tennessee, or the United States. These data and preliminary assessment of potential impacts and suggested mitigation will enable the National Park Service staff to prepare the final environmental impact statement for the construction and operation of the Foothills Parkway.

${ }^{1}$ Tennessee Technological University, Cookeville.

${ }^{2}$ The University of Tennessee, Knoxville.

\section{Effects of Temperature on Growth and Survival of Hydropsyche depravata in East Fork Poplar Creek Are Determined}

V. R. Tolbert, R. E. Martinez-Morales, ${ }^{\prime}$ and J. G. Smith

The density of the caddisfly, Hydropsyche depravata, in East Fork Poplar Creek was determined to be substantially lower at a monitoring point [East Fork kilometer (EFK) 23.4] immediately below the Oak Ridge Y-12 Plant (a nuclear weapons components production facility) than $\sim 10 \mathrm{~km}$ downstream at EFK 13.8. To determine if temperature alone could account for the differences in density at the two stream locations, laboratory studies were conducted on growth and survival responses of individuals of the spring cohort of $H$. depravata to different temperatures $(21,24,27$, and $\left.30^{\circ} \mathrm{C}\right)$.

The two higher temperatures reflect the maximum temperatures at the two sites, with the highest temperature maxima occurring at EFK 23.4. Field 
measurements show that the temperature maxima consistently differ for the two sites [EFK $23.4\left(31^{\circ} \mathrm{C}\right)$ and EFK $\left.13.8\left(28^{\circ} \mathrm{C}\right)\right]$.

Randomly selected third and fourth instar larvae from EFK 13.8 were weighed and held in the laboratory in each of three replicate tanks (ten individuals/tank) at each of the four temperatures throughout the 2-week experimental period. Larvae in each experimental tank were daily fed a slurry of food equivalent to $2 \%$ of their total body weight. All parameters except temperature were equivalent among treatments.

The results of this laboratory study show that the elevated temperature typical of EFK 23.4 had no significant effect $(p>0.05)$ on growth of the caddisfly $H$. depravata. Additionally, there was no significant difference $(p>0.05)$ in the overall survival of this species for the different temperatures tested. These results suggest that the elevated ternperature at EFK 23.4 alone is not a direct factor in the lower number of individuals at this site.

${ }^{1}$ High school student, Naranjito, Puerto Rico.

\section{ESD Helps Prepare Environmental Assessment Sourcebook for EPA}

\section{L. Sigal}

The U.S. Environmental Protection Agency (EPA) Office of Federal Activities (OFA) asked ORNL to develop an environmental assessment (EA) sourcebook to satisfy OFA's increasing national and international requests for such information. In December 1991, ESD hosted an international workshop of EA experts to develop an outline for the sourcebook. Participants identified these major activities required for successful EA development: early planning and initiation, scoping, assessment, decision making, assessment, and postdecision analysis. Each of these activities is described in the sourcebook, and subsections are devoted to the associated needs, tools, issues, linkages, and references.

Because the generic elements of the EA process are emphasized, the sourcebook is useful to project managers, preparers, and reviewers of EA documents at all levels of government worldwide. Decision makers can use it as a checklist to ensure that environmental effects and issues are identified and presented for easy integration with economic and technical analyses. In addition, EPA uses the sourcebook as the basis for its computer-aided instruction software for EA.

At the request of EPA, the sourcebook was presented at an international workshop on methods for implementing the Economic Commission for Europe's Convention on Environmental Impact Assessment in a Transboundary Context. ESD's continuing work for EPA/OFA is a major contributing factor to the division's national and international reputation for EA expertise.

\section{Technical Review of Draft CERCLA/NEPA Documentation Enhances Integrity of $h$ smedial Action Decision Process}

\section{E. D. Smith}

DOE decisions on remediation of environmental contamination are typically made 
through the Comprehensive Environmental Response, Compensation, and Liability Act (CERCLA) Remedial Investigation/ Feasibility Study (RI/FS) process, which is integrated with the National Environmental Policy Act (NEPA) environmental impact assessment process in accordance with current DOE policy.

ORNL has been supporting DOE headquarters oversight of NEPA aspects of the integrated CERCLA/NEPA decision process by conducting a multidisciplinary review of draft decision documents (e.g., RI/FS-environmental impact statements) for proposed DOE remedial actions at the sites of past and present federal facilities that used radioactive materials.

Subjects receiving particular attention in these reviews include the appropriateness of the range of alternatives considered, completeness of identification of potential environmental impacts, scientific integrity of the analysis of impacts and of the documentation of that analysis, compliance with various environmental laws governing federal actions typically integrated with the NEPA process (e.g., the Endangered Species Act), and accuracy and balance of the comparative evaluation of alternatives.

Among the shortcomings frequently encountered in these reviews are inadequate documentation of the rationale for excluding certain high-cost remedial options from serious consideration; incomplete analysis of potential radiological risks from proposed remediation activities; failure to complete or document the interagency consultation required under the Endangered Species Act, National Historic Preservation Act, and other environmental laws; failure to consider the environmental impacts that may result from the acquisition of large quantities of borrow soil; inadequate attention to potential impacts on wetlands and floodplains; and inadequate consideration of potential impacts from planned off-site transportation and disposal of residues generated by remedial actions. By providing early identification of potentially serious shortcomings, this continuing review activity is helping DOE to ensure that decisions on remedial action are effectively documented and are based on full consideration of potential environmental consequences.

\section{9 silvicultural Practices Decrease Carbon Pools in Northem Wotland}

\section{C. Trettin}

Accumulation of soil carbon is a common function of northern, forested wetlands. The stored carbon affects chemical, physical, and hydrological properties of the wetland and serves as a reservoir within the terrestrial carbon cycle. An experiment was initiated in 1988 to determine how intensive silvicultural practices affect decomposition processes and carbon allocation on a forested wetland in northern Michigan.

The site was characterized by a jack pine, tamarack, and black spruce overstory and an understory community dominated by ericaceous sl.rubs and Sphagnum. The soil had a histic epipedon overlaying an acid, sandy solum. Ti ree treatments were selected to represent different degrees of site disturbance: whole-tree harvesting (WTH), WTH plus disk trenching, and WTH plus bedding. An undisturber forest was used as a control. Periodic measurements have been taken since 1988 on soil carbon, organic matter decomposition (using the cotton strip assay), soil temperature, soil oxidation depth, and 
vegetation recovery. Harvesting removed approximately $86 \%$ of the aboveground carbon. Following disturbance, soil carbon pools were reduced by $29 \%$ compared to the reference stand.

Within the top $25 \mathrm{~cm}$ of soil, organic matter decomposition was greater in the bedding and disk-trenching treatments than in the WTH treatment. Increases in soil temperature and aeration resulting from bedding and disk trenching were the primary factors affecting organic matter decomposition. Organic matter decomposition was also affected by sampling position within the wetland; the spatial influence was particularly important during periods of flooding or high water table.

The increased organic matter decomposition associated with silvicultural practices reversed the net carbon flux in the wetland from an accumulation state to an export state. Recent measurements on vegetation recovery show that species and community dynamics have changed; this finding suggests that carbon storage and flux are different than predisturbance conditions.

\section{Level of Environmental Impact from Advanced Oil Recovery Technology Is Similar to That of Current Oil Production}

W. E. Schramm, G. F. Cada, L. K. Mann, R. L. Miller, ${ }^{l}$ and B. M. Vogt $^{l}$

DOE's proposed Oil R.csearch Program (ORP) is intended to support and hasten the widespread commercialization of advanced oil recovery (AOR) technologies in order to maximize the economic producibility of the U.S. oil resource. This will be accomplished, in part, through costshared demonstration projects.

The analysis predicts that widespread AOR commercialization will result in a $4 \%$ rise in U.S. oil production in the year 2010 compared to present production levels, as opposed to a production decline of $40 \%$ in the absence of the ORP. Decreasing production levels are a consequence of the declining economic viability of production from mature fields.

While some of the chemicals used and wastes generated by AOR (particularly in biotechnology and chemical flood technology) differ from those of current conventional and secondary oil recovery efforts, the types of impacts assoc iated with AOR were found not to differ greatly from present effects of oil production.

In existing oil fields, expected environmental impacts would be greater under the ORP than under a scenario of declining production. However, because the quantity of imported oil and associated ocean tanker traffic would be less under the ORP, impacts in other geographical areas are expected to be smaller.

${ }^{1}$ Energy Division, ORNL.

\section{ESD Assists DOE in Preparing NEPA Compliance Guide}

M. S. Salk, J. A. Dickerman, and L. L. Sigal

On April 24, 1992, DOE published a final regulation in the Federal Register that revised procedures for implementing the National Environmental Policy Act (NEPA). This revision had been initiated by DOE's Office of NEPA Oversight 
(EH-25) as the result of Secretary of Energy Notice 15-90 (SEN-15). Another requirement of SEN-15 was for EH-25 to update and revise the NEPA Compliance Guide, which provides guidance to DOE staff and contractors on complying with NEPA. ESD personnel have been assisting EH-25 in revising this guidance manual.

The revision initially involved updating the 1988 draft NEPA Compliance Guide to reflect both DOE's 1992 NEPA regulation and other guidance that had been developed in the intervening years. In addition, new sections have been added on recent laws whose compliance can be integrated with preparation of NEPA documents (e.g., the Native American Graves Protection and Repatriation Act). Finally, where appropriate, information from the recent literature on environmental assessment has been incorporated into the revision. This revised NEPA Compliance Guide should provide a basis for DOE staff and contractors to comply with both the letter and the spirit of NEPA.

\section{Ecological Implications of Geothermal Development in Hawaii Are Studied}

\section{R. Tolbert and C. C. Trettin}

Proposed development of $500 \mathrm{MW}$ of geothermal energy on the island of Hawaii and associated energy transmission becween islands would involve sensitive and unique ecological resources.

Notably, this areas supports the only temperate rainforest in the United States, a large number of threatened and endangered species (both on land and sea), ethnobotanical species, wetlands, and coastal zones. Existing data are being supplemented with studies of forest birds, threatened and endangered species, invertebrates, rainforest vegetation, Hoary bats, and wetlands to support analyses of the environmental effects of developing geothermal energy.

A Geographic Information System is being used to (1) model the spatial and temporal distribution of the ecological resources based on existing data and field studies conducted in support of this project; (2) identify natural changes in ecosystem distribution that are associated with lava flows as a means of identifying potential effects of rainforest fragmentation; (3) evaluate the effects of geothermal development on landscape fragmentation; (4) model invasion of alien plant species into the rainforest; and (5) test for common occurrences of ecologically, geologically, and culturally important sites or plant species.

The results of these analyses will be used along with other research findings to prepare a congressionally mandated environmental impact statement for the Hawaii Geothermal Project.

83 Visit to Guatemala Lays Groundwork for Increased ORNL Assistance in Environmental Matters

\section{J.W. Webb}

Recently, i he U.S. Agency for International $D_{1}$ :velopment mission in Guatemala (AID/G) has undertaken or planned a number of development projects with a strong environmental component. Travel to Guatemala City in July 1992 involved meeting with the AID/G 
concerning potential additional technical assistance in environmental areas. The purpose of the trip was to develop and explore ORNL environmental research and development roles in Latin America in support of DOE and other U.S. agency programs and to increase field experience related to such roles. Chief areas of immediate interest were to assist AID/G in (1) monitoring and evaluating their Maya Biosphere Reserve Project (a large sustainable development effort located in the Department of El Petén) and (2) supporting the Guatemalan environmental protection organization, CONAMA, in the area of environmental assessment.

Accordingly, a visit to El Peten included consulting with parties involved in the Maya Biosphere Reserve Project and examining various sites and activities involved with the project. Organizations consulted included the Consejo National de Areas Protegidas (the oversight government agency) and several nongovernmental organizations under contract to AID/G to perform various activities (CARE, Centro Agronómico Tropical para Investigacion y Enseñanza, Conservation International, and The Nature Conservancy).

Activities viewed included slash and burn agriculture, timber harvesting, secondary forest products extraction, National Park development, and research on natural areas. Following additional discussions with AID/G, an introductory meeting was held with CONAMA in Guatemala City.

Partly as a result of this trip, ORNL has developed two proposals to AID/G for technical assistance. Development of increased assistance to AID/G has the potential to significantly increase ORNL involvement and visibility in international environmental assessment and related areas.
84 Environmental Analyses and Reviews Help the U.S. Antarctic Program Minimize Impacts, Improve Planning. and Comply with Mandates

\section{J. W. Webb}

Antarctic research for the United States must comply with environmental review requirements of U.S. legislation and the international Antarctic Treaty. Environmental analysts in ESD and Energy Division are helping the U.S. Antarctic Program minimize environmental impacts and meet these treaty and regulatory obligations.

ORNL staff visited Antarctica in 1992 and 1993. First-hand knowledge of research and support activities in Antarctica provides a foundation for subsequent review of plans and proposals and for the preparation of environmental documents. ORNL staff have prepared analyses for several Antarctic research and support activities. Analyses of research activities include the use of explosives, drilling, and research balloons.

Support activities analyzed for environmental impacts include the preparation of a new ice runway, relocation of existing facilities, building of new facilities, planning of wastewater treatment at McMurdo Station, and construction of a new station at the geographic South Pole. Major areas of environmental concern associated with the U.S. Antarctic Program are waste minimization, treatment, and disposal; fuel use; and introduction of chemicals and other materials into sensitive environments. ORNL's assessment and review activities enhance efforts to anticipate and minimize environmental impacts in Antarctica. 


\section{Staff Assist U.S. Army Europe in Environmental Compliance Activities}

\section{B. E. Booker}

ESD staff are assisting Headquarters of U.S. Army Europe (HQ USAREUR) in developing environmental compliance assessment manuals and in using these manuals for pilot assessments.

The first task consists of revising current environmental compliance assessment manuals to reflect existing European conditions and legal standards.

Now that the Cold War has ended, some stationing agreements between the United States and European nations hosting U.S. troops had to be modified to reflect post-Cold War situations.

One of the major modifications in those agreements involves an increasing emphasis on environmental issues and a requirement for U.S. forces to "respect" environmental legislation of host nations.

ESD personnel are currently developing a broad-based European environmental compliance assessment manual that could be used by U.S. forces stationed anywhere in the European theater, as well as country-specific environmental compliance assessment manuals for troops in Belgium, Germany, Italy, and the Netherlands. Because of their vast environmental compliance assessment experience, ESD personnel are also helping HQ USAREUR to use the manuals in pilot assessments and to restructure USAREUR's entire environmental compliance assessment program.

\section{ESD Aids Air Combat Command in Analyzing Environmental Compliance Deficiencies}

\author{
C. F. Sigmon
}

ESD is currently assisting the U.S. Air Force's Headquarters of the Air Combat Command (HQ ACC) in identifying remedies for environmental compliance deficiencies that could result in environmental damage or regulatory notices of violation (NOVs).

The first phase in developing effective remedies is identifying recurring problems. Approximately $52 \%$ of the open NOVs in Air Combat Command are associated with hazardous waste management. During Environmental Compliance Assessment and Management Program (ECAMP) assessments, HQ ACC and ESD's environmental regulatory experts have identified recurring compliance deficiencies that could result in NOVs.

Approximately $43 \%$ of the total number of compliance deficiencies identified in the ECAMP assessments are associated with hazardous materials and hazardous waste management, both of which could contribute to hazardous waste NOVs. Of the hazardous waste findings, $30 \%$ involve deficiencies in waste acc ımulation at satellite and 90-d accumulation points. Approximately $31 \%$ of the findings involve inappropriate disposal of potentially hazardous wastes as solid wastes and absence of adequate waste characterization to determine appropriate disposal. Approximately $17 \%$ of the hazardous waste findings are associated with management of interim-status or permitted treatment, storage, or disposal facilities. 
Although smaller in percentage, remaining important compliance deficiencies involve inadequate documentation and record keeping. For example, failure to comply with Land Disposal Restrictions and manifest requirements could result in hazardous waste fines and penalties. Approximately $47 \%$ of the hazardous materials deficiencies relate to imprope: storage. These deficiencies could be indirectly linked to hazardous waste because improper storage could result in releases producing hazardous waste or - unusable chemicals that become hazardous waste. Identification of recurring problems has led to a second phase of ECAMP: developing tools at Headquarters that can provide solutions throughout Air Combat Command.

\section{Environmental Compliance Group Assists DOE Nevada Field Office in RCRA Compliance}

\section{F. Sigmon}

To effectively plan for hazardous-waste management activities on the Nevada Test Site (NTS), the DOE Nevada Field Office (NFO) requested assistance from the Environmental Compliance Group (ECG) in its mixed and hazardous-waste permitting activities. ECG reviewed the hazardous-waste permit application, visited the units to be permitted, and trained NFO and support contractor personnel in assessing compliance for the permit application as well as other Resource Conservation and Recovery Act-related activities on the NTS. This permit review and assistance task is a part of the ongoing support ECG provides to the NFO hazardous-waste compliance program.

The first phase of the task was a review of the Part B permit application for completeness and adequacy. The permit application encompasses hazardous and mixed waste storage and mixed waste disposal units. The second phase of the task was a site visit. The site visit included inspection of the units and associated records for compliance with interim-status permitting requirements and for correspondence between actual activities and those described in the permit application. The third phase of the task was training NFO personnel in assessing hazardous waste compliance.

The training included modules on reviewing permit applications and sections on the "cradle to grave" hazardous-waste management system and compliance elements. The training required that personnel work through real-world examples to develop their hazardous-waste compliance assessment skills. Through compliance evaluations and training (two areas in which ECG has much experience), ECG assisted NFO in its continuing efforts to develop a more effective hazardous-waste compliance program.

88 Imprint of 1967 Atmospheric Release from Soviet Kyshtym Site Is Observed in Analysis of ${ }^{137} \mathrm{Cs}$ Uptake by Terrestrial Biota

\section{J. R. Trabalka}

Data from Soviet nuclear accidents, including Chernobyl, could improve environmental assessment and dose reconstruction models. Accidental atmospheric releases in 1957 and 1967, along with liquid discharges during the period 1949-1956, required the evacuation of over 18,000 persons near the 
first Soviet plutonium production site (Kyshtym). However, the complex history and incomplete information involving releases has thus far yielded data of limited use for modeling.

The 1967 event is very poorly documented. High winds dispersed contaminated shoreline soils and sediments from a small lake (Lake Karachay) used for disposal of highly radioactive wastes. About $600 \mathrm{Ci}$ of radioactivity, primarily ${ }^{137} \mathrm{Cs}$, was deposited onto part of the area contaminated by a 1957 high-level waste explosion. Comparisons of aggregated transfer coefficients for ${ }^{137} \mathrm{Cs}$ in terrestrial biota, derived from studies conducted during 1967-1969 and originally thought to have been related to the 1957 accident, were made with European data obtained following the 1986 Chernobyl reactor accident.

Considering the reported chemical similarity of ${ }^{137} \mathrm{Cs}$ deposited by the 1957 explosion and in Europe by the Chernobyl accident, researchers expected that ${ }^{137} \mathrm{Cs}$ transfers to biota would also be comparable, but the relative uptake by biota from the Kyshtym area was 1-3 orders of magnitude lower.

The apparent explanation for the difference is that the Soviet studies were conducted soon after the 1967 release from Lake Karachay and bear the radioactive fingerprint of that release rather than that of the 1957 accident (much higher total radioactivity, but very low ${ }^{137} \mathrm{Cs}$ content). The biological availability of stormdispersed ${ }^{137} \mathrm{Cs}$, sorbed onto soils and sediments, should have been relatively low. These findings illustrate the value of full disclosure of information's the Kyshtym site to maximize the usefulness of Soviet experiences to the world community.

\section{ESD Helps Prepare ORNL Strategic Plan for Waste Management}

\section{J. R. Trabalka}

An Environmental Compliance Group staff member provided technical support to the development of a strategic plan for waste management by ORNL's Waste Management and Remedial Action Division (WMRAD). The strategic plan was created during FY 1992 by applying a group process that included creative brainstorming techniques. The strategic planning group consisted of all WMRAD managers and technical support staff. The technical support staff also reviewed key background information (e.g., ORNL, Energy Systems, and DOE planning information; regulatory environment) as input to the process.

Strategic planning was a stepwise process, involving the sequential development of a mission statement, situation analysis, vision of the future, strategic objectives and obstacles, and strategies to overcome obstacles and achieve objectives. The time horizon for the strategic plan was defined as the period 1992-2020. The situation analysis revealed many continuing or developing concerns, as well as major opportunities for ORNL waste management. Progress is hampered by the lack of a full complement of technically qualified waste-management staff, and facility and programmatic needs will not be realized for more than a decade for some waste streams.

However, the growing scope of waste management within DOE affords opportunities for ORNL to play a lead role in new programs if resource limitations and technical challenges of existing ORNL 
waste management concerns do not limit involvement. This possibility highlights the importance of a formal strategic planning process to support the waste-management mission. The draft plan emphasizes the need for aggressive, innovative approaches to maximize waste reduction and to eliminate releases in order to meet the challenges of waste management at ORNL.

Developing an implementation plan (i.e., translating strategies into actions) and updating the strategic plan to reflect recent changes in the situation analysis will be this next steps in this process.

\section{Aquatic Toxicity Benchmarks Are Developed for Identifying Potential Contaminants}

\section{G. W. Suter II}

The initial stage in ecological risk assessment of hazardous waste sites is determining those contaminants worthy of further consideration, a process termed "contaminant screening." Screening is performed by comparing concentrations in ambient inedia with benchmark concentrations that indicate either a high likelihood of significant effects (upper screening benchmarks) or a very low likelihood of significant effects (lower screening benchmarks). Exceeding an upper screening benchmark indicates that the chemical in question is clearly of concern, and remedial actions will likely be needed.

Exceeding a lower screening benchmark indicates that a contaminant is of concern unless other information indicates that the data are unreliable or the comparison is inappropriate.
Chemicals with concentrations below the lower benchmark are not of concern if the ambient data are judged to he adequate. Potential screening benchmarks were developed to protect aquatic life from contaminants in water. Because no guidance exists for screening benchmarks, a set of alternative benchmarks was developed using different conceptual approaches to estimating concentrations that would cause significant effects. These benchmarks are being used to identify contaminants of concern on the Oak Ridge Reservation and at the Portsmouth site.

\section{Text on Ecological Risk Assessment Is Published}

\section{G. W. Suter II}

A basic textbook, Ecological Risk Assessment, was written and published to fill the need for technical guidance in this new field. Ecological risk assessment estimates risks to nonhuman organisms, populations, and ecosystems in a manner analogous to human health risk assessment. The U.S. Environmental Protection Agency requires that ecological risk assessments be performed for hazardous waste sites and other regulatory actions but has given only a brief framework for guidance.

The text first provides an introduction to ecological risk assessment, explains basic concepts, and includes a conceptual paradigm. Next, the components of exposure assessment are discussed, including environmental chemistry, transport and fate modeling, and modeling of uptake by nonhuman organisms.

The following section examines effects assessment at the individual organism, population, and ecosystem levels of 
organization. These exposure and effects assessment sections focus on predictions of risks due to releases of chemicals and chemical mixtures.

The last section of the book discusses less conventional types of ecological risk assessment: retrospective assessments, assessment of risks due to exotic organisms, assessment of regional risks, and the - le of risk assessment in environmental monitoring.

\section{Characterization of} Resources at Six National Laboratories Will Aid Development of Methodology for Ecological Risk Assessment

\section{K. Mann, L. W. Barnthouse, and L. L. Sigal}

As part of the programmatic environmental impact statement for the DOE Integrated Environmental Restoration and Waste Management Program, ecological resources at six of the national laboratories will serve as endpoints for the ecological risk assessment.

Ecological resources suitable for use as endpoints have been characterized at the Oak Ridge, Hanford, Idaho, Los Alamos, Nevada, and Savannah River reservations.

The six general categories of resources characterized for these sites are

(1) threatened and endangered species, (2) wetlands, (3) recreational fish and wildlife, (4) agricultural or timber production, (5) parks and other public lands, and (6) biodiversity.

Methods are being developed to assess ecological risks from exposure to effluents and emissions and from construction related to restoration scenarios.

\section{Threatened and Endangered Species Habitats in South Carolina Are Vulnerable to Rise in Sea Lovel}

\section{T. W. White and R. C. Daniels}

The Endangered Species Act of 1973 defines methods for identifying and protecting threatened and endangered species and their habitats. Established under the premise that the climate remains stable, this act does not consider the potential adverse impacts of global warming on the location and viability of a given habitat typs. To examine the potential impacts of sea-level rise on threatened and endangered species habitats, a study correlating a "coastal vulnerability index" with the habitats of threatened and endangered species in South Carolina was conducted.

This analysis identified nine species whose habitats are at risk to sea-level rise because of the following geophysical factors: elevation, erodible substrates, subsidence, shoreline retreat, and high wave and tide energies. The species (and percent of habitat at risk) are Bachman's warbler $(67 \%)$; red-cockaded woodpecker, brown pelican, and bald eagle (50\%); loggerhead sea turtle and wood stork (40\%); American alligator and piping plover (35\%); and shortnose sturgeon (14\%).

With the exception of the shortnose sturgeon, all of these species nest along the coastline. The continued existence of nesting habitat is essential for the survival and reestablish-ment of these species. The nationally endangered Bachman's warbler 
will be most affected by sea-level rise, particularly since the species is already near extinction in South Carolina.

\section{U.S. Southeast Coastlines Are at Risk from Sea-Level Rise}

\section{T. W. White and R. C. Daniels}

A coastal risk assessment data base was developed for use with a geographic information system to identify coastal areas in the U.S. Southeast at risk from sea-level rise. The coastline studied extends from the Virginia-North Carolina border along the Atlantic Coast to the Mexico border along the Gulf Coast. The data base consists of 13 land, marine, and climatological variables. The three factors that were studied, along with the variables used to assess each, are as follows: (1) erosion potential-geology, geomorphology, erosion, wave heights, and tidal-range data; (2) permanent inundation-elevation and local vertical movement (i.e., sea-level change); and (3) episodic inundation- tropical storm probabilities, annual hurricane probabilities, hurricane frequency and intensity indices, tropical cyclone mean forward velocities, annual number of extratropical cyclones, and mean hurricane surges.

An algorithm was used to calculate a "coastal vulnerability index," which weighted each factor according to its risk in the event of sea-level rise: erosion potential (45\%), permanent inundation (35\%), and episodic inundation $(20 \%)$.

This analysis identifies the U.S. Southeast as one of our nation's most vulnerable regions; more than $40 \%$ of its $34,000-\mathrm{km}$ coastline is at high risk in regard to sealevel rise. The vulnerability is due primarily to the low relief (i.e., $89 \%$ of the coastline lies at elevations $<5 \mathrm{~m}$ ) and the composition of unconsolidated sediments in this area. This finding is particularly significant because $85 \%$ of U.S. coastal wetlands and $50 \%$ of the barrier islands lie within this region. 


\section{Section Staff and Guests}

\section{F. E. Sharples}

A. A. Aramowicz ${ }^{1}$

S. I. Auerbach ${ }^{2}$

C. F. Baes

J. R. Barker ${ }^{3}$

L. W. Barnthouse

M. L. Bell ${ }^{4}$

P. R. Bell ${ }^{2}$

T. A. Boden

B. E. Booker

M. D. Burtis

S. W. Christensen

C. Coppock ${ }^{5}$

L. J. Cosko ${ }^{4}$

D. P. Coughlin ${ }^{4}$

P. J. Crabtı.

R. M. Cushman

R. C. Daniels ${ }^{5}$

A. P. Dennis

S. A. Deppen ${ }^{6}$

J. A. Dickerman
D. L. Dodson

G. K. Eddlemon

M. H. Eisenbies ${ }^{5}$

C. C. Evans ${ }^{4}$

J. S. Fackenthal

G. M. Godfrey ${ }^{4}$

E. S. Gorrell ${ }^{4}$

J. A. Griffith ${ }^{7}$

G. T. Hawkins ${ }^{8}$

C. G. Heckman ${ }^{8}$

R. N. Hull ${ }^{1}$

C. T. Hunsaker

J. J. Johnston ${ }^{6}$

S. B. Jones

D. P. Kaiser ${ }^{9}$

A. Kozyr ${ }^{5}$

R. L. Kroodsma

M. A. Langston ${ }^{8}$

D. L. Lue ${ }^{5}$

M. K. Lyday ${ }^{10}$
L. K. Mann

L. K. McDonald

P. Morgan ${ }^{4}$

L. J. Morris

T. R. Nelson ${ }^{11}$

P. M. O'Connell ${ }^{4}$

F. M. O'Hara ${ }^{2}$

R. V. O'Neill

M. J. Palmer

R. C. Peters ${ }^{7}$

C. M. Poole

A. $\mathrm{Rak}^{12}$

W. S. H. Ramsey

C. B. Ravina ${ }^{13}$

M. J. Rooks ${ }^{7}$

M. S. Salk

B. E. Sample

G. G. Santore ${ }^{1}$

W. E. Schramm

R. J. Sepanski ${ }^{5}$
D. E. Shepherd

L. L. Sigal

C. F. Sigmon

E. D. Smith

T. W. Stamm ${ }^{5}$

C. A. Stiles

F. W. Stoss ${ }^{5}$

P. L. Sullenberger

G. W. Suter

B. J. Thomas

V. R. Tolbert

J. R. Trabalka

C. C. Trettin

C. S. Tucker

R. S. Vose

J. W. Webb

T. W. White

G. F. Wise 1

C. T. Woodard

${ }^{9}$ Science Applications Intemational

${ }^{1} J A Y C O R$, Oak Ridge, Tennessee. Corporation, Oak Ridge, Tennessee.

${ }^{2}$ Self-employed.

${ }^{3}$ Systematic Management Services, Inc., Oak Ridge, Tennessee.

'Oak Ridge Institute for Science and Education, Oak Ridge, Tennessee.

${ }^{5}$ The University of Tennessee, Knoxville.

${ }^{6}$ Indiana University, Bloomington.

${ }^{7}$ Environmental Careers Organization, Inc., Boston.

${ }^{8}$ Health Sciences Research Division, ORNL.

${ }^{10}$ Automated Sciences Group, Inc., Oak Ridge, Tennessee.

${ }^{11}$ Computing Applications Division, ORNL.

${ }^{12}$ Duke University, Durham, North Carolina.

${ }^{13}$ All-Russian Research Institute of Hydrometeorological Information-World Data Center, Obninsk, Russia. 


\section{Environmental Biotechnology}

\section{Introduction}

The Environmental Biotechnology Section of the Environmental Sciences Division (ESD) at Oak Ridge National Laboratory (ORNL) carries out basic and applied research on (1) mechanisms that influence the response of biological systems to contaminants, (2) effects of receiving systems on the availability and distribution of materials to which they are exposed, and (3) modifications of biological systems to enhance degradation or immobilization of contaminants. Experimental, observational, and simulation studies are conducted at different levels of biological organization, from the subcellular to the biochemical to the ecosystem level. Section activities are supported by the U.S. Department of Energy (DOE) Headquarters; the U.S. Environmental Protection Agency; the U.S. Department of Defense; the Electric Power Research Institute; and the environmental compliance and remedial action programs at ORNL, the Oak Ridge Y-12 Plant, the Oak Ridge K-25 Site, the Paducah Gaseous Diffusion Plant, and the Portsmouth Gaseous Diffusion Plant.

\section{Biological Markers}

The Biols gical Markers Group assists in the assessment of the health of the environment by identifying and evaluating biological responses induced in biota exposed to contamination. Biological responses are studied at the molecular, biochemical, and physiological levels, both to understand the basic toxicological mechanisms that underlie responses elicited by exposure to environmental contaminants and to relate these responses to effects observed at higher levels of biological organization.

Using the measurement of strand breaks in deoxyribonucleic acid (DNA) as a biological marker of environmental genotoxicity, researchers studying redbreast sunfish downstream of the Y-12 Plant showed that DNA structural integrity in this species increased (i.e., strand breaks decreased) over the past several years, probably in response to the implementation of various remedial actions. Another biomarker, a form of glutathione-S-transferase, was isolated and purified in a locally abundant, freshwater snail and is being evaluated to determine its usefulness as an indicator of pollutant exposure. In addition to their applications to ecological monitoring programs on the Oak Ridge Reservation (ORR), biomarkers were recently used to assess the effects of polychlorinated biphenyl (PCB) contamination in Hartwell Reservoir in South Carolina and Georgia and pulpmill effluent discharges to the Pigeon River in North Carolina and Tennessee.

\section{Biological Monitoring and Assessment}

The Biological Monitoring and Assessment Group conducts projects that evaluate the ecological health of aquatic and terrestrial ecosystems near the three DOE facilities on ORR and those associated with the DOE facilities in Paducah, Kentucky, and Portsmouth, Ohio. The biological monitoring programs provide a basis for assessing compliance with environmental regulations. The programs also help identify causes of adverse ecological impacts and assess the effectiveness of 
remedial action programs by documenting ecological recovery. Biological monitoring techniques range from manipulative field experiments and new in situ bioassays to more conventional approaches, including quantitative biotic surveys and laboratory toxicity tests. The Biological Monitoring and Assessment Group consists of three projects that reflect different aspects of the biological monitoring programs: Ecotoxicology, Biomonitoring, and Ecological Monitoring.

\section{Ecotoxicology}

The biological monitoring programs not Only use established biomonitoring protocols but also include the development of new procedures, as appropriate, for assessing toxicity. The goals of the Ecotoxicology Project are (1) to develop alternative methods for assessing water quality through the use of lower trophic level indicators, such as the autotrophs (algae) and heterotrophs (fungi, bacteria, and protozoans) that comprise stream periphyton communities, and (2) to apply these methods in both DOE regulatory monitoring programs and work-for-others projects. The project also conducts experimental studies of community structure and food webs in contaminated and noncontaminated streams, ponds, and wetlands to determine how contaminants modify aquatic communities or indirectly alter populations, communities, or ecological processes.

During FY 1993, staff duveloped and evaluated a test for determining the toxicity of soils to earthworms. With the capability of measuring mortality, growth, and reproduction, the 14-day test will improve the quality of ecological risk assessments for terrestrial species. Other studies on communities of periphyton (attached algae) showed that the large surface area occupied by periphyton and its ability to sorb contaminants may have a significant impact on contaminant transport and fate in streams. Results of these studies should lead to the development of a general model of contaminant loading by stream periphyton.

\section{Biomonitoring}

Biomonitoring is a major component of the environmental compliance programs at all five DOE facilities managed by Martin Marietta Energy Systems, Inc. The Biomonitoring Project uses various aquatic and terrestrial species in laboratory tests to detect acute and chronic toxicity of water (both effluents and receiving streams), sediment, and soils. These tests are necessary to comply with the requirements of the National Pollutant Discharge Elimination System (NPDES) permits issued under the Clean Water Act and to comply with requirements of the Comprehensive Environmental Response, Compensation, and Liability Act of $\mathbf{1 9 8 0}$ that are related to ecological risk assessment. The Biomonitoring and Ecotoxicology projects support the ESD concept of biomonitoring as a combination of established toxicity-testing protocols and innovative ecotoxicological approaches that together can be used to assess regulatory compliance and ensure environmental protection and restoration.

In FY 1993, new laboratory bioassays were developed for assessing the toxicity of stream and reservoir sediments. This process included the identification of suitable test species, development of a quality assurance (QA) plan and standard operating procedures, and the successful completion of an external QA audit. Also in FY 1993, laboratory toxicity tests and chemical analyses were used to identify the cause of a fish kill at the Y-12 Plant. 
The toxicant was ammonia (or a nitrogenous compound with properties similar to those of ammonia), and the source was an upgradient urea storage area.

\section{Ecological Monitoring}

Biological monitoring programs must characterize contaminant exposure and the effects of contaminants on aquatic and terrestrial species to provide an accurate assessment of current impacts and to document future recovery. The Ecological Monitoring Project conducts periodic surveys to assess the concentration of radiological and nonradiological contaminants in biota and performs studies to link potential sources of these contaminants with observed effects on individual species and whole communities. New assessment techniques are being developed to screen contaminants for risk to human health, identify contaminant sources through the use of selected species as monitors of contamination, and evaluate the biotic integrity of streams. The studies conducted by the Ecological Monitoring Project recognize that realistic goals for environmental restoration (ER) must be based on ecological endpoints (e.g., the health of stream communities) and that regulatory agencies are placing greater emphasis on biological criteria for assessing environmental compliance.

During FY 1993, staff led an interdisciplinary team of ESD scientists in developing an alternative, site-specific limit on the concentration of mercury in Y-12 Plant outfalls. The proposed criterion, which not only protects aquatic biota from chronic toxicity but also protects consumers of fish from methylmercury, was presented to the state regulatory agency for consideration during the current review of the NPDES permit for the Y-12 Plant. In related studies on mercury speciation in fish, results suggested that dissolved inorganic mercury (DIM) more readily converts to methylmercury than particle-associated mercury, indicating that remedial actions to eliminate DIM discharges at the Y-12 Plant may be very effective in reducing mercury concentrations in fish. A revised Biological Monitoring and Abatement Program for the K-25 Site was prepared and submitted to the state regulatory agency, which approved the revision. The plan is a requirement of the renewed NPDES permit for the facility and will be used to determine if the effluent limits in the permit protect the growth and propagation of aquatic life, as well as other designated uses of the receiving streams.

\section{Contaminant Transport}

The mission of the Contaminant Transport Group is to assist the ER Program in reducing both on-site and off-site risks to human health and the environment that result from past waste disposal practices. The group, which was formed in August 1993, (1) provides data to identify contaminant sources in the ORNL waste disposal areas and to prioritize areas for remediation, (2) characterizes contaminant transport mechanisms through surface water and shallow subsurface pathways to select and design effective remediation strategies, and (3) assesses the performance of remedial actions in reducing contaminant risks.

The group's mission is accomplished principally by implementation of the ER Waste Area Grouping 2 (WAG 2) Remedial Action and Site Investigations Project. Staff monitor surface water tributaries and seeps to collect data to evaluate temporal discharge patterns and fluxes during both baseline and transient 
storm events. They also collect data to characterize the spatial distribution of contaminants in sediments and the distribution of contaminants between dissolved and particle-associated phases in suspended sediments. Other activities include data base manipulation and data visualization using geographic information system techniques, safety and quality assurance/quality control oversight, and project coordination and management. In September 1993 a Phase I Remedial Investigation Report for the WAG 2 Project was completed and submitted to DOE.

\section{Environmental Chemistry}

The Environmental Chemistry Group investigates the transport, transformation, and accumulation of materials in surface water environments, including sediments and biota. Furthermore, the dispersal of contaminants through the subsurface environment is being examined, especially with respect to the role of organic and inorganic colloidal particles in enhancing the mobility of hazardous chemicals in groundwater. Investigations conducted by the Environmental Chemistry Group form an important link between information on basic principles and processes and their applications to current applied research, such as ER and remedial actions.

The group's primary activities are associated with the implementation of the Clinch River Environmental Restoration Program, which is designed to (1) address the off-site transport, fate, and distribution of waterborne contaminants released from ORR and (2) assess the potential risks to human health and the environment associated with those contaminants. A report summarizing the first phase of the remedial investigation was published, and an extensive sampling and analysis plan for the second phase of the investigation was developed and implemented in August 1993.

\section{Microbial Interactions}

The Microbial Interactions Group uses powerful new techniques of molecular biology to complement traditional microbiological methods in attempting to understand the processes by which microorganisms transform hazardous chemical contaminants in soils, surface water, and groundwater. The goals of these investigations are to optimize microbial degradation of hazardous chemical contaminants and to demonstrate the application of innovative microbial techniques and bioremediation approaches to the solution of contamination problems at DOE sites.

During FY 1993, in collaboration with The University of Tennessee Center for Environmental Biotechnology, staff developed and tested an innovative bioreactor for trichloroethylene degradation with funding from the U.S. Air Force. ESD researchers also successfully demonstrated the utility of molecular techniques for monitoring bacterial transport in experiments in the vadose zone and in a shallow aquifer. Both DNA probe technology and polymerase chain reaction amplification were used to track microorganisms through complex soil matrices. These technologies were incorporated in a field study in which several microorganisms were applied in a three-dimensional groundwater flowpath.

\section{Reservation Data Systems}

The Reservation Data Systems (RDS) Group provides data management support 
for ER projects conducted at all Energy Systems facilities. The group has assumed data management responsibilities for investigations of the Clinch River, WAG 2, and Biological Monitoring and Abatement Program, as well as managed data for the ORNL ER Program in general this past year. RDS staff also continue to lead the development of the Oak Ridge Environmental Information System (OREIS). OREIS is mandated by the DOE Oak Ridge Operations Office to fulfill the environmental data requirements of both the ORR Federal Facilities Agreement (FFA) and the Tennessee Oversight Agreement, which were instituted in response to ER activities across ORR. The group also supports ER through leading an Environmental Restoration Data Management Program aimed at developing common data management practices among Energy Systems' ER projects. The successful implementation of this program will promote consistency in the data, increase their legal defensibility, and enhance the cost-effectiveness of restoration activities.

Data from several investigations representing each of the DOE Oak Ridge facilities were incorporated into OREIS, and procedures for data transmittal and a standard coding system were developed in FY 1993. In fulfilling the FFA requirement for a consolidated data base, OREIS staff identified a significant need to formalize the methods used to manage environmental data. This formalization includes standards for the structuring, encoding, and documentation of the data. 


\section{Technical Summaries}

\section{Potentially Novel Microorganisms Are Cultured from Deep Subsurface Sediments}

\section{T. J. Phelps, S. M. Pfiffner, ${ }^{l}$ and \\ D. C. White}

Knowledge of microbial survival and transport and the utility of subsurface microorganisms for contaminant remediation provides an important base on which to evaluate the potential of bioremediation technologies. ESD researchers and other collaborators have examined subsurface environments at DOE installations and in Taylorsville Triassic Basin sediments $>2500 \mathrm{~m}$ beneath the land surface. These investigations have resulted in the culturing of microorganisms from deep subsurface formations that appear to be distinct from known taxa.

One project objective is to develop sampling and quality assurance/quality control protocols suitable for diverse coring technologies ranging from near-surface to mud-rotary operations at $>9000 \mathrm{ft}$ below land surface. A second objective is to develop a comparative knowledge base on microbial abundance, diversity, and capabilities in varied subsurface environments. Questions concern the abundance and diversity of microorganisms and the geologic and biological factors limiting their growth and activities.

In the Triassic Basin study, establishing the compatibility of cultured microorganisms with the typically anaerobic, brackish, and thermophilic in situ environmental conditions was important.
How these microorganisms metabolize nutrients and survive the in situ conditions is also of interest. Accomplishments include publications that describe protocols and identify geochemical features that limit microbial mass and activities in subsurface environments. Developed procedures are used by DOE demonstration projects and by environmental consulting firms.

${ }^{1}$ Oak Ridge Institute for Science and Education, Oak Ridge, Tennessee.

${ }^{2}$ The University of Tennessee, Knoxville.

\section{Source of Groundwater, Not Source of Bacteria, Dominates Assimilation Pattems of Natural Dissolved Organic Matter}

\section{A. V. Palumbo, J. M. Strong-Gunderson, and J. F. McCarthy}

A rapid and efficient method for assessing bacterial growth has been developed and used to determine the bioavailability of natural organic matter (NOM) from various groundwater sources. Microbial growth, measured as increases in optical density over time, on the NOM dissolved in groundwater (or on fractions of the NOM) is assayed using 96-well microliter plates. Using this technique, we can determine bioavailability of up to five different water fractions, with a normalized NOM concentration of $2 \mathrm{mg}$ carbon per liter, and up to 20 isolates per day.

The bioavailability of the NOM from the subsurface was compared by using groundwater and bacteria from the Deep Subsurface Microbiology sites-Savannah River Laboratory (SRL), Idaho National Engineering Laboratory (INEL), and 

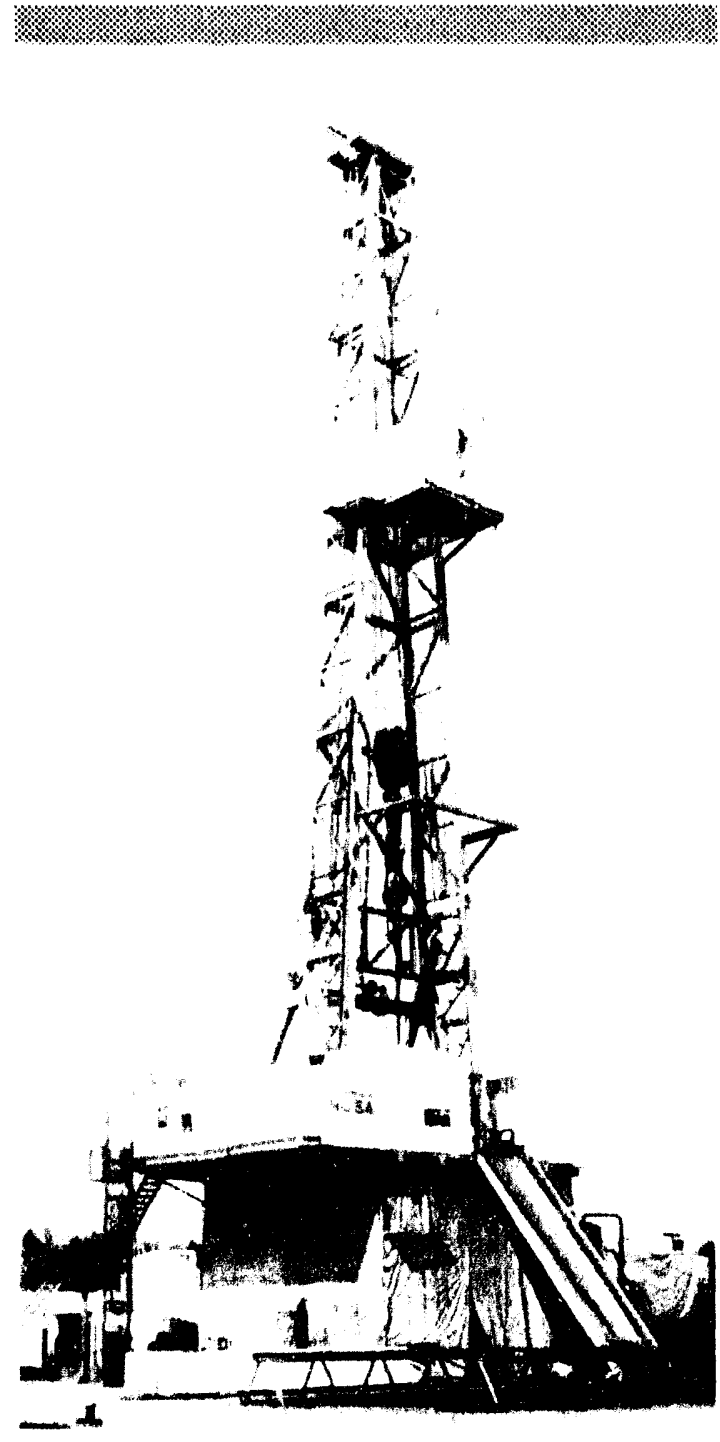

$A$ drill rig at a research site where $O R N L$ scientists obtained core samples from $>9000 \mathrm{ft}$ below the land surface during a collaborative venture with the petroleum industry.

Hanford. Bacteria were selected for testing from the subsurface microbiology culture collection at Florida State University or from isolation of bacteria from sediments at the Hanford or INEL sites. Selection was designed to facilitate comparison of bacteria from different regions (e.g., SRL vs INEL) and different locations in the same aquifer (different wells in Middendorf aquifer at SRL) and to represent bacteria with significant differences in their ability to use simple carbon sources (based on API test strips and/or Biolog plates).

NOM from Hanford well DB11 was the most bioavailable regardless of the source of the bacteria used in the tests. Well DB11 was substantially different in groundwater chemistry from other wells tested: the highest fraction was hydrophobicneutral, and reducing conditions were present.

The water from the other sources showed persistent patterns in bioavailability; water from INEL supported more growth than water from SRL or well DC6 at Hanford. These experiments provide information on factors controlling microbial populations in the subsurface and will yield insights into requirements needed for increasing microbial growth for the bioremediation of hazardous waste sites.

\section{Movement of PAHs from Soil to Vegetation Is Minimal}

\section{B. T. Walton, N. T. Edwards, and A. M. Hoylman'}

Recently completed studies indicate that polycyclic aromatic hydrocarbons (PAHs) in soils are not likely to be taken up by vegetation. A review of the published scientific literature showed very little evidence of PAH uptake by plants, yet very few of the reported studies were carried out under conditions favorable to plant uptake. Specifically, conditions did not include the use of rapidly growing 
herbaceous species exposed to high concentrations of low-molecular-weight PAHs in soil of low organic carbon content.

Laboratory studies were subsequently designed to measure uptake of four ${ }^{14} \mathrm{C}$-PAHs under laboratory conditions selected to maximize plant uptake and minimize the competing processes of soil sorption and microbial degradation of the PAHs. These studies, conducted by ESD, showed that less than $0.89 \%$ of the total ${ }^{14} \mathrm{C}$ recovered after naphthalene exposure was found in aboveground foliage of white sweetclover. Furthermore, less than $0.02 \%$ of the ${ }^{14} \mathrm{C}$ from phenanthrene, pyrene, or fluoranthene moved from soils to roots to aboveground foliage.

Based on the literature review and these laboratory studies, we conclude that transport of PAHs from surface and subsurface soils to vegetation is not likely to be an important pathway for exposure of terrestrial animals to PAHs in soils.

${ }^{1}$ The University of Tennessee, Knoxville.

\section{Innovative Biotreatment System Is Developed to Remove Trichloroethylene from Water}

\section{S. E. Herbes, A. V. Palumbo, and J. M. Strong-Gunderson}

Trichloroethylene (TCE) is the most widely reported groundwater contaminant at U.S. Environmental Protection Agency Superfund sites as well as throughout the DOE complex. Enhancing the degradation of TCE by microorganisms, both in situ and in aboveground bioreactors, has been a national remediation research effort for several years. A problem for biotreatment processes is that TCE is degraded conetabolically (i.e., microorganisms must be provided with an additional growth substrate for TCE degradation to occur). This added substrate (usually either methane or monoaromatic compounds) competes with TCE for the degradative enzyme, thus significantly slowing the remediation process.

To circumvent this problem, ESD researchers are collaborating with the University of Tennessee's Center for Environmental Biotechnology in developing and testing a bench-scale two-stage bioreactor that separates microbial growth from exposure to TCE.

Microorganisms are grown to a high density in a continuously stirred tank reactor in the presence of high methane levels; the cells are then pumped into sequential columnar reactors where they contact an aqueous stream containing TCE. Following TCE degradation, the cells are separated from the waste stream and returned to the CSTR for renewal of their degradative capacity. In initial tests, the bioreactor has effectively reduced TCE from $200 \mu \mathrm{g} / \mathrm{L}$ in a $2-\mathrm{mL} / \mathrm{min}$ influent stream to undetectable levels $(<5 \mu \mathrm{g} / \mathrm{L}$ ) during a single pass through the system.

Additional studies are under way to evaluate treatment at higher influent TCE levels, to develop more effective means of promoting degradative capability of the cells following TCE exposure, and to optimize process efficiency.

Results of these tests will provide the technical basis for scale-up to a larger system $(1 \mathrm{~L} / \mathrm{min})$ for eventual testing and demonstration for remediation of contaminated groundwater at an Air Force site. 


\section{Biodegradation of Related Compounds by Bacteria Depends on Chemical Avallability}

\section{R. S. Burlage}

The degradation of organic contaminants by microorganisms, both in aboveground reactors and in situ, holds great promise for the remediation of contaminated soil and groundwater. Contaminated sites often harbor bacteria that can degrade the site wastes, at least under laboratory conditions. Why these bacteria do not degrade the contaminants in situ is not fully understood, although many factors have been suggested, including lack of specific nutrients, presence of metabolic inhibitors, and partitioning of chemicals in a soil matrix (bioavailability). The efficient use of microorganisms clearly requires a greater understanding of their physiology and genetic expression, as well as an appreciation of contaminant chemistry.

\section{A bioluminescent reporter strain of} Pseudomonas putida, RB1401, was created as an indicator of bioavailability of toluene and xylene and as a reporter of $x y l$ gene activity. Several known inducer compounds were tested with this strain. Toluene and the xylenes induced the $x y l$ genes to high levels of expression under any conditions of incubation, including growth at fast and slow rates. Induction with benzyl alcohol and $\mathbf{m}$-methyl benzyl alcohol, in contrast, was possible only during a slow growth rate of the culture (i.e., a nutrient-limited condition) or when the osmolarity of the medium was abruptly changed during fast growth.

This work demonstrates that bioavailability of chemicals is not uniform and suggests that in situ conditions might be altered to enhance biodegradation of contaminants.
These results suggest that bioremediation may be more efficient under nutrientlimited conditions, but a more thorough examination of microbial physiology is needed.

\section{0 sunfish in East Fork Poplar Creek Experience Decrease in Genotoxic Stress}

\section{R. Shugart}

The measurement of strand breaks in the deoxyribonucleic acid (DNA) of sunfish as a biological marker for environmental genotoxicity was incorporated into the East Fork Poplar Creek (EFPC) Biological Monitoring and Abatement Program in 1987. The structural integrity of DNA has been proposed as a biological parameter for detecting environmental genotoxicants. This proposal is based on the observation that carcinogenic or mutagenic chemicals cause deleterious modifications to DNA in living organisms.

Data analyses on the occurrence of strand breaks in the DNA of sunfish taken from the headwaters of EFPC (near the Oak Ridge Y-12 Plant) and at a reference stream (Hinds Creek) over the 4-year period 1987-1991 were used to determine the temporal presence of environmental genotoxicants at these sampling sites.

These analyses show that the structural integrity of DNA from sunfish sampled at the reference site was high (low number of strand breaks) and relatively constant over the 4-year sampling period. These data indicate that these sunfish were not being exposed to genotoxicants.

Sunfish from EFPC, however, demonstrated a different response. During the 
sampling periods of 1987 and 1988, the DNA structural integrity was low (high number of strand breaks). This condition indicates genotoxic stress. In 1989, the level of strand breaks began to decrease in the resident population of sunfish; during 1990 and 1991, the reported values were similar to those for sunfish at the reference site.

In all probability, the large genotoxic stress response observed in sunfish at EFPC in 1987 and 1988 was related to the presence of chemicals that entered this stream via New Hope Pond at the Y-12 Plant.

Diminution of this response in subsequent years may be due to the facility's remediation work to attenuate the release of pollutants into EFPC. This remediation included capping New Hope Pond and creating Lake Reality as a new settling basin for discharges from the Y-12 Plant.

\section{Glutathione S-Transferases from Freshwater Snail Are Purified and Characterized}

K. L. Lee, L. R. Shugart, and A. J. Stewart

Glutathione S-transferases (GSTs) are unique multifunctional enzymes that play

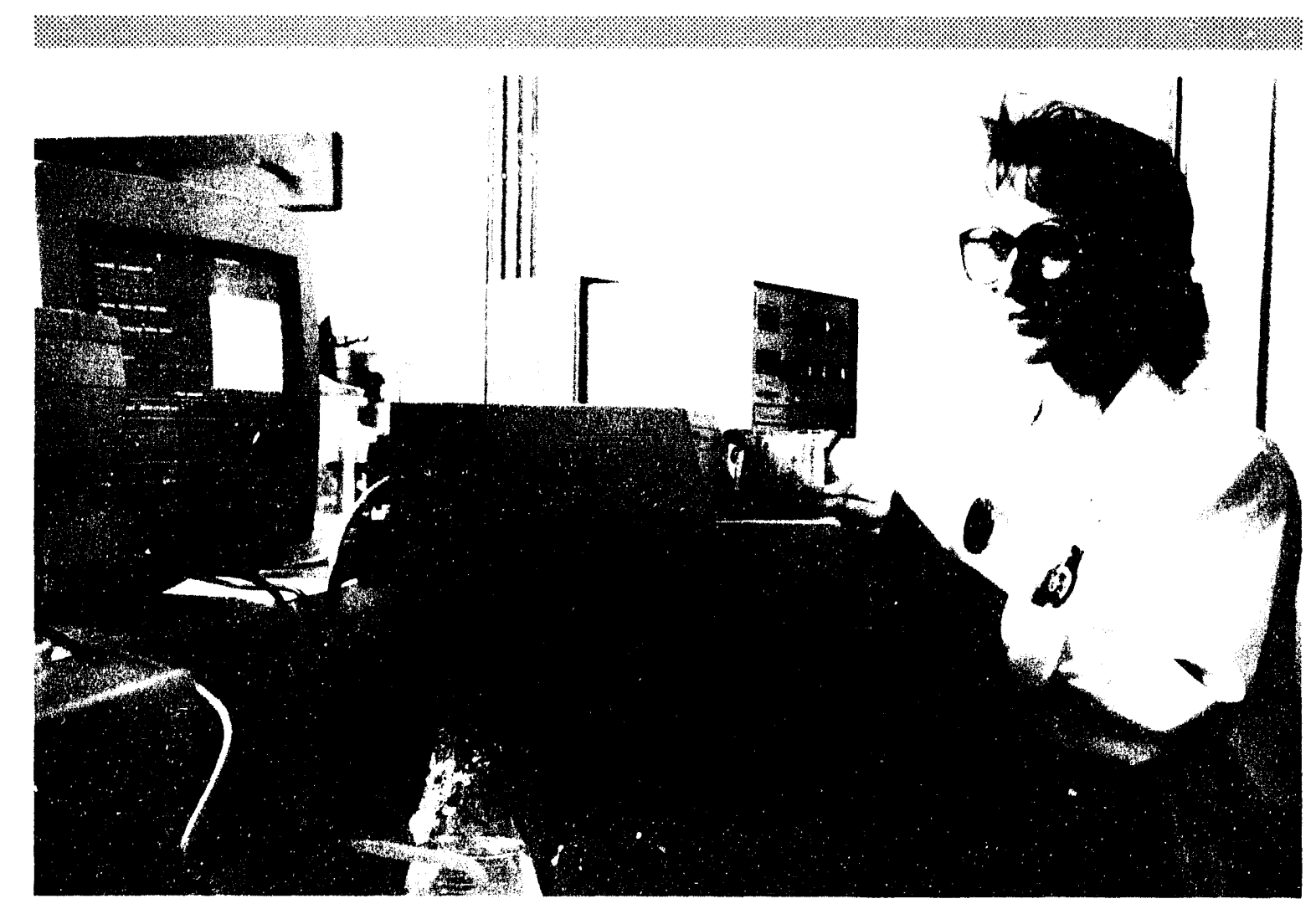

Janet Strong-Gunderson, a postdoctoral researcher, uses an automated 96-well plate reader for studying bacterial utilization of natural organic carbon and identifying bacterial isolates. 
a key role in the biotransformation and detoxification of various xenobiotics. Interest in GSTs in aquatic organisms is growing because of their importance as a cellular defense mechanism against organic toxicants in aquatic environments. The freshwater snail Elimia clavaeformis is currently used in several laboratories as a model organism in ecotoxicological studies.

To understand the protective function of GST in Elimia and to establish the potential usefulness of this animal's GST as an indicator of exposure to pollutants, we purified and characterized the GSTs from this organism. Its digestive gland is relatively rich in GST, which constituted $1 \%$ of the cytosolic protein. Further, at least three forms of GSTs, all in the anion form, were identified. The GST isozyme pattern and the subunit composition appear to be different from those reported for the giant African land snail. A major form of the GSTs was purified to homogeneity. Its activity with 1-chloro-2,4dinitrobenzene is one of the highest ever recorded. The native form of this GST has a molecular weight of 46,000 ; it is a heterodimer with subunit sizes of 23,100 and 23,500 daltons. Ongoing work includes determining the contribution of individual isozymes against toxic chemicals and the possible alteration of GST isozyme patterns of snails collected from polluted aquatic environments.

\section{2 РCB Contamination of Hartwell Lake Adversely Affects Fish Health and Reproductive Competence}

\section{S. Greeley, Jr., and S. M. Adams}

Lake Hartwell, which lies along the border of South Carolina and Georgia, is contaminated by polychlorinated biphenyls (PCBs) from an electrical component plant formerly located upstream of Twelve Mile Creek on the Seneca River arm of the lake.

ESD researchers are examining the environmental effects of this PCB contamination on fish health and reproductive competence as part $n f$ the Remedial Investigation/Feasibility study for this site.

A diverse suite of molecular, biochemical, physiological, and reproductive biomarkers of contaminant exposure and effects was measured in tissue and fluid samples collected from largemouth bass (Micropterus salmoides) in both the contaminated Seneca River arm and the uncontaminated Tugaloo River arm of the lake.

Fish from the contaminated arm exhibited several signs of moderate to severe physiological stress. Elevated body burdens of total PCBs were correlated with the induction of the detoxifying multifunction oxidase system of the liver, a decreased abundance of white blood cells suggesting impaired immune function, diminished estrogen receptor binding capacities of the liver, increased DNA repair activity, decreased plasma testosterone concentrations, and elevated levels of liver lipids.

These findings strongly suggest that environmental PCB contamination has quantifiable and potentially damaging consequences for exposed fish populations. The results of this investigation have relevance both in deciding the course of future remedial actions on Hartwell Lake and in interpreting the results of similar studies currently conducted on or around the Oak Ridge Reservation. 


\section{Biological Indicators Are Used to Assess Health of Fish Communities Exposed to Pulp Mill Effluents}

\author{
S. M. Adams, W. D. Crumby, ${ }^{1}$ and \\ M. S. Greeley, Jr.
}

Pulp mill effluents elicit stress responses in fish at various levels of biological organization, ranging from the biochemical level to the population and community levels. Even though pulp mill contaminants are often implicated when changes are observed in the health of fish, defensible causative relationships between specific toxicants and their effects at the population and community levels are difficult to establish. The lack of intermediate-level response indicators (which link stre ssors to effects), combined with the influence of environmental factors that modify effects, complicates the interpretation of stress responses in organisms.

We assessed the health of fish populations residing in a river that received effluents from a bleached kraft mill plant by applying a suite of multiresponse indicators ranging from the biochemical to community levels. Our results suggest that a primary mechanism by which pulp mill effluents affect fish populations is through impacts of toxicants on early life-history stages (eggs and larvae). Reductions in population size as a result of early life-history effects can decrease intraspecific competition and may increase availability of resources, thereby allowing greater growth rates of survivors. Similar bioindicator studies to assess ecosystem health are being conducted as a component of the Biological Monitoring and Abatement Program on the Oak Ridge Reservation and also as a part of the
Clinch River-Watts Bar Reservoir Environmental Restoration Program.

'Automated Sciences Group, Inc., Oak Ridge, Tennessee.

\section{Great Blue Herons Nesting on the Oak Ridge Reservation Are Potentially at Risk from Exposure to Environmental Contaminants}
R. S. Halbrook, S. J. D'S. 14., and
L. R. Shugart

The screening-level risk assessment for off-site ecological effects in surface waters downstream from the DOE Oak Ridge Reservation (ORR) indicated that piscivorous wildlife along the Clinch River is at risk from exposure to environmental contaminants. Great blue herons feeding at White Oak and Poplar creeks within ORR would be expected to accumulate and concentrate radionuclides, mercury, and PCBs with potential adverse effects to the population.

ESD staff have begun a field study to determine the concentration of radionuclides, PCBs, and mercury in selected great blue herons nesting on Poplar Creek near the Oak Ridge K-25 Site and the potential risk from that exposure. Biochemical assays, including biomarkers of DNA integrity, microscmal enzyme induction, and tissue histology, in addition to physical condition and reproductive success, will be used to evaluate the general health of the ORR great blue heron population. Preliminary results indicate that mercury and PCB concentrations are higher in great blue herons nesting on Poplar Creek near the K-25 Site in comparison to those nesting 
on Long Island in the Tennessee River (off the reservation).

\section{Problems Are Noted in Processing Data for Oak Ridge Environmental Information System}

\section{J. Allison}

The Oak Ridge Environmental Information System (OREIS) is be ing developed in response to a Federal Facilities Agreement between DOE, the U.S. Environmental Protection Agency, and the state of Tennessee regarding environmental restoration of three Oak Ridge Reservation facilities. Data resulting from environmental restoration studies at these facilities must be transmitted to OREIS according to the schedule defined by the Federal Facilities Agreement. To date, OREIS has received and processed data associated with five investigations representing each of the Oak Ridge facilities as well as offsite contaminated areas.

Many problems with the data were identified during this process, including incomplete data sets and inconsistencies in analytical methods codes, analyte names, units of measure, and station identifiers. As a result, the data processing time has been much too long. Standard codes for methods, data qualifiers, and analytes have been developed to solve some of these problems. These code lists are included in the OREIS Data Dictionary (Appendix A) in the Data Management Plan for OREIS (ES/ER/TM-9). In addition, a procedure describing the requirements and action steps for transmitting data to OREIS from site data sources has been written: "Transmitting Data to the Oak Ridge Environmental Information System"
(ER/C-P2701). Copies of these documents are provided to the data generators who transmit data to OREIS to assist the facilities in providing data consistent with OREIS formats.

\section{Advances in Information Technology and Expanded Regulatory Agreements Change Methods of Managing Environmental Restoration Data}

\section{R. A. McCord and L. A. Hook}

The data nanagement methods used for environmental projects, particularly those associated with environmental restoration (ER), have significantly changed during the past 3-6 years because of advances in information technology and expanding regulatory agreements. During this time, the power of computing resources (e.g., processing speed, storage capacity, and sophistication of applications software) that are readily available for environmental projects has increased by an order of magnitude, thereby enabling environmental scientists to accommodate more data and analyses for ER studies. Data sets typically analyzed have increased from hundreds to tens of thousands of records. Regulatory agreements have simultaneously encouraged the use of larger, integrated data sets so that environmental studies can provide better representations of the scope of environmental problems.

The ability and demand for processing large or integrated data sets, however, have exceeded the robustness of traditional environmental data management. Current data management practices require significant effort and may result in uncertainty during the building of integrated environmental data sets. For example, the Federal 
Facility Agreement between DOE, the U.S. Environmental Protection Agency, and the state of Tennessee requires that all of the data from ER studies from the DOE Oak Ridge Reservation (ORR) be available in a single consolidated data base.

ESD is developing the Oak Ridge Environmental Information System (OREIS) to fulfill this consolidated data base requirement. OREIS development has identified a significant need for the formalization of methods used to manage environmental data. This formalization includes standards for structuring, encoding, and documenting environmental data. At the encouragement of OREIS staff, the ER Program is sponsoring a Data Management Program managed by ESD to implement formalized methods across ORR. Implementation of OREIS and the Data Management Program will enable environmental scientists to effectively manage and use the large, integrated data sets that are required.

\section{Transport and Fate of Contaminants in Clinch River and Watts Bar Reservoir System Are Assessed by Using ${ }^{137} \mathrm{Cs}$}

\section{R. B. Cook, B. L. Kimmel, K. A. Rose,} A. L. Brenkert, C. C. Brandt, I. L. Larsen, C. J. Ford, D. A. Levine, ${ }^{l}$ and C. R. Olsen ${ }^{2}$

The Clinch River and Watts Bar Reservoir are being investigated as part of the Clinch River Environmental Restoration Program to assess the potential risk to human health and the environment associated with offsite contamination downstream from the DOE Oak Ridge Reservation. For site characterization, we have used techniques at a variety of spatial scales to examine the transport and fate of one of the primary contaminants $\left({ }^{137} \mathrm{Cs}\right)$ in the river-reservoir system.

Individual sediment cores taken throughout the reservoir reveal that ${ }^{137} \mathrm{Cs}$, in levels corresponding to peak release in the $1950 \mathrm{~s}$, is buried deep within the sediments. A sediment accumulation/mixing model showed that sediment accumulation was the primary process affecting the vertical distribution of ${ }^{137} \mathrm{Cs}$ and that sediment mixing did not significantly redistribute the ${ }^{137} \mathrm{Cs}$.

We used data from 60 sediment cores and nearly 1000 surface sediment samples to estimate the spatial distribution of ${ }^{137} \mathrm{Cs}$ in the reservoir. This analysis indicates that a significant percentage of the ${ }^{137} \mathrm{Cs}$ originally released from the reservation is still present in the reservoir and that the accumulation patterns are spatially heterogeneous. In the upper portion of the reservoir, ${ }^{137} \mathrm{Cs}$ accumulated in deeper embayments and in the adjacent main channel. In the lower portion of the reservoir, more ${ }^{137} \mathrm{Cs}$ accumulated in the main channel than in embayments. The ${ }^{137} \mathrm{Cs}$ concentration in surface sediment samples is consistently low downstream of the confluence of the Tennessee River and the Clinch River. Surface sediment ${ }^{137} \mathrm{Cs}$ concentrations in the Clinch River were highest near White Oak Creek, the source of ${ }^{137} \mathrm{Cs}$ in the reservoir. The highest concentrations of ${ }^{137} \mathrm{Cs}$ in the Clinch River and Watts Bar Reservoir are primarily located in river-channel sediments, where exposure to humans is unlikely. The estimated contaminant distribution in the reservoir will be used to guide future sampling efforts.

\footnotetext{
${ }^{1}$ Automated Sciences Group, Inc., Oak Ridge, Tennessee.

${ }^{2} D O E$, Office of Health and Environmental Research.
} 


\section{Technical Review Enhances Integrity of Clinch River Environmental Restoration Data}

\author{
S. K. Holladay, M. S. Bevelhimer, \\ C. C. Brandt, C. J. Ford, D. A. Levine, \\ L. A. Hook, R. B. Cook, M. J. Gentry, \\ R. C. Longman, R. L. Moody, \\ W. D. Crumby, S. E. Madix, C. D. Rash, \\ and L. F. Williams
}

Assessing the usability of data produced for Phase 1 of the Clinch River Remedial Investigation (CRRI) was necessary to ensure that the following QA objectives were met: (1) that the data were technically sound; (2) that appropriate procedures for field sampling, chain-ofcustody, laboratory analyses, and data reporting were used to gather data; and (3) that the precision and accuracy of the data were well defined. Phase 1 of the CRRI was a preliminary site characterization in selected areas of the Clinch River/Watts Bar Reservoir. Approximately 1700 inorganic sarnples, 1500 organic samples, and 2200 radiological samples were analyzed and validated. The dataquality indicators of precision, accuracy, representativeness, comparability, completeness, and sensitivity were evaluated to determine limitations associated with the data.

Overall, Phase 1 media (sediment, water, and fish) and analyses were $88 \%$ complete. Valid data were obtained for $98 \%$ of the water samples. Most of the rejected analyses were found faulty because of improper sample preservation, holding time exceedance, or poor surrogate recoveries. Both sediment core and grab samples were evaluated. Valid data were obtained for $96 \%$ of the core samples and $91 \%$ of the grab samples. Some data were rejected because of low spike recoveries, holding time exceedance, and calibration difficulties. For fish tissue analyses, only $68 \%$ of the data were considered valid, and $50 \%$ of the semivolatile data were rejected because of inadequate surrogate recoveries. The results of this data assessment will be published in a report on quality assurance and quality control for Phase 1. Lessons learned during Phase 1 are summarized in the report and are being used to design the baseline risk assessment comprising Phase 2 of the CRRI.

\section{Seasonal Changes in Water Quality Influence Chemical Speciation and Behavior of Arsenic in Freshwater Ecosystems}

\author{
C. J. Ford, J. T. Byrd, ${ }^{1}$ J. M. Grebmeier, ${ }^{2}$ \\ R. A. Harris, ${ }^{3}$ S. E. Madix, C. D. Rash, \\ M. E. Smith, R. C. Moore, ${ }^{4}$ and \\ M. O. Barnett
}

We studied arsenic biogeochemistry in the Clinch River/Watts Bar Reservoir (CR/WBR) system as part of the Clinch River Remedial Investigation. Arsenic, a natural component of coal-bearing rock, is a common contaminant in CR/WBR downstream from the Oak Ridge Reservation. Arsenic contamination can result from the burning and disposal of ash from coal-fired steam plants. Arsenic is considered highly toxic; regulatory limits protective of fish and aquatic life $(0.77 \mathrm{ppb})$ are lower than standard analytical detection limits (1.3 ppb).

Sediments are a significant repository of arsenic in the CR/WBR system. Changes in arsenic chemistry are related to changes in redox chemistry, specifically that involving iron and manganese. Arsenic is typically removed from surface waters by 
coprecipitation with iron and manganese oxyhydroxides. Arsenic availability and speciation change when oxidized iron or manganese is exposed to a reducing environment, and arsenic dissolves into either interstitial water within the sediment matrix or surrounding surface water. The dissolved arsenic may be either oxidized As(V) or reduced As(III). Arsenic cycling in the CR/WBR system is driven by seasonal changes in the dissolved oxygen content of the surface water and sediment pore waters.

At locations where the sediments serve as the primary source for arsenic, water column concentrations tend to be lowest in the winter and spring because of high dissolved oxygen content in the water column. This condition results in the oxidation of iron and manganese and the coprecipitation of arsenic, within both the water column and the surface sediments.

As the surface water warms and the water column stratifies during the late spring, dissolved oxygen levels are depleted by respiration and decay of organic matter; dissolved oxygen levels at some sites may be depressed enough to reduce iron and manganese, releasing arsenic to the interstitial sediment pore water and eventually into the water column itself. A potentially significant flux of arsenic from sediments to the water column has been observed near the Watts Bar Dam (TRK 849.6) and in the McCoy Branch Embayment during this season.

In the fall, as water temperatures cool and the water column stratification breaks down, dissolved oxygen levels increase, iron and manganese reoxidize, and arsenic precipitates onto suspended particles or the sediments. The effects of this seasonal cycling of arsenic on the ecosystem and on human health in the CR/WBR system are also being evaluated in the Clinch River Remedial Investigation.

'Amstrong College, Savannah, Georgia.

${ }^{2}$ The University of Tennessee, Knoxville.

'Automated Sciences Group, Inc., Oak Ridge, Tennessee.

${ }^{4}$ U.S. Geological Service, Indianapolis.

${ }^{5}$ University of North Carolina, Chapel Hill.

\section{Monitoring Provides Results on Contaminant Concentrations and Water Quality During and After Construction of Sediment-Retention Structure}

\author{
C. J. Ford, B. L. Kimmel, D. A. Levine, ${ }^{\prime}$ \\ S. E. Madix, and T. J. Stephens
}

Sediments and surface water in the White Oak Creek Embayment (WOCE) have been radiologically contaminated by White Oak Dam (WOD) discharges since 1943, with peak releases occurring during the 1950s. The mouth of White Oak Creek, located approximately $1 \mathrm{~km}$ downstream from the WOD, has its confluence with the Clinch River $5 \mathrm{~km}$ downstream from the Melton Hill Dam. The predominant particle-associated contaminant in WOCE is ${ }^{137} \mathrm{Cs}$ (having a 30 -year half-life), a waste product of reactor research at ORNL.

Sediments were sampled in 1990 for Phase 1 of the Clinch River Remedial Investigation, and these results were confirmed during a subsequent site characterization. These investigations revealed the presence of ${ }^{137} \mathrm{Cs}$-contaminated surface sediment greatly exceeding that expected near the mouth of WOCE. A sedimentretention structure was constructed during 1991 and 1992 as an interim corrective measure to control highly contaminated, erodible surface sediments in WOCE. 
Monitoring was conducted to detect disturbance, release, and transport of contaminants into the Clinch River during and after construction of the sedimentretention structure. Monitoring included collection of stage height and standard water-quality data and collection of water samples for ${ }^{137} \mathrm{Cs}$, suspended sediment, and turbidity determinations. Sampling focused on sediment-disturbing events.

Initial results from monitoring activities indicate that (1) the sediment-retention structure appears to function as designed, reducing the particle-associated ${ }^{137} \mathrm{Cs}$ levels immediately downstream from the site; (2) contaminants are still transported out of WOCE during seasonal storm events; and (3) construction activities did not release quantities of ${ }^{137} \mathrm{Cs}$ from the embayment in excess of current surface water input from WOD. These results provide evidence that the release of contaminants during construction was minimized and that remediation has reduced the movement of contaminated sediments to the off-site environment.

${ }^{1}$ Automated Sciences Group, Inc., Oak Ridge, Tennessee.

\section{Effluent Dechlorination Does Not Alter Survival or Growth of Clams in East Fork Poplar Creek}

\section{J. G. Smith, W. S. Wilkerson, ${ }^{\prime}$}

J. R. Sumner, ${ }^{2}$ J. J. Beauchamp, and R. L. Hinzman

Chlorine, associated with several of the Oak Ridge Y-12 Plant's effluent discharges, has been implicated as one of the major factors affecting the biotic communities in upper East Fork Poplar Creek
(EFPC). To improve water quality in upper EFPC, the Oak Ridge Y-12 Plant began a project to dechlorinate two of its major effluent discharges. An in situ bioassay using an endemic clam (Sphaerium fabale) as an ecological indicator was one of several studies initiated to assess the effects of dechlorinating these two effluents. In this study, clams were placed at three sites in EFPC and one site in a nearby, relatively undisturbed reference stream (Beaver Creek) for five 3-week exposure periods before and after dechlorination (i.e., from middle to late February through late May in 1992 and 1993). The two more upstream sites in EFPC served as test sites; one was located $-375 \mathrm{~m}$ and $\sim 1375 \mathrm{~m}$ downstream of the two affected outfalls (EFK 24.4), and the other (EFK 23.4), $\sim 1 \mathrm{~km}$ downstream of EFK 24.4. The third and most downstream site in EFPC (EFK 13.8) served as an additional reference site.

Results indicated that the patterns in growth and survival of clams observed before dechlorination did not change at the test site after dechlorination. During both periods, growth was inhibited at EFK 24.4 and suppressed at EFK 23.4, while survival was not strongly affected at either site. These results indicate that dechlorination had no discernible effects on clam growth and survival within the test sites. This conclusion also implies that biota with similar tolerances to chlorine would likewise be unaffected in these same reaches. However, because of the distance of the two test sites from the dechlorinated effluents, these results do not preclude the possible benefits of effluent dechlorination, particularly in those reaches of stream closer to the affected outfalls. These results also suggest that some other factors (e.g., elevated temperatures, habitat instability, and toxicants within sediments) may also adversely affect the clam and that the 
factors could be acting alone, acting with the effects of chlorine, or overriding the effects of chlorine.

IJAYCOR, Oak Ridge, Tennessee.

${ }^{2}$ Advanced Sciences, Inc., Oak Ridge, Tennessee.

\section{Total Residual Chlorine Can Affect Mortality Rates of Central Stoneroller and Striped Shiner} E. M. Schilling, R. L. Hinzman, and
M. G. Ryon

A chronic fish kill has been monitored since July 1990 in a stream adversely affected by effluent. Elevated levels of total residual chlorine (TRC) may contribute to fish mortality. Daily surveys revealed that $60-80 \%$ of the dead fish were central stonerollers (Campostoma anomalum). Biannual quantitative sampling of fish populations since 1990 showed that striped shiners (Luxilus chrysocephalus) occurred in densities up to three times greater than the densities of the central stoneroller.

To test the hypothesis that central stonerollers are more sensitive to TRC than striped shiners are, flow-through toxicity tests were performed with chlorinated tap water at concentrations observed in the stream $(0.77 \pm 0.05$, $0.39 \pm 0.03$, and $0.19 \pm 0.01 \mathrm{mg}$ of TRC per liter; mean $\pm S D$ ). Dechlorinated tap water was used as a control. The measured endpoint was "time-to-death" (TTD), the length of time that elapsed between initial contact with TRC and death. Mean TTD did not differ between the two species at either of the two highest TRC concentrations tested (one-way analysis of variance).
At $0.77 \mathrm{mg}$ of TRC per liter, mean TTD $( \pm S E)$ was $160 \pm 5$ min for central stonerollers and $154 \pm 8 \mathrm{~min}$ for striped shiners; at $0.39 \mathrm{mg}$ of TRC per liter, mean TTD was $311 \pm 14 \mathrm{~min}$ for central stonerollers and $319 \pm 13 \mathrm{~min}$ for striped shiners. At $0.19 \mathrm{mg}$ of TRC per liter, a significant difference $(p<0.0003)$ occurred between mean TTD for central stonerollers (1403 $\pm 76 \mathrm{~min})$ and mean TDD for striped shiners (929 $\pm 96 \mathrm{~min})$. Because striped shiners died faster than central stonerollers at $0.19 \pm 0.01 \mathrm{mg}$ of TRC per liter in the toxicity test, some factor other than TRC (e.g., behavior or another toxicant) likely causes the greater mortality of central stonerollers in the st ream.

\section{Dispersal Study of Dead Fish in Upper East Fork Poplar Creek Indicates Localized Toxicity}

\author{
M. G. Ryon, B. A. Carrico, ${ }^{\prime}$ R. L. Hinzman, \\ W. K. Roy, and E. M. Schilling
}

Since July 18,1990 , daily to weekly surveys have been conducted along East Fork Poplar Creek (EFPC) immediately downstream and within the Oak Ridge Y-12 Plant to investigate chronic fish kills. As part of this investigation, the downstream dispersal of fish that died at major discharges to upper EFPC was studied in July 1992. The primary objectives were to determine the (1) dispersal pattern, rate, and downstream drifting distance of dead fish; (2) effectiveness of daily surveys; and (3) impact of scavengers on daily totals of dead fish.

Results indicated that dispersal patterns are dependent on location. Dispersal from upstream outfalls was limited; generally, dead fish found in an area died in that 
area. However, some dispersal (10-20\% of total) did occur over long distances. Surveys were highly effective when conducted shortly after adding dead fish to the stream (i.e., $50-80 \%$ of the dead fish were recovered). However, loss of dead fish to scavengers was very high (80\%), particularly overnight. Thus, although the effectiveness of daily surveys is consistently high, the surveys probably underestimate the actual mortality by $50-90 \%$. This study suggests that peaks in numbers of dead fish result from localized toxicity in a limited area. The distribution of dead fish throughout a long reach of the stream probably reflects toxicity from a pulse of water moving downstream, rather than extensive downstream drifting of dead fish.

${ }^{1}$ JAYCOR, Oak Ridge, Tennessee.

\section{Caged Blacknose Dace Are Used to Detect Mercury in Streams}

\author{
M. J. Peterson, G. R. Southworth, and \\ W. D. Crumby
}

To identify and evaluate possible sources of biologically available mercury, uncontaminated blacknose dace (Rhinichthys atratulus) were placed in cages and put into small tributary streams of a larger mercury-contaminated stream/reservoir system.

Caged dace rather than resident sunfish were used because prior sampling of some tributary streams suggested that resident sunfish at some sites may be seasonal migrants that accumulate mercury from the nearby contaminated stream/reservoir.

After a 12-week exposure period, mercury concentrations in the muscle tissue of caged dace placed in two of the tributaries significantly exceeded concentrations in dace from the reference stream.

However, mercury accumulation was low at all monitored sites. Mercury concentrations in caged dace showed a site-to-site pattern similar to that of the dace inhabiting the streams, but concentrations were higher in resident dace at all sites. These differences appear to be a consequence of limited food availability in the caged treatments.

Although the caged dace probably did not reflect the possible extent of mercury accumulation, this study suggests that a hardy forage species such as blacknose dace can be successfully used to detect the presence of biologically available mercury in small streams or discharges.

${ }^{1}$ Automated Sciences Group, Inc., Oak Ridge, Tennessee.

\section{Risk Assessment Methodology Evaluates Likelihood of Adverse Human Health Effects from Construction Project}

\section{L. Frank and A. L. Brenkert}

An engineering study is under way to consider the feasibility of installing a pipeline in the channel of Poplar Creek at the Oak Ridge K-25 Site to transport effluent from the Central Neutralization Facility to the Clinch River. Because the pipe-laying operation could disturb contaminated bottom sediments in the creek, a risk screening analysis based on human health criteria was performed to determine whether the suspended sediments could adversely affect the health of workers at the site or others using the Clinch River 
downstream of Poplar Creek. The most likely way for an individual to be exposed to the suspended sediment would be by drinking unfiltered water or through dermal absorption (e.g., swimming, falling into the water, or having hands and arms in the water).

Reasonable Maximum Exposure (RME) parameter values and guidelines and toxicity factors developed by the U.S. Environmental Protection Agency for Superfund sites were used to evaluate the potential for adverse health effects. Estimated contaminant concentrations for Poplar Creek were based on water and sediment samples taken as part of the Clinch River Remedial Investigation. A sediment transport model was used to calculate contaminant concentrations in Clinch River water 1 mile downstream from Poplar Creek.

Although over 30 contaminants were screened, only three [a polychlorinated biphenyl (Aroclor 1260), benzo(a)pyrene, and arsenic] were found to be of concern. Using the RME assumptions (which tend to overestimate the risk of health effects), only two exposure pathways were found to be of concern: (1) dermal exposure of hands and arms and (2) consumption of Poplar Creek water. For workers who expose their hands and arms to Poplar Creek water at the work site $4 \mathrm{~h} / \mathrm{d}$ for $40 \mathrm{~d}$, the lifetime risk of an increased incidence of cancer from the two organic contaminants is approximately $5 \times 10^{-4}$. Results based on a scenario in which a worker would drink $2 \mathrm{~L}$ of unfiltered creek water during the $40 \mathrm{~d}$ needed to lay the pipe indicate that the intake of arsenic would exceed recommended levels.

Risks of adverse health effects from exposure to suspensed sediment by persons using Clinch River water downstream from
Poplar Creek were below levels of concern. Risk assessment methodology, used primarily to identify contaminants of concern and critical exposure pathways, can provide a practical approach for quantitatively evaluating the risk of adverse effects that environmental contaminants may have on human health.

\section{Raccoons from White Oak Creek Watershed Contain Higher Fur Concentrations

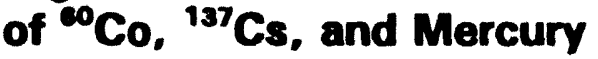

T. L. Ashwood

Most biological monitoring on the Oak Ridge Reservation (ORR) has been conducted with aquatic organisms because most contaminant transport occurs in the aquatic system. However, terrestrial predators may accumulate significant levels of many contaminants from aquatic prey. In White Oak Creek and White Oak Lake, for example, aquatic biota contain measurable concentrations of ${ }^{60} \mathrm{Co},{ }^{137} \mathrm{Cs}$, mercury, and some organic compounds. Sediment in the White Oak Creek floodplain also represents a source of contaminants to terrestrial organisms.

Raccoons are being used as an ecological indicator species to monitor the uptake of biologically important contaminants from aquatic systems and floodplain soils. Raccoons are abundant in floodplain areas dominated by mixed hardwoods and feed on a wide variety of plants, terrestrial and aquatic invertebrates, and fish. In studies throughout North America, raccoons have been shown to accumulate trace metals and chlorinated organic compounds. ESD researchers have begun a long-term monitoring program using raccoons to evaluate the effects of remedial actions on 
contaminant concentrations in terrestrial biota. Initial program results indicate that maximally exposed raccoons from the White Oak Creek watershed contain much higher fur concentrations of ${ }^{60} \mathrm{Co}$ (3.4 pCi/g), ${ }^{137} \mathrm{Cs}(43.6 \mathrm{pCi} / \mathrm{g})$, and mercury $(10.6 \mu \mathrm{g} / \mathrm{g})$ than do raccoons from the Freels Bend area of ORR or the Chuck Swan Wildlife Management Area on Norris Lake. These findings confirm that contamination from the White Oak Creek system is being incorporated into the terrestrial biota, and we expect to use the long-term trends in raccoon contaminant concentrations to evaluate the effectiveness of remedial actions. Beginning in 1993, samples of adipose tissue were collected from raccoons so that concentrations of pesticides and polychlorinated biphenyls can be monitored as well.

\section{Periphyton Communities Sorb Contaminants in Streams}

\section{W. R. Hill and B. R. Gray}

Hard substrates (such as rocks) in aquatic ecosystems are covered with a layer of

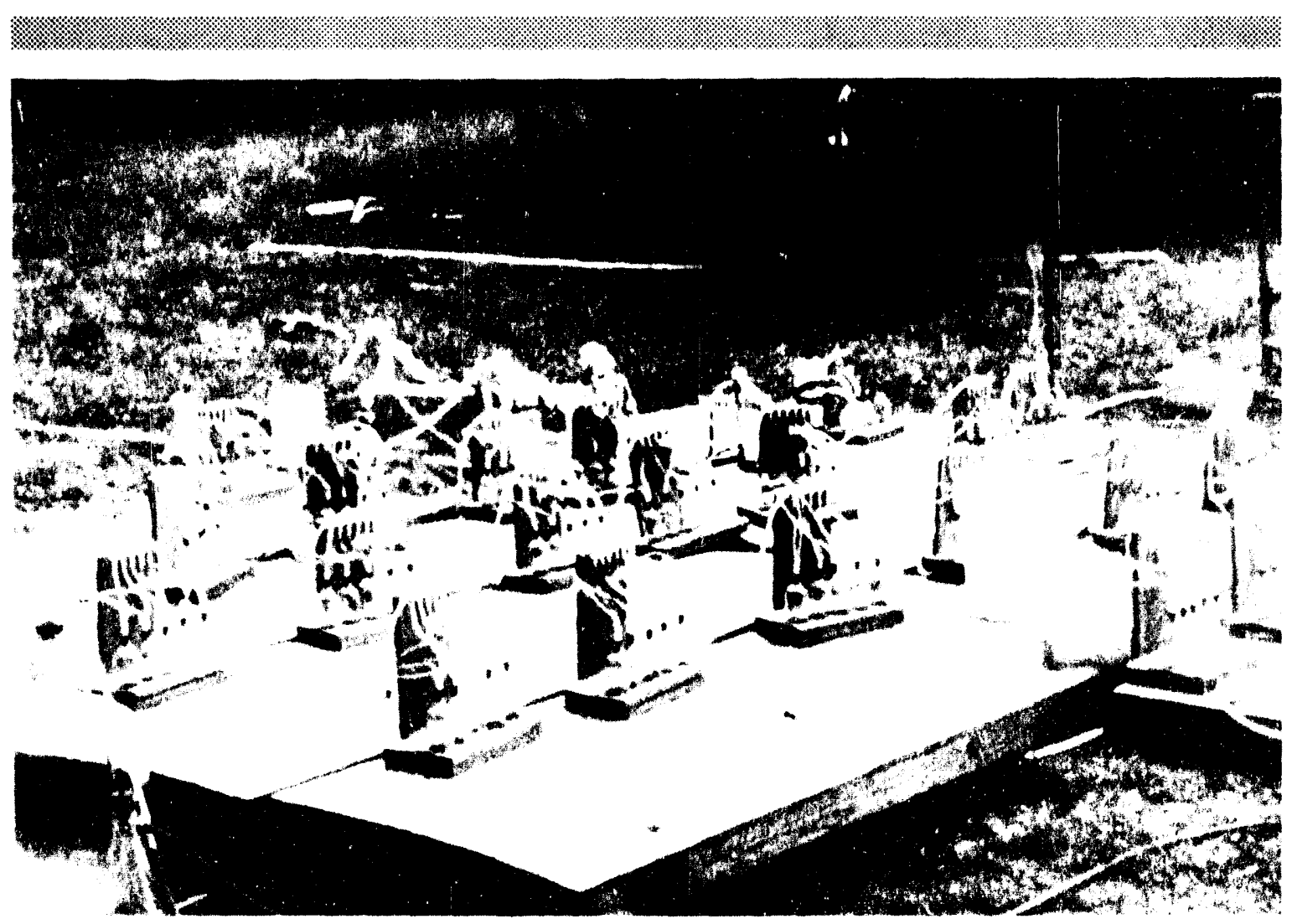

A sampling system for withdrawing groundwater from a shallow sandy aquifer in Georgetown, South Carolina. Researchers injected the site with pond water containing $\sim 30 \mathrm{mg}$ chloride per liter and monitored the transport of the chloride. The experiment was conducted to leam more about the mobility of natural organic matter and potential effects upon the transport of contaminants. 
algae and heterotrophic microbes collectively termed periphyton. Periphyton's large surface area and its ability to concentrate contaminants suggest that it has a considerable effect on contaminant transport and fate in aquatic ecosystems, especially streams. We conducted experiments to explore factors affecting periphyton's ability to sorb contaminants. The results of these studies provide insights that should lead to a general model of contaminant loading by stream periphyton.

Experiments with nickel (a metal previously associated with toxicity in upper East Fork Poplar Creek) revealed two components of sorption: "passive" sorption, which is unrelated to metabolic activity, and "active" sorption, which occurs only in metabolically active periphyton. The active component is strongly related to photosynthetic activity of algae in the periphyton communities: their patterns of nickel sorption vs irradiance mirrored their patterns of photosynthesis vs irradiance. The photosynthetically related sorption of nickel by periphyton was readily reversible, as evidenced by significant desorption of the metal when light was decreased. The results of these experiments have strong implications for temporal variation in the concentrations of metal contaminants in water: they suggest that nighttime concentrations of at least some metals will be much greatur than daytime concentrations.

Other experiments demonstrated that nickel sorption by periphyton was related both to periphyton surface area and mat thickness (biomass); this finding is contrary to that in previous reports. Nickel sorption increased nonlinearly with periphyton biomass, probably because of diffusionrelated constraints in thicker mats or because lower layers of cells in thick mats of periphyton have lower rates of metabolic activity. As an important food resource for grazers in streams, periphyton may provide a critical entrance point for toxic substances into stream food webs. Future studies will explore periphyton sorption of polychlorinated biphenyls and mercury; these two contaminants occur at high concentrations in periphyton-eating fish (stoneroller minnows) in upper East Fork Poplar Creek.

\section{Composting Is Assessed as a Method for Ecologically Remediating Soils Contaminated with TNT}

\section{T. Grizzard, C. A. Gunderson, and A. J. Stewart}

At least 28 military and munitions installations in the United States are now being required to remediate soils or lagoon sediments extensively contaminated with explosives such as TNT, RDX, HMX, and/or N-Tetryl. Incineration is possible but expensive (e.g., $\$ 200-\$ 300$ per ton). Recent studies have shown that 20-40 d of composting are sufficient to greatly lower the concentrations of explosives in such soils and that composting can markedly reduce the toxicity of TNT-tainted soils.

We initiated a study to determine whether the final product of such composting was ecologically suitable for land application. Two composts-one previously containing soil with a TNT concentration in excess of $1000 \mathrm{ppm}$ and one containing a similar but noncontaminated soil-are being evaluated in a greenhouse experiment. The study emphasize consideration of factors that are expected to link soil toxicity to ecological status through direct and indirect effects pathways. Key factors in the 
experimental design include compost type $(N=2)$ and duration of exposure $(N=3$, with harvests being conducted 30,60 , and $150 \mathrm{~d}$ after the experiment started). Five replicates, each containing about $100 \mathrm{~L}$ of compost, are used for each treatment combination. We measured response variables related to the success of three plant species (e.g., seed germination, biomass accumulation, root-to-shoot ratios, flowering, and seed-set); earthworms (survival, growth, reproduction, and sizestructure of the populations at harvest); a generalized detritivorous isopod (survival, growth, and reproduction); soil microbes (by lipid-class analyses); $\mathbf{N}_{\mathbf{2}}$-fixing bacteria (an acetylene reduction assay of nitrogenase activity in legume root nodules); and soil microarthropod communities (by analysis of taxonomic structure).

\section{Now Earthworm Soil Toxicity Test Can Improve Terrestrial Ecological Risk Assessments}

\section{H. Gibbs, L. F. Wicker, and A. J. Stewart}

Earthworms are used in ecological risk assessment because of their important role in terrestrial ecosystems. The worms are vital to soil fertility because of their tunneling activities and their processing of organic matter. They also are important as food for many birds and small mammals. Because earthworms consume and push their way through the soil, they can accumulate contaminants and pass them on to their predators or be directly affected by soil contaminants. The most commonly used earthworm toxicity test is the artificial soils test [Organisation for Economic Co-Operation and Development (OECD) guideline No. 207] or a close variant. This 14-d test typically involves four replicate populations of ten worms tested in glass jars. The test quantifies mortality, or occasionally growth, in comparison with that of a noncontaminated control. LD $_{50}$ values (i.e., the concentration of contaminated soil needed to kill $50 \%$ of the worms) derived from this test are moderately reproducible, but $\mathrm{LD}_{50}$ data have little ecological relevance. Furthermore, few useful data are obtained by using this test procedure when the soils being tested are not toxic enough to kill a substantial fraction of the worms.

We developed and evaluated an alternative earthworm soil toxicity test to overcome these problems. In each replicate, two earthworms are placed in a small resealable plastic bag with $100 \mathrm{~mL}$ of soil and $2 \mathrm{~g}$ of a standardized food. Thirty replicate bags are used; the bags are punctured to permit air exchange, water is added to the soil to achieve an appropriate moisture level, and the bags are kept at $20^{\circ} \mathrm{C}$ in an environmental chamber. After $21 \mathrm{~d}$, mortality, growth, and reproduction data are obtained for the worms in each bag. The results of the tests can be analyzed statistically through a chi-square contingency test. If desired, an additional 35-d incubation of the soil samples can be used to assess hatching rates of the cocoons and growth of the juveniles.

This toxicity test procedure shows excellent potential for ecological risk assessment because it yields data for several sensitive response variables (i.e., reproduction and juvenile growth). In terms of efficiency, the new procedure increases the ratio of data output to materials input by a factor of at least 5 , in comparison with the OECD method. Additionally, materials costs are lower, waste is minimized, and precision is greater. The procedure was verified through the use of two kinds of 
reference soils, various food supplements, soils from a composting project using trinitrotoluene, and a reference toxicant.

\section{ESD Assists Four DOE Facilities in Negotiations for NPDES Permits}

\section{A. Kszos}

ESD's Toxicology Laboratory initiated toxicity testing of Oak Ridge Y-12 Plant effluents in 1985. Subsequently, toxicity tests have been conducted for ORNL, the Oak Ridge K-25 Site, and the Paducah Gaseous Diffusion Plant (Paducah), as required by each facility's National Pollutant Discharge Elimination System (NPDES) permit. In 1990, each facility initiated the process of renewing its NPDES permit. The K-25 Site received its renewed permit in October 1992, and the Y-12 Plant and ORNL have received draft permits. The Paducah permit has been stayed until issuance of an Agreed Order.

The Toxicology Laboratory's technicai expertise and experience with method development since 1985 were successfully applied to the permit negotiations. Ambiguous language for toxicity testing in the initial draft permit was deleted or modified. Also, a review of historical toxicity test data resulted in recommendations regarding appropriate test frequencies, reporting times, toxicity limits, and estimates on the number of permit violations that might occur.

The review of toxicity data for the Y-12 Plant contributed to decisions concerning (1) appropriate compliance points for toxicity evaluations [at wastewater treatment facility outfalls or in East Fork Poplar Creek (EFPC), the receiving stream], (2) appropriate mercury limits, and (3) the need for a guaranteed minimum flow for EFPC. Contributions to the K-25 Site permit included (1) evaluation of a project to construct a pipeline from the Central Neutralization Facility to the Clinch River and (2) elimination of toxicity limits at two discharge points. Contributions to the ORNL permit included (1) assessment of the need for guaranteed minimum flow in White Oak Creek, (2) elimination of toxicity limits for the receiving stream, and (3) selection of appropriate metal limits for the Nonradiological Wastewater Treatment Plant. Participation in the Paducah permit negotiations led to special studies to determine appropriate limits for $\mathrm{pH}$, temperature, and metals. Perhaps most importantly, all the facilities will benefit from lessons learned from each negotiating session.

\section{Sediment and Water Toxicity Tests Are Developed to Assess : :ological Risk Off-Site}

\author{
T. L. Phipps, ${ }^{1}$ A. M. Gonzalez, ${ }^{1}$ and \\ L. A. Kszos
}

The screening-level assessment for ecological risk of contaminants conducted under Phase 1 of the Clinch River Remedial Investigation revealed that additional data were needed to conduct an ecological risk assessment. Under Phase 2, laboratory toxicity tests will be used to assess the toxicity of water and sediment from the Clinch River downstream of White Oak Creek and from Poplar Creek below discharge points permitted under the National Pollutant Discharge Elimination System (NPDES). Data obtained from toxicity tests will provide one measure 
of ecological effects for the weight-ofevidence approach to ecological risk assessment.

The water tests chosen for the assessment were the 7-d Ceriodaphnia and larval fathead minnow tests, both widely used on the Oak Ridge Reservation under the NPDES permit system and in the Biological Monitoring and Abatement Programs.

A suite of sediment tests with Hyalella azteca (an amphipod), Daphnia magna (a crustacean), Anodonta imbecillis (a freshwater mussel), and Photobacterium phosphorum (a bacterium) was chosen to reflect both state-of-the-art testing procedures and species that exhibit different types of habitat interactions. For example, $H$. azteca burrows into the sediment, whereas $D$. magna is pelagic and scavenges on the surface sediment.

During the past year, ESD's Toxicology Laboratory has established cultures, obtained the necessary testing equipment, written standard operating procedures, conducted reference tests with all species, and participated in operation readiness reviews and audits. The first water tests were conducted in April 1993. No toxicity was observed at any of the sites. Sediment performance evaluation tests were completed in July 1993.

In addition to these sediment toxicity tests, additional investigations are needed for the ecological risk assessment in the area of sediment chemistry and toxicity. These innovative studies will evaluate the effects of sediment composition and particle size on (1) partitioning of various contaminants (i.e., metals and organics) to sediments, (2) speciation behavior of divalent metals in natural sediment/water systems, and (3) alteration of metal bioavailability by natural and laboratory-formulated sediments.

${ }^{1}$ Advanced Sciences, Inc., Oak Ridge, Tennessee.

\section{Field-Scale Transport of Natural Organic Matter Is Studied}

\author{
J. F. McCarthy, B. Gu, L. Liang, \\ T. M. Williams, ${ }^{1}$ C.-T. J. Yeh, ${ }^{2}$ and \\ J. Mas-Pla
}

To better understand the role that natural organic matter (NOM) plays in the transport of contaminants that sorb to NOM, a two-well forced-gradient field manipulation was conducted to examine NOM mobility.

Water from a wetlands pond, diluted with groundwater to $-30 \mathrm{mg}$ of carbon per liter, was injected into a shallow sandy coastal aquifer in Georgetown, South Carolina, for $\sim 600 \mathrm{~h}$. Groundwater was then withdrawn from a pumping well $5 \mathrm{~m}$ from the injection well.

Before the NOM injection, the researchers characterized the injection site by conducting 312 slug tests in 32 wells to estimate the spatial distribution of hydraulic conductivity. A three-dimensional flow model was verified by monitoring chloride transport at 132 spatial locations. On the basis of these results, sampling locations for NOM were selected at two horizons at $1,2,3$, and $4 \mathrm{~m}$ from the injection well and the pumping well.

In addition to point-breakthrough curves, researchers obtained a representation of the breakthrough mass and arrival times of the NOM and chloride plumes by measuring NOM and chloride at 132 spatial locations several times during the 
adsorption and desorption phases of the injection experiment.

Results confirm that the macroscopic transport of NOM is consis-tent with mechanistic studies of NOM adsorption and desorption. Some of the injected NOM was mobile in the aquifer, but spatial moments analysis indicated that NOM moved with the chloride for the first $40 \mathrm{~h}$ and was then retarded. This behavior is consistent with slow NOM adsorption kinetics measured in the laboratory.

The height of the NOM plateau decreased as a function of distance from the injection source, indicating adsorption of NOM; however, the adsorption rates diminished with time, suggesting that continuous adsorption for long periods of time modifies the intensity of the adsorption. The NOM desorption rates were close to those of the conservative tracer, indicating that NOM desorption was very slow.

These characteristics of field-scale transport are consistent with the findings of laboratory studies that demonstrated the dependence of NOM adsorption affinity on surface coverage and hysteresis in NOM desorption. Differences were observed in the mobility of different subcomponents of NOM.

Smaller and more hydrophilic NOM was more mobile, whereas NOM with higher molecular weight was more strongly retained by the aquifer. NOM with low molecular weight migrated twice as rapidly and experienced only a third of the mass loss during transport as did the macromolecular components of NOM.

These results have implications for contaminant transport because different components of NOM have different affinities for binding-and potentially cotransporting-organic and inorganic contaminants.

${ }^{1}$ Clemson University, Clemson, South Carolina.

${ }^{2}$ University of Arizona, Tucson.

\section{Fish Exposed to High Concentrations of Dissolved Organic Mercury Accumulate Predominantly Methylmercury}

\section{G. R. Southworth, R. R. Turner, M. J. Peterson, and M. A. Bogle}

Unlike most aquatic systems in which mercury accumulation in fish is a concern, upper East Fork Poplar Creek (EFPC) within the Oak Ridge Y-12 Plant has relatively high dissolved inorganic mercury concentrations that usually exceed $1 \mu \mathrm{g} / \mathrm{L}$. Laboratory studies indicate that inorganic mercury is rapidly taken up by fish and accumulated to concentrations more than a thousandfold greater than that in the exposure water. According to current worldwide research, however, mercury in fish from both industrially contaminated and remote sites is predominantly (>90\%) methylmercury, which is the more toxic transformation product.

Recent improvements in water quality at the Oak Ridge Y-12 Plant have allowed fish to colonize a previously toxic reach of stream where the dissolved inorganic mercury concentration is highest. Currently, total mercury concentrations in fish from that reach are high ( $>1 \mathrm{ppm})$ in relation to the concentrations in fish collected previously from upper EFPC. These data suggest that the "excess" was inorganic mercury. Therefore, samples of fish from sites within the Oak Ridge Y-12 Plant and farther downstream in EFPC were analyzed for methylmercury 
and inorganic mercury by means of gas chromatography with atomic fluorescence detection.

Fish from the stream reach with the highest concentrations of dissolved inorganic mercury in water and total mercury in fish contained predominantly $(84 \%)$ methylmercury. Very little $(<5 \%)$ inorganic mercury was present in fish from the other sites. These results suggest that the presence of dissolved inorganic mercury at $1-2 \mu \mathrm{g} / \mathrm{L}$ is unlikely to result in a substantial accumulation of inorganic mercury in fish in relation to the accumulation of methylmercury expected to occur in a mercury-contaminated system. While the assumption may be incorrect that all mercury accumulated by fish in such a system is methylmercury, the magnitude of error associated with that assumption is likely to be small.

Additionally, fish from stream reaches that contain high dissolved inorganic mercury accumulated higher concentrations of methylmercury than fish at the next site downstream, where total aqueous mercury concentrations were similar but most of the mercury was particle-associated rather than dissolved. This observation suggests that (1) dissolved inorganic mercury is more readily converted to methylmercury by microorganisms than particle-associated mercury and (2) natural processes that sequester mercury in sediments and suspended particulates may act to lessen the production of methylmercury in contaminated waters. If this is true, remedial efforts that eliminate inputs of dissolved inorganic mercury may be highly effective for reducing mercury concentrations in fish in upper EFPC.

\section{Biosensors Measure Bioavailability of Sorbed Organic Contaminants}

\section{J. M. Strong-Gunderson ${ }^{1}$ and A. V. Palumbo}

The bioremediation of sites contaminated with materials that sorb onto the soil matrix is very difficult because of the contaminants' low solubility. These compounds also have a reduced bioavailability to microbial degradation. We have found that contaminant bioavailability is increased following the addition of microbialproduced biosurfactants; Tween, a synthetic surfactant; or an oleophilic fertilizer.

We measure this direct increase in bioavailability by using a lux biosensor. This biosensor is a genetically engineered microbial bioreporter strain of Pseudomonas putida. This strain was engineered so the lux genes, which code for light production, are transcriptionally fused with genes that code for contaminant degradation and are thus induced in the presence of specific compounds. By using a bicreporter, we can compare the microbial bioavailability of the contaminants to analytical methods that quantify the amount of compound free in solution-which does not necessarily represent its bioavailability to degradation.

${ }^{1}$ Oak Ridge Associated Universities, Oak Ridge, Tennessee. 
Section Staff and Guests

\section{W. Gehrs}

S. M. Adams

L. J. Allison

T. L. Ashwood

L. A. Baron ${ }^{1}$

B. K. Beane

A. T. Bednarek ${ }^{2}$

D. A. Beeler ${ }^{3}$

T. C. Bennett ${ }^{4}$

S. B. Benson ${ }^{5}$

S. L. Bergman

M. S. Bevelhimer ${ }^{4}$

B. G. Blaylock

L. R. Bond

H. L. Boston

C. N. Bowden 6

M. A. Boyd ${ }^{2}$

P. W. Braden

C. A. Branson ${ }^{8}$

C. A. Brennesholtz ${ }^{9}$

R. L. Brewer ${ }^{6}$

S. A. Brooks ${ }^{6}$

M. O. Brown ${ }^{10}$

M. D. Bryant ${ }^{4}$

S. M. Bunch ${ }^{11}$

D. L. Bunting ${ }^{6}$

R. S. Burlage

J. L. Capizzi ${ }^{12}$

A. S. Carr $^{13}$

B. A. Carrico ${ }^{13}$

J. A. Chandler ${ }^{13}$

M. N. Cheran ${ }^{9}$

B. Clark ${ }^{9}$

B. F. Clark ${ }^{13}$

R. B. Cook

R. J. Cornell ${ }^{6}$

D. K. Cox

D. W. Crumby ${ }^{4}$

W. C. Dickinson ${ }^{13}$

S. M Dimick ${ }^{9}$

C. E. Duncan
J. E. Egner ${ }^{14}$

R. G. Epler

M. A. Evans

L. S. Ewald ${ }^{2}$

C. H. Fairfax

M. K. Filson ${ }^{9}$

C. J. Ford

M. L. Frank

R. H. Gardner

M. J. Gentry ${ }^{6}$

D. G. Gera $^{6}$

M. H. Gibbs ${ }^{9}$

A. M. Gonzalez ${ }^{1}$

M. S. Greeley

C. T. Gregory

N. A. Griffith

T. Grizzard

B. $\mathrm{Gu}^{9}$

L. S. Haff

K. D. Ham $^{6}$

J. S. Hammonds ${ }^{15}$

A. F. Hardesty ${ }^{1}$

D. L. Harris ${ }^{4}$

R. A. Harris ${ }^{4}$

M. W. Hatch ${ }^{9}$

K. Y. Henley

S. E. Herbes

W. R. Hill

R. L. Hinzman

R. L. $\mathrm{Hix}^{9}$

R. P. Hoffmeister ${ }^{13}$

S. K. Holladay

V. L. Holt ${ }^{13}$

L. A. Hook

B. M. Horwedel ${ }^{10}$

A. M. Hoylman ${ }^{6}$

M. Ikaiddi ${ }^{16}$

L. J. Ivey ${ }^{9}$

L. G. Jackson ${ }^{17}$

T. Jackson?
S. R. Jardine

J. B. Jenkins

T. R. Johnson ${ }^{9}$

D. S. Jones ${ }^{9}$

C. R. Knight ${ }^{13}$

T. L. Knowles ${ }^{6}$

L. A. Kszos

C. T. D. Kuo ${ }^{6}$

W. C. Kyker

M. L. Land ${ }^{18}$

C. L. Lane ${ }^{9}$

G. D. Lay ${ }^{10}$

K.-L. Lee

K. L. Levenhagen

D. A. Levine ${ }^{4}$

L. Liang ${ }^{6}$

J. M. Loar

J. W. Lotts ${ }^{9}$

A. E. Luttrell ${ }^{9}$

S. E. Madix

K. J. McAfee ${ }^{1}$

J. F. McCarthy

R. A. McCord

M. K. McCracken

C. K. McGuffin ${ }^{8}$

J. A. McNabb

A. W. McWhorter ${ }^{13}$

T. L. Mehlhorn

D. E. Miller ${ }^{4}$

E. J. Miller ${ }^{9}$

U. Minocha ${ }^{6}$

R. L. Moody ${ }^{19}$

B. A. Moore ${ }^{6}$

G. W. Morris

J. L. Morris ${ }^{13}$

J. G. Mural ${ }^{6}$

G. E. Napolitano ${ }^{6}$

S. L. Niemela ${ }^{4}$

D. E. Nivens ${ }^{6}$

M. L. Odom ${ }^{6}$
J. B. Oliver ${ }^{6}$

B. R. O'Neal ${ }^{13}$

E. A. Orbacz ${ }^{9}$

J. G. Paar ${ }^{1}$

A. V. Palumbo

J. M. Paulk

J. A. Payne ${ }^{7}$

M. R. Pelton ${ }^{15}$

W. E. Peters ${ }^{11}$

M. J. Peterson

R. B. Petrie ${ }^{13}$

S. M. Pfiffner ${ }^{9}$

T. J. Phelps

T. L. Phipps ${ }^{1}$

J. R. Platt ${ }^{9}$

C. M. Poole

W. J. Pottorf ${ }^{20}$

R. S. Powers

E. W. Price ${ }^{9}$

L. P. Price ${ }^{21}$

C. S. Rains

C. D. Rash

S. Ratnayake ${ }^{6}$

O. Reedy ${ }^{1}$

J. K. Reid ${ }^{22}$

J. E. Richmond

D. Ringleberg ${ }^{6}$

A. L. Roberts ${ }^{7}$

W. K. Roy

M. G. Ryon

L. H. Sadler

- Veiga $^{23}$

E. R. Sain ${ }^{6}$

T. K. Sawyer

G. S. Sayler ${ }^{6}$

S. O. Scarborough

W. H. Schacher ${ }^{13}$

E. M. Schilling

J. Schmitt ${ }^{6}$

D. D. Schmoyer ${ }^{10}$ 


\begin{tabular}{|c|c|c|c|}
\hline S. K. Sharp ${ }^{6}$ & J. Stair ${ }^{6}$ & J. K. Thomas ${ }^{18}$ & D. K. Weaver ${ }^{6}$ \\
\hline J. S. Short ${ }^{13}$ & T. J. Stephens & E. E. Thompson' & O. F. Webb ${ }^{6}$ \\
\hline L. R. Shugart & E. A. Stetar ${ }^{26}$ & K. Trowbridge ${ }^{9}$ & M. T. Wefer ${ }^{15}$ \\
\hline S. J. Shults ${ }^{9}$ & R. T. Stevens ${ }^{9}$ & J. J. Urbanik & D. C. White ${ }^{6}$ \\
\hline D. Simbeck ${ }^{2 A}$ & A. J. Stewart & L. D. Voorhees & L. F. Wicker \\
\hline J. E. Slate 25 & J. Strong- & B. T. Walton & L. F. Willianıs ${ }^{6}$ \\
\hline J. G. Smith & Gunderson ${ }^{9}$ & J. N. Walz & R. F. Winterfield ${ }^{6}$ \\
\hline M. S. Smith ${ }^{10}$ & L. M. Stubbs & A. D. Walzel ${ }^{28}$ & J. A. Wojtowicz ${ }^{13}$ \\
\hline S. A. Smith & J. R. Sumner? & M. C. Warriner ${ }^{9}$ & Z. K. Yang ${ }^{29}$ \\
\hline G. R. Southw & C. W. Theodorakis & Watts & \\
\hline
\end{tabular}

${ }_{1}^{1}$ Advanced Sciences, Inc., Oak Ridge, Tennessee.

${ }^{15}$ Self-employed.

${ }^{2}$ Oak Ridge Research Institute, Oak Ridge, Tennessee.

${ }^{3}$ PEER Consultants, Knoxville, Tennessee. 'Automated Sciences Group, Oak Ridge,

Tennessee.

${ }^{5}$ Quality Division, ORNL.

${ }^{6}$ The University of Tennessee, Knoxville.

${ }^{7}$ Temp Systems, Inc., Knoxville, Tennessee.

${ }^{8}$ Midwest Technical, Inc., Oak Ridge, Tennessee.

${ }^{9}$ Oak Ridge Institute for Science and Education, Oak Ridge, Tennessee.

${ }^{10}$ Computing Applications Division, ORNL.

${ }^{11}$ Computing and Telecommunications Services, Martin Marietta Energy Systems, Inc.

${ }^{12}$ U.S. Fish and Wildife Service, College Station, Texas.

${ }^{13}$ JAYCOR, Oak Ridge, Tennessee.

${ }^{14}$ Tennessee Technological University, Cookeville.

${ }^{16}$ Florida A. \& M. University, Tallahassee.

${ }^{17}$ Knarville College, Knoxville, Tennessee.

${ }^{18}$ Health Sciences Research Division, ORNL.

${ }^{19}$ Science. Applications International Corporation, Oak Ridge, Tennessee.

${ }^{20}$ West Georgia College, Carrollton.

${ }^{21}$ Xavier University, New Orleans.

${ }^{2}$ Environmental Careers Organization, Boston.

${ }^{23}$ National Nuclear Energy Commission, Rio de Janeiro.

${ }^{24}$ Tennessee Valley Authority, Knaxville, Tennessee.

${ }^{25}$ University of Louisville, Louisville.

${ }^{26}$ Performance Technology Group, Nashville, Tennessee.

${ }^{27}$ Tulane University, New Orleans.

${ }^{28}$ Texas A\&I University, Kingsville.

${ }^{29}$ University of Indiana, Bloomington. 


\section{Division Operations}

\section{Introduction}

The Division Operations Section of the Environmental Sciences Division (ESD) at Oak Ridge National Laboratory (ORNL) supports ESD in the following areas: administration; environment, safety, and health; finance; information; and operations. At the close of FY 1993, ESD employed 244 staff; more than 348 guests and staff from other divisions also worked on ESD projects during the fiscal year. The division is housed mainly in five facilities, which contain offices, research laboratories, and special-purpose rooms. ESD is responsible for two large field installations and several other field locations on the Oak Ridge Reservation.

The Administrative Support Group handles personnel and staffing-related functions, education efforts, and the day-to-day oversight of activities in the ESD facilities. The group also is responsible for interactions with U.S. Department of Energy representatives; organizational units within Martin Marietta Energy Systems, Inc.; and other ORNL divisions and offices.

The Environment, Safety, and Health Group focuses on helping the division meet the multitude of environmental, safety, and health requirements set forth to ensure that work is conducted in a manner that is safe for staff and the environment. This group helps the division decipher requirements relating to such concerns as safety reviews and documentation, waste- related activities, training, and radiation protection. During the last quarter of FY 1993, two staff members from the central support organizations were housed in ESD to assist in identifying and meeting environmental, safety, and health compliance requirements for division-wide and project-specific activities.

The Finance Group provides support coordinated by a staff member from the Finance and Materials Division. The group assists ESD in tracking budgets and meeting reporting requirements, in establishing subcontracts, and in estimating costs for work proposals.

The Information Support Group provides editing, graphics, library, and information processing services. The information processing services include assistance with publication clearance forms, the compilation of division statistics, and the production of division-level reports and other information. Support for special projects is also available.

The Operations Support Group offers computer networking assistance, as well as support from the Plant and Equipment Division and the Instrumentation and Controls Division. The group's activities include scheduling work priorities for the staff from other divisions and ensuring that ESD receives the best possible research and maintenance support. Computing support provides a network backbone for the division and fulfills such administrative requirements as inventories and security-related concerns. 


\section{Section Staff and Guests}

\section{E. Fowler}

C. H. Abner ${ }^{1}$

J. A. Aebischer ${ }^{2}$

T. S. Anderson ${ }^{3}$

E. R. Barham ${ }^{4}$

K. F. Barnes ${ }^{5}$

R. E. Booker ${ }^{5}$

S. D. Bridges ${ }^{1}$

E. B. Bryant ${ }^{6}$

E. F. Carringer

L. C. Combs ${ }^{1}$

L. S. Corrill ${ }^{2}$

M. S. Denton
E. A. Ford ${ }^{4}$

R. L. Freeman ${ }^{7}$

K. N. Gibson

N. A. Griffith

O. J. Grooms

L. M. Hardin

J. B. Harper

L. A. Henderson

M. S. Hendricks

G. F. Houser ${ }^{8}$

L. J. Jennings

A. W. Lewis
L. W. Littleton

G. M. Logsdon ${ }^{2}$

G. A. Lomax ${ }^{9}$

R. K. McConathy

D. H. Ogle

S. Y. Porter

D. D. Rhew

D. L. Rich

J. L. Rich ${ }^{2}$

J. S. Rirgs ${ }^{7}$

L. E. Koberson ${ }^{10}$

P. C. Rohde ${ }^{11}$
B. M. Ross

J. L. Seiber

W. J. Selvidge

L. K. Shaw ${ }^{2}$

R. Smith?

T. T. Vann ${ }^{11}$

M. Williamson ${ }^{5}$

A. R. Wilson ${ }^{2}$

D. Wolfe ${ }^{12}$

M. E. Zeigler ${ }^{1}$

${ }^{1}$ Plant and Equipment Division, ORNL.

${ }^{2}$ Publications Division, Martin Marietta

Energy Systems, Inc.

${ }^{3}$ The University of Tennessee, Knoxville.

'Office of Safety and Health Protection, ORNL.

'Graphics Division, Martin Marietta

Energy Systems, Inc.

${ }^{6}$ Midwest Technical, Inc., Oak Ridge,

Tennessee.

${ }^{7}$ Instrumentation and Controls Division, ORNL.

${ }^{8}$ Office of Radiation Protection, ORNL.

9 Information Services Division, Martin

Marietta Energy Systems, Inc.

${ }^{10}$ Quality Department, ORNL.

${ }^{11}$ Finance and Materials Division, ORNL.

${ }^{12}$ DOE Teacher Research Associate, South-Doyle Middle School, Knoxville, Tennessee. 


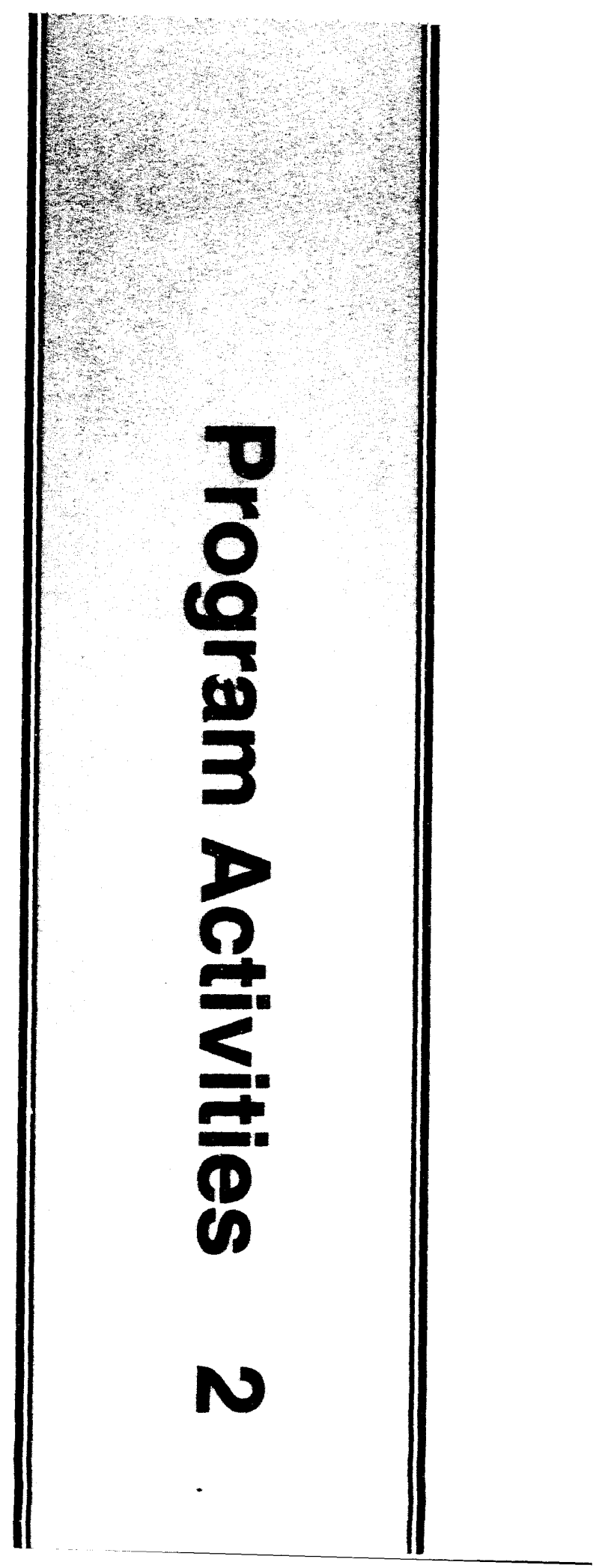




\section{Biofuels Feedstock Development Program}

\section{Introduction}

New biomass energy technologies appear to offer environmental and economic benefits in many parts of the United States. Biomass-based technologies for producing liquid transportation fuels, power, and chemicals are being planned or rapidly approaching commercialization. Although the first facilities will use wood, municipal, and agricultural wastes, the expansion of biomass energy systems will depend on the sustained production of energy crops. The Environmental Sciences Division (ESD) of Oak Ridge National Laboratory (ORNL) manages the U.S. Department of Energy's (DOE's) national effort to develop such crops.

The mission of the Biofuels Feedstock Development Program (BFDP) is to lead the nation in research, development, and demonstration of environmentally acceptable and commercially viable biomass supply systems in a way that integrates and promotes multiple objectives in agriculture, energy, and the environment; seeks and fosters the best research, development, and demonstration in the private, academic, and government sectors; and ensures information on biomass supply systems is accurate, understandable, and accessible.

ESD has provided field management, research, and analysis for BFDP since 1980. The program's five areas are Model Wood Energy Species, Model Herbaceous Energy Species, Environmental Research and Analysis, Economic Analysis and Integration, and Energy Crop Data and Information Management. Universities and U.S. Department of Agriculture (USDA) research facilities perform much of the research in the program, particularly in the first two areas. The program has included 25 to 35 such cooperators at any given time throughout its history. ORNL's research efforts have emphasized basic genetics, physiology, and biotechnology projects that support the development of woody and herbaceous crops, resource assessments and economic analyses, and environmental research and analysis.

BFDP's primary DOE sponsor is the Biofuels Systems Division in the Office of Transportation Technologies. BFDP also works with other government and private organizations. Recent activities include assessments, cooperative projects, and work-for-others efforts with the National Renewable Energy Laboratory, the U.S. Environmental Protection Agency, the Electric Power Research Institute, the Tennessee Valley Authority, USDA, the U.S. Agency for International Development, and the National Audubon Society.

\section{Model Wood Energy Species}

BFDP has supported research on the production of short-rotation woody crops since 1978. Previous and current work focuses on the development of the genus Populus as an energy crop. Although much has been learned about Populus, information on or efforts toward improving its productivity, site adaptability, and tolerance for biotic and abiotic stresses is still required before broad-scale resource deployment can be realized. Five current and ongoing Populus crop development projects are addressing the above-noted 
topics. Two additional projects, one with hybrid willow in the Northeast and the other with silver maple in the Midwest, also obtained field productivity estimates for these species under research plot conditions.

In FY 1993, projects on nutrient/irrigation interactions in Populus, clone/spacing interactions in Populus, black locust improvement in the Southeast, and sycamore improvement in the Southeast were successfully completed. A new crop development project for Populus in the Southeast is planned for FY 1994.

\section{Model Herbaceous Energy Species}

Seven funded projects in the herbaceous energy task cover the management, breeding, physiology, and tissue culture of switchgrass, the herbaceous species chosen for development as a model species for herbaceous crops research. Six of the projects were funded initially in FY 1992 in response to a request for proposals (RFP) released in November 1991. The focus of that RFP and all of the funded projects is to develop the management techniques, physiological understanding, and breeding technology to establish, produce, and harvest switchgrass in an economically and environmentally sound manner. The objectives of the breeding and tissue culture research are to foster concurrent studies on the techniques to characterize, improve, and protect switchgrass as a biofuels crop over the long term.

Current projects incorporate production researci and regional field trials at three locations-Texas A\&M University, Virginia Polytechnic Institute and State University, and Auburn University; breeding research at Oklahoma State University; development of techniques to propagate and screen switchgrass through tissue culture techniques at The University of Tennessee; and physiological characterization of switchgrass at ORNL. Ongoing research in a seventh project, a collaborative effort with the USDA Agricultural Research Service at Lincoln, Nebraska, has been expanded to encompass production research, germ plasm characterization, and breeding of switchgrass lines suitable for the Midwest.

Important advances during the first year of this research include a demonstration of high yield potential of selected cultivars, the development of an accelerated breeding technique for increasing selection of superior plants, and the development of culture techniques for reproducing switchgrass through tissue culture. Research during the coming year will increase emphasis on nitrogen economy and the role of rhizosphere chemistry and biology on nutrient uptake.

\section{Environmental Research and Analysis}

Interests in industry, utilities, the environment, and public policy are being fed by results from energy crop biodiversity studies, initial investigations into nonpoint agricultural chemical fates related to energy crops, and the initiation and monitoring of scaled-up energy crop plantings in the Midwest and elsewhere. Each of these efforts retains a landscape or cumulative environmental effects component not apparent in past fuel cycle studies. Results are promising for environmental improvements in groundwater quality, selected woodland species diversity, wetland quality, greenhouse gas reduction, and soil improvement in landscapes where energy crops occupy a significant portion of agricultural land. As these efforts mature, 
greater focus will be placed on questions that regulatory agencies and environmental groups will ask about near-term environmental permitting. The research efforts provide the National Biofuels Roundtable with valuable contributions in regard to how to deploy energy crops for greatest environmental benefit.

\section{Economic Analysis and Integration}

Researchers associated with Economic Analysis and Integration ensure that all factors affecting the viability of biomassbased fuel cycles, including factors from economic and environmental standpoints, are considered in BFDP research and planning. ESD or Energy Division staff and cooperators at The University of Tennessee conduct most of the research. Considerable support is given directly to the DOE Office of Transportation Technology and to the National Renewable Energy Laboratory for national biomass energy planning and analysis.

In 1994, a modeling system to project cost-supply relationships of herbaceous energy crops at the national level will be completed and the data developed to produce national supply curves for energy crops. A major new initiative under this task will be an integrated assessment of the potential for energy crops in the Midwest, which includes issues concerning transportation, environment, production, and conversion. The initiative will develop a Geographic Information System for biomass energy so spatially specific analyses can be undertaken and policies that affect land-use decisions can be modeled.

\section{Energy Crop Data and Information Management}

Accessible information about energy crops is crucial to their acceptance as alternatives to existing fuels. In 1993, a data base for research projects on herbaceous energy crops was initiated, and a draft outlining the design was distributed for feedback. Also during this period, two issues of Energy Crops Forum were published and distributed to almost 3000 subscribers worldwide. Techniques that will enhance BFDP's information management and distribution capabilities are being assessed. 


\section{Technical Summaries}

\section{Plant-Tissue Culture Systems Can Help Identify Hybrid Poplars Tolerant to Water Stress}

\section{G. A. Tuskan and T. J. Tschaplinski}

Except for the bacterium Septoria, water stress is the most limiting factor in the expression of high productivity rates found in improved hybrid poplar (Populus spp.) clones. The ability to maintain growth under water stress would greatly expand the acreage potentially suitable for poplar energy plantings, as well as increase productivity on currently available sites. Water-stress tolerance (i.e., the ability of individual cells or tissue to osmotically adjust to stress) could overcome the limitations associated with drought.

The objectives of this study were to characterize the degree of genetic variability and limits of water stress tolerance in a poplar pedigree consisting of black cottonwood ( $P$. trichocarpa) and eastern cottonwood ( $P$. deltoides) parental clones and four hybrid progeny. Trees from all six clones have been grown in the field under repeated cyclic stress. The abilities of each clone to maintain growth under stress, to maintain high baseline concentrations of osmotica, and to osmotically adjust in response to stress have been characterized. In vitro assays of waterstress tolerance would greatly reduce the time and effort needed to characterize the genetic potential of selected clones. Efforts have been undertaken to establish aseptic cell-suspension cultures of each of the six genotypes in the forementioned pedigree. Various methods to surface- sterilize explants have been attempted. A combination of ethanol followed by bleach $(\mathrm{NaOCl})$ provided the least amount of contamination. Percentage contamination after treatment across genotypes ranged from 0 to $11 \%$.

Two media formula have been tested for callus initiation; the woody plant medium with organic additives worked best across all genotypes. Several combinations of growth regulators have also been tested for callus initiation, with 1-napthaleneacetic acid and 6-benzylaminopurine producing the highest percentage of callus formation. Callus initiation across genotypes ranged from 26 to $68 \%$. Leaf explants performed better than stem explants. All callus cultures were used unsuccessfully to initiate cell-suspension cultures based on the same media formula. Roots or shoots were initiated from some of the culture, indicating that the phytohormone levels were inappropriate for cell suspensions. This study will continue to investigate optimum medium requirements for Populus cellsuspension cultures.

\section{Osmotic Adjustment to Water Stress in Tolerant Poplar Clones Is Constituted by Potassium, Malic Acid, and Soluble Carbohydrates}

\section{T. J. Tschaplinski and G. A. Tur'kan}

Water-stress tolerance is a determinant of productivity in hybrid poplar, particularly if grown on sites that experience periodic drought. Plant species tolerate water stress by maintaining low osmotic potential and by osmotic adjustment, the active accumulation of solutes in response to water stress. The objective of this study was 
to characterize the biochemical bases of water-stress tolerance in a pedigree consisting of black cottonwood (Populus trichocarpa Torr. and Gray \$) and eastern cottonwood ( $P$. deltoides Bartr. $\left.\delta^{\star}\right)$ parental clones and four hybrid progeny. Trees were grown outdoors in pots; well-watered trees $(>-0.03 \mathrm{MPa})$ were kept moist in trays, and stressed trees $(<-2.0 \mathrm{MPa})$ were subjected to repeated cyclical stress of 1-2 days' duration over the 14-week study.

Analysis of the major metabolites and ions in fully expanded leaves demonstrated that the greatest degree of osmotic adjustment was displayed by hybrid $242{ }^{\circ}$, the $P$. deltoides ot parent, and 239 ot to a lesser extent. Osmotic adjustment in the leaves of both hybrid $242 \delta$ and the $P$. deltoides $\delta$ parent was primarily constituted by malic acid, potassium, sucrose, and glucose; the same metabolites also increased in fine roots of hybrid 242 o, the only clone to display osmotic adjustment in roots.

Clones $240 \%$ and $P$. deltoides $\delta$ displayed organic solute-based adjustments to water stress that were offset by declines in inorganic ions, particularly sodium and magnesium. Given that the $P$. trichocarpa

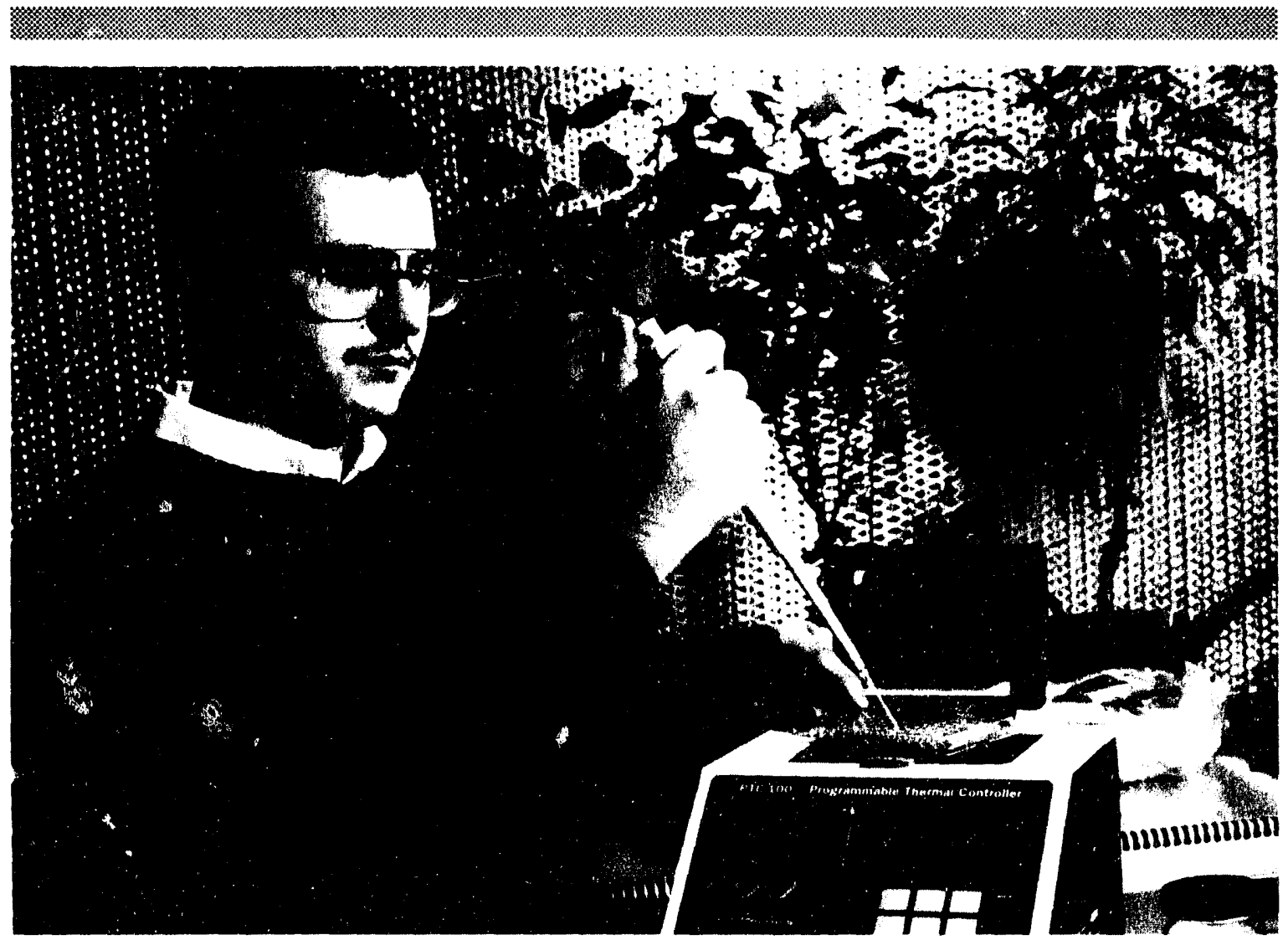

Greg Roberts, student intern working with Jerry Tuskan in ESD, loads a programmable thermal cycler with DNA templates in order to identify DNA markers associated with drought tolerance in hybrid poplars. 
parent did not display osmotic adjustment in either tissue, the hybrids' capacity for adjustment was likely conferred by the $P$. deltoides ot parent. These studies indicate that potassium, malic acid, and soluble carbohydrate accumulation under water stress may be used as biochemical indicators of water-stress tolerance and, hence, be used as selection criteria in breeding programs.

\section{Biomass Energy Technology Could Supply Economical Power to the Tennessee Valley Authority Region}

\section{R. L. Graham and M. E. Downing}

Biomass is becoming an increasingly attractive fuel to the Tennessee Valley Authority (TVA) because of (1) the Clean Air Act (CAA), which calls for reductions in sulfur emissions; (2) federal energy legislation, which gives contained biomass power plants (those fueled by biomass grown specifically for the particular power plant) a 1.5-cent kWh tax credit; and (3) the proposed Btu tax, which would affect coal but not biomass energy.

For the same amount of electricity production, a coal-fired power plant will release 26,000 times more $\mathrm{SO}_{x}$ and 20 times more $\mathrm{NO}_{x}$ than a wood-fired plant, even if the coal power plant has scrubbers sufficient to meet current CAA emission standards. For a price to the farmer of $<\$ 50 /$ dry ton ( $<\$ 3 / \mathrm{MBtu}$ ), over 40 million dry tons of wood could be grown annually on agri-cultural land in the TVA region on a sustainable basis.

This amount of wood could supply $8000 \mathrm{MW}$ of base-load power. If modest increases $(25 \%)$ in energy crop yields occur, the price for the same supply would drop to $<\$ 2.25 / \mathrm{MBtu}$. Most of this wood would be grown in the western portion of the TVA region. Regional water quality would be improved because land erosion would be reduced significantly, as would the regional use of fertilizers and pesticides.

'Oak Ridge Institute for Science and Education, Oak Ridge, Tennessee.

\section{Environmental Studies of Energy Crops Demonstrate Successful Way to Organize Cooperative Research}

\section{J. W. Ranney}

To successfully implement biomass energy (energy crops and other forms of biomass), the operations and environmental communities have needed to develop closer cooperation to avoid confrontations on environmental issues and to improve opportunities for environmental benefits of energy crops. Limited funds also required that cost-sharing opportunities be pursued. One aspect of this effort has concentrated on effects of energy crops on biodiversity in an array of landscape patterns.

Studies were initiated with a series of previously established 4- to 10-ha shortrotation hardwood plantations across the prairie-forest transition in Wisconsin, Minnesota, and South Dakota. Seven plantations and major surrounding land uses were surveyed for the presence and movement of birds and small mammals. A separate study on large industrial plantings was initiated to validate small plantation findings. Cooperators in these studies 
were the U.S. Department of Agriculture Forest Service, National Audubon Society, University of Minnesota, and Domtar Paper Company. An \$85K project was parlayed into a $\$ 235 \mathrm{~K}$ comprehensive effort by the stakeholders of diverse interests working together.

Results are revealing some unanticipated landscape-level dynamics related to edge effects, introduction of unique habitats, and roles of artificial (plantation) habitats. By reducing edge effect, for example, short-rotation plantations can functionally increase woodlot interior area without changing the sizes of woodlots. These findings have important policy ramifications on managing landscapes for improved biodiversity, as well as on meeting energy needs, increasing nonfood crop productivity, and increasing soil qualities (reversing soil degradation). Placing value on these benefits may be necessary for energy crops to successfully compete in the agricultural and energy arenas. This work demonstrates a successful way to conduct scientific inquiries with many diverse cooperators while maintaining scientific integrity. 


\section{Program Staff and Guests}

\section{J. H. Cushman}

L. S. Cooper ${ }^{1}$

D. H. Dawson ${ }^{2}$

M. A. Doan ${ }^{3}$

M. E. Downing ${ }^{4}$

A. R. Ehrenshaft ${ }^{5}$

R. L. Graham ${ }^{1}$
P. L. Henry

S. A. Martin ${ }^{3}$

S. B. McLaughlin ${ }^{1}$

N. McLetchie ${ }^{6}$

W. A. McNabb

R. D. Perlack?

\footnotetext{
${ }^{1}$ Ecosystem Studies Section, ESD.

${ }^{2}$ Self-employed.

${ }^{3}$ The University of Tennessee, Knoxville.

'Oak Ridge Institute for Science and Education, Oak Ridge, Tennessee.

${ }^{5}$ Health Sciences Research Division, ORNL
}

M. Plaza ${ }^{8}$

J. W. Ranney ${ }^{1}$

N. H. Rice ${ }^{9}$

D. G. Roberson ${ }^{10}$

K. Seigert ${ }^{11}$

T. J. Tschaplinski ${ }^{1}$
A. F. Turhollow ${ }^{7}$
G. A. Tuskan ${ }^{1}$
H. Van Miegroet ${ }^{1}$
Y. C. Wang ${ }^{12}$
L. L. Wright ${ }^{1}$
S. D. Wullschleger ${ }^{1}$

${ }^{6}$ University of Kentucky, Lexington.

${ }^{7}$ Energy Division, ORNL.

${ }^{8}$ Universidad Interamericana de Puerto Rico.

${ }^{9}$ University of Wisconsin, Stevens Point.

${ }^{10}$ Wesleyan University, Macon, Georgia.

${ }^{11}$ Western Illinois University, Macomb.

${ }^{12}$ The University of Texas, Austin. 


\section{Environmental Information Analysis Program}

\section{Introduction}

The Environmental Information Analysis

Program was created within the Environmental Sciences Division (ESD) at Oak Ridge National Laboratory (ORNL) in fiscal year (FY) 1992 to consolidate ongoing research data management projects under common leadership. The program highlights the division's abilities to support large, integrated environmental data base projects with extensive data analysis components. The management of research data has become a vital component of modern observational and theoretical science. The significant global change projects of the 1990s-such as the U.S. Department of Energy (DOE) Atmospheric Radiation Measurement (ARM) project; the DOE Computer Hardware, Advanced Mathematics and Model Physics project; and the National Aeronautics and Space Administration's (NASA's) comprehensive Earth Observing System Program-have large data management components that are vital to their success. The ability to intelligently manage and analyze large environmental data sets is one of ESD's historically unique capabilities.

The Environmental Information Analysis Program consists of four components: the ARM Archive, which supports the DOE ARM project; the Carbon Dioxide Information Analysis Center (CDIAC), which supports DOE's global change-related research; the NASA Distributed Active Archive Center (DAAC), which supports NASA's Earth
Observing System Program; and the Oak Ridge Environmental Information System (OREIS), which supports the data needs of local restoration efforts at DOE facilities in Oak Ridge.

\section{Atmospheric Radiation Measurement Archive}

ESD manages the long-term archive for data collected during the ARM Program, a DOE field project that will obtain precise measurements of atmospheric radiation-related phenomena to improve general circulation models used in predicting future climate. The ARM Archive will store, manage, and process data collected during the ARM project and make that data available to ARM scientists and the wider scientific community.

Significant progress in the development of the ARM Archive has been made. The initial version of the data reception system that stores and retrieves files on the ORNL Mass Storage Tape ' 'ower is operational, as is a prototype of the initial user interface that will allow users to directly request data files. Since June 1992, the archive has received data from the first field site (in northern Oklahoma), and since December 1992, the archive has provided the scientific community with data. Design work for the next version of the archive is proceeding. The ARM Archive project is closely integrated with the ORNL Center for Global Environmental Studies and is closely coordinated with ORNL's High Performance Computing initiative. The new Intel Paragon supercomputer and the massive ARM data archive will be linked to allow complete, close interaction of the 
two systems. The archive in its mature state will store multiple terabytes of information each year and will be a worldwide resource of meteorological information useful not only for refining general circulation models but also for understanding hail formation, downbursts, and other atmospheric phenomena.

During FY 1993, staff archived and managed more than 3 gigabytes of data from the Southern Great Plains Site and gave data to the ARM Experiment Support Team, Instruments Mentors, and Science Team Members, thereby helping them compute new data products, develop new calibration values for instruments, and verify data quality. In addition, archive staff moved data holdings from the ORNL general mass storage system to an interim system in preparation for operating the ARM Archive Mass Storage System. The archive procured the first increment of its mass storage system, which consists of hardware ranging from high-speed disks to a robotically managed tape system. The initial increment of the system will be able to store approximately 4.8 terabytes of data with access times of approximately $1 \mathrm{~min}$ for any file.

\section{Carbon Dioxide Information Analysis Center}

CDIAC, operational since 1982 , is a fully integrated information analysis center that acquires, compiles, quality-assures, documents, archives, and distributes data and other information related to $\mathrm{CO}_{2}$, other greenhouse gases, and climate in support of DOE's Global Change Research Program. The center supports the extensive data and information needs of the international research, policy-making, education, and corporate communities to assist them in the evaluation of complex environmental issues associated with elevated concentrations of $\mathrm{CO}_{2}$ and other greenhouse gases in the atmosphere.

CDIAC staff identify users' needs by attending workshops, reviewing literature, and maintaining personal contacts. The center obtains and evaluates data, articles, and reports for potential worldwide distribution; produces digital numeric data and computer model packages; distributes DOE reports; and produces the newsletter CDIAC Communications (which has a worldwide distribution of more than 7500) and the DOE Research Summary series. The center has published such varied information products as Trends '91: $A$ Compendium of Data on Climate Change (the second issue in the Trends series) and Glossary: Carbon Dioxide and Climate.

In FY 1993, CDIAC was named to operate the newly established World Data Center-A for Atmospheric Trace Gases, part of the World Data Center System coordinated by the International Council of Scientific Unions. CDIAC published several important global-change data and information products, including the numeric data package Surface Water and Atmospheric Carbon Dioxide and Nitrous Oxide Observations by Shipboard Automated Gas Chromatography: Results from Expeditions Between 1977 and 1990 (in collaboration with the Scripps Institution of Oceanography); the report Climatic Data Bases of the People's Republic of China, 1841-1988 (in collaboration with the Institute of Atmospheric Physics, Beijing; the State University of New York, Albany; and the National Climatic Data Center, Asheville, North Carolina); the dual-language bibliography Selected Translated Abstracts of Russian-Language Climate-Change Publications: I. Surface Energy Budget (in collaboration with the All-Russian Research Institute of Hydrometeorological 
Information-World Data Center, Obninsk, Russia); and the two-disk CD-ROM (compact disk, read-only memory) CDLAC's Numeric Data Package Collection.

CDIAC was presented an Exceptional Public Service Award signed by DOE Secretary Hazel O'Leary in recognition of the center's "exceptional service to the global change research community worldwide, creative innovations in the field of numerical data and information exchange, development of a model data center, achievement of international acclaim and recognition in the area of atmospheric trace gases, and significant contribution to the success of the Department of Energy's Global Change Research Program."

\section{NASA Distributed Active Archive Conter}

In July 1993, NASA awarded ESD funding that will expand the division's role in efforts to understand the global environment. NASA provided funding to develop and operate the DAAC for Biogeochemical Dynamics, one of eight data centers established for the NASA Earth Observing System Data and Information System (EOSDIS). The DAAC at ORNL gathers, quality-assures, documents, archives, and distributes data and data products in support of NASA field projects and other global change research and policy-making efforts. The center focuses on data from ground-based studies related to biogeochemical dynamics and links to data and products available through other DAACs as a part of the EOSDIS project.

Initial holdings at the ORNL center will include data from NASA's Boreal Ecosystem-Atmosphere Study (BOREAS). The BOREAS experiment consists of surface, airborne, and satellite-based observations, which will be used to develop techniques to measure biological and physical processes and conditions that govern the exchange of energy, water, heat, carbon, and trace gases between boreal forest ecosystems and the atmosphere, particularly those processes that may be sensitive to global change. This information will be used to develop models and algorithms to relate such processes to the regional scale. The DAAC will also house data from NASA's former Pilot Land Data System, which includes a variety of biogeochemical dynamics data from numerous field projects. Users will be able to electronically retrieve these and other data from the DAAC by July 1994 or sooner.

\section{Oak Ridge Environmental Information System}

The Environmental Restoration (ER) programs at the DOE Oak Ridge Field Operations and at Martin Marietta Energy Systems, Inc., initiated the development of OREIS to meet requirements described in the Federal Facilities Agreement and the Tennessee Oversight Agreement.

According to these agreements, regulators expect DOE to centralize and consolidate environmental data from all restoration and compliance programs on the Oak Ridge Reservation.

The first goals of the OREIS development team are to make the data useful to more environmental programs, to improve the consistency of the data quality, to improve the defensibility of the data and its analytical products, and to reduce the redundancy of data collection and handling by different environmental programs. Subsequent goals include specifying minimal data management 
standards and developing a robust data base and information system to manage, display, and analyze the data. The OREIS framework - the data base, standards, and information system-will be used to implement the data management program for ER activities at the DOE facilities in Oak Ridge, Tennessee; Paducah, Kentucky; and Portsmouth, Ohio.
During FY 1993, staff revised the OREIS model and data dictionary, developed software that integrates commercial software (Oracle, SAS, and $\mathrm{ARC} / \mathrm{INFO}$ ) to meet user specifications, and provided regulators with data packages based on ER reports for the Clinch River, East Fork Poplar Creek, and ORNL Waste Area Grouping 1. 


\section{Technical Summaries}

\section{Atmospheric Radiation Measurement Archive Is Being Developed}

\section{P. T. Singley}

The objective of the Atmospheric Radiation Measurement (ARM) project is to provide an experimental test bed for studying the effects of atmospheric phenomena, particularly cloud interactions, on long-wave radiative processes. This information will be used to improve the modeling of atmospheric and radiative processes, with the ultimate goal of improving general circulation models.

Members of ESD are developing the ARM Archive facility to manage the scientific data gathered by the project. This effort includes developing a computerized system to store and manage the tens to hundreds of terabytes of data that will be produced during the ARM project's 10-year life.

In addition, staff are developing methods to document and summarize the data and provide user access tools. Documenting and summarizing the ARM data will be particularly critical because the archive will be the primary source for the general scientific community seeking data from the ARM project.

Currently, ARM Archive staff are developing data-management software and are acquiring the first increment of a mass storage system. This system will be able to store approximately 5 terabytes of data. The ARM Archive facility has been receiving data from the first field site (located in northern Oklahoma) since June
1992 and has been providing data for reanalysis by the ARM Science Team since December 1992.

\section{OREIS Offers Environmental Restoration Data for Analysis and Planning}

\section{R. J. Olson and R. A. McCord}

Environmental restoration (ER) is a major focus at DOE facilities. The Oak Ridge

Environmental Information System (OREIS) provides consolidated, consistent, and well-documented environmental data and products to support the ER activities at the DOE facilities managed by the Oak Ridge Field Office.

OREIS brings together data from a variety of sites and projects to provide regulators with data in electronic formats and to provide long-term data storage and retrieval as specified in the Federal Facility Agreement between DOE, the U.S. Environmental Protection Agency, and the state of Tennessee. The OREIS system will enter the initial operational phase in late 1993.

The OREIS data base contains data associated with remedial investigation reports produced by six ER projects. These data have also been given to regulators. Metadata, information about the stored data, can aid users in understanding how to analyze and interpret the material on the basis of the Jriginal context of the data. As more data and associated metadata are entered into OREIS, the data base will become an increasingly valuable tool for planning and monitoring future environmental restoration activities. 


\section{1 coIAC Completes Second Volume of Russian- English Climate-Change Bibliographies}

\section{D. Burtis, C. B. Ravina, ${ }^{1}$ and R. M. Cushman}

The Carbon Dioxide Information Analysis Center (CDIAC), in collaboration with the All-Russian Research Institute of Hydrometeorological Information-World Data Center (RIHMI-WDC) (Obninsk, Russia), has compiled the citations for the second of four dual-language volumes in its series Selected Translated Abstracts of Russian-Language Climate-Change Publications. The first volume (ORNL/ CDIAC-57; Proceedings of RIHMI-WDC, Issue 158) covers the topic of the earth's surface energy budget; the second (ORNL/CDIAC-64; Proceedings of RIHMI-WDC, Issue 159) covers clouds. Volumes three and four are planned to cover aerosols and general circulation models, respectively. This series makes available to western researchers a wealth of climate-change literature that has previously been available only in Russian.

${ }^{1}$ All-Russian Research Institute of Hydrometeorological Information-World Data Center, Obninsk, Russia.

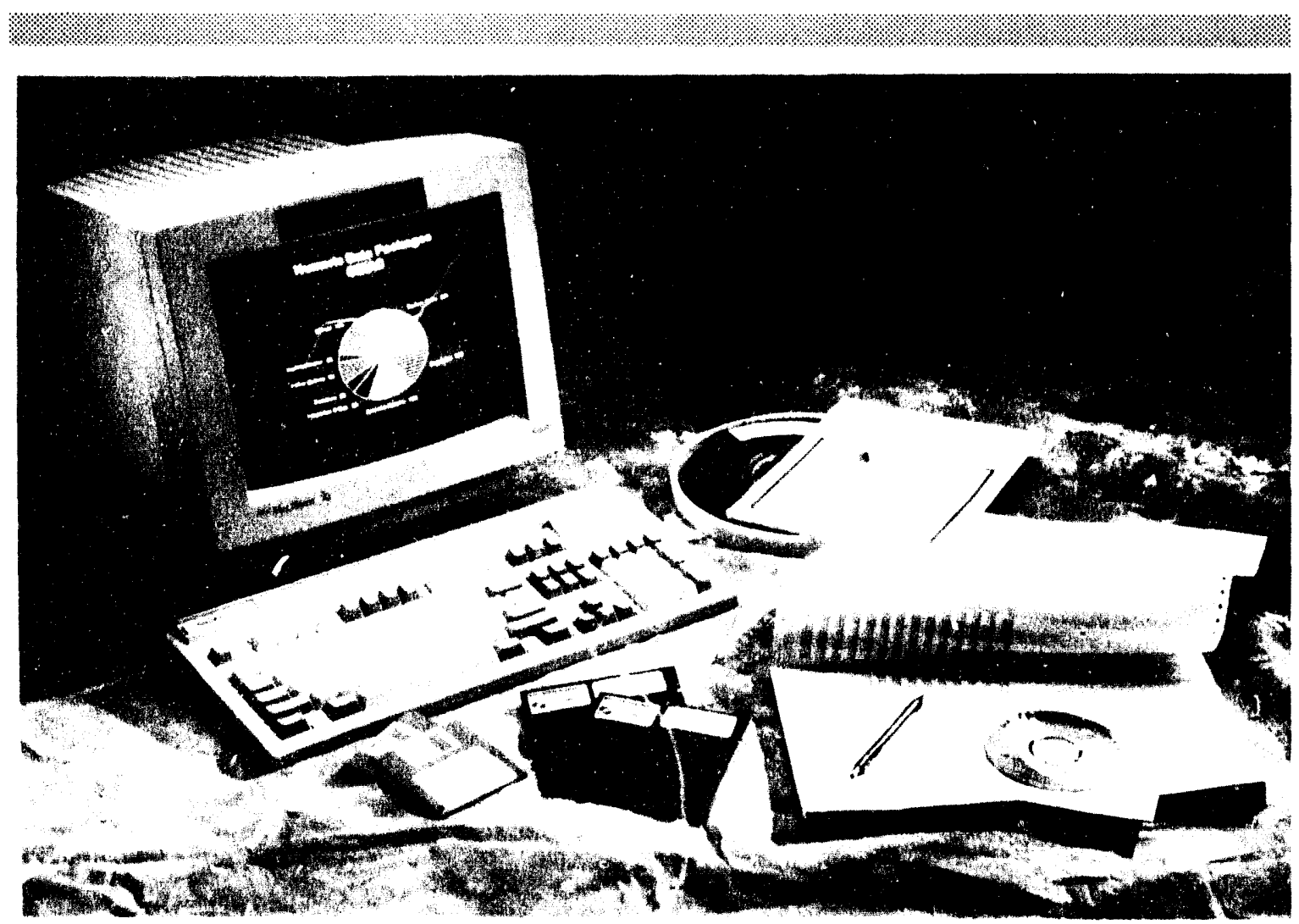

Information products distributed worldwide by ESD's Carbon Dioxide Information Analysis Center. The center provides researchers, policymakers, and educators with computer model packages, numeric data packages, and publications on subjects related to $\mathrm{CO}_{2}$, other trace gases, and climate change. 


\section{Program Staff and Guests}

\section{P. Kanciruk}
J. D. Bell ${ }^{1}$
P. R. Bell ${ }^{2}$
T. E. Birchfield ${ }^{3}$
T. A. Boden ${ }^{4}$
E. A. Bright ${ }^{1}$
M. O. Brown'
S. M. Bunch ${ }^{3}$
M. D. Burtis ${ }^{4}$
M. D. Cheng ${ }^{1}$
J. N. $\mathrm{Coe}^{5}$
P. R. Coleman ${ }^{1}$
P. J. Crabtree ${ }^{4}$
R. M. Cushman ${ }^{4}$
R. C. Daniels ${ }^{6}$
P. F. Daugherty ${ }^{7}$
R. C. Durfee ${ }^{1}$
C. T. Garten?
M. J. Gentry ${ }^{6}$

P. Y. Gray ${ }^{8}$

N. A. Griffith

J. Grubb ${ }^{6}$

D. D. $\mathrm{Herr}^{3}$

C. A. Hubbs ${ }^{1}$

T. L. James ${ }^{6}$

S. B. Jones ${ }^{4}$

D. P. Kaiser

A. Kozyr ${ }^{6}$

M. L. Land ${ }^{8}$

F. E. Latham ${ }^{1}$

G. D. Lay ${ }^{6}$

D. L. Lue $^{6}$

S. M. Margle ${ }^{1}$

R. A. McCord ${ }^{9}$

R. W. $\mathrm{McNeil}^{6}$

G. Meglitsch ${ }^{6}$

C. Miller ${ }^{6}$
M. R. Miller ${ }^{6}$

B. W. Moll'

F. E. Monroe ${ }^{3}$

L. J. Morris ${ }^{4}$

E. J. Nall ${ }^{3}$

T. R. Nelson ${ }^{1}$

M. P. North ${ }^{3}$

F. M. O'Hara ${ }^{2}$

R. J. Olson ${ }^{10}$

M. R. Palmer ${ }^{6}$

B. R. Primm

C. B. Ravina ${ }^{11}$

R. J. Sepanski ${ }^{6}$

A. K. Sexton ${ }^{1}$

D. E. Shepherd ${ }^{4}$

D. E. Sill ${ }^{3}$

J. W. Simmons ${ }^{3}$

P. T. Singley ${ }^{7}$
A. W. Smith ${ }^{1}$

P. E. Smith $^{6}$

J. L. Smyre'

T. W. Stamm ${ }^{6}$

F. W. Stoss ${ }^{6}$

P. L. Sullenberger ${ }^{4}$

A. G. Teeters ${ }^{3}$

J. K. Thomas ${ }^{8}$

E. P. Tinnel ${ }^{1}$

J. G. Tuggle ${ }^{1}$

R. S. Turner ${ }^{7}$

M. A. Tuttle

L. D. Voorhees ${ }^{9}$

R. S. Vose

T. W. White ${ }^{4}$

T. G. Yow'

B. C. Zygmunt ${ }^{1}$

${ }^{1}$ Computing Applications Division, ORNL.

${ }^{2}$ Self-employed.

${ }^{3}$ Computing and Telecommunications Services,

Martin Marietta Energy Systems, Inc.

${ }^{4}$ Environmental Analyses Section, ESD.

${ }^{5}$ Science Applications International

Corporation, Oak Ridge, Tennessee.

${ }^{6}$ The University of Tennessee, Knoxville.

${ }^{7}$ Earth and Atmospheric Sciences Section, ESD.

${ }^{8}$ Health Sciences Research Division, ORNL.

${ }^{9}$ Environmental Biotechnology Section, ESD.

${ }^{10}$ Ecosystem Studies Section, ESD.

"All-Russian Research Institute of Hydrometeorological Information-World Data Center, Obninsk, Russia. 


\section{Environmental Restoration Program}

\section{Introduction}

The Environmental Restoration (ER) Program of the Environmental Sciences Division (ESD) at Oak Ridge National Laboratory (ORNL) coordinates and manages activities performed by various ESD staff members in support of the U.S. Department of Energy (DOE) ER ard the ER Division of Martin Marietta Energy Systems, Inc. DOE ER has embarked on a 30-year mission to reduce or eliminate risks to human health and the environment as a result of past DOE operations. ESD staff are involved in all aspects of the ER process, including the preliminary assessment and identification of problems, site characterization, identification and selection of remedial actions, cleanup and site closure, and development of performance criteria and monitoring to assess the effectiveness of remediation activities.

Restoration of the environment continues to challenge scientists to develop innovative, cost-effective, and technically sound approaches to environmental problem solving. ESD is involved in approximately 30 projects supported by DOE or Energy Systems' ER Division and approximately 50 projects closely related to efforts supported by the DOE Waste Management Program, the DOE Office of Technology Development, and other DOE programs, as well as the U.S.

Environmental Protection Agency, the U.S. Department of Defense, the Electric Power Research Institute, and others. Efforts for DOE and Energy Systems' ER Division link ESD resources with those of other ORNL organizations, other DOE facilities, federal agencies, academia, and industry to provide a broad base of technical expertise. These activities are grouped into five general areas on ESD's organization chart: On-Site and Off-Site Investigations, Groundwater Operable Units, Technical Support and Integration, Information Systems, and Remediation Demonstrations. Some ER-supported projects are described below; other examples are presented elsewhere in the section activities described in this report.

Current ESD activities focus on the DOE sites operated by Energy Systems (at Oak Ridge, Tennessee; Paducah, Kentucky; and Portsmouth, Ohio), although significant efforts are under way at other sites. Among other things, researchers at Energy Systems sites are working to identify natural hydrologic integrators of contaminant fluxes, such as surface water and groundwater drainages. The Clinch River is an example of a hydrologic integrator for the contaminant releases from the three DOE facilities in Oak Ridge. Environmental characterization and monitoring within these hydrologic integrator areas support risk-based prioritization of efforts, development of conceptual models of environmental processes to guide and focus investigations, feasibility studies, and assessment of the effectivencss of remedial actions.

Groundwater investigations also take a holistic approach to guiding characterization and remediation. Groundwater efforts include nonintrusive geophysical methods that allow rapid characterization of subsurface features and contaminant flow pathways without the use of expensive drilling or the generation of 
contaminated spoils. Conceptual and numerical models are being developed, evaluated, and improved to guide the investigation and remediation of contaminated groundwater at the DOE sites operated by Energy Systems. A supercomputer-supported, threedimensional model of groundwater flow is used to predict the effects that remedial actions (e.g., capping of buried waste) have on groundwater flow and contaminant movement.

The ER Program also supports the Energy Systems Groundwater Program Office, which provides technical support and guidance on groundwater issues to all five Energy Systems facilities.

Surface water hydrologic monitoring activities support models of contaminant flux and are linked with investigations of subsurface processes and pathways of contaminant movement. These efforts provide tools to assist in ER decision making and provide opportunities to test fundamental hypotheses about issues ranging from microscale soil processes to large-scale watershed phenomena.

Assessments of human health and ecological risk integrate information about contaminated media, contaminant movement, and the ecosstem and help focus ER efforts on the contaminants, pathways, areas, biotic populations, and communities of greatest concern. Risk assessment is essential for the selection of appropriate remedial actions. New tools for risk assessment are being developed, evaluated, and improved in conjunction with ER tasks and activities.

Biological monitoring provides information needed to assess ecological health, identify problem areas, guide remediation efforts, and document recovery at various levels: at the individual contaminated site, within the watershed, and at the facility as a whole (e.g., the DOE Oak Ridge Reservation). Biomarkers, measures at the genetic or biochemical level, provide sensitive indicators of the exposure and response of organisms to toxic chemicals and other environmental stresses.

Population studies provide a means of quantifying impacts and tracking the responses of populations to remedial actions. Investigations of terrestrial and aquatic ecosystems integrate the effects of multiple impacts, track the transfer of contaminants through the food chain, and provide information at scales appropriate for predicting and evaluating the effectiveness of remedial actions.

ESD staff are in the vanguard in developing data management systems such as the Oak Ridge Environmental Information System, which will provide a consolidated, consistent, and user-friendly point of access for all ER and environmental compliance data for Energy Systems. Remote sensing, global positioning, and geographical information systems have been powerful tools for supporting $E R$ activities.

The Clinch River Remedial Investigation includes (1) examination of the nature and extent of contamination in sediment, surface water, and biota; (2) identification and evaluation of remediation alternatives; and (3) implementation of remedial actions and interim measures needed to protect human health and the environment. The primary approach is to conduct a phased remedial investigation on the Clinch River-Watts Bar Reservoir system, use information to identify high-priority sources of contaminants to the off-site surface water system, carry out interim and final remediation in the river-reservoir if necessary, and perform long-term 
monitoring of the river-reservoir system to assess the effectiveness of both off-site and on-site remediation activities.

Technology demonstrations are an increasingly important aspect of ESD's restoration activities. The in situ vitrification demonstrations, in which soil and simulated wastes are melted to form leach-resistant glass and crystalline material, are leading to applications suitable for disposal trenches at ORNL. Soil remediation demonstrations at the Portsmouth facility, where volatile organic compounds have been successfully removed at low cost, have resulted in full-scale application with significant cost savings.

ESD plays a key role in merging basic research and efforts for $E R$, waste management, and technology development. Through the merger, we are in a better position to find new technologies and approaches, to implement these technologies at DOE sites, and to create links with the private sector so the technologies will be available in the global marketplace. 


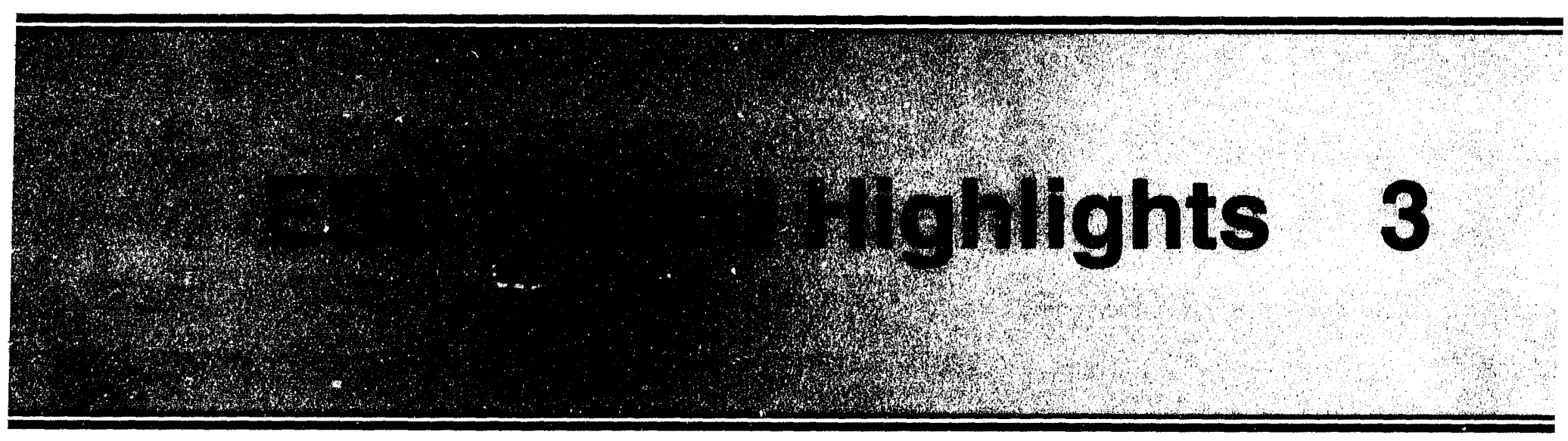




\section{ESD Scientific, Operational, Technical, and Administrative Awards}

\section{Scientific Achievement}

ESD presented its 1992 Distinguished Scientific Achievement Award to Richard J. Norby for his experimental research on the physiological ecology of forest trees and on the effects of pollutants on plants. The award recognizes Norby's national and international reputation in applying the principles of physiological ecology to understanding tree growth responses to a changing chemical environment.

Norby's work specifically addresses the effects that elevated levels of $\mathrm{CO}_{2}$ have on forest trees. His research has contributed significantly to evaluations of the dimensions and consequences of global environmental change. Research by Norby and his colleagues has been a model of sequential hypotheses and testing to determine the basic principles that control carbon assimilation and the cycling of carbon from an increasingly $\mathrm{CO}_{2}$-enriched atmosphere. The research has helped scientists quantify the degree to which $\mathrm{CO}_{2}$-induced changes in forests affect the global carbon cycle.

Norby has shown outstanding initiative and team leadership in experimental research related to plant responses to environmental change. He has played an important role in the development of scientific direction within the U.S. Department of Energy's Direct Effects Program.

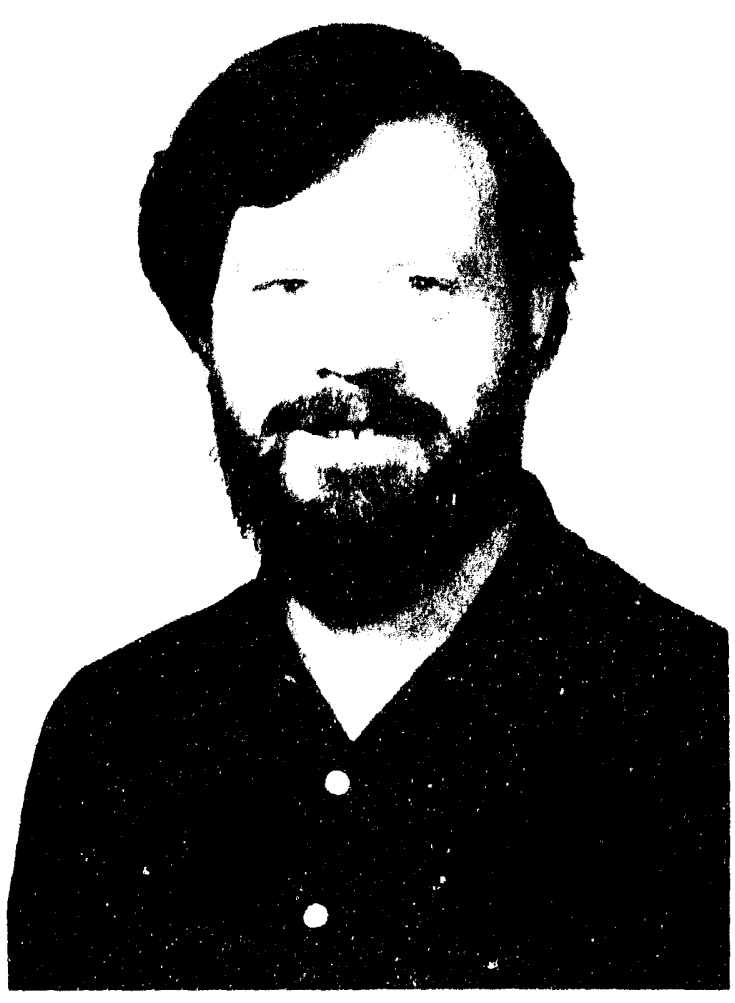

Richard Norby 


\section{Operational Achievement}

I. Lauren Larsen received ESD's Inaugural Distinguished Operational Achievement Award for his long-standing contributions to the division. The award was initiated to recognize exceptional contributions or performance by ESD staff members who support the division's mission. Larsen was honored for being responsible for ESD's routine and unique analyses of radionuclides in environmental samples.

Over the years, Larsen has given significant support to dozens of major ESD projects, including methods development, quality assurance programs, and training in radioanalytical techniques. In addition, he has authored and coauthored many research articles. In 1993, he was awarded a patent for a radiation-detecting apparatus that he developed with two members of the ORNL Instrumentation and Controls Division. Larsen has shown reliability in producing high-quality work, and he is highly sought by ORNL staff and international researchers for his expertise and his talent for participating in collaborative research.

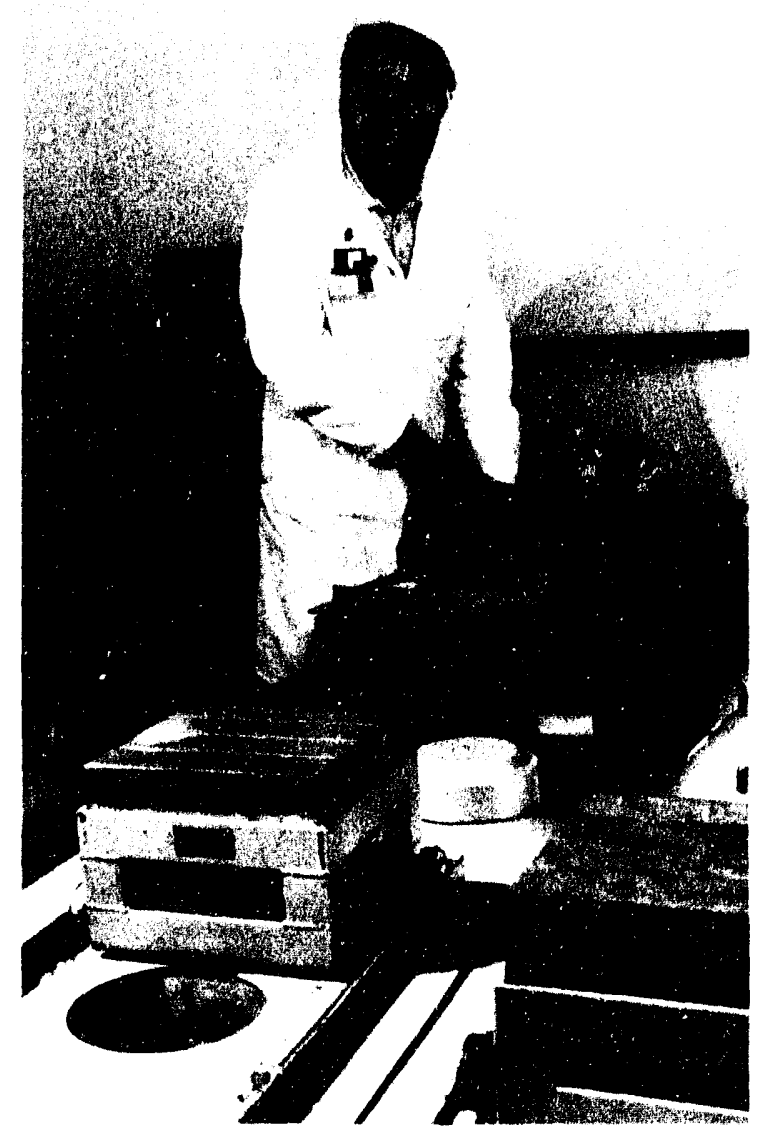

Lauren Larsen 


\section{Technical Achievement}

ESD presented to Scott Gregory the 1992 Distinguished Technical Achievement Award in recognition of his exceptional levels of technical competence, creativity, and commitment to quality. The awards committee cited Gregory for developing calibration protocols and written procedures to improve systems for collecting field data.

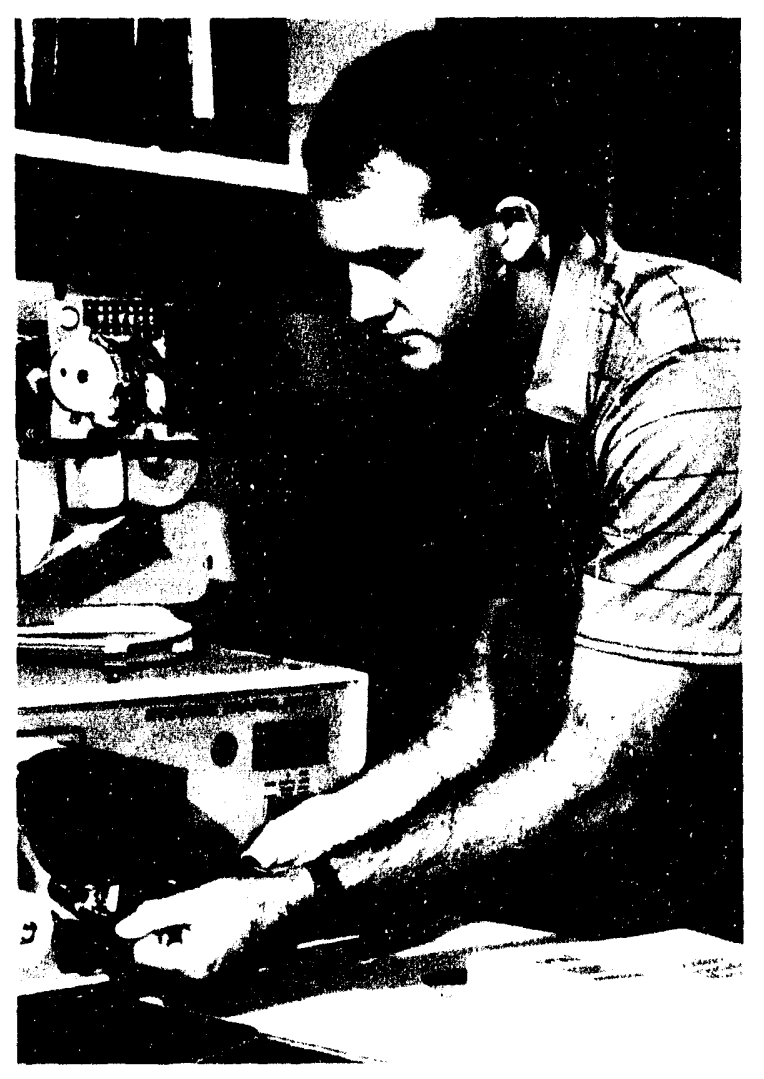

Scott Gregory

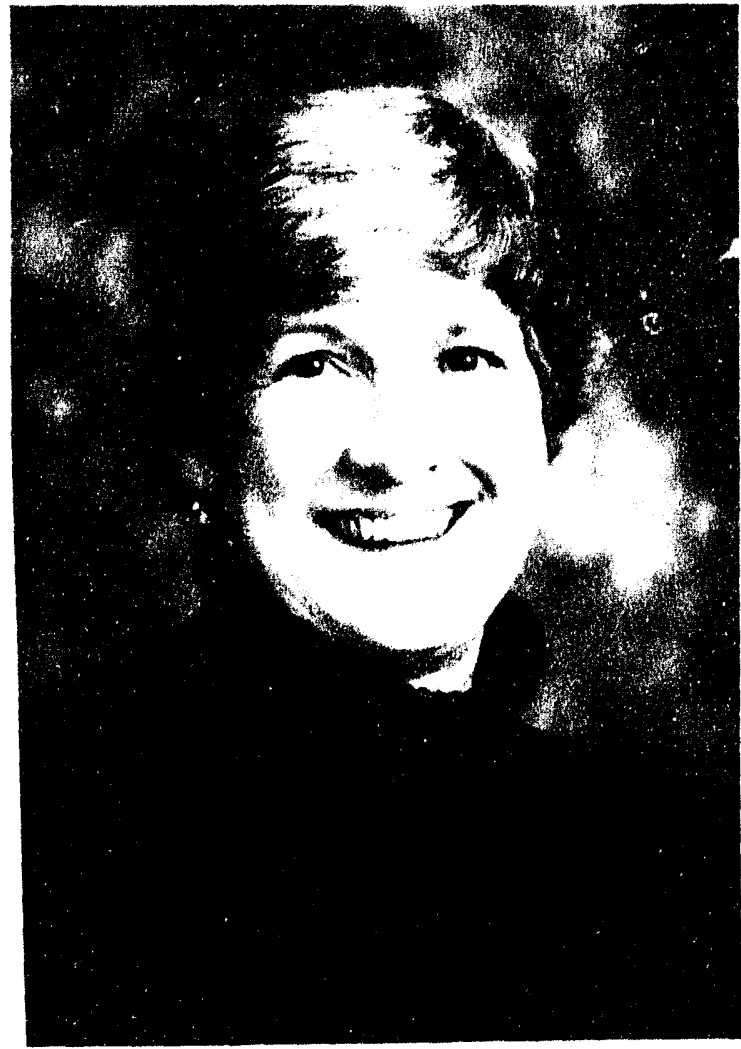

Marvel Burtis

\section{Administrative Achievement}

Marvel D. Burtis received the 1992 Distinguished Administrative Achievement Award for her continuing outstanding contribution to the Carbon Dioxide Information Analysis Center, especially for playing a major role in improving the design and content of the center's publications and progress reports. 


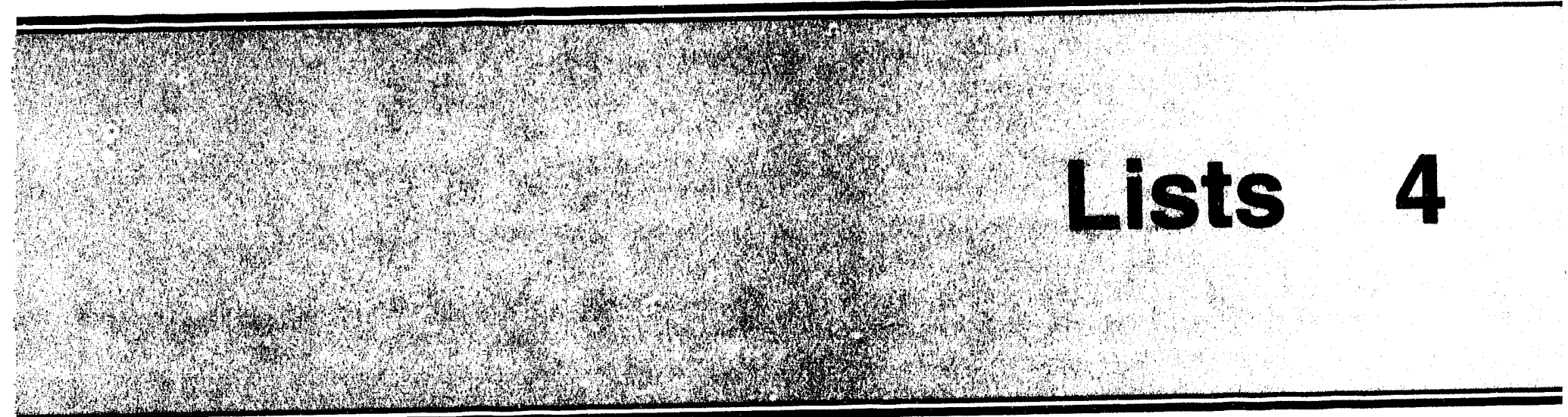




\section{Awards and Honors}

The following ESD personnel received professional, corporate, and/or organizational awards during this reporting period.

\section{S. M. ADAMS}

Award of Excellence, book category, Technical Publications Competition, East Tennessee Chapter, Society for Technical Communication

\section{W. BARNTHOUSE}

Editor, Hazard Assessment, Society for Environmental Toxicology and Chemistry; Editor, Society for Environmental Toxicology and Chemistry

\section{T. A. BODEN}

Award of Merit, category of technical reports, Technical Publications Competition, East Tennessee Chapter, Society for Technical Communication

\section{B. E. BOOKER}

Appointment to the Knox County Regional Solid Waste Planning Board, Knox County, Tennessee

\section{D. BURTIS}

Distinguished Administrative Achievement Award, ESD; Operations Support Award, Martin Marietta Energy Systems, Inc.; Award of Achievement, category of whole periodicals, Technical Publications Competition, East Tennessee Chapter, Society for Technical Communication

\section{S. W. CHRISTENSEN}

Most Value-Able Player Award, ORNL; World-Class Teamwork Award, for contributions as a member of ESD's self-directed Geographical Information Systems Work Team, conferred by the ORNL Values Committee;
ESD Teamwork Award, for contributions as a member of the ESD Electronic Communications Committee

\section{C. COUTANT}

Election as Second Vice President, American Fisheries Society; appointment to the Award Review Panel, Science Achievement Awards program, U.S. Environmental Protection Agency; Award of Merit, category of trade/news articles, Technical Publications Competition, East Tennessee Chapter, Society for Technical Communication

\section{R. M. CUSHMAN}

Award of Achievement, category of whole periodicals, Technical Publications Competition, East Tennessee Chapter, Society for Technical Communication; Exceptional Public Service Award, U.S. Department of Energy (accepting for the Carbon Dioxide Information Analysis Center)

\section{H. DALE}

Member, Science Advisory Board, U.S. Environmental Protection Agency (term ending 1994)

\section{R. C. DANIELS}

World-Class Teamwork Award, for contributions as a member of ESD's selfdirected Geographical Information Systems Work Team, conferred by the ORNL Values Committee; Plaque for 1993 ORNL Science Honors Programs, ORNL

\section{R. K. DAVIS}

1992 Best Paper Award, Symposium for the Application of Geophysics to Engineering and Environmental Problems, Environmental and Engineering Geophysical Society 


\section{L. DEANGEILIS}

Author of the Year Award, Martin Marietta Energy Systems, Inc.; Board of Editors, Ecological Society of America; Evaluation Committee for Research in Aquatic Ecology, Swedish Natural Sciences Research Council; Award of Merit, book category, Technical Publications Competition, East Tennessee Chapter, Society for Technical Communication

\section{W. E. DOLL}

1992 Best Paper Award, Symposium on the Application of Geophysics to Engineering and Environmental Problems, Environmental and Engineering Geophysical Society

\section{N. T. EDWARDS} 1992 Best Student Poster Award, Society of Environmental Toxicology and Chemistry

\section{N. D. FARROW}

Technical Achievement Award, Martin Marietta Energy Systems, Inc.; Waste Minimization Award, DOE Oak Ridge Operations

\section{T. A. FONTAINE}

Chairman, Surface Hydrology Technical Working Group, American Water

Resources Association

C. T. GARTEN, JR.

Appointment as Associate Editor, Journal of Environmental Radioactivity

D. D. GATES

National Urban League Black Executive Exchange Program, National Urban League

\section{R. L. GRAHAM}

Appointment to review panel, Environmental Monitoring and
Assessment Program, U.S. Environmental Protection Agency; Invitation to serve on the Review Panel, Forest/Rangeland/Crop Ecosystem Competitive Grants Program, U.S. Department of Agriculture; Chairperson, Technical Steering Committee, Center for Forest Environmental Studies, U.S. Department of Agriculture Forest Service; World-Class Teamwork Award, for contributions as a member of ESD's self-directed Geographical Information Systems Work Team, conferred by the ORNL Values Committee

\section{J. M. GREBMEIER}

Appointment to Ocean Atmosphere-Ice Interactions Science Steering Committee, Arctic System Sciences National Science Foundation; Appointment to Committee on the Bering Sea Ecosystem, National Research Council

\section{S. M. GREGORY}

Distinguished Technical Achievement Award, ESD

\section{N. A. GRIFFITH}

World-Class Teamwork Award, for contributions as a member of ESD'r selfdirected Geographical Information Systems Work Team, conferred by the ORNL Values Committee

\section{J. B. HARPER}

ESD Teamwork Award, for contributions as a member of the ESD Electronic Communications Committee

R. D. HATCHER

President, Geological Society of America

\section{F. M. HOFFMAN}

ESD Teamwork Award, for contributions as a member of the ESD Electronic Communications Committee 


\section{R. A. HOPKINS}

1992 Best Paper Award, Symposium

for the Application of Geophysics

to Engineering and Environmental

Problems, Environmental and Engineering

Geophysical Society

\section{A. M. HOYLMAN}

Student Travel Award, Foundation for Environmental Education, Society of Environmental Toxicology and Chemistry; 1992 Best Student Poster Award, Society of Environmental Toxicology and Chemistry

\section{D. HUFF}

Appointment as Finance Chairperson, 1994 National Symposium, American

Water Resources Association

\section{T. HUNSAKER}

Chair, Applied Ecology Section, Ecological Society of America; Directorat-Large, Board of Control, Water Environment Federation; World-Class Teamwork Award, for contributions as a member of ESD's self-directed Geographical Information Systems Work Team, conferred by the ORNL Values Committee

\section{J. M. KELLY}

Fellow, Soil Science Society of America

\section{N. E KORTE}

Appointment to the High School GrantIn-Aid Committee, Arizona-Nevada Academy of Science; appointment to the Outstanding Science Teacher Award Committee, Arizona-Nevada Academy of Science; Waste Minimization Award, DOE Oak Ridge Operations

\section{A. KSZOS}

Appointment to Ecology Committee, Water Environment Federation

\section{L LARSEN}

Distinguished Operational Achievement Award, Inaugural Award, ESD; Patent No. 5229604, U.S. Patent Office

\section{A. LEVINE}

World-Class Teamwork Award, for contributions as a member of ESD's self-directed Geographical Information Systems Work Team, conferred by the ORNL Values Committee

\section{S. E LINDBERG}

President's Award for Continuous Improvement, Martin Marietta Energy Systems, Inc.

\section{W. LITTLETON}

ESD Teamwork Award, for contributions as a member of the ESD Electronic Communications Committee

\section{J. F. McCARTHY}

1992 Editors' Citation for Excellence in Refereeing Technical Papers, American Geophysical Union; appointment to the Scientific Review Panel, Waste Isolation Pilot Project, DOE

\section{R. A. McCORD}

World-Class Teamwork Award, for contributions as a member of ESD's selfdirected Geographical Information Systems Work Team, conferred by the ORNL Values Committee

\section{J. MORRIS}

Award of Achievement, category of organizational manuals, Technical Publications Competition, East Tennessee Chapter, Society for Technical Communication

\section{P. J. MULHOLLAND}

Award of Merit, category of scholarly/professional articles, Technical 
Publications Competition, East

Tennessee Chapter, Society for Technical Communication

\section{T. NANEY}

President's Award for Continuous

Improvement, Martin Marietta Energy

Systems, Inc.

\section{R. J. NORBY}

Scientific Achievement Award, ESD; appointment to Editorial Review Board, Tree Physiology

\section{J. E NYQUIST}

Best Paper Award, Annual Symposium for the Application of Geophysics to Engineering and Environmental Problems, Environmental and Engineering Geophysical Society (accepting for coauthors)

E. G. O'NEILL

Delegate to ORNL Committee for Review of DOE Programs for Women

\section{P. D. PARR}

Award of Excellence, poster category, Art Competition, East 'Tennessee Chapter,

Society for Technical Communication

\section{W. M. POST III}

ESD Teamwork Award, for contributions as a member of the ESD Electronic Communications Committee

\section{A. W. RENSHAW}

YWCA Tribute to Women Award, Science and Technology Category; Winter '93 Martin Marietta Energy Systems, Inc., Equal Employment Opportunity Award; appointment as chairperson, 1993-94 Educational Foundation, American Association of University Women; Award of Merit, category of periodic activity reports, Technical Publications
Competition, East Tennessee Chapter, Society for Technical Communication

\section{B. M. ROSS}

Award of Achie ement, category of organizational manuals, Technical Publications Competition, East Tennessee Chapter, Society for Technical

Communication

\section{J. SALE}

President-Elect, Tennessee Section, American Water Resources Association; appointment to committee on Water, Law, Science, and Policy Issues, American Water Resources Association

\section{S. SALK}

Award of Achievement, category of whole periodicals, Technical Publications Competition, East Tennessee Chapter, Society for Technical Communication

\section{T. K. SAWYER}

Operations Support Award, Martin Marietta Energy Systems, Inc.

\section{R. J. SEPANSKI}

Award of Merit, category of technical reports, Technical Publications

Competition, East Tennessee Chapter, Society for Technical Communication

\section{F. E SHARPLES}

Election to rank of Fellow, American Association for the Advancement of Science; appointment to second 3-year term on the Committee on Science, Engineering, and Public Policy, American Association for the Advancement of Science

\section{E. SHEPHERD}

ESD Teamwork Award, for contributions as a member of the ESD Electronic Communications Committee 
L. R. SHUGART

Member, Expert Group on Scoping Document; member, Expert Group on Indicators of Marine Ecosystem Health

\section{R. L. SIEGRIST}

Significant Event Award, ORNL; appointment to the Groundwater Committee, Water Environmental Federation; appointment as Contributing Editor, Journal of Environmental Engineering, American Society of Civil Engineers

\section{L SIGAL}

President's Award for Continuous Improvement, Martin Marietta Energy System, Inc.

\section{F. SIGMON}

Distinguished Service, Association for Women in Science

\section{K. SOLOMON}

1992 Alumni Gold Award, University of Waterloo, Ontario, Canada

\section{F. W. STOSS}

Award of Merit, category of technical reports, Technical Publications Competition, East Tennessee Chapter, Society for Technical Communication; Award of Achievement, category of whole periodicals, Technical Publications Competition, East Tennessee Chapter, Society for Technical Communication; Award of Achievement, category of newsletters, Technical Publications Competition, East Tennessee Chapter, Society for Technical Communication

\section{S. H. STOW}

Member-at-Large, Executive Committee, American Geological Institute

\section{J. M. STRONG-GUNDERSON}

Award of Achievement, category of scholarly/professional articles,
Technical Publications Competition, East Tennessee Chapter, Society for Technical Communication; ESD Teamwork Award, for contributions as a member of the ESD Electronic Communications Committee

\section{B. K. THOMPSON}

World-Class Teamwork Award, for contributions as a member of ESD's self-directed Geographical Information Systems Work Team, conferred by the ORNL Values Committee

\section{S. P. TIMMINS \\ World-Class Teamwork Award, for contributions as a member of ESD's self-directed Geographical Information Systems Work Team, conferred by the ORNL Values Committee}

\section{G. TURNER}

Selection to serve on the Ecosystem Panel (3-year term), National Science Foundation; Editorial Board, Landscape Ecology; Terrestrial Ecology Technical Fanel, National Aeronautics and Space Administration

\section{B. T. WALTON}

Center for Ecological Health Research Science Advisory Committee, University of California, Davis; 1992 Best Student Poster Award, Society of Environmental Toxicology and Chemistry

\section{J. A. WATTS}

Significant Achievement Award, ESD; WATTec Service Award, WATTec Sponsors Committee

\section{C. WHITE}

1993 Procter and Gamble Award in Applied and Environmental Microbiology, American Society for Microbiology; election to American Academy of Microbiology 


\section{T. W. WHITE}

World-Class Teamwork Award, for contributions as a member of ESD's selfdirected Geographical Information Systems Work Team, conferred by the ORNL Values Committec

\section{F. WICKER}

World-Class Teamwork Award, for contributions as a member of ESD's selfdirected Geographical Information Systems Work Team, conferred by the ORNL Values Committee

\section{R. A WINTERFIELD}

World-Class Teamwork Award, for contributions as a member of ESD's selfdirected Geographical Information Systems Work Team, conferred by the ORNL Values Committee

\section{A. WOOD}

World-Class Teamwork Award, for contributions as a member of ESD's selfdirected Geographical Information Systems Work Team, conferred by the ORNL Values Committee 


\section{International Activities}

ESD staff have developed a sound base of international activities and work with a variety of foreign governments and research organizations. Following is a list of the FY 1993 activities.

- Participation in a research coordination meeting in Vienna on the validation of environmental transfer models for radionuclides. Representatives from 27 countries attended the meeting, which was sponsored by the International Atomic Energy Agency in July 1993 (B. G. Blaylock)

- Participation in the Sixth Science Team Meeting for Joint Research on Greenhouse Effect in Beijing in September 1993 and a meeting with scientists at the Research Center for Eco-Environmental Sciences (T. A. Boden)

- Development of environmental compliance assessment manuals with Headquarters, U.S. Army Europe, and assistance in the use of these manuals in pilot assessments. Because of their vast experience in environmental compliance assessment, ESD personnel are also helping to restructure USAREUR's entire environmental compliance assessment program (B. E. Booker, C. G. Heckman, and C. F. Sigmon)

- Discussions with scientists in Japan as part of a U.S.-Japan collaborative research program sponsored by the National Science Foundation. The principal topics were the mathematical analysis of direct and indirect effects in complex systems of interacting populations; termite-microbial-detritus systems; and large-scale modeling by researchers at Lake Biwa Research
Institute, the Center for Ecological Research of Kyoto University, and several Japanese universities in and around Kyoto (T. P. Burns and B. C. Patten)

- Presentations at an international symposium on Applications of Isotope Techniques in Studying Past and Current Environmental Changes in the Hydrosphere and the Atmosphere, held at the International Atomic Energy Agency in Vienna in April 1993. The ESD researchers also participated in an informal follow-up workshop hosted by the Forschungzentrum -ir Unwelt and Gesundheir in Neuherberg, Germany (L. W. Cooper and J. M. Grebmeier)

- Participation on two oceanographic research cruises in the Bering, Chukchi, and Beaufort seas. In July and August 1993, researchers collected samples in support of the U.S. Navy Office of Naval Research's program assessing Arctic radionuclide contamination. In August and September 1993, scientists from the Institute of Global Climate and Ecology of the Russian Academy of Sciences and the Far Eastern Research Institute in Vladivostok, Russia, worked jointly with 26 American and Canadian scientists aboard the marine vessel Ocean. ESD researchers collected water and sediment samples relating to the Arctic radionuclide contamination problem, conducted experiments on sediment oxygen metabolism incubation for a University of Tennessee project supported by the National Science Foundation, and incubated viral DNA solutions under in situ ultraviolet light conditions to follow up earlier work supported by the Oak Ridge 
Seed Money Program (L. W. Cooper and J. M. Grebmeier)

- Participation in a 2-week research cruise on the Black Sea in March 1993. In cooperation with the P. P. Shirshov Institute of Occanology and the Institute of Energy Problems of Chemical Physics, researchers investigated the biological and biogeochemical consequences of increased ultraviolet radiation on marine productivity. ORNL-led studies included assays for DNA damage in phytoplankton, deployment of molecular (DNA) dosimeters, and sediment coring activities that will be used to search for possible changes in ultraviolet radiation over time (L. W. Cooper, J. M. Grebmeier, L. Shugart, and J. Mural)

- Collaboration with the All-Russian Research Institute of Hydrometeorological Information-World Data Center in Obninsk, Russia, to produce Selected Translated Abstracts of Russian-Language Climate-Change Publications: II. Clouds, the second in a series of four dual-language bibliographies of important Russian climate change literature. This project was conducted under the auspices of a 1972 U.S.-U.S.S.R. agreement on protection of the environment (R. M. Cushman)

- Presentation of an invited paper at a workshop on Data Management for Global Environmental Studies, part of the joint meeting of the International Association of Meteorology and Atmospheric Physics and the International Association of Hydrological Sciences in Yokohama, Japan, in July 1993 (R. M. Cushman)
- Visit to Manaus, Brazil, on an exchange program between The University of Tennessee in Knoxville and the University of Amazonas in August 1993. The program's objective is to promote communication between the two institutions and to enhance scientific research among institutions in the two cities. The program's theme is how social and environmental sciences can jointly address policy issues (V. Dale)

- Appointment to the Swedish Natural Science Research Council's Evaluation Committee for Research in Aquatic Ecology. The appointee critiqued numerous research reports and participated in formal evaluations in Sweden during the fall of 1993 (D. L. DeAngelis)

- Visit to Moscow in September 1993 to attend the Mission to Planet Earth Workshop sponsored by the National Aeronautics and Space Administration. Participants discussed the use of remote sensing in boreal forests to learn more about their role in global environmental change (W. R. Emanuel)

- Meeting in Sheffield, England, in December 1993 with the Fossil Fuel Era Working Group of the Global Analysis, Interpretation, and Modeling Task Force of the International Geosphere-Biosphere Program to pursue how the coupling of plant productivity models treats photosynthetic processes (W. R. Emanuel)

- Collaboration with Ronit Nativ, a visiting scientist from Israel, in a study of the groundwater system on the 
Oak Ridge Reservation (ESD hydrogeologists)

- Presentation of invited lectures, "Dynamic Mechanisms for the Development of Terrestrial Ecosystems" and "Biodiversity and Stability of Tropical Forests," at two symposia within the Ecology and Environmental Botany Section of the 15th International Botanical Congress in Yokohama, Japan, August 1993. The researcher also discussed models of tree growth and physiology, artificial life and computer modeling, and the use and misuse of tropical rainforests by indigenous peoples (M. A. Huston)

- Participation in meetings on global change and environmental data management that were attended by representatives from the National Aeronautics and Space Administration; the Russian Space Academy; and other U.S., Russian, French, and German agencies. The meetings were held aboard a cruise ship sailing between Moscow and St. Petersburg in May 1993 (P. Kanciruk)

- Trip to Beijing in September 1993 to attend a meeting of the International Council of Scientific Unions' Panel on World Data Centers, which convened to consider establishing a World Data Center for Atmospheric Trace Gases at ORNL (P. Kanciruk)

- Attendance at the Fourth International Conference on $\mathrm{CO}_{2}$ Measurements and Analysis in Carqueiranne, France, in September 1993 (A. W. King)

- Presentation of an invited paper, "The Last Two and One-Half Hours of Creation," at an International
Workshop on Terrestrial Biospheric Fluxes on terrestrial carbon budgets and fluxes, in Bad Harzberg, Germany, in March 1993. The paper was also presented at a conference on ecophysiology and genetics of trees and forests in a changing environment, held in Viterbo, Italy, in May 1993 (R. J. Luxmoore)

- Chair of a symposium and presentation of a paper, "Homeostasis and SoilPlant Nutrient Relationships in a Changing Environment," at the 15th International Botanical Congress, in Yokohama, Japan, in August 1993 (R. J. Luxmoore)

- Participation in a workshop in As Jose Dos, Brazil, in March 1993 to discuss the inventory of emissions of carbon gases from anthropogenic sources (G. H. Marland)

- Participation in discussions on how to improve international energy data bases and their utility for estimating greenhouse gas emissions. The discussions were conducted at the International Atomic Energy Agency in Vienna in April 1993

(G. H. Marland)

- Presentation of a paper, "Effect of Interhemispheric Carbon Transport on Global Carbon Cycle," at the Ocean Science Institute in Sidney, British Columbia, Canada, in November 1992 (T.-H. Peng)

- Presentation of a paper, "Sensitivity Evaluation for Oceanic Uptake of Fossil Fuel $\mathrm{CO}_{2}$ Based on Global ${ }^{13} \mathrm{C}$ Distribution," at the International Conference on Global AtmosphericBiospheric Chemistry in Eilat, Israel, in April 1993 (T.-H. Peng) 
- Presentation of a paper, "Regarding Ocean $\mathrm{CO}_{2}$ Uptake Based on ${ }^{14} \mathrm{C}$ Distribution in the Ocean," at the Weizmann Institute of Science in Rehovot, Israel, in April 1993 (T.-H. Peng)

- Trip to Carqueiranne, France, in September 1993 to present a paper, "Inventories of Bomb-Produced ${ }^{14} \mathrm{C}$ in the Ocean, ${ }^{\prime}$ at the Fourth International $\mathrm{CO}_{2}$ Conference (T.-H. Peng)

- Invitation to present a seminar on microbial ecology and in situ bioremediation of toxicants in subsurface sediments at the University of Konstanz, Germany, in September 1993 (T. J. Phelps)

- Invited speakers at the Second International Symposium on Subsurface Microbiology in Bath, England, in September 1993 (T. J. Phelps and A. V. Palumbo)

- Participation in a workshop in Berlin evaluating the role of nonliving organic matter in the earth's carbon cycle in September 1993 (W. M. Post)

- Presentation at the Seventh European Conference of Biomass Energy and the Environment in Florence, Italy, in November 1992. An ESD researcher summarized the results of current environmental research on energy crops in a paper entitled "Can Biomass Energy Crops Really Improve Overall Environmental Quality?" (J. W. Ranney)

- Member of an expert group that met in Geneva in November 1992 to prepare a document on indicators of n. srine ecosystem health for the
U.N. Environmental Program

(L. R. Shugart)

- Collaboration with Russian Academy of Sciences (RAS), January-March 1993 , on research on the effects of UV-B light on primary productivity and geochemical processes in the Black Sea, including a 2-week oceanographic cruise in the Black Sea with the RAS Institute of Oceanology in Gelendyhik, Russia (L. R. Shugart)

- Trip to Kwajalein Island, Republic of the Marshall Islands, in December 1992 to provide continued support of the Bioremediation Demonstration (R. L. Siegrist)

- Continued collaboration with the Norwegian Centre for Environmental Research concerning the measurement and transport and fate of volatile organic matter in soil and groundwater (R. L. Siegrist)

- Invited speaker and workshop participant at the 13th Annual Meeting of the International Association for Impact Assessment in Shanghai, China, June 1993. The traveler's paper and workshop discussion focused on policylevel environmental impact assessment and the integration of the concept of sustainability (L. L. Sigal)

- Chair of a session at the Geoconfine '93, Geology and Confinement of Toxic Waste International Conference, held in Montpellier, France, in June 1993 (S. H. Stow)

- Chair of a commission finalizing a report to be distributed internationally on the siting of hazardous waste disposal facilities in Krakow, Poland, in September 1993 (S. H. Stow) 
- Participation in the International Workshop on Terrestrial Biospheric Fluxes in Bad Harzburg, Germany, in March 1993. Invited papers were presented at the meeting, which was designed to develop a series of synthesis reports on carbon pool sizes, fluxes, and anticipated changes in carbon pools and fluxes for major terrestrial ecosystems (L. L. Wright and R. J. Luxmoore) 


\section{Research and Development Subcontracts and Interagency Agreements}

\section{O. J. Grooms}

Presented here are the businesses and organizations with whom ESD had a subcontract or interagency agreement during this reporting period. The ESD researcher who served as technical contact is given in parentheses after the title of the project.

Advanced Sciences Group, Inc.

Provide ESD with technical assistance in assessing environmental impacts of the DOE Integrated Environmental Restoration and Waste Management Program (L. W. Barnthouse)

Provide experienced biologist/chemist to support the remediai investigation for Waste Area Grouping at ORNL and components of the Biological Monitoring and Abatement Program (BMAP) at Y-12 (H. L. Boston)

Provide technical help and expertise in the area of ion chromatography and chelate chemistry (P. M. Jardine)

Provide experienced biologist to assist with the collection and processing of environmental samples (L. A. Kszos and A. J. Stewart)

Amana Society, Inc. Establishment and maintenance of silver maple monoculture viability trials (L. L. Wright)

American Water Resources Association Support for the 1992 International Conference and Symposia on
"Managing Water Resources During Global Change" (D. S. Shriner)

Analysas Corporation Geographic Information Analysis and Computer Programming

(C. T. Hunsaker)

Technical support in geographic information and analysis of effects of acidic deposition on aquatic resources (R. S. Turner)

Arizona, University of Analysis and modeling of hydrology and particle transport in support of a DOE project on field mobility of colloidal particles (J. F. McCarthy)

Auburn University

Development of optimal establishment and cultural practices for switchgrass as an energy crop (S. B. McLaughlin)

Automated Sciences Group, Inc. Technical support of a physiological ecologist for analysis on effects of stress on aquatic organisms (S. M. Adams)

Technical support of a laboratory biochemist in assays and measurement of biological and sediment samples (S. M. Adams)

Develop and adopt geophysical methods for the solution of problems in radioactive and hazardous waste management (R. B. Dreier) 
Provide technicial services support of regulatory and policy analysis activities of the Environmental Assessment Group in planning, organizing, and developing meetings, documents, and training materials (L. L. Sigal)

\section{Avalon Consultants}

Discuss capabilities with the ARM Archive Team on aspects of the Unitree storage management software for the ARM Archive (P. T. Singley)

Battelle Pacific Northwest Laboratory Support in the application of in situ vitrification at ORNL (G. K. Jacobs)

Brooks Rand, Ltd.

Chemical analysis of methylmercury water samples (G. R. Southworth and R. R. Turner)

\section{California, University of} Quantitative histopathological analysis of selected organs of fish collected as a component of the BMAP, Clinch River environmental restoration projects, and the Hartwell project (S. M. Adams)

Explores the feasibility of using growth enhancers developed at Los Alamos National Laboratory to increase biomass yields in woody and herbaceous energy crops (G. A. Tuskan)

\section{CER Corporation}

Provide support for compliance assessments of Holloman, Barksdale, and Beale Air Force bases

(C. F. Sigmon)

Assist in environmental compliance assessment of Ellsworth, Fairchild, and Ki Sawyer Air Force bases

(C. F. Sigmon)
Support compliance assessments at Seymour Johnson, Offutt, Shaw, and Whiteman Air Force bases (C. F. Sigmon)

Clarion University of Pennsylvania Quantitative analysis of estrogen receptor binding capacity and kinetics of liver cells from fish collected in conjunction with the Hartwell Reservoir study, the BMAP investigation of East Fork Poplar Creek, and the Clinch River Environmental Restoration Program (M. S. Greeley)

\section{Clemson University} Complete DOE-sponsored field injection experiment and initiate hydrologic characterization of a new field site (J. F. McCarthy)

\section{Colorado State University}

Involvement with the National Atmospheric Deposition Program that requires sample analysis by a central analytical laboratory for comparability of data on atmospheric deposition on a national scaic (S. C. Lindberg)

Learn more about the environmental issues associated with large acreages of short-rotation woody crop (SRWC) plantations (L. L. Wright)

Cornell University Support services for coordinator for EPRI COMPMECH Key Species Project on Percids (W. Van Winkle)

\section{Duke University}

Authorize funding to cover student support for ESD (D. S. Shriner) 


\section{Energy Performance Systems}

Analysis and reviews on how to match the objectives of the Short Rotation Woody Crops Program with the needs of potential utility users of wood (L. L. Wright)

\section{Environmental Careers Organization Assist with the coordination of the Environmental Monitoring and Assessment Program's (EMAP) ecological indicators effort and contribute to landscape characterization tasks (C. T. Hunsaker)}

Hawaii Geothermal EIS-act as GIS analyst (C. T. Hunsaker)

Assist with Environmental Compliance Assessment Tasks at Grand Forks Air Force Base (C. F. Sigmon)

Provide assistance with USAF Environmental Compliance Assessment Tasks at Holloman, Moody, Offutt, Shaw, and Whiteman Air Force bases (C. F. Sigmon)

Provide summer internships for three students from Fort Valley State College for Environmental Toxicology, Environmental Analysis, and Ecosystem Studies sections (S. H. Stow)

\section{Environmental Systems \& Technologies}

Provide modeling services to evaluate the effectiveness of the UVB system in the in situ remediation of groundwater contamination (P. M. Kearl)

Geo/Resource Consultants, Inc. Provide technical assistance in developing and implementing training in environmental laws and regulations, perform regulatory analyses and develop compliance guidance, and perform environmental compliance assessments at federal facilities (F. E. Sharples)

Georgia Institute of Technology Assist ORNL in concentrating natural organic matter (NOM) from groundwater for a DOE project on characterization and microbial utilization of NOM (J. F. McCarthy)

Georgia, University of Cosponsorship of the 1993 U.S. National Rapeseed Variety Trials (J. H. Cushman)

Optimizing energy yields in black locust through genetic selection (G. A. Tuskan)

Huntsman Marine Science Provide services of coordinator for the Flatfish Key Species Project, which is part of the EPRI-funded Program on Compensatory Mechanisms in Fish Populations (COMPMECH) (W. Van Winkle)

ICF Technology, Inc.

Technical support in reviewing environmental documents (E. D. Smith)

Idaho, University of Landscape pattern analysis, EPAEMAP (C. T. Hunsaker)

\section{Indiana University}

Student support for Environmental Analysis Section (S. G. Hildebrand)

\section{Iowa State University} Support in selection of forage species for energy crops in the Great Plains (A. F. Turhollow)

Breeding clones for intensive culture of biomass for energy (part of DOE's 
Short Rotation Woody Crops Program)

(G. A. Tuskan)

Iowa, University of

Assistance to ORNL researchers-

co-occurrence statistics (S. H. Stow)

\section{JAYCOR}

Provide written comments on a Notice of Proposed Rulemaking (C. F. Baes)

Provide technical support for field, laboratory, and data management aspects of the reservation-wide waterfowl program (H. L. Boston)

Provide technical support for laboratory and data management for the Biological Monitoring and Abatement Program and the Remedial Investigation of ORNL Waste Area Grouping (WAG 2 RI) (H. L. Boston)

Process benthic macroinvertebrate samples collected from McCoy Branch near the Y-12 Plant and several streams near the Paducah Gaseous Diffusion Plant (J. M. Loar)

Process benthic macroinvertebrate samples collected from East Fork Poplar Creek and Bear Creek near the Y-12 Plant and several reference streams on and off the Oak Ridge Reservation (J. M. Loar)

Process benthic macroinvertebrate samples collected from Mitchell Branch at the K-25 Site (J. M. Loar)

Effort of receiving, coordinating, documenting, and conducting environmental survey requests on the Oak Ridge Reservation (P. D. Parr)
Provide support in the category of Environmental Biology (Task Title: Fish Support Studies) (M. G. Ryon)

Provide ESD with support in the category of Environmental Biology (Task Title: Environmental Regulatory Analysis) (F. E. Sharples)

Provide Associate Environmental Biologist support (Task Title:

Regulatory Analysis, Update, and

Environmental Surveys)

(F. E. Sharples)

Provide ESD with on-site support in the category of Environmental Biology (G. R. Southworth)

Kentucky, University of

Conduct field study on biomass production by fescue and switchgrass alone and in mixed swards with legumes (J. H. Cushman)

\section{Knoxville College}

Technical support for studies of biological communities and instream toxicity in East Fork Poplar Creek (H. L. Boston)

Support in studies of the biodegradation of polychlorinated biphenyls (H. L. Boston)

\section{Michigan State University}

Research on plant biological diversity in a short-rotation Populus landscape using data collected at the Kellogg long-term ecological research site (J. W. Ranney)

Support for "Early Selection Criteria and Clonal Propagation" as part of DOE's Short-Rotation Woody Crops Program (G. A. Tuskan) 
Minnesota, University of

Allow the Biofuels Feedstock

Development Program (BFDP) to participate in the Aspen Genetics Cooperative, thereby gaining access for the BFDP and its subcontractors to data on hybrid aspen growth and performance and to superior clones of aspen for research purposes (G. A. Tuskan)

\section{Mississippi State University}

Technical support in early selection criteria and clonal propagation systems (J. W. Johnston)

\section{National Audubon Society}

Evaluate bird diversity in energy plantations and investigate policy options that will encourage biodiversity of these plantations throughout the United States (J. W. Ranney)

National Oceanic and Atmospheric Administration Global historical climate network (R. M. Cushman)

North Carolina, University of Support research on toxicant-degrading microorganisms in the rhizosphere of plants and the potential use of oleophilic fertilizers for bioremediation of chemically contaminated surface soils (B. T. Walton)

North Dakota State University Support on the selection of forage species for energy crops in the Great Plains (A. F. Turhollow)

\section{Oak Ridge Associated Universities} Provide postdoctoral services for ESD to support short-term programmative needs in areas where staff capability and/or funding uncertainties preclude ORNL staff commitments (S. E. Herbes)

Provide support for the Savannah River integrated demonstration of TCE degradation by assisting in the monitoring of bioremediation (T. J. Phelps)

\section{Oak Ridge Research Institute}

Instream monitoring and technical support in the field of aquatic bioassays (L. A. Kszos)

Provide for a short-term laboratory technician for the analysis of samples obtained from the Black Sea, Russia (L. R. Shugart)

OtJahoma State University

Breeding and selection of new switchgrass varieties for increased biomass production (S. B. McLaughlin)

Maintain Populus germ plasm collection for use in tree breeding programs within the Biofuels Feedstock Development Program (G. A. Tuskan)

\section{Research Triangle Institute}

Provide personnel to develop and present training materials on the economic procedures involved in Natural Resource Damage Assessment for a series of workshops on Natural Resource Trusteeship and Ecological Evaluation (F. E. Sharples)

Roane State Community College Student support for fieldwork (R. J. Norby)

\section{Rochester, University of}

Analysis of tritium and helium isotopes in groundwater (D. K. Solomon) 
Analysis of groundwater samples

(D. K. Solomon)

Science \& Technology, Inc.

Technical services for Environmental

Training and Analysis of regulations

(F. E. Sharples)

\section{Science Applications International Corporation}

Assist in the review of literature relating to the effects of water velocity on survival of migrating juvenile salmon (G. F. Cada)

Provide services of one scientific database manager in the Data Systems Group of the Carbon Dioxide Information Analysis Center (R. M. Cushman)

Provide on-site junior-level data management support (M. A. Huston)

On-site junior-level data management support for Y-12, Bear Creek study, and Walker Branch (M. A. Huston)

Assist with obtaining data and perform socioeconomic analyses at the Wilsonville, Alabama, Coal Liquefaction R\&D facility (N. E. Korte)

Provide off-site programming support for enhancements to and preparation of documentation for the Carbon Dioxide Information Analysis Center's RequestResponse-Record Database System (T. R. Nelson)

\section{Shirshov Institute of Oceanology}

Covers rental cost of oceanographic research vessel for the Institute of Oceanology, Moscow, Russia, optical data collections data report, and final report in relation to ORNL-supported research in the Black Sea in 1993

(S. E. Lindberg)

South Alabama, University of Coordination of the Striped Bass and Bay Anchovy Key Species Projects (W. Van Winkle)

\section{Southern Illinois University}

Genetic biomass and growth analysis of clonal silver maple in several locations (L. L. Wright)

\section{State University of New York}

Participate in a University/Industrial Consortium for the production of bioenergy from hybrid willow plantations: Specific subcontracting for the nursery scale-up of improved hybrid willow clones (G. A. Tuskan)

Systematic Management Services, Inc. Provide special expertise for ensuring the proper sequencing and integration of NE-33 Environmental Program Activities (G. K. Eddlemon)

\section{Tennessee Technological University}

Participate in waste-related research project designed to test the efficacy of using created wetlands to lower toxicity and sulfate concentrations in sulfaterich wastewater at Oak Ridge DOE facilities (A. J. Stewart)

Tennessee, The University of Provide for undergraduate assistant support (S. M. Adams and C. W. Gehrs)

Provide for an Oceanographic Data Analyst with training and experience aboard oceanographic research vessels and handling of oceanographic measurements (T. A. Boden) 
Provide support for Dr. Lisa Shevenell to serve as a hydrogeologist in support of environmental restoration and ORHSP activities at ORNL (R. B. Clapp)

Perform X-ray fluorescence and diffraction analyses on sediment samples collected from the Clinch River and Watts Bar Reservoir (R. B. Cook)

Provide assistance in limnological, sedimentological, and water-qualityrelated data collection, sample preparation and analysis, task coordination, and reporting in relation to the Clinch River Environmental Restoration Program (R. B. Cook)

Provide assistance for Clinch River RCRA Facility (R. B. Cook)

Provide the services of an Information Assistant based on specific training in the areas of database computer applications and communication work (R. M. Cushman)

Provide the services of an Information Assistant based on specific training in the areas of database computer applications, global change scientific information, and communications work (R. M. Cushman)

Provide the services of an Information Specialist based on specific training in the areas of scientific data publication and information science (R. M. Cushman)

Provide the services of a Scientific Data Coordinator based on training in the areas of development and analysis of environmental data bases

(R. M. Cushman)

Provide the services of a Scientific Data Coordinator (three separate contracts) based on training in the areas of development and analysis of environmental data bases (R. M. Cushman)

Provide the services of a Personal Computing Specialist based on training and experience in the area of personal computer hardware and software systems (R. M. Cushman)

Provide technical assistance in the CDIAC program administration (R. M. Cushman)

Provide technical assistance in the CDIAC data analysis and manipulation (R. M. Cushman)

Provide research programs with computer programming support in ESD (D. L. DeAngelis)

Technical support on groundwater monitoring compliance at Y-12 and the Oak Ridge Reservation (R. B. Dreier)

A cooperative venture between ESD and The University of Tennessee Graduate Program in Geological Sciences (R. B. Dreier)

Provide services for projects related to groundwater monitoring compliance at the Oak Ridge Y-12 Plant and to the Oak Ridge Reservation Hydrologic and Geologic Study (ORRHAGS) (R. B. Dreier) 
Provide UT support services for projects related to groundwater monitoring compliance at the Oak Ridge Y-12 Plant and to the Oak Ridge Reservation Hydrologic and Geologic Study (ORRHAGS) (R. B. Dreier and D. D. Huff)

Initiate studies with the long-term objective to characterize the viable biomass, community structure, and nutritional status of microbiota associated with the different MCB field plots at SRL using in situ signature lipid analysis (N. T. Edwards)

Initiate studies with the long-term objective to correlate the frequency and activity of oxygenase genes in rhizosphere microbial populations with degradation and/or mobilization of TCE under various treatment regimes of the MCB site, Savannah River Laboratory in Aiken, South Carolina (N. T. Edwards)

Provide ESD with the opportunity to procure research product for short-term and exploratory programmatic needs in areas where staff capability and/or funding uncertainty preclude ORNL staff commitment (D. E. Fowler)

Life Sciences Distinguished Scientist, David White (C. W. Jehrs)

Estimate changes in regional agricultural crops, fertilizer and pesticide use, and erosion with the introduction of biomass energy crops at three locations in the Midwest using a linear program model designed to maximize regional net return (R. L. Graham)
Evaluation of factors controlling microbial degradation of trichloroethylene (TCE), and for modification, operation, and scaled-up design of an innovative bench-scale bioreactor for TCE degradation (S. E. Herbes)

Perform seismic imaging of the ISV Melt (G. K. Jacobs)

Perform computational science in support of earth science research activities (G. K. Jacobs)

Allow the investigation of adsorption of heavy metals and radioelements on minerals and rocks from aqueous solutions (P. M. Jardine)

Provide for the analysis of storm effluent samples via novel ion chromatograph techniques. The techniques use state-of-the-art electrochemical detection coupled with spectral array detection to quantify reactive tracers in complex aqueous solutions (P. M. Jardine)

Support for DOE project on groundwater colloids (J. F. McCarthy)

Development of in vitro culture systems for switchgrass (S. B. McLaughlin)

Conduct research on the role of algal and microbial communities in streams on phosphorus cycling and total metabolism. The work will be conducted in natural streams on the Oak Ridge DOE Reservation and in laboratory streams at ORNL (P. J. Mulholland)

Provide monitoring and maintenance of biodegradation experiments
(A. V. Palumbo) 
Develop DNA and RNA probes for measurement of methanotrophic bacterial populations of the integrated demonstration at the Savannah River Site (A. V. Palumbo)

Expand the number of environmental samples to be analyzed from the SRS Integrated Demonstration (A. V. Palumbo)

Assessment of bald eagle habitat sustainability of Melton Hill Reservoir and adjacent areas on ORR, including the proposed ANS site (P. D. Parr)

Microbiological and biochemical characterization of subsurface samples from DOE sites (T. J. Phelps)

Analyze microbial cultures from DOE sampling sites. Analyses will be on the thermophilic anaerobic microorganism isolated from Taylorsville Triassic Basin sediments and include characterization of the physiological types of microorganisms observed (T. J. Phelps)

Analytical preparation and determination of ${ }^{18} 0 /{ }^{16} 0$ ratio on subsurface storm water using mass spectrophotometry and hydrogeochemical evaluation of deep groundwater flow (D. K. Solomon)

Provide coordination, analysis, and reporting for the Y-12 Maynardville Exit Pathways Project and geochemical analysis for the Westbay Project (D. K. Solomon)

Provide support to analyze chlorine dynamics in upper East Fork Poplar Creek and in White Oak Creek
(A. J. Stewart)

Periphyton analyses in biomonitoring (A. J. Stewart)

Provide for historical earthquake studies as part of the Advanced Neutron Source Project (S. H. Stow)

Life Sciences Distinguished Scientist, Robert Hatcher (S. H. Stow)

Provide research assistance support in soil chemistry (S. H. Stow)

Conduct soil and water characterization studies for the wetlands component of the Bear Creek BMAP Program (C. C. Trettin)

Modify existing national interregional agricultural model to include dedicated biomass energy crops. Model will be used to address issues of how much biomass can be grown and the associated environmental and policy impacts (A. F. Turhollow)

Modify existing national interregional model to include biomassm energy cr sp activities (A. F. Turhollow)

Provide The University of Tennessee with funds to collec $\hat{i}$ and analyze data from a mature black locust provenance study planted at two sites in East Tennessee (G. A. Tuskan)

Provide on-site data management support for the Distributed Active Archive Center Project (L. D. Voorhees)

Conduct experimental research on the interaction of polycyclic aromatic hydrocarbons and microbial communities in the plant rhizosphere (B. T. Walton) 
Tennessee Valley Authority

Dynamic responses of mature forest trees to chemical and physical environmental changes

(S. B. McLaughlin)

\section{Texas A\&I University}

Technical assistance to ORNL-

Protocols for in situ remediation

(S. E. Herbes)

\section{Texas A\&M University}

Evaluation of switchgrass cultivars and cultural methods for biomass production in the southcentral United States (S. B. McLaughlin)

\section{U.S. Department of Agriculture}

Genetic variation among switchgrasses for agronomic traits, forage quality, and biomass fuel production (J. H. Cushman)

Bird and mammal usage of hybrid poplar plantations (J. W. Ranney)

Increasing yields of Populus energy plantations on Woody Biomass Program (L. L. Wright)

\section{U.S. Fnvironmental Protection Agency}

Collaborative research on bioremediation of mercury in aquatic systems (R. R. Turner)

\section{Vanderbilt University}

Develop new techniques for chemical analysis of plant tissues

(S. B. McLaughlin)

\section{Virginia Polytechnic Institute \& State}

\section{University}

Switchgrass as a biofuels crop for the upper Southeast: Variety trials and cultural improvements

(S. B. McLaughlin)

Washington, University of

Chemical analysis of soil solutions and soil extracts for ammonium and nitrate (H. Van Miegroet)

Evaluation and genetic improvement of black cottonwood for short-rotation coppice culture (L. L. Wright) 


\section{Technology Transfer}

\section{L. Lamen}

Janet Strong-Gunderson and Tony Palumbo of the Microbial Interaction Group filed a patent disclosure entitled "Natural Soil Inducers for Contaminant Degradation Released by Physical and/or Chemical Manipulations." This disclosure discusses methods for inducing trichlorethylene (TCE) degradation by cometabolic processes that do not involve the addition of hazardous chemicals such as toluene. The technique was developed from samples associated with both an industrial cleanup site and a DOE site. The work is based on the use of lux biosensors, supported by the ORNL Director's Research and Development Fund and developed by collaborators at The University of Tennessee Center for Environmental Biotechnology.

Steve Herbes and Tony Palumbo of ESD and Hal Jennings, Terry Donaldson, and Andrew Lucero of the Chemical Technology Division were the key participants in a Cooperative Research and Development Agreement (CRADA) between Martin Marietta Energy Systems, Inc., and Envirogen, a bioremediation company with headquarters in New Jersey. The agreement is to demonstrate the effectiveness of a benchscale, vapor-phase bioreactor treatment system in removing TCE from a groundwater seepage stream at the Oak Ridge K-25 Site.

T. J. Phelps, at the invitation of DOE, has been offering workshops regarding drilling and sample handling. The workshops describe the nature and usefulness of innovating drilling and sampling protocols developed by the subsurface science program of the DOE Office of Health and Environmental Research. Workshop attendees included personnel from the DOE Operations Office, environmental restoration managers, members of other government agencies, and contractors at DOE sites.

Gordon Blaylock and scientists from the former Soviet Union are investigating data on radioactivity from the Chernobyl accident along with data on the Clinch River to test predictions of hydrologic transport models. The work has included exchange visits between ESD and the former Soviet Union. 


\section{Education Activities}

\section{J. A. Watts and J. L. Seiber}

ESD continues to develop and maintain strong relationships with many educational institutions. The division provides opportunities for student and faculty guests to participate in ongoing ESD research activities. In addition, staff are encouraged to develop collaborative research programs with university and college researchers.

The ORNL Science Education and External Relations Office and the Oak Ridge Institute for Science and Education (ORISE) administers guest appointments for high school and college students, individuals who have completed master's or doctoral programs, science teachers, and university faculty. The Environmental Careers Organization and subcontracts that ESD initiates with individual universities and colleges also engender collaborative research activities with ESD researchers. Table 1 lists the educational programs that enabled students and faculty to participate in ESD research during FY 1993.

In addition to offering research opportunities for university students, ESD pays particular attention to precollege students and science teachers. The DOE High School Honors Workshop in Environmental Sciences, hosted by ESD, completed it sixth year in 1993. A total of 58 students from 48 states, Puerto Rico, and $\mathbf{8}$ foreign countries participated in the 2-week workshop. Students worked on projects concerning wildlife ecology, geochemistry, water resources, environmental toxicology, geographic information systems, human genome, biotechnology, and forestry with 59 scientists from ESD and the Energy, Health Sciences Research, and Biology divisions. Students also participated in "theme groups" to explore the complexities of a national or global issue and role-played opposing factions in public forums. Each team prepared a written report and gave an oral presentation.

ESD and the Metals and Ceramics Division hosted the DOE/Appalachian Regional Commission-sponsored Summer Science Academy for 34 students and 8 teachers from the Appalachian region. The division also hosted high school students from Puerto Rico and the East Tennessee region participating in the Summer Educational Experience for the Disadvantaged program (Project SEED), sponsored by the American Chemical Society. Science teachers from across the nation participated in a summcr research experience through the DOE Teacher Research Associate (TRAC) program.

Twenty-five middle and high school teachers participated in the 4-week Restoring Our Waters (ROW) Institute, hosted by ESD in a collaborative effort with ORISE. The institute, sponsored by DOE and the Federal Coordinating Council for Science, Engineering and Technology, aims to (1) expand teachers' knowledge of water resources, (2) assist in the development of teachers' skills in teaching concepts of water resources, and (3) illustrate the role water quality has as a tool for monitoring the contamination, pollution, and cleanup of an area.

Scientists from ORNL, The University of Tennessee, and the Tennessee Valley Authority participated in ROW's field and laboratory studies, translated high-tech science into classroom activities that could be conducted by students using simple and readily obtainable equipınent, and helped develop a hands-on curricula that the program participants could use in class. 

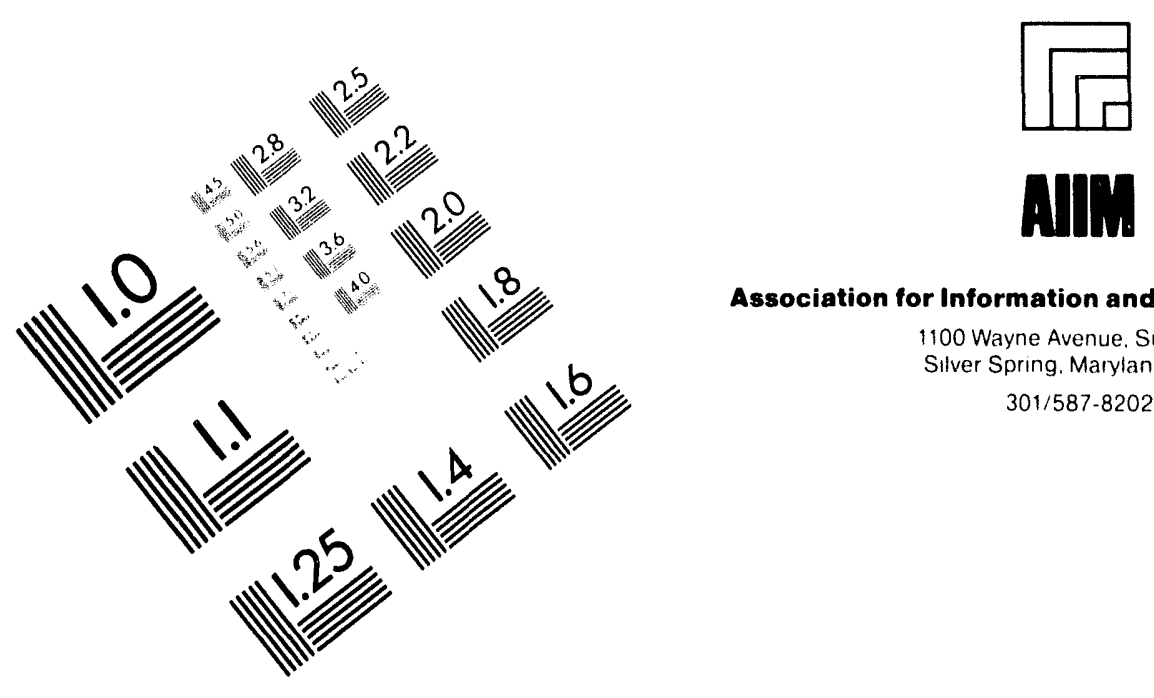

Association for Information and Image Management

1100 Wayne Avenue. Suite 1100

Silver Spring. Marytand 20910

301/587-8202

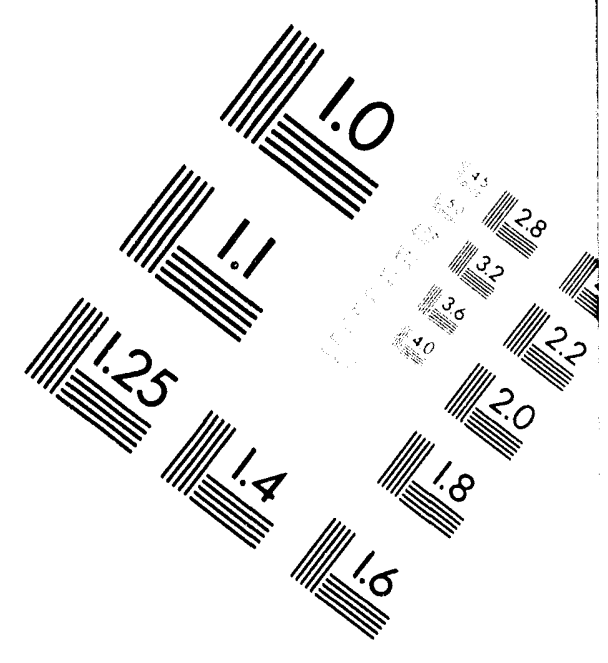

Centimeter

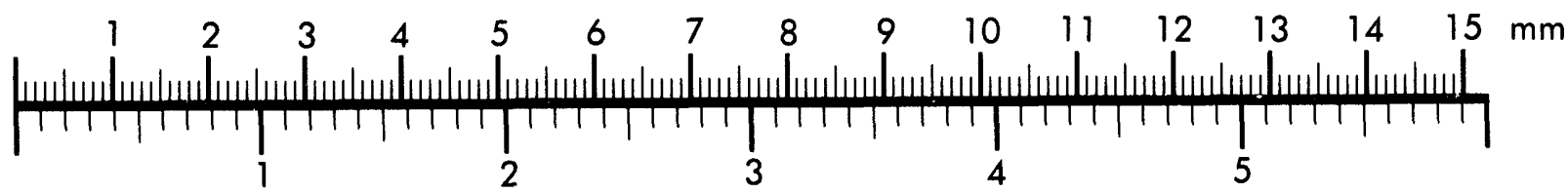

Inches

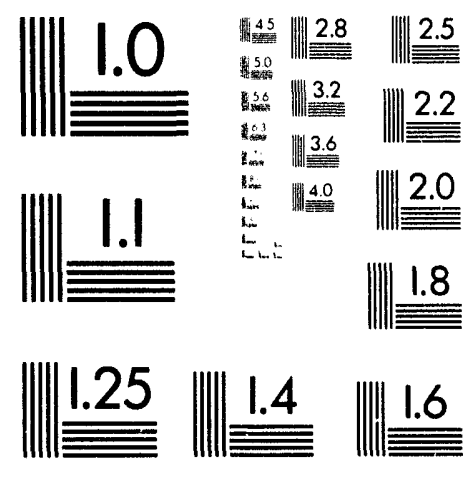

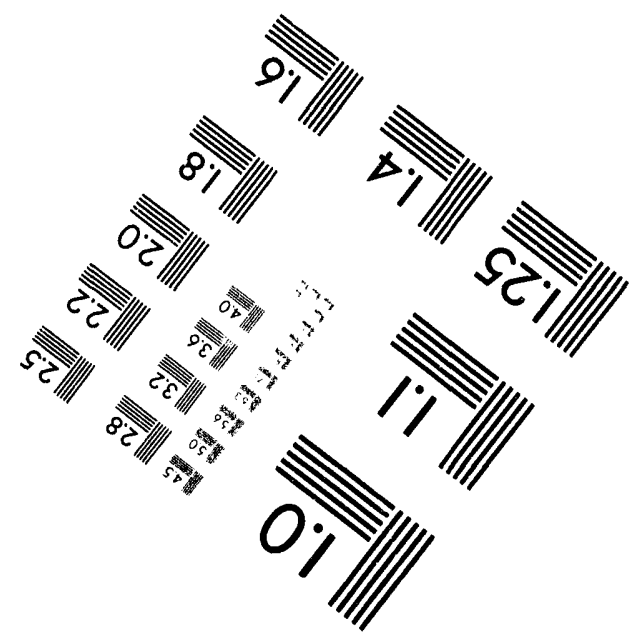

MANUFACTURED TO AIIM STANDARDS

BY APPLIED IMAGE. INC.

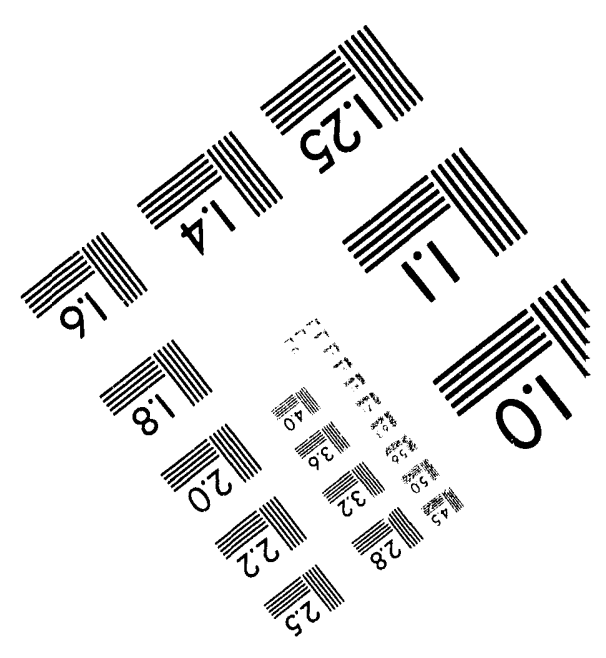



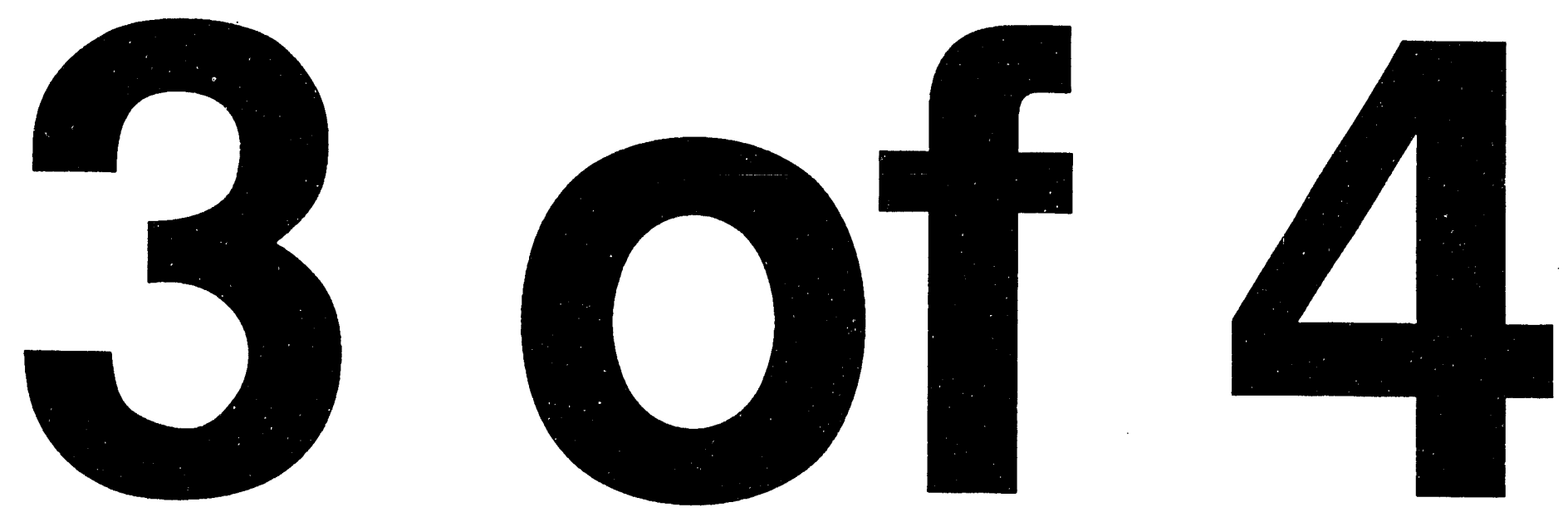
Three areas of concentration were selected: watershed concepts, water quality chemistry, and biomonitoring as a measure of success or failure in pollution cleanup. Other modules will be developed in the future.

ESD increased its efforts to attract guests from underrepresented groups in FY 1993. These efforts primarily addressed three areas: (1) increasing the participation of minority and female students in the division's education programs;

(2) encouraging minority faculty to collaborate with ESD researchers and to participate in faculty research programs in the division; and (3) providing opportunities for undergraduate and graduate minority students to work with ESD researchers.

\section{As part of a DOE Environmental} Restoration and Waste Management program, ESD hosted four students (which included two minority females and one minority male) in a joint collaboration with Xavier and Tulane universities in a 10week summer internship. From these universities two faculty members (one of whom was a minority) completed a 5-week assignment in a faculty research program. ESD staff attended career fairs at minority institutions and successfully recruited three minority students, one of whom was female, from Fort Valley State College in Georgia. We will continue to follow these students in their graduate programs and encourage them to return to ESD for additional internships. Plans are under way to expand the programs with Xavier, Tulane, and Fort Valley in FY 1994. Collaborations with other historically black colleges and universities and minority educational institutions are also being explored.
ESD hosted 55 minority middle school students from the East Tennessee region who were participating the National Science Foundation-sponsored ScienceQuest program, a 4-week summer workshop. Staff members gave demonstrations in water quality, and the students conducted a dehydration experiment.

In August 1993, ESD hosted the Minority Environmental Career Conference, which six other ORNL divisions or programs cosponsored. Working with the Environmental Careers Organization, ESD selected 25 minority students, ranging from undergraduate to doctoral, to participate in a 2-day workshop. The objective was to introduce these students to environmental research at ORNL, help them learn about opportunities at the Laboratory, and encourage them to pursue careers in environmental studies. Several students want to return to ORNL to complete an internship or fellowship. Two students-one who has since completed a master's degree; the other, a doctorate-are seeking fellowship assignments at the Laboratory. Another student returned for an internship in early 1994. The goal is to eventually recruit some of these students as employees of the DOE subcontractor group.

The enthusiasm, fresh insight, and expertise of our guests provide a continuing source of research creativity that benefits the division and research sponsors. In return, participation in ongoing ESD research allows our guests to apply their textbook knowledge, expand their expertise, and help solve environmental problems. 
Table 1. Educational programs supporting students and faculty in ESD during FY 1993

Program Number

AWU-DOE Science Program 4

DOE-TRAC

DOE Young Faculty Award 1

EMCOM 1

ER\&WM 4

Fort Valley 3

FRP 1

GLCA 10

GSRP 6

Hollaender 1

LIP 2

PIP 19

Postgraduate Research Training 20

SEED 3

SERS 18

SRP 2

Tulane/Xavier 6

$\begin{array}{ll}\text { Total* } & 105\end{array}$

AWU = Associated Western Universities;

DOE = Department of Energy; TRAC = Teacher Research Association; EMCOM = Environmental Management Career Opportunities for Minorities; ER\&WM = Environmental Restoration and Waste Management; FKP = Faculty Research Program; GLCA = Great Lakes Colleges Association; GSRP = Graduate Student Research Participation Program; LIP = Legal Internship Program;

PIP = Professional Internship Program;

SEED = Summer Educational Experience for the Disadvantaged; SERS = Science and Engineering Research Semester Program; SRP = Summer Research Program.

*The total does not include participants in the DOE High School Honors Workshop in Environmental Sciences, the DOE/Appalachian Regional Commission Summer Science Academy, ScienceQuest, or the Restoring Our Waters Institute. 


\section{Affirmative Action}

\section{R. Tolbert and J. A. Watts}

ESD continues to strongly support the Martin Marietta Energy Systems, Inc., Equal Employment Opportunity (EEO) program and the ORNL Affirmative Action (AA) program. In support of this commitment, the division makes conscientious efforts to ensure job equality and opportunity for all employees regardless of race, color, religion, sex, and national origin. In addition, ESD has taken steps to expand employment and developmental opportunities for minorities, women, and the disabled. The commitment of ESD management and staff to equal opportunity and affirmative action has been recognized. In fiscal year (FY) 1993 the division received an award for being the Outstanding Division for EEO/AA at ORNL.

During FY 1993, ESD continued to support affirmative action principles in recruiting and hiring, promotions, career development, and education programs. The division continues to build upon the groundwork laid in the past and to expand efforts to identify and recruit minority staff for positions within the division and the laboratory as a whole. Based on information provided by ESD managers, the following summarizes efforts to enhance diversity within the division during this reporting period.

- ESD continues to develo and maintain close relationships with sc: aral minority educational institutions (MEIs). These relationships enable the division to identify candidates for educational exchanges and summer research opportunities in ESD. These interactions help the division cultivate potential minority employees, and they offer opportunities for subcontract interactions as well as the further development of MEI capabilities.

- The division continues to interact with Virginia State University, Xavier University, Clark Atlanta University, Tennessee State University, and Fort Valley State College and to identify opportunities for increased collaboration between these educational institutions and ESD staff.

- The division's Education Committee continues to involve minority students in research. Minority students are actively recruited for research opportunities through the historically black colleges and universities (HBCU) program and the Summer Education Experience for the Disadvantaged (SEED) program. Seven HBCU students and three minority SEED students worked in ESD during the summer. One minority teacher participated in the DOE Teacher Research

Associates program, and eight other minorities from other educational institutions were guests in the division during FY 1993.

- ESD organized and directed a workshop and an information exchange program at ORNL for 25 minority students as part of the Environmental Careers Organization Fair through the Center for Environmental Intern Programs. The students were encouraged to submit applications for employment 
to ORNL; scveral applications have been received. A minority female was successfully recruited and hired under a subcontract with the Environmental Analyses Section.

- The division continues to participate in the HBCU Exposition for minority students.

- ESD has pursued equal employment opportunity and affirmative action efforts through hiring and staffing during the year.

- The division recruited, interviewed, and hired professional females and minorities. Of 14 professional staff hired during FY 1993, 7 were females, including 2 minority females, and 1 was a minority male. A minority female is on assignment at the National Acid Precipitation Assessment Program office in Washington, D.C. She is also working with the Water Resources and Environmental Management Consortium, which is being developed by 23 minority educational institutions in collaboration with ORNL.

- ESD hired a number of female laboratory technicians, student interns, and summer clerical employees. A student intern and the summer clerical employees were minorities. The division's current level of employment of females as laboratory technicians is higher than the level generally found throughout the region.

- The division recruited and hired three minority secretarial candidates for job openings. ESD's current level of employment of minority females as secretarial staff is higher than that generally found throughout the region.

- ESD is committed to increasing opportunities for disabled individuals.

- Hearing-impaired employees are encouraged to participate in developmental courses and activities; interpreters are provided at these as well as at other meetings that hearing-impaired individuals desire to attend.

- ESD hosted a lunch seminar entitled "Silent Minority," about working with and accommodating hearingimpaired individuals.

- Female professional staff members continue to be actively involved in activities to encourage the professional development of peers and students.

- Female professional staff members serve as officers and members of the local chapter of the Association for Women in Science (AWIS). An ESD female staff member received the Outstanding AWIS Service Award for 1993.

- Female staff members actively support developmental programs for female students. Examples include the Women in Science Program, which encourages female college students to consider careers in science, and the SHADES (SHaring ADventures in Engineering and Science) program for middle school females, which is sponsored by the Greater Knox Science/Math Coalition, AWIS, and the American Association of University Women. 
- ESD female staff members (one, a minority) participated in the DOE Minority Challenge Program for area schools, served on the WATTec Science-in-Action Education Committee, and coordinated the DOE High School Honors Program and Science Quest.

- Female staff members participated on the Oversight Committee for 1993 DOE Review of Programs for Women at DOE Facilities, and one was a delegate to the review.

- A minority female in ESD participated in the Black Executive Exchange Program, and a minority female received an award for sustained EEO/AA program contributions at ORNL.

- The division developed community and ORNL programs for Women's History Month, focusing on increased opportunities for minorities and women in science as well as barriers to women in science; the speakers at the two programs were minority females.

- ESD has promoted affirmative action objectives by extending to its employees further opportunities for professional development and skills training.

- Female professional staff members attended a variety of national and international conferences and workshops and were involved in training opportunities as either leaders or participants.

- Female staff members participated in the Engineer/Scientist as a
Manager training course at The University of Tennessee.

- ESD has taken steps to include more women and minorities in the various training and educational programs that are open to visiting students, faculty, and scientists. These efforts will help the division develop additional potential employees from these groups.

- The division hosted the 2-week DOE National High School Honors Workshop in Environmental Sciences, which enabled outstanding high school students from each of the $\mathbf{5 0}$ states and from 7 foreign countries to learn more about science and to participate in hands-on research efforts while visiting ESD. A female chaired the workshop, and 8 minority students participated.

- Three minority SEED students worked in ESD during the summer. The division has maintained contact with several minority students and is encouraging them to reapply for the summer of 1994 . Efforts are under way to establish a formalized program between ESD and two HBCUs-Fort Valley State College and Xavier University-to establish an internship program to increase the number of minority students involved in the division's research activities.

- Division management continues a relationship with a company that identifies interns, particularly minority interns, who are cligible to participate in ESD programs. The division actively solicits applications for minority internships. 


\section{Visitors Hosted}

\section{E. F. Carringer}

During CY 1993 a total of 980 persons visited the ESD facilities as part of tour groups. The diversity of visitors reflects interest in the many areas of environmental research conducted in the division.

Tour groups hosted by ESD during CY 1993

\begin{tabular}{|c|c|c|c|c|c|}
\hline Institution ${ }^{a}$ & Date & $\begin{array}{l}\text { Number } \\
\text { in tour }\end{array}$ & Institution ${ }^{a}$ & Date & $\begin{array}{l}\text { Number } \\
\text { in tour }\end{array}$ \\
\hline Judge Webster & $12 / 04 / 92$ & 1 & Horace Maynard High School & $5 / 27 / 93$ & 15 \\
\hline SERS & $1 / 11 / 93$ & 37 & Berea College Summer Science & 6/09/93 & 26 \\
\hline ORAU Epidemiological Group & $1 / 12 / 93$ & 6 & Focus Program & & \\
\hline Ferrum College & $2 / 04 / 93$ & 15 & $\begin{array}{l}\text { St. Lawrence University } \\
\text { "Comparative Regional Issues" }\end{array}$ & $6 / 11 / 93$ & 11 \\
\hline Elizabethtown Community College & $2 / 19 / 93$ & 15 & TRAC & $6 / 14 / 93$ & 60 \\
\hline $\begin{array}{l}\text { 28th Annual Junior Science and } \\
\text { Humanities Symposium }\end{array}$ & $2 / 26 / 93$ & 13 & Tom Perry and W. G. Ripley & $6 / 18 / 93$ & 2 \\
\hline Group of High School Students & $3 / 03 / 93$ & 69 & SEED Students & $6 / 22 / 93$ & 30 \\
\hline $\begin{array}{l}\text { Clay County High School } \\
\text { Advanced Science Students }\end{array}$ & $3 / 11 / 93$ & 36 & ORNL Deans' Day 1993 & $\begin{array}{l}6 / 23- \\
24 / 93\end{array}$ & 38 \\
\hline $\begin{array}{l}\text { Murray County High School } \\
\text { Chemistry Class }\end{array}$ & $3 / 18 / 93$ & 21 & $\begin{array}{l}\text { Tennessee Press Association } \\
\text { Summer Meeting }\end{array}$ & $6 / 24 / 93$ & 21 \\
\hline Fletcher Academy & $3 / 19 / 93$ & 10 & $\begin{array}{l}\text { Visitors Day/Summer Research } \\
\text { Programs }\end{array}$ & $6 / 24 / 93$ & 18 \\
\hline $\begin{array}{l}\text { DePaul University, University } \\
\text { Ministry Groups }\end{array}$ & $3 / 25 / 93$ & 24 & $\begin{array}{l}\text { Mountain Empire Community } \\
\text { College Governor's School }\end{array}$ & 6/30/93 & 25 \\
\hline Japanese Visitors & $4 / 21 / 93$ & 12 & Shepherd College Nuclear & $7 / 02 / 93$ & 17 \\
\hline Energy Systems Co-Op Students & $4 / 29 / 93$ & 12 & Chemistry Class & & \\
\hline $\begin{array}{l}\text { Sandia National Laboratory } \\
\text { Visitors }\end{array}$ & $4 / 23 / 93$ & 10 & $\begin{array}{l}\text { Congressional Tennessee } \\
\text { Delegation }\end{array}$ & $7 / 07 / 93$ & 10 \\
\hline $\begin{array}{l}\text { DOE Review for Laboratory } \\
\text { Women }\end{array}$ & $5 / 11 / 93$ & 20 & $\begin{array}{l}\text { Bill Landry } \\
\text { DOE High School Honors and }\end{array}$ & $\begin{array}{l}7 / 13 / 93 \\
7 / 19 / 93\end{array}$ & $\begin{array}{r}2 \\
110\end{array}$ \\
\hline $\begin{array}{l}\text { Gaffney High School Physics/ } \\
\text { Advanced Placement Chemistry } \\
\text { Students }\end{array}$ & $5 / 19 / 93$ & 25 & $\begin{array}{c}\text { ARC Workshop } \\
\text { "Spectacles” Group }\end{array}$ & $7 / 20 / 93$ & 45 \\
\hline $\begin{array}{l}\text { Middle Tennessee State University } \\
\text { Environmental Problems Class }\end{array}$ & $5 / 20 / 93$ & 13 & $\begin{array}{l}\text { Energy Systems Co-Op Students } \\
\text { DOE Lyndhurst Interns }\end{array}$ & $\begin{array}{l}7 / 22 / 93 \\
7 / 28 / 93\end{array}$ & $\begin{array}{l}15 \\
16\end{array}$ \\
\hline $\begin{array}{l}\text { HBCU Summer Interns Nuclear } \\
\text { Energy Training }\end{array}$ & $5 / 26 / 93$ & 8 & $\begin{array}{l}\text { Energy Systems Summer Tech } \\
\text { Students }\end{array}$ & 7/29/93 & 20 \\
\hline
\end{tabular}


Tour groups hosted by ESD during CY 1993 (continued)

\begin{tabular}{|c|c|c|c|c|c|}
\hline Institution ${ }^{4}$ & Date & $\begin{array}{c}\text { Number } \\
\text { in tour }\end{array}$ & Institution ${ }^{a}$ & Date & $\begin{array}{l}\text { Number } \\
\text { in tour }\end{array}$ \\
\hline Bud Davidson/DOE-HQ & $8 / 02 / 93$ & 2 & Hungarian Community College & $8 / 26 / 93$ & 15 \\
\hline HAZWRAP Summer Guests & $8 / 04 / 93$ & 20 & Exchange Program & & \\
\hline $\begin{array}{l}\text { Visiting Reporter, Larry Spohn, } \\
\text { Albuquerque Tribune }\end{array}$ & $8 / 20 / 93$ & 1 & $\begin{array}{l}\text { First Baptist Church-Sr. Adults } \\
\text { Tour for Mrs. Victor Reis }\end{array}$ & $\begin{array}{l}9 / 16 / 93 \\
9 / 23 / 93\end{array}$ & $\begin{array}{r}30 \\
2\end{array}$ \\
\hline GLCASERS participants & $8 / 23 / 93$ & 60 & Maryville College Tri Beta Honor & $9 / 24 / 93$ & 19 \\
\hline $\begin{array}{l}\text { Carolina Power and Light Co. } \\
\text { Raleigh, North Carolina, } \\
\text { Educational Services Staff }\end{array}$ & $8 / 26 / 93$ & 3 & Total & & $\overline{980}$ \\
\hline
\end{tabular}

DOE = U.S. Department of Energy; Energy Systems = Martin Marietta Energy Systems, Inc.; DOE-HQ = DOE Headquarters; GLCA $=$ Great Lakes Colleges Association; HAZWRAP = Hazardous Waste Remedial Action Program; HBCU = Historically Black Colleges and Universities; ORAU = Oak Ridge Associated Universities; ORISE = Oak Ridge Institute for Science and Education; SERS = Science and Engineering Research Semester; SEED = Summer Education Experience for the Disadvantaged; and TRAC $=$ Teacher Research Associates.

Note: All educational fellowships, GLCA, and the SERS Program are administered through ORISE. 


\section{Conferences Organized or Chaired}

During the past year, ESD staff members actively participated in numerous conferences. Listed below are conferences organized or chaired by members of the division.

Eighth Annual Oak Ridge Model Conference, sponsored by DOE, Oak Ridge, Tennessee, October 1992. Chair: Sharples, F. E.

International Humic Substances Society Meeting, Bari, Italy, October 1992. Chair: McCarthy, J. F.

International Symposium on Organic Substances in Soil and Water, sponsored by Royal Society of Chemistry, Lancaster, United Kingdom, October 1992. Chair: McCarthy, J. F.

The Fifth Tennessee Water Resources Symposium, sponsored by American Water Resources Association, American Institute of Hydrology, and others, Nashville, Tennessee, October 1992. Organizer: Huff, D. D.

Sensitivity of U.S. Power Systems to Global Climate Change Impacts on Water Resources, sponsored by American Water Resources Association, Reno, Nevada, November 1992. Chair and organizer: Shriner, D. S.

Workshop on the CompMech Smallmouth Bass Project, sponsored by Electric Power Research Institute, Richmond, Virginia, November 1992. Chair:

Van Winkle, W.

Symposium on Colloid-Facilitated Transport, sponsored by American Geophysical Union, San Francisco, December 1992. Chair: McCarthy, J. F.
Symposium on Hydrology and Contaminant Transport, sponsored by American Geophysical Union, San Francisco, December 1992. Chair and organizer: Stow, S. H.

Taylorsville Triassic Basin Working Group, sponsored by DOE Office of Health and Environmental Research, Annapolis, Maryland, December 1992. Chair: Phelps, T. J.

National Symposium on Measuring and Interpreting VOCs in Soils:

State of the Art and Research Needs, sponsored by U.S. Environmental Protection Agency, DOE, U.S. Army, American Petroleum Institute, et al., Las Vegas, January 1093. Chair and organizer: Siegrist, R. L.

Specialty Conference on Development of Soil and Groundwater Cleanup Standards for Contaminated Sites, sponsored by Water Environment Federation, Washington, D.C., January 1993. Program committee member: Siegrist, R. L.

Midyear Technical Meeting of the Southern Division of the American Fisheries Society, sponsored by Tennessee and Georgia chapters of American Fisheries Society, Chattanooga, Tennessee, February 1993.

Chair: Bevelhimer, M. S.

Eighth Annual U.S. Landscape Ecology Symposium, Oak Ridge, Tennessee, March 1993. Chair: Turner, M. G.

Fourth Annual Walker Branch Watershed Research Symposium, sponsored by DOE, Oak Ridge, Tennessee, March 1993.

Chair: Huston, M. A. 
Fourth Annual Women in Science Conference, sponsored by ORNL and Oak Ridge Institute for Science and Education, Knoxville, Tennessee, March 1993. Program chair and organizer: Sharples, F. E.

Symposium on Health, Safety, and Training Issues During Site Characterization and Remediation, sponsored by American Chemical Society, Denver, March-April 1993. Chair and organizer: Korte, N. E.

National Atmospheric Deposition Program Workshop on Sampling Mercury in Precipitation, sponsored by National Atmospheric Deposition Program and Tennessee Valley Authority, Tarpon Springs, Florida, April 1993. Chair: Lindberg, S. E.

Society of Aquatic Ecosystem Health, Blacksburg, Virginia, April 1993. Chair: Adams, S. M.

1993 DOE Review of Laboratory Programs for Women, sponsored by DOE Office of University and Science Education, Oak Ridge, Tennessee, May 1993.

Cochair and organizer: Cushman, J. H.

Eighth North American Forest Soils Conference, sponsored by Soil Science Society of America, Society of American Foresters, and Canadian Soil Science Society, Gainesville, Florida, May 1993. Organization committee member: Joslin, J. D.

Fourth National Technology Information Exchange Workshop, sponsored by DOE, Knoxville, Tennessee, May 1993. Chair: Huff, D. D.

Geoconfines International Conference, sponsored by the French Committee for Engineering Geology, Department of
Environment, Montpellier, France, May 1993. Chair: Stow, S. H.

Natural Resource Trusteeship and Ecological Evaluation Workshops, sponsored by DOE Office of Environmental Guidance, Richland, Washington, April 1993; Santa Fe, New Mexico, May 1993. Organizer and co-instructor: Sharples, F. E.

\section{Belowground Responses to Rising} Atmospheric $\mathrm{CO}_{2}$ : Implications for Plants, Soil Biota and Ecosystem Processes, sponsored by EPA, Electric Power Research Institute, and University of Michigan Biological Station, Pellston, Michigan, May-June 1993. Chair:

O'Neill, E. G.

Soil Decon 93, sponsored by DOE Office of Technology Development, Gatlinburg, Tennessee, June 1993.

Chair and organizer: Francis, C. W.

Workshop on the CompMech Striped Bass Project, sponsored by Electric Power Research Institute, Newburgh, New York, June 1993. Chair: Van Winkle, W.

Carbon Cycle Global Change Institute, sponsored by University Corporation for Atmospheric Research, Boulder, Colorado, July 1993. Steering committee member:

Emanuel, W. R.

ECO Minority Conference in Envi onmental Careers, sponsored by ORNL and Environmental Cari:ers Organization, Oak Ridge, Tenuessee, August 1993. Cochairs: Gates, D. D., S. G. Hildebrand, and J. A. Watts.

Approaching Sustainability from the Bottom Up: Preserving the Soil, Annual Meeting, Ecological Soriety 
of America, Madison, Wisconsin, August 1993. Chair: O'Neill, E. G.

Global Change Impacts on Plant Ecophysiological Processes, sponsored by 15 th International Botanical Congress, Yokohama, Japan, August 1993. Chair and organizer: Luxmoore, R. J.

Round Table on Mycorrhizal Role in Sustainability of Soil Systems, Ninth North American Conference on Mycorrhizae, Guelph, Ontario, Canada, August 1993. Chair: O'Neill, E. G.

The Second Taylorsville Triassic Basin Working Group, sponsored by DOE Office of Health and Environmental Research, Annapolis, Maryland, August 1993.

Chair: Phelps, T. J.

Workshop on Sustainable Environmental Management, sponsored by Society of Environmental Toxicology and Chemistry and Ecological Society of America,
Pellston, Michigan, August 1993. Chair: Barnthouse, L. W.

Environmental Workshop, sponsored by Society of Exploration Geophysicists, Washington, D.C., September 1993. Organizer: Nyquist, J. E.

SAMAB Conference on Wetland Ecology, Management, and Conservation, sponsored by ESD, ORNL, Knoxville, Tennessee, September 1993. Chair and organizer: Trettin, C. C.

The Advancement of Environmental Geophysics, sponsored by Society of Exploration Geophysicists, Washington, D.C., September 1993. Chair and organizer: Doll, W. E.

Workshop on Airborne Electromagnetic Methods, sponsored by Laboratory for Advanced Surface Imaging, Tucson, Arizona, September 1993. Chair: Nyquist, J. E. 
ESD staff and guest assignees cleared the following with the ORNL Laboratory Records Department for publication during FY 1993.

Abraham, T. J., J. B. Berry, D. O. Campbell, E. D. Collins, S. M. DePaoli, D. D. Lee, S. M. Robinson, and J. R. Trabalka. 1993. Review of the strategy and program plan for management of ORNL's radioactively contaminated liquid waste, Oak Ridge National Laboratory, Oak Ridge, Tennessee. ORNL/CF-93/87.

Adams, S. M. 1993. Comparison of integrative approaches for evaluating the effects of contaminant-related stress on fish population health. p. 12. In Program and Abstracts, Third International Conference on Aquatic Ecosystem Health, Virginia Polytechnic Institute and State University, Blacksburg, May 23-27, 1993.

Adams, S. M., A. M. Brown, and R. W. Goede. 1993. A quantitative health assessment index for rapid evaluation of fish condition in the field. Trans. Am. Fish Soc. 122:63-73.

Adams, S. M., G. F. Cada, M. S. Greeley, Jr., and L. R. Shugart. 1993. Evaluating effects of environmental stress on fish communities using multiresponse indicators. pp. 170-77. In S. G. Hildebrand and J. B. Cannon (eds.), Proceedings of Ninth Life Sciences Symposium, The Scientific Challenges of NEPA: Future Directions Based on 20 Years of Experience, Knoxville, Tennessee, October 24-27, 1989. Environmental Analysis: The NEPA Experience. Lewis Publishers, Chelsea, Michigan.
Adams, S. M., W. D. Crumby, and M. S. Greeley, Jr. 1992. A biomonitoring strategy for assessing the health of fish populations exposed to pulp mill effluents. p. 34. In Proceedings of the 13th Annual Meeting of the Society for Environmental Toxicology and Chemistry, Cincinnati, November 8-12, 1991.

Adams, S. M., W. D. Crumby, and M. S. Greeley, Jr. 1992. Relationships between physiological and fish population responses in a contaminated stream. p. 10. In Book of Abstracts, Annual Meeting of the American Fisheries Society, Rapid City, South Dakota, September 13-17, 1992.

Adams, S. M., W. D. Crumby, M. S. Greeley, Jr., M. G. Ryon, and E. M. Schilling. 1992. Relationships between physiological and fish population responses in a contaminated stream. Environ. Toxicol. Chem. 11:1549-57.

Adams, S. M., W. D. Crumby, M. S. Greeley, Jr., L. R. Shugart, and C. F. Saylor. 1992. Responses of fish populations and communities to pulp mill effluents: A holistic assessment. Ecotoxicol. Environ. Saf. 24:347-60.

Allen, F. H., B. L. Bandurski, and A. W. King. 1993. The ecosystem approach: Theory and ecosystem integrity. ORNL/M-2848.

Apps, M. J., W. A. Kurz, R. J. Luxmoore, L. O. Nilsson, R. A. Sedjo, R. Schmidt, L. G. Simpson, and T. S. Vinson. 1993. Boreal forest and tundra. pp. 39-53. In J. Wisniewski and R. N. Samson (eds.), Terrestrial Biospheric Carbon Fluxes: Quantification of Sinks and Sources of $\mathrm{CO}_{2}$. Kluwer Academic Publishers, Dordrecht, The Netherlands. 
Arrage, A. A., T. J. Phelps, R. E. Benoit, A. V. Palumbo, and D. C. White. 1993. Bacterial sensitivity to UV light as a model for ionizing radiation resistance. J. Microbiol. Methods 18(3):127-36.

Asher, W. E., and P. J. Farley. 1993. DOE Research Summary, No. 23, January. ORNLM-2651.

Asher, W. E., P. M. Smith, and E. C. Monahan. 1992. DOE Research Summary, No. 21, November. ORNL/M-2590.

Ashwood, T. L. (ed.) 1993. Seventh Oak Ridge National Laboratory report on the Biological Monitoring and Abatement Program for White Oak Creek Watershed and the Clinch River. ORNL/TM-12385 (draft).

Ashwood, T. L., and D. S. Hicks. 1993. Environmental monitoring of subsurface low-level waste disposal facilities at Oak Ridge National Laboratory. pp. 170-87. In Proceedings of the 14th DOE Low-Level Radioactive Waste Management Conference, Phoenix, Arizona. EG\&G Idaho.

Ashwood, T. L., J. D. Story, I. L. Larsen, and F. J. Schultz. 1992. An experimental approach to determining subsurface leakage from a surface impoundment using a radioisotope tracer. ORNL/M-2372.

Atwood, D. E., and D. E. Miller. 1992. Quality assurance plan for the remedial investigation of Waste Area Grouping 2 at Oak Ridge National Laboratory, Oak Ridge, Tennessee. ORNL/ER-134.

Auerbach, S. I. 1992. Current developments in radiation ecology. 3rd ed., Gordon and Breach, Philadelphia. Encycl. Environ. Sci. Eng. 2:958-63.
Auerbach, S. I. 1993. A history of the Environmental Sciences Division of Oak Ridge National Laboratory. ORNL/M-2732.

Baes, C. F., III. 1993. Land disposal restrictions (LDR) program overview (brochure). ORNL/M-2757.

Baker, J., W. Warren-Hicks, J. Gallagher, and S. W. Christensen. 1993. Fish populat. on losses from Adirondack lakes: The role of surface water acidity and acidification. Water Resour. Res. 29:861-74.

Barkay, T., R. R. Turner, E. Sacuter, and J. Horn. 1992. Mercury biotransformations and their potential for re nediation of mercury contamination. Biudegrad. 3:147-59.

Barnthouse, L. W. 1993. Expert initial review of Columbia River Basin salmonid management models: Summary report. ORNL/TM-12493.

Barnthouse, L. W. 1993. Population-level effects. pp. 247-74. In G. W. Suter (ed.), Ecological Risk Assessment, Lewis Publishers, Chelsea, Michigan.

Barnthouse, L. W. 1993. The role of models in Ecological Risk Assessment: A 1990 perspective. Environ. Toxicol. Chem. 11(12):1751-60.

Bascietto, J. J., R. W. Dunford, F. E. Sharples, and G. W. Suter. 1993. Integrating natural resource damage assessment and environmental restoration activities at DOE facilities. pp. 1-15. In Proceedings of the Federal Environmental Restoration Conference, Washington, D.C.

Belnap, J., L. L. Sigal, M. Moir, and S. Eversman. 1993. Identification of 
sensitive species. In Lichens as Bioindicators of Air Quality. General Technical Report, The Forest Service, U.S. Department of Agriculture, U.S. Government Printing Office.

Bevelhimer, M. S., D. A. Levine, S. M. Adams, B. G. Blaylock, R. B. Cook, E. L. Etnier, C. J. Ford, M. S. Greeley, R. S. Halbrook, F. O. Hoffman, L. A. Hook, P. L. Hovell, B. L. Kimmel, L. A. Kszos, and G. W. Suter. 1993. CR-ERP Phase-2 sampling and analysis plan. Report DOE/OR/01-1111 \& D3 (draft).

Blake, T. J., and T. J. Tschaplinski. 1993. Water relations. pp. 66-94. In P. C. Mitchell, L. Sennerby-Forsse, and T. M. Hinkley (eds.), Ecophysiology of Short Rotation Forest Crops, Elsevier Science Publishers, Amsterdam.

Blaylock, B. G., C. J. Ford, M. L. Frank, F. O. Hoffman, and L. A. Hook. 1993. White Oak Creek embayment site characterization and contaminant screening analysis. ORNL/ER-81.

Blaylock, B. G., M. L. Frank, and D. K. Cox. 1993. Biological Monitoring and Abatement Program (BMAP) waterfowl monitoring. ORNL/M-3048.

Boden, T. A., R. M. Cushman, F. W. Stoss, F. M. O'Hara, and D. Siegel. 1992. CDIAC communications special issue: CDIAC's tenth anniversary, No. 16, Winter. ORNL/M-1930.

Boden, T. A., F. M. O'Hara, Jr., and F. W. Stoss. 1993. CDIAC catalog of numeric data packages and computer model packages. ORNL/CDIAC-62.

Bogle, M. A., and R. R. Turner. 1993. Comparison of water quality at BCK-12.46 and BCK-11.97 in Upper Bear Creek, February 1980-June 1992. Y/TS-945. Oak Ridge Y-12 Plant, Oak Ridge, Tennessee.

Bondczek, R. R., J. Carter, J. M. Loar, G. Reside, G. W. Suter, and C. C. Travis. 1993. Management strategy for the surface water integrator unit at the Paducah Gaseous Diffusion Plant, Paducah, Kentucky. ORNL/M-3172.

Borders, D. M., J. A. Watts, R. B. Clapp, B. J. Frederick, S. M. Gregory, and T. D. Moore. 1993. Hydrologic data summary for the White Oak Creek Watershed at Oak Ridge National Laboratory, Oak Ridge, Tennessee (January-December 1992). ORNL/ER-166.

Boston, H. L. 1992. Biological Monitoring and Abatement Program (BMAP) periphyton community monitoring. ORNL/FPO-93-6.

Boston, H. L. 1992. Preliminary data from the first round of seep sampling in Waste Area Grouping 2 at Oak Ridge National Laboratory, Oak Ridge, Tennessee. ORNL/M-2425.

Burlage, R. S., A. Heitzer, and G. S. Sayler. 1992. Bioluminescence: A versatile bioreporter for monitoring bacterial activity. Biotech. Forum Europe 9(11-12):704-9.

Burlage, R. S., and A. V. Palumbo. 1993. Toluene and $m$-methylbenzyl alcohol show different patterns of induction in Pseudomonas putida: Evidence for reduced uptake of a substrate during exponential growth. p. 404. In Abstracts of the 93rd General Meeting of the American Society for Microbiology, Atlanta, May 16-20, 1993. 
Burns, T. P. 1992. Fitness in clonal organisms-a special case of extensive fitness. Oikos 65(3):535-37.

Byrne, R. H., and K.-H. Kim. 1993. Rare earth precipitation and coprecipitation behavior: The limiting role of $\mathrm{PO}_{4}^{3-}$ on dissolved rare earth concentrations in seawater. Geochim. Cosmochim. Acta 57:519-26.

Cada, G. F. 1993. Use of rapid bioassessment approaches to examine benthic macroinvertebrate responses to hydropower flow diversions. Bull. North Am. Benthol. Soc. 10(1):113.

Cada, G. F., and D. W. Jones. 1993. Benefits of fish passage and protection measures at hydroelectric projects. pp. 139-48. In W. D. Hall (ed.), Waterpower '93: Proceedings of the International Conference on Hydropower, American Society of Civil Engineers, New York.

Cada, G. F., J. E. Francfort, B. N. Rinehart, M. J. Sale, and G. L. Sommers. 1993. DOE hydropower program, Biennial Report 1992-1993 (excerpts). ORNL/M-2906 (draft).

Cada, G. F., and M. J. Sale. 1993. Status of fish passage facilities at nonfederal hydropower projects. Fisheries 18(7):4-12.

Cardwell, H., and M. J. Sale. 1993. Optimization to identify alternative instream flow releases from multi-purpose projects. p. 349. In Abstracts, AWRA 29th Annual Conference, American Water Resource Association, Bethesda, Maryland.

Clapp, R. B., and J. A. Watts. 1993. Second annual report of the Environmental Restoration Monitoring and
Assessment Program at Oak Ridge National Laboratory. ORNL/ER-180.

Clapp, R. B., and D. S. Marshall. 1992. SWSA 6 interim corrective measures environmental monitoring: FY 1991 results. ORNL/ER-87.

Clapp, R. B., R. W. Arnseth,

T. L. Ashwood, S. A. Blair, A. K. Brill, D. M. Borders, H. L. Boston, B. B. Burgoa, A. K. Day, R. B. Dreier, T. A. Fontaine, S. M. Gregory, D. S. Hicks, R. H. Kettelle, S. Y. Lee, J. M. Loar, D. E. Miller, G. K. Moore, J. E. Nyquist, D. J. Pridmore, M. F. Tardiff, L. E. Toran, J. A. Watts, R. C. Wilson, and T. F. Zondlo. 1992. Annual report of the Environmental Restoration Monitoring and Assessment Program at Oak Ridge National Laboratory for FY 1992. ORNL/ER-124.

Cline, S. T., B. E. Reed, R. E. Moore, and M. R. Matsumoto. 1993. Soil washing of various forms of lead and organically contaminated soils. pp. 195-204.

Proceedings of the Water Environment Federation 66th Annual Conference and Exposition, Anaheim, California, October 3-7, 1993.

Committee on Risk Assessment Methodology. 1993. Topics in Risk Assessment. National Academy Press, Washington, D.C.

Cook, R. B., S. M. Adams, J. J. Beauchamp, M. S. Bevelhimer, B. G. Blaylock, C. C. Brandt, C. J. Ford, M. L. Frank, M. G. Gentry, S. K. Holladay, L. A. Hook, D. A. Levine, R. C. Longman, C. W. McGinn, J. L. Skiles, G. W. Suter, and L. F. Williams. 1992. Phase 1 data summary report for the Clinch River remedial investigation: Health risk and 
ecological risk screening assesstient. ORNL/ER-155.

Cook, R. B., S. M. Adams, J. J. Beauchamp, M. S. Bevelhimer, B. G. Blaylock, C. C. Brandt, E. L. Etnier, C. J. Ford, M. L. Frank, M. G. Gentry, M. S. Greeley, R. S. Halbrook, R. A. Harris, S. K. Holladay, L. A. Hook, P. L. Howell, L. A. Kszos, D. A. Levine, J. L. Skiles, and G. W. Suter. $19 y 3$. Phase 2 sampling and analysis plan, quality assurance project plan, and environmental health and safety plan for the Clinch River remedial investigation: An addendum to the Clinch River RCRA facility investigation plan. DOE/OR/01-1111 \& D3. U.S. Department of Energy, Oak Ridge, Tennessee.

Cook, R. B., C. J. Ford, R. A. Harris, G. J. Haynes, and L. A. Hook. 1993. Environmental Sciences Division administrative procedure.

ORNL/FPO-93/49.

Cooper, L. W. 1992. Review of an introduction to marine biogeochemistry by Susan M. Libes. Wiley, New York. Aquat. Toxicol. 23:290-91.

Cooper, L. W., C. Solis, D. L. Kane, and L. D. Hinzman. 1993. Application of oxygen-18 tracer techniques to Arctic hydrological processes. Arct. Alp. Res. 25(3):247-55.

Coutant, C. C. 1992 . Testing the waters. Electr. Perspect. 16(4):32-40.

Cunningham, M., L. Pounds, S. Oberholster, P. D. Parr, L. Edwards, B. A. Rosensteel, and L. K. Mann. 1993. Resource management plan for the Oak Ridge Reservation. Vol. 29: Rare plants on the Oak Ridge Reservation. ORNL/NERP-7.
Cushman, J. H. 1992. National biofuels roundtable formed. Biologue 10(1):60.

Cushman, R. M., and M. D. Burtis. 1993. Catalog of data bases and reports.

ORNL/CDIAC-34/R3.

Cushman, R. M., D. B. Hunsaker, Jr., M. S. Salk, and R. M. Reed. 1993. Global climate change and NEPA analyses. pp. 442-62. In S. G. Hildebrand and J. B. Cannon (eds.), Proceedings of Ninth Life Sciences Symposium, The Scientific Challenges of NEPA: Future Directions Based on 20 Years of Experience, Knoxville, Tennessee, October 24-27, 1989. Environmental Analysis: The NEPA Experience. Lewis Publishers, Chelsea, Michigan.

Cushman, R. M., and F. W. Stoss. 1993. Carbon Dioxide Information and Analysis Center: FY 1992 activities. ORNL/CDIAC-58.

Cushman, R. M., and F. W. Stoss. 1993. Carbon Dioxide Information and Analysis Center. Environ. 35:5 and 45.

Dale, V. H. 1992. Diversity impact and recovery at Mount St. Helens: A function of disturbance. Northwest Environ. J. 8(1):185-87.

Dale, V. H. 1992. Exotic seeds reduce biodiversity on the Mount St. Helens debris avalanche. Northwest Environ. J. 8(1):183-85.

Dale, V. H. 1992. The Amazon: A timeless battleground-Book review. Forum Appl. Res. Pub. Policy 7:124-25.

Dale, V. H., R. A. Houghton, A. Grainger, A. E. Lugo, and S. Brown. 1993. Emissions of greenhouse gases from tropical deforestation and subsequent uses 
of the land. pp. 215-61. In Board of Agriculture's Book on Sustainable Agriculture, National Academy Press, Washington, D.C.

Dale, V. H., R. V. O'Neill, F. Southworth, and F. Loureiro. 1992. Analyzing simulated patterns of land use change. In Proceeding of Remote Sensing/American Congress on Surveying and Mapping and Resource Technology ' 92 Convention on Monitor ing and Mapping Global Change, Washington, D.C., August 3-8, 1992.

Am. Soc. Photogramm. 5:284-93.

Dale, V. H., and M. A. Pedlowski. 1992. Farming the forests. Forum Appl. Res. Pub. Policy 7(4):20-21.

Daniels, R. C., V. M. Gornitz, A. J. Mehta, S.-C. Lee, and R. M. Cushman. 1992. Adapting to sea-level rise in the U.S. southeast: The influence of built infrastructure and biophysical factors on the inundation of coastal areas.

ORNL/CDIAC-54.

Daniels, R. C., T. W. White, and K. K. Chapman. 1993. Sea-level rise: Destruction of threatened and endangered species habitat in South Carolina. Environ. Manage. 17(3):373-85.

DeAngelis, D. L., and L. J. Gross. 1992. Individual-Based Models and Approaches in Ecology. Routledge, Chapman and Hall, New York.

DeAngelis, D. L., and M. A. Huston. 1993. Further considerations on the debate over herbivore optimization theory. Ecol. Appl. 3(1):30-31.

DeAngelis, D. L., and P. J. Mulholland, 1993. Annual progress report to the National Science Foundation (Ecosystem Studies Program): Spatial gradients in nutrient recycling and their effect on stream ecosystems stability.

C.RNL/M-2603.

DeAngelis, D. L., and K. A. Rose. 1992. Which individual-based approach is most appropriate for a given problem? pp. 67-87. In Individual-Based Models and Approaches in Ecology. Routledge, Chapman and Hall, New York.

Dickerman, J. A., et al. 1993. Environmental assessment for Environmental Restoration Program Kansas City Plant, Kansas City, Missouri. U.S. Department of Energy, Oak Ridge, Tennessee (draft).

Dickerman, J. A., V. R. Tolbert, M. S. Salk, and A. A. Richmond. 1993. Techniques and guidelines for streamlining NEPA: Four ideas, nine tools. pp. 308-22. In Current and Future Priorities for Environmental Management, 18th Annual Conference Proceedings, NAEP, Washington, D.C.

Dickerman, J. A., V. R. Tolbert, M. S. Salk, and A. A. Richmond. 1993. Techniques and guidelines for streamlining NEPA: Four ideas, nine tools. p. 307. In Current and Future Priorities for Environmental Management, National Association of Environmental Professional, Raleigh, North Carolina.

Doll, W. E., C. D. Rea, J. E. Ebel, S. J. Craven, and J. J. Cipar. 1992. Analysis of shallow microearthquakes in the South Sebec Seismic Zone, Maine, 1989-90. Seismol. Res. Lett. 63(4):557-66.

Donaldson, T. L., H. L. Jennings, A. J. Lucero, G. W. Strandberg, M. I. Morris, A. V. Palumbo, P. A. Boerman, and R. L. Tyndall. 1992. Cometabolic biotreatment of TCEcontaminated groundwater-laboratory 
and bench-scale development studies. pp. 633-37. In Proceedings of the 18th American Nuclear Society Symposium on Waste Management, Waste Management '92, Tucson, Arizona, March 1-5, 1992.

Donaldson, T. L., A. J. Lucero, H. L. Jennings, and S. E. Herbes. 1993. Pilot-scale field tests for the methanotrophic technology cometabolic bioreactor demonstration at the Oak Ridge K-25 Site. ORNL/TM-12235.

Dreier, R. B., and A. J. Caldanaro. 1993. Installation summary for the DNAPL characterization multiport wells, GW-726, GW-727, GW-729, GW-730 and GW-790. Y/ER-117. Oak Ridge Y-12 Plant, Oak Ridge, Tennessee.

Drc ${ }^{\circ}$, R. B., T. O. Early, and H. L. King. 1993. Results and interpretation of groundwater data obtained from multiportinstrumented coreholes (GW-131 through GW-135), FYs 1990 and 1991. Y/TS-803. Oak Ridge Y-12 Plant, Oak Ridge, Tennessee.

Dreier, R. B., J. Switek, and B. A. Couzens. 1992. Construction and installation summary for FY 1992 of the Hydraulic Head Monitoring Stations at Oak Ridge National Laboratory, Oak Ridge, Tennessee. ORNL/ER-125.

D'Surney, S. J., T. J. Tschaplinski, N. T. Edwards, and L. R. Shi.g rt. 1993. Biological responses of two soy oean cultivars exposed to enhanced UVB radiation. Environ. Exp. Bot. 33(3):347-56.

Dunbar, N. W., G. K. Jacobs, and M. T. Naney. 1992. Effect of cooling rate on timing and dynamics of crystallization within a man-made magma body. Abstracts and Programs, 104th Annual Meeting of the Geological Society of America, Inc./Expo, Cincinnati, October 26-29, 1992. Geol. Soc. Am. 24(7):263.

Dzombak, D. A., P. L. Labieniec, and R. L. Siegrist. 1993. The need for uniform soil clcanup goals. Environ. Sci. Technol. 27(5):765-66.

Eddlemon, G. K., and M. S. Salk. 1992. Uranium enrichment environmental program planning manual. DOE Uranium Enrichment Program, Oak Ridge National Laboratory, Oak Ridge, Tennessee.

Eddlemon, G. K., J. W. Webb, D. B. Hunsaker, and R. L. Miller. 1993. Actual versus predicted impacts of three ethanol plants on aquatic and terrestrial resources. pp. 272-87.

In National Association of Environmenial Professionals 18th Annual Conference Procedure on Current and Future Priorities for Environmental Management, Raleigh, North Carolina, May 24-26, 1993.

Eddlemon, G. K. (contributor). 1992. Draft environmental impact statement for the proposed Healy clean coal project. U.S. Department of Energy, Washington, D.C. DOE/EIS-0186.

Eddlemon, G. K. (contributor). 1993. Environment Compliance Assessment and Management Program (ECAMP) assessment of Shaw Air Force Base, Sumter, South Carolina. Preliminary Report. U.S. Air Force Air Combat Command.

Eddlemon, G. K. (contributor). 1993. ECAMP assessment of Griffis Air Force Base, Rome, New York. Preliminary Report. U.S. Air Force Air Combat Command. 
Eddlemon, G. K. (contributor). 1993. ECAMP assessment of Seymour Johnson Air Force Base, Goldsboro, North Carolina. Preliminary Report. U.S. Air Force Air Combat Command.

Edgerton, S., and T. Mizuno. 1993. A report from the second U.S./Japan workshop on global change research: Environmental response technologies (mitigation and adaptation), Honolulu, February 1-3, 1993. CONF-932085.

Edwards, N. T. 1993. State-of-the-art UV.B field-exposure techniques do not qualitatively simulate expected global increases in UV-B irradiance. Bull. Ecol. Soc. Am. 73(2):165.

Edwards, N. T. 1993. There is a need for improved UV-B exposure systems for studying $U V \cdot B$ effects on vegetation. p. 20. In Proceedings of UV-B Critical Issues Workshop, Cocoa Beach, Florida, February 24-26, 1993. Center for Global Environmental Studies, ORNL.

Ehrenshaft, A. R. 1993. Energy crops forum, Summer. ORNL/M-2942.

Ehrenshaft, A. R., L. L. Wright, and S. A. Martin. 1993. Energy crop information resources at Oak Ridge National Laboratory. 205th American Chemical Society National Meeting, Denver, March 28-April 2, 1993.

Elless, M. P. 1993. Calculation of clay mineral for aulae from chemical analyses using LOTUS ${ }^{\mathrm{M}}$ 1-2-3 spreadsheets. p. 123. In Clay Minerals Society Meeting Program and Abstracts, Clay Minerals Society, Boulder, Colorado.

Elless, M. P., S. Y. Lee, and M. E. Timpson. 1993. Application of a magstream $^{\mathrm{TM}}$ density separator in soil mineralogy. p. 143. In Clay Minerals Society Meeting Program and Abstracts, Clay Minerals Society, Boulder, Colorado.

En.minger, J. T., R. J. Andermann, T. J. Blasing, C. R. Boston, E. L. Hillsman, R. O. Johnson, J. W. Saulsbury, W. P. Staub, V. R. Tolbert, and G. P. Zimmerman. 1992. Disposal of chemical agents and munitions stored at Pine Bluff Arsenal, Pine Bluff, Arkansas, Draft Environmental Impact Statement. U.S. Army, Oak Ridge National Laboratory. ORNL/M-2400.

Fackenthal, J. S. 1992. Air/Water/ Radiation Ufdate. Vol. 92(4), October. ORNL/M-2521.

Fackenthal, J. S. 1993. Air/Water/ Radiation Update. Vol. 93(1), January. ORNL/M-2644.

Fackenthal, J. S. 1993. Executive order 12580: Superfund implementation. Information Brief: U.S. DOE CERCLA Information Brief. EH-231-05/0593.

Flamm, R. O., M. G. Turner, D. Wear, and J. Chazel. 1992. The effects of land use on forest cover. p. 35. In Agenda and Abstracts, Third Annual Southern Appalachian Man and Biosphere Conference, Gatlinburg, Tennessee, November 9-10, 1992.

Flamm, R. O., M. G. Turner, R. Gottfried, R. G. Lee, R. J. Naiman, N. Schumaker, and D. Wear. 1993. Simulating landscape change in the Southern Appalachians using spatially-explicit socioeconometric data. p. 46. In Program and Abstracts, Eighth Annual U.S. Landscape Ecology Symposium, Oak Ridge, Tennessee, March 24-27, 1993. 
Fontaine, T. A. 1992. Contaminated sediment transpurt during floods. pp. 210-12. In $M$. Jennings and N. G. Bhomik (eds.), H;draulic Engineering. American Society of Civil Engineers, New York.

Fontaine, T. A. 1992. Measuring the spatial distribution of evaporation using atmometers. p. 49. In Managing Water Resources During Global Change. American Water Resources Association, Bethesda, Maryland.

Fontaine, T. A., and D. E. Todd, Jr. 1993. Measuring evaporation with ceramic Bellani plate atmometers. Water Resour. Bull. 29(5):785-95.

Ford, C. J. 1993. Compilation of statements of work for the White Oak Creek embayment water quality monitoring project. ORNL/M-2609.

Ford, C. J. 1993. Compilation of sample identification number communications for the White Oak Creek embayment water quality monitoring project. ORNL/M-2068.

Ford, C. J., D. E. Miller, M. L. Frank, B. G. Blaylock, B. L. Kimmel, and S. L. Niemela. 1993. Contaminated surface sediment in White Oak Creek embayment, Tennessee: Elevated levels of Cs-137. p. 10. In Final Program: First International Specialized Conference on Contaminated Aquatic Sediments: Historical Recorcis, Environmental Impact, and Remediation. International Association on Water Quality, Milwaukee, Wisconsin, June 14-16, 1993.

Ford, C. J., and M. T. Wefer. 1993. Water quality monitoring report for the White Oak Creek embayment interim corrective measure time-critical CERCLA removal action, June 1991 through April 1992. ORNL/ER-150.

Francfort, J. E., and G. F. Cada. 1993. Environmental requirements at hydroelectric power projucts. Book of Abstracts, 205th American Chemical Society National Meeting, Denver, March 28-April 2, 1993.

Francis, C. W. (team leader), et al. 1993. Proceedings of Soil Decon '93: Technology targeting radionuclides and heavy metals, Gatlinburg, Tennessee, June 16-17, 1993. ORNL-6769.

Francis, C. W., C. D. Farmer, and R. G. Stansfield. 1993. In situ grouting of the low-level radioactive waste disposal silos at ORNL's Solid Waste Storage Area Six. ORNL/TM-12283.

Francis, C. W., R. D. Spence, T. Tamura, and B. P. Spalding. 1993. In situ grouting of low-level burial trenches with a cementbased grout at Oak Ridge National Laboratory. ORNL/TM-11838.

Francis, C. W., L. K. Hyder, S. C. Howard, J. E. Cline, and R. B. Clapp. 1993. Pilot uranium lysimeter studies at the Oak Ridge Y-12 Plant. ORNL/TM-12217.

Francis, C. W., A. J. Mattus, M. P. Elless, and M. E. Timpson. 1993. Selective leaching of uranium from uranium contaminated soils using carbonate- and citrate-based leaching solutions. Part 1. In C. W. Francis (ed.), The Removal of Uranium from Uranium Contaminated Soils, Oak Ridge National Laboratory, Oak Ridge, Tennessee. ORNL-6762.

Francis, C. W., A. J. Mattus, L. L. Farr, M. P. Elless, and S. Y. Lee. 1993.

Selective leaching of uranium from uranium contaminated soils: Progress 
Report I, Oak Ridge National Laboratory, Oak Ridge, Tennessee. ORNL/TM-1:2177.

Froelich, P. N., V. Blanc, R. A. Mortlock, S. N. Chillrud, W. Dunstan, A. Odomkit, and T.-H. Peng. 1992. River fluxes of dissolved silica to the ocean were higher during glacials: $\mathrm{Ge} / \mathrm{Si}$ in diatoms, rivers, and oceans. Paleoceanography 7(6):739-67.

Gates, D. D., and R. L. Siegrist. 1993. Evaluation of in situ peroxidation of clay soils contaminated by trichloroethylene. In Fourth National Technology Information Exchange Workshop, Knoxville, Tennessee, May 11-13, 1993.

Gates, D. D., and R. L. Siegrist. 1993. In situ peroxidation of TCE contaminated soil. Joint CSCE-ASCE National Conference on Environmental Engineering, Montreal, Quebec, Canada.

Gates, D. D., C. W. Francis, L. M. Laster, and R. Kimmitt. 1993. Pilot and fieldscale uranium lysimeter studies at the Oak Ridge Y-12 Plant. p. 865. In Scientific Basis for Nuclear Waste Management XVI, Proceedings, Fall Meeting of Material Resource Society, Boston, November 30-December 4, 1992. Material Resource Society, Pittsburgh.

Gates, D. D., and R. L. Siegrist. 1993. The X-231B technology demonstration for in situ treatment of contaminated soil: Laboratory evaluation of chemical oxidation using hydrogen peroxide. ORNL/TM-12259.

Genereux, D. P., H. F. Hemond, and P. J. Mulholland. 1993. Spatial and temporal variability in streamflow generation on the West Fork of Walker Branch Watershed. J. Hydrol. 142:137-66.
Genereux, D. P., H. F. Hemond, and P. J. Mulholland. 1993. Use of Radon-222 and calcium as tracers in a three-end-member mixing model for streamflow generation on the West Fork of Walker Branch Watershed. J. Hydrol. 142:167-211.

Gierke, J. S., O. M. Reyes, and R. L. Siegrist. 1992. Modeling volatile organic chemical removal by in situ soil mixing/steam stripping. pp. 397-411. In Proceedings of National Water Wells Association Meeting on Solving Ground Water Problems with Models, Dallas, February 11-13, 1992. NWWA.

Goldstrand, P. M. 1993. Paleogeographic and paleotectonic development of laramide basins of southwestern Utah. Proceedings of the Meeting of Geological Society of America, Reno, Nevada, May 24-27, 1993. Geol. Soc. Amer. 25:43.

Goldstrand, P. M. 1993. The mesozoic geologic evolution of the Northern Wallowa Terrane, northeastern Oregon and western Idaho. Geology of the Blue Mountains Region of Orc gon, Idaho, and Washington. U.S. Geol. Surv. 1438:21-45.

Graham, R. L., L. L. Wright, and A. F. Turhollow. 1992. The potential for short-rotation woody crops to reduce U.S. $\mathrm{CO}_{2}$ emissions. Clim. Change 22:223-38.

Greeley, M. S., Jr., S. M. Adams, W. D. Crumby, S. L. Niemela, A. M. Brown, D. L. Dycus, R. L. Self, and C. M. Alexander. 1992. An integrated study of fish health in a PCB-contaminated reservoir. p. 86. In Proceedings of the 13th Annual Meeting of the Society for Environmental Toxicology and Chemistry, Cincinnati, November 8-12, 1992. Science Engineering and Technology Applications Corporation. 
Greene, D. W. 1993. X-231B technology demonstration for in situ treatment of contaminated soil: Laboratory evaluation of in situ vapor stripping.

ORNL/TM-12260.

Griest, W. H., A. J. Stewart, R. L. Tyndall, J. E. Caton, C.-H. Ho, K. S. Ironside, W. M. Caldwell, and E. Tan. 1993. Chemical and toxicological testing of composed explosives-contaminated soil. Environ. Toxicol. Chem. 12:1105-16.

Griffith, J. A., C. T. Hunsaker, S. P. Timmins, and B. L. Jackson. 1993. Analysis of landscape metrics at different resolutions for environmental monitoring. p. 89. In Book of Abstracts, 89th Annual Meeting of the Association of American Geographers, Atlanta, April 6-10, 1993. Association of American Geographers, Washington, D.C.

Gu, B., J. Schmitt, L. Liang, and J. F. McCarthy. 1992. On the adsorption mechanisms of natural organic matter by iron-oxide and its coated quartz. Eos, Trans. Am. Geophys. Union 73(43):166-67.

Gunderson, C. A., R. J. Norby, E. G. O'Neill, and S. D. Wullschleger. 1992. Responses of Liriodendron tulipifera and Quercus alba to three years of $\mathrm{CO}_{2}$ enrichment under field conditions: Increased growth efficiency and no photosynthetic acclimation. The Role of Physiology and Genetics in Forest Ecosystem Research and Monitoring, Proceedings of North American Forest Biology Workshop, Sault Ste. Marie, Ontario, Canada, August 17-20, 1992. Ont. Minist. Nat. Resour. 1:108.

Gunderson, C. A., R. J. Norby, and S. D. Wullschleger. 1993. Effects of elevated atmospheric $\mathrm{CO}_{2}$ on coppice growth in yellow poplar. Program and
Abstracts, Fourth Annual Walker Branch Watershed Research Symposium, Oak Ridge, Tennessee, March 18-19, 1993.

Gwo, J. P., G. T. Yeh, and P. M. Jardine. 1992. Multi-region modeling of soil column tracer injections. Eos, Trans. Am. Geophys. Union 73(43): 156.

Gwo, J. P., P. M. Jardine, G. T. Yeh, and G. V. Wilson. 1993. Model subsurface flow and transport in the Melton Branch watershed using multiple pore region models. p. 27. In Fourth National Technology Information Exchange Workshop, Knoxville, Tennessee, May 11-13, 1993.

Halbrook, R. S., L. R. Shugart, A. P. Watson, N. B. Munro, and R. D. Linnabary. 1992. Characterizing biological variability in livestock blood cholinesterase activity for biomonitoring organophosphate nerve agent exposure. J. Am. Vet. Med. Assoc. 201:714-25.

Halbrook, R. S., and G. W. Suter. 1992. Use of great blue heron monitoring data in risk assessments for a superfund site. p. 61. In Proceedings of the 13th Annual Meeting of the Society for Environmental Toxicology and Chemistry, Cincinnati, November 8-12, 1992.

Ham, K. D., and M. J. Peterson. 1992. Effect of fluctuating low-level chlorine concentrations on valve movement behavior of the Asiatic clam (Corbicula Sp.). p. 17. In Abstracts of the 13th Annual Meeting of the Society for Environmental Toxicology and Chemistry, Cincinnati, November 8-12, 1992. SETAC.

Hanson, P. J., and C. T. Garten, Jr. 1992. Deposition of $\mathrm{H}^{15} \mathrm{NO}_{3}$ vapor to foliage: Experimental observations and a generalized model. Plant Physiol. 99:97. 
Hanson, P. J., and C. T. Garten, Jr. 1992. Deposition of $\mathrm{H}^{15} \mathrm{NO}_{3}$ vapor to white oak, red maple, and loblolly pine foliage: Experimental observations and a generalized model. New Phytol. 122:329-37.

Hanson, P. J., and W. A. Hoffman. 1993. Carbon dioxide and non-methane hydrocarbon emissions from the forest floor of an upland oak forest. Abstracts, Greenhouse Gas Emissions and Carbon Sequestration, Ohio State University, Columbus, April 5-9, 1993. USDA.

Hanson, P. J., and W. A. Hoffman. 1993. Emission of non- $\mathrm{CO}_{2}$, non- $\mathrm{CH}_{4}$ volatile organics from hardwood and conifer forest floor cores. Program and Abstracts, Fourth Annual Walker Branch Watershed Research Symposium, Oak Ridge, Tennessee, March 18-19, 1993.

Hanson, P. J., L. J. Samuelson, S. D. Wullschleger, and G. S. Edwards. 1993. Impacts of ozone on photosynthesis and conductance of tree versus seedling Quercus rubra L. foliage. Plant Physiol. 102(1):151.

Hanson, P. J., and R. S. Turner. 1992. Nitrogen deposition to forest ecosystems: Forms, regional inputs, and effects. Proceedings of 85th Annual Meeting/ Exhibition, Air and Waste Management Association, Kansas City, Missouri, June 21-26, 1992. Air Waste Manage. Assoc. 92:71.04.

Hanson, P. J., S. D. Wullschleger, S. A. Bohlman, and D. E. Todd. 1993. Seasonal and topographic patterns of forest floor $\mathrm{CO}_{2}$ efflux from an upland oak forest. Tree Physiol. 13:1-15.

Harris, R. A. 1993. Determination of alkalinity in water samples.

ORNL/M-2975.
Hatano, K., C. C. Trettin, C. H. House, and A. G. Woolum III. 1993. Microbial populations and decomposition activity in three subsurface flow constructed wetlands. In G. A. Moghiri (ed.), Constructed Wetlands for Water Quality Improvement, Lewis Publishers, Chelsea, Michigan.

Hatcher, R. D., Jr., P. J. Lemiszki, R. B. Dreier, R. H. Ketelle, R. R. Lee, D. A. Lietzke, W. M. McMaster, J. L. Foreman, and S. Y. Lee. 1992. Status report on the geology of the Oak Ridge Reservation. ORNL/TM-12074.

Heitzer, A., R. S. Burlage, P. M. DiGrazia, and G. S. Sayler. 1992. Bioluminescent reporters for catabolic gene expression and pollutant bioavailability. pp. 298-306.

In Proceedings of the Second International Marine Biotechnology Conference, Baltimore, October 17-18, 1991. Society for Industrial Microbiology.

Hendricks, M. S. 1992. Waste reduction plan for Environmental Sciences Division. ORNL/FPO-92/70.

Hildebrand, S. G. (ed.) 1992. Agenda and abstracts, Environmental Sciences Division Annual Information Meeting, Oak Ridge National Laboratory, Oak Ridge, Tennessee, May 5-7, 1992.

Hildebrand, S. G., and J. B. Cannon. 1993. Preface and Chapter 1 Introduction. pp. 3-6. In S. G. Hildebrand and J. B. Cannon (eds.), Proceedings of Ninth Life Sciences Symposium, The Scientific Challenges of NEPA: Future Directions Based on 20 Years of Experience, Knoxville, Tennessee, October 24-27, 1989. Environmental Analysis: The NEPA Experience. Lewis Publishers, Chelsea, Michigan. 
Hildebrand, S. G., D. E. Fowler, R. K. McConathy, B. M. Ross, and M. S. Hendricks. 1993. Self-assessment report of the Environmental Sciences Division, FY 1992. ORNL/FPO-93/38.

Hill, W. R. 1993. Canopy closure over two headwaier streams: Consequences for periphyton, grazers, and nutrients. Bull. North Am. Benthol. Soc. 10:89-90.

Hill, W. R., S. C. Weber, and A. J. Stewart. 1992. Food limitarion of two lotic grazers: Quantity, quality, and size-specificity. J. North Am. Benthol. Soc. 11(4):420-32.

Hinzman, R. L., S. M. Adams, M. C. Black, H. L. Boston, W. Burton, A. J. Gatz Jr., M. S. Greeley Jr., W. R. Hill, J. M. Loar, J. F. McCarthy, M. J. Peterson, M. G. Ryon, J. G. Smith, G. R. Southworth, A. J. Stewart, and V. R. Tolbert. 1993. Second report on the Oak Ridge Y-12 Plant Biological Monitoring and Abatement Program for East Fork Poplar Creek, Y-12 Plant, Oak Ridge, Tennessee. Y/TS-888. Oak Ridge Y-12 Plant, Oak Ridge, Tennessee.

Hinzman, R. L., A. J. Stewart, G. R. Southworth, and M. K. Filson. 1993. Evaluation of the environmental effects of stormwater pollutants for Oak Ridge National Laboratory. Office of Environmental Compliance and Documentation, Oak Ridge, Tennessee (draft).

Hoffman, F. O. 1992. International biospheric model validation: Implications for environmental risk assessment. pp. 4-5. In Agenda and abstracts, Environmental Sciences Division Annual Information Meeting, Oak Ridge National Laboratory, Oak Ridge, Tennessee, May 5-7, 1992.
Hoffman, W. A., and P. J. Hanson. 1992. Emission of non- $\mathrm{CO}_{2}$ non- $\mathrm{CH}_{4}$ volatile organics from hardwood and conifer forest floor cores. p. 348. Agronomy Abstracts, 84th Annual Meeting of the Soil Science Socicty of America, Minneapolis, November 1-6, 1992. American Society of Agronomy.

Hoffman, F. O., K. M. Thiessen, M. L. Frank, and B. G. Blaylock. 1992. Quantification of the interception and initial retention of radioactive contaminants deposited on pasture grass by simulated rain. Atmos. Environ. 26A(18):3313-21.

Hoffman, F. O., and V. S. Tripathi. 1993. The development of a geochemical expert system prototype using object-oriented knowledge representation and a production rule system. Comput. Geosci. 19(1):53-60.

Hoffman, F. O., K. M. Thiessen, and R. M. Rael. 1992. Comparison of initial interception and retention of wet-deposited contaminants on leaves of coniferous and broad-leafed forest species with other common vegetation types. Book of Abstracts, Seminar on Dynamics of the Behaviour of Radionuclides in Contaminated Forests, Stockholm, May 18-22, 1992. Swedish Radiation Protection Institute, Stockholm.

Holdren, G. R., Jr., T. C. Strickland, B. J. Cosby, D. Marmorek, D. Bernard, R. Santore, C. T. Drisull, L. Puralo, and R. S. Turner. 1993. A national critical loads framework for atmospheric deposition effects assessment: IV: Model selection applications and critical loads mapping. Environ. Manage. 17(3):355-63.

Holdren, G. R., Jr., T. C. Strickland, B. Rosenbaum, R. S. Turner, P. F. Ryan, M. K. McDowell, G. D. Bishop, 
G. E. Griffith, K. Smythe, and P. L. Ringold. 1992. Comparison of selected critical loads estimation approaches for assessing the effects of sulfate deposition on lakes in the northeastern United States. ORNL/M-2630.

Holdren, G. R., Jr., T. C. Strickland, P. W. Shaffer, P. F. Ryan, P. L. Ringold, and R. S. Turner. 1993. Sensitivity of critical load estimates for surface waters to model selection and regionalization schemes. J. Environ. Qual. 22:279-89.

Holladay, S. K., M. S. Bevelhimer, C. C. Brandt, R. B. Cook, W. D. Crumby, C. J. Ford, M. J. Gentry, L. A. Hook, D. A. Levine, R. C. Longman, S. E. Madix, R. L. Moody, C. D. Rash, and L. F. Williams. 1993. Quality assurance, quality control summary report for Phase 1 of the Clinch River remedial investigation. ORNL/ER-152.

Holland, M. M., D. M. Lawrence, D. J. Marrin, C. T. Hunsaker, D. Inouye, A. Janetos, H. R. Pulliam, W. Robertson, and J. Wilson. 1992. Profiles of ecologists: Results of a survey of the membership of the Ecological Society of America. Ecological Society of America, Washington, D.C.

Homer, V. J., Z. H. Chen, and J. F. McCarthy. 1992. Fractal dimension: A probe of humic aggregation properties. p. 373. Agronomy Abstracts, 84th Annual Meeting of the Soil Science Society of America, Minneapolis, November 1-6, 1992. American Society of Agronomy.

Houlberg, L. M., G. T. Hawkins, E. B. Lewis, and M. S. Salk. 1992. Environmental regulatory update table, September/October. ORNL/M-1929/R4.
Houlberg, L. M., G. T. Hawkins, E. B. Lewis, and M. S. Salk. 1993. Environmental regulatory update table, November/December. ORNL/M-1929/R5.

Houlberg, L. M., G. T. Hawkins, M. S. Salk, G. S. Danford, and E. B. Lewis. 1993. Environmental regulatory update table, January/February, March/April, May/June, and July/August.

ORNL/M-2648 and R1/R2/R3.

Hoylman, A. M., N. T. Edwards, and B. T. Walton. 1992. Uptake and translocation of polycyclic aromatic hydrocarbons by vegetation. p. 238. In Book of Abstracts, 13th Annual Meeting of the Society for Environmental Toxicology and Chemistry, Cincinnati, November 8-12, 1992. Society for Environmental Toxicology and Chemistry.

Hoylman, A. M., N. T. Edwards, and B. T. Walton. 1992. Uptake and translocation of selected polycyclic aromatic hydrocarbons by white sweetclover (Melilotus alba Desr.) under laboratory conditions. ORNL/M-3015.

Huang, B., T. W. Wang, R. Burlage, and G. Sayler. 1992. Development of a novel sensor for bioreactor operation. Paper 20. In Proceedings of the 14th Symposium on Biotechnology for Fuels and Chemicals, The University of Tennessee, Knoxville, May 11-15, 1992.

Huang, B., T. W. Wang, R. Burlage, and G. Sayler. 1993. Development of an online sensor for bioreactor operation. Appl. Biochem. Biotechnol. 39/40:371-82.

Hughes, P. J., R. A. Hawsey, R. L. Graves, R. N. McGill, M. Olszewski, G. Wood, T. Simmons, J. E. Christian, P. D. Fairchild, W. R. Mixon, M. A. Brown, J. H. Cushman, 
M. A. Karnitz, D. R. Johnson, P. Angelini, P. J. Blau, and V. J. Tennery. 1993. Energy efficiency and renewable energy program monthly report for the period ending July. ORNL/CF-93/213.

Hunsaker, C. T. 1993. Ecosystem assessment methods for cumulative effects at regional and global scales. pp. 480-93. In S. G. Hildebrand and J. B. Cannon (eds.), Proceedings of Ninth Life Sciences Symposium, The Scientific Challenges of NEPA: Future Directions Based on 20 Years of Experience, Knoxville, Tennessee, October 24-27, 1989. Environmental Analysis: The NEPA Experience. Lewis Publishers, Chelsea, Michigan.

Hunsaker, C. T., R. Graham, R. S. Turner, R. L. Ringold, G. R. Holdren, and T. C. Strickland. 1993. A National critical loads framework for atmospheric deposition effects assessment: II. Defining assessment endpoints, indicators, and functional subregions. Environ. Manage. 17(3):335-41.

Hunsaker, C. T., and D. A. Levine. 1993. Hierarchical approaches to large river landscapes. Proceedings of Annual Meeting of Ecological Society of America, Madison, Wisconsin, July 31-August 3, 1993. Ecological Society of America, Washington, D.C. Bull. Ecol. Soc. Am. 74(2):286.

Hunsaker, C. T., S. P. Timmins, B. L. Jackson, J. A. Griffith, and R. V. O'Neill. 1993. Landscape pattern analysis for ecoregions. p. 60. Program and Abstracts, Eighth Annual U.S. Landscape Ecology Symposium, Oak Ridge, Tennessee.

Hurst, D. H., K. G. Robinson, and R. L. Siegrist. 1993. Hydrogen peroxide treatment of TCE contaminated soil.
Proceedings of the Third International Symposium on Chemical Oxidation: Technology for the Nineties. International Chemical Oxidation Association, Nashville, Tennessec, February 17-19, 199.

Huston, M. A. 1993. Fourth Annual Walker Branch Watershed Research Symposium Program and Abstracts, March 18-19, 1993. Oak Ridge National Laboratory, Oak Ridge, Tennessee. CONF-930371.

Jackson, B. L. 1993. SAS data base of chemical substance information from the Environmental Protection Agency's "The 1990 List of Lists." Proceedngs of SAS User's Group International 17th Annual Users Conference, Cary, North Carolina, April 12-15, 1993. SAS Institute.

Jackson, B. L. 1993. SAS macros for converting between ARC/NFO singlevariable files and SAS data sets. pp. 846-47. In Proceedings of the 18th SAS Users Group International Conference, SAS Institute, Cary, North Carolina, May 9-12, 1993.

Jacobs, G. K., V. Alexiades, N. W. Dunbar. and M. T. Naney. 1992. Conductiondiffusion simulation of the crystallization. and cooling behavior of a field-scale melting experiment. Eos, Trans. Am. Geophys. Union 73(43):647.

Jacobs, G. K., B. P. Spalding, and J. S. Tixier. 1992. In situ vitrification: Immobilizing radioactive contaminants in place by melting soils into man-made rocks. Abstracts and Program, Meeting of Geological Society of America, Cincinnati, November 2-6, 1992. Geol. Soc. Am. 24(7) 73 .

Jacobs, G. K., B. P. Spalding, J. S. Tixier, and T. D. Powell. 1993. Stabilization of 
contaminated soils by in situ vitrification. pp. 425-30. In Proceedings of Information Exchange Meeting on Waste Retrieval, Treatment and Processing, Houston, March 15-17, 1993. CONF-930149.

Jager, H. I., M. J. Sale, M. J. Sabo, W. Van Winkle, and D. D. Schmoyer. 1993. Verification of a model to simulate the response of young-of-year smallmouth bass to flow in the North Anna River, Virginia. p. 18. In Abstracts of First Annual Mid-Year Technical Meeting of American Fisheries Society, Southern Division, Chattanooga, Tennessee, February 25-26, 1993. American Fisheries Society.

Jardine, P. M., G. K. Jacobs, and G. V. Wilson. 1993. Unsaturated transport processes in undisturbed heterogeneous porous media: I. Inorganic Contaminants. Soil Sci. Soc. Am. J. 57:945-953.

Jardine, P. M., G. K. Jacobs, and J. D. O'Dell. 1993. Unsaturated transport processes in undisturbed heterogeneous porous media:

II. Co-Contaminants. Soil Sci. Soc. Am. J. 57:954-962.

Johnson, D. W., S. E. Lindberg, H. Van Miegroet, G. M. Lovett, D. W. Cole, and D. Binkley. 1993. Atmospheric deposition, forest nutrient status, and forest decline: Implications of the integrated forest study. pp. 66-81. In Proceedings of Conference on Forest Decline in the Atlantic and Pacific Region, Hilo, Hawaii, June 2-6, 1991. SpringerVerlag, New York.

Jones, D. W., and R. V. O'Neill. 1992. Endogenous environmental degradation and land conservation: Agricultural land use in a large region. Ecol. Econ. 6:79-101.

Jones, D. W., and R. V. O'Neill. 1992. Land use with endogenous environmental degradation and conservation. Resour. Energy 14:381-400.

Jones, D. W., and R. V. O'Neill. 1993. Human-environmental influences and interactions in shifting agriculture. pp. 297-309. In Structure and Change in the Space Economy, Springer-Verlag.

Jones, D. W., and R. V. O'Neill. 1993. Human-environmental influences and interactions in shifting agriculture when farmers form expectations rationally. Environ. Plann. A 25:121-36.

Kaiser, D. 1993. Cloud amount and sunshine duration in the People's Republic of China, 1954-88. pp. 224-32. Eighth Conference on Applied Climatology, 73rd American Meteorological Society Annual Meeting, Anaheim, California, January 17-22, 1993. American Meteorological Society, Boston.

Kaiser, D., S. Tao, C. Fu, Z. Zeng, Q. Zhang, W-C. Wang, and T. Karl. 1992. Climatic data bases of the People's Republic of China, 1841-1988. ORNL/M-2592.

Kearl, P. M., F. G. Gardner, and M. J. Gunderson. 1993. Groundwater flow delineation study at the Massachusetts Military Reservation using the colloidal borescope. ORNL/TM-12139.

Kelly, J. M., G. E. Taylor Jr., N. T. Edwards, M. B. Adams, G. S. Edwards, and A. L. Friend. 1993. Growth, physiology, and nutrition of loblolly pine seedlings stressed by ozone and acidic precipitation: A summary of the 
ROPIS-south project. Water Air Soil Pollut. 69:363-91.

Kim, K.-H., and M. O. Andreae. 1992. Carbon disulfide in the estuarine, coastal, and oceanic environments. Mar. Chem. 40:179-97.

Kim, K.-H., S. E. Lindberg, P. J. Hanson, T. P. Meyers, and J. G. Owens. 1993. Application of micrometeorological methods to measurements of mercury emissions over contaminated soils. pp. 328-31. In Heavy Metals in the Environment, Toronto, Canada.

Kim, K.-H., K. M. Turnage, S. Y. Lee, J. E. Foss, I. L. Larsen, R. J. Lewis, and M. E. Timpson. 1992. Soil erosion and deposition rates calculated within sinkholes using ${ }^{137} \mathrm{Cs}$ redistribution. Agronomy Abstracts, 84th Annual Meeting of the Soil Science Society of America, Minneapolis, November 1-6, 1992. American Society of Agronomy.

Kocher, D. C., and F. O. Hoffman. 1992. Reply to Weisburger regarding "Regulating Environmental Carcinogens." Environ. Sci. Technol. 26:845-46.

Koppenaal, R. T., J. J. Tschaplinski, and S. J. Colombo. 1991. Carbohydrate accumulation and turgor maintenance in seedling shoots and roots of two boreal conifers subjected to water stress. Can. J. Bot. 69:2522-28.

Korte, N. E., and D. E. Brown. 1993. Referee analyses-A better approach than data validation. Environ. Auditor 17(2):277-80.

Korte, N. E., P. M. Kearl, T. A. Gleason, and J. S. Beale. 1992. The inadequacy of commonly used risk assessment guidance for determining whether solvent- contaminated soils can affect groundwater at arid sites. J. Environ. Sci. Health 27(8):2251-61.

Korte, V. M., T. J. Phelps, P. R. Bienkowski, and D. W. White. 1993. Biodegradation of chlorinated aliphatics and aromatic compounds in total-recycle expanded-bed biofilm reactors. Appl. Biochem. Biotechnol. 39/40:631-41.

Krause, C. H., J. W. Pearce, M. A. Huston, K. U. Vandergriff, J. H. Hannah,

A. J. Mattus, S. S. Talmage, and

B. T. Walton. 1992. Oak Ridge National Laboratory Review, Vol. 25, No. 1. ORNL/M-1998.

Kszos, L. A., S. M. Adams, T. L. Ashwood, B. G. Blaylock, M. S. Greeley, R. L. Hinzman, J. M. Loar, M. J. Peterson, M. G. Ryon, B. A. Shoemaker, J. G. Smith, and G. R. Southworth. 1993. Biological Monitoriig and Abatement Program for the Oak Ridge K-25 Site. K/EM-24/R2. Oak Ridge K-25 Site, Oak Ridge, Tennessee.

Kszos, L. A., A. J. Stewart, L. F. Wicker, and L. E. Roberson. 1992. Toxicology laboratory quality assurance program. ORNL/FPO-92/29.

Kszos, L. A., A. J. Stewart, L. F. Wicker, L. E. Roberson, and T. L. Phipps. 1992. Environmental Sciences Division toxicology laboratory quality assurance program. ORNL/FPO-92/52.

Kszos, L. A. (ed), R. L. Hinzman, T. G. Jett, M. J. Peterson, M. G. Ryon, J. G. Smith, and G. R. Southworth. 1993. Report on the Biological Monitoring and Abatement Program at Paducah Gaseous Diffusion Plant, December 1990 to November 1992, Oak Ridge, Tennessee. ORNL/TM-12338 (draft). 
Labieniec, P. A., D. A. Dzombak, and R. L. Siegrist. 1993. Risk implications of approaches to setting soil remediation goals. pp. 121-30. In Proceedings of Conference on Cleanup Standards for Contaminated Sites. Water Environment Federation, Washington, D.C.

Lackey, L. W., T. J. Phelps, P. R. Bienkowski, and D. C. White. 19y3. Biodegradation of chlorinated aliphatic hydrocarbon mixtures in a single-pass packed bed reactor. Appl. Biochem. Biotechnol. 39/40:701-13.

Land, M. L., R. J. Olson, L. D. Voorhees, R. A. McCord, J. K. Thomas, E. P. Tinnel, and R. C. Durfee. 1993. Initiation, review, revision, approval, and issuance of OREIS procedures and instructions. ORNL/M-2729.

Land, M. L., R. J. Olson, L. D. Voorhees, R. A. McCord, J. K. Thomas, E. P. Tinnel, and R. C. Durfee. 1993. Registration of OREIS users. ORNL/M-2730.

Land, M. L., R. J. Olson, L. D. Voorhees, R. A. McCord, J. K. Thomas, E. P. Tinnel, and R. C. Durfee. 1993. Backup, archival, and recovery of the Oak Ridge Environmental Information System. ORNL/M-2731.

Land, M. L., J. K. Thomas, R. A. McCord, R. J. Olson, R. C. Durfee, E. P. Tinnel, and D. Herr. 1993. Receiving, processing, and maintaining records for the Oak Ridge Environmental Information System (OREIS). ORNL/M-2861.

Landrum, C. L., T. L. Ashwood, and D. K. Cox. 1993. Belted kingfishers as ecological monitors of contamination: A review. ORNL/M-2533.
Larsen, I. L. 1993. Environmental Sciences Division technical procedures for QA/QC operations of ND 6700 in Room 169. ORNL/M-2709.

Leavitt, S. W., E. A. Paul, B. A. Kimball, and G. R. Hendry. 1992. DOE Research Summary, No. 22, December.

ORNL/M-2575.

Lee, S. Y., B. Burgoa, T. Ammons, D. A. Leitzke, J. Branson, and D. R. Watkins. 1992. Background soil characterization for DOE Environmental Restoration Program. Agronomy Abstracts, 84th Annual Meeting of the Soil Science Society of America, Minneapolis, November 1-6, 1992. American Society of Agronomy.

Lee, R. G., R. A. Cantor, L. W. Barnthouse, C. E. Easterly, G. F. Cada, T. D. Jones, R. L. Kroodsma, A. J. Krupnick, A. Schaffhauser, Jr., H. Smith, and R. S. Turner. 1992. U.S.-EC fuel cycle study: Background document to the approach and issues. ORNL/M-2500.

Lee, S. Y., M. P. Elless, and C. W. Francis. 1992. Mineralogical characterization of uranium contaminated soils at DOE Fernald Site. p. 375. In Agronomy Abstracts, American Society of Agronomy, Madison, Wisconsin.

Lee, R. G., R. Flamm, M. G. Turner, C. Bledsoe, P. Chandler, C. DeFerrari, R. Gottfried, R. J. Naiman, N. Schumaker, and $D$. Wear. 1992. Integrating sustainable development and environmental vitality: A landscape ecology approach. pp. 499-521. In Watershed Management, Springer-Verlag, New York.

Lee, D. W., D. C. Kocher, J. R. Trabalka, D. L. Feldman, K. R. Elam, and 
T. J. Abraham. 1993. Energy Systems, waste management organization: Waste management strategy. ORNL/TM-12354.

Lee, R. E., Jr., M. R. Lee, and J. M. Strong-Gunderson. 1993. Insect cold-hardiness and ice nucleating active microorganisms including their potential use for biological control. J. Insect. Physiol. 39(1):1-12.

Lemiszki, P. J., and R. D. Hatcher, Jr. 1992. Structural analysis of the Copper Creek and Whiteoak Mountain faults in east Tennessee: Implications for the thrusting sequence and growth of the southern Appalachian foreland fold-thrust belt. p. A362. In Geological Society of America Abstracts with Programs, Vol. 24. Geological Society of America, Boulder, Colorado.

Lemiszki, P. J., P. S. Neuhoff, and R. B. Dreier. 1993. Core analysis combined with electromagnetic borehole flowmeter surveys is an effective way to document transmissive geologic structures. p. 41. In Fourth National Technology Information Exchange Workshop, Knoxville, Tennessee, May 11-13, 1993.

Levine, D. A., C. T. Hunsaker, S. P. Timmins, and J. J. Beauchamp. 1993. A geographic information system approach to modeling nutrient and sediment transport. ORNL-6736.

Lewis, A. W. 1993. Environmental Sciences Division chemical hygiene plan. ORNL/FPO-93/56.

Lewis, A. W. 1993. Environmental Sciences Division radio use procedure, ES-ADM-93-009. ORNL/FPO-93/55.

Liang, L. 1992. Chemical stability and colloid stability of iron oxyhydroxide and the effects on colloid transport in subsurface environments. ACS National Meeting, Am. Chem. Soc. 32(1):715-716.

Liang, L., J. F. McCarthy, L. W Jolley, J. A. McNabb, and T. L. Mehlhorn. 1993. Iron dynamics-observations of transformation during injections of natural organic matter in a sandy aquifer. Geochim. Cosmochim. Acta 57:1987-99.

Liang, L., J. McNabb, J. Paulk, B. Gu, and J. F. McCarthy. 1993. Kinetics of Fe(II) oxygenation at low $p$ al pressure of oxygen in the presc ' 2 of natural organic matter. Environ. Scl. iechnol. 27(9):1864-70.

Lindberg, S. E., C. T. Garten Jr., J. N. Cape, and W. Ivens. 1992. Can sulfate fluxes in forest canopy throughfall be used to estimate atmospheric sulfur deposition? A Summary of Recent Results. pp. 1379-90. In Precipitation Scavenging and Atmosphere-Surface Exchange, Vol. 3, Applications and Appraisals, Hemisphere Publishers, Washington, D.C.

Lindberg, S. E., and J. G. Owens. 1993. Throughfall studies of deposition to forest edges and gaps in montane ecosystems. Biogeochem. 19:173-94.

Loar, J. M. 1992. Second report on the Oak Ridge National Laboratory Biological Monitoring and Abatement Program for White Oak Creek Watershed and the Clinch River. ORNL/TM-10804.

Loar, J. M., S. M. Adams, L. J. Allison, M. C. Black, H. L. Boston, A. J. Gatz, Jr., R. L. Hinzman, M. A. Huston, B. D. Jimenez, J. F. McCarthy, S. D. Reagan, J. G. Smith, G. R. Southworth, and A. J. Stewart. 1992. First report on the Oak Ridge 
Y-12 Plant Biological Monitoring and Abatement Program for East Fork Poplar Creek. Y/TS-886. Oak Ridge Y-12 Plant, Oak Ridge, Tennessee.

Lucero, A. J., A. F. Walker, Jr., T. L. Donaldson, T. J. Phelps, and R. L. Siegrist. 1993. Bioremediation demonstration at Kwajalein Atoll. In Situ and Ori Site Bioreclamation, San Diego, California.

Luxmoore, R. J. 1993. Homeostasis and soil-plant nutrient relationships in a changing environment. p. 63. In Abstracts, XV International Botanical Congress. International Union of Biological Sciences, Yokohama, Japan.

Luxmoore, R. J., M. Cunningham, L. K. Mann, and M. G. Tjoelker. 1993. Urea fertilization effects on nutrient uptake and growth of Platanus occidentalis during plantation establishment. Trees 7:250-57.

Luxmoore, R. J., and L. A. Ferrand. 1992. Towards pore-scale analysis of preferential flow and chemical transport. pp. 45-60. In D. Russo and G. Dagan (eds.), Water Flow and Solute Transport in Soils: Developments and Applications. SpringerVerlag, New York.

Luxmoore, R. J., and M. L. Tharp. 1993. Simulation of barrier heterogeneity and preferential flow effects on the performance of shallow land burial facilities. ORNL/TM-12058.

Luxmoore, R. J., S. D. Wullschleger, and P. J. Hanson. 1993. Forest responses to $\mathrm{CO}_{2}$ enrichment and climate warming. Water Air Soil Pollut. 70:309-23.

Luxmoore, R. M. 1993. Global change and forests: The last $2 \frac{1}{2}$ hours of creation. pp. 7-8. In Proceedings of Ecophysiology and Genetics of Trees and Forests in a Changing Environment, University of Tuscia, Viterbo, Italy, May 23-30, 1993.

Madix, S. 1993. Determination of total suspended particles in a water sample. ORNL/M-2897.

Madix, S. 1993. Determination of turbidity in a water sample.

ORNL/M-2898.

Malachowsky, K., T. J. Phelps, and D. C. White. 1992. Aerobic degradation of trichloroethylene (TCE), vinyl chloride (VC), and aromatic compounds by type IV actinomycetes. p. 382. In Proceedings of the Annual Meeting of the American Society for Microbiology, New Orleans, May 27, 1992.

Marcus, M. D., and D. D. Gulley. 1992. Physiological, toxicology, and population responses of smallmouth bass to acidification. Electric Power Research Institute, Palo Alto, California. EPRI TR-101062.

Marland, G., V. H. Dale, R. L. Graham, R. J. Luxmoore, S. Marland, S. B. McLaughlin, R. J. Norby, W. M. Post, T. J. Tschaplinski, G. A. Tuskan, and L. L. Wright. 1993. Forest management for fixing and sequestering carbon. Second U.S./Japan Workshop on Global Change, Honolulu, February 1-3, 1993.

Marsh, J. D., Jr., T. L. Ashwood, J. F. McCarthy, and D. S. Hicks. 1993. Hydrology geochemical factors influencing the behavior and migration of ${ }^{244} \mathrm{Cm}$ and ${ }^{241} \mathrm{Am}$ in groundwater at a shallow waste burial site at Oak Ridge National Laboratory. p. 39. In Fourth National Technology Information Exchange Workshop, Knoxville, Tennessee, May 11-13, 1993. 
Marsh, J. D., Jr., T. L. Ashwood, and D. S. Hicks. 1993. Geochemical factors influencing the occurrence of $\mathrm{Cm}-244$ and Am-241 in groundwater at a shallow waste burial site at Oak Ridge National Laboratory. Book of Abstracts, 205th American Chemical Society National Meeting, Denver, March 28-April 2, 1993. American Chemical Society, Washington, D.C.

Marzolf, E. R., and C. R. Foldman. 1992. The effect of temperature-induced free convection within the sediments and boundary layer on benthic nutrient fluxes in Castle Lake, California. Meeting Program, Annual Meeting of American Society of Limnology and Oceanography, Santa Fe, New Mexico, February 9-13, 1992.

Marzolf, E. R., P. J. Mulholland, and A. D. Steinman. 1993. An in situ whole stream approach to measurement of stream metabolism and implications for nutrient utilization and light limitation. Program and Abstracts, Fourth Annual Walker Branch Watershed Research Symposium, Oak Ridge, Tennessee, March 18-19, 1993.

Maskarinec, M. P., C. K. Bayne, R. A. Jenkins, L. H. Johnson, and S. K. Holladay. 1992. Stability of volatile organics in environmental soil samples, final report.

ORNL/TM-12128.

Mas-Pla, J., T.-C. J. Yeh, J. F. McCarthy, and T. J. Williams. 1992. Numerical simulation of a two-well tracer experiment. Ground Water 30(6):958-64.

McCarthy, J. F. 1993. Summary. pp. 5-13. In Manipulation of Groundwater for Environmental Restoration. Lewis Publishers, Chelsea, Michigan.
McCarthy, J. F., L. Liang, B. Gu, J. A. McNabb, T. W. Mehlhorn, T. M. Williams, J. Mas-Pla, and C.-T. J. Yeh. 1992. Field mobility of natural organic matter in a sandy aquifer. Eos, Trans. Am. Geophys. Union 473(43): 167.

McCarthy, J. F., L. Liang, P. M. Jardine, and T. M. Williams. 1993. Mobility of natural organic matter injected into a sandy aquifer. pp. 35-40. In Manipulation of Groundwater for Environmental Restoration. Lewis Publish rs, Chelsea, Michigan.

McCarthy, J. F., T. M. Williams, L. Liang, P. M. Jardine, L. W. Jolley, D. L. Taylor, A. V. Palumbo, and L. W. Cooper. 1993. Mobility of natural organic matter in a sandy aquifer. Environ. Sci. Technol. 27(4):667-76.

McCarthy, J. F., and F. J. Wobber. 1993. Introduction and scope. pp. 1-4. In Manipulation of Groundwater for Environmental Restoration. Lewis Publishers, Chelsea, Michigan.

McCarthy, J. F., and F. J. Wobber. 1993. Manipulation of groundwater colloids for environmental restoration. p. 371. In Proceedings of a Workshop in Manteo, North Carolina, October 15-18, 1990. Lewis Publishers, Chelsea, Michigan.

McConathy, R. K. 1992. ESD environment, safety and health bulletin, October. ORNL/FPO-92/68.

McConathy, R. K. 1992. Using firearms in ESD to collect biological and scientific samples. ORNL/FPO-92/60.

McConathy, R. K. 1993. Emergency plan for Buildings 1503, 1504, 1505, and 1506. ORNL/FPO-93/26. 
McEvers, J. A., M. S. Hileman, and N. T. Edwards. 1993. Air pollution effects field research facility: 3. UV-B exposure and monitoring system. ORNL/TM-11607.

McLaughlin, S. B., M. G. Tjoelker, and W. K. Roy. 1993. Acid deposition alters red spruce physiology: Laboratory studies support field observations. Can. J. For. Res. 23(3):380-86.

Meyers-Schöne, L., L. R. Shugart, J. J. Beauchamp, and B. T. Walton. 1993. Comparison of two freshwater turtle species as monitors of radionuclide and chemical contamination: DNA damage and residue analysis. Environ. Toxicol. Chem. 12.1487-96.

Milne, B. T., M. G. Turner, J. A. Wiens, and A. R. Johnson. 1992. Interactions between the fractal geometry of landscapes and allometric herbivory. Theor. Popul. Biol. 41:337-53.

Mitchell, T. J., O. R. West, and R. L. Siegrist. 1993. Statistical simulation and 3-dimensional visualization for analysis of VOC datasets. Proceedings of the National Symposium on Measuring and Interpreting VOCs in Soils. U.S. Environmental Protection Agency, Las Vegas, Nevada.

Mitchell, T. J., O. R. West, and R. L. Siegrist. 1993. Statistical simulation and 3-dimensional visualization for analysis of VOC datasets. In Extended Abstract, National Symposium on Measuring and Interpreting VOCs in Soils. U.S. Environmental Protection Agency, Las Vegas, Nevada.

Moline, G. R., J. M. Bahr, G. C. Nadon, and P. A. Drzewiecki. 1993. The role of diagensis in controlling hydrologic characteristics: St. Peter Sandstone,
Michigan basin. Eos, Trans. Am. Geophys. Union 74(16)Suppl:135.

Moore, G. K. 1992 . Injection tests versus slug tests for wells in fractured rocks. pp. 2-5. In Extended Abstracts, Fifth Tennessee Water Resources Symposium, Nashville, Tennessee, October 19-21, 1992. American Water Resources Association.

Moore, G. K., and L. E. Toran. 1992. Supplement to a hydrologic framework for the Oak Ridge Reservation, Oak Ridge, Tennessee. ORNL/TM-12191.

Morris, L. J., and G. M. Logsdon. 1992. Environmental Sciences Division orientation handbook.

ORNL/FPO-90/144/R1.

Mosjidis, J. A. 1993. Variability for biomass production and plant composition in Sericea Lespedeza Germplasm, final report on a field and laboratory research program for the period September 20 , 1990, to December 31, 1991.

ORNL/Sub/90-SG301/1.

Mulholland, P. J. 1992. Regulation of nutrient concentrations in a temperate forest: Roles of upland, riparian and instream processes. Limnol. Oceanogr. 37:1512-26.

Mulholland, P. J. 1993. River conservation and management-book review. J. North Am. Benthol. Soc. 12:100-101.

Mulholland, P. J. 1993. Role of benthic algae in nutrient cycling in freshwater ecosystems. Bull. North Am. Benthol. Soc. $10: 89$.

Mulholland, P. J., and A. D. Rosemond. 1992. Periphyton response to longitudinal nutrient depletion in a woodland stream: 
Evidence of upstream-downstream linkage. J. North Am. Benthol. Soc. 11:405-19.

Mulholland, P. J., A. D. Steinman, A. V. Palumbo, D. L. DeAngelis, and E. R. Marzolf. 1992. The use of artificial streams in stream ecosystem studies. p. 13. In Abstracts of the 13th Annual Meeting of the Society for Environmental Toxicology and Chemistry, Cincinnati, November 8-12, 1992.

Naney, M. T., G. K. Jacobs, M. S. Ghiorso, and N. W. Dunbar. 1993. Comparison of results from the thermodynamic model MELTS to the crystallization history of a field-scale melting experiment. Eos, Trans. Am. Geophys. Union 74:336.

Napolitano, G. E., and R. G. Ackman. 1993. Incorporation of phytoplankton fatty acids and sterols by the filter-feeding scallop Placopecten magellanicus. J. Am. Oil Chem. Soc. 4(4):534.

Napolitano, G. E., R. G. Ackman, and M. A. Silva-Serra. 1993. Incorporation of dietary sterols by the sea scallop Placopecten magellanicus (Gmelin) fed on microalgae. Mar. Biol. 117(4):647-55.

Napolitano, G. E., W. R. Hill, A. J. Stewart, and D. C. White. 1993. Periphyton analysis as a toxicity assessment instrument-lipid analysis of periphyton for biomonitoring. ORNL/M-2863.

Napolitano, G. E., C. Mero, and A. J. Stewart. 1993. Structural and storage lipids in algae: Their relationship with light and biomass measurements. Bull. North Am. Benthol. Soc. 10(1):135.

Nativ, R., and A. E. Hunley. 1993. The deep hydrogeologic flow system underlying the Oak Ridge Reservation. ORNL/GWPO-003.
Neuhoff, P. S., P. J. Lemiszki, and R. B. Dreicr. 1993. Geologic characteristics of permeable groundwater intervals defined by electromagnetic borehole flowmeter surveys on the Oak Ridge Rescrvation. Program and Abstracts, Mecting of Geological Socicty of America, Southeast Section, Tallahassec, Florida, April 7, 1993. Geol. Soc. Am. 25:59.

Niemcla, S. L., M. S. Greeley, T. K. Elston, L. R. Shugart, C. G. Hull, and J. R. Platt. 1992. The use of a medaka embryo-larval test to examine the development toxicity of streams and rivers draining the Oak Ridge Federal Reservation. p. 248. In Abstracts of the 13th Annual Meeting of the Society for Environmental Toxicology and Chemistry, Cincinnati, November 8-12, 1992.

Niemela, S. L., M. S. Greeley, and M. K. McCracken. 1993. Application of a Japanese medaka embryo-larval toxicity test in a river receiving pulp and paper mill effluent. 1993 SETAC Conference, Houston, Texas.

Norby, R. J., C. A. Gunderson, S. D. Wullschleger, E. G. O'Neill, and M. K. McCracken. 1991. Growth efficiency and compensatory responses of yellow-poplar saplings in elevated $\mathrm{CO}_{2}$. Nature 357:322-24.

Nyquist, J. E., and W. E. Doll. 1993. Comparison of surface and aerial geophysics for characterizing a hazardous waste site: A case study. pp. 468-71. In Extended Abstracts, 63rd Annual Meeting of the Society of Exploration Geophysicists. Society of Exploration Geophysicists, Tulsa, Oklahoma.

Nyquist, J. E., W. E. Doll, J. S. Holladay, L. Pellenn, and V. F. Labson. 1993. 
Environmental characterization of the Oak Ridge Reservation using helicopter geophysics. p. 2. In International Workshop on Airborne Electromagnetic Methods, Laboratory for Advanced Subsurface Imaging (LASI), Tucson, Arizona.

Nyquist, J. E., and M. S. Emery. 1993. Electromagnetic survey of K1070A Burial Ground. K/ER-56. Oak Ridge K-25 Site, Oak Ridge, Tennessee.

O'Connell, P. M., and A. Wilson. 1993. RCRA/CERCLA Update, Vol. 93(2). July. ORNL/M-2995.

O'Hara, F. M., Jr. 1992. Carbon Dioxide Information Analysis Center Communications: Summer 1992, No. 17.

CDIAC/ORNL, Oak Ridge, Tennessee.

O'Hara, F. M., Jr. 1993. Carbon Dioxide Information Analysis Center Communications: Spring 1993, No. 18.

CDIAC/ORNL, Oak Ridge, Tennessee.

Olsen, C. R., I. L. Larsen, P. J. Mulholland, K. L. Von Damm, J. M. Grebmeier, L. C. Schaffner, R. J. Diaz, and M. M. Nichols. 1993. The concept of equilibrium surface applied to particle sources and contaminant distributions in estuarine sediments. Estuaries 16:683-96.

Olson, R. J., L. D. Voorhees, R. A. McCord, J. K. Thomas, M. L. Land, R. C. Durfee, and E. P. Tinnel. 1993. Processing and review associated with data transmitted to the Oak Ridge Environmental Information Systems (OREIS-12801, Rev. 0). ORNL/M-2781.

O'Neill, R. V., C. T. Hunsaker, and D. A. Levine. 1992. Monitoring challenges and innovative ideas. pp. 1443-60, Vol. 2. In D. McKenzie, E. Hyatt and J. McDonald (eds.), Ecological Indicators, Elsevier Applied Sciences, New York.

Palumbo, A. V., P. M. Jardine, R. S. Burlage, S. Scarborough, and G. V. Wilson. 1993. Transport of bacteria in an unsaturated pedon. p. 419. In Abstracts of the 93rd General Meeting of the American Society for Microbiology, Atlanta, May 16-20, 1993.

Palumbo, A. V., S. Y. Lee, and P. Boerman. 1993. The effect of media composition on EDTA degradation by agrobacterium radiobacter. p. 127. Program and Abstracts, 15th Symposium on Biotechnology for Fuels and Chemicals, Colorado Springs, Colorado, May 1993.

Palumbo, A. V., J. F. McCarthy, R. S. Burlage, P. M. Jardine, and G. V. Wilson. 1993. The application of molecular techniques to bacterial transport experiments: Examples from vadose zone and aquifer studies. p. E-06. In Programme and Abstracts, 1993 International Symposium on Microbiology of the Deep Subsurface, Bath, England, September 1993.

Palumbo, A. V., A. Parker, J. F. McCarthy, T. J. Phelps, and J. Strong-Gunderson. 1993. Potential for microbial growth in arid subsurface sediment. p. 128. In Proceedings of 15th Symposium on Biotechnology for Fuels and Chemicals, Colorado Springs, Colorado, May 1993.

Palumbo, A. V., T. J. Phelps, G. S. Saylor, D. C. White, and S. M. Pfiffner. 1993. Integrated demonstration of TCE degradation: Biological monitoring of critical populations. pp. 139-45. In Proceedings of Information Exchange Meeting on Waste Retrieval, Treatment 
and Processing, Houston, March 15-17, 1993.

Palumbo, A. V. and L. Shugart. 1993. Biotechnology, biological activity, and biological effects. U.S. Department of Energy, Office of Health and Environmental Research, Program Directors Meetings, Oak Ridge, Tennessee, September 1993.

Palumbo, A. V., J. M. Strong-Gunderson, and J. F. McCarthy. 1993. Bioavailability of natural organic matter to deep subsurface microbiota. p. B-05. In Programme and Abstracts, 1993 International Symposium on Microbiology of the Deep Subsurface, Bath, England, September 1993.

Parrish, D. J., D. D. Wolf, and W. L. Daniels. 1993. Perennial species for optimum production of herbaceous biomass in the piedmont (management study 1987-91). ORNL/Sub/85-27413/7.

Pastor, J., and W. M. Post. 1993. Linear regressions do not predict the transient responses of eastern North American forests to $\mathrm{CO}_{2}$-induced climate change. Clim. Change 23:111-19.

Peakall, D. B., and L. R. Shugart. 1992. Biomarker research and application in the assessment of environmental health. In NATO ASI Series, Springer-Verlag, Heidelberg. Cell Biol. 68:146

Peng, T.-H. 1992. Possible effects of ozone depletion on global carbon cycle. Radiocarbon 34(3):772-79.

Peng, T.-H. 1993. Possible reduction of atmospheric $\mathrm{CO}_{2}$ by iron fertilization in the Antarctic Ocean. pp. 263-85. In Geophysical/Geochemical Aspects of Global Warming, Lewis Publishers, Chelsea, Michigan.
Peng, T.-H., and W. S. Broecker. 1992. Effect of oceanic carbon transport on global carbon cycle. Prociedings of Western Pacific Geophysics Meeting, American Geophysical Union, Hong Kong, August 17-21, 1992.

Peng, T.-H., and W. S. Broecker. 1992. Estimates of interhemispheric ocean carbon transport. Proceedings of National Spring Meeting American Geophysical Union, Montreal, May 12-15, 1992.

Peng, T.-H., and W. S. Broecker. 1992. Reconstruction of radiocarbon distribution in the glacial ocean. pp. 75-92. In Radiocarbon After Four Decades: An Interdisciplinary Perspective, SpringerVerlag, New York.

Peng, T.-H., and W. S. Broecker. 1993. Sensitivity evaluation for oceanic uptake of fossil fuel $\mathrm{CO}_{2}$ based on global ${ }^{13} \mathrm{C}$ distribution. p. 30. In Book of Abstracts, Global Atmospheric-Biospheric Chemistry, Eilat, Israel, April 18-22, 1993.

Peng, T.-H., E. Maier-Reimer, and W. S. Broecker. 1993. The distribution of ${ }^{32} \mathrm{Si}$ in the world ocean: Model compared to observation. Global Biogeochem. Cycle 7(2):463-74.

Peng, T.-H., and T. Takahashi. 1993. Ocean uptake of carbon dioxide. HTD 246:117-34. In R. A. Amano, R. H. Pletcher, S. A. Sherif, R. G. Watts, and A. N. Anand (eds.), Symposium on Heat and Mass Transfer in Oceans, Atlanta, August 8-11, 1993. American Society of Mechanical Engineers.

Perlack, R. D., J. W. Ranney, and L. L. Wright. 1992. Environmental emissions from biomass energy feedstocks. pp. 58-65. In Liquid Fuels from Renewable Resources: Proceedings of 
Alternative Energy Conference, Nashville, Tennessee.

Perlack, R. D., J. W. Ranney, and L. L. Wright. 1992. Environmental emissions and socioeconomic considerations in the production, storage, and transportation of biomass energy feedstocks. ORNL/TM-12030.

Peterson, M. J., G. R. Southworth, and W. D. Crumby. 1993. Detecting the presence of biologically-available mercury contamination in small streams using blacknose dace (Rhinichthys atratulus). p. 75. In Abstracts, 123rd Annual Meeting of the American Fisheries Society. American Fisheries Society, Portland, Oregon.

Peterson, M. J., G. R. Southworth, and K. D. Ham. 1993. Evaluation of the asiatic clam (Corbicula fluminea) as a monitor of PCB contamination in chlorine impacted streams. Bull. North Am.

Benthol. Soc. 10(1):144-45.

Peterson, T. C., and R. S. Vose. 1992. The Global Historical Climatology Network (GHCN): Present and future. pp. 172-77. In Proceedings of 17th Annual Climate Diagnostics Workshop, U.S. Department of Commerce, Norman, Oklahoma, October 18-23, 1992.

Phelps, T. J., and R. L. Siegrist. 1992. Bioremediation of petroleum-contaminated soil on Kwajalein Island: Column biotreatability studies. ORNL/TM-12273.

Phelps, T. J., R. L. Siegrist, N. E. Korte, D. A. Pickering, J. M. Strong-Gunderson, A. V. Palumbo, J. F. Walker, C. M. Morrissey, and R. Mackowski. 1993. Bioremediation of petroleum hydrocarbons in soil column lysimeters from Kwajalein Island. Proceedings of the 15th Symposium on Biotechnology for Fuels and Chemicals. U.S. Department of Energy, Colorado Springs, Colorado.

Pickering, D. A., A. D. Laase, and D. A. Locke. 1993. Potential effect of natural gas wells on alluvial groundwater contamination at the Kansas City Plant. ORNL/TM-12226.

Post, W. M., III. 1992. Uncertainties in the terrestrial carbon cycle. pp. 116-32. In Vegetation Dynamics and Global Change. Chapman and Hall Publisher.

Post, W. M., IIl. 1993. Organic carbon in soil and the global carbon cycle.

pp. 227-302. In M. Heimann and G. Pearman (eds.), The Global Carbon Cycle. Proceedings of the NATO Advanced Research Institute Workshop on the Global Carbon Cycle, El Ciocco, Italy, September 8-20, 1991. NATO ASI Series, Vol. I, Springer-Verlag, Heidelberg, FRG.

Post, W. M., W. R. Emanuel, and A. W. King. 1992. Soil organic matter dynamics and the global carbon cycle. pp. 107-19. In Proceedings of International Workshop on World Inventory of Soil Emission Potentials, International Soil Reference and Information Centre, Wageningen, The Netherlands, August 24-27, 1992.

Pounds, L. R., P. D. Parr, and M. G. Ryon. 1993. Volume 30: Oak Ridge National Environmental Research Park Natural areas and reference areas-Oak Ridge Reservation environmentally sensitive sites containing special plants, animals, and communities. ORNL/NERP-8.

Railsback, S. F. 1992. Mixing characteristics of submerged and surface wastewater outfalls at McMurdo Station. Polar Rec. 28(165):149-54. 
Reed, R. M., and C. R. Boston. 1993. Federal and state experience: Introduction. pp. 605-7. In S. G. Hildebrand and J. B. Cannon (eds), Proceedings of Ninth Life Sciences Symposium, The Scientific Challenges of NEPA: Future Directions Based on 20 Years of Experience, Knoxville, Tennessee, October 24-27, 1989. Environmental Analysis: The NEPA Experience. Lewis Publishers, Chelsea, Michigan.

Renshaw, A. W. 1993. Bibliography of publications on water resources by Oak Ridge National Laboratory staff (brochure). ORNL/M-3047.

Renshaw, A. W. 1993. Directory of organizations with responsibilities for water resources in the United State of America (brochure). ORNL/M-3018.

Renshaw, A. W., and R. S. Turner. 1993. Water resources activities and goals at Oak Ridge National Laboratory (brochure). ORNL/M-2947.

Rhew, D. D. 1992. Environmental Sciences Division publications 3825-4026. ORNL/M-2800.

Rice, J. A. L. B. Crowder, and K. A. Rose. 1993. Interactions between size-structured predator and prey populations: Experimental test and model comparison. Trans. Am. Fish. Soc. 122(3):481-91.

Rice, J. A., T. J. Miller, K. A. Rose, L. B. Crowder, E. A. Marschall, A. S. Trebitz, and D. L. DeAngelis. 1993. Growth rate variation and larval survival: Inferences from an individual-based sizedependent predation model. Can. J. Fish. Aquat. Sci. 50(1):133-42.

Roberson, L. E. 1993. ESD operating procedures. ORNL/FPO-93/21.
Roberson, L. E. 1993. ESD QA program. ORNL/FPO-93/29.

Rose, K. A., A. L. Brenkert, G. A. Schohl, H. Onomhi, S. Hayworth, F. Holly, W. Perkins, L. Beard, R. B. Cook, and W. Waldrop. 1993. Multiple model analysis of sediment fragment and contaminant distribution in the Clinch River/Watts Bar Reservoir, Tennessee. pp. 57-70. In Water Science and Technology. Preprint IAWQ Proceedings.

Rose, K. A., S. W. Christensen, and D. L. DeAngelis. 1993. Individual-based model of populations with high mortality: A new method on following a fixed number of model individuals. Ecol. Model. 68:273-92.

Rose, K. A., and J. H. Cowan. 1993. Individual-based model of young-of-theyear striped bass population dynamics. I. Model description and baseline simulations. Trans. Am. Fish. Soc. 122(3):415-38.

Rose, K. A., J. H. Cowan, G. D. Houde, and C. C. Coutant. Individual-based modeling of environmental quality effects on early life stages of fish: A case study using striped bass. American Fisheries Society Symposium.

Rosemond, A. D. 1993. Interactions among irradiance, nutrients, and herbivores constrain a stream algal community. Oecologia 94:585-94.

Rosemond, A. D., P. J. Mulholland, and J. W. Elwood. 1993. Top-down and bottom-up control of stream periphyton: Effects of nutrients and herbivores. Ecology 74(4):1264-80.

Rothstein, E., T. Janaushek, M. Bodnar, T. S. Steenhuis, and W. E. Sanford. 
Density stratification in rock-reed filters. Eos, Trans. Am. Geophys. Union 74(16): 146.

Rubin, P. A, and P. J. Lemiszki. 1992. Structural and stratigraphic controls on cave development in the Oak Ridge Area, Tennessee. pp. 111-17. In Extended Abstracts from Fifth Tennessee Water Resources Symposium, Nashville, Tennessee, October 19-21, 1992.

Rubin, P. A., P. J. Lemiszki, P. S. Neuhoff, B. Zerr, G. J. Davies, and J. Aiken. 1993. Preliminary hydrogeologic studies in carbonate aquifers of the Oak Ridge Reservation, Tennessee. Program and Abstracts, Fourth Annual Walker Branch Watershed Research Symposium, Oak Ridge, Tennessee, March 18-19, 1993.

Rubin, P. A., P. J. Lemiszki, and R. S. Poling. 1992. Strategy for definition and protection of East Tennessee karst groundwater basins. pp. 7-10. In Extended Abstracts from Fifth Tennessee Water Resources Symposium, Nashville, Tennessee, October 19-21, 1992.

Salk, M. S. 1993. DOE information brief: Management of cultural resources at Department of Energy facilities, August. ORNL/M-3044.

Salk, M. S., C. G. Heckman, and M. E. Langston. 1993. Environmental guidance program reference books: Clean Water Act (excluding Sect. 404), Revision 6. ORNL/M-2263.

Salk, M. S., C. G. Heckman, and M. E. Langston. 1993. Environmental guidance program reference books: Safe Drinking Water Act, Revision 6. ORNLM-1899.
Salk, M. S., C. G. Heckman, and M. E. Langston. 1993. Environmental guidance program reference books: Comprehensive Environmental Response, Compensation, and Liability Act, Revision 12. ORNL/M-2261.

Sanford, W. E., J.-Y. Parlange, and T. S. Steenhuis. 1993. Hillslope drainage with sudden drawdown: Closed from solution and laboratory experiments. Water Resour. Res. 29(7):2313-21.

Sanford, W. E., D. K. Solomon, J. F. McCarthy, and T. M. Williams. 1992. Noble gases as tracers in a sandy aquifer. Eos, Trans. Am. Geophys. Union 73(43):215.

Sanford, W. E., J. M. Surface, T. S. Steenhuis, and J. H. Peverly. 1992. Flow characteristics of rock-reed filters for treating landfill leachate. p. 85. In Program and Abstracts, Global WetlandsOld and New World, INTECOL's IV International Wetlands Conference. International Association for Ecology, Columbus, Ohio.

Schilling, E. M. 1993. Fishes. In T. L. Ashwood (ed.), Seventh Annual Report on the ORNL Biological Monitoring and Abatement Program. ORNL/TM report (draft).

Schilling, E. M., and M. G. Ryon. 1993. Reproductive biology of the Tennessee dace (Phoxinus tennesseensis) on the DOE Oak Ridge Reservation. p. 274. In Program and Abstracts of Combined Meetings of American Society of Ichthyologists and Herpetologists, Herpetologists' League, 17th Annual Larval Fish Conference and American Elasmobranch Society, Austin, Texas. 
Schramm, W. E., and S. S. Schramm. 1993. A proactive approach to environment management: Meeting environmental and competitive challenges. pp. 213-25. In D. L. Wise and D. J. Trantolo (eds.), Handbook of Process Engineering for Pollution Control and Waste Minimization, Marcel Dekker, Inc., Newy York.

Selifonova, O., R. S. Burlage, and T. Barkay. 1993. mer-lux based biosensors for detection of $\mathrm{Hg}$ (II) in contaminated water. p. 363 . In Proceedings of the 93rd General Meeting of the American Society for Microbiology, Atlanta, May 16-20, 1993.

Sharples, F. E., R. W. Dunford, J. J. Bascietto, and G. W. Suter II. 1993. Integrating natural resource damage assessment and environmental restoration at federal facilities. Fed. Facil. Environ. J. 4:295-317.

Sharples, F. E., and E. D. Smith. 1993. NEPA/CERCLA/RCRA integration: A panel discussion. pp. 71-80. In S. G. Hildebrand and J. B. Cannon (eds.), Proceedings of Ninth Life Sciences Symposium, The Scientific Challenges of NEPA: Future Directions Based on 20 Years of Experience, Knoxville, Tennessee, October 24-27, 1989. Environmental Analysis: The NEPA Experience, Lewis Publishers, Chelsea, Michigan.

Shevenell, L. S., R. B. Dreier, and W. K. Jago. 1993. Summary of FYs 1991 and 1992 construction, hydrologic and geologic data obtained from the Maynardville Limestone Exit Pathway Monitoring Program. Y/TS-814. Oak Ridge Y-12 Plant, Oak Ridge, Tennessee.
Shevenell, L. A., G. K. Moore, and R. B. Dreier. 1992. Contaminant spread and flushing in fractured rocks at the S-3 Ponds Site near Oak Ridge, Tennessee. p. 228. Eos, Trans. Am. Geophys. Union.

Shevenell, L. S., R. B. Dreier, L. Toran, and G. Moore. 1993. Use of the multiport monitoring systems at the Y-12 Plant to identify 3-D compositional variabilities. p. 22. In Fourth National Technical Information Exchange Workshop, Knoxville, Tennessee, May 11-13, 1993.

Shriner, D. S. 1993. Regional and global analysis: Introduction. pp. 439-41. In S. G. Hildebrand and J. B. Cannon (eds.), Proceedings of Ninth Life Sciences Symposium, The Scientific Challenges of NEPA: Future Directions Based on 20 Years of Experience, Knoxville, Tennessee, October 24-27, 1989. Environmental Analysis: The NEPA Experience. Lewis Publishers, Chelsea, Michigan.

Shugart, H. H., T. M. Smith, and W. M. Post. 1992. The potential for application of individual-based simulation models for assessing the effects of global change. Annu. Rev. Ecol. Syst. 23:15-38.

Shugart, L. R. 1993. State of the art-Ecological biomarkers. In C. C. Travis (ed.), Proceedings of the NATO Advance Research Workshop. NATO ASI Series. Use of Biomarkers in Assessing Health and Environmental Impacts of Chemical Pollutants, Plenum Press, New York.

Shugart, L. R., and R. S. Halbrook. 1993. The use of biomarkers to assess environmental health. pp. 199-204. In Proceedings of the International 
Conference on Monitoring Toxic Chemicals and Biomarkers, Berlin, June 22-26, 1992. The Society of Photo-Optical Instrumental Engineers, Bellingham, Washington.

Siegrist, R. L. 1992. Demonstration of in situ soil mixing and treatment of chlorinated organic compounds and radioactive substances in clay soils: The X-231B technology demonstration. Technical project fact sheet. ORNL/M-1886.

Siegrist, R. L., M. I. Morris, T. L. Donaldson, A. V. Palumbo, S. E. Herbes, R. A. Jenkins, C. M. Morrissey, and M. T. Harris. 1993. The X-231B technology demonstration for in situ treatment of contaminated soils: Technology evaluation and screening. ORNL/TM-12257.

Siegrist, R. L., T. J. Phelps, N. E. Korte, and D. A. Pickering. 1993. Characterization and biotreatability of petroleum contaminated soils in a coral atoll in the Pacific Ocean. Proceedings of the 15th Symposium on Biotechnology for Fuels and Chemicals. U.S. Department of Energy, Colorado Springs, Colorado.

Siegrist, R. L., R. Smed-Hildmann, P. D. Jenssen, and Z. Filip. 1993. Humic substance formation during soil infiltration of wastewater. Research Report from the Centre for Environmental Research, Aas, Norway, and the Federal Institute for Water, Soil and Air, Langen, West Germany.

Siegrist, R. L., O. F. Webb, M. O. Ally, W. E. Sanford, P. M. Kearl, and J. J. Zutman. 1993. In situ treatment of VOCs by recirculation technologies. DOE International Technology Exchange Program, Oak Ridge National Laboratory, Oak Ridge, Tennessee. ORNL/TM-12317.
Siegrist, R. L., M. I. Morris,

O. R. West, D. D. Gates, D. A. Pickering,

R. A. Jenkins, T. J. Mitchell, D. W. Greene, C. A. Muhr, S. E. Herbes, T. M. Gilliam, H. J. Jennings, A. J. Lucero, J. Zutman, T. McKnight, J. S. Gierke, K. G. Robinson, D. T. Davenport, R. O. Barnett, Jr., and J. S. Watson. 1993. Evaluation of physicochemical processes coupled with soil mixing for in situ treatment of contaminated soils. Fourth National Technology Information Exchange Workshop, Knoxville, Tennessee, May 11-13, 1993.

Siegrist, R. L., M. I. Morris, O. R. West, D. D. Gates, D. A. Pickering, R. A. Jenkins, T. J. Mitchell, D. W. Greene, C. A. Muhr, S. E. Herbes, T. M. Gilliam, H. L. Jennings, A. J. Lucero, J. Zutman, J. S. Gierke, K. G. Robinson, D. T. Davenport, R. O. Barnett, Jr., and J. S. Watson. 1992. Evaluation of in situ treatment technologies for contaminated clay soils: Highlights of the X-231B technology demonstration. Proceedings of the Eighth Annual Oak Ridge Model Conference, U.S. Department of Energy, Oak Ridge, Tennessee.

Siegrist, R. L., M. I. Morris, O. R. West, D. D. Gates, D. A. Pickering, R. A. Jenkins, T. J. Mitchell, D. W. Greene, C. A. Muhr, S. E. Herbes, T. M. Gilliam, H. L. Jennings, A. J. Lucero, J. Zutman, T. McKnight, D. T. Davenport, and J. S. Watson. 1993. Field evaluation of in situ treatment by physicochemical processes. Proceedings of the Waste Management '93. U.S. Department of Energy, Tucson, Arizona.

Sigal, L. L. 1993. EIA for policies, plans, and programmers in EIA newsletter. EIA Centre, University of Manchester, UK. 
Sigal, L. L. 1993. Other nations follow U.S. lead on NEPA. Appl. Res. Public Policy 8(2):98-100.

Sigal, L. L. 1993. Sourcebook for the Environmental Assessment (EA) process. U.S. Environmental Protection Agency, Washington, D.C.

Sigal, L. 1993. The evolution of EIA from projects to policy to sustainable development. Environ. Prof. 15(1):91-103.

Sigal, L. L., and J. W. Webb. 1992. Application of environmental impact assessment principles to policies, plans and programmers. ECE/ENVWA/27, United Nations, New York.

Singley, P. T. 1992. Atmospheric radiation measurement (ARM) archive user requirements. Managing Terabyte Databases in the 90 s and Beyond, Proceedings of Terabyte Database Conference, McLean, Virginia, September 16, 1992.

Smethie, W. M., Jr., D. K. Solomon, S. L. Schiff, and G. G. Mathieu. 1992. Tracing groundwater flow in the borden aquifer using krypton-85. J. Hydrol. 130:279-97.

Smith, E. D. 1993. Future challenges of NEPA: A panel discussion. pp. 81-97. In S. G. Hildebrand and J. B. Cannon (eds.), Proceedings of Ninth Life Sciences Symposium, The Scientific Challenges of NEPA: Future Directions Based on 20 Years of Experience, Knoxville, Tennessee, October 24-27, 1989. Environmental Analysis: The NEPA Experience. Lewis Publishers, Chelsea, Michigan.

Smith, I. M., and M. J. Sale. 1993.

Standardizing instream flows at hydropower projects in the Cascade Mountains, Washington. American Society of Civil Engineers, New York.

Smith, J. G., S. M. Adams, L. A. Kszos, J. M. Loar, M. G. Ryon, and G. R. Southworth. 1993. First report on the Oak Ridge K-25 Site Biological Monitoring and Abatement Program for Mitchell Branch. ORNL/TM-11073.

Socolof, M., et al. 1993. Environmental assessment interim replacement of chlorofluorocarbons at the Department of Energy's Gaseous Diffusion Plants ecology resources and assessment. U.S. Department of Energy, Oak Ridge, Tennessee (draft).

Soil Decon Task Group (C. W. Francis, Task Group Leader). 1993. Removal of uranium from uranium-contaminated soils. Phase 1: Bench-scale testing. ORNL-6762.

Sojka, R. E., and R. J. Luxmoore (guest eds.). 1992. October Issue, Soil Science.

Sojka, R. E., and R. J. Luxmoore. 1992. The career and achievements of Professor Lewis H. Stolzy. Soil Sci. 154:257-58.

Solomon, D. K., V. Alexiades, G. K. Jacobs, M. T. Naney, and M. Olszewski. 1992. Latent heat thermal energy storage for lunar oxygen production. Proceedings of Conference on Fundamentals of Phase Change: Freezing, Melting and Sublimation, Anaheim, California, November 8-13, 1992. American Society of Mechanical Engineering.

Solomon, D. K., N. D. Farrow, T. O. Early, and J. L. Clausen. 1993. Drive point profiling of groundwater contaminant 
distribution. p. 11. In Fourth National Technology Information Exchange Workshop, Knoxville, Tennessee, May 11-13, 1993.

Solomon, D. K., G. K. Moore, L. E. Toran, R. B. Dreier, and W. M. McMaster. 1992. Status Report: A hydrologic framework for the Oak Ridge Reservation. ORNL/TM-12026.

Solomon, D. K., S. L. Schiff, R. J. Poreda, and W. B. Clark. 1993. A validation of the ${ }^{3} \mathrm{H} /{ }^{\beta} \mathrm{He}$ method for determining groundwater recharge. Water Resour. Res. 29(9):2951-62.

Southworth, G. R. 1992. Bioaccumulation monitoring. ORNL/FPO-92/75.

Southworth, G. R. 1993. Personal communication from G. R. Southworth to S. Mitz, SAIC dated April 23, 1993. ORNL/M-2826.

Spalding, B. P., G. K Jacobs, N. W. Dunbar, M. T. Naney, J. S. Tixier, and T. D. Powell. 1992. Tracer-level radioactive pilot-scale test of in situ vitrification for the stabilization of contaminated soil sites at ORNL. ORNL/TM-12201.

Steinman, A. D. 1992. Disturbing trends in artificial stream research? Bull. North Am. Benthol. Soc. 9:120.

Steinman, A. D. 1992. Does an increase in irradiance influence periphyton in a heavily-grazed woodland stream? Oecologia 91:163-70.

Steinman, A. D., and H. L. Boston. 1993. The ecological role of aquatic bryophytes in a woodland stream.

J. North Am. Benthol. Soc. 12(1):17-26.
Steinman, A. D., P. J. Mulholland, A. V. Palumbo, D. L. DeAngelis, and T. E. Flum. 1992. Lotic ecosystem response to a chlorine disturbance. Ecol. Appl. 2(4):341-55.

Stetar, E. A., H. L. Boston, I. L. Larsen, and M. H. Mobley. 1993. The removal of radioactive cobalt, cesium, and iodine in a conventional municipal wastewater treatment plant. Water Environ. Res. 65(5):630-39.

Stewart, A. J., W. R. Hill, and H. L. Boston. 1993. Grazers, periphyton, and toxicant movement in streams. Environ. Toxicol. Chem. 12:955-57.

Stoss, F. W. 1992. The Carbon Dioxide Information Analysis Center: Providing information support for DOE's global change research program. pp. 105-9. In Proceedings of INFOTECH '92, DOE Technical Information Meeting, OSTI, Oak Ridge, Tennessee, October 21-22, 1992. DOE/OSTI, CONF-9210158.

Stoss, F. W. 1992. The Carbon Dioxide Information Analysis Center: Responding to changing information needs. Green Library J. 1(3):3-13.

Strong-Gunderson, J. M., A. V. Palumbo, S. E. Herbes, and S. Bergman. 1993. The effect of formate and methane on the recovery of soluble methane monooxygenase enzyme (sMMO) in methylosinus trichosporium (OB3b). p. 379. In Proceedings of 93rd General Meeting of the American Society for Microbiology, Atlanta, May 16-20, 1993.

Strong-Gunderson, J. M., A. V. Palumbo, and S. O. Scarborough. 1992. New method for rapidly determining microbial utilization of volatile contaminants. p. 371. In Book of Abstracts of the 93rd General 
Meeting of the American Society for Microbiology, New Orleans, May 26-30, 1992.

Sullivan, T. J., R. S. Turner, D. F. Charles, B. F. Cumming, J. P. Smol, C. L. Schofield, C. T. Driscoll, B. J. Cosby, H. J. B. Birks, A. J. Uutala, J. C. Kingston, S. S. Dixit, J. A. Bernert, P. F. Ryan, and D. R. Marmorek. 1992. Use of historical assessment for evaluation of processbased model projections of future environmental change: Lake acidification in the Adirondack Mountains, New York. Environ. Pollut. Ser. A 77:253-62.

Surface, J. M., J. H. Peverly, T. S. Steenhuis, and W. E. Sanford. 1992. Landfill-leachate treatment by means of a constructed wetland. p. 102. In Global Wetlands-Old and New World: INTECOL's IV International Wetlands Conference, International Association for Ecology, Columbus, Ohio.

Surface, J. M., J. H. Peverly, T. S. Steenhuis, and W. E. Sanford. 1993. Chapter 50: Effect of season, substrate composition, and plant growth on landfill leachate treatment in a constructed wetland. pp. 461-72. In G. A. Moshiri (ed.), Constructed Wetlands for Water Quality Improvement. Lewis Publishers, Chelsea, Michigan.

Suter, G. W., II. 1992. A strategy for ecological risk assessment of the DOE Oak Ridge hazardous waste sites. p. 8. In Book of Abstracts, 13th Annual Meeting of the Society for Environmental Toxicology and Chemistry, Cincinnati, November 8-12, 1992.

Suter, G. W., II. 1993. A critique of ecosystem health concepts and indices. Environ. Toxicol. Chem. 12(9):1533-39.
Suter, G. W., II. 1993. Adapting ecological risk assessment for ecosystem valuation. Program Book, Annual Meeting of American Association for the Advancement of Science, Boston, February 11-16, 1993.

Suter, G. W., II. 1993. Impact, hazard, and risk assessment of toxic effects on nonhuman organisms. pp. 163-69. In S. G. Hildebrand and J. B. Cannon (eds.), Proceedings of Ninth Life Sciences Symposium, The Scientific Challenges of NEPA: Future Directions Based on 20 Years of Experience, Knoxville, Tennessee, October 24-27, 1989. Environmental Analysis: The NEPA Experience. Lewis Publishers, Chelsea, Michigan.

Suter, G. W., II. 1993. Modeling. pp. 43-48. In Proceedings of Application of Ecological Risk Assessment to Hazardous Waste Site Remediation, Washington, D.C., January 10-13, 1993. Water Environment Federation, Alexandria, Virginia.

Suter, G. W., II. (ed.). 1993. Ecological Risk Assessment. Lewis Publishers, Chelsea, Michigan.

Suter, G. W., II, and L. W. Barnthouse. 1993. Assessment concepts. pp. 21-47. In G. W. Suter (ed.), Ecological Risk Assessment. Lewis Publishers, Chelsea, Michigan.

Suter, G. W., II, and F. O. Hoffman. 1992. A strategy for estimation of distributions of uncertain parameters in ecological risk assessments. p. 129. In Book of Abstracts, 13th Annual Meeting of the Society for Environmental Toxicology and Chemistry, Cincinnati, November 8-12, 1992.

Suter, G. W., II, R. J. Luxmoore, and E. D. Smith. 1993. Compacted soil 
barriers at abandoned landfill sites are likely to fail in the long run. J. Environ. Qual. 22(2):217-26.

Suter, G. W., II, A. E. Rosen, J. J. Beauchamp, and T. T. Kato. 1992. Results of analyses of fur samples from the San Joaquin Kit Fox and associated soil and water samples from the Naval Petroleum Reserve No. 1, Tupman, California. ORNL/TM-12244.

Taylor, G. E., Jr., J. G. Owens, T. Grizzard, and W. J. Selvidge. 1993. Atmosphere-canopy interactions of nitric acid vapor in loblolly pine (Pinus taeda L.) grown in open-top chambers. J. Environ. Qual. 22(1):70-80.

Theodorakis, C. W., S. J. D'Surney, and L. R. Shugart. 1992. Assessing genotoxicity via electrophoretic examination of DNA strand breaks and chromosomal proteins in fish red blood cells. p. 157. In Book of Abstracts, 13th Annual Meeting of the Society for Environmental Toxicology and Chemistry, Cincinnati, November 8-12, 1992.

Theodorakis, C. W., S. J. D'Surney, and L. R. Shugart. 1992. Sequential development of biomarkers in fish exposed to contaminated sediment. p. 9. In Book of Abstracts, 13th Annual Meeting of the Society for Environmental Toxicology and Chemistry, Cincinnati, November 8-12, 1992.

Thompson, B. K. 1993. Data base dictionary for the Oak Ridge Reservation hydrology and geology study groundwater database. ORNL/TM-11909.

Thompson, B. K. 1993. Management plan for the Oak Ridge Reservation hydrology and geology study groundwater database. ORNL/TM-12048.
Tidwell, V. C., S. Y. Lee, D. E. Morris, D. L. Perry, C. Carnahan, J. C. Cunnane, S. D. Conradson, V. Gill, and M. D. Nickelson. 1992. An integrated approach to the characterization of uranium-contaminated soils. pp. 221-27. In SPECTRUM '92, Proceedings of International Topics Meeting on Nuclear and Hazardous Waste Management, Boise, Idaho, August 23-27, 1992. American Nuclear Society.

Tixier, J. S., G. K. Jacobs, B. P. Spalding, and T. D. Powell. 1992. ISV of a simulated seepage trench: A radioactive field test at ORNL. Trans. Am. Nucl. Soc. 65:27-28.

Tolbert, V. R., and P. M. Kotila. 1992. Environmental requirements. pp. 79-85. In Current and Selected Bibliographies in Benthic Biology 1991. Special Publication of the North American Benthological Society, Allen Press, Lawrence, Kansas.

Tolbert, V. R., and P. M. Kotila. 1992. Environmental requirements. In Current and Selected Bibliographies in Benthic Biology (on-line data base). University of Notre Dame, Gopher.nd.edu, Notre Dame, Indiana.

Tolbert, V. R., and P. M. Kotila. 1993. Environmental requirements for benthos. In Current and Selected Bibliographies in Benthic Biology. ORNL/M-2814.

Tolbert, V. R., R. E. Martinez-Morales, and J. G. Smith. 1992. Effects of temperature on growth and survival of Hydropsyche depravata. Bull. North Am. Benthol. Soc. 10(1):210.

Toran, L., O. R. West, and J. P. Gwo. 1993. Supercomputer model of an Oak Ridge National Laboratory waste area. p. 10. In Fourth National 
Technology Information Exchange Workshop, Knoxville, Tennessee, May 11-13, 1993.

Trettin, C. C. 1992. Research initiative on forested wetlands and the impact of forest management practices. Great Lakes Wetlands Newsletter 3(2):1-4.

Trettin, C. C., M. R. Gale, M. F. Jurgensen, and J. W. McLaughlin. 1992. Carbon storage response to harvesting and site preparation in a forested mire in northern Michigan, U.S.A. Suo 43(4-5):281-84.

Tschaplinski, T. J., and R. J. Norby. 1993. Physiological indicators of nitrogen response in a short rotation sycamore plantation. II. Nitrogen metabolism. Can. J. Bot. 71:841-47.

Tschaplinski, T. J., and G. A. Tuskan. 1993. Water stress tolerance of black cottonwood and eastern cottonwood clones and four of their hybrid progeny: Metabolites and inorganic ions that constitute osmotic adjustment. Program and Abstracts, Fourth Annual Walker Branch Watershed Research Symposium, Oak Ridge, Tennessee, March 18-19, 1993.

Tschaplinski, T. J., and G. A. Tuskan. 1993. Water stress tolerance of black cottonwood and eastern cottonwood clones and four of their hybrid progeny. American Society of Plant Physiologists, Beltsville, Maryland. Plant Physiol. (Suppl.) 102(1):157.

Turner, M. G. 1993. Pattern and process in landscape ecology. Program and Abstracts, Eighth Annual U.S. Landscape Ecology Symposium, Oak Ridge, Tennessee, March 24-27, 1993. ORNL/M-2725.
Turner, M. G., R. H. Gardner, R. V. O'Neill, and S. M. Pearson. 1993. Multi-scale organization of landscape heterogeneity. ORNL/M-2815.

Turner, R. R. 1992. Effect of chemical form of mercury on the performance of dosed soils in standard leaching tests: EP and TCLP. pp. 81-85. In Proceedings of Arsenic and Mercury: Workshop on Removal, Recovery, Treatment, and Disposal, Alexandria, Virginia, August 17-20, 1992. EPA/600/R-92/105.

Turner, R. R., T. Barkay, and E. Saouter. 1993. Bioreduction of mercury in contaminated effluents. p. 38-40. In Emerging Technologies in Hazardous Waste Management V. American Chemical Society.

Turner, R. R., and M. A. Bogle. 1993. Ambient air monitoring for mercury around an industrial complex. pp. 162-72. In W. Chow and K. K. Connor (eds.), Managing Hazardous Air Pollutants: State of the Art. Proceedings of EPRI conference, Washington, D.C., November 4-6, 1991. Lewis Publishers, Chelsea, Michigan.

Turner, R. R., M. A. Bogle, R. B. Clapp, K. Dearstone, R. B. Dreier, T. O. Early, S. E. Herbes, J. M. Loar, P. D. Parr, and G. R. Southworth. Remedial investigation work plan for Bear Creek (Y02-S600) at the Oak Ridge Y-12 Plant, Oak Ridge, Tennessee. ES/ER-19\&D2.

Turner, R. S., P. F. Ryan, D. R. Marmorek, K. W. Thornton, T. J. Sullivan, J. P. Baker,

S. W. Christensen, and M. J. Sale. 1992. Sensitivity to change for low-ANC eastern U.S. lakes and streams and brook trout populations under alternative sulfate deposition scenarios. Environ. Pollut. 77:269-77. 
Tuskan, G. A. 1992. Preface for a special issue of the "Canadian Journal of Forest Research." Can. J. For. Res. 22:999-1000.

Tuskan, G. A. 1992. Realized and potential value of genetics and biotechnology for biofuel feedstock improvement. pp. 107-10. In Proceedings of Annual Automotive Technology Development Contractors Coordination Meeting (DOE Headquarters Meeting), Dearborn, Michigan, November 2-5, 1992.

Society of Automotive Engineers, Inc.

Tuskan, G. A., T. J. Tschaplinski, S. J. D'Surney, and N. T. Edwards. 1992. UV-B radiation reduces germination capacity of loblolly pine (Pinus taeda L.) and red spruce (Pica rubens Sarg.) pollen. p. 67. In Proceedings of North American Forest Biology Workshop, Sault Ste. Marie, Ontario, Canada, August 17-21, 1992. Ontario Ministry of Natural Resources.

Tyler, J. A. 1993. Effects of water velocity, group size, and prey availability on the stream-drift prey capture efficiency of blacknose dace, Rhinicthys atratulus. Can. J. Fish. Aquat. Sci. 50(5):1055-61.

Unseren, M. A., and F. M. Hoffman. 1993. Errata report on Herbert Goldstein's Classical mechanics, Second Edition. ORNL/TM-12176.

Van Hook, R. I. 1992. The need for increased emphasis on the role of the biosphere in global change. Committee Hearing Record, Testimony before the Subcommittee on Environment, Committee on Science, Space, and Technology, U.S. House of Representatives, Washington, D.C., May 5, 1992.
Van Hook, R. I. 1993. Environmental Sciences Division annual progress report for period ending September 30, 1992. ORNL-6733.

Van Hook, R. I. 1993. Environmental Sciences Division statistics for 1992. ORNL/M-2811.

Van Miegroet, H., P. S. Homann, and D. W. Cole. 1993. Soil nitrogen dynamics following harvesting and conversion of red alder and Douglas fir forests. SSSA J. 56(4):1311-18.

Van Winkle, W., K. A. Rose, and R. C. Chambers. 1993. Individual-based approach to fish population dynamics: An overview. Trans. Am. Fish. Soc. 122:397-403.

Van Winkle, W., K. A. Rose, K. Winemiller, D. L. DeAngelis, S. W. Christensen, R. G. Otto, and B. J. Shuter. 1993. Linking life history theory, environmental setting, and individual-based modeling to compare responses of different fish species to environmental change. Trans. Am. Fish. Soc. 122:459-66.

Vermette, S. J., M. E. Peden, S. Hamdy, T. C. Willoughby, L. Schroder, S. E. Lindberg, J. G. Owens, and A. D. Weiss. 1992. A pilot network for the collection and analysis of metals in wet deposition. The Deposition and Fate of Trace Metals in Our Environment, General Technical Report NC-150, USDA Forest Service.

Voorhees, L. D., R. A. McCord, R. C. Durfee, J. C. Goyert, M. L. Land, R. J. Olson, J. K. Thomas, and E. P. Tinnel. 1992. Oak Ridge Environmental Information System (OREIS): 
Phase I-System definition document. ES/ER/TM-34.

Voorhees, L. D., R. A. McCord, R. C. Durfee, M. L. Land, R. J. Olson, J. K. Thomas, and E. P. Tinnel. 1992. Data management plan for the Oak Ridge Environmental Information System, Version 1.1. ES/ER/TM-39.

Voorhees, L. D., R. A. McCord, R. J. Olson, R. C. Durfee, E. P. Tinnel, M. Palmer, B. C. Zygmunt, M. L. Land, and J. K. Thomas. 1993. Oak Ridge Environmental Information System (OREIS) site workstation information packet for OREIS, Version 2. ES/ER/TM-57.

Vose, R. S. 1992. Compilation of longterm monthly temperature, precipitation, and pressure data sets. Book of Abstracts, Annual Meeting of the Association of American Geographers, San Diego, April 18-20, 1992.

Vose, R. S., T. C. Peterson, R. L. Schmoyer, J. K. Eischied, P. M. Steurer, R. Heim, and T. R. Karl. 1993. The global historical climatology network: Long-term monthly temperature, precipitation, and pressure data. pp. 312-17. In Eighth Conference on Applied Climatology, 73rd American Meteorological Society Annual Meeting, Anaheim, California. American Meteorological Society, Boston.

Walton, B. T., and T. A. Anderson. 1992. Plant-microbe treatment systems for toxic waste. Curr. Opin. Biotech. 3:267-70.

Walton, B. T., C. W. Gehrs, R. J. Luxmoore, and E. F. Neuhauser. 1993. Use of vegetation to promote microbial degradation of polycyclic aromatic hydrocarbons in surface soils. ORNL/M-2642.

Walton, B. T., M. S. Hendricks, T. A. Anderson, W. H. Griest, R. Merriweather, C. W. Francis, and J. J. Beauchamp. 1992. Soil sorption of volatile and semivolatile organic compounds in a mixture. J. Environ. Qual. 21:552-58.

Walton, B. T., A. M. Hoylman, and R. F. Christman. 1993. Plant defenses against toxic substances in soils: Implications for in situ bioremediation. Picogram 45:77.

Walton, B. T., S. S. Talmage, and D. L. DeAngelis. 1992. A critique of small mammal population studies as endpoints of toxicant exposure. Book of Abstracts, 13th Annual Meeting of the Society for Environmental Toxicology and Chemistry, Cincinnati, November 8-12, 1992.

Watkins, D. R., J. T. Ammons, J. L. Branson, B. B. Burgoa, T. M. French, T. L. Hatmaker, L. A. Hook, B. L. Jackson, S. Y. Lee, D. A. Lietzke, J. Switek, and J. C. Wright. 1993. Phase II data for the background soil characterization project at the Oak Ridge Reservation, Oak Ridge, Tennessee. ES/ER/INT-87.

Watkins, D. R., J. T. Ammons, J. L. Branson, B. B. Burgoa, P. L. Goddard, T. L. Hatmaker, L. A. Hook, B. L. Jackson, C. W. Kimbrough, S. Y. Lee, D. A. Lietzke, C. W. McGinn, B. D. Nourse, R. L. Schmoyer, R. A. Shaw, S. E. Stinnette, J. Switek, and J. C. Wright. 1993. Annual report on the background soil characterization project on the 
Oak Ridge Reservation: Results of Phase I investigation, Oak Ridge National Laboratory, Oak Ridge, Tennessee. ES/ER/TM-43 (DOE/OR/01-1136).

Watkins, D. R., S. Y. Lee, and T. L. Hatmaker. 1993. Background soil characterization project for the Oak Ridge Reservation. p. 35. In Fourth Technical Information Exchange Workshop, DOE/ER (Environmental Restoration), Blacksburg, Virginia.

Watts, J. A. (D. Counce, ed.). 1993. Women in science and engineering: Women scientists and engineers at Oak Ridge National Laboratory. U.S. Department of Energy/Oak Ridge National Laboratory, Oak Ridge, Tennessee. ORNL/M-2803.

Webb, J. W., and L. L. Sigal. 1992. Strategic environmental assessment in the United States. Proj. Appra. 7(3):137-41.

Webb, O. F., T. J. Phelps, and P. R. Bienkowski. 1993. Multicomponent adsorption of polycyclic aromatic hydrocarbons in manufactured gas plant soil. Sep. Sci. Technol. 28:873.

Weiss, R. F., F. A. Van Woy, P. K. Salameh, and R. J. Sepanski (ed.). 1992. Surface water and atmospheric carbon dioxide and nitrous oxide observations by shipboard automated gas chromatography: Results from expeditions between 1977 and 1990. ORNL/CDIAC-59.

West, D. C., F. D. Dickens, L. W. McMahon, and J. B. Murphy. 1993. Oak Ridge Reservation environmental report for 1992. ES/ESH-31/V1.

West, D. C., F. D. Dickens, L. W. McMahon, and J. B. Murphy. 1993.
Oak Ridge Reservation environmental report for 1992. ES/ESH-31/V2.

West, D. C., T. W. Doyle, M. L. Tharp, J. J. Beauchamp, W. J. Platt, and D. J. Downing. 1993. Recent growth increases in old-growth longleaf pine. Can. J. For. Res. 23(5):846-53.

West, D. C., and W. Malis. 1993. Paducah Gaseous Diffusion Plant environmental report for 1992. ES/ESH-36.

West, D. C., and G. W. Snyder. 1993. Portsmouth Gaseous Diffusion Plant environmental report for 1992. ES/ESH-37.

West, O. R., and R. L. Siegrist. 1993. Measurement and spatial modeling of VOC contamination in soils. p. 89. In 34th ORNL/DOE Conference on Analytical Chemistry in Energy Technologies, Oak Ridge National Laboratory/U.S. Department of Energy, Oak Ridge, Tennessee.

West, O. R., R. L. Siegrist, A. J. Lucero, H. L. Jennings, D. W. Green, and S. W. Schmunk. 1993. The X-231B technology demonstration for in situ treatment of contaminated soil: Laboratory evaluation of in situ vapor stripping. ORNL/TM-12260.

West, O. R., R. L. Siegrist, A. J. Lucero, H. L. Jennings, and S. W. Schmunk. 1993. Vapor stripping of VOC-contaminated clay soils. p. 1385. In Proceedings of Joint CSCE-ASCE National Conference on Environmental Engineering. The GEO Technical Research Center of McGill University, Montreal, Quebec, Canada.

West, O. R., R. L. Siegrist, T. J. Mitchell, D. A. Pickering, D. W. Greene, and 
R. A. Jenkins. 1993. The X-231B technology demonstration for in situ treatment of contaminated soils: Contaminant characterization and three dimensional spatial modeling. ORNL/TM-12258.

White, W. B. 1992. Carbonate terrain hydrogeology at the Oak Ridge Reservation. ORNL/M-2782.

Wilkerson, R. V., R. G. Epler, M. S. Hendricks, and D. E. Fowler. 1993. Environmental Sciences Division waste guidance document. ORNL/FPO-93/24.

Wilson, G. V., P. M. Jardine, and J. P. Gwo. 1992. Modeling the hydraulic properties of a multiregion soil. Soil Sci. Soc. Am. J. 56(6):1731-37.

Wilson, G. V., P. M. Jardine, J. D. O'Dell, and M. Collineau. 1993. Field-scale transport from a buried line source in unsaturated soil. J. Hydrol. 145:83-109.

Winemiller, K. O. 1992. Ecological divergence and convergence in freshwater fishes. Natl. Geogr. Res. 8:308-27.

Winemiller, K. O., and K. A. Rose. 1992. Patterns of life-history diversification in North American fishes: Implications for population regulation. Can. J. Fish. Aquat. Sci. 49:2196-218.

Winemiller, K. O., and K. A. Rose. 1993. Why do most fish produce many tiny offspring? Am. Nat. 142(4):585-603.

Wise, F. J., and K. H. King-Jones. 1992. RCRA/CERCLA Update, Vol. 92(4), December. ORNL/M-2576.

Wright, L. L. 1993. Biomass resource potential using energy crops. Abstracts, 205th American Chemical Society National
Meeting, Denver, March 28-April 2, 1993. American Chemical Society.

Wright, L. L., and J. H. Cushman. 1992. Biofuels feedstock development program. Biologue 10(1):59-60.

Wright, L. L., J. H. Cushman, A. R. Ehrenshaft, S. B. McLaughlin, W. A. McNabb, J. W. Ranney, G. A. Tuskan, and A. F. Turhollow. 1992. Biofuels feedstock development program annual progress report for 1991 . ORNL-6742.

Wu, Y.-L., C. I. Davidson, S. E. Lindberg, and A. G. Russell. 1992. Resuspension of particulate chemical species at forested sites. Environ. Sci. Technol. 26(12):2428-35.

Wu, Y., D. L. DeAngelis, L. J. Gross, and D. M. Fleming. 1993. SIMDEL: A spatially explicit individual-based model for white-tailed deer on everglades landscapes. Abstracts, Eighth Annual Landscape Ecology Symposium, Oak Ridge, Tennessee, March 24-27, 1993.

Wullschleger, S. D. 1993. Biochemical limitations to carbon assimilation in $\mathrm{C}_{3}$ plants-a retrospective analysis of the $\mathrm{A} / \mathrm{Ci}$ curves from 109 species. J. Exper. Bot. 44(262):907-20.

Wullschleger, S. D. 1993. Growth response of forest tree species to atmospheric $\mathrm{CO}_{2}$ enrichment: A review of the literature. Program and Abstracts, Fourth Annual Walker Branch Watershed Research Symposium, Oak Ridge, Tennessee, March 18-19, 1993.

Wullschleger, S. D., P. J. Hanson, and C. A. Gunderson. 1992. Assessing the influence of exogenous ethylene on electron transport and fluorescence 
quenching in leaves of glycine max. Environ. Exp. Bot. 32(4):449-55.

Wullschleger, S. D., R. J. Norby, and C. A. Gunderson. 1992. Growth and maintenance respiration in leaves of Liriodendron tulipifera $\mathrm{L}$. exposed to long-term carbon dioxide enrichment in the field. New Phytol. 121(4):515-23.

Wullschleger, S. D., R. J. Norby, G. S. Edwards, P. J. Hanson, and C. A. Gunderson. 1992. Respiration in response to carbon dioxide and ozone. Proceedings of Third Symposium on Gaseous Pollutant Plant Metabolism, Virginia Polytechnic Institute and State University, Blacksburg, Virginia, June 13-16, 1992.
Wullschleger, S. D., and D. M. Oosterhuis. 1992. Photosynthesis, transpiration, and water-use efficiency of cotton leaves and fruit. Photosynthetica 25:505-15.

Zimmerman, G. P., E. L. Hillsman, R. O. Johnson, R. L. Miller, T. G. Patton, G. M. Schoepfle, V. R. Tolbert, D. L. Feldman, D. B. Hunsaker, Jr., R. L. Kroodsma, J. Morrissey, L. W. Rickert, W. P. Staub, and D. C. West. 1993. Disposal of chemical agents and munitions stored at Umatilla Depot Activity, Hermiston, Oregon, Final Phase 1 Environmental Report. ORNL/TM-11212. 


\section{Presentations}

ESD staff cleared the following with the ORNIL Laboratory Records Department for presentation during FY 1993.

Adams, S. M. 1993. "Comparison of Integrative Approaches for Evaluating the Effects of Contaminant-Related Stress on Fish Population Health." Third International Conference on Aquatic Ecosystem Health, Virginia Polytechnic Institute and State University, Blacksburg, May.

Adams, S. M., W. D. Crumby, and R. G. Epler. 1993. "Importance of Physiological Variables in Evaluating the Health of Fish Populations." Annual Meeting, American Fisheries Society, Portland, Oregon, August-September.

Adams, S. M., W. D. Crumby, and M. S. Greeley, Jr. 1992. "A Biomonitoring Strategy for Assessing the Health of Fish Populations Exposed to Pulp Mill Effluents." 13th Annual Meeting, Society of Environmental Toxicology and Chemistry, Cincinnati, November.

Ashwood, T. L. 1993. "Safety Considerations During Sediment Collection Using SCUBA." 205th American Chemical Society Annual Meeting, Denver, March-April.

Ashwood, T. L., and D. S. Hicks. 1992. "Environmental Monitoring of Subsurface Low-Level Waste Disposal Facilities at Oak Ridge National Laboratory." 14th Annual DOE Low-Level Waste Management Conference, Phoenix, Arizona, November.

Baes, C. F., III. 1993. "Environmental Regulatory Management Support." U.S. Army's Manufacturing Science and Technology, Oak Ridge Y-12 Plant, Oak Ridge, Tennessee, August.
Baes, C. F., III, and C. F. Sigmon. 1993. "Environmental Compliance Auditing." U.S. Army's Manufacturing Science and Technology, Oak Ridge Y.12 Plant, Oak Ridge, Tennessee, August.

Barnthouse, L. W. 1993. "Ecological Risk Assessment-The CRAM Perspective." Workshop on Application of Ecological Risk Assessment to Hazardous Waste Site Remediation, Washington, D.C., January.

Barnthouse, L. W. 1993. "Issues in Ecological Risk Assessment.” Conference on the Risk Assessment Paradigm After 10 Years, Dayton, Ohio, April.

Beauchamp, J. J. 1993. "Statistics: An Aid to Better Understanding." Restoring Our Waters Workshop, Oak Ridge, Tennessee, July.

Bevelhimer, M. S. 1993. "Research on Contaminant-Update Mechanisms and Ecological Effects Can Lead to Active Management of Contaminated Systems." 123rd Annual Meeting, American Fisheries Society, Portland, Oregon, August.

Blaylock, B. G., M. L. Frank, F. O. Hoffman, P. D. Miller, S. T. Purucker, A. Redfearn, and R. K. White. 1993. "Human Health Risk Assessment Screening Approach for Evaluating Contaminants at Source Control and Integrator Operable Units." Water Federation Environment Specialty Conference on How Clean is Clean?

Washington, D.C., January.

Boden, T. A. 1992. "Global Data Bases for Assessing Potential Greenhouse-Gas-Induced Climate Changes." 13th International Committee on Data for Science and Technology Conference on New Data Challenges in 
Our Information Age, Beijing, China, October.

Boden, T. A. 1992. “Metadata Compiled and Distributed by the Carbon Dioxide Information Analysis Center for Global Climate Change and Greenhouse GasRelated Data Bases." Scientific Data Management Workshop on the Role of Metadata in Managing Large Environmental Sciences Datasets, Salt Lake City, November.

Boden, T. A., D. P. Kaiser, R. J. Sepanski, L. J. Morris, D. E. Shepherd, and S. B. Jones. 1993. "Data Archival, Documentation, and Distribution Activities Performed by the Carbon Dioxide Information Analysis Center in Support of the U.S./DOE-PRC/CAS Bilateral." Sixth Science Team Meeting Joint Research on Greenhouse Effect, Beijing, China, September.

Bodenstein, G. W., R. A. McCord, and R. C. Durfee. 1993. "Oak Ridge Environmental Information System (OREIS) and the Use of GIS for Environmental Restoration." Bricfing for U.S. Department of Energy Headquarters, EM 40 GIS Subcommittee, DOE, Oak Ridge, Tennessee, February.

Boston, H. L., A. J. Kuhaida, Jr., and S. B. Garland. 1992. "An Integrated Performance Measure for Environmental Restoration at Oak Ridge National Laboratory." Eighth Annual U.S. Department of Energy Model Conference on Waste Management and Environmental Restoration, Oak Ridge, Tennessee, October.

Brenkert, A. L., R. B. Cook, K. A. Rose, C. C. Brandt, K. C. Dearstone, M. A. Wood, L. Beard, and G. A. Schohl. 1992. "A Comparison of Two Methods for Estimating Spatial Patterns of Sediment Accumulation in the Clinch River-Watts Bar Reservoir System." Fifth Tennessee Water Resource Symposium, Nashville, Tennessee, October.

Brenkert, A. L., G. A. Schohl, K. A. Rose, F. Holly, L. Beard, R. B. Cook, and Y. Onishi. 1993. "Using Multiple Models to Predict Sediment Transport and Contaminant Distribution in the Clinch River/Watts Bar Reservoir." Tennessee Contaminated Aquatic Sediments:

Historical Records, Environmental Impact, and Remediation Specialized Conference, Milwaukee, June.

Brockman, F. J., J. K. Fredrickson, S. W. Li, C. M. Spadoni, S. M. Pfiffner, J. M. Johannesen, and T. J. Phelps. 1993. "Stimulation of the Microbial Community by Nutrient Amendment and Storage of Saturated Sediments with Low Biomass and Numbers of Culturable Microorganisms." International Symposium on Subsurface Microbiology, Bath, Great Britain, September.

Brockman, F. J., D. Ringelberg, D. C. White, J. K. Fredrickson, D. L. Balkwill, T. Kieft, T. J. Phelps, and W. C. Ghiorse. 1993. "Estimates of Intact but Nonviable, and Viable but Unculturable Microorganisms in Subsurface Sediments from Six Boreholes Located in Wet and Dry Climatic Regions of the U.S." International Symposium on Subsurface Microbiology, Bath, Great Britain, September.

Burlage, R. S., D. C. T. Kuo, and A. V. Palumbo. 1993. "Catabolic Gene Expression is Monitored by Bioluminescence in Bioreactor Studies." Second International Symposium on In Situ and On-Site Bioreclamation, San Diego, April. 
Burlage, R. S., and A. V. Palumbo. 1993. "Toluene and $m$-Methylbenzyl Alcohol Show Different Patterns of Induction in Pseudomonas putida: Evidence for Reduced Uptake of a Substrate During Exponential Growth." 93rd General Meeting, American Society of Microbiology, Atlanta, May.

Burlage, R. S., A. V. Palumbo, A. Heitzer, and G. Sayler. 1993. "Bioluminescent Reporter Bacteria Detect Contaminants in Soil Samples." 15th Symposium on Biotechnology for Fuels, Chemicals and Materials, Colorado Springs, Colorado, May.

Cada, G. F. 1993. "Benefits of Fish Passage and Protection Measures at Hydroelectric Projects." Waterpower '93, Nashville, Tennessee, August.

Cada, G. F. 1993. "Use of Rapid Bioassessment Approaches to Examine Benthic Macroinvertebrate Responses to Hydropower Flow Diversions." 41st Annual Meeting, North American Benthological Society, Calgary, Alberta, Canada, May.

Cardwell, H., and M. J. Sale. 1993. "Optimization to Identify Alternative Instream Flow Releases from MultiPurpose Projects." 29th Annual Conference, American Water Resources Association, Tucson, Arizona, August-September.

Chatfield, T. A. and R. L. Graham. 1993. "A Land Use/Land Cover Map of the Oak Ridge Reservation and Surrounding Lands." American Congress on Surveying and Mapping/American Society for Photogrammetry and Remote Sensing Technical Program, New Orleans, February.
Christensen, S. W., and E. J. Nall. 1993. "An Overview of the Internet." Meeting of East Tennessee PC Users Group/ Internet Special Interest Group, The University of Tennessee College of Veterinary Medicine, Knoxville, July.

Clapp, R. B., D. S. Hicks, D. K. Solomon, D. M. Borders, D. D. Huff, and H. L. Boston. 1992. "Groundwater, Surface Water, and Movement of Contaminants at the Oak Ridge Reservation." Fall Meeting, American Geophysical Union, San Francisco, December.

Clapp, R. B., S. P. Timmins, and M. A. Huston. 1993. "Visualizing the Surface Hydrodynamics of a Forested Watershed." Fourth Annual Walker Branch Watershed Research Symposium, Oak Ridge, Tennessee, March.

Cline, S. R., B. E. Reed, R. E. Moore, and M. R. Matsumoto. 1993. "Soil Washing of Various Forms of Lead and Organically Contaminated Soils." Water Environment Federation 66th Annual Conference and Exposition, Anaheim, California, October.

Cook, R. B. 1992. "Clinch River Environmental Restoration Program." Health Studies Committee, Tennessee Oversight Agreement, Nashville, October.

Cooper, L. W., and J. M. Grebmeier. 1993. "Influence of the St. Lawrence Island Polynya upon Benthic Productions: Indications from the Oxygen Isotope Composition of Tunicate Cellulose." Third Scientific Meeting of the Oceanography Society, Seattle, April.

Cooper, L. W., J. M. Grebmeier, I. L. Larsen, C. Solis, and C. R. Olsen. 1993. "Cesium-137 Inventories in Alaskan Tundra, Lake, and Marine 
Sediments." Workshop on Arctic Contamination, Interagency Arctic Research Policy Committee, Anchorage, Alaska, May.

Cooper, L. W., and R. J. Norby. 1993. "Doubling $\mathrm{CO}_{2}$ Levels Can Increase the ${ }^{18} \mathrm{O}$ Content of Leaf Water and Cellulose: Paleoclimatic and Ecophysiological Implications." IAEA/UNESCO International Symposium on Applications of Isotope Techniques in Studying Past and Current Environmental Changes in the Hydrosphere and the Atmosphere, Vienna, April.

Crowder, L. B., R. A. Wright, K. A. Rose, T. H. Martin, and J. A. Rice. 1992. "Direct and Indirect Effects of Southern Flounder Predation on a Spot Population: Experimental and Model Analyses." Gutshop '92, Orcas Island, Washington, November.

Crumby, W. D., and K. D. Ham. 1993. "Video Image Measurement in Age and Growth Analyses." Technical Meeting, American Fisheries Society, Southern Division, Chattanooga, Tennessee, February.

Cushman, J. H. 1993. "United States Potential for Forest Biomass as a LargeScale Energy Source." Forest Products Society, Clearwater, Florida, June.

Cushman, J. H., and A. F. Turhollow. 1992. "Lignocel'ulosic Crops for Bioenergy." Crop Science Society of America, Minneapolis, November.

Cushman, R. M., and P. Kanciruk. 1993. "The Role of CDIAC in Providing Information for the Global ClimateChange Issue." IAMAP-IAHS '92 (International Association of Meteorology and Atmospheric Physics-International
Association of Hydrological Sciences) Joint International Meeting, Yokohama, Japan, July.

Daniels, R. C. 1993. "Impacts of SeaLevel Rise Induced Erosion on Nags Head, North Carolina." 89th Annual Meeting, Association of American Geographers, Atlanta, April.

Daugherty, P. F., and P. T. Singley. 1992. "Metadata in Archives: The Atmospheric Radiation Measurement (ARM) Archive Experience." Scientific Data Management Workshop, Salt Lake City, November.

Davies, G. J., P. A. Rubin, and J. F. Quinlan. 1993. "Indirect Observation of the Rapid-Flow and Slow-Flow Components of Recharge to the Knox Aquifer, Oak Ridge, Tennessee." Fourth Annual Walker Branch Watershed Research Symposium, Oak Ridge, Tennessee, March.

DePaoli, D. W., O. A. Basaran, and S. E. Herbes. 1993. "Investigation of Soil Aeration Performance of Bioventing Systems." Summer National Meeting of the American Institute of Chemical Engineers, Seattle, August.

Dickerman, J. A., V. R. Tolbert, M. S. Salk, and A. A. Richmond. 1993. "Techniques and Guidelines for Stream. lining NEPA: Four Ideas, Nine Tools." National Association of Environmental Professionals, Raleigh, North Carolina, May.

Doll, W. E., J. E. Nyquist, J. S. Holladay, V. F. Labson, and L. Pellerin. 1993. "Preliminary Results of a Helicopter-Borne Electromagnetic and Magnetic Survey of the Oak Ridge Reservation, Tennessee, for Environmental and Geologic Site Characterization." Symposium on 
Application of Geophysics to Engineering and Environmental Problems, San Diego, April; Fourth National Technology Information Exchange Workshop, Knoxviiie, Tennessee, May.

Dreier, R. B., A. J. Caldanaro, B. A. Couzens, D. Hollon, and J. A. Lea. 1993. "Construction Activities and Preliminary Hydraulic Head Results from Multiport Wells Constructed to Monitor DNAPL at the Y-12 Burial Grounds." Fourth National Technology Information Exchange Workshop, Knoxville, Tennessee, May.

Dreier, R. B., and L. E. Toran. 1992. "Geologic Controls on Flow Patterns in the Appalachian Fold and Thrust Belt." Fall Meeting, American Geophysical Union, San Francisco, December.

Dreier, R. B., and L. E. Toran. 1993. "Geologic Controls on Flow Patterns at the Oak Ridge Reservation." Fourth National Technology Information Exchange Workshop, Knoxville, Tennessee, May.

Dunbar, N. W., G. K. Jacobs, and M. T. Naney. 1992. "Effect of Cooling Rate on Timing and Dynamics of Crystallization Within a Man-Made Magma Body." 104th Annual Meeting, Geological Society of America, Cincinnati, October.

Duncan, C. E., and S. W. Christensen. 1993. "Overview of Data Integration for the Biological Monitoring and Abatement Program." Middle School Teachers Workshop on Restoring Our Waters, ESD, ORNL, Oak Ridge, Tennessee, July.

Durfee, R. C., R. A. McCord, and J. E. Dobson. 1993. "The Application of GIS and Remote Sensing Technologies for
Site Characterization and Environmental Assessment." Federal Environmental Restoration (FER '93) Conference, Washington, D.C., May.

Eddlemon, G. K. (contributor). 1993. "Introduction To and Overview of the DOE NEPA Compliance Program." Albuquerque Field Office, Course on Environmental Laws and Regulations, Albuquerque, New Mexico, June.

Eddlemon, G. K. (contributor). 1993. "The New DOE NEPA Rule 10 CFR 1021." Albuquerque Field Office, Course on Environmental Laws and Regulations, Albuquerque, New Mexico, June.

Eddlemon, G. K., J. W. Webb, D. B. Hunsaker, and R. L. Miller. 1993. "Actual Versus Predicted Impacts of Three Ethanol Plants on Aquatic and Terrestrial Resources." 18th Annual Conference of National Association of Environmental Professionals on Current and Future Priorities for Environmental Management, Raleigh, North Carolina, May.

Edwards, G. S., L. J. Samuelson, J. M. Kelly, P. J. Hanson, and S. D. Wullschleger. 1993. "Ozone Sensitivity in Quercus rubra L. Depends on Growth Stage." Liphook Conference, Cambridge, Great Britain, March.

Edwards, N. T. 1993. "There is a Need for Improved UV-B Exposure Systems for Studying UV-B Effects on Vegetation." UV-B Critical Issues Workshop, Cocoa Beach, Florida, February.

Egert, C. M., D. D. Schmoyer, and J. D. Howe. 1993. "The Application of Design of Experiments to a Multilayer Optical Coating Process." SPIE International Symposium on Optics, San Diego, July. 
Ehrenshaft, A. R., L. L. Wright, and S. A. Martin. 1993. "Energy Crop Information at ORNL." 205th American Chemical Society National Meeting, Denver, March-April.

Elless, M. P. 1993. "Calculation of Clay Mineral Formulae from Chemical Analyses Using LOTUS ${ }^{\text {TM }}$ 1-2-3

Spreadsheets." Clay Mineral Society, San Diego, September.

Elless, M. P., S. Y. Lee, and M. E. Timpson. 1993. "Application of a Magstream $^{\text {TM }}$ Density Separator in Soil Mineralogy." Clay Mineral Society, San Diego, September.

Emanuel, W. R. 1993. "Carbon Dioxide Increase and the Global Carbon Cycle." U.S. Department of Energy Office of Health and Environmental Research Program Directors' Meeting, Oak Ridge, Tennessee, February.

Flamm, R. O., W. W. Hargrove, A. Leibhold, and R. H. Gardner. 1992. "A Spatially-Explicit Model of Gypsy Moth Population Dynamics." Annual Meeting, Entomological Society of America, Baltimore, December.

Flamm, R. O., M. G. Turner, R. Gottfried, R. G. Lee, R. J. Naiman, N. Schumaker, and D. Wear. 1993. "Simulating Landscape Change in the Southern Appalachians Using Spatially-Explicit Socioeconometric Data." Eighth Annual U.S. Landscape Ecology Symposium, Oak Ridge, Tennessee, March.

Flamm, R. O., M. G. Turner, D. Wear, and J. Chazel. 1992. "The Effects of Land Use on Forest Cover." Second Annual Southern Appalachian Man and the Biosphere Conference, Gatlinburg, Tennessee, November.
Fontaine, T. A. 1992. "Contaminated Sediment Transport During Floods." Water Forum '92, American Society of Civil Engineers, Baltimore, August.

Fontaine, T. A. 1992. "Measuring the Spatial Distribution of Evapotranspiration Using Atmometers." 28th Annual Conference, American Water Resources Association, Reno, Nevada, November.

Fontaine, T. A., and K. W. Potter. 1993. "Estimating Exceedance Probabilities of Extreme Floods." International Symposium on Engineering Hydrology, San Francisco, July.

Ford, C. J., D. E. Miller, M. L. Frank, B. G. Blaylock, B. L. Kimmel, and S. L. Niemela. 1993. "Contaminated Surface Sediment in the White Oak Creek Embayment, Tennessee: Elevated Levels of Cs-137." Contaminated Aquatic Sediments: Historical Records, Environmental Impact, and Remediation, Milwaukee, June.

Francfort, J. E., and G. F. Cada. 1993. "Environmental Requirements at Hydroelectric Power Projects." 205th American Chemical Society National Meeting, Denver, March-April.

Francis, C. W., A. J. Mattus, L. L. Farr, M. P. Elless, and S. Y. Lee. 1993.

"Selective Leaching of Uranium from Uranium-Contaminated Soils."

Second Semiannual Office of Technology Development Information Meeting. Houston, January; Waste Manag. -nt '93, Tucson, Arizona, February-March.

Gardner, R. H., A. W. King, and V. H. Dale. 1992. "Interactions Between Forest Harvesting, Landscape Heterogeneity, and Species Persistence." Workshop on Modeling Sustainable 
Forest Ecosystems, Washington, D.C., November.

Gardner, R. H., A. W. King, and V. H. Dale. 1993. "Forest Management, Landscape Heterogeneity, and Species Persistence." Eighth Annual U.S. Landscape Ecology Symposium on Pattern and Process in Landscape Ecology, Oak Ridge, Tennessee, March.

Garten, C. T., Jr., and H. Van Miegroet. 1992. "Nitrogen Isotope Ratios in Plants as an Indicator of $\mathbf{N}$ Status in the Great Smoky Mountains." Second Annual Conference on Southern Appalachian Man and the Biosphere, Gatlinburg, Tennessee, November.

Gates, D. D. 1993. "Proposed Cryogenic Demonstration at Oak Ridge National Laboratory." U.S. Army Corps of Engineers, Cold Regions Research and Engineering Laboratory, Hanover, New Hampshire, June.

Gates, D. D., C. W. Francis, L. M. Laster, and R. Kimmitt. 1992. "Pilot and Field-Scale Uranium Lysimeter Studies at the Oak Ridge Y-12 Plant." Scientific Basis for Nuclear Waste Management XVI, Fall Meeting Material Research Society, Boston, November-December.

Gates, D. D., C. W. Francis, L. M. Laster, and R. Kimmitt. 1993. "Pilot and Field-Scale Uranium Lysimeter Studies at the Oak Ridge Y-12 Plant." Fourth National Technology Information Exchange Workshop, Knoxville, Tennessee, May.

Gates, D. D., and R. L. Siegrist. 1993. "Evaluation of In Situ Peroxidation of Clay Soils Contaminated by Trichloroethylene." Fourth National Technology Information
Exchange Workshop, Knoxville, Tennessee, May.

Gates, D. D., and R. L. Siegrist. 1993. "In Situ Peroxidation of TCE Contaminated Soil." Joint CSCE-ASCE National Conference on Environmental Engineering, Montreal, Quebec, Canada, July.

Goldstrand, P. M. 1993. "A Late Cambrian Orogeny in the Ellsworth Mountains of West Antarctica: Implications to the Evolution of the Paleo-Pacific Margin of Gondwana." East Tennessee Geological Society, Oak Ridge, Tennessee, May.

Goldstrand, P. M. 1993. "Late Cretaceous to Eocene Tectonostratigraphy of Southwestern U.S.A." Department ot Geology, The University of Tennessee, Knoxville, February.

Goldstrand, P. M. 1993. "Paleogeographic and Paleotectonic Development of Laramide Basins of Southwest Utah." Meeting of the Geological Society of America, Reno, Nevada, May.

Graham, R. L., and M. Downing. 1993. "Renewable Biomass Energy: Understanding Regional Scale Environmental Impacts." Eighth Annual U.S. Landscape Ecology Symposium, Oak Ridge,

Tennessee, March.

Grebmeier, J. M., L. W. Cooper, I. L. Larsen, C. Solis, and C. R. Olsen. 1993. "Cesium-137 Inventories in Alaskan Tundra, Lake and Marine Sediments: An Indicator of Recent Organic Material Transport?" IAEA/UNESCO International Symposium on Applications of Isotope Techniques in Studying Past and Current Environmental Changes in the Hydrosphere and the Atmosphere, Vienna, April. 
Greeley, M. S., Jr., and S. M. Adams. 1993. "Bioindicator Assessment of Fish Health and Reproductive Competence in Lake Hartwell and Twelve Mile Creek." Annual Meeting, Carolinas Society of Environmental Toxicology and Chemistry Chapter, Clemson University, Pendleton, South Carolina, May.

Greeley, M. S., Jr., S. M. Adams, W. D. Crumby, S. L. Niemela, A. M. Brown, D. L. Dycus, R. L. Self, and C. M. Alexander. 1992. "An Integrated Study of Fish Health in a PCB-Contaminated Reservoir." 13th Annual Meeting, Society of Environmental Toxicology and Chemistry, Cincinnati, November.

Greeley, M. S., Jr., and S. L. Niemela. 1993. "Reevaluation of Methods for Estimating the Fecundity of Largemouth Bass (Micropterus salmoides)." Annual Meeting, American Fisheries Society on Shared Responsibility for Shared Resources, Portland, Oregon, August-September.

Griffin, W. T., T. J. Phelps, F. S. Colwell, R. M. Lehman, B. F. Russell, J. P. McKinley, and T. O. Stevens. 1993. "Subsurface Bricrobial Ecology of the Taylorsville Triassic Basin, King George County, Virginia." Annual Meeting, American Association of Petroleum Geologists, New Orleans, April.

Griffith, J. A., C. T. Hunsaker, S. P. Timmins, and B. L. Jackson. 1993. "Analysis of Landscape Metrics at Different Resolutions for Environmental Monitoring." 89th Annual Meeting, Association of American Geographers, Atlanta, April.
Gu, B., J. Schmitt, L. Liang, and J. F. McCarthy. 1992. "On the Adsorption Mechanisms of Natural Organic Matter by Iron-Oxide and Its Coated Quartz." Annual Meeting, American Geophysical Union, San Francisco, December.

Gunderson, C. A., R. J. Norby, and S. D. Wullschleger. 1993. "Effects of Elevated Atmospheric $\mathrm{CO}_{2}$ on Coppice Growth in Yellow-Poplar." Fourth Annual Walker Branch Watershed Research Symposium, Oak Ridge, Tennessee, March.

Gwo, J. P., P. M. Jardine, G. T. Yeh, and G. V. Wilson. 1993. "Modeling Subsurface Flow and Transport in the Melton Branch Watershed Using Multiple Pore Region Models." Fourth National Technology Information Exchange Workshop, Knoxville, Tennessee, May.

Gwo, J. P., G. T. Yeh, and P. M. Jardine. 1992. "Multi-Region Modeling of Soil Column Tracer Injections.” Annual Meeting, American Geophysical Union, San Francisco, December.

Halbrook, R. S., and G. W. Suter. 1992. "Use of Great Blue Heron Monitoring Data in Risk. Assessments for a Superfund Site." 13th Annual Meeting, Society of Environmēntal Toxicology and Chemistry, Cincinnati, November.

Ham, K. D., and W. H. Neill. 1993. "Photoregulatory Behavior of Bluegill, Lepomis macrochirus, in a Virtual Light Gradient." Annual Meeting, American Fisheries Society, Portland, Oregon, August-September.

Ham, K. D., and M. J. Peterson. 1992. "Effects of Fluctuating Low-Level Chlorine Concentrations on Valve Movement Behavior of the Asiatic Clam 
(Corbicula sp.)."13th Annual Meeting, Society of Environmental Toxicology and Chemistry, Cincinnati, November.

Hanson, P. J., and W. A. Hoffman. 1993. "Carbon Dioxide and Non-Methane Hydrocarbon Emissions from the Forest Floor of an Upland Oak Forest." Greenhouse Gas Emissions and Carbon Sequestration, Ohio State University, Columbus, April.

Hanson, P. J., and W. A. Hoffman. 1993. "Emission of Non- $\mathrm{CO}_{2}$, Non- $\mathrm{CH}_{4}$ Volatile Organics from Hardwood and Conifer Forest Floor Cores." Fourth Annual Walker Branch Watershed Research Symposium, Oak Ridge, Tennessee, March.

Hanson, P. J., L. J. Samuelson, S. D. Wullschleger, and G. S. Edwards. 1993. "Impacts of Ozone on Photosynthesis and Conductance of Tree Versus Seedling Quercus rubra L. Foliage." Annual Meeting, American Society of Plant Physiologists, Minneapolis, July-August.

Hargrove, W. W., R. O. Flamm, A. Liebhold, and R. H. Gardner. 1992. "A Spatially Explicit Simulation of the Efficacy of Spray Barriers to Gypsy Moth Migration." Annual Meeting, Entomological Society of America, Baltimore, December.

Hargrove, W. W., R. H. Gardner, M. G. Turner, W. H. Romme, and D. G. Despain. 1993. "A Grid-Based Model for Simulating Fire Patterns in Heterogeneous Landscapes." Eighth Annual U.S. Landscape Ecology Symposium, Oak Ridge, Tennessee, March.

Herbes, S. E., T. L. Donaldson, H. L. Jennings, A. J. Lucero, M. I. Morris, and A. V. Palumbo. 1993. "Cometabolic
Techniques Demonstration at the Oak Ridge K-25 Site." Office of Technology Development Information Exchange, Houston, January.

Hetrick, D. M., R. J. Luxmoore, and M. L. Tharp. 1993. "Hypercube Sampling with the SESOIL Model." Eighth Annual Conference on Hydrocarbon Contaminated Soils-Analysis, Fate, Environmental and Public Health Effects, Remediation and Regulatory Issues, Amherst, Massachusetts, September.

Hicks, D. S., D. K. Solomon, and N. D. Farrow. 1993. "Subsurface Contaminant Transport to Streams." American Water Resources Association Conference on Innovations in Ground Water Mainagement, Tucson, Arizona, August-September.

Hildebrand, S. G. 1993. "Ecological Risk Assessment Process." Setting Ecological Risk Priorities, University of Iowa, Iowa City, June.

Hildebrand, S. G. 1993. "Opening Remarks." Southern Appalachian Man and the Biosphere Conference on Wetland Ecology, Management, and Conservation, Knoxville, Tennessee, September.

Hill, W. R. 1993. "Canopy Closure Over Two Hecdwater Streams: Consequences for Periphyton, Grazers, and Nutrients." 41st Annual Meeting, North American Benthological Society, Calgary, Alberta, Canada, May.

Hinzman, R. L., and S. W. Christensen. 1992. "What Do Environmental Scientists Need from Geographic Information Systems?" Third Geographic Information Systems Information Exchange Meeting, Gatlinburg, Tennessee, November. 
Hoffman, W. A., and P. J. Hanson. 1992. "Emission of Non- $\mathrm{CO}_{2}$ Non- $\mathrm{CH}_{4}$ Volatile Organics from Hardwood and Conifer Forest Floor Cores." Annual Meeting, Amcrican Socicty of Agronomy/Soil Science Society of America, Minneapolis, November.

Homer, V. J., Z. H. Chen, and J. F. McCarthy. 1992. "Fractal Dimension: A Probe of Humic Aggregation Properties." Annual Meeting, Soil Science Society of America, Minneapolis, November.

Hoylman, A. M., N. T. Edwards, and B. T. Walton. 1992. "Uptake and Translocation of Polycyclic Aromatic Hydrocarbons by Vegetation." 13th Annual Meeting, Society of Environmental Toxicology and Chemistry, Cincinnati, November.

Huff, D. D. 1993. "Land Use and Hydrology-Review of Oak Ridge Reservation Hydrologic Framework as It Relates to Contaminated Sites and CleanUp Actions." Oak Ridge Land Use Plan for lowa State Department of Community and Regional Planning, Ames, Iowa, June-July.

Huff, D. D., D. K. Solomon, G. K. Moore, L. E. Toran, R. B. Dreier, and

W. M. McMaster. 1992. "The Hydrology of the Oak Ridge Reservation-A Conceptual Model." Fifth Tennessee Water Resources Symposium, Nashville, Tennessee, October.

Huff, D. D., D. K. Solomon, G. K. Moore, L. E. Toran, R. B. Dreier, and

W. M. McMaster. 1993. "A Conceptual Model of the Hydrology of the Oak Ridge Reservation." American Institute of Hydrology International Conference, Crystal City, Arlington, Virginia, May;
Fourth National Technology Information Exchange Workshop, Knoxville, Tennessee, May.

Hull, C. G., L. R. Shugart, and M. S. Greeley, Jr. 1992. "Diverse Applications of a Medaka Embryo-Larval Assay: Evaluation of the Toxicity of a Single Compound, Soil Extracts and Stream Effluents." 13th Annual Meeting, Society of Environmental Toxicology and Chemistry, Cincinnati, November.

Hull, R. N. 1993. "What Is the Ecological Equivalent of Cancer?" The University of Tennessee Graduate Course on Legal and Societal Aspects of Toxicology, Knoxville, Tennessee, April.

Hunsaker, C. T., and D. A. Levine. 1993. "Hierarchical Approaches to Large River Landscapes." 78th Annual Meeting, Ecological Society of America, Madison, Wisconsin, July-August.

Hunsaker, C. T., and S. P. Timmins. 1993. "Tools for Visualizing Landscape Pattern Analysis for Large Geographic Areas." Second International Conference/Workshop on Integrating Geographic Information Systems and Environmental Modeling, Breckenridge, Colorado, September.

Hunsaker, C. T., S. Timmins, B. Jackson, J. Griffith, and R. V. O'Neill. 1993.

"Landscape Pattern Analysis for

Ecoregions." Eighth Annual U.S. Landscape Ecology Symposium, Oak Ridge, Tennessee, March.

Hurst, D. H., K. G. Robinson, and R. L. Siegrist. 1993. "Hydrogen Peroxide Treatment of TCE Contaminated Soil." Third International Conference on Chemical Oxidation, Nashville, Tennessee, February. 
Huston, M. A., C. T. Garten, J. W. Chason, S. P. Timmins, P. J. Hanson, and D. E. Todd. 1993. "Use of a Hydrologic Model to Predict Ecosystem Properties." Ecological Society of America, Madison, Wisconsin, August.

Jackson, B. L. 1993. "SAS Macros for Converting Between ARC/INFO Single Variable Files and SAS Data Sets." SAS Users-Group International Conference, New York, May.

Jacobs, G. K. 1992. "In Situ Vitrification: Melting Contaminated Soils and Studying Magmatic Processes." Department of Geology, Vanderbilt University, Nashville, Tennessee, November.

Jacobs, G. K., V. Alexiades, N. W. Dunbar, and M. T. Naney. 1992. "ConductionDiffusion Simulation of the Crystallization and Cooling Behavior of a Field-Scale Melting Experiment." Annual Meeting, American Geophysical Union, San Francisco, December.

Jacobs, G. K, B. P. Spalding, and J. S. Tixier. 1992. "In Situ Vitrification: Immobilizing Radioactive Contaminants in Place by Melting Soils into Man-Made Rocks." 104th Annual Meeting, Geological Society of America, Cincinnati, November.

Jacobs, G. K., B. P. Spalding, J. S. Tixier, and T. D. Powell. 1993. "Stabilization of Contaminated Soils by In Situ Vitrification." Office of Technology Development Meeting, Houston, March.

Jager H. I., C. C. Coutant, M. J. Sale, M. S. Bevelhimer, and D. L. DeAngelis. 1993. "An Individual-Based Model of Chinook Salmon Response to Flow in the Tuolumne River, California." Annual Meeting, American Fisheries Society,
Western Division, Sacramento, California, July.

Jager, H. I., D. L. DeAngelis, M. J. Sale, W. Van Winkle, D. D. Schmoyer, M. J. Sabo, and D. J. Orth. 1993. "Verification of a Model to Simulate the Response of Young-of-Year Smallmouth Bass to Flow in North Anna River, Virginia." Southern Division of American Fisheries Society, Chattanooga, Tennessee, February.

Jager, H. I., M. J. Sale, M. J. Sabo, D. D. Schmoyer, and D. L. DeAngelis. 1993. "Modeling Spatial Distribution of Smallmouth Bass in the North Anna River, Virginia." Waterpower '93, Nashville, Tennessee, August.

Jager, H. I., D. D. Schmoyer, M. J. Sale, M. J. Sabo, W. Van Winkle, and D. L. DeAngelis. 1993. "Spatial Simulation of Smallmouth Bass Streams." Waterpower '93, Nashville, Tennessee, August.

Jago, W. K., R. Dreier, L. Shevenell, and S. Jones. 1992. "Status of the Bear Creek Valley Exit Pathway Monitoring Program, Y-12 Plant, Oak Ridge Tennessee."

Eighth Annual DOE Model Conference on Waste Management and Environmental Restoration, Oak Ridge, Tennessee, October.

Jennings, H. L., A. J. Lucero, T. H. Donaldson, and S. E. Herbes. 1993. "Cometabolic Biotreatment of TCEContaminated Groundwater." In Situ and On-Site Bioreclamation, San Diego, April.

Jones, S. B., L. J. Morris, D. E. Shepherd, and T. W. Stamm. 1993. "CDIAC's PCBased Information Management System." Tenth Office of Information Technology Conference, Knoxville, Tennessee, July. 
Kaiser, D. 1993. "Cloud Amount and Sunshine Duration in the People's Republic of China, 1954-1988." Eighth Conference on Applied Climatology/ 73rd Annual Meeting, American Meteorological Society, Anaheim, California, January.

Kim, K.-H., S. E. Lindberg, P. J. Hanson. T. P. Meyers, and J. Owens. 1993. "Application of Micrometeorological Methods to Measurements of Mercury Emissions Over Contaminated Soils." Heavy Metal Conference, Toronto, Ontario, Canada, September.

Kim, K.-H., K. M. Turnage, S. Y. Lee, J. E. Foss, I. L. Larsen, R. J. Lewis, and M. E. Timpson. 1992. "Soil Erosion and Deposition Rates Calculated Within Sinkholes Using Cs-137 Redistribution." Annual Meeting, Soil Sciences Society of America, Minneapolis, November.

King, A. D., D. M. Carden, W. E. Doll, and R. C. Durfee. 1993. "Aerial Remote Sensing Surveys: Oak Ridge Reservation." Remote Sensing Liaison Working Group, Desert Research Institute, Las Vegas, March.

King, A. D., W. E. Doll, and R. C. Durfee. 1993. "Aerial Remote Sensing SurveysOak Ridge Reservation." Westinghouse Savannah River Co./Martin Marietta Energy Systems, Inc., Environmental Restoration Technical Information Exchange, Augusta, Georgia, February.

King, A. D., W. E. Doll, R. C. Durfee, and D. T. Bell. 1993. "Aerial Remote Sensing Surveys-Oak Ridge Reservation." DOE Headquarters Meeting on Aerial Remote Sensing, Gaithersburg, Maryland, January.

King, A. W. 1993. "A Model of Theory in Ecology." Annual Meeting, Ecological
Society of America, Madison, Wisconsin, July-August.

King, A. W., W. R. Emanuel, S. D. Wullschleger, and W. M. Post. 1993. "Terrestrial Biospheric Response to Atmospheric $\mathrm{CO}_{2}$ and the Missing Carbon." Annual Meeting, Ecological Society of America, Madison, Wisconsin, July-August.

Kohring, L. L., G. E. Napolitano, A. J. Stewart, and D. C. White. 1993. "Analysis of Periphyton Pigments of HPLC: Comparison of Extraction Solvents and Formation of Degradation Products." 41st Annual Meeting, North American Benthological Society, Calgary, Alberta, Canada, May.

Korte, N., and P. Kearl. 1993. "Data Validation and Risk Assessment-Some Pitfalls when Evaluating VOC Measurements." National Symposium on Measuring and Interpreting VOCs in Soils: State of the Art and Research Needs, Las Vegas, January.

Korte, N., P. Kearl, and D. Koehler. 1993. "Strategies to Define and Implement Large-Scale Watershed Restoration Policy on the Navajo Nation." Riparian Management: Common Threads and Shared Interests, Albuquerque, New Mexico, February.

Korte, N., P. Kearl, and G. Rajen. 1993. "Non-Point Source Pollution Control and Watershed Restoration on Indian Reservations in the Western United States." Fourth Annual Walker Branch Watershed Research Symposium, Oak Ridge, Tennessee, March.

Korte, N., and J. Thate. 1993. "Health and Safety at Hazardous Waste Sites-Is it Possible to be Too Careful? ${ }^{n}$ American 
Chemistry Society National Symposium on Health, Safety, and Training Issues During Site Characterization and Remediation, Denver, March.

Kuo, C.-T., N. Handagama, R. S. Burlage, and A. V. Palumbo. 1993. "A Mathematical Model for a CFSTR System of a Genetically Engineered Pseudomonas putida Strain, RB1401." Annual Meeting, American Society of Microbiology, Atlanta, May.

Laase, A. D. $1993 .{ }^{\text {"Use of Seepage }}$ Meter and Mini-Piezometers to Characterize Groundwater Discharge to Surface Water." Fourth National Technology Information Exchange Workshop, Knoxville, Tennessee, May.

Labieniec, P. A., D. A. Dzombak, and R. L. Siegrist. 1993. "Risk Implications of Approaches to Setting Soil Remediation Goals." Developing Cleanup Standards, Washington, D.C., January.

Lee, I., C. C. Coutant, and E. T. Arakawa. 1993. "Trace Contaminant Determination in Fish Scale by Laser Ablation Technique." Second International Conference on Laser Ablation, Knoxville, Tennessec, April.

Lee, S. Y., B. Burgoa, T. Ammons, D. A. Leitzke, J. Branson, and D. R. Watkins. 1992. "Background Soil Characterization for DOE Environmental Restoration Program." American Society of Agronomy, Minneapolis, November.

Lee, S. Y., M. P. Elless, and C. W. Francis. 1992. "Mineralogical Characterization of Uranium Contaminated Soils at DOE Fernald Site." Annual Meeting, Soil Science Society of America Minneapolis, November.
Leiby, P. N., R. Lee, G. Liepins, and K. Rose. 1993. "Using Evolutionary Algorithms to Characterize TechnoEconomic Systems--An Application to Alternative Transportation Technology Choice." Conference on Computing for the Social Sciences, University of Illinois at Urbana-Champaign, May.

Lemiszki, P. J., and R. D. Hatcher, Jr. 1992. "Structural Analysis of the Cooper Creck and Whiteoak Mountain Faults in East Tennessee: Implications for the Thrusting Sequence and Growth of the Southern Appalachian Foreland Fold." 104th Annual Meeting, Geological Society of America, Cincinnati, October.

Lemiszki, P. J., P. S. Neuhoff, and R. B. Dreier. 1993. "Core Analysis Combined with Electromagnetic Borehole Flowmeter Surveys Is an Effective Way to Document Transmissive Geologic Structures." Fourth National Technology Information Exchange Workshop, Knoxville, Tennessee, May.

Levine, D. A., C. T. Hunsaker, and J. C. Randolph. 1993. "A Geographic Information System Approach to Modeling Non-Point Source Pollution in Watersheds." Symposium on Geographic Information Systems and Water Resources (AWRA), Mobile, Alabama, March.

Levine, D. A., M. A. Wood, and R. Cook. 1993. "Cesium-137 Concentrations in the Surface Sediments of Watts Bar Reservoir, Tennessee." Contaminated Aquatic Sediments: Historical Records, Environmental Impact and Remediation, Milwaukee, June.

Lewis, W. J., D. J. Waters, J. Strong-Gunderson, and J. J. Hamm. 1992. "Multitactal Use of Transgenic Endotoxins and Larval Parasitoid for Notuid Control: Behavioral and 
Physiological Compatibilities." Meeting of the Entomological Society of America, Baltimore, December.

Liang, L. 1992. "Kinetics of $\mathrm{Fe}$ (II)/Fe(III) Transformation in Groundwater." Environmental Sciences Division, Oak Ridge National Laboratory, Oak Ridge, Tennessee, December.

Liang, L., J. A. McNabb, B. Gu, and J. F. McCarthy. 1992. "Effect of Natural Organic Matter on the Transport of Iron Oxide Colloid in Quartz-Packed Columns and in a Sandy Aquifer." Annual Meeting, American Geophysical Union, San Francisco, December.

Lucero, A J., J. F. Walker, Jr., T. L. Donaldson, T. J. Phelps, H. I. Adler, and R. L. Siegrist. 1993. "Bioremediation Demonstration at Kwajalein Atoll." In Situ and On-Site Bioreclamation, San Diego, April.

Luxmoore, R. J. 1992. "An Approach to Scaling Up Physiological Responses of Forests to Environmental Variables." Modeling Forest Response to Global Change, Delaware, Ohio, November.

Luxmoore, R. J. 1993. "Global Change and Forests: The Last 2 $1 / 2$ Hours of Creation." Ecophysiology and Genetics of Trees and Forests in a Changing Environment, Viterbo, Italy, May.

Luxmoore, R. J. 1993. "Homeostasis and Soil-Plant Nutrient Relationships in a Changing Environment." International Botanical Congress, Yokohama, Japan, August-September.

Luxmoore, R. J., and D. D. Baldocchi. 1992. "Modelling Interactions of Carbon
Dioxide, Forests, and Climate." Biotic Feedbacks in the Global Climate System, Woods Hole, Massachusetts, October.

Luxmoore, R. J., and L. A. Ferrand. 1992. "Towards Pore-Scale Analysis of Preferential Flow and Chemical Transport." Annual Meeting, Soil Science Society of America, Minneapolis, November.

Marland, G. 1993. "Strategies for Using Trees to Minimize Net Emissions of $\mathrm{CO}_{2}$ to the Atmosphere." Remarks Before the U.S. House of Representatives Committee on Energy and Commerce, Subcommittee on Energy and Power, Washington, D.C., July.

Marland, G., V. Dale, R. Graham, R. Luxmoore, S. Marland, S. McLaughlin, R. Norby, W. M. Post, T. Tschaplinski, J. Tuskan, and L. Wright. 1993. "Forest Management for Fixing and Sequestering Carbon." Second United States/Japan Workshop on Global Change, Honolulu, February.

Marsh, J. D., Jr., T. L. Ashwood, and D. S. Hicks. 1993. "Geochemical Factors Influencing the Occurrence of ${ }^{244} \mathrm{Cm}$ and ${ }^{2 A 1} \mathrm{Am}$ in Groundwater at a Shallow Waste Burial Site at ORNL." 205th American Chemical Society Annual Meeting, Denver, April; Fourth National Technology Information Exchange Workshop, Knoxville, Tennessee, May.

Marzolf, E. R., P. J. Mulholland, and A. D. Steinman. 1993. "An In Situ Whole-Stream Approach to Measurement of Stream Metabolism and Implications for Nutrient Utilization and Light Limitation." Fourth Annual Walker Branch Watershed Research Symposium, Oak Ridge, Tennessee, March. 
Marzolf, E. R., P. J. Mulholland, and A. D. Steinman. 1993. "A Whole Stream Approach to Metabolism Measurement with Implications for Nutrient Utilization and Light Limitation." 41st Annual Meeting, North American Benthological Society, Calgary, Alberta, Canada, May.

McCarthy, J. F., L. Liang, B. Gu, J. A. McNabb, T. W. Mehlhorn, T. M. Williams, J. Mas-Pla, and C.-T. J. Yeh. 1992. "Ficld Motility of Natural Organic Matter in a Sandy Aquifer." American Geophysical Union Symposium, H18: Colloid Facilitated Transport in Groundwater, San Francisco, December.

McCord, R. A. 1993. "An Overview of the Oak Ridge Field Office Environmental Information System (OREIS)." Office of Scientific and Technical Information on Research Data Management Overview, Oak Ridge National Laboratory, Oak Ridge, Tennessee, May; Environmental Sciences Division Information Meeting, Data Management Discussion, Oak Ridge National Laboratory, Oak Ridge, Tennessee, May; DOE Headquarters and DOE/ORE IRM Staff, Oak Ridge, Tennessee, August.

McCord, R. A., and C. Holmes. 1993. "Status of Compliance Data Integration Into OREIS for TOA Deliverable A.7.1.3: Consolidated Data Base." DOE TOA Steering Committee, Technical Oversight Agreement, DOE, Oak Ridge, Tennessee, July.

McCord, R. A., and L. D. Voorhees. 1993. "An Overview of the Oak Ridge Environmental Information System: A Consolidated Data Base." Office of Scientific and Technical Information on Research Data Management Overview, Oak Ridge
National Laboratory, Oak Ridge,

Tennessee, May.

Mclaughlin, S. B. 1992 . “New

Switchgrass Biofuels Research Program for the Southeast." Automotive Technology Development Contractors' Coordination Meeting, Dearborn, Michigan, November.

Mitchell, T. J., O. M. West, and R. L. Siegrist. 1993. "Statistical Simulation and Three-Dimensional Visualization for Analysis and Interpretation of Soil VOC Data Sets." National Symposium on Measuring and Interpreting VOCs (Volatile Organic Compounds) in Soils, Las Vegas, January.

Moline, G. R., J. M. Bahr, G. C. Nadon, and P. A. Drzewiecki. 1993. "The Role of Diagenesis in Controlling Hydroiogic Characteristics: St. Peter Sandstone, Michigan Basin." Spring Meeting of the American Geophysical Union, Baltimore, May.

Moore, G. K. 1992. "Injection Tests Versus Slug Tests for Wells in Fractured Rocks." Fifth Tennessee Water Resources Symposium, Nashville, October.

Morrissey, C. M., and T. L. Ashwood. 1992. "Environmental Monitoring of the Tumulus Low-Level Waste Disposal Facilities at Oak Ridge National Laboratory." 14th Annual DOE LowLevel Waste Management Conference, Phoenix, Arizona, November.

Morrissey, C. M., S. E. Herbes, A. V. Palumbo, T. J. Phelps, and T. C. Hazen. 1993. "Use of Laboratory Soil Columns to Optimize In Situ Biotransformation of Tetrachloroethylene." Second International Symposium on In Situ and On-Site Bioreclamation, San Dicgo, April. 
Mulholland, P. J. 1993. "Are Valley Bottoms the Wetlands of Upland Catchments: A Streamwater Chemistry Perspective." Southern Appalachian Man and the Biosphere (SAMAB) Conference on Wetland Ecology, Management, and Conservation, Knoxville, Tennessee, September.

Mulholland, P. J. 1993. "Hydrological, Geochemical, and Biological Interactions Control Streamwater Nutrient Concentrations in Walker Branch.” Fourth Annual Walker Branch Watershed Research Symposium, Oak Ridge, Tennessee, March.

Mulholland, P. J. 1993. "Regulation of Stream Chemistry: Effects of Hydrological, Geochemical, and Biological Processes." Environmental Sciences Department Seminar Series, University of Virginia, Charlottesville, March.

Mulholland, P. J. 1993. "Role of Benthic Algae in Nutrient Cycling in Freshwater Ecosystems." 41st Annual Meeting, North American Benthological Society, Calgary, Alberta, Canada, May.

Mulholland, P. J. 1993. "Stream Chemistry: A Reflection of the Hydrologic Coupling of Bios-ochemical Processes in Forested Catchments." Gordon Conference on Hydrologic, Geochemical, and Biological Processes in Forested Catchments, Plymouth, New Hampshire, August.

Mullholand, P. J., D. L. DeAngelis, E. R. Marzolf, A. D. Steinman, and M. Loreau. 1993. "Hydraulic Storage Zones and Nutrient Cycling in Streams." Fourth Annual Walker Branch Watershed Research Symposium, Oak Ridge, Tennessee, March.
Mulholland, P. J., A. D. Steinman, A. V. Palumbo, D. L. DeAngelis, and E. R. Marzolf. 1992. "The Use of Artificial Streams in Stream Ecosystem Studies." 13th Annual Meeting, Society of Environmental Toxicology and Chemistry, Cincinnati, November.

Naney, M. T. 1992. "In Situ Vitrification: Immobilizing Radioactive Contaminants in Artificial Rocks." Department of Geology Seminar, California State University, Fresno, December.

Naney, M. T., G. K. Jacobs, M. S. Ghiorso, and N. W. Dunbar. 1993. "Comparison of Results from the Thermodynamic Model MELTS to the Crystallization History of a Field-Scale Melting Experiment." Spring Meeting, American Geophysical Union, Baltimore, May.

Napolitano, G. E., and R. G. Ackman. 1993. "Incorporation of Phytoplankton Fatty Acids and Sterols by the FilterFeeding Scallop Placopecten magellanicus." 84th Annual Meeting, American Oil Chemists' Society, Anaheim, California, April.

Napolitano, G. E., W. R. Hill, A. J. Stewart, J. B. Guckert, and D. C. White. 1992. "Periphyton Lipids for Quantitative Toxicity Assessments." 13th Annual Meeting, Society of Environmental Toxicology and Chemistry, Cincinnati, November.

Napolitano, G. E., W. R. Hill, A. J. Stewart, J. B. Guckert, S. C. Nold, and D. C. White. 1993. "Changes in Periphyton Community Structure, Lipid and Fatty Acid Compositions in ChlorineImpacted Streams." Third International Conference on Aquatic Ecosystem Health, Virginia Polytechnic Institute and State University, Blacksburg, May. 
Napolitano, G. E., C. Mero, and A. J. Stewart. 1993. "Structural and Storage Lipids in Algae: Their Relationship with Light and Biomass Measurements." 41st Annual Meeting, North American Benthological

Society, Calgary, Alberta, Canada, May.

Neuhoff, P. S., P. J. Lemiszki, and R. B. Dreier. 1993. "Geologic Characteristics of Permeable Groundwater Intervals Defined by Electromagnetic Borehole Flowmeter Surveys on the Oak Ridge Reservation." Meeting of Geological Society of America, Southeast Section, Tallahassee, Florida, April.

Niemela, S. L., M. S. Greeley, Jr., T. K. Elston, and L. R. Shugart. 1992. "The Use of the Medaka Embryo-Larvel Test to Examine the Development Toxicity of Streams and Rivers Draining the Oak Ridge Federal Reservation." 13th Annual Meeting, Society of Environmental Toxicology and Chemistry, Cincinnati, November.

Norby, R. J. 1992. "Responses of Forest Trees to Carbon Dioxide Enrichment of the Atmosphere: Physiological Studies to Address Ecological Questions."

St. Olaf College, Northfield, Minnesota, November.

Norby, R. J. 1993. "Below Ground Responses to Increasing Atmospheric $\mathrm{CO}_{2}$ : A Critical Link Between Carbon and Nutrient Cycling in Forests." Eighth North American Forest Soils Conference, Gainesville, Florida, May.

Norby, R. J. 1993. "Responses of Roots to Elevated $\mathrm{CO}_{2}$." Belowground Responses to Rising Atmospheric $\mathrm{CO}_{2}$,
Michigan Biological Station, Pellston, Michigan, May.

Norby, R. J., C. A. Gunderson, E. G. O'Neill, and S. D. Wullschleger. 1993. "Responses of Deciduous Forest Trees to $\mathrm{CO}_{2}$ Enrichment." 15th International Botanical Congress, Yokohama, Japan, August.

Norby, R. J., E. G. O'Neill, S. D. Wullschleger, C. A. Gunderson, and C. T. Nietch. 1993. "Growth Enhancement of Quercus alba Saplings by $\mathrm{CO}_{2}$ Enrichment under Field Conditions." Annual Meeting, Ecological Society of America, Madison, Wisconsin, July-August.

Nyquist, J. E., and W. E. Doll. 1993. "Comparison of Airborne and Surface Geophysical Surveys at Solid Waste Storage Area 4." Fourth National Technology Information Exchange Workshop, Knoxville, Tennessee, May.

Olson, R. J., M. L. Land, and R. A. McCord. 1993. "Managing Environmental Data to Support Restoration Activities: The OREIS System." Fourth National Technology Information Exchange, Knoxville, Tennessee, May.

O’Neill, E. G. 1993. " Responses of Soil Biota to Elevated Atmospheric Carbon Dioxide." Belowground Responses to Atmospheric $\mathrm{CO}_{2}$ Implications for Plants, Soil Biota and Ecosystem Processes Workshop, Pellston, Michigan, May-June.

Palumbo, A. V. 1993. "GEMs Release Research Objectives/Research Focus." Microbial Physiology/Biodegradation Subprogram Meeting, Gaithersberg, Maryland, January. 
Palumbo, A. V., R. S. Burlage, J. F. McCarthy, P. M. Jardine, and G. V. Wilson. 1993. "The Application of Molecular Techniques to Bacterial Transport Studies: Examples from Vadose Zone and Aquifer Studies." International Symposium on Subsurface Microbiology, Bath, Great Britain, September.

Palumbo, A. V., P. M. Jardine, R. S. Burlage, S. Scarborough, and G. V. Wilson. 1993. "Transport of Bacteria in an Unsaturated Pedon." 93rd General Meeting, American Society of Microbiology, Atlanta, May.

Palumbo, A. V., A. Parker, J. McCarthy, T. J. Phelps, and J. Strong-Gunderson. 1993. "Potential for Microbial Growth in Arid Subsurface Sediments." 15th Symposium on Biotechnology for Fuels and Chemicals, Colorado Springs, Colorado, May.

Palumbo, A. V., and T. J. Phelps. 1993. "OR-1111-01 (3BAC)-Integrated Demonstration of TCE Degradation." Integrated Demonstration Review, Aiken, South Carolina, February.

Palumbo, A. V., T. J. Phelps, G. S. Sayler, D. C. White, and S. M. Pfiffner. 1993. "Integrated Demonstration of TCE Degradation (Biological Monitoring of Critical Populations)." Office of Technology Development Information Exchange, Houston, January.

Palumbo, A. V., and L. Shugart. 1993. "Biotechnology, Biological Activity, and Biological Effects." DOE Office of Health and Environmental Research Program Directors' Meeting, Oak Ridge, Tennessee, February.
Palumbo, A. V., J. M. Strong-Gunderson, and J. F. McCarthy. 1993. "Bioavailability of Natural Organic Matter to Deep Subsurface Microbiota." International Symposium on Subsurface Microbiology, Bath, Great Britain, September.

Parr, P. D. 1993. "Opening Doors in Environmental Understanding: The Role of the Oak Ridge National Environmental Research Park." WATTec '93, 20th Annual Technical Conference and Exhibition, Knoxville, Tennessee, February.

Pearson, S. M. 1993. "Natural Populations and Habitat Heterogeneity at Multiple Scales." Conference of International Association for Landscape Ecology, Oak Ridge, Tennessee, March.

Pearson, S. M. 1993. "Understanding the Impacts of Forest Fragmentation in the Southern Appalachian Mountains.” Forest Ecosystem Management at Landscape Level: The Role of Remote Sensing and GIS Resource Management / lanning, Analysis, and Decision Making, Oak Ridge, Tennessee, March.

Peng, T.-H. 1992. "Effect of Oceanic Carbon Transport on Global Carbon Cycle." Institute of Ocean Sciences, Sidney, British Columbia, November; Battelle Marine Sciences Laboratory, Sequim, Washington, November.

Peng, T.-H. 1992. "Interhemispheric Ocean Carbon Transport and Global Carbon Cycle." National Center for Atmospheric Research, Boulder, Colorado, December.

Peng, T.-H. 1993. "Distribution of Bomb-Produced Radiocarbon in the 
Ocean." Chemical Oceanography Gordon Conference, Kimball Union Academy, Meridian, New Hampshire, August.

Peng, T.-H., and W. S. Broecker. 1993. "Inventories of Bomb- ${ }^{14} \mathrm{C}$ in the Ocean." Fourth International $\mathrm{CO}_{2}$ Conference, Carqueiranne, France, September.

Peng, T.-H., and W. S. Broecker. 1993. "Sensitivity Evaluation for Oceanic Uptake of Fossil Fuel $\mathrm{CO}_{2}$ Based on Global ${ }^{13} \mathrm{C}$ Distribution." Global AtmosphericBiospheric Chemistry, Eilat, Israel, April.

Peng, T.-H., and T. Takahashi. 1993. "Ocean Uptake of Carbon Dioxide." Symposium on Heat and Mass Transfer in Oceans, 29th National Heat Transfer Conference, Atlanta, August.

Peterson, M. J., G. R. Southworth, and W. D. Crumby. 1993. "Detecting the Presence of Biologically Available Mercury Contamination in Small Streams Using Blacknose Dace (Rhinichthys atratulus)." Annual Meeting, American Fisheries Society, Portland, Oregon, August-September.

Peterson, M. J., G. R. Southworth, and K. D. Ham. 1993. "Evaluation of the Asiatic Clam (Corbicula fluminea) as a Monitor of PCB Contamination in Chlorine Impacted Streams."

41st Annual Meeting, North American Benthological Society, Calgary, Alberta, Canada, May.

Peterson, T. C., D. R. Easterling, R. S. Vose, and J. K. Eischeid. 1993. "The Global Historical Climatology Network Precipitation Data." Symposium on Precipitation and Evaporation, Bratislava, Slovaka, September.
Pfiffner, S. M., R. Mackowski, D. Ringelberg, D. C. White, and T. J. Phelps. 1993. "Monitoring of Microbial Populations and Activities from Groundwater for In-Situ Trichloroethylene Bioremediation." Annual Meeting, American Society of Microbiology, Atlanta, May.

Pfiffner, S. M., T. J. Phelps, D. Ringelberg, and D. C. White. 1993. "Microbial Population Changes in Subsurface Environments Amended with Air, Methane, and Nutrients." International Symposium on Subsurface Microbiology, Bath, Great Britain, September.

Phelps, T. J. 1992. "Evidence for TCE Degradation at the WSRS Demonstration." Westinghouse Savannah River Site Integrated Demonstration Technical Support Group Meeting, Aiken, South Carolina, October.

Phelps, T. J. 1992. "The Terrestrial Subsurface, an Uncharted Environment." Biotechnology Program, The University of Tennessee, Knoxville, October.

Phelps, T. J., S. M. Pfiffner, R. Mackowski, D. Ringelberg, D. C. White, and A. V. Palumbo. 1993. "Application of Microbial Biomass and Activity Measures to Assess In-Situ Bioremediation of Chlorinated Solvents." Second International Symposium on In Situ and On-Site Bioreclamation, San Diego, April.

Phelps, T. J., and B. F. Russell. 1993. "Sampling and Quality Assurance Procedures Used Within the U.S. DOE Subsurface Science Program." International Symposium on Subsurface Microbiology, Bath, Great Britain, September. 
Ranney, J. W. 1992. “Can Biomass Energy Crops Really Improve Overall Environmental Quality?" Seventh European Conference on Biomass for Energy and Environment, Agriculture and Industry Session on Biomass and Environment, Florence, Italy, October.

Rashleigh, B. L., V. A. Kelson, and R. S. Turner. 1992. "Estimating Climate Change Effects on Water Temperature." American Water Resources Association 28th Annual Conference/Symposium on Managing Water Resources During Global Change-An International Conference, Reno, Nevada, November.

Rothstein, E., T. Janaushek, M. Bodnar, T. S. Steenhuis, and W. E. Sanford. 1993. "Density Stratification in Rock-Reed Filters.” Spring Meeting, American Geophysical Union, Baltimore, May.

Rubin, P. A. 1992. "Land-Use Planning and Watershed Protection in Karst Terranes." Third Conference on Hydrogeology, Ecology, Monitoring and Management of Ground Water in Karst Terranes, Nashville, Tennessee, November.

Rubin, P. A., and P. J. Lemiszki. 1992. "Structural and Stratigraphic Controls on Cave Development in the Oak Ridge Area, Tennessee." Fifth Tennessee Water Resources Symposium, Nashville, Tennessee, October.

Rubin, P. A., P. J. Lemiszki, P. S. Neuhoff, B. Zerr, G. J. Davies, and J. Aiken. 1993. "Preliminary Hydrogeologic Studies in Carbonate Aquifers of the Oak Ridge Reservation, Tennessee." Fourth Annual Walker Branch Watershed Research Symposium, Oak Ridge, Tennessee, March.
Rubin, P. A., P. J. Lemiszki, and R. S. Poling. 1992. "Strategy for Definition and Protection of East Tennessee Karst Groundwater Basins." Fifth Tennessee Water Resources Symposium, Nashville, Tennessee, October.

Russell, B. F., W. T. Griffin, T. J. Phelps, F. S. Colwell, and T. Stevens. 1993. "Microbiological Sampling Strategies: Fundamentals for the Collections of Representative Materials." International Symposium on Subsurface Microbiology, Bath, Great Britain, September.

Salk, M. S. 1992. "Other Environmental Laws and Regulations: Flood Plains/ Wetlands, Historic Preservation, Endangered Species, etc." Environmental Laws and Regulations Training Course, Golden, Colorado, November.

Sanford, W. E., D. K. Solomon, J. F. McCarthy, and T. M. Williams. 1992. "Noble Gases as Tracers in a Sandy Aquifer." Fall Meeting, American Geophysical Union, San Francisco, December.

Sanford, W. E., J. M. Surface, T. S. Steenhuis, and J. H. Peverly. 1992. "Flow Characteristics of Rock-Reed Filters for Treating Landfill Leachate." Fourth INTECOL International Wetlands Conference, Columbus, Ohio, September.

Schilling, E. M., and M. G. Ryon. 1993. "Reproductive Biology of the Tennessee Dace (Phoxinus tennesseensis) on the DOE Oak Ridge Reservation." 73rd Annual Meeting, American Society of Ichthyologists and Herpetologists, Austin, Texas, May-June.

Schramm, W. E. 1993. "Implications of Pollution Prevention Experience for Environmental Management." 
18th Annual Conference, National Association of Environmental Professionals, Raleigh, North Carolina, May.

Selifonova, O., R. Burlage, and

T. Barkay. 1993. "Mer-lux Based

Biosensors for Detection of $\mathrm{Hg}$ (II) in Contaminated Water.” Annual Meeting, American Society of Microbiology, Atlanta, May.

Sharp, S. K., S. M. Adams, and M. S. Greeley, Jr. 1992. "Serum Levels of Reproductive Steroids as Biomarkers of Reproductive Dysfunction in a MultipleSpawning Freshwater Teleost." 13th Annual Meeting, Society of Environmental Toxicology and Chemistry, Cincinnati, November.

Shevenell, L. 1993. "Overview of Hydrologic Studies at the Y-12 Plant, Oak Ridge, Tennessee." Seminar, Department of Civil and Environmental Engineering, Duke University, Durham, North Carolina, March.

Shevenell, L., R. B. Dreier, L. E. Toran, and G. K. Moore. 1993. "Use of Multiport Monitoring Systems at the Y-12 Plant to Identify 3-D Compositional Variabilities." Fourth National Technology Information Exchange Workshop, Knoxville, Tennessee, May.

Shevenell, L., G. K. Moore, and R. B. Dreier. 1992. "Contaminant Spread and Flushing in Fractured Rocks at the S-3 Ponds Site Near Oak Ridge, Tennessee." Fall Meeting, American Geophysical Union, San Francisco, December.

Siegrist, R. L. 1992. "Data Quality Management for Difficult Contaminants: Volatile Organic Compounds." Data Sufficiency and Decision Making for Site
Remediation Workshop, Madison, Wisconsin, November.

Siegrist, R. L. 1993. "Data Quality Management for Difficult Contaminants: Volatile Organic Compounds." Workshop on Data Sufficiency and Decision Making for Site Remediation, Chicago, June.

Siegrist, R. L. 1993. "VOC Measurement in Soils: The Nature and Validity of the Process." National Symposium on Measuring and Interpreting VOCs in Soils: State of the Art and Research Needs, Las Vegas, January.

Siegrist, R. L., M. I. Morris, O. M. West, D. D. Gates, D. A. Pickering, R. A. Jenkins, T. J. Mitchell, D. W. Greene, C. A. Muhr, S. E. Herbes, T. M. Gilliam, H. L. Jennings,

A. J. Lucero, J. Zutman, T. McKnight, D. T. Davenport, and J. S. Watson. 1993. "Full-Scale Field Demonstration and Testing of Physicochemical Processes for In Situ Treatment of Contaminated Soil." Waste Management '93, Tucson, Arizona, February-March.

Siegrist, R. L., M. I. Morris, O. M. West, D. D. Gates, D. A. Pickering, R. A. Jenkins, T. J. Mitchell, D. W. Greene, C. A. Muhr, S. E. Herbes, T. M. Gilliam, H. L. Jennings,

A. J. Lucero, J. Zutman, T. McKnight, J. S. Gierke, K. G. Robinson, D. T. Davenport, R. O. Barnett, Jr., and J. S. Watson. 1992. "Evaluation of In Situ Treatment Technologies for Contaminated Clay Soils: Highlights of the X-231B Technology Demonstration." Eighth Annual DOE Model Conference, Oak Ridge, Tennessee, October.

Siegrist, R. L., M. I. Morris, O. M. West, D. D. Gates, D. A. Pickering, 
R. A. Jenkins, T. J. Mitchell, D. W. Greene, C. A. Muhr, S. E. Herbes, T. M. Gilliam, H. L. Jennings, A. J. Lucero, J. Zutman, T. McKnight, J. S. Gierke, K. G. Robinson, D. T. Davenport, R. O. Barnett, Jr., and J. S. Watson. 1993. "Evaluation of Physicochemical Process Coupled with Soil Mixing for In Situ Treatment of Contaminated Soils." Fourth National Technology Information Exchange Workshop, Knoxville, Tennessee, May.

Siegrist, R. L., T. J. Phelps, N. E. Korte, D. A. Pickering, R. Mackowski, and L. W. Cooper. 1993. "Characterization and Biotreatability of Petroleum Contaminated Soils in a Coral Atoll in the Pacific Ocean." 15th Symposium on Biotechnology for Fuels and Chemicals, Colorado Springs, Colorado, May.

Sigal, L. L. 1993. "The Evolution of EIA from Projects to Policy to Sustainable Development." National Association of Environmental Professionals Annual Meeting, Current and Future Priorities for Environmental Management, Raleigh, North Carolina, May.

Sigal, L. L. 1993. "Introduction to and Overview of DOE NEPA Compliance Program." Stanford Linear Accelerator Center, Stanford, California, February.

Sigal, L. L. 1993. "NEPA Compliance Planning and Review." Stanford Linear Accelerator Center, Stanford, California, February.

Sigmon, K. 1993. "Environmental Compliance Management." Technology Transfer, Oak Ridge Y-12 Plant, Oak Ridge, Tennessee, August.
Smith, E. D. 1993. "Overview of Required and Recommended Evaluations of Sensitive Resources at National Priorities List Sites." Ninth Annual Oak Ridge Model Conference, Oak Ridge, Tennessee, August.

Smith, I. M., and M. J. Sale. 1993. "Standardizing Instream Flows at Hydropower Projects in the Cascade Mountains, Washington." Waterpower '93, Nashville, Tennessee, August.

Solomon, A. D., V. Alexiades, G. Jacobs, M. Naney, and M. Olszewski. 1992. "Latent Heat Thermal Energy Storage for Lunar Oxygen Production." Annual Winter Meeting, American Society of Mechanical Engineers, Anaheim, California, November.

Solomon, D. K., N. D. Farrow, T. O. Early, and J. L. Clausen. 1993. "Drive Pcint Profiling of Groundwater Contaminant Distribution." Fourth National Technology Information Exchange Workshop, Knoxville, Tennessee, May.

Southworth, G. R., R. R. Turner, M. A. Bogle, S. R. Kindon, M. J. Peterson, and N. A. Bloom. 1992. "Waterborne vs Sediment-Associated Mercury as Bioaccumulation Sources in a Highly Contaminated Stream." 13th Annual Meeting, Society of Environmental Toxicology and Chemistry, Cincinnati, November.

Spalding, B. P. 1993. "Decontamination of Soil Containing Cesium-137." Soil Decon '93: Radionuclides and Heavy Metals, Gatlinburg, Tennessee, June.

Spalding, B. P., and G. K. Jacobs. 1993. "Treatability Study of In Situ Vitrification Using Oak Ridge National Laboratory Seepage Pit 1." Fourth National 
Technology Information Exchange Workshop, Knoxville, Tennessee, May.

Stoss, F. W. 1992. "The Carbon Dioxide Information Analysis Center." Global Energy Strategies: Living with Restricted Greenhouse Gas Emissions, Washington, D.C., December.

Stoss, F. W. 1992. "The Carbon Dioxide Information Analysis Center: Providing Information Support for DOE's Global Change Research Program." INFOTech '92, DOE Technical Information Meeting, Oak Ridge, Tennessee, October.

Stow, S. H. 1993. "Environmental Restoration at ORNL." Martin Marietta Energy Systems, Inc., Technology Transfer Conference, Oak Ridge, January.

Stow, S. H. 1993. "Environmental Restoration Challenges at Oak Ridge." University of Kentucky, Lexington, February.

Stow, S. H., and D. K. Solomon. 1992. "Hydrogeologic and Contaminant Transport Studies on the Department of Energy's Oak Ridge Reservation, East Tennessee." 104th Annual Meeting, Geological Society of America, Cincinnati, October.

Strong-Gunderson, J. M., J. J. Hamm, and W. J. Lewis. 1992. "Suitability of Bacillus thuringiensis Intoxicated Noctuid Larvae for the Development of the Parasitoid Cotesia marginiventris." Meeting of the Entomological Society of America, Baltimore, December.

Strong-Gunderson, J. M., A. V. Palumbo, B. L. Clark, and R. S. Burlage. 1993. "Biosurfactants and Bioreporters:
Their Use in Hazardous Waste Remediation Technologies." Meeting of the American Chemical Society, Atlanta, September.

Strong-Gunderson, J. M., A. V. Palumbo, S. E. Herbes, and S. Bergman. 1993. "The Effect of Formate and Methane on the Recovery of Soluble Methane Monooxygenase Enzyme (sMMO) in Methylosinus trichosporium (0B3b)." 93rd General Meeting, American Society of Microbiology, Atlanta, May.

Strong-Gunderson, J. M., A. V. Palumbo, J. McCarthy, S. Scarborough, and T. Mehlhorn. 1993. "Differential Bioavailability of Deep Subsurface Natural Organic Matter to Microbial Isolates: Implications to In Situ Bioremediation." 15th Symposium on Biotechnology for Fuels and Chemicals, Colorado Springs, Colorado, May.

Strong-Gunderson, J. M., A. V. Palumbo, and S. Vance. 1993. "Application of Surfactant to In Situ Bioremediation." DOE's Information Exchange Meeting on Waste Retrieval Treatment and Processing, Washington, D.C., February.

Surface, J. M., J. H. Peverly, T. S. Steenhuis, and W. E. Sanford. 1992. "Landfill-Leachate Treatment by Means of a Constructed Wetland." 1992 INTECOL IV International Wetlands Conference, Columbus, Ohio, September.

Suter, G. W., II. 1992. "A Strategy for Ecological Risk Assessment of the DOE Oak Ridge Hazardous Waste Sites." 13th Annual Meeting, Society of Environmental Toxicology and Chemistry, Cincinnati, November. 
Suter, G. W., II. 1993. "Adapting Ecological Risk Assessment for Ecosystem Valuation." Annual Meeting, American Association for the Advancement of Science (AAAS), Boston, February. Suter, G. W., II. 1993. "Modeling." Ecological Risk Assessment-Application of the Process, Washington, D.C., January.

Suter, G. W., II. 1993. "Prospects for Ecological Risk Assessment." Environmental Defense Fund Board of Directors Meeting, Warren, Vermont, September.

Suter, G. W., II, and F. O. Hoffman. 1992. "A Strategy for Estimation of Distributions of Uncertain Parameters in Ecological Risk Assessments." 13th Annual Meeting, Society of Environmental Toxicology and Chemistry, Cincinnati, November.

Suter, G. W., II, and C. T. Hunsaker. 1993. "Regional Ecological Risk Assessment for Comparative Risk and Priority Setting." Fourth U.S.-Dutch Internatiunal Symposium on Comparative Risk Analysis and Priority Setting for Air Pollution Issues, Keystone, Colorado, June.

Taub, F. B., K. A. Rose, G. L. Swartzman, and J. H. Taub. 1992. "Translating Population Toxicity to Community Effects." 13th Annual Meeting, Society of Environmental Toxicology and Chemistry, Cincinnati, November.

Theodorakis, C. W., S. J. D'Surney, and

L. R. Shugart. 1992. "Assessing Genotoxicity via Electrophoretic Examination of DNA Strand Breaks and Chromosomal Proteins in Fish Red Blood Cells." 13th Annual Meeting, Society of Environmental Toxicology and Chemistry, Cincinnati, November.

Theodorakis, C. W., S. J. D'Surney, and L. R. Shugart. 1992. "Sequential
Development of Biomarkers in Fish Exposed to Contaminated Sediment." 13th Annual Meeting, Society of Environmental Toxicology and Chemistry, Cincinnati, November.

Thorne, D. J., P. M. Kearl, and L. M. McDowell-Boyer. 1992. "International Atomic Energy Agency Coordinated Research Program on the Safety Assessment of Near-Surface Radioactive Waste Disposal Facilities.” Second Coordinated Research Program of the IAEA NSARS (Near Surface Safety Assessment Reliability Study), Augusta, Georgia, November.

Tichler, J. L., H. J. Bernstein, S. F. Bobrowski, R. B. Melton, A. P. Campbell, D. M. Edwards, P. Kanciruk, and P. T. Singley. 1992. "Design and Implementation of a Computer Based Site Operations Log for the ARM Program." Scientific Data Management Workshop, Salt Lake City, November.

Timmins, S. P., and C. T. Hunsaker. 1993. "Tools for Visualizing Landscape Pattern for Large Geographic Areas." Second International Conference/Workshop on Information Systems and Environmental Modeling, Breckenridge, Colorado, September.

Tixier, J. S., B. P. Spalding, G. K. Jacobs, and T. D. Powell. 1993. "Implementation of In Situ Vitrification Technology for Remediation of Oak Ridge Contaminated Soil Sites: Past Results and Future Plans." Waste Management '93, Tucson, Arizona, February-March.

Tolbert, V. R., R. E. Martinez-Morales, and J. G. Smith. 1993. "Effects of Temperature on Growth and Survival of Hydropsyche depravata." Annual Meeting, 
North American Benthological Society, Calgary, Alberta, Canada, May.

Toran, L., O. R. West, and J. P. Gwo. 1993. "Supercomputer Model of an Oak Ridge National Laboratory Waste Area." Fourth National Technology Information Exchange Workshop, Knoxville, May.

Trettin, C. C. 1992. "Ecology and Management of Forested Wetlands." Seminar, U.S. Forest Service Silvicultural Certification Program, Michigan Technological University, Houghton, October-November.

Trettin, C. C., D. J. Frederick, and R. Lea. 1992. "Created Wetlands." Society of American Foresters Convention, Richmond, Virginia, October.

Trettin, C. C., M. F. Jurgensen, M. R. Gale, and J. W. McLaughlin. 1993. "Soil Carbon Response to Intensive Silviculture in a Boreal Wetland." Eighth North American Forest Soils Conference, Gainesville, Florida, May.

Tschaplinski, T. J., and G. A. Tuskan. 1993. "Water Stress Tolerance of Black Cottonwood and Eastern Cottonwood Clones and Four of Their Hybrid Progeny: II. Metabolites and Inorganic Ions that Constitute Osmotic Adjustment." Fourth Annual Walker Branch Watershed Research Symposium, Oak Ridge, Tennessee, March.

Tschaplinski, T. J., and G. A. Tuskan. 1993. "Water Stress Tolerance of Black Cottonwood and Eastern Cottonwood and Four of Their Hybrid Progeny." American Society of Plant Physiologists, Minneapolis, August.
Turnage, K. M., J. E. Foss, S. Y. Lee, and R. J. Lewis. 1992. "Identification of Buried Soils Using Elemental Distributions Within Profiles and Morphological and Organic Carbon Techniques." Annual Meeting, Soil Science Society of America, Minneapolis, November.

Turner, M. G. 1993. "Ecosystem Adjustment." DOE Office of Health and Environmental Research Program Directors' Meeting, Oak Ridge, Tennessee, February.

Turner, R. R., T. Barkay and E. Saouter. 1993. "Bioreduction of Mercury in Contaminated Effluents." ACS Emerging Technologies in Hazardous Waste, Atlanta, September.

Turner, R. S. 1992. "Climate and Land Cover Influences on Watershed Processes, Water Quality, and Biological Response in the Tennessee River Basin." Global Change Assessment for Forestry, Agriculture and Water Resources, University Park, Pennsylvania, October.

Turner, R. S. 1993. “Data Management for Global Change Research: Supporting the Science-Policy Interface." Aspen Global Change Institute Summer Science Session on the Early Detection of Global Change, Aspen, Colorado, August.

Tuskan, G. A. 1992. "Realized and Potential Value of Genetics and Biotechnology for Biofucl Feedstock Improvement." Annual Meeting, DOE Transportation Sector, Dearborn, Michigan, November.

Van Miegroet, H., P. J. Norby, and D. M. Chandler. 1992. "Nitrogen Cycling and Recovery after Fertilization of Short-Rotation Sycamore Plantations." Annual Meeting, Soil Science 
Society of America, Minneapolis, November.

Van Winkle, W., H. I. Jager, R. G. Otto, and S. F. Railsback. 1993. "Individual-Based Model Framework for Sympatric Brown and Rainbow Trout Populations." . Innual Meeting, American Fisheries Society, Western Division, Sersion on Modeling of Salmonid Populations, Sacramento, California, July.

Voorhees, L. D. 1992. "Determining GIS User Requirements." GIS (Geographic Information System) Information Exchange Meeting, Gatlinburg, Tennessee, Novemher.

Voorhees, L. D. 1993. "An Overview of the Oak Ridge National Laboratory Distributed Active Archive Center." Office of Scientific and Technical Information, ORNL, Oak Ridge, Tennessee, May.

Voorhees, L. D., P. F. Daugherty, R. S. Turner, and P. Kanciruk. 1993. "The Oak Ridge National Laboratory DAAC for Biogeochemical Dynamics." National Academy of Sciences, Oak Ridge, Tennessee, August.

Voorhees, L. D., and R. C. Durfee. 1992. "Oak Ridge Environmental Information System." Briefing for K-25 Groundwater Program Staff, Oak Ridge National Laboratory, Oak Ridge, Tennessee, October.

Voorhees, L. D., and R. A. McCord. 1993. "An Overview of the Oak Ridge Environmental Information System." Briefing for DOE-HQ, EM-423, ORNL, Oak Ridge, Tennessee, March.
Voorhees, L. D., R. J. Olson, and R. A. McCord. 1992. "Oak Ridge Environmental Information System." Briefing for DOE-OR and Energy Systems ER Program Managers, Museum of Atomic Energy, Oak Ridge, Tennessee, November.

Vose, R. S., T. C. Peterson, R. L. Schmoyer, J. K. Eischeid, P. M. Steurer, R. R. Heim, Jr., and T. R. Karl. 1993. "The Global Historical Climatology Network: Long-Term Monthly Temperature, Precipitation, and Pressure Data." Meeting of the American Meteorological Society, Anaheim, California, January.

Wallace, L. L., M. G. Turner, W. H. Romme, and Y. Wu. 1993. "Bison and Fire: Landscape Analysis of Ungulate Response to Yellowstone's Fires." First International Bison Conference, La Crosse, Wisconsin, July.

Walton, B. T., A. M. Hoylman, and R. F. Christman. 1993. "Plant Defenses Against Toxic Substances in Soils: Implications for In Situ Bioremediation." 206th American Chemical Society National Meeting, Chicago, August.

Walton, B. T., S. S. Talmage, and D. L. DeAngelis. 1992. "A Critique of Small Mammal Population Studies as Endpoints of Toxicant Exposure." 13th Annual Meeting, Society of Environmental Toxicology and Chemistry, Cincinnati, November.

Waters, D. J., W. Sheehan, J. Strong-Gunderson, and W. J. Lewis. 1992. "Combining a Biopesticide (MVP) with a Parasitoid for Control of Noctuid Larvae: Field Assessments." Meeting of the Entomological Society of America, Baltimore, December. 
Watkins, D. R., S. Y. Lee, and

T. L. Hatmaker. 1993. "Background Soil Characterization Project for the Oak Ridge Reservation." Fourth National Technology Information Exchange Workshop, Knoxville, Tennessee, May.

Wechsler, A. E. 1993. "Relationships Between Phusphorus Uptake and Microbial Metabolism in Stream Microbial Communities." 41st Annual Meeting, North American Benthological Society, Calgary, Alberta, Canada, May.

West, O. R. 1992. "Measurement and Spatial Modeling of VOC Contamination in Soils." 34th Conference ORNL/DOE Analytical Chemistry in Energy Technology, Gatlinburg, Tennessee.

West, O. R. 1993. "Experimental Study and Analytical Modeling of Compressive Fracture in Brittle Materials." International Society for Rock Mechanics, Safety and Environmental Issues in Rock Engineering, Lisbon, Portugal, June.

West, O. R., R. L. Siegrist, A. J. Lucero, H. L Jennings, and S. W. Schmunk. 1993. "In Situ Vapor Stripping of FineTextured VOC-Contaminated Soils." Fourth National Technology Information Exchange Workshop, Knoxville, Tennessee, May.

West, O. R., R. L. Siegrist, A. J. Lucero, H. L Jennings, and S. W. Schmunk. 1993. "Vapor Stripping of VOC-Contaminated Clay Soils." Joint Canadian Society of Civil Engineers-American Society of Civil Engineers National Conference on Environmental Engineering, Montreal, Quebec, Canada, July.

Wright, L. L. 1993. "Biomass Resource Potential Using Energy Crops." 205th American Chemical Society, National Meeting, Denver, March-April.

Wright, L. L., and J. H. Cushman. 1992. "Energy Crops: Realizing the Potential." Biobased Products Expo '92, St. Louis, October.

Wright, L. L., J. H. Cushman, and R. Overland. 1993. "Potential of Biomass Energy for Reducing U.S. $\mathrm{CO}_{2}$ Emissions." First Biomass Conference of the Americas: Energy Environment, Agriculture, and Industry, Burlington, Vermont, August-September.

Wright, L. L., and E. E. Hughes. 1993. "U.S. Carbon Offset Potential Using Biomass Energy Systems." International Workshop on Terrestrial Biospheric Fluxes: Quantification of Sinks and Sources of $\mathrm{CO}_{2}$, Bad Harzburg, Germany, March.

Wu, Y., D. L. DeAngelis, L. J. Gross, and D. M. Fleming. 1993. "SIMDEL: A Spatially Explicit Individual-Based Model for White-Tailed Deer on Everglades Landscapes." Eighth Annual Landscape Ecology Symposium, Oak Ridge, Tennessee, March.

Wu, Y., D. L. DeAngelis, L. J. Gross, and D. M. Fleming. 1993. "SIMDEL: A Spatially Explicit Individual-Based Model for Panther and White-Tailed Deer in Everglades Landscapes." Annual Meeting, Ecological Society of America, Madison, Wisconsin, July-August.

Wullschleger, S. D. $1993 .{ }^{\text {"Growth }}$ Response of Forest Tree Species to Atmospheric $\mathrm{CO}_{2}$ Enrichment-A Review of the Literature." Fourth Annual Walker Branch Watershed Research Symposium, Oak Ridge, Tennessee, March. 


\section{Other Professional Activities}

ADAMS, S. $M$.

Chair: Society of Aquatic

Ecosystem Health, Blacksburg, Virginia, April 1993.

Member: AFS, Publication Awards, 1993-94; Aquatic Ecosystem Health Society, Board of Directors, 1993-.

Participant: Annual Meeting, AFS, Rapid City, South Dakota, September 1992; Third International Conference on Aquatic Ecosystems Health, sponsored by Society of Aquatic Ecosystems Health, Virginia Polytechnic Institute and State University, Blacksburg, Virginia, May 1993; Annual Meeting, American Fisheries Society, Portland, Oregon, August 1993; Program Review of DOE Activities, sponsored by Tulane and Xavier universities, New Orleans, September 1993; Annual Meeting, Society of Environmental Toxicology and Chemistry, Cincinnati, November 1993.

Faculty: Adjunct Faculty, Graduate Program in Ecology, The University of Tennessee; Adjunct Faculty, School of Environment, Duke University. Advisor: C. Gettys-Hull and K. D. Ham, Ph.D. candidates, The University of Tennessee; Stan Sharp, S. R. Kindon, and B. A. Carrico, M.S. candidates, The University of Tennessee.

Ad Hoc Reviewer: Transactions of the American Fisheries Society; Association of Southern Biologists Journal; North American Journal of Fisheries Management; Journal of Aquatic Animal Health; Journal of Aquatic Ecosystems; proposal for seed money.

Other: Environmental Restoration Project, Science Fair, Oak Ridge, Tennessee; ORNL Animal Care Committee, 1989-93; Coordinator of ESD University of Tennessee Undergraduate Subcontract, 1992-.

\section{ANDRES, $\mathbf{R}$.}

Member: Global Emissions Inventory Activity, IGAC/IGBP, 1992-; Commission on the Chemistry of Volcanic Gases, IAVCEI, 1989-; Sigma Xi, 1988-; AGU, 1987-; GSA, 1986-.

Participant: Summer School for Earth Sciences: Processes of Global Change, sponsored by NASA, Pasadena, California, August 1993; Gordon Research Conference on the Impact of Volcanism on Climate, Gordon Research Conferences, Henniker, New Hampshire, July 1993.

Faculty: Postdoctoral researcher, Department of Earth Sciences, Tennessee Technological University, 1992-.

Advisor: Steve Bischoff, M.S. candidate, University of Michigan.

Ad Hoc Reviewer: Geochemical Journal; proposal for NSF; Geophysical Research Letters; Journal of Geophysical Research.

Other: Seminar speaker at Vanderbilt University, Nashville, Tennessee; TTU Regional Science Fair judge, Tennessee.

ASHWOOD, T. L.

Member: The Wildlife Society, 1991.

Participant: 14th Annual Low-Level Waste Management Conference, sponsored by DOE, Phoenix, Arizona, November 1992; 205th Annual Meeting, ACS, Denver, April 1993.

Advisor: Shyamala Ratnayeke, Ph.D. candidate, The University of Tennessee; Richard T. Stevens, M.S. candidate, Tennessee Technological University; Carrie Landrum, B.S. candidate, North Texas State University; R. J. Burger, B.S. candidate, The University of Tennessee; Sarah A. Conditt, B.S. candidate, Trinity University.

Other: Roane County Environmental Review Board; Local Oversight 
Committec; Docent, Knoxville Zoo;

Restoring Our Waters Institute, National Teacher Education Program, ORNL.

BARNTHOUSE, L W. Chair: Society for Risk Analysis, Ecological Risk Topic Group, 1991-93; Workshop on Sustainable Environmental Management, sponsored by Society of Environmental Toxicology and Chemistry and Ecological Society of America, Pellston, Michigan, August 1993.

Member: Committee on Risk Assessment Methodology, National Research Council, 1990-93; Society for Environmental Toxicology and Chemistry, Research Priorities Committee, 1992-93. Participant: Annual Meeting of Society of Environmental, Toxicology and Chemistry, Cincinnati, November 1992; Annual Meeting of Society for Risk Analysis, San Diego, December 1992; Workshop for Ecological Risk Assessment Applied to Hazardous Water Site Remediation, Water Environment Federation, Washington, D.C., January 1993; Conference on Ecological Effects of Chemicals, Scientific Group on Methods for Safety Evaluation of Chemicals, Montpellier, France, March 1993; Conference on the Risk Assessment Paradigm, EPADOD, Dayton, Ohio, April 1993.

Advisor: Stephen Deppen and Jerry Johnston, M.S. candidates, Indiana University; Andrew Rave, M.S. candidate, Duke University.

Editor: Hazard Assessment Editor, Environmental Toxicology and Chemistry, 1992-95.

Ad Hoc Reviewer: Proposals for DOD.

\section{BEVELHIMER, M. S.}

Chair: Midyear Technical Meeting of the Southern Division of the
American Fisheries Society, sponsored by Tennessee and Georgia chapters of AFS, Chattanooga, Tennessec, February 1993. Officer: President, Tennessee Chapter, AFS, 1993-94. Participant: First Midyear Technical Meeting of the Southern Division, AFS, Chattanooga, Tennessee, February 1993; PCBs in Fish Tissue, sponsored by EPA, Washington, D.C., May 1993; Annual Meeting of the American Fisheries Society, Portland, Oregon, August 1993. Editor: Associate Editor, North American Journa, if Fisheries Management, 1991-93.

BLAYLOCK, B. G. Officer: Treasurer, North American Branch, International Union Radioecologists, 1988-. Member: Health Physics Society, 1967-; Genetics Society, 1967-; National Council Radiation Protection and Measurements, Scientific Committee 64, 1990-96.

Participant: 12th International Exchange Conference, Lewis-Clark State College, Lewiston, October 1992; Developing Cleanup Standards for Contaminated Soil, Sediment, and Groundwater, ASTDR and EPA, Washington, D.C., January 1993; Coordinated Research Program on the VAMP, International Atomic Energy Agency, Commission of European Countries, Vienna, July 1993. Faculty: Adjunct Professor, Graduate Program in Ecology, The University of Tennessee. Advisor: Lene Holanda Sadler Veiga, M.S. candidate, International Atomic Energy Fellowship. Ad Hoc Reviewer: Proposal for National Research Council; Health Physics. 
BODEN, T. A

Participant: Scientific Data Management Workshop on the Role of Metadata in Managing Large Environmental Sciences Datasets, sponsored by DOE/EPA/NSF, Salt Lake City, November 1992; Seventh DOE $/ \mathrm{CO}_{2}$ Science Team Meeting, sponsored by DOE, Seattle, November 1992;

U.S. JGOFS Steering Committee Meeting, sponsored by NSF, Seattle, November 1992; WSR-88D Level II Data User's Workshop, sponsored by NOAA/National Weather Service, Norman, Oklahoma, February 1993; NOAA/CMDL Annual Meeting, Boulder, Colorado, March 1993; Eighth DOE $/ \mathrm{CO}_{2}$ Science Team Meeting, sponsored by DOE, Miami, March 1993; Study on the Long-Term Retention of Selected Scientific and Technical Records of the Federal Government, sponsored by NAS, Irvine, California, July 1993; Sixth Science Team Meeting for Joint Research on the Greenhouse Effect, sponsored by U.S. DOE/PRC CAS, Beijing, September 1993.

Other: ORNL Metric Coordination Committee; Metric Coordinator for Environmental, Life, and Social Sciences Directorate, October 1993-.

BOGLE, M. A

Participant: East Fork Poplar Creek Technical Workshop: Exploring the FS-EIS Issues, sponsored by DOE, Oak Ridge, Tennessee, March 1993.

Other: Presenter, EnvironMENTAL

Fair, Oak Ridge, Tennessee, October 1992.

\section{BRENKERT, A. L}

Participant: First International Specialized Conference on Contaminated Aquatic Sediments: IAWQ, Milwaukee, June 1993.

Ad Hoc Reviewer: IAWQ, 17th

Biennial International Conference paper.

\section{BURGOA, B.}

Participant: ASA, CSSA, and SSSA Annual Mecting, Minneapolis, November 1992; 24th Annual Conference and Erosion/Sediment Control Workshop, sponsored by The International Erosion Control Association, Indianapolis,

February 1993; Hazardous Waste Site Field Sampling Workshop, sponsored by EPA, Region IV and ORNL, Oak Ridge, Tennessee, June 1993.

\section{BURLAGE, R. S.}

Member: Kentucky-Tennessee Branch, American Society for Microbiology;

Sigma Xi.

Faculty: Adjunct Professor,

Department of Chemical Engineering, The University of Tennessee, 1992-. Advisor: Debi Kuo and Greg Wagner,

$\mathrm{Ph}$.D. candidates, The University of

Tennessee; B. Huang, M.S. candidate, The

University of Tennessee.

Editor: Joumal of Microbiological Methods, 1991-.

Ad Hoc Reviewer: Ecotoxicology;

Biotechnology and Bioengineering.

Other: Science fair judge, Oak Ridge

Middle School.

\section{CADA, G. F.}

Participant: Upper Mississippi RiverIllinois Waterway System-Navigation Study Adult Fish Workshop, sponsored by U.S. Army Corps of Engineers, St. Louis, July 1993.

Ad Hoc Reviewer: Transactions of American Fisheries Society.

\section{CARDWELL, $\mathrm{H}$.}

Participant: USCOLD, Engineering Solutions to Environmental Changes, sponsored by USCOLD, Chattanooga, Tennessee, May 1993; 29th Annual Conference, AWRA, Tucson, Arizona, August 1993. 
CHRISTENSEN, $S$. W.

Member: Sigma Xi, 1975-; Ecological

Society of America, 1972-; Society of

Environmental Toxicology and Chemistry, 1985-; AFS, 1982-; AAAS, 1975-

Participant: Third Geographic

Information Systems Information Exchange

Meeting, sponsored by DOE, Gatlinburg,

Tennessee, November 1992

Ad Hoc Reviewer: Ecotaxicology; North American Journal of Fisheries Management.

Other: Conveyor, Internet Special

Interest Group, East Tennessee PC Users

Group.

CLAPP, R. B.

Member: AGU, Groundwater

Committee; AWRA, Education

Committee, 1993-.

Participant: Constructed Wetlands

Workshop for Electric Power Utilities, sponsored by TVA, Chattanooga,

Tennessee, August 1993; WREMCON of

HCBUs and MIs, sponsored by DOE,

Washington, D.C., June 1993.

Faculty: Adjunct Professor,

Department of Civil and Environmental

Engineering, The University of Tennessee.

\section{CLINE, S. R.}

Member: Water Environment

Federation; ASCE; HMCRI.

COOK, R. B.

Member: American Geophysical Union;

American Society for Limnology and

Oceanography.

Ad Hoc Reviewer: Biochemistry;

Limnology and Oceanography.

COOPER, L. W.

Participant: Annual Meeting, The

Oceanography Society, Seattle, April 1993;

International Conference on Applications

of Isotope Techniques in Studying Past and Current Environmental Changes in the Hydrosphere and the Atmosphere, sponsored by International Atomic Energy
Agency, Vienna, April 1993; Workshop on Arctic Contamination, Interagency Arctic Research Policy Committee, Anchorage, Alaska, May 1993.

Faculty: Faculty Associate, Graduate

Program in Ecology, The University of

Tennessee.

Ad Hoc Reviewer: Proposals for NSF;

Aquatic Toxicology.

COUTANT, C. C.

Cochair: Technical Advisory

Committee, sponsored by Commonwealth

Edison Company, 1990-.

Officer: Second Vice President, AFS.

Member: Scientific Review Group,

Bonneville Power Administration.

Participant: California Central Valley

Chinook Salmon Workshop, sponsored by

University of California, Davis, January 1993; Annual Striped Bass Workshop, sponsored by National Marine Fisheries Service, Annapolis, Maryland, February 1993; Midyear Meeting, Tennessee Chapter and Southern Division, sponsored by AFS, Chattanooga, Tennessee, February 1993; Trinity River (California) Technical Workshop on Salmon Modeling, sponsored by USFWS, Weaverville, California, March 1993; Annual Meeting, AFS, Portland, Oregon, August 1993.

Faculty: Adjunct Professor, Graduate Program in Ecology, The University of Tennessee.

Advisor: Ken Ham, Ph.D. candidate, The University of Tennessee; Sandra Davis, M.S. candidate, The University of Tennessee.

Editor: Coeditor, Transactions of the American Fisheries Society, 1991-.

Ad Hoc Reviewer: Ecology; USFWS; proposals, San Francisco Bay Program, EPA.

Other: Overseas Advisor, Technical Advisory Committee for Huntly Power Station, Electricity Corporation of New Zealand, 1991-; Oak Ridge 50th Birthday 
Celebration Committee, Oak Ridge, Tennessee; ORNL 50th Anniversary Committee; renovation of Graphite Reactor, New Bethel Church, 1990-93.

CRUMBY, W. D.

Participant: Workshop: Introduction

to Fish Health, sponsored by USFWS, Fort Collins, Colorado, May 1993; Annual Meeting, AFS, Portland, Oregon, August 1993.

Other: Restoring Our Waters Institute, National Teacher Education Program, ORNL.

\section{CUSHMAN, J. H.}

Cochair and organizer: 1993 DOE

Review of Laboratory Programs for Women, sponsored by DOE Office of University and Science Education, Oak Ridge, Tennessee, May 1993. Member: Technical Planning Committee, Southeastern Regional Biomass Energy Program, 1987-93; Renewable Energy Project Technical Advisory Committee, Union of Concerned Scientists, 1992-93; National Biofuels Roundtable, 1993-94.

Participant: Midwest Plant Biotechnology Symposium, sponsored by Midwest Plant Biotechnology Consortium, Indianapolis, November 1992; Contractors' Workshop, sponsored by BFDP, East Lansing, Michigan, November 1992; Annual Meeting, ASA, Minneapolis, November 1992; Automotive Technology Development Contractors Coordination Meeting, sponsored by DOE Office of Transportation Technology, Dearborn, Michigan, November 1992; National Biofuels Roundtable, sponsored by EPRI and National Audubon Society, Dallas, December 1992; Washington, D.C., April 1993; Morrilton, Arizona, June 1993; Washington, D.C., September 1993; Renewable Energy Project Technical Advisory Meeting, sponsored by the Union of Concerned Scientists, Chicago, December 1992; Southeastern Regional Biomass Energy Program Technical Review, sponsored by TVA, Washington, D.C., March 1993; Review of Laboratory Programs for Women, sponsored by DOE Office of University and Science Education, Oak Ridge, Tennessee, May 1993; Annual Meeting, Forest Products Society, Clearwater Beach, Florida, June 1993; Energy from Biomass Minigrant Meeting, sponsored by Consortium for Plant Biotechnology Research, Chicago, July 1993; Terrestrial Biofuels Interface Review, sponsored by National Renewable Energy Laboratory, Lakewood, Colorado, September 1993; 1993 Contractors' Workshop, sponsored by BFDP, Auburn, Alabama, September 1993.

Editor: Editorial Board, Bioresource Technology, 1990-. Ad Hoc Reviewer: Proposals for Consortium for Plant Biotechnology, National Renewable Energy Laboratory, and Southeastern Regional Biomass Energy Program; proposal for USDA Alternative Agriculture Resource and Commercialization Center; research program, National Renewable Energy Laboratory.

\section{CUSHMAN, R. M.}

Participant: Committee on Geophysical and Environmental Data Meeting, sponsored by NAS, Washington, D.C., November 1992; Meeting of the U.S. National Committee for CODATA, sponsored by NAS, Washington, D.C., May 1993; Data Center Directors' Meeting, sponsored by NAS, Sicux Falls, South Dakota, July 1993; Workshop on Data Management for Global Environmental Studies, International Association of Meteorology and Atmospheric Physics, Yokohama, Japan, July 1993. 
Ad Hoc Reviewer: Proposals for Natural Sciences and Engineering Research Council of Canada; Great Plains Regional Center for Global Environmental Change; Environmental Management.

DALE, V. H.

Officer: Treasurer, Oak Ridge Chapter, Sigma Xi.

Member: Panel Member, Human

Dimensions of Global Change, sponsored by NSF, 1993; Ecological Processes and Effects Committee, Scientific Advisory Board, sponsored by EPA; ORNL Human Resources Committee on Skills Enhancement.

Participant: Cary Conference on Integrated Regional Models, Millbrook, New York, October 1992; Workshop on Integrated Assessments, Pennsylvania State University, October 1992; Review of EPA's Selected Projects, EPA Science Advisory Board, October 1992; Workshop on USDA Forest Service's Global Change Program, sponsored by U.S. Forest Service, Delaware, Ohio, November 1992; Review of EMAP, EPA Science Advisory Board, November 1992; Human Dimensions of Global Change Review Panel, sponsored by NSF, December 1992; Workshop on Forest Ecosystem Management at the Landscape Level, Forest Policy Center, Oak Ridge, Tennessee, March 1993; Human Dimensions of Global Change Review Panel, sponsored by NSF, May 1993; Review of EPA's selected projects, EPA Science Advisory Board, June 1993; Review of EPA's Climate Change Program, EPA Science Advisory Board, September 1993.

Faculty: Exchange Faculty between the University of Amazonas and The University of Tennessee; Adjunct Faculty, Graduate Program in Ecology, The University of Tennessee.
Advisor: Robert Frohn, Ph.D. Student, University of California at Santa Barbara; Holly Offerman, DOE's Science and Engineering Rescarch Semester, University of Richmond; Brad McRae, DOE Global Climate Change Fellow, University of Wisconsin.

Editor: Associate Editor, Environmental Reviews, National Research Council of Canada, 1992-93.

Ad Hoc Reviewer: National Geographic Research and Exploration; Global Biogeochemical Cycles; Ecology; BioScience; USDA Forest Service; Ecotoxicology; Ecological Applications; proposals for NSF; EPA Science Advisory Board Review of Ecological Risk Assessment Chapter of RCRA.

Other: Chair, Steering Committee, Citizens for Quality Growth, Oak Ridge, Tennessee; presentations to Girl Scouts, Knoxville, Tennessee, and area schools.

DANIELS, R. C.

Member: Association of American Geographers, 1989-; American Society for Photogrammetry and Remote Sensing, 1989-; Urban and Regional Information System Association, 1990-.

Participant: Annual Meeting, Association of American Geographers, Atlanta, April 1993; Annual Information Meeting, ESD, Oak Ridge, Tennessee, May 1993; DOE High School Honors Workshop in Environmental Sciences, hosted by ESD, Metals and Ceramics Division, and Energy Division, ORNL, July 1993.

Ad Hoc Reviewer: Proposal for National Geographic Society.

DeANGELIS, D. L

Participant: Review of North Temperate Lakes Long-Term Ecological Study, sponsored by NSF, Madison and Trout Lake, Wisconsin, July 1993; 
Cary Conference, sponsored by Institute for Ecosystem Studies, Millbrook, New York, May 1993; International Congress in Botany, Botanical Societies, Yokohama, Japan, August-September 1993.

Faculty: Adjunct Professor, Department of Mathematics and Graduate Program in Ecology, The University of Tennessee.

Advisor: Mark Clark, Yiannis Matsinos, and Daryl Neergaard, Ph.D. candidates, The University of Tennessee.

Editor: Associate Editor, Ecology and Ecological Monographs, 1992-95; Associste Editor, Mathematical Bioscience, 1988-. Other: Sabbatical Position, Visiting Professor, Clemson University, Clemson, South Carolina, 1993.

\section{DICKERMAN, J. A.} Member: NAEP '94 Conference Committee, 1993-94.

Participant: 18th Annual Conference NAEP, sponsored by NAEP, Raleigh, North Carolina, May 1993; Constructed Wetlands Workshop for Electric Power Utilities, sponsored by TVA, Chattanooga, Tennessee, August 1993; SAMAB Conference on Wetland Ecology Management and Conservation, sponsored by ORNL/ESD, Knoxville, Tennessee, September 1993. Ad Hoc Reviewer: Office of Technology Assessment, U.S. Congress; Meta/Berger, Inc.

Other: Judge for 41st Annual Southern Appalachian Science and Engineering Fair, East Tennessee.

DOLL, W. E.

Chair and onganizer: The Advancement of Environmental Geophysics, sponsored by Society of Exploration Geophysicists, Washington, D.C., September 1993. Advisor: Ronald Kaufmann, M.S. candidate, Georgia Institute of
Technology; Les Beard, postdoctoral candidate, University of Utah Ad Hoc Reviewer: Journal of Geophysical Research.

\section{DREIER, R. B.}

Participant: Annual Fall Meeting, AGU, San Francisco, December 1992-; Probability, Statistics and Geostatistics for Environmental Professionals, sponsored by NGA, Tampa, Florida, January 1993; Characterizing and Remediating Dense Non Aqueous Phase Liquids at Hazardous Sites, sponsored by EPA, Atlanta, July 1993; Annual Meeting, GSA, Cincinnati, October 1993; Site Characterization of DNAPL in Porous and Fractured Media, sponsored by University of Waterloo, Chicago, November 1993.

Faculty: Assistant Professor, Geology, The University of Tennessee.

Advisor: Phillip Neuhoff, B.S. candidate, University of Iowa; Laurie Menefee, B.S. candidate, Appalachian State University; Kathryn Demarais, rising first-year graduate student, Beloit College, Duke University.

EARLY, T. O.

Chair: Session on DNAPLs, Fourth Environmental Restoration Technical Information Meeting, sponsored by DOEHQ, Knoxville, Tennessee, May 1993.

\section{EDDLEMON, G. $\mathbf{K}$}

Participant: Quarterly

Environmental/Waste Management Issues Meeting, sponsored by DOE Uranium Enrichment Program, Portsmouth, Ohio, October 1992; Lexington, Kentucky, January 1993, May 1993; ECAMP Assessment of Seymour Johnson Air Force Base, Goldsboro, North Carolina, sponsored by U.S. Air Force Headquarters, Air Combat Command, April 1993; ECAMP Assessment of Shaw Air Force 
Base, Sumter, South Carolina, sponsored by U.S. Air Force Headquarters, Air Combat Command, May 1993; Annual Meeting of the National Association of Environmental Professionals, NAEP, Raleigh, North Carolina, May 1993; Course on Environmental Laws and Regulations (Teacher), Albuquerque Field Office, Albuquerque, New Mexico, June 1993; ECAMP Assessment of Griffiss Air Force Base, New York, sponsored by U.S. Air Force Headquarters, Air Combat Command, August 1993; NEPA SelfAssessment of ESD, ORNL, Oak Ridge, Tennessee, September 1993; U.S. Antarctic Program Orientation Conference, sponsored by NSF's U.S. Antarctic Program, Arlington, Virginia, September 1993.

Other: Search and Rescue, Knox and Sevier counties.

\section{EDWARDS, N. T.} Member: UV-B Steering Committee, DOE UV-B Critical Issues Workshop, October 1992-October 1993. Participant: UV-B Critical Issues Workshop, sponsored by DOE, Cocoa Beach, Florida, February 1993; NATO Advanced Research Workshop, sponsored by NATO, Gainesville, Florida, June 1993. Advisor: Shaun Crooks, B.S. candidate, Roane State Community College. Ad Hoc Reviewer: ACS; proposals for USDA; ORNL Director's R\&D Fund.

\section{ELLESS, $M$.}

Participant: Clay Minerals Society and Soil Science Society of America, CMS and ASA, Minneapolis, November 1992; Layer Charge Characteristics of Clays, sponsored by CMS, Minneapolis, November 1992; Soil Decon '93: Technology Targeting Radionuclide and Heavy Metals, sponsored by ORNL and FERMCO, Gatlinburg, Tennessee, June 1993; CMS, San Diego, September 1993; Computer Applications to X-ray Powder Diffraction Analysis of Clay Minerals, sponsored by CMS, San Diego, September 1993.

\section{EMANUEL, W. R.}

Chair: Carbon Cycle Global Change Institute, sponsored by University Corporation for Atmospheric Research, Boulder, Colorado, July 1993.

Member: IGBP Task Force on Global Analysis, Interpretation, and Modeling, February 1992-; Management Organization Working Group, NASA Modeling, Data, and Information Systems, October 1992-; Biogeochemical Cycling Working Group, NASA Earth Observing Systems Data Archive Center, September 1993-.

Participant: Global Climate Research Workshop, sponsored by EPA, Athens, Georgia, March 1993; Carbon Cycle Global Change Institute, University Corporation for Atmospheric Research, Snowmass, Colorado, July 1993; Land-Use Team Meeting, Working Group I, Intergovernmental Panel on Climate Change, Woods Hole, Massachusetts, September 1993; Global Change Data Forum, Committee on Geophysical and Environmental Data, National Research Council, Wastington, D.C., September 19.13; Global Soils Workshop, International Geosphere-Biosphere Program, Silsoe, United Kingdom, October 1993.

Faculty: Faculty Associate, Graduate Program in Ecology, The University of Tennessee, 1988-.

Ad Hoc Reviewer: Nature; Science; Journal of Climate; proposals for DOE, NASA, NSF, and EPA.

\section{FONTAINE, T. A.}

Chair: Surface Hydrology Technical

Working Group, AWRA.

Participant: 28th Annual

Conference, sponsored by AWRA, Reno, Nevada, November 1992; HSPF Modeling 
Workshop, sponsored by Hydrocomp, Inc., Redwood City, California, May 1993; International Symposium on Engineering Hydrology, sponsored by ASCE, San Francisco, July 1993. Ad Hoc Reviewer: Journal of Hydraulic Engineering, ASCE.

FORD, C. J.

Participant: Contaminated Aquatic Sediments: Historical Records, Environmental Impact and Remediation, sponsored by IAWQ, Milwaukee, June 1993.

FRANCIS, C. W.

Chair: Soil Decon '93, sponsored by DOE/OTD, Gatlinburg, Tennessee, June 1993.

Ad Hoc Reviewer: Health Physics; proposals for National Research Council; Environmental Science and Technology.

GARDNER, R. H.

Chair: Ecological Society of America, Sustainable Biosphere Initiative Scientific Review, 1993-95.

Member: Member, Advisory Board, Randall Environmental Studies Center, Taylor University; High Performance Computing, Environmental Life and Social Sciences, ORNL, 1993.

Participant: Task Leader, Program for Global Change and Terrestrial Ecosystems, IGBP, 1993-.

Faculty: Adjunct Professor, Graduate Program in Ecology, The University of Tennessee.

Advisor: K. Minser, M.A. candidate, The University of Tennessee.

Ad Hoc Reviewer: Health Physics; Ecological Applications; Landscape Ecology; Ecology; American Naturalist, NSF.

GARTEN, C. T., JR.

Editor: Associate Editor, Journal of Environmental Radioactivity, 1993-.
Advisor: Alison B. Schwab, B.S. candidate, Washington and Lee University; Terri Shirshac, B.S. candidate, University of Connecticut.

Ad Hoc Reviewer: Journal of

Environmental Radioactivity; proposal for NSF; Healih Physics.

GATES, D. D.

Member: ASCE.

Participant: Minority Environmental Career Fair, sponsored by ORNL and ECO, Oak Ridge, Tennessee; Women in Science Conference, sponsored by AWIS, Knoxville, Tennessee, March 1993; Fourth National Technology Information Exchange Workshop, sponsored by DOE/ER, Knoxville, Tennessee, May 1994; Conference on Environmental Engineering, sponsored by CSCE/ASCE, Montreal, July 1993; Materials Research Society Conference, Boston, December 1992.

Advisor: Sherianne James, B.S. candidate, University of Florida.

Other: Mentor, Minority Challenge Program.

\section{GREELEY, M. S.}

Member: AFS; Society of

Environmental Toxicology and Chemistry.

Participant: Annual Meeting, Carolina Chapter of Society of Environmental Toxicology and Chemistry, Pendleton, South Carolina, May 1993; Annual Meeting, AFS, Portland, Oregon, August-September 1993; 13th Annual Meeting, Society of Environmental Toxicology and Chemistry, Cincinnati, November 1992; Interagency Meeting on NRDA, sponsored by Energy Systems, Oak Ridge, Tennessee, June 1993; Annual Information Meeting, ESD, Oak Ridge, Tennessee, May 1993.

Advisor: C. Gettys-Hull, Ph.D. candidate, and Stan Sharp, M.S. candidate, The University of Tennessee; Eric Garcia, 
M.S. candidate, Clarion University of Pennsylvania; Chris Lane, Associate Degree candidate, Mountain Empire Community College; Lynda J. Ivey, Associate Degree candidate, Roane State Community College.

Ad Hoc Reviewer: North American

Journal of Fisheries Management;

Proceedings of Annual Conference

Southeastern-Associate Fish and

Wildlife Agency; Hartwell Reservoir

Remediation Options Draft Strategy

Document.

Other: Volunteer, EnvironMENTAL

Fair '92, Oak Ridge, Tennessee.

\section{GREBMEIER, J. M.}

Member: National Research Council's Committee on the Bering Sea Ecosystem, sponsored by NAS, 1993-94; Arctic Systems Sciences: Ocean-Atmosphere-Ice Interactions, 1993-96; Arctic System

Sciences: Panel Member, 1993-96.

Faculty: Research Assistant Professor,

Graduate Program, The University of

Tennessee

Ad Hoc Reviewer: Proposal for NSF.

Other: Career Day, Robertsville Junior High School, Oak Ridge.

\section{GUNDERSON, C. A}

Member: American Society of Plant

Physiologists.

Participant: Fourth Annual

Walker Branch Watershed Research Symposium, sponsored by ESD, ORNL, Oak Ridge, Tennessee; 78th Annual ESA Meeting: Ecology and Global Sustainability, sponsored by ESA, Madison, Wisconsin, August 1993. Advisor: Joanne M. Kostuk, B.S. candidate, University of Wisconsin; Emily Long Childs, A.S. candidate, Roane State Community College.

Ad Hoc Reviewer: Ecotoxicology; Plant Physiology.
GWO, J. P.

Participant: Fall Meeting, AGU, San Francisco, December 1992;

Fourth National Technology Information

Exchange Workshop, sponsored by DOE/ER, Knoxville, Tennessee, May 1993;

Partnership in Computational Sciences Meeting, sponsored by ORNL, Oak Ridge, Tennessee, May 1993; Workshop for Parallel Programming on the Intel iPSC/860, sponsored by Intel Corporation and The University of Tennessee, Knoxville, June 1993. Advisor: Sarah Wignall, B.S. candidate, University of North Carolina. Ad Hoc Reviewer: Water Resources Research.

\section{HANSON, P. J.}

Member: American Association for the Advancement of Science; ASA/ASSS; American Society of Plant Physiologists. Advisor: Shawn Duan, Ph.D. candidate, The University of Tennessee; Todd Tabberer, B.S. candidate, Michigan State University. Ad Hoc Reviewer: Joumal of Environmental Quality; Plant Physiology and Biochemistry; Water, Air, and Soil Pollution; Tellus; Physiologia Plantarum; proposal for USDA; proposals for EPA, and EPRI.

HATCHER, R. D., JR. Chair: Session, Penrose Conference, GSA, Death Valley, California, October 1992.

Member: President, Executive Committee, GSA, October 1992-93; Education Committee, GSA; Board on Radioactive Waste Management, NAS, 1990-93; Earth Sciences Advisory Committee at Savannah River Site, Westinghouse Savannah River Company, 1989-93; American Geological Institute Council, 1991-92; Cochair, EDGE Planning Committee, $15^{\wedge} 9-92$; 
Board of Directors, DOSECC, Inc., 1989-92.

Participant: Geological Society of America Penrose Conference, Las Vegas, October 1992; Geological Society of America Annual Meeting, Cincinnati, October 1992; Nuclear Regulatory Commission Advisory Committee on Nuclear Waste and Work Group Meecing on the Impact of Long-Range Climale Change in the Area of the Southern Basin and Range, sponsored by NAS, Bethesoia. Maryland, November 1992; Board on Radioactive Waste Management, sponsored by NAS, Irvine, California, December 1992; Workshop on the Formulation of a "White Paper" to present to the Clinton/Gore Administration, sponsored by American Geological Institute, Washington, D.C., February 1993; Institute for the Study of the Continents, Discussion of Proposed Ural Mountains Research Project, sponsored by Cornell University, Ithaca, New York, February-March 1993; Steering Committee on Establishing a National Geoscience Data Repository System, sponsored by American Geological Institute, Alexandria, Virginia, March 1993; Board Member on Radioactive Waste Management, sponsored by NAS, Washington, D.C., March 1993; SouthCentral Section Meeting, sponsored by GSA, Dallas-Fort Worth, March 1993; Northeast Section Meeting and Geosphere Alliance Committee Meeting, sponsored by GSA, Burlington, Vermont, March 1993;

Southeast Section Meeting, sponsored by GSA, Tallahassee, Florida, March-April 1993; Guest Speaker, sponsored by University of Kentucky, Lexington, April 1993; National Geoscience Data Repository Committee Meeting, sponsored by American Geological Institute, New Orleans, April 1993; American Association of Petroleum Geologists Annual Convention, New Orleans,
April 1993; Investments Committec and Foundation Trustees Meetings, sponsored by GSA, New Orleans, April 1993; Geological Society of America Council Mecting, Boulder, Colorado, May 1993; Cordilleran/Rocky Mountain Section Mecting, sponsored by GSA, Reno, Nevada, May 1993; Geochemical Joint Spring Meeting, sponsored by American Geophysical Union, Baltimore, May 1993; Institute for the Study of the Continents, Discussion of Ural Mountains Proposed Research Project, sponsored by Cornell University, Ithaca, New York, June 1993; Chattooga River Project, sponsored by USFS, Asheville, North Carolina, June 1993; Board Member on Radioactive Waste Managemeni, sponsored by NAS, Las Vegas, June 1993; DOE/American Geological Institute Meetings, Washington, D.C., July 1993; National Geoscience Dat. Repository Committee Meeting, sponsored by American Geological Institute, Dallas-Fort Worth, July 1993; Committee on Pilot Program for Accreditation of U.S. Geoscience Professional Degrees, sponsored by American Geological Institute, Alexandria, Virginia, August 1993; Lectures on the state of the Earth, Science, and Society/Discussion of Ural Mountains Proposed Research Project, sponsored by Cornell University, Ithaca, New Y'ork, August 1993; Association of Earth Sciences Editors Annual Meeting, Madison, Wisconsin, September 1993; Keynote Speaker, sponsored by Unicoi State Park Southern Forest Hydrology and Soils Workshop, Helen, Georgia, October 1993.

Faculty: UT/ORNL Distinguished Scientist, Science Alliance; Professor, Department of Geological Sciences, The University of Tennessee, 1986-.

Advisor: Jeffery B. Connelly, Janet Hopson, and Elizabeth A. McClellan, Ph.D. candidates, The University of 
Tennessee; John O. Costello, Ph.D. candidate, The University of Tennessee/University of South Carolina; Mark W. Carter, Donald J. Geddes, Steven L. Martin, Camilo Montes, and Gregory M. Yanagihara,

M.S. c andidates, The University of Tennessee.

Ad Hoc Reviewer: Proposals for ORNL (Director's Seed Money Fund); National Science and Engineering Research Council (Canada) Lithoprobe; NSF (Earth Sciences Division) Tectonics, Crustal Dynamics, Petrology, Geochemistry, Geology, and Paleo Panels; U.S. Geological Survey, Gilbert Research Fui d Program; Natural Resources and Environment Research Council (Great Britain); American Journal of Science; Geology; GSA Today; Southeastern Geology; Journal of Geophysical Research; Journal of Metamorphic Geology; NAS Report; Norsk Geologisk Tidschrift.

HERBES, S. E.

Participant: In Situ Remediation

Planning Workshop, sponsored by

DOE-ER/ISRIP, April 1993.

Faculty: Adjunct Professor, Graduate

Program in Ecology, The University of

Tennessee, 1992-95.

Advisor: Allen D. Walzel,

M.S. candidate, Texas A\&I University.

Ad Hor Reviewer: DOE In Situ

Remediation Integrated Program.

HICKS, D. S.

Participant: 29th Annual Conference, AWRA, Tucson, Arizona, August 1993.

Other: EnvironMENTAL Fair,

Oak Ridge, Tennessee.

HILDEBRAND, S. G.

Participant: Annual Meeting, AAAS, Boston, February 1993; Comparative Risk Workshop, sponsored by Joyce Foundation and University of Iowa, Iowa City,
June 1993; Minority Opportunities

Program Review, sponsored by

Environmental Careers Organization Inc.,

Boston, July 1993.

Faculty: Adjunct Faculty Associate,

Graduate Program in Ecology, The

University of Tennessee.

HILL, W. R. Advisor: Brian Gray, M.A. candidate, University of Kentucky. Ad Hoc Reviewer: Proposal for Canadian NSERC; Ecology; Canadian Journal of Fisheries and Aquatic Sciences; Journal of the North American Benthological Society; New Zealand Journal of Marine and Freshwater Resources.

\section{HINZMAN, R. L}

Advisor: Melanie Filson,

B.S. candidate, Wesleyan College;

Angela Bednack, B.S. candidate, Notre

Dame.

Other: Saturday School-ORRI,

Oak Ridge; Restoring Our Waters

Institute, National Teacher Education

Program, ORNL.

HOLLADAY, S. K.

Member: ASTM, D-34; American

Business Women's Association, American Water Works Association.

HUFF, D. D.

Chair: Organizer and finance manager, Fifth Tennessee Water Resources Symposium, sponsored by AWRA, American Institute of Hydrology, and others, Nashville, Tennessee, October 1992; Fourth National Technology Information Exchange Workshop, sponsored by DOE, Knoxville, Tennessee, May 1993.

Member: President, American Institute of Hydrology, Tennessee Section, 1990-; Finance Chair, Board Member, Tennessee Section, AWRA, Fall 1991-93; Nominating 
Committee, American Institute of Hydrology, July 1993-94.

Faculty: Adjunct Associate Professor, Geology, The University of Tennessee.

Ad Hoc Reviewer: Proposals for Department of Agriculture National Research Initiative Competitive Grants Program; NSF Hydrologic Sciences Program; AWRA Symposium abstracts; Tennessee Proposed Groundwater Classification System.

HULL, R. N.

Chair: ASTM Subtask E47.13:

Ecological Risk Assessment Data Needs, ASTM, October 1992-.

Member: SETAC; Canadian Society of Zoologists.

Participant: SETAC, Cincinnati, November 1992; Superfund Environmental Evaluation Workshop, sponsored by EPA, Minneapolis, February 1993; SETACWorld, sponsored by Society of Environmental Toxicology and Chemistry, Lisbon, March 1993; ASTM Subtask E47, sponsored by ASTM, Atlanta, April 1993.

\section{HUNSAKER, C. T.}

Member: Advisory Council, The Committee on the National Institute for the Environment, August 1993; Public Affairs, Ecological Society of America, 1989; Women and Minorities, Ecological Society of America, 1992; Ecology, Water Environment Federation, 1993-96.

Participant: Eighth Annual U.S. Landscape Ecology Symposium, sponsored by International Association for Landscape Ecology, Oak Ridge, Tennessee, March 1993; 18th Annual Meeting, Ecological Society of America, Madison, Wisconsin, July/August 1993; 67th Annual Conference, Water Environment Federation, New Orleans, October 1992; Workshop on Women, Minorities, and Education, sponsored by Ecological Society of America,
Washington, D.C., June 1993;

Proposal Review for Ecological

Indicators, sponsored by EPA, Office of

Research and Development, Columbia, Maryland, June 1993; Europe-America Conference for Emerging Leaders, Baltimore, November 1992; Fourth Annual Southern Appalachian Man and the Biosphere Conference, sponsored by TVA. Gatlinburg, Tennessee, November 1992; Cumulative Coastal Environmental Impacts Workshop, sponsored by Marine Law Institute, University of Maine, Narragansett, Rhode Island, May 1993; Biodiversity Research Consortium, sponsored by EPA, Corvallis, Oregon, September 1993. Editor: Advisory Buard, The Environmental Professional, NAEP, January 1989. Ad Hoc Reviewer: The Environmental Professional; Environmental Management; Columbia University Press; Proposals for cological Indicators, EPA; Science of the Total Environment; Ecological Applications; Water Resources Bulletin; Environmental Toxicology and Chemistry; The Nature Conservancy; Office of Technology Assessment.

HUSTON, M. A. Chair: Fourth Annual Walker Branch Watershed Research Symposium, sponsored by DOE, Oak Ridge, Tennessee, March 1993.

Faculty: Adjunct Associate Professor, Graduate Program in Ecology, The University of Tennessee. Advisor: Milena Holmgren, Ph.D. candidate, The University of Tennessee; Brian Pederson, DOE Global Change Postdoctoral Fellow; Michael Hayes, B.A. candidate, Coe College.

Other: Restoring Our Waters Institute, National Teacher Education Program, ORNL. 
JACKSON, B. L.

Participant: SUGI 18 Conference, SAS Users Group International,

New York, May 1993.

Member: Computing Technology

Advisory Board, Pellissippi State

Community College, Knoxville, Tennessee.

JACOBS, G. $\mathbf{K}$

Member: Board of Advisors,

Department of Geological Sciences, The

University of Tennessee, 1993-96.

Participant: Strategies and Mechanisms

for Field Research in Environmental

Bioremediation, sponsored by American

Academy of Microbiology, San Antonio,

Texas, January 1993.

Faculty: Adjunct Associate Professor,

Department of Geological Sciences, The

University of Tennessee.

Ad Hoc Reviewer: Waste Management

Journal; proposals for NSF; ASME.

\section{JAGER, H. I.}

Participant: Smallmouth Bass

Workshop, sponsored by EPRI, Glenn

Allen, Virginia, October 1992; Trout

Modeling Workshop, sponsored by

USFWS, Fort Collins, Colorado, June

1993; Western Division, AFS, Sacramento,

California, July 1993.

Ad Hoc Reviewer: Environmental

Biology of Fishes.

\section{JARDINE, P. M.}

Member: Soil Science Society of

America.

Participant: Savannah River Ecological

Lab Seminar Series, Savannah River

Laboratury, Aiken, South Carolina,

February 1992; National Meeting, GSA,

Cincinnati, October 1992; National

Meeting, ASA, SSSA, Minneapolis,

November 1992; DOE SERDP Planning

Initiative, DOE, Denver, November, 1992,

University of Delaware Seminar Series,

University of Delaware, Newark, Delaware,
October 1992; DOE Co-Contaminant Chemistry Subprogram Meeting, DOE, Gaithersburg, Marylar ', December 1992.

Faculty: Ph.D. Committee Member, Penn State University; M.S. Committee Member, The University of Tennessee.

Advisor: Zorawar Kooner, postdoctoral fellow, The University of Tennessee; Rachel O'Brien, postmaster's fellow, Washington State University; Oren Reedy, M.S. candidate, The University of Tennessee; Yemi Turnage, B.S. candidate, The University of Texas.

Editor: Associate Editor, Soil Science Society of America Journal, 1991-94.

Ad Hoc Reviewer: Water Resource Research; Soil Science; Soil Science Society of America Journal.

JOSLIN, J. D.

Chair: Organization committee member and chair, paper selection committee, Eighth North American Forest Soils Conference, sponsored by SSSA, Society of American Foresters, and CSSS, Gainesville, Florida, May 1993.

Participant: American Society of Agronomy Annual Meeting, sponsored by ASA/CSSA/SSSA, Minneapolis, November 1992; Third Annual Southern Appalachian Man and the Biosphere, sponsored by TVA, Gatlinburg, Tennessee, November 1992; Eighth North American Forest Soils Conference, sponsored by

SAF/SSSA/CSSS, Gainesville, Florida, May 199.3.

Faculty: Instructor, Forestry, Wildlife, and Fisheries, The University of Tennessee.

Advisor: April Stone, Ph.D. candidate, The University of Tennessee.

Ad Hoc Reviewer: Canadian Journal

of Forest Research; Journal of Environmental Quality; Water, Air, and Soil Pollution; Proceedings, Eighth North American Forest Soils Conference, INRA Centre de la Recherche Forestiere. 
KAISER, D. P.

Participant: 73rd Annual Meeting of American Meteorological Society/Eighth Conference on Applied Climatology, Anaheim, California, January 1993; Environmental Information Management and Analysis: Ecosystem to Global Scales, sponsored by NSF, Albuquerque, New Mexico, May 20-22, 1993.

Other: Judge, Southern

Appalachian Science and Engineering Fair, East Tennessee.

\section{KANCIRUK, $P$.}

Member: DOE representative, Committee on Earth and Environmental Sciences, Interagency Working Group on Data Management for Global Change, 1990-; DOE liaison, CODATA, NAS, 1992-.

Participant: Joint USA/Russia Workshop on Global Change Space Data, sponsored by NASA and the Russian Space Agency, Moscow and St. Petersburg, Russia, May 1993.

\section{KELLY, J. M.}

Chair: NADP/NTN Technical

Committee, November 1992-93.

Participant: Eighth North American

Forest Soils Conference, sponsored by SSSA, Society of American Foresters, CSSS, Gainesville, Florida, May 1993; Liphook Conference, sponsored by National Power, Cambridge, England, March 1993.

Faculty: Adjunct Professor, Graduate Program in Ecology, 'The University of Tennessee.

Editor: Associate Editor, Soil Science Society of America Journal, 1988-94.

\section{KING, A. W.}

Participant: Fourth Annual Walker Branch Watershed Research Symposium; sponsored by DOE; Oak Ridge,
Tennessee, March 1993; NASA/EOS

University of New Hampshire Project

Review, Durham, New Hampshire, May 1993; 78th Annual Meeting of the Ecological Society of America, Madison, Wisconsin, August 1993; Fourth International $\mathrm{CO}_{2}$ Conference, WMO, Carqueiranne, France, September, 1993; IPCC Scientific Assessment (WGI) Sessior, on the Link between Emissions and Atmospheric $\mathrm{CO}_{2}$, IPCC, LaValerane, Carqueiranne, France, September 1993.

Ad Hoc Reviewer: Global

Biogeochemical Cycles; Ecological Applications; Water, Air, and Soil Pollution; proposals for NSF, USDA, NRICGP, DOE, and PER.

\section{KORTE, N. E.}

Chair: Symposium on Health, Safety, and Training Issues During Site Characterization and Remediation, sponsored by ACS, Denver, May-April 1993.

Participant: Research Needs for Riparian Management Workshop, sponsored by Colorado Riparian Association, Steamboat Springs, Colorado, November 1992; National Meeting on Interpreting and Measuring VOCs in Soils, sponsored by ORNL/EPA/University of Wisconsin, Las Vegas, January 1993; Emerging Technologies in Hazardous Waste Remediation, sponsored by ACS, Atlanta, September 1993; National Meeting, ACS, Denver, March 1993.

Faculty: Adjunct Professor, Department of Geology/Environmental

Restoration, Mesa State College, Grand Junction, Colorado.

Ad Hoc Reviewer: Environment International; Environmental Management.

KROODSMA, R. L. Ad Hoc Reviewer: Wildlife Society Bulletin; Avian Interactions with Utility Structures of EPRI. 
KSZOS, L A

Member: Ecology Committee, Water

Environment Federation, January 1993-94.

Participant: Water Environment

Federation, New Orleans, September 1992;

Society of Environmental Toxicology and

Chemistry, Cincinnati, November 1992.

Advisor: Shannon Smith,

A.S. candidate, Santa Fe Community

College; Jessica Urbanik, B.S. candidate,

Loyola University; Michelle Cheran,

B.S. candidate, The University of

Tennessee.

Other: Restoring Our Waters

Institute, National Teacher Education

Program, ORNL.

\section{LAASE, A. D.}

Participant: National Technical Information Exchange Workshop, sponsored by DOE, Knoxville, Tennessee, May 1993; Parameter Optimization, sponsored by International Groundwater Modeling Center, Golden, Colorado, August 1993; International Groundwater Modeling Center Conference on Groundwater Modeling, Golden, Colorado, June 1993; Conference on Aquifer Restoration, sponsored by National Groundwater Association, Las Vegas, October 1992.

Ad Hoc Reviewer: Soil Science Society of America Journal.

\section{LARSEN, I. L.}

Advisor: Kelly Turnage and Kerry Leach, M.S. candidates, The University of Tennessee.

Other: Advisor/Consultant, Oak Ridge Wastewater Treatment Plant.

\section{LEE, S. Y.}

Member: Council for Society, CMS, September 1993-95; Honorary Research Scientist, Institute of Rural Development, Department of Agriculture and Fisheries,
Republic of Korea, January

1992-December 1995.

Faculty: Adjunct Professor,

Department of Plant and Soil Science,

The University of Tennessee.

Advisor: Yel Roh, Ph.D. candidate,

The University of Tennessee;

K. M. Turage and Kerry Leach, M.S. candidates, The University of Tennessee.

Ad Hoc Reviewer: Soil Science

Society of America Journal; Journal

of Environmental Quality; Soil Science;

Clays and Clay Minerals; Environmental

Science and Technology.

\section{LEMISZKI, P. J.}

Participant: Appalachian Brine

Workshop, sponsored by Oak Ridge

Hydrologic and Geologic Study,

Oak Ridge, Tennessee, September 1993.

\section{LIANG, L.}

Chair: Symposium on Surface

Chemistry of Natural Materials, Goldschmidt Conference, sponsored by Geochemical Society, Reston, Virginia, May 1992.

Participant: Annual Meeting, AGU, San Francisco, December 1992; Groundwater Treatability Studies for Reactive Gates for TCE/Tc-99, sponsored by DOE, Paducah, Kentucky, April 1993; Groundwater Treatability Studies for Reactive Gates for TCE/Tc-99, sponsored by DOE, Oak Ridge K-25 Site, Oak Ridge, Tennessee, May 1993. Advisor: Birgit Satmark, Ph.D. candidate, Chalmers University of Technology.

Ad Hoc Reviewer: Separation Science and Technology; E\&T; Journal of Environmental Radioactivity; Journal of Contaminant Hydrology; Langmuir, DOE-ER Proposal Review. 
LINDBERG, S. E

Chair: Workshop on Sampling Mercury in Precipitation, sponsored by NADP and TVA, Tarpon Springs, Florida, April 1993.

Member: Technical Committee, Ninth International Conference on Heavy Metals in the Environment, sponsored by EPA, World Health Organization, Environment Canada, and Canada Center for Inland Waters, Toronto, September 1993.

Participant: Annual Technical Meeting of the NADP, Cocoa Beach, Florida, October 1992; Nordic Council of Ministers Workshop on Deposition, Goteborg, Sweden, November 1992; NOAA AirMon Planning Meeting, Silver Springs, Maryland, February 1993; Program Review, EPRI Mercury Research, Tarpon Springs, Florida, April 1993; UNECE Commission on Long-Range Transboundary Air Pollution Workshop on Emissions and Modeling of Atmospheric Transport of Persistent Organic and Heavy Metals, Durham, North Carolina, May 1993; Ninth International Conference on Heavy Metals in the Environment, Toronto, September 1993.

Faculty: Research Professor, Department of Forestry, The University of Tennessee.

Advisor: Allen Pendergrass, B.S. candidate, Auburn University.

Editor: Advances in Environmental Science, Springer-Verlag, 1986-; associate editor, Environmental Reviews, 1992-.

Ad Hoc Reviewer: Environmental Reviews; Journal of Geophysical Research; Atmospheric Environment; Water, Air, and Soil Pollution; Biogeochemistry.

LOAR, J. M.

Participant: East Fork Poplar Creek Technical Workshop: Exploring FS/EIS Issues, sponsored by DOE, Oak Ridge, Tennessee, March 1993. Ad Hoc Reviewer: North American Journal of Fisheries Management;
Transactions of the American Fisheries Society.

\section{LUXMOORE, R. J.}

Chair: Global Change Impacts on Plant Ecophysiological Processes, sponsored by 15 th International Botanical Congress, Yokohama, Japan, August 1993; Editorial Affairs, Policies, and Practices Committee, sponsored by SSSA, 1991-93.

Officer: Deputy Coordinator, Physiology Subject Group, International Union of Forestry Research Organizations, 1991-96.

Member: Promotion Review Board, EPA, October 1992; Scientific Council, Siberian International Centre for Research of Boreal Forests, 1993-.

Participant: Biotic Feedbacks in the Global Climate System, sponsored by Intergovernmental Panel on Climate Change, Woods Hole, Massachusetts, October 1992; Regional and National Models for Global Change, sponsored by USDA Forest Service, Delaware, Ohio, November 1992; Terrestrial Biospheric Carbon Fluxes, sponsored by EPA, USFS, and Edison Electric Institute, Bad Harzburg, Germany, February-March 1993; Ecophysiology and Genetics of Trees and Forests, sponsored by IUFRO, University of Tuscia, Viterbo, Italy, May 1993; 15th International Botanical Congress, sponsored by Japanese Botanical Societies, Yokohama, Japan, August-September 1993.

Faculty: Adjunct Professor, Department of Plant and Soil Sciences, The University of Tennessee, 1992-. Advisor: Vicki Homer, postdoctoral fellow, ORISE.

Editor: Editor-in-Chief, Soil Science Society of America Journal, 1991-93; Editorial Advisory Board, Modeling of GeoBiosphere Processes, 1990-; Monographs Committee; American Society of Agronomy, 1991-93. 
Ad Hoc Reviewer: Proposals for NSF; Joumal of Hydrology; Soil Science; Natural Environmental Research Council, United Kingdom; Water, Air, and Soil Pollution.

Other: Ph.D. Thesis Examiner, Board of Examiners, Madurai Kamaraj University, India, 1992; Expert Assessor, Appointments Board, Swedish University of Agricultural Sciences, Uppsala, 1992-93; Ph.D. Thesis Examiner, Swedish University of Agricultural Sciences, Uppsala, 1993; consultant on a landfill, Save Our Cumberland Mountains, Oliver Springs, Tennessee.

MADIX, S. E.

Participant: Hazardous Waste Site

Field Sampling Workshop, sponsored by EPA, Oak Ridge, Tennessee, June 1993. Other: 1992 EnvironMENTAL Fair, Knox County Sixth, Seventh and Eighth Graders; Career Day, Robertsville Junior High School Students.

MANN, L K

Member: SAMAB Natural Resources Committee; SSSA.

Participant: SAMAB Conference on

Wetland Ecology, Management, and Conservation, sponsored by ORNL/ESD,

Knoxville, Tennessee, September 1993. Ad Hoc Reviewer: Soil Science; Bulletin of the Torrey Botanical Club; Eighth North American Forest Soils Conference.

Other: Soil Conservation Service Board of Supervisors, Treasurer, Roane County.

MARLAND, $\mathbf{G}$.

Member: National Technical Advisory

Committee, National Institute for Global

Environmental Change, 1991-; Advisory

Group on Energy Data Bases,

International Atomic Energy Agency, 1993. Participant: U.S./Japan Conference on

Global Change, sponsored by DOE/DOA IPOS, Honolulu, February 1993; Latin American Emissions Workshop,
Intergovernmental Panel on Climate Change, Sao Jose Dos Campos, Brazil, March 1993; Global Change Postdoctoral Fellowship Program Review, sponsored by ORISE, Tucson, Arizona, April 1993;

Climate Mitigation, sponsored by EPRI, La Jolla, California, September 1993. Advisor: Robert Andres, postdoctoral fellow; Steve Bischoff, M.S. candidate, University of Michigan.

MARSH, J. D.

Member: ACS; Geochemical Society.

Participant: 205th American Chemical

Society National Meeting, Denver, April 1993; Fourth National Technology Information Exchange Workshop, sponsored by DOE, Knoxville, Tennessee, May 1993.

MARSHALI, D. S.

Participant: Fundamentals of Groundwater Contamination, sponsored by Geraghty and Miller, Inc., Arlington, Virginia, October 1992.

\section{MARZOLF, E R.}

Ad Hoc Reviewer: Journal of North

American Benthological Society.

MCCARTHY, J. F.

Chair: International Symposium on Organic Substances in Soil and Water, sponsored by Royal Society of Chemistry, Lancaster, United Kingdom, October 1992; Meeting of International Humic Substances Society, Bari, Italy, October 1992; Symposium on Colloid-Facilitated Transport, sponsored by AGU, San Francisco, December 1992.

Participant: Keynote speaker, International Symposium on Organic Substances in Soil and Water, sponsored by Royal Society of Chemistry, Lancaster, United Kingdom, October 1992; Keynote speaker, Sixth International Humic Substances Society Meeting, Bari, Italy, 

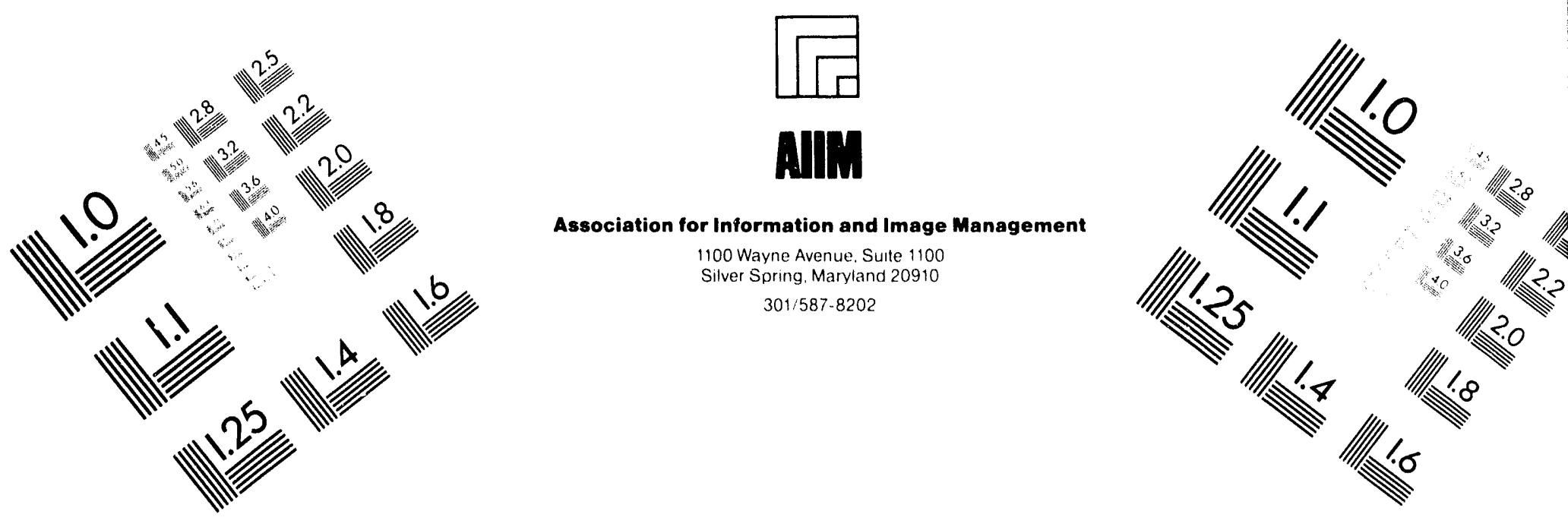

\section{Centimeter}

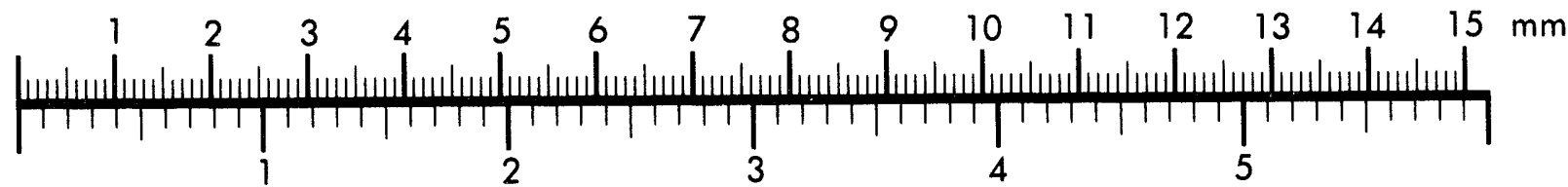
Inches
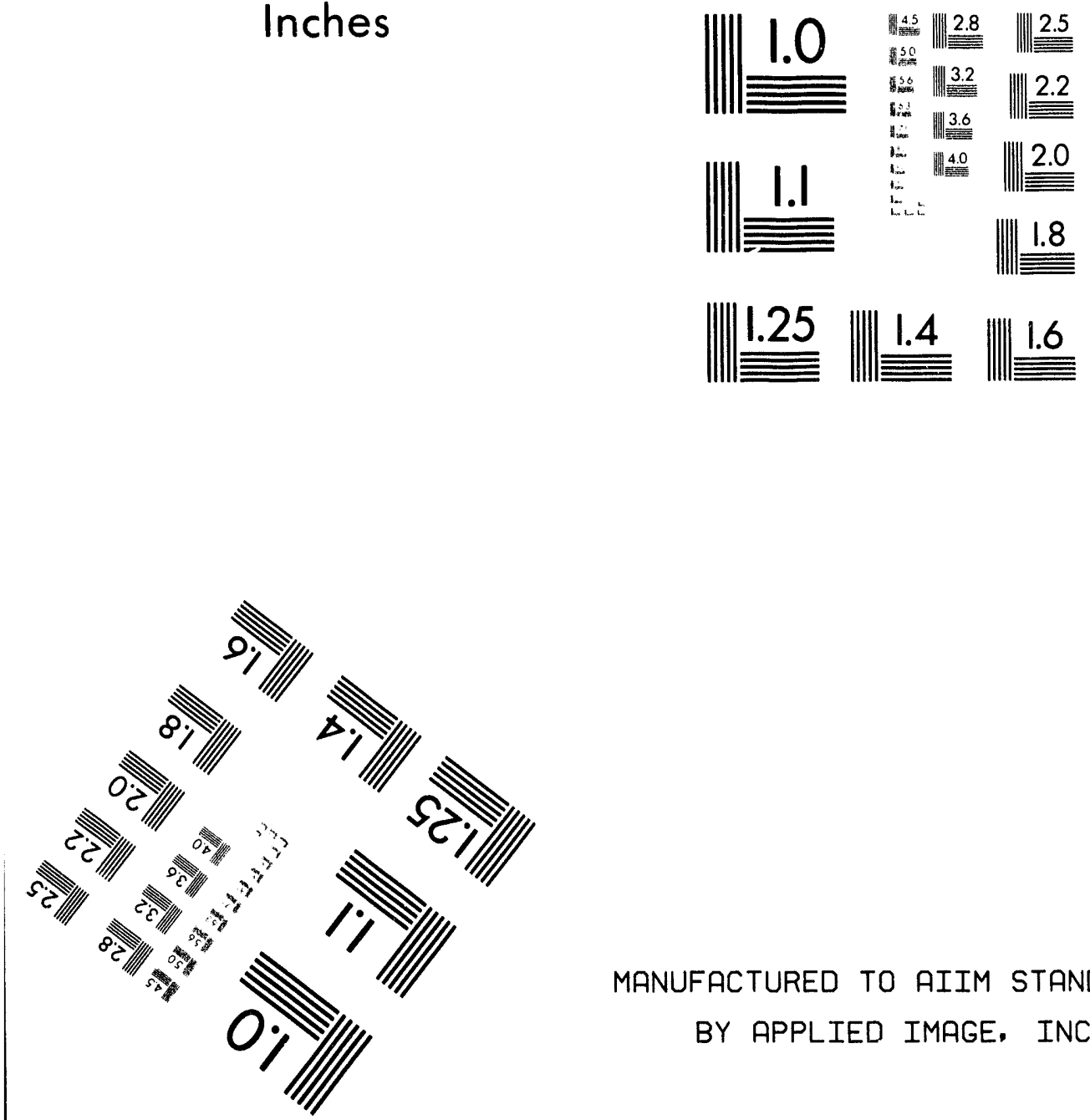

MANUFACTURED TO AIIM STANDARDS

BY APPLIED IMAGE, INC.

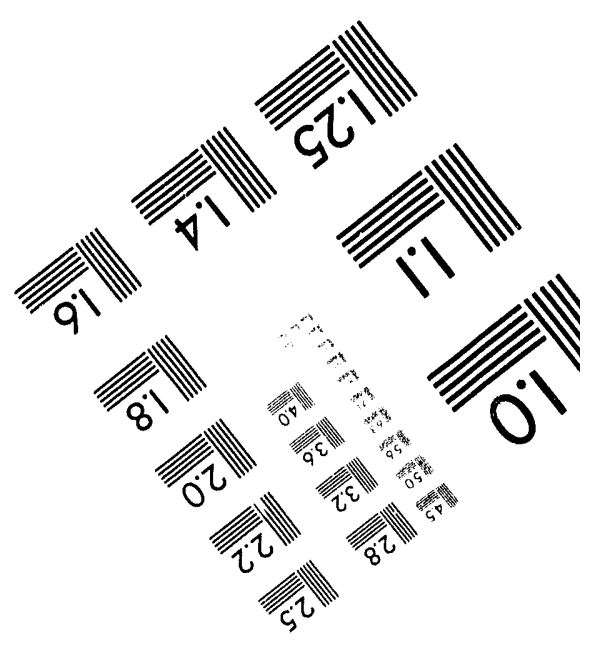



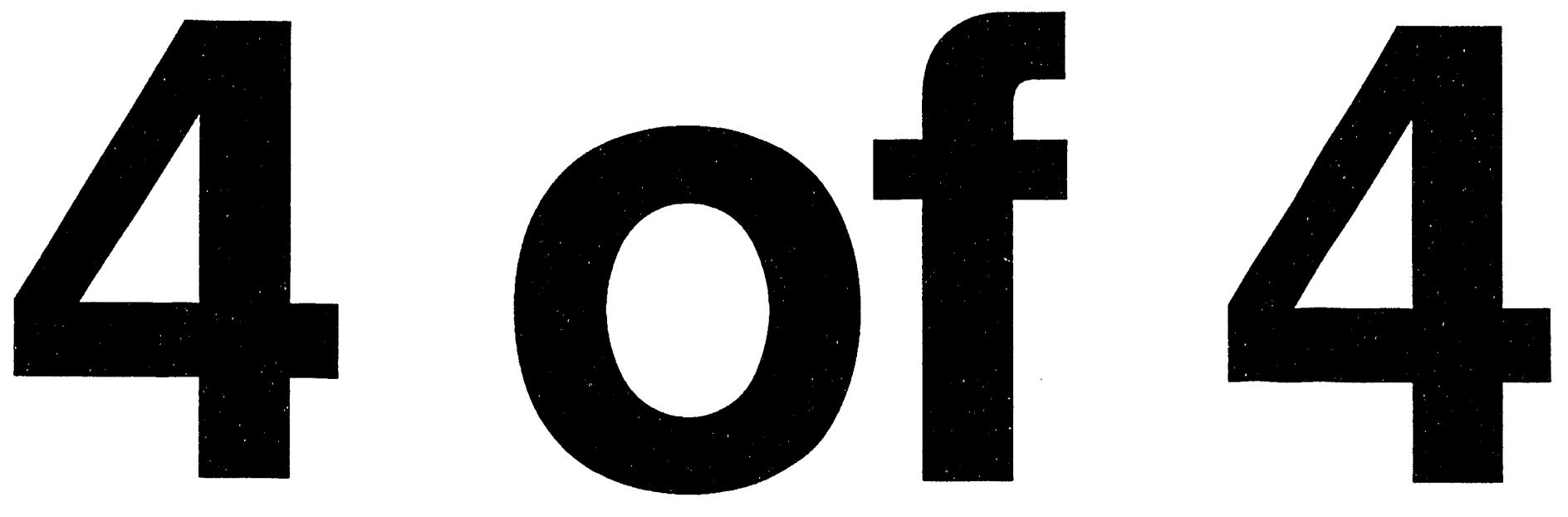
October 1992; Yucca Mountain Colloid Workshop, sponsored by DOE/LANL, Sante Fe, New Mexico, May 1993.

Faculty: Adjunct Faculty, Ecology,

The University of Tennessee, 1988-. Ad Hoc Reviewer: Environmental Sciences and Technology; Water Resources Research; proposals for DOE and USDA.

McCORD, R. A

Member: Steering Committee, GIS

Information Exchange Meeting, sponsored by DOE-ER, Gatlinburg, Tennessee, November 1992.

Participant: GIS Information Exchange Meeting, sponsored by DOE-ER, Gatlinburg, Tennessee, November 1992. Other: Data Management Expert, Energy Systems Resource Management Organization, April 1993-.

MOLINE, G. R.

Participant: Spring Meeting, AGU, Baltimore, May 1993; Technical Information Exchange Workshop, sponsored by DOE, Knoxville, Tennessee, May 1993.

MOODY, R. L.

Participant: Hazardous Waste Site

Field Sampling Workshop, sponsored by

EPA, Oak Ridge, Tennessee, June 1993.

Faculty: Adjunct Professor,

Chemistry Department, Pellissippi State

Technical Community College,

February-May 1993.

MULHOLLAND, P. J.

Participant: Workshop on National Needs for Controlled Environments in Ecology and Environmental Science, sponsored by NSF, Lake Tahoe, Nevada, February 1993; Annual Meeting, North American Benthological Society, Calgary, Alberta, Canada, May 1993; Gordon Research Conference on Hydrology, Geochemistry and Biology of Forested Catchments, Plymouth, New Hampshire, August 1993; SAMAB Conference on Wetland Ecology, Management, and Conservation, sponsored by ORNL/ORNL, Knoxville, Tennessee, September 1993.

Faculty: Faculty Associate, Graduate Program in Ecology, The University of Tennessee.

Advisor: Mark Mitch, Ph.D. candidate, University of Virginia; Amy Rosemond, Ph.D. candidate, Vanderbilt University; Elizabeth Jay, M.S. candidate, University of North Carolina, Chapel Hill; Alycia Bayboyan, B.S. candidate, Coc College; Chad Cook, B.S. candidate, University of Wisconsin, Stevens Point; Catherine Geil, B.S. candidate, University of California-Davis; Abigail Wechsler, B.A. candidate, Dartmouth College.

Editor: Editorial board, Ecology and Ecological Monographs, 1990-.

Ad Hoc Reviewer: Journal of the North American Benihological Society; Watershed Response Program, EPA; Internationale Vereinigung fuer Theoretische und Angewandte Limnologie; Limnology and Oceanography; NSF Ecosystems program; Biogeochemistry; Oikos; Canadian Journal of Fisheries and Aquatic Sciences.

\section{NANEY, M. T.}

Participant: OPA Review of Office of Basic Energy Sciences, Geosciencc Research Project, sponsored by OPA, Boston, September 1993; DOE Geosciences Workshop, sponsored by DOE/Office of Basic Energy Sciences, Geosciences Program, Dedham, Massachusetts, September 1993; Annual Spring Meeting, AGU, Baltimore, May 1993.

Ad Hoc Reviewer: NSF.

NAPOLITANO, G. E.

Participant: Annual Meeting, American Oil Chemists' Society, Anaheim, California, 
April 25-29, 1993; Third International Symposium on Health of Aquatic Systems, sponsored by International Society for the Health of Aquatic Systems, Blacksburg, Virginia, May 24-27, 1993; Annual Meeting, North American Benthological Society, Calgary, Alberta, Canada, May 1993.

Advisor: Lisa Kohring, M.S. candidate, The University of Tennessee.

Ad Hoc Reviewer: Ecotaxicology; Lipids; NATO Collaborative Research Grant.

NIEMELA, S. L.

Member: AFS.

Participant: 13th Annual Meeting, Society of Environmental Toxicology and Chemistry, Cincinnati, November 1992; 123rd Annual Meeting, AFS, Portland, Oregon, August-September 1993.

NORBY, R. J.

Participant: Coordination of Research Activities, sponsored by USDA Forest Service, Raleigh, North Carolina, October 1992; Annual Meeting: Forest Response to $\mathrm{CO}_{2}$, sponsored by EPRI and DOE, Durham, North Carolina, January 1993; FACE Experiments in Forests Workshop, sponsored by DOE, Orlando, Florida, March 1993; Eighth North American Forest Soils Workshop, sponsored by SSSA, Gainesville, Florida, May 1993; Belowground Responses to Rising $\mathrm{CO}_{2}$, sponsored by Michigan Biological Station and ORNL, Pellston, Michigan, May 1993; rapporteur, $\mathrm{CO}_{2}$ and Climate Change Workshop, sponsored by SCOPE, Washington, D.C., May 1993; 15th International Botanical Congress, sponsored by the International Union of Biological Sciences, Yokohama, Japan, August 1993.

Faculty: Adjunct Associate, Graduate Program in Ecology, The University of Tennessee, 1988-.
Advisor: Glenn Berntson, Ph.D. candidate, Harvard University; Chris Nietch, B.A. candidate, Kalamazoo College. Ad Hoc Reviewer: Nature; Plant, Cell and Environment; Tree Physiology; Canadian Journal of Forest Research; Ecological Applications; Biogeochemistry; Forest Science; Ecology; Plant and Soil; NSF; DOE; USDA.

Other: Science fair judge, Jefferson Junior High School, Oak Ridge, Tennessee.

NYQUIST, J. E.

Chair: Workshop on Airborne

Electromagnetic Methods, sponsored by Laboratory for Advanced Surface Imaging, Tucson, Arizona, September 1993; Environmental Workshop, sponsored by Society of Exploration Geophysicists, Washington, D.C., September 1993.

Member: Publication Committee, Environmental and Engineering Geophysical Society, March 1993-94. Participant: Fcurth National Technology Information Exchange, sponsored by DOE/ER, Knoxville, Tennessee, May 1993; Symposium for the Application of Geophysics to Environmental and Engineering Problems, sponsored by Environmental and Engineering Geophysical Society, San Diego, April 1993; Workshop on Airborne Electromagnetic Methods, sponsored by Laboratory for Advanced Subsurface Imaging, Tucson, Arizona, September 1993; Annual Meeting of the Society of Exploration Geophysicists, sponsored by Society of Exploration Geophysicists, Washington, D.C., September 1993.

Faculty: Adjunct Assistant

Professor, Department of Geological Sciences, The University of Tennessee. 
OLSON, R. J.

Member: Interagency Committee on Environmental Trends, 1992-; Federal Agencies organized by CEQ.

Participant: GIS Information Exchange for Environmental Restoration, sponsored by DOE, Gatlinburg, Tennessee, November 1992; Fourth National Techno'ogy Information Exchange Workshop, sponsored by DOE, Knoxville, Tennessee, May 1993; Environmental Information Management and Analysis Ecosystem to Global Scales, sponsored by NSF, Albuquerque, New Mexico, May 1993.

Ad Hoc Reviewer: Scientific Information Systems: A Conceptual Framework.

O'NEILL, E G.

Chair: Belowground Responses to Rising Atmospheric $\mathrm{CO}_{2}$ : Implications for Plants, Soil Biota and Ecosystem Processes, sponsored by EPA, EPRI, and University of Michigan Biological Station, Pellston, Michigan, May-June 1993; Approaching Sustainability from the Bottom Up: Preserving the Soil, Annual Meeting, Ecological Society of America, Madison, Wisconsin, August 1993; Round Table on Mycorrhizal Role in Sustainability of Soil Systems, Ninth North American Conference on Mycorrhizae, Guelph, Ontario, Canada, August 1993.

Officer: Treasurer, U.S. Soil Ecology Society, 1989-93.

Member: ESA.

Participant: Steering rommittee Workshop, FACE Experi. znts in Forests, sponsored by DOE, Orlando, Florida, March 1993; UMBS/ORNL Workshop on Belowground Response to Elevated $\mathrm{CO}_{2}$, sponsored by EPA, EPRI, and University of Michigan Biological Station, Pellston, Michigan, May 1993; DOE Review of Laboratory Programs for Women, sponsored by DOE, Oak Ridge, Tennessee,
May 1993; Annual Meeting, Ecological Society of America, Madison, Wisconsin, August 1993; Ninth North American Conference on Mycorrhizae, Guelph, Ontario, Canada, August 1993; Workshop on the Use of PCR Techniques for Identification of Mycorrhizae, Ninth North American Conference on Mycorrhizae, Guelph, Ontario, Canada, August 1993.

Editor: Guest Editor, Plant and Soil, 1993-.

Ad Hoc Reviewer: Tree Physiology;

Plant and Soil; Soil Science

Society of America Journal; Nature; USDA Competitive Research Grant Program; DOE Program in Ecosystem Research; Springer-Verlag Ecological Studies Series; The Encyclopedia of Science; American Chemical Society.

\section{O'NEILL, R. V.}

Chair: Awards Committee,

U.S. Association for Landscape Ecology, 1991-94.

Faculty: Adjunct Professor, Graduate Program in Ecology, The University of Tennessee.

\section{PALUMBO, A. V.}

Participant: Meeting of the Biotreatment Support Group, SRS Integrated Demonstration, Aiken, South Carolina, October 1992; Workshop on Planned Research on Heterogeneity, SERDP, Denver, November 1992; 13th Annual Meeting, Society of Environmental Toxicology and Chemistry, Cincinnati, November 1992; Meeting of the Biotreatment Support Group, SRS Integrated Demonstration, Atlanta, December 1992; DOE/OHER Microbial Physiology/Biodegradation Subprogram Meeting, Gaithersburg, Maryland, January 1993; DOE/OTD Non-Arid Site Integrated Demonstration Review, Aiken, South Carolina, February 1993; 
Information Exchange Meeting on Waste Retrieval, Treatment and Processing, sponsored by DOE, Houston, March 1993; DOE In Situ Remediation Integrated Program Proposal Review Meeting, DOE, Germantown, Maryland, May 1993; 15th Symposium on Biotechnology for Fuels and Chemicals, Colorado Springs, Colorado, May 1993; 93th Annual Meeting, American Society for Microbiology, Atlanta, May 1993; Second International Symposium on Microbiology of the Deep Subsurface, sponsored by DOE, Bath, England, September 1993.

Faculty: Adjunct Faculty, Graduate Program in Environmental Toxicology, The University of Tennessee.

Advisor: Janet Strong-Gunderson and Susan Pfiffner, postdoctoral fellows, ORISE; D. Hedrick, Chiung-Tai Kuo, and Udet Minocha, Ph.D. candidates, The University of Tennessee.

Editor: Editorial Board, Ecotoxicology, 1992-.

Ad Hoc Reviewer: Proposals for DOE/OTD In Situ Program; Ecotoxicology; DOE SBIR Program; Second International Symposium on On-Site and In Situ Bioremediation; Water Resources Research. Other: Judge, Regional Competition for Odyssey of the Mind.

PARR, P. D.

Officer: Treasurer and Business

Manager, Association of Southeastern Biologists, 1990-93.

Participant: Research Park Coordinators Meeting, sponsored by DOE, Chicago, November 1992; Southern Appalachian Man and Biosphere Conference, Gatlinburg, Tennessee, November 1992; Association of Southeastern Biologists, Virginia Beach, Virginia, April 1993.

Advisor: Cindy Gabrielsen, M.S. candidate, The University of Tennessee.
PEARSON, S. M.

Participant: SAMAB, Gatlinburg, Tennessee, November 1992; International Association for Landscape Ecology, Oak Ridge, Tennessee, March 1993; Conference on Statistics, sponsored by EPA, Baltimore, March 1993; Forest Ecosystem Management at the Landscape Level, sponsored by American Forests, Oak Ridge, Tennessee, March 1993; Effects of Fire in Greater Yellowstone, sponsored by U.S. Department of Interior Park Service, Yellowstone National Park, Wyoming, September 1993; Annual meeting, Wisconsin Department of Natural Resources Bureau of Research, Wisconsin Dells, Wisconsin, September 1993;

SAMAB Conference on Wetland Ecology, Management, and Conservation, sponsored by ORNL/ESD, Knoxville, Tennessee, September 1993.

Faculty: Research Associate, Graduate Program in Ecology, The University

Tennessee, 1993-94.

Ad Hoc Reviewer: EPA; Landscape Ecology.

\section{PENG, T.-H.}

Member: Scientific Steering

Committee, U.S. Joint Global Ocean Flux Studies, NSF, 1991-94; U.S. DOE $\mathrm{CO}_{2}$, Science Team, DOE, 1991-; UNAM/ORNL Joint MOU Steering Committee, ORNL, 1991-.

Participant: International Conference on Global Atmospheric-Biospheric Chemistry, Eilat, Israel, April 1993; Symposium on Heat and Mass Transfer in the Oceans, 29th National Heat Transfer Conference, Atlanta, August 1993; Gordon Conference on Chemical Oceanography, Kimball Union Academy, Meridian, New Hampshire, August 1993; Fourth International $\mathrm{CO}_{2}$ Conference, Carqueiranne, France, September 1993. Ad Hoc Reviewer: Journal of Geophysical Research; Earth and Planetary 
Sciences Letter; Global Biogeochemical Cycle; Geochemica et Cosmochemica Acta; Science; Nature; proposals for NSF and DOE Carbon Dioxide Research Program; NOAA.

PETERSON, M. J.

Member: Pollution Committee, Southern Division, AFS, 1992-.

Participant: National Technical Workshop on PCBs in Fish Tissue, sponsored by EPA, Washington, D.C., May 1993; Technical Meeting of the Sonthern Division of the AFS, Chattanooga, Tennessee, February 1993; 123rd Annual Meeting, AFS, Portland, Oregon, August 1993; 41st Annual Meeting, North American Benthological Society, Calgary, Canada, May 1993.

Other: Restoring Our Waters Institute, National Teacher Education Program, ORNL.

PFIFFNER, S. $M$. Officer: President, Association for Women in Science. Advisor: Jennifer Foote and Robin Quinn, B.S. candidates, The University of Tennessee.

Other: Co-organizer and moderator, NAACP community forum, Oak Ridge, Tennessee, July 1993; SHADES workshop, Museum of Science and Energy, Oak Ridge, October 1992.

PHELPS, T. J. Chair: Taylorsville Triassic Basin Working Group, sponsored by DOE/OHER, Annapolis, Maryland, December 1992; The Second Taylorsville Triassic Basin Working Group, sponsored by DOE/OHER, Annapolis, Maryland, August 1993.

Participant: WSRS Integrated Demonstration of TCE Degradation Task Summary Group, sponsored by WSRS, OTD, Augusta, Georgia, October 1992;
Stocktaking Meeting of the Taylorsville Triassic Basin Working Group, sponsored by DOE/OHER Subsurface Science Program, Annapolis, Maryland, December 1992; Kwajalein Field Working Group, sponsored by HAZWRAP, Kwajalein Island, USAKA, December 1992; WSRS Integrated Demonstration of TCE Degradation Task Summary Group, sponsored by WSRS, OTD, Augusta, Georgia, February, 1993; Subsurface Science Program Coordinators Meeting, sponsored by DOE/OHER Subsurface Science Program, Annapolis, Maryland, March 1993; Drilling and Sampling Technology Transfer Workshop, sponsored by DOE/OHER Subsurface Science Program and PNL/ESRC, Sante Fe, New Mexico, March 1993; In-Situ and OnSite Bioreclamation, sponsored by Battelle, San Diego, April 1993; ASM Conference on Water Quality in the Western Hemisphere, sponsored by American Society for Microbiology, San Juan, Puerto Rico, April 1993; Annual Meeting, American Association of Petroleum Geologists, New Orleans, April 1993; 15th Symposium on Biotechnology of Fuels and Chemicals, sponsored by ORNL, Colorado Springs, Colorado, May 1993; Annual Meeting, American Society for Microbiology, Atlanta, May 1993; Second Stocktaking Meeting of the Triassic Basin Working Group, sponsored by DOE/OHER Subsurface Science Program, Annapolis. Maryland, August 1993; Second International Symposium on Subsurface Microbiology, sponsored by DOE, Bath, United Kingdom, September 1993.

Faculty: Research Associate Professor, Department of Chemical Engineering, The University of Tennessee, 199-95; Adjunct Professor, Biotechnology Program, The University of Tennessee, 1992-.

Advisor: Chris Kelly, Ph.D. candidate, The University of Tennessee; Jennifer 
Foote, B.S. candidate, The University of Tennessee.

Editor: Editorial Board, Journal of

Microbiological Methods, 1991-.

Ad Hoc Reviewer: Applied and

Environmental Microbiology; Environmental

Science and Technology; proposals for

DOD, DOE/SBIR, DOE/OTD, and NSF;

Hudson River Research; National

Geographic.

POST, W. M., III .

Participant: Synthesis Center

Workshop, sponsored by NSF,

Albuquerque, New Mexico, October 1992;

Global Soils Database Workshop, sponsored by IGBP, Silsoe, England, October 1992; Workshop on Modeling Soil

Organic Matter Turnover, sponsored by European Community, Rothamsted, England, May 1993; USDA Forest Service Workplan Review, sponsored by Forest Science Laboratory, Grand Rapids, Minnesota, June 1993; Role of Non-Living Organic Matter in the Global Carbon Cycle, Dahlem Conferences, sponsored by Free University of Berlin, Berlin, September 1993.

Faculty: Adjunct Professor, Graduate Program in Ecology, The University of Tennessee, 1985-.

Editor: Editorial Board, American Naturalist, 1992-95.

\section{RENSHAW, A W.}

Chair: Board of Directors, Educational

Foundation, American Association of

University Women, 1992-93. Officer: Secretary, ORNL Strategic

Planning Committee, 1991-92.

Member: American Association of Artificial Intelligence; American Nuclear Society, Knoxville-Oak Ridge Chapter; Society of Black Physicists; FOCUS Group, Energy Systems.

Participant: Keynote speaker, Martin Luther King, Jr., Fellowship
Breakfast, sponsored by Energy Systems, January 1993; FWI Council meetings, Washington, D.C., December 1992, March and August 1993; FWI pilot project meeting with TVA and NASA, Huntsville, Alabama, March 1993; Roundtable, Fourth Women in Science Conference, sponsored by ORNL and ORISE, March 1993; Walker Branch Watershed Research Symposium, sponsored by DOE, March 1993; Environmental Conference, sponsored by the Junior League of Knoxville, April 1993; RAINS-Asia workshop, sponsored by the World Bank, Washington, D.C., September 1993.

Other: Off-site assignment, NAPAP Office, Washington, D.C., September 1993-March 1994.

\section{ROSE, $\mathrm{K}$ A.}

Faculty: Adjunct Faculty, Graduate Program in Ecology, The University of Tennessee.

\section{ROSENSTEEL, B. A.}

Participant: Second Biennial Wetland Biogeochemistry Symposium, spunsored by Wetland Biogeochemistry Institute, Louisiana State University, Baton Rouge, February 1993; Creating Wetlands for Habitat Enhancement and Mitigation, sponsored by University of WisconsinMadison, Department of Engineering Professional Development, Madison, May 1993; Constructed Wetlands Workshop for Electric Power Utilities, sponsored by TVA, Chattanooga, Tennessee, August 1993; SAMAB Conference on Wetland Ecology, Management, and Conservation, sponsored by ORNL/ESD, Knoxvil. Tennessee, September 1993.

SALK, M. S.

Participant: NEPA Compliance Officers Meeting, sponsored by DOE's Office of NEPA Oversight, EH-25, 
Arlington, Virginia, March 1993; NEPA Compliance Officers Meeting, sponsored by DOE's Office of NEPA Oversight, EH-25, Washington, D.C., August 1993; SAMAB Conference on Wetland Ecology, Management, and Conservation, sponsored by ORNL/ESD, Knoxville, Tennessee, September 1993.

Ad Hoc Reviewer: OCRWM NEPA

Procedures Manual for EH-25; DOE-ID NEPA Procedures for EH-25; DOE-SR Guide for NEPA Coordinators for EH-25.

SCHILINNG, E M.

Member: Pollution Committee of the Southern Division of the AFS.

Participant: 73rd Annual Meeting, American Society of Ichthyologists and Herpetologists, Austin, Texas, May-June, 1993; Southeastern Fish Recovery Meeting, sponsored by TVA, Knoxville, Tennessee, April 1993.

Advisor: Joel K. Reid, B.A. candidate, Fort Valley State College.

Other: Restoring Our Waters

Institute, National Teacher Education Program, ORNL.

SCHMOYER, D. D.

Participant: National Symposium on Measuring and Interpreting VOCs in Soils, Las Vegas, January 1993; Optics Modil Industrial Briefing, sponsored by Energy Systems, Oak Ridge, Tennessee, October 1992.

Other: Adopt-a-School Coordinator, Claxton.

\section{SCHRAMM, W. E.}

Participant: 18th Annual Meeting, Southwestern Soil Science Association, New Orleans, March 1993; 18th Annual Conference, NAEP, Raleigh, North Carolina, May 1993; Environmental Impact Assessment for Developing Countries Workshop, sponsored by U.S.
Agency for International Development, Knoxville, Tennessee, June 1993.

SHARPLES, F. E.

Chair: Eighth Annual Oak Ridge Model Conference, sponsored by DOE, Oak Ridge, Tennessee, October 1992; Program chair and organizer, Fourth Annual Women in Science Conference, sponsored by ORNL and ORISE, Knoxville, Tennessee, March 1993; Session cochair and coorganizer, AAAS '93 Annual Meeting of Symposium on Ecosystem Valuation: Assigning Economic Values to Ecosystem Damage, sponsored by AAAS, Boston, February 1993; Session chair and coorganizer, 18th Annual Colloquium on Science and Technology Policy, Redirecting Environmental R\&D, sponsored by AAAS, Washington, D.C., April 1993; Organizer and coinstructor, Natural Resource Trusteeship and Ecological Evaluation Workshop, sponsored by DOE Office of Environmental Guidance, Richland, Washington, April 1993, and Santa Fe, New Mexico, May 1993.

Member: AAAS-Committee on Science, Engineering, and Public Policy; ORNL Showcase Seminar Committee.

Participant: Committee on Science Engineering and Public Policy, sponsored by AAAS, Washington, D.C., October 1992, February 1993 and July 1993.

Other: Volunteer Reader, Recording for the Blind, Oak Ridge; Board of Directors, Recording for the Blind, Dak Ridge.

\section{SHEPHERD, D. E.}

Id Hoc Reviewer: CDIAC Catalog of Numeric Data Packages and Computer Model Packages.

\section{SHRINER, D. S.}

Chair: Sensitivity of U.S. Power Systems to Global Climate Change Impacts 
on Water Resources, sponsored by

AWRA, Reno, Nevada, November 1992.

Member: Executive Committee, Southern Appalachian Man and the Biosphere Program, 1992-; Chairman, Joint Institute for Energy and Environment, Water Resources Working Group, February 1992-September 1993;

Tennessee Water Resources Research Institute, Statewide Steering Committee, February 1991-.

Participant: Managing Water Resources During Global Change, sponsored by AWRA, Reno, Nevada, November 1992; Global Change Effects Program Review, sponsored by USFS, Washington, D.C., June 1993; EMAP Terrestrial Systems Program Review, sponsored by EPA, Raleigh, North Carolina, September 1993.

Ad Hoc Reviewer: USFS Forest Health Monitoring Program; EPA EMAP Terrestrial Integration; Water, Air and Soil Pollution.

SHUGART, L R.

Member: Working Group on Indicators of Marine Ecosystem Health, United Nations Environmental Program, Geneva, 1992-present; Technical Committee, Society of Environmental Toxicology and Chemistry; Consultant, Science Advisory Board, EPA, 1991-95.

Participant: Critical Issues in UV-B, sponsored by DOE/OHER, Cocoa Beach, Florida, February 1993; Indicators of Marine Ecosystem Health, sponsored by United Nations Environmental Program, Geneva, November 1992; Collaborative Research Endeavors on UV-B, sponsored by ORNL and Russian Academy of Science, Moscoiv, February 1993; Joint Cruise in Black Sca with Russian Scientists, sponsored by NATO and ORNL Director's R\&D Program, Moscow and Gelendzhik (Black Sea), Russia, January-February 1993 and March 1993.
Faculty: Adjunct Associate Professor, Oak Ridge Graduate School of Biomedical Sciences, The University of Tennessee. Advisor: C. Gettys-Hull and Chris Theodorakis, Ph.D. candidates, The University of Tennessee.

Editor: Ecotoxicology, Chapman and Hall.

\section{SIEGRIST, R. L}

Chair: National Symposium on Measuring and Interpreting VOCs in Soils: State of the Art and Research Needs, sponsored by EPA, DOE, U.S. Army, American Petroleum Institute, Las Vegas, January 1993; Program committee and session chair, Specialty Conference on Development of Soil and Groundwater Cleanup Standards for Contaminated Sites, sponsored by Water Environment Federation, Washington, D.C., January 1993; In Situ Physical/Chemical Treatment Technical Support Group, sponsored by DOE, Germantown, Maryland, May 1993; Session chair, Fourth Technology Information Exchange Meeting, sponsored by DOE, Knoxville, May 1993.

Member: ASCE, Water Environment Federation; Groundwater Committee, Water Environmental Federation; International Committee Task Force, Water Environment Federation; DOE Planning Committee for In Situ Remediation Technology Development.

Participant: Emerging Technologies for Hazardous Waste Management, sponsored by ACS, Atlanta, September 1992; Eighth Annual Oak Ridge Model Conference, sponsored by DOE, Oak Ridge, Tennessee, October 1992; Data Sufficiency for Site Remediation Decision Making, sponsored by University of Wisconsin Engineering Professional Development, Madison, November 1992; National Symposium on Measuring and Interpreting VOCs in Soils, sponsored by EPA, Las Vegas, January 1993; Developing Cleanup Standards: 
How Clean Is Clean?, sponsored by Water Environment Federation, Washington, D.C., January 1993; American Society of Quality Control, Oak Ridge, Tennessee, April 1993; Waste Management '93, sponsored by DOE, Tucson, Arizona, March 1993; Data Sufficiency for Site Remediation Decision Making, Oak Ridge, Tennessee, May 1993; Session chair, Fourth Technology Information Exchange Meeting, sponsored by DOE, Knoxville, Tennessee, May 1993; 15th Symposium on Biotechnology for Fuels and Chemicals, sponsored by DOE, Colorado Springs, Colorado, May 1993; Data Sufficiency for Site Remediation Decision Making, Chicago, June 1993; National Environmental Health Association Conference, Orlando, Florida, July 1993; Program Reviews: DOE Integrated Program for In Situ Remediation, Core Planning Group and Principal Investigators Meeting, Park City, Utah, April 1993; DOE Integrated Program for In Situ Remediation, Program Peer Review Meeting, Washington, D.C., May 1993.

Faculty: Adjunct Associate Professor, Department of Civil and Environmental Engineering, The University of Tennessee, October 1992-95.

Advisor: Oren F. Webb, postdoctorate, The University of Tennessee;

Scott Dickson and Jay Emerson, Ph.D. candidates, University of Iowa; Paula Labieniec, Ph.D. candidate, Carnegie Mellon University; John Caime and Dan Hurst, M.S. candidates, The University of Tennessee; Steve Schmunck and Mike Carpenter, M.S. candidates, Michigan Technological University; Donna Young, B.S. candidate, Tennessee Technological University. Editor: Joumal of Environmental Engineering, ASCE, September 1993-94. Ad Hoc Reviewer: Environmental Science and Technology; Joumal of
Environmental Engineering; Behavior and Measurement of Volatile Organic Compounds, EPA; Methods Compendium for Analysis of Environmental Samples, DOE-HQ; Program documents for Integrated Program for In Situ Remediation, DOE-HQ; Program documents for Integrated Demonstration for VOCs in an Arid Site, DOE-HQ; Energy Systems Environmental Restoration Division.

Other: Instructor, graduate-level course at The University of Tennessee, 1993.

SIGAL, L L $\mathbf{L}$

Participant: Current and Future Priorities for Environmental Management, sponsored by NAEP 18th Annual Conference, Raleigh, North Carolina, May 1993; NEPA Compliance Officer's Meeting, sponsored by DOE, Washington, D.C., August 1993; Development and the Environment, sponsored by 13th Annual Meeting of the International Association for Impact Assessment, Shanghai, China, June 1993; Preparing for the Reality of Biomass Energy Commercialization, sponsored by DOE BFDP, Auburn, Alabama, September 1993.

Ad Hoc Reviewer: The Bryologist;

Cryptogamic Botany.

SIGMON, C. F.

Chair: WATTec '93, sponsored by Association for Women in Science, Knoxville, Tennessee, February 1993.

SMITH, E. D. Participant: Ninth Annual Oak Ridge Model Conference, sponsored by DOE, Oak Ridge, Tennessee, August 1993. Ad Hoc Reviewer: Modeling of Geo-

Biosphere Processes. Other: Member and Vice-Chairperson, Environmental Quality Advisory Board, Oak Ridge, Tennessee. 
SMTTH, I. M.

Member: ASCE, October 1993; AWRA-Tennessee Section, October 1992.

Participant: Fifth Tennessee Water Resources Symposium, sponsored by FERC, Nashville, Tennessee, October 1992; ASCE Annual Water Resources Planning and Management Division Conference, sponsored by FERC, Seattle, April-May 1993; Waterpower ' 93 Conference, sponsored by FERC, Nashville, Tennessee, August 1993.

SOUTHWORTH, G. R.

Advisor: Sharon Kindon, M.S. candidate, The University of Tennessee. Ad Hoc Reviewer: Environmental Science and Technology; Water, Air, and Soil Pollution.

STOSS, F. W. Chair: Session Planner for Information Program on the Great Lakes, Special Libraries Association Annual Meeting and Exhibition, sponsored by Environment and Resource Management Division, Cincinnati, June 1993; Special Libraries Association/Science and Technology Division, Networking Committee, June 1993-94; Steering Committee for the National Library for the Environment, National Institute or the Environment; Information Servic es, Center for Environmental Information, Technical Advisory Board, 1990-.

Member: President-elect, Special Libraries Association/Southern Appalachian Chapter, June 1993-94; Steering Committee for the National Library for the Environment, 1992; Interagency Working Group on Data Management for Global Change, Library/Information Subgroup, August 1991; Environment Abstracts, Technical Advisory Board, 1989; Green Library Journal, Editorial Board, 1991.
Participant: Global Energy Strategies: Living with Restricted Greenhouse Gas Emissions, sponsored by Center for Environmental Information, Washington, D.C., December 1992; Special Interest Group-Wide Area Network Servers Meeting, sponsored by U.S. Geological Survey, Reston, Virginia, March 1993; Annual Meeting and Exhibition, Special Libraries Association, Cincinnati, June 1993; INFOTech, DOE Technical Information Meeting, sponsored by DOE Office of Scientific and Technical Information, Oak Ridge, Tennessee, October 1992.

Editor: Reviewer, Green Library Journal, Environmental Education, 1991. Ad Hoc Reviewer: E.R.M.D. Newsletter, Review Column Editor (Special Libraries Association); Green Library Journal, Environmental Education Reviews Column Editor.

Other: Southern Appalachian Science fair judge, Knoxville Region.

\section{STOW, S. H.}

Chair: Symposium on Hydrology and Contaminant Transport, sponsored by American Geophysical Union, San Francisco, December 1992; Geoconfines International Conference, sponsored by the French Committee for Engineering Geology, the Department of Environment, Montpellier, France, May 1993; Commission on the Hydrogeology of Hazardous Waste (International Association of Hydrogeologists), Krakow, Poland, September 1993.

Member: Secretary/Treasurer, Geoscience Education Division, GSA, 1992-94; American Geological Institute, Executive Committee, 1992-94; GSA, Committee on Registration of Geologists, 1993-95; Auburn University Dean's Advisory Committee, 1984-. 
Participant: Annual Meeting of Geological Society of Amcrica, Cincinnati, October 1992; AAAS, Boston, February 1993; Southeastern Section, GSA, Tallahassee, Florida, March 1993; Geoconfines, Montpellier, France, May 1993; American Association of Petroleum Geologists, New Orleans, April 1993; OREIS Review Panel for ER/WM grants, Washington, D.C., April 1993; American Geological Institute Meeting, Alexandria, Virginia, February 1993; AGU Meeting, San Francisco, December 1992; Tennessee Water Resources Conference, Nashville, Tennessee, October 1992.

Faculty: Adjunct Professor, Geological Sciences, The University of Tennessee. Editor: Editorial Board, Environmental Geology and Water Sciences.

SUTER, G. W., II Cochair and coorganizer: Session on Ecosystem Valuation: Assigning Economic Values to Ecosystem Damage, sponsored by AAAS, Boston, February 1993. Member: Publications Committee, Society for Environmental Toxicology and Chemistry, November 1992-95; EPA, Aquatic Life Criteria Committee, November 1992-.

Participant: Sustainability-Based Environmental Management, sponsored by SETAC/ESA, Pellston, Michigan, August 1993; Workshop on Methods for Aquatic Ecological Risk Assessment, sponsorcd by Water Environment Federation, Ft. Mitchell, Kentucky, November 1992; Review of the EPA Alternative Fuels Research Strategy, sponsored by EPA, Science Advisory Board, Clean Air Scientific Advisory Committee, Research Triangle Park, North Carolina, June-July 1993. Advisor: Elizabeth M. Will, postdoctorate, ORISE; Christopher C.
Evans, B.S. candidate, The University of Tennessee, Chattanooga. Ad Hoc Reviewer: Alternative Fuels Research Strategy, EPA; Ecological Risk Assessment of Dioxins EPA; Environmental Toxicology and Chemistry; Environmental Management, Ecotoxicology; Environment International; Journal of Crustacean Biology; Pisk Analysis; European Workshop on Freshwater Field Tests; and SETA Special Publications.

\section{THOMPSON, B. $\mathrm{K}$.}

Participant: Customizing ARC/INFO with AML, sponsored by Environmental Systems Research Institute, Redlands, California, September 1993;

Computer-Based Solutions in

Environmental Investigation, sponsored by Dynamic Graphics, Inc., Oak Ridge, Tennessee, August 1993; Probability, Statistics, and Geostatistics for Environmental Professionals, sponsored by National Groundwater Association, Clearwater Beach, Florida, January 1993; 3D Modeling and Analysis, sponsored by Dynamic Graphics, Inc., Alameda, California, May 1993.

Ad Hoc Reviewer: OREIS User Interface Manual for Systems and Maintenance Users, Version 1.0; OREIS User Interface Manual for General Users, Version 1.0.

\section{TIMPSON, M. E.}

Member: ASA/Tennessee State Membership Committee, Government Representative, January 1993.

Participant: Soil Decon '93, sponsored by ORNL and FERMCO, Gatlinburg, Tennessee, June 1993; Annual Meeting, CMS, San Diego, September 1993; Computer Applications to $\mathrm{X}$-ray Powder Diffraction Analysis of Clay Minerals Workshop, sponsored by CMS, San Diego, September 1993. 


\section{TOLBERT, V. R.}

Chair: Association of Southeastern

Biologists, Audit Committee, 1991-94.

Member: Treasurer, North American

Benthological Society, 1988-reelected

1993; Association for Women in

Science, Awards Committee, 1990-94.

Participant: Annual Meeting,

sponsored by North American

Benthological Society, Calgary, Alberta,

Canada, May 1993.

TORAN, L E

Participant: Fourth Technology

Information Exchange, Knoxville, Tennessee, May 1993; Program Review of the Center for Computational Science, sponsored by DOE Office of Scientific Computing, Oak: Ridge, Tennessee, April 1993.

Faculty: Adjunct Professor, The University of Tennessee.

Advisor: Jin Ping Gwo, Ph.D. candidate, Pennsylvania State University; Sarah Wignall, B.A. candidate, University of North Carolina.

Ad Hoc Reviewer: Water Resources Research; NSF.

TRABALKA, J. R.

Member: Scientific Committee 64-9 on Effects of Radiation on Aquatic Organisms, National Council on Radiation Protection and Mersurements, January 1987-.

Participant: Scientific Integrity in the Public Policy Process, sponsored by International Institute of George Mason University and the Science and Environmental Policy Project, Washington, D.C., May 1993.

Ad Hoc Reviewer: American Nuclear Society; Health Physics; Journal of Environmental Radioactivity.
TRETTIN, C. C.

Chair: SAMAB Wetland Conference on Wetland Ecology, Management, and Conservation, sponsored by ORNL/ESD, Knoxville, Tennessee, September 1993. Faculty: Adjunct Assistant Professor, School of Forestry, Michigan Technological University. Advisor: Mark Eisenbies and Marjorie Palmer, M.S. candidates, The University of Tennessee. Ad Hoc Reviewer: Journal of Environmental Quality: Wetlands; Proceedings of the Eighth North American Forest Soils Conference; Soil Science Society of America Journal.

\section{TSCHAPLINSKI, T. J.}

Participant: International Energy Agency: Task VIII Growth Processes Activity Workshop, sponsored by International Energy Agency, Burlington, Vermont, September 1993; BFDP Subcontractor's Meeting, sponsored by DOE, Auburn, Alabama, September 1993; Annual Meeting, American Society of Plant Physiologists, Minneapolis, August, 1993; Fourth Annual Walker Branch Watershed Research Symposium, sponsored by DOE, Oak Ridge, Tennessee, March 1993.

Ad Hoc Reviewer: Ecotoxicology; Tree Physiology; Physiology Plantarum; USDA Competitive Grants proposals; Ecological Monitoring and Assessment Program proposal; BFDP proposal.

\section{TURNER, M. G.}

Chair: Eighth Annual U.S. Landscape Ecology Symposium, sponsored by ORNL and US-IALE, Oak Ridge, Tennessee, March 1993.

Member: Committee on Federal Acquisition of Lands for Conservation, National Academy of Sciences, 1990-92; 
Ecosystem Management Committee, 1992-93, and Future Meetings Committee, ESA, 1989-92.

Participant: Workshop for the National Center for Ecological Synthesis and Analysis, Albuquerque, New Mexico, October 1992; Workshop on the Application of Spatially Explicit Models to Conservation and Management of Animal Populations, sponsored by University of Georgia, Athens, Georgia, November 1992; International Workshop on Biodiversity Survey, Inventory and Data Management, sponsored by Smithsonian Institution, Washington, D.C., January 1993; Terrestrial Ecology Technical Panel, sponsored by NASA, Washington, D.C., March 1993; Eighth Annual Landscape Ecology Symposium, sponsored by ORNL and US-IALE, Oak Ridge, Tennessee, March 1993; Fifth Cary Conference, sponsored by Institute of Ecosystem Studies, Millbrook, New York, May 1993.

Faculty: Faculty Associate, Graduate Program in Ecology, The University of Tennessee, 1990-.

Advisor: Yiannis Matsinos, Ph.D. candidate, The University of Tennessee; Nathan Schumaker, Ph.D. candidate, University of Washington; Jane Comiskey, M.S. candidate, The University of Tennessee.

Editor: Editorial Board, Climate Research, 1989-; Editorial Board, Ecological Applications, 1992-95; Editorial Board, Landscape Ecology, 1992-. Ad Hoc Reviewer: Ecological Applications; Ecology; Landscape Ecology; Climate Research; Wetlands; Conversation Biology; Theory and Application in Fish Feeding Ecology; Photogrammetric Engineering and Remote Sensing; Ecological Economics; Geographical Analysis; Remote Sensing and Image Interpretations; Environmental
Taxicology and Chemistry; Oikos; propos :!c, for NSF, DOE, USFS, and NASA.

\section{TURNER, R. R.}

Faculty: Research Assistant

Professor, College of Liberal Arts-Cen wer of Excellence-Biology Consortium, The

University of Tennessee. Advisor: Mark Barnett, Ph.D. candidate, University of North Carolina at Chapel Hill; William Hamilton and Sharon Kindon, M.S. candidates, The University of Tennessee. Ad Hoc Reviewer: Environment International; Environmental Toxicology and Chemistry; EPA proposals under EPSCOR-SEERS; Gas Research Institu:. document; Michigan Great Lakes Protection Fund proposal.

TURNER, R. S.

Member: Freshwater Imperative Coordinating Council, NSF/Interagency, 1991-.

Participant: Global Change Assessment for Forestry, Agriculture, and Water Resources, sponsored by Pennsylvania State University, University Park, Pennsylvania, October 1992; 28th Annual Conference on Managing Water Resources During Global Change, sponsored by AWRA, Reno, Nevada, November 1992; 10th Anniversary Symposium, sponsored by NRC Water Science and Technology Board, Washington, D.C., November $10 \%$. Planning Workshop, sponsored by NAP $P$, Washington, D.C., November 1992; National Water Quality Assessment Information Meeting, sponsored by USGS and TVA, Chattanooga, Tennessis. November 1992; BOREAS Investigators Planning Workshop, sponsored by NASA, Greenbelt, Maryland, December 1992; Freshwater Imperative Coordinating Council Planning Meetings, sponsored by NSF, Washington, D.C., December 1992, May 1992; Adirondack Effects 
Assessment Workshop, sponsored by Rensselaer Polytechnic Institute and EPA, Troy, New York, January 1993; DAAC Workshops and Planning Meetings, sponsored by NASA, Greenbelt, Maryland, January-April 1993; EOSDIS Quarterly Review, sponsored by NASA, Greenbelt, Maryland, February 1993; Pilot Land Data System Transition Team Meeting, sponsored by NASA, St. Louis, March 1993; Walker Branch Symposium, sponsored by DOE, Oak Ridge, Tennessee, March 1993; BOREAS Project Planning Workshop, sponsored by NASA, Winnipeg, Manitoba, Canada, May 1993; User Working Group Meeting, sponsored by Langley DAAC and NASA, Hampton, Virginia, July 1993; Summer SciencesSession: The Early Detection of Global Change, sponsored by Aspen Global Change Institute, Aspen, Colorado, August 1993; EOSDIS Science Operations Focus Team Meetings, sponsored by NASA, Greenbelt, Maryland, August-September 1993; EOSDIS Core System Requirements Review, sponsored by NASA, Greenbelt, Maryland, September 1993.

Advisor: Brenda Rashleigh, Ph.D. candidate, Indiana University. Ad Hoc Reviewer: Soil Science Society of America Journal; DOE; EPSCOR Review, Global Change Fellowships, NASA; The Nature Conservancy.

TUSKAN, G. A. Member: USDA Competitive Grants, Plant Response to the Environment, March-May 1993; Midwest Plant Biotechnical Consortium, Proposal Review Committee, March-June 1993.

Participant: North Central Poplar Research, sponsored by BFDP, St. Paul, January 1993; University of Washington Poplar Improvement Meeting, sponsored by University of Washington, Puyallup, February 1993; U.S. Poplar Council
Meeting, Minneapolis, July 1993;

BFDP Review, sponsored by BFDP, Oak Ridge, Tennessee, July 1993.

Faculty: Adjunct Professor, Horticulture and Forestry, North Dakota State University.

Advisor: Kirk Francis, B.S. candidate, Iowa State University; Karen Segert, B.S. candidate, Western Illinois University.

VAN WINKLE, W.

Chair: Workshop on the CompMech Smallmouth Bass Project, sponsored by EPRI, Richmond, Virginia, November 1992; Workshop on the CompMech Striped Bass Project, sponsored by EPRI, Newburgh, New York, June 1993.

Member: Technical Advisory Committee for the South Atlantic Bight Recruitment Experiment, National Marine Fisheries Service, 1990-; Scientific Advisory Committee for the Coastal Ocean Program/Coastal Fisheries Ecosystems, NOAA, 1990-; Advisory Committee on Modeling for Chesapeake Bay Research and Monitoring Division, Maryland Department of Natural Resources, 1990-93; Sigma Si, Oak Ridge Chapter, Treasurer, 1989-93.

Participant: CompMech Coordinators Workshop, sponsored by EPRI, Dauphin Island, Alabama, December 1992; MidYear Technical Session, sponsored by AFS, Southern Division, Chattanooga, Tennessee, February 1993; Trinity River Technical Workshop, sponsored by USFWS, Weaverville, California, March 1993; Larval Fish Conference, sponsored by AFS, Austin, Texas, June 1993; Meeting on Trout Populations, sponsored by USFWS and EPRI, Fort Collins, Colorado, June 1993; Workshop on Navigation Impacts on Fish Populations in the Upper Mississippi River, sponsored by U.S. Army Corps of Engineers, St. Louis, September 1993; Annual Meeting, 
Western Division, sponsored by AFS, Sacramento, California, July 1993.

Faculty: Adjunct Faculty, Graduate Program in Ecology, The University of Tennessee.

Ad Hoc Reviewer: Manuscript for Transactions of the American Fisheries Society; Rivers; proposals tor the California Interagency Ecological Studies Program; North Carolina Sea Grant Program.

VOORHEES, L $\mathbf{D}$.

Participant: EM Strategic Task Force Meeting, sponsored by DOE, Gaithersburg, Maryland, October 1992; GIS Information Exchange Meeting, sponsored by DOE, Gatlinburg, Tennessee, November 1992; EOSDIS Quarterly Review, sponsored by NASA, Greenbelt, Maryland, February 1993; DAAC Workshop and Planning Meeting, sponsored by NASA, Greenbelt, Maryland, March 1993; EOSDIS User Services Working Group Meeting, sponsored by NASA, Boulder, Colorado, May 1993;

BOREAS Workshop, sponsored by NASA, Winnipeg, Manitoba, Canada, May 1993; DAAC Managers Meetings, sponsored by NASA, Greenbelt, Maryland, August-September 1993; EOSDIS Science Operations Focus team meetings, sponsored by NASA, Greenbelt, Maryland, AugustSeptember 1993; EOSDIS Core System Requirements Review, sponsored by NASA, Greenbelt, Maryland, September 1993.

WATKINS, D. R.

Participant: Fourth National Technology Information Exchange Workshop, sponsored by DOE/ER, Knoxville, Tennessee, May 1993; Ninth Annual Oak Ridge Model Conference, sponsored by DOE, Oak Ridge, Tennessee, August 1993.
WATTS, J. A.

Chair: Technical Program, DOE Review of Laboratory Programs for Women, sponsored by DOE, Oak Ridge, Tennessee, May 1993; Minority Conference in Environmental Careers Conference, sponsored by OR NL and Environmental Careers Organization, Oak Ridge, Tennessee, August 1993.

Member: Association for Women in Science-East Tennessee Chapter, Education Committee, Awards Committee, June 1992-94; American Association of University Women-Knoxville Branch, Vice President for Membership, July 1993-June 1995; Board of Directors, Secretary of Board, and Science-In-Action Chairperson, WATTec, Inc., February 1993-96.

Participant: Review of Laboratory Programs for Women, sponsorer by DOE, Oak Ridge, Tennessee, May 1993; Women in Science Conference, sponsored by DOE/ORNL, ORISE, Knoxville, Tennessee, March 1993; North American Association for Environmental Education, Big Sky, Montana, September 1993, Water Resources Conference, sponsored by AWRA, Tennessee Technological University, Cookeville, Tennessee, April 1993; ORNL Representative Member, SAMAB and SAMAB Education Committee, sponsored by SAMAB Consortium, Asheville, North Carolina, April 1993.

Other: SHADES Conferences, Oak Ridge, Knoxville, and surrounding counties; Volunteer, Knoxville Zoological Gardens, Knoxville; Restoring Our Waters Institute, National Teacher Education Program, ORNL.

WEST, O. F. Member: Sigma Xi, The Scientific Research Society; American Institute for Chemical Engineers. 
Participant: Seminar on Characterizing and Remediating Dense Nonaqueous Phase Liquids, sponsored by EPA, Atlanta, July 1993.

Ad Hoc Reviewer: Item for Separation Science and Technology Journal.

WEST, O. R.

Member: ASCE; National Groundwater Association.

Participant: Safety and Environmental Issues in Rock Engineering, sponsored by International Society for Rock Mechanics, Lisbon, June 1993; Joint CSCE-ASCE Conference on Environmental Engineering, sponsored by ASCE, Montreal, July 1993; Fourth National Technology Information Exchange Workshop, sponsored by DOE, Knoxville, Tennessee, May 1993; 34th ORNL/DOE Analytical Chemistry in Energy Technology, sponsored by ORNL, DOE, Gatlinburg, Tennessee, October 1993; Partnership in Computational Science Workshop, sponsored by DOE, Columbia, South Carolina, February 1993.

Advisor: Michael Carpenter and Stephen W. Schmunk, M.S. candidates, Michigan Technological University; Mariel Colon-Eliza, High School (Project Seed participant), Yabucoa, Puerto Rico.

Ad Hoc Reviewer: Separation Science and Technology; Applied Biochemistry and Biotechnology.

Other: Minority Environmental Career Conference.

WHITE, D. C.

Chair: Scientific Advisory Review Committee, NSF Center for Biofilm Engineering, Montana State University, 1991-; Procter and Gamble Award in Experimental \& Applied Microbiology, American Academy of Microbiology, 1993-95.

Member: Center for 'Theological Inquiry, Princeton University, Princeton
Theological Seminary, 1984-93; Michigan

State University, NSF Center for

Microbial Ecology, Scientific Advisory

Committee, 1990-.

Participant: Quantifying Sedimentary

Geochemical Process, Royal Society, London, January 1993; Meeting, National Association of Corrosion Engineers, New Orleans, March 1993; Molecular Interaction at Marine Interfaces, Office of Naval Research Workshop, Chapel Hill, North Carolina, April 1993; Southeast Regional Center National Institute for Global Environmental Change, DOE, Tuscal ısa, Alabama, April, 1993; American Society of Microbiology, Atlanta, May 1993.

Faculty: Distinguished Scientist, Oak Ridge National Laboratory, The University of Tennessee; Professor, Division of Biological Sciences, The University of Tennessee, Executive Director, Center for Environmental Biotechnology, The University of Tennessee. Advisor: Chiung-Tai Debra Kuo and Holly Pinkart, Ph.D. candidates, The University of Tennessee; Lisa Kohring, M.S. candidate, The University of Tennessee.

Editor: Founder, Editor-in-Chief, Journal of Microbiological Methods. Ad Hoc Reviewer: Proposals for NSF, EPA, DOE; Applied Experimental Microbiology; Canadian Journal of Microbiology; Microbial Ecology; American Water Works Association research grants. Other: Ossoli Circle, Knoxville Women's Club, Knoxville.

WHITE, T. W. Participant: Annual ESRI

User Conference, sponsored by Environmental Systems Research Institute, Palm Springs California; Meeting, American Association of Geographers, Atlanta, 1993. 
Other: Occasional referee, Environmental Management.

WOOD, M. A.

Participant: Women in Science

Conference, sponsored by ORNL and

ORISE for DOE, Knoxville, Tennessee, March 1993; Annual Conference, sponsored by Environmental Systems Research Institute, Palm Springs, California, June 1993.

WRIGHT, L L.

Chair: Session on Information Resources for Renewable Energy Technologies, ACS, Denver, March-April 1993.

Member: Secretary, Oak Ridge

Chapter of Sigma Xi, 1993-95.

Participant: Review of TVA

Greenhouse Gas Reduction Study, sponsored by TVA, Washington, D.C., October 1992; Workshop on Economics of Biofuels, sponsored by EPRI, Nashville, Tennessee, October 1992; New Cultural Treatments Activity, sponsored by International Energy Agency, Toronto, October 1992; BFDP Workshop, sponsored by ORNL/Michigan State University, Lansing, November 1992; DOE Automotive Technology Development Annual Meeting, sponsored by DOE, Dearborn, Michigan, November 1992; Review of TVA Greenhouse Gas Reduction Study, sponsored by TVA, Washington, D.C., November 1992; Alternative Feedstocks Pr gram, Review Workshop, sponsored by JOE, Chicago, December 1992; BFDP Review by DOEHQ, sponsored by DOE, Washington, D.C., January 1993; Review of TVA Greenhouse Gas Reduction Study, sponsored by TVA, Chattanooga, Tennessee, February 1993; International Workshop on Sinks and Sources of $\mathrm{CO}_{2}$, sponsored by EPA, German EPA equivalent, Bad Harzburg, Germany,
February-March 1993; Review of TVA Greenhouse Gas Reduction Study, sponsored by TVA, Washington, D.C., March 1993; 205th National Meeting, sponsored by ACS, Denver, March-April 1993; SOLTECH, Washington, D.C., April 1993; BFDP Review by DOE-HQ, sponsored by DOE, Washington, D.C., July 1993; BFDP Review by External Reviewers, sponsored by ORNL, Uak Ridge, Tennessee, July 1993; First Biomass Conference of the Americas, sponsored by DOE, USDA, Burlington, Vermont, August-September 1993; BFDP, sponsored by ORNL/BFDP, Auburn, Alabama, September 1993.

Ad Hoc Reviewer: Biomass and Bioenergy; Climate Research.

WULLSCHLEGER, S. D.

Chair: Modeling session, Belowground Responses to Rising Atmospheric $\mathrm{CO}_{2}$, University of Michigan, ORNL, May-June 1993.

Participant: Biotic Feedbacks in the Global Climatic System-An IPCC Review, sponsored by Woods Hole Research Center, Woods Hole, Massachusetts, October 1992; Regional and National Models for Global Change, sponsored by USFS, Delaware, Ohio, November 1992; Regional Ozone Vegetation Effects Workshop, sponsored by TVA and EPRI, Knoxville, Tennessee, March 1993; AMTEX/DOE Exploratory Meeting on Biotechnology, sponsored by Cotton Inc., Memphis, May 1993; Belowground Responses to Rising Atmospheric $\mathrm{CO}_{2}$, sponsored by University of Michigan and ORNL, Pellston, Michigan, June 1993.

Editor: Editorial Review Board, Tree Physiology, 1993-95.

Ad Hoc Reviewer: Crop Science;

Tree Physiology; Journal of Experimental Botany; Canadian Journal of Botany; Physiologia Plantarum. 


\section{Organization Chart 5}




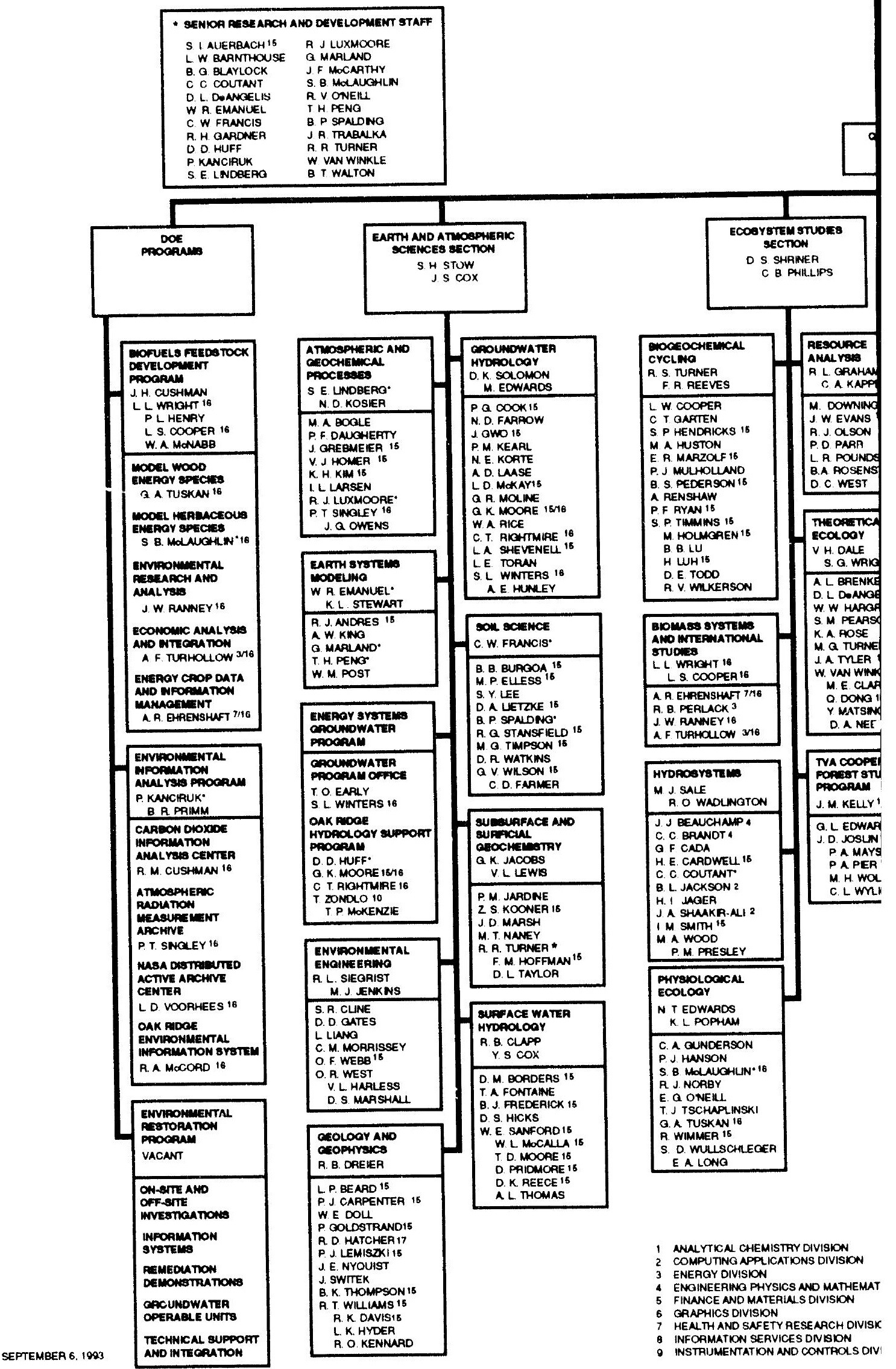




\section{ONMENTAL SCIENCES DIVISION}

SEPTEMBER 1993

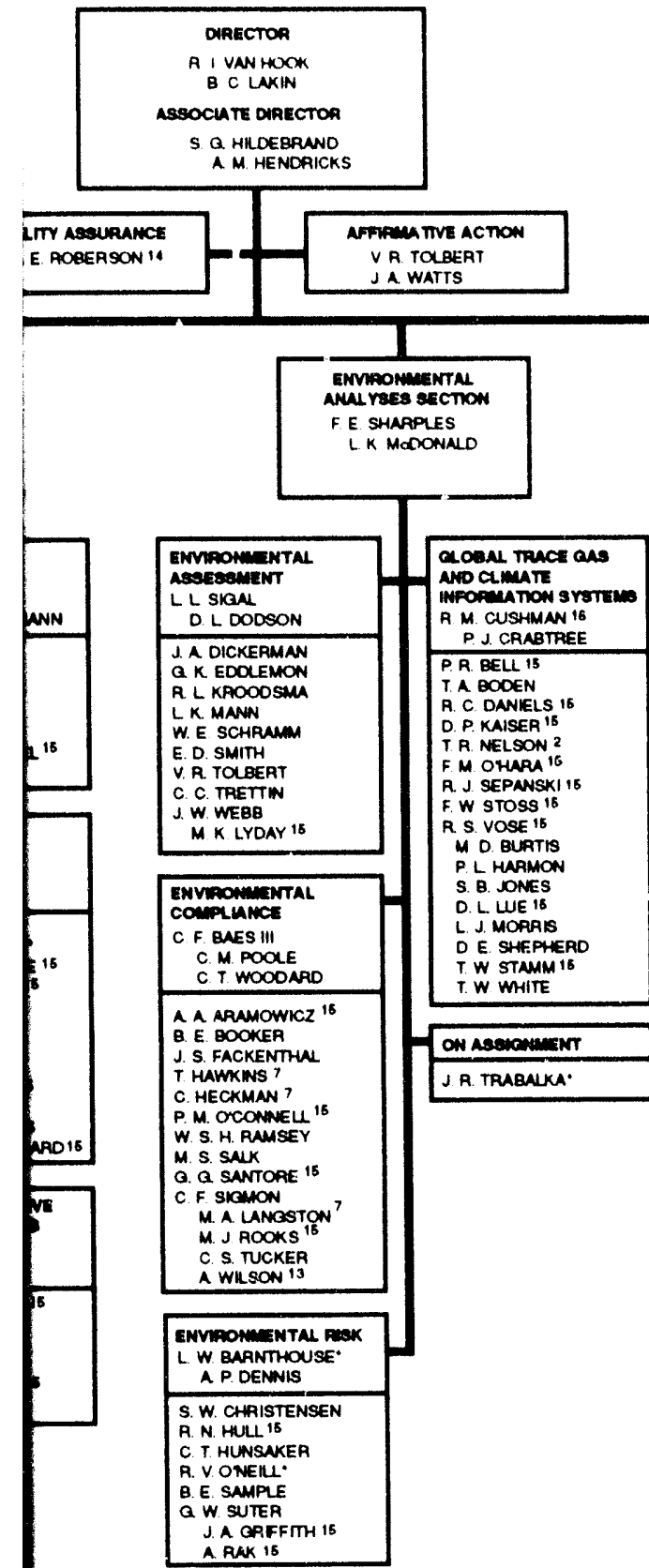

10 OFFICE OF ENV'RONMENTA COMPIIANCE NDD DOC UMENTATDN

ATION PAOTECTION

12 PLANT AND EOUIPMENT ON

13 PUBLICATIONS DIVISION

is VISTING NVESTIOATORS MND OTHER QUESTS

If VISITING NVESTIOA

17 UTHORN OISTINGUISHED SCIENTIST

18 OFFICE OF SAFETY S HENLTH PAOTECTION

\begin{tabular}{|c|c|}
\hline & $\begin{array}{l}\text { ENVIAOML"GNTAL } \\
\text { GOTECHWOLOOY BECTON } \\
\text { C W GEHRS } \\
\text { C H FAPFAX }\end{array}$ \\
\hline $\begin{array}{l}\text { WOLOCICAL } \\
\text { MARKLFA } \\
\text { L A SHUQNAT } \\
\text { D. C ROCEAS }\end{array}$ & $\begin{array}{l}\text { CONTAMMMANT TRAMGPOAT } \\
\text { S. E HERBES } \\
\text { K. Y. HENLEY } \\
\end{array}$ \\
\hline 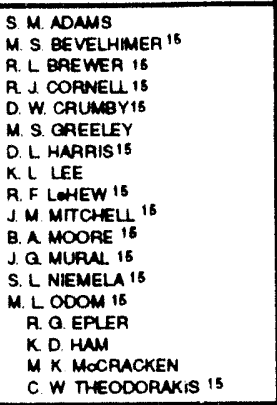 & 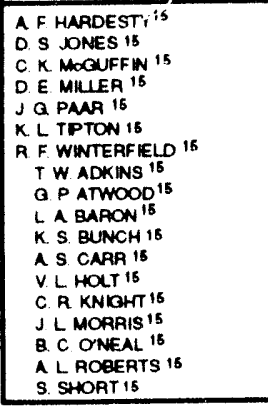 \\
\hline \multirow{2}{*}{ 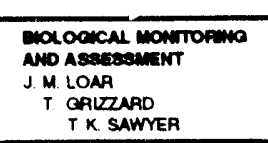 } & 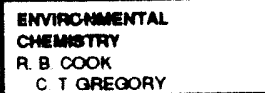 \\
\hline & $\begin{array}{l}\text { T. C. BENWETT IS } \\
\text { S. B. BENSON } 14\end{array}$ \\
\hline $\begin{array}{l}\text { Domontronewo } \\
\text { L. A KSZOS }\end{array}$ & \\
\hline 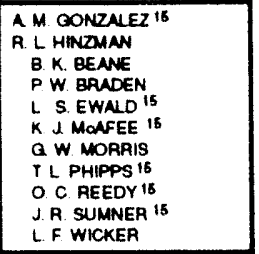 & 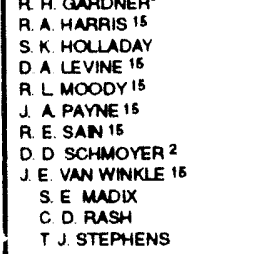 \\
\hline $\begin{array}{l}\text { ECOTOXICOLOOY } \\
\text { A J. STEWART } \\
\text { J. BENKINS }\end{array}$ & MCROELAL NTERACTONS \\
\hline \multirow{2}{*}{$\begin{array}{l}\text { W R. HIL } \\
\text { O E NAPOLITANO } 15 \\
\text { C A BRANSON } 15 \\
\text { S. R JARDNE } \\
\text { J. E. RICHMOND }\end{array}$} & $\begin{array}{l}\text { A V. PNLUMBO } \\
\text { c S PAANS }\end{array}$ \\
\hline & $\begin{array}{l}\text { A S. BURLACE } \\
\text { S.M PFIFFNER } 16 \\
\text { T. J PHELPS }\end{array}$ \\
\hline $\begin{array}{l}\text { ECOLOOCAL MONTKCAMTA } \\
\text { Q R SOUTHMOATH } \\
\text { L S HAFF. }\end{array}$ & $\begin{array}{l}\text { I M STROOKCOUNOERSON } 16 \\
\text { B T. WALTON: } \\
\text { D. C. WHTTE 17 }\end{array}$ \\
\hline \multirow{2}{*}{ 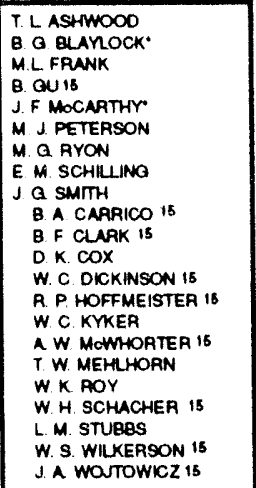 } & $\begin{array}{l}\text { S. M. HOVMAN IS } \\
\text { S. P. SCARECAOUCH } \\
\text { RESER NATION DATA } \\
\text { SYSTEMS } \\
\text { L. O VOOAHEES } 16 \\
\text { M A EVNNS }\end{array}$ \\
\hline & 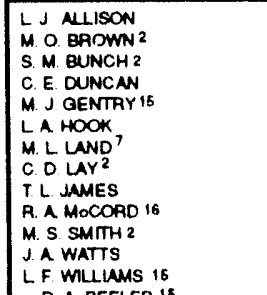 \\
\hline & N. A OAFFTTH \\
\hline
\end{tabular}

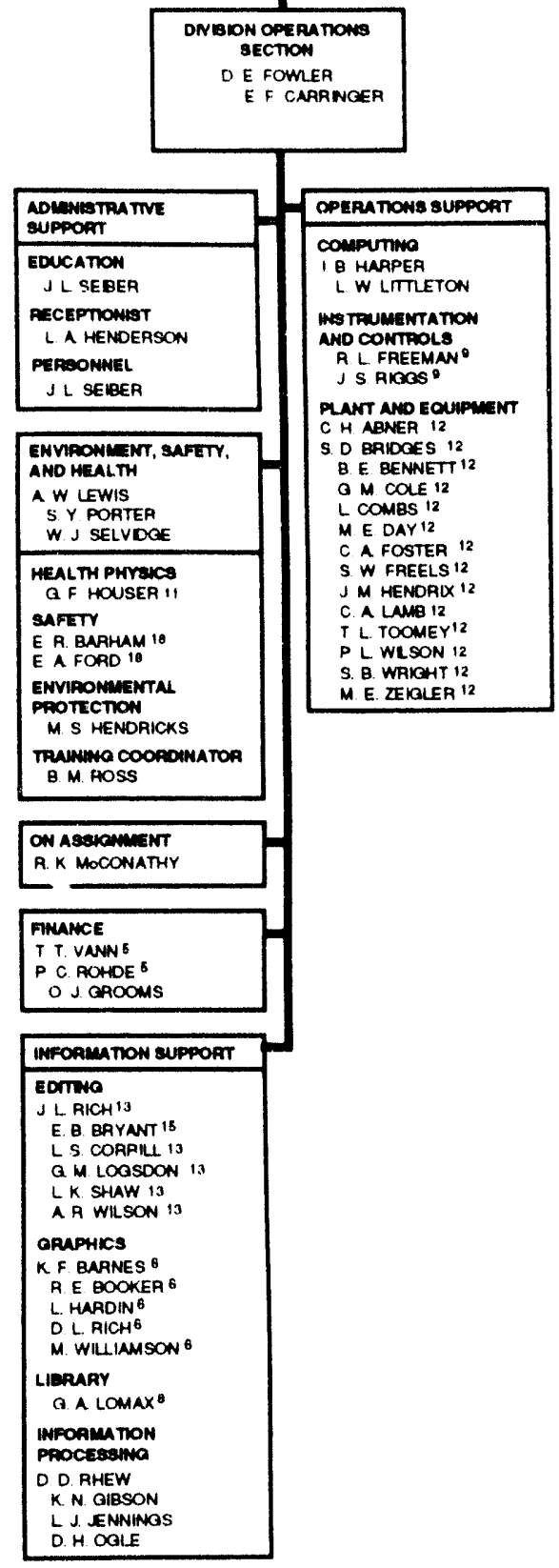




\section{Author Index}

The technical summaries are indexed here by author and number. The page number is given in parentheses.

Aaams, S. M., 102 (97), 103 (98)

Alexiades, V., 22 (24), 23 (25)

Allison, L. J., 105 (99)

Ammons, J. T., 38 (35)

Ashwood, T. L., 28 (29), 29 (29), $116(106)$

Barnett, M. O., 109 (101)

Barnthouse, L. W., 92 (84)

Beauchamp, J. J., 111 (103)

Bevelhimer, M. S., 59 (57), 108 (101)

Bogle, M. A., 47 (42), 123 (112)

Booker, B. E., 85 (80)

Boston, H. L., 46 (41)

Brandt, C. C., 107 (100), 108 (101)

Branson, J. L., 38 (35)

Brenkert, A. L., 107 (100), 115 (105)

Burgoa, B. B., 38 (35), 39 (36)

Burlage, R. S., 99 (95)

Burtis, M. D., 131 (134)

Byrd, J. T., 109 (101)

Cada, G. F., 58 (57), 80 (77)

Cardwell, H. E., 2 (10), 57 (56)

Carrico, B. A., 113 (104)

Christensen, S. W., 73 (66)

Clapp, R. B., 13 (18)

Cook, R. B., 107 (100), 108 (101)

Cooper, L. W., 15 (19), 60 (58), 61 (58)

Coutant, C. C., 56 (55), 59 (57)

Crumby, W. D., 103 (98), 108 (101), 114 (105)

Cushman, R. M., 131 (134)

D'Surney, S. J., 104 (98)

Dale, V. H., 70 (64)

Daniels, R. C., 93 (84), 94 (85)

Davenport, D. T., 33 (32)

Davis, R. K., 8 (15)

DeAngelis, D. L., 59 (57), 64 (60), 71 (64), 73 (66)

Dickerman, J. A., 81 (77)

Dickerson, K. S., 20 (23)

Doll, W. E., 8 (15)

Douthitt, J. W., 2 (10), 57 (56)
Downing, M. E., 67 (62), 127 (126)

Dreier, R. B., 4 (11), 6 (13), 7 (14)

Dunbar, N. W., 22 (24), 23 (25), 24 (26)

Early, T. O., 1 (10)

Edwards, G. S., 74 (67)

Edwards, N. T., 54 (54), 97 (93)

Emanuel, W. R., 41 (37), 43 (39)

Etnier, D., 75 (74)

Evans, J. W., 69 (6.3)

Farmer, C. D., 40 (37)

Fontaine, T. A., 12 (17), 62 (59)

Ford, C. J., 107 (100), 108 (101), 109 (101), $110(102)$

Francis, C. W., 40 (37)

Frank, M. L., 115 (105)

Gardner, R. H., 72 (66)

Gates, D. D., 33 (32), 35 (33)

Gentry, M. J., 108 (101)

Ghiorso, M. S., 24 (26)

Gibbs, M. H., 119 (109)

Goddard, P. L., 38 (35)

Goff, F., 49 (43)

Goldstrand, P. M., 6 (13), 10 (16), $17(21), 48(42)$

Gonzalez, A. M., 121 (110)

Graham, R. L., 67 (62), 127 (126)

Gray, B. R., 117 (107)

Grebmeicr, J. M., 60 (58), 109 (101)

Greeley, M. S., Jr., 102 (97), 103 (98)

Grizzard, T., 118 (108)

Gu, B., 122 (111)

Gunderson, C. A., 50 (52), 52 (53), 118 (108)

Gwo, J. P., 26 (27)

Halbrook, R. S., 104 (98)

Hall, D. F., 34 (33)

Hamilton, W. P., 30 (30)

Hanson, P. J., 44 (40), 51 (52), 55 (55), 74 (67)

Harrington, B. K., 21 (24)

Harris, R. A., 109 (101)

Harvey, M., 75 (74) 
Hatcher, R. D., Jr., 5 (12), 9 (15)

Hatmaker, T. L., 38 (35)

Herbes, S. E., 98 (94)

Hicks, D. S., 11 (17), 28 (29)

Hill, W. R., 117 (107)

Hinzman, R. L., 111 (103), 112 (104), $113(104)$

Hoffman, W. A., 51 (52), 54 (54)

Holladay, S. K., 108 (101)

Hook, L. A., 38 (35), 106 (99), 108 (101)

Hopkins, R. A., 8 (15)

Hoylman, A. M., 97 (93)

Huff, D. D., 2 (10), 57 (56)

Hunsaker, C. T., 65 (61)

Huston, M. A., 62 (59), 65 (61)

Jackson, B. L., 38 (35)

Jacobs, G. K., 22 (24), 23 (25), 24 (26), 25 (26)

Jager, H. I., 59 (57)

Jardine, P. M., 25 (26), 26 (27), 27 (28)

Jenkins, R. A., 33 (32)

Kelly, J. M., 74 (67)

Kim, K.-H., 44 (40), 55 (55)

Kimbrough, C. W., 38 (35)

Kimmel, B. L., 107 (100), 110 (102)

King, A. W., 41 (37), 43 (39)

Kooner, Z. S., 27 (28)

Korte, N. E., 20 (23)

Kriger, A. A., 31 (31)

Kszos, L. A., 120 (110), 121 (110)

Landes, J. D., 9 (15)

Larsen, I. L., 18 (22), 46 (41), 60 (58), $107(100)$

Lee, K. L., 101 (96)

Lee, S. Y., 38 (.35)

Lemiszki, P. J., 4 (11), 5 (12), 9 (15), 10 (16)

Levine, D. A., 107 (100), 108 (101), $110(102)$

Liang, L., 122 (111)

Lietzke, D. A., 38 (35)

Lindberg, S. E., 44 (40), 45 (40), 55 (55)

Longman, R. C., 108 (101)

Luxmoore, R. J., 26 (27)
Madix, S. E., 108 (101), 109 (101), 110 (102)

Mann, L. K., 75 (74), 80 (77), 92 (84)

Marsh, J. D., Jr., 15 (19), 28 (29), 29 (29)

Martinez-Morales, R. E., 76 (74)

Marzolf, E. R., 63 (60), 64 (60)

Mas-Pla, J., 122 (111)

McCarthy, J. F., 19 (22), 29 (29), 96 (92), 122 (111)

McCord, R. A., 68 (63), 106 (99), 130 (133)

McGinn, C. W., 38 (35)

Meyers, T. P., 44 (40)

Miller, R. L., 80 (77)

Mitchell, T. J., 33 (32)

Mobley, M. H., 46 (41)

Moody, R. L., 108 (101)

Moore, R. C., 109 (101)

Morris, M. I., 33 (32)

Morrissey, C. M., 34 (33)

Mulholland, P. J., 63 (60), 64 (60)

Naney, M. T., 23 (25), 24 (26)

Neuhoff, P. S., 4 (11)

Norby, R. J., 50 (52), 52 (53), 61 (58)

Nourse, B. D., 38 (35)

O'Dell, J. D., 26 (27)

O'Neill, R. V., 72 (66)

Olsen, C. R., 107 (100)

Olson, R. J., 68 (63), 130 (133)

Otto, R. G., 73 (66)

Owens, J. G., 44 (40), 45 (40), 55 (55)

Palumbo, A. V., 64 (60), 96 (92), 98 (94), 124 (113)

Parr, P. D., 69 (63)

Pastor, J., 41 (37)

Peng, T.-H., 42 (38)

Peterson, M. J., 114 (105), 123 (112)

Pfiffner, S. M., 95 (92)

Phelps, T. J., 95 (92)

Phipps, T. L., 121 (110)

Pickering, D. A., 33 (32)

Plotnick, R. E., 72 (66)

Post, W. M., 41 (37), 43 (39)

Pounds, L. R., 75 (74)

Ranney, J. W., 128 (126) 
Rash, C. D., 108 (101), 109 (101)

Ravina, C. B., 131 (134)

Rose, K. A., 73 (66), 107 (100)

Roy, W. K., 113 (104)

Ryon, M. G., 112 (104), 113 (104)

Sale, M. J., 2 (10), 57 (56), 59 (57)

Salk, M. S., 81 (77)

Samuelson, L. J., 74 (67)

Sanford, W. E., 18 (22), 19 (22)

Schilling, E. M., 112 (104), 113 (104)

Schmoyer, R. L., 38 (35)

Schramm, W. E., 80 (77)

Shaw, R. A., 38 (35)

Shevenell, L. A., 6 (13), 15 (19), 16 (20), 17 (21), 49 (43)

Shriner, D. S., 66 (61)

Shugart, L. R., 100 (95), 101 (96), 104 (98)

Siegrist, R. L., 32 (31), 33 (32)

Sigal, L. L., 77 (75), 81 (77), 92 (84)

Sigmon, C. F., 86 (80), 87 (81)

Singley, P. T., 129 (133)

Smith, D. K., 75 (74)

Smith, E. D., 78 (75)

Smith, J. G., 76 (74), 111 (103)

Smith, M. E., 109 (101)

Solomon, D. K., 19 (22)

Southworth, G. R., 114 (105), 123 (112)

Spalding, B. P., 37 (35)

Stansfield, R. G., 40 (37)

Steinman, A. D., 64 (60)

Stephens, T. J., 110 (102)

Stetar, E. H., 46 (41)

Stewart, A. J., 101 (96), 118 (108), 119 (109)

Stinnette, S. E., 38 (35)

Stoddart, W. C., 12 (17)

Story, A. M., 69 (63)

Strong-Gunderson, J. M., 96 (92), 98 (94), 124 (113)
Sumner, J. R., 111 (103)

Suter, G. W., II, 90 (83), 91 (83)

Switek, J., 3 (11), 38 (35)

Timmins, S. P., 62 (59), 65 (61)

Tolbert, V. R., 76 (74), 82 (78)

Toran, L. E., 14 (19), 15 (19)

Trabalka, J. R., 88 (81), 89 (82)

Trettin, C. C., 79 (76), 82 (78)

Tschaplinski, T. J., 50 (52), 125 (124), 126 (124)

Turner, R. R., 30 (30), 31 (31), 47 (42), 123 (112)

Turner, R. S., 27 (28), 66 (61)

Tuskan, G. A., 125 (124), 126 (124)

Van Winkle, W., 73 (66)

Vogt, B. M., 80 (77)

Wagner, S. E., 20 (23)

Walton, B. T., 97 (93)

Watkins, D. R., 38 (35)

Watts, J. A., 13 (18)

Wauchope, R. D., 39 (36)

Webb, J. W., 83 (78), 84 (79)

Webb, O. F., 36 (34)

West, O. R., 14 (19), 33 (32)

White, D. C., 95 (92)

White, T. W., 93 (84), 94 (85)

Wicker, L. F., 119 (109)

Wilkerson, W. S., 111 (103)

Williams, L. F., 108 (101)

Williams, T. M., 122 (111)

Wilson, G. V., 26 (27)

Winemiller, K. O., 73 (66)

Winters, S. L., 1 (10)

Wright, J. C., 38 (35)

Wullschleger, S. D., 50 (52), 52 (53), 53 (53), 74 (67)

Yeh, C.-T. J., 122 (111)

Yeh, G. T., 26 (27), 27 (28) 


\section{Photo Index}

Below are listed the ORNL numbers assigned to the photographs in this report. The page numbers are given on the right.

ORNL-7833-92

ORNL-2904-88

ORNL-831-93

ORNL-9605-92

ORNL-11613-93

ORNL-960-93

ORNL-1561-93

ORNL-3213-92

ORNL-10974-93

ORNL-10648-93

ORNL-2001-92

ORNL-6128-89

ORNL-7283-90

ORNL-6787-90

ORNL-2766-93
Mac Post and Mark Wittenberger 11

Cloud cap in Great Smoky Mountains 14

Two undisturbed sediment cores from Toolik Lake, Alaska 20

Yellow-poplar saplings in an open-top chamber

Pat Mulholland conducting a tracer experiment

Throughfall displacement experiment

Drill rig for obtaining core samples 93

Janet Strong-Gunderson and a 96-well plate reader $\quad 96$

Sampling system for withdrawing groundwater 107

Greg Roberts with programmable thermal cycler 125

CDIAC information products $\quad 134$

Richard Norby (portrait) 143

Lauren Larsen $\quad 144$

Scott Gregory $\quad 145$

Marvel Burtis (portrait) 145

Photo credits: Curtis Boles (pp. 96 and 145, right column), Curtis Boles and Tom Cerniglio (p. 134), Tom Cerniglio (p. 56), Terry Marler (p. 144), and Bill Norris (pp. 62; 125; and 145, left column). 


\section{Internal Distribution}

\begin{tabular}{|c|c|c|c|}
\hline 1. & C. H. Abner & 42. & M. W. Bradley \\
\hline 2. & S. M. Adams & 43. & C. C. Brandt \\
\hline 3. & T. W. Adkins & 44. & C. A. Branson \\
\hline 4. & L. J. Allison & 45. & J. L. Branson \\
\hline 5. & J. T. Ammons & 46. & A. L. Brenkert \\
\hline 6. & R. J. Andres & 47. & M. A. Brewer \\
\hline 7. & A. A. Aramowicz & 48. & R. L. Brewer \\
\hline 8. & T. L. Ashwood & 49. & S. D. Bridges \\
\hline 9. & G. P. Atwood & 50. & M. D. Bryant \\
\hline 10. & S. I. Auerbach & 51. & W. Bryant \\
\hline 11. & C. F. Baes & 52. & J. K. Bryson \\
\hline 12. & J. B. Ball & 53. & D: A. Buehler \\
\hline 13. & T. Barkay & 54. & K. S. Bunch \\
\hline 14. & K. F. Barnes & 55. & D. L. Bunting \\
\hline 15. & J. C. Barnett & 56. & B. B. Burgoa \\
\hline 16. & M. O. Barnett & 57. & R. S. Burlage \\
\hline 17. & L. W. Barnthouse & 58. & M. Burtis \\
\hline 18. & L. A. Baron & 59. & A. R. Buttram \\
\hline 19. & F. P. Baxter & 60. & J. T. Byrd \\
\hline 20. & A. Baybayan & 61. & G. F. Cada \\
\hline 21. & B. K. Beane & 62. & R. S. Carlsmith \\
\hline 22. & L. P. Beard & 63. & K. R. Campbell \\
\hline 23. & J. L. Beauchamp & 64. & H. E. Cardwell \\
\hline 24. & D. A. Beeler & 65. & P. J. Carpenter \\
\hline 25. & J. D. Bell & 66. & A. S. Carr \\
\hline 26. & B. E. Bennett & 67. & B. A. Carrico \\
\hline 27. & T. C. Bennett & 68. & L. S. Chambers \\
\hline 28. & S. B. Benson & 69. & K. D. Chapatwala \\
\hline 29. & S. L. Bergman & 70. & J. W. Chason \\
\hline 30. & B. A. Berven & 71. & C. M. Chavannes \\
\hline 31. & M. S. Bevelhimer & 72. & E. A. Childs \\
\hline 32. & R. M. Bishop & 73. & S. W. Christensen \\
\hline 33. & A. A. Blake & 74. & R. B. Clapp \\
\hline 34. & B. G. Blaylock & 75. & B. Clark \\
\hline 35. & T. A. Boden & 76. & B. F. Clark \\
\hline 36. & M. A. Bogle & 77. & M. E. Clark \\
\hline 37. & L. R. Bond & 78. & S. R. Cline \\
\hline 38. & D. M. Borders & 79. & G. M. Cole \\
\hline 39. & C. N. Bowden & 80. & L. C. Combs \\
\hline 40. & J. P. Bowman & 81. & C. W. Comstock \\
\hline 41. & P. W. Braden & 82. & S. A. Conditt \\
\hline
\end{tabular}


83. P. G. Cook

84. R. B. Cook

85. L. S. Cooper

86. L. W. Cooper

87. C. Coppock

88. L. J. Cosko

89. C. C. Coutant

90. D. K. Cox

91. J. S. Cox

92. Y. S. Cox

93. P. J. Crabtree

94. D. F. Craig

95. M. W. Craig

96. S. C. Crooks

97. D. W. Crumby

98. J. H. Cushman

99. R. M. Cushman

100. V. H. Dale

101. R. C. Daniels

102. P. F. Daugherty

103. G. L. Davidson

104. R. K. Davis

105. S. L. Davis

106. D. H. Dawson

107. M. E. Day

108. D. L. DeAngelis

109. L. K. Demaree

110. A. P. Dennis

111. S. A. Deppen

112. C. E. Dews

113. J. A. Dickerman

114. W. C. Dickinson

115. M. A. Doan

116. D. L. Dodson

117. W. E. Doll

118. Q. Dong

119. M. E. Downing

120. R. B. Dreier

121. C. E. Duncan

122. L. B. Dunlap

123. J. T. Dunning

124. T. O. Early

125. G. K. Eddlemon

126. S. M. Edmonds

127. G. S. Edwards

128. L. B. Edwards

129. M. K. Edwards
130. N. T. Edwards

131. A. R. Ehrenshaft

132. M. H. Eisenbies

133. M. P. Elless

134. W. R. Emanuel

135. R. G. Epler

136. M. A. Evans

137. L. S. Ewald

138. J. S. Fackenthal

139. C. H. Fairfax

140. B. Faison

141. C. D. Farmer

142. M. P. Farrell

143. N. D. Farrow

144. Y. Feng

145. R. E. Ferstermaker

146. J. M. Field

147. T. A. Fontaine

148. C. J. Ford

149. E. A. Ford

150. J. E. Foss

151. D. E. Fowler

152. C. W. Francis

153. M. L. Frank

154. B. J. Frederick

155. S. W. Freels

156. R. L. Freeman

157. W. Fulkerson

158. C. A. Gabrielsen

159. R. H. Gardner

160. A. S. Garrett

161. C. T. Garten

162. D. D. Gates

163. C. W. Gehrs

164. M. J. Gentry

165. R. K. Genung

166. D. B. Gibbs

167. M. H. Gibbs

168. K. N. Gibson

169. M. A. Gillman

170. G. S. Goad

171. P. M. Goldstrand

172. J. D. Goodlaxson

173. R. L. Graham

174. J. M. Grebmeier

175. S. Greco

176. M. S. Greeley 
177. L. A. Greenman

178. C. T. Gregory

179. N. A. Griffith

180. T. Grizzard

181. O. J. Grooms

182. B. $\mathrm{Gu}$

183. C. A. Gunderson

184. J. P. Gwo

185. L. S. Haff

186. B. T. Hale

187. A. L. Halleran

188. M. C. Halley

189. K. D. Ham

190. W. P. Hamilton

191. J. S. Hammonds

192. J. L. Hammontree

193. P. S. Hampson

194. J. A. Hanson

195. P. J. Hanson

196. A. F. Hardesty

197. W. W. Hargrove

198. V. L. Harless

199. B. J. Harper

200. D. L. Harris

201. R. A. Harris

202. F. C. Hartman

203. R. D. Hatcher

204. C. J. Haugh

205. T. Hawkins

206. M. J. Hayes

207. G. J. Haynes

208. C. G. Heckman

209. L. A. Henderson

210. A. M. Hendricks

211. M. S. Hendricks

212. J. M. Hendrix

213. C. M. Henry

214. P. L. Henry

215. S. E. Herbes

216. C. L. Hewitt

217. A. C. Hickey

218. D. S. Hicks

219. S. G. Hildebrand

220. G. E. Hileman

221. W. R. Hill

222. R. L. Hinzman

223. S. F. Hixson
224. F. M. Hoffman

225. R. P. Hoffmeister

226. B. D. Holcomb

227. S. K. Holladay

228. E. F. Hollyday

229. M. Holmgren

230. V. L. Holt

231. F. J. Homan

232. V. J. Homer

233. R. B. Honea

234. L. A. Hook

235. G. F. Houser

236. A. M. Hoylman

237. C. A. Hubbs

238. D. D. Huff

239. A. E. Hunley

240. C. T. Hunsaker

241. M. A. Huston

242. L. K. Hyder

243. B. J. Jackson

244. G. K Jacobs

245. V. M. Jacomino

2.16. Y. I. Jager

247. P. M. Jardine

248. J. B. Jenkins

249. L. J. Jennings

250. E. A. Jerde

251. G. C. Johnson

252. S. E. Johnson

253. J. J. Johnston

254. D. S. Jones

255. J. E. Jones, Jr.

256. S. B. Jones

257. J. D. Joslin

258. H. E. Julian

259. D. P. Kaiser

260. P. Kanciruk

261. C. A. Kappelmann

262. P. M. Kearl

263. J. M. Kelly

264. R. O. Kennard

265. I. W. Khor

266. K.-H. Kim

267. A. W. King

268. K. L. Kliewer

269. J. M. Klopatek

270. C. R. Knight 


\begin{tabular}{|c|c|}
\hline \\
\hline \multicolumn{2}{|c|}{ 271. T. L. Knowles } \\
\hline \multicolumn{2}{|c|}{ 273. M. W. Kohring } \\
\hline \multicolumn{2}{|c|}{ 274. K. S. Kooner } \\
\hline \multicolumn{2}{|r|}{ F. C. Kornegay } \\
\hline \multicolumn{2}{|r|}{ N. E. Korte } \\
\hline & N. D. Kosier \\
\hline \multicolumn{2}{|r|}{ A. Kozyr } \\
\hline \multicolumn{2}{|r|}{ A. Kriger } \\
\hline \multicolumn{2}{|r|}{ R. L. Kroodsma } \\
\hline 281. & L. A. Kszos \\
\hline \multicolumn{2}{|r|}{ B. H. Kueper } \\
\hline \multicolumn{2}{|r|}{ C-T. D. Kuo } \\
\hline 284. & W. C. Kyker \\
\hline \multicolumn{2}{|r|}{ A. D. Laase } \\
\hline \multicolumn{2}{|r|}{ D. E. Ladd } \\
\hline \multicolumn{2}{|r|}{$\begin{array}{l}\text { C. Lafon } \\
\text { B. C. Lakin }\end{array}$} \\
\hline 288. & B. C. Lakin \\
\hline \multicolumn{2}{|l|}{289.} \\
\hline \\
\hline \multirow{2}{*}{\multicolumn{2}{|c|}{$\begin{array}{l}\text { M. A. Langston } \\
\text { I. L. Larsen }\end{array}$}} \\
\hline & I. L. Larsen \\
\hline \multicolumn{2}{|r|}{ K. Leach } \\
\hline 294. & H. L. Lee \\
\hline 295. & K. L. Lee \\
\hline 296. & S. Y. Lee \\
\hline 297. & R. F. LeHew \\
\hline 298. & P. J. Lemiszki \\
\hline 299. & D. A. Levine \\
\hline 300. & A. W. Lewis \\
\hline 301. & J. G. Lewis \\
\hline 302. & V. L. Lewis \\
\hline 303. & L. Liang \\
\hline 304. & D. A. Lietzke \\
\hline 305. & S. E. Lindberg \\
\hline 306. & J. A. Little \\
\hline 307. & L. W. Littleton \\
\hline 308. & J. M. Loar \\
\hline 309. & G. M. Logsdon \\
\hline 310. & G. A. Lomax \\
\hline 311. & J. W. Lotts \\
\hline 312. & B. Lu \\
\hline 313. & D. L. Lue \\
\hline 314. & H.-K. Luh \\
\hline 315. & R. J. Luxmoore \\
\hline 31 & M. K. Lyday \\
\hline O & D D \\
\hline
\end{tabular}

318. S. E. Madix

319. R. L. Madura

320. A. P. Malinauskes

321. L. K. Mann

322. G. Marland

323. H. K. Marotto, Jr.

324. J. D. Marsh

325. D. S. Marshall

326. E. R. Marzolf

327. Y. G. Matsinos

328. P. A. Mays

329. K. J. McAfee

330. W. L. McCalla

331. J. F. McCarthy

332. R. K. McConathy

333. R. A. McCord

334. M. K. McCracken

335. D. M. McDermot

336. J. A. McDonald

337. L. K. McDonald

338. C. K. McGuffin

339. L. D. McKay

340. S. B. McLaughlin

341. B. W. McMaster

342. W. A. McNabb

343. A. W. McWhorter

344. S. A. Meacham

345. T. W. Mehlhorn

346. L. S. Meneffee

347. R. D. Miller

348. V. E. Miller

349. U. Minocha

350. K. C. Misra

351. M. E. Mitch

352. J. M. Mitchell

353. M. W. Mittelman

354. G. R. Moline

355. R. L. Moody

356. B. A. Moore

357. G. K. Moore

358. M. L. Moore

359. T. D. Moore

360. O. B. Morgan

361. P. Morgan

362. G. W. Morris

363. J. L. Morris

364. L. J. Morris 
365

366. T. R. Morrison

367. C. M. Morrissey

368. P. J. Mulholland

369. M. Mumby

370. J. G. Mural

371. L. C. Musson

372. M. T. Naney

373. G. E. Napolitano

374. R. Nativ

375. D. A. Neergaard

376. T. R. Nelson

377. K. A. Newman

378. S. L. Niemela

379. D. E. Nivens

380. R. J. Norby

381. J. E. Nyquist

382. R. O'Brien

383. P. M. O'Connell

384. M. L. Odom

385. D. H. Ogle

386. S. M. Ogle

387. F. M. O'Hara, Jr.

388. C. E. Oliver

389. R. J. Olson

390. B. C. O'Neal

391. E. G. O'Neill

392. R. V. O'Neill

393. J. G. Owens

394. J. G. Paar

395. M. J. Palmer

396. A. V. Palumbo

397. P. D. Parr

399. J. A. Payne

400. S. M. Pearson

401. B. S. Pedersen

402. M. R. Pelton

403. T.-H. Peng

404. M. J. Peterson

405. R. B. Petrie

406. S. M. Pfiffner

407. T. J. Phelps

408. C. B. Phillips

409. T. D. Phillips

410. T. L. Phipps

411. P. A Pier

412. M. Plaza
413. C. M. Poole

414. W. T. Pope

415. K. L. Popham

416. S. Y. Porter

417. M. Post

418. W. J. Pottorf

419. L. R. Pounds

420. M. L. Poutsma

421. P. M. Presley

422. D. Price

423. D. J. Pridmore

424. B. R. Primm

425. C. E. Pugh

426. C. ${ }^{r}$. ains

427. W A. Ramsey

428. J. W. Ranney

429. C. D. Rash

430. B. Rashleigh

431. S. M. Ratnayeke

432. C. B. Ravina

433. D. K. Reece

434. O. C. Reedy

435. F. R. Reeves

436-439. D. E. Reichle

440. A. Renshaw

441. D. D. Rhew

442. J. L. Rich

443. C. R. Richmond

444. J. E. Richmond

445. J. S. Riggs

446. C. T. Rightmire

447. K. H. Riitters

448. D. B. Ringelberg

449. L. E. Roberson

450. J. B. Roberto

451. A. L. Roberts

452. G. T. Roberts

453. D. C. Rogers

454. P. C. Rohde

455. W. H. Romme

456. M. J. Rooks

457. K. A. Rose

458. B. A. Rosensteel

459. M. W. Rosenthal

460. B. M. Ross

461. T. H. Row

462. K. Roy 


\begin{tabular}{|c|c|}
\hline 63. & C. D. Runck \\
\hline 464. & P. F. Ryan \\
\hline 465. & M. G. Ryon \\
\hline 466. & R. E. Sain \\
\hline 467. & M. J. Sale \\
\hline 468. & M. S. Salk \\
\hline 469. & M. J. Saltmarsh \\
\hline 470. & B. E. Sample \\
\hline 471. & W. E. Sanford \\
\hline 472. & G. G. Santore \\
\hline 473. & E. R. Saouter \\
\hline 474. & T. K. Sawyer \\
\hline 475. & G. S. Sayler \\
\hline 476. & S. P. Scarborough \\
\hline 477. & P. Scarbrough \\
\hline 478. & W. H. Schacher \\
\hline 479. & E. M. Schilling \\
\hline 480. & D. Schmoyer \\
\hline 481. & W. E. Schramm \\
\hline 482. & A. B. Schwab \\
\hline 483. & K. E. Seedhouse \\
\hline 484. & J. L. Seiber \\
\hline 485. & W. J. Selvidge \\
\hline 486. & R. J. Sepanski \\
\hline 487. & J. A. Shaakir-Ali \\
\hline 488. & S. H. Shakir \\
\hline 489. & S. K. Sharp \\
\hline 490. & F. E. Sharples \\
\hline 491. & J. A. Shaulis \\
\hline 492. & L. K. Shaw \\
\hline 493. & J. Sheffield \\
\hline 494. & R. B. Shelton \\
\hline 495. & D. E. Shepherd \\
\hline 496. & J. S. Short \\
\hline 497. & D. S. Shriner \\
\hline 498. & R. G. Shropshire \\
\hline 499 & L. R. Shugart \\
\hline 500 & W. D. Shults \\
\hline 501. & D. J. Shure \\
\hline 502. & R. J. Siegrist \\
\hline 503. & L. L. Sigal \\
\hline 504. & C. F. Sigmon \\
\hline 505 & D. E. Sill \\
\hline 50 & C. S. Sims \\
\hline $50^{\prime}$ & P. T. Singley \\
\hline 50 & E. D. Smith \\
\hline & E. P. Smith \\
\hline
\end{tabular}

510. I. M. Smith

511. J. G. Smith

512. K. R. Smith

513. R. Smith

514. C. Solis

515. G. R. Southworth

516. B. P. Spalding

517. J. Stair

518. T. M. Stamm

519. R. G. Stansfield

520. T. J. Stephens

521. E. A. Stetar

522. R. T. Stevens

523-527. A. J. Stewart

528. K. L. Stewart

529. J. O. Stiegler

530. C. A. Stiles

53i. A. T. Stone

532-556. F. W. Stoss

557. S. H. Stow

558. W. Stratton

559. J. M. Strong-Gunderson

560. L. M. Stubbs

561. P. L. Sullenberger

562. J. Summers

563. J. R. Sumner

564. G. W. Suter

565. J. H. Swanks

566. J. Switek

567. T. A. Tabberer

568. D. L. Taylor

569. G. L. Taylor

570. C. W. Theodorakis

571. A. L. Thomas

572. P. F. Thomas

573. B. K. Thompson

574. S. P. Timmins

575. M. E. Timpson

576. K. L. Tipton

577. D. E. Todd

578. M. L. Todd

579. V. R. Tolbert

580. T. L. Toomey

581. L. E. Toran

582. J. R. Trabalka

583. C. C. Trettin

584. T. J. Tschaplinski 
585. J. G. Tuggle

586. K. M. Turnage

587. M. G. Turner

589. R. R. Turner

590. R. S. Turner

591. T. D. Turner

592. G. A. Tuskan

593. J. A. Tyler

594. R. L. Van Hook

595. J. E. Van Winkle

596. W. V. Van Winkle

597. T. V. Vann

598. L. D. Voorhees

599. R. S. Vose

600. B. A. Wade

601. R. O. Wadlington

602. D. S. Walker

603. J. S. Walker

604. L. L. Wallace

605. B. T. Walton

606. Y.C Wang

607. R. C. Ward

608. D. A. Waters

609. D. R. Watkins

610. J. A. Watts

611. O. F. Webb

612. W. Webb

613. S. L. Webster

614. D. C. West

615. O. R. West

616. D. C. White

617. T. W. White

618. J. T. Whitehead

619. L. F. Wicker
620. R. V. Wilkerson

621. W. S. Wilkerson

622. E. Will

623. R. T. Williams

624. A. D. Wilson

625. C. L. Wilson

626. G. V. Wilson

627. P. L. Wilson

628. R. Wimmer

629. R. F. Winterfield

630. S. L. Winters

631. K. A. With

632. J. A. Wojtowicz

633. M. H. Wolfe

634. M. A. Wood

635. M. N. Wood

636. L. L. Wright

637. S. B. Wright

638. S. G. Wright

639. T. Y. Wright

640. S. D. Wullschleger

641. C. L. Wylie

642. S. C. Young

643. T. G. Yow

644. T. F. Zondlo

645. J. L. Zutman

646. Central Research Library

647. ER Document Management Center

648-802. ESD Library

803-804. Laboratory Records Dept.

805. Laboratory Records

806. ORNL Patent Office

807. Y-12 Technical Library 


\section{External Distribution}

808. A. S. Abdul, Environmental Sciences Department, Box 9055, 6 M Research Labs, 30500 Mount Road, Warren, MI 48090-9055

809. V. D. Adams, Director, Center for the Management Utilization and Protection of Water Resources, Tennessee Technological University, Box 5082, Cookeville, TN 38505

810. W. D. Adams, Federal Building, Room 3013, U.S. Department of Energy, Oak Ridge, TN 37831

811. J. Allsup, Office of Alternative Fuels, CE33, U.S. Department of Energy, Washington, DC 20585

812. F. Andersson, Swedish Coniferous Forest Project, Department of Ecology and Environmental Research, Swedish University of Agricultural Sciences, P.O. Box S-750 07, Uppsala, SWEDEN

813. K. Andrasko, Office of Policy Analysis, U.S. Environmental Protection Agency, 401 M Street SW, PM-221, Washington, DC 20460

814. R. H. Annan, U.S. Department of Energy, Solar Thermal and Biomass Power Division, DOE CE-132, Room 5F-81, 1000 Independence Avenue SW, Washington, DC 20585

815. R. Ball, U.S. Department of Energy, Office of Environmental Analysis, EP-63, 1000 Independence Avenue SW, Washington, DC 20585

816. J. Barkenbus, Director, Energy, Environment, and Resources Center, The University of Tennessee, 327 South Stadium Hall, Knoxville, TN 37996

817. A. Bartuska, Program Staff, USDA-Forest Service, Forest Environment Research, USFS, Washington, DC 20090

818. J. Bascietto, Office of Environmental Guidance, U.S. Department of Energy, 1000 Independence Avenue, Washington, DC 20585

819. K. Baun, AGR/St/USAID, Room 403 D, SA-18, Washington, DC 20523

820. D. Bear, 4019 18th Street NW, Washington, DC 20011

821. B. L. Bedford, Ecosystems Research Center, 105 Wing Hall, Cornell University, Ithaca, NY 14853

822. L. Bell, The University of Tennessee, EERC, 327 S. Stadium Hall, Knoxville, TN 37996

823. D. A. Bennett, U.S. Environmental Protection Agency, RD 680, 401 M Street SW, Washington, DC 20460

824. C. W. Berish, U.S. Environmental Protection Agency, Region IV, 345 Courtland Street NE, Atlanta, GA 30365

825. R. P. Berube, Deputy Assistant Secretary for Environment, EH-20, U.S. Department of Energy, Washington, DC 20585

826. R. Bierbaum, Executive Office of the President, Office of Science and Technology Policy, Washington, DC 20500

827. J. B. Birk, Electric Power Research Institute, P.O. Box 10412, Palo Alto, CA 94303

828. B. Bolin, Department of Meteorology, University of Stockholm, S-106 91, Stockholm, SWEDEN 
829. C. M. Borgstrom, Director, Office of NEPA Oversight, EH-25,

U.S. Department of Energy, Washington, DC 20585

830. C. E. Bradley, Jr., Office of Operations and Facility Reliability, NE-33, Room A-184, U.S. Department of Energy, 19901 Germantown Road, Germantown, MD 20874

831. D. T. Bradshaw, Tennessee Valley Authority, Research and Development, 3N 71A Missionary Ridge Place, 1101 Market Street, Chattanooga, TN 37402-2801

832. B. Breed, U.S. Department of Energy, Office of Environmental Analysis/EP-63, 1000 Independence Avenue SW, Washington, DC 20595

833. W. S. Broecker, Lamont-Doherty Geological Observatory, Columbia University, Palisades, NY 10964

834. R. Brooks, Water Resources, Tennessee Valley Authority, Knoxville, TN 37996

835. P. Brookshire, Idaho Operations Office, U.S. Department of Energy, 785 DOE Place, Idaho Falls, ID 83402

836. D. L. Bunting, Graduate Program in Ecology, The University of Tennessee, Knoxville, TN 37996-1610

837. G. Burch, U.S. Department of Energy, 1000 Independence Avenue SW, Washington, DC 20585

838. H. T. Burn, Technical Librarian, ORUSE/MERT, Oak Ridge, TN 37831

839. J. Cairns, Center for Environmental Studies, Virginia Polytechnic Institute and State University, Blacksburg, VA 24061

840. J. Thomas Callahan, Associate Program Director, Ecosystem Studies Program, Room 336, 1800 G Street NW, National Science Foundation, Washington, DC 20550

841. C. Chambers, 1205 Avenue Drive Penfield, Department of Biology, McGill University, Montreal, Quebec, CANADA H3A 1B1

842. D. F. Charles, U.S. Environmental Protection Agency, 200 SW 35th Street, Corvallis, OR 97333

843. N. Christenson, Dean, School of the Environment, Duke University, Durham, NC 27706

844. R. Clark, Council on Environmental Quality, Executive Office of the President, 722 Jackson Place NW, Washington, DC 20503

845. D. W. Cole, College of Forest Resources, University of Washington, Seattle, WA 98105

846. W. E. Colglazier, Office of International Affairs, National Academy of Sciences, 2102 Constitution Avenue, Washington, DC 20418

847. R. R. Colwell, Director, Maryland Biotechnology Institute, Microbiology Building, University of Maryland, College Park, MD 20742

848. Commander and Director, USAE Waterways Experiment Station, ATTN: CEWES-IM-MI-R, Alfrieda S. Clark, CD Department \#1067, 3909 Halls Ferry Road, Vicksburg, MS 39180-6199

849. R. Conway, 14th and Independence SW, Room 144E Administration Building, Washington, DC 20250-266

850. W. E. Cooper, Department of Zoology, College of Natural Sciences, Michigan State University, East Lansing, MI 48824 
851. R. Costello, U. S. Department of Energy, Biofuels Systems Division, 1000 Independence Avenue SW, Washington, DC 20585

852. P. A. Covich, 202 Sutton Hall, Zoology Department, University of Oklahoma, Norman, OK 73019

853. J. H. Cowan, Chesapeake Biological Laboratory, University of Maryland, Solomons, MD 20688

854. C. E. Cushing, Ecosystems Department, Battelle-Northwest Laboratories, Richland, WA 99352

855. R. C. Dahlman, Environmental Sciences Division, Office of Health and Environmental Rescarch, U.S. Department of Energy, ER-74, Washington, DC 20585

856. D. H. Dawson, P.O. Box 1321, Rhinelander, WI 54501

857. J. F. Decker, Office of Energy Research, U.S. Department of Energy, Washington, DC 20585

858. H. Delcourt, Geography Department, 408 G\&G Building, The University of Tennessee, Knoxville, TN 37996-1420

859. Director, Life Sciences Division, NASA, Federal Building No. 6, 600 Maryland Avenue SW, Washington, DC 20546

860. J. Eaton, Environmental Research Laboratory-Duluth, 6201 Congdon Boulevard, Duluth, MN 55804

861. J. A. Edmonds, Battelle-Pacific Northwest Laboratory, 2030 M Street NW, Washington, DC 20036

862. T. H. Ellis, Director, Southern Forest Experiment Station, T-10210, U.S. Postal Service Building, 701 Loyola Avenue, New Orleans, LA 70113

863. T. Elston, 212 N. Purdue Avenue \#303, Oak Ridge, TN 37830

864. J. W. Elwood, Environmental Sciences Division, Office of Health and Environmental Research, U.S. Department of Energy, ER-74, Washington, DC 20585

865. R. N. Farvolden, Professor, Department of Earth Sciences, University of Waterloo, Waterloo, Ontario N2L 3G1 CANADA

866. J. E. Ferrell, Biofuels Systems Division, CE-331 Forrestal Building, U.S. Department of Energy, Washington, DC 20585

867. M. Finger, Librarian, Meteorology Department, University of Melbourne, Parkville Victoria AUSTRALIA 3052

868. P. Firth, National Science Foundation, 1800 G. Street NW, Room 305, Washington, DC 20550

869. J. V. Flynn, U.S. Department of Energy, Division Geothermal \& Hydropower Technology, CE-324, 1000 Independence Avenue SW, Room 5F-035B, Washington, DC 20585

870. G. Foley, Acting Assistant Administrator, Office of Research and Development, U.S. Environmental Protection Agency, RD-680, 40 M Street SW, Washington, DC 20460

871. J. Foss, Department of Plant and Soil Science, The University of Tennessee, Knoxville, TN 37996

872. R. Fox, Booneville Power Administration, P.O. Box 3621, Portland, OR 97208 
873. S. A. Fox, USDA Forest Service, 1509 Varsity Drive, Raleigh, NC 27606

874. J. F. Franklin, Bloedel Professor of Ecosystem Analysis, College of Forest Resources, University of Washington, Anderson Hall (AR-10), Seattle, WA 98195

875. D. Friedman, Hazardous Waste Management Division (WH-565), Office of Solid Waste, U.S. Environmental Protection Agency, 401 M Street SW, Washington, DC 20460

876. R. M. Friedman, Office of Technology Assessment, U.S. Congress, 600 Pennsylvania Avenue SE, 4th Floor, Washington, DC 20003

877. I. Y-S. Fung, NASA Goddard Space Flight Center, 2880 Broadway, New York, NY 10025

878. A. M. Georges, Legislative Assistant, U.S. House of Representatives, Congressman David R. Obey, 7th District, Wisconsin, 2462 Rayburn Building, Washington, DC 20515

879. J. H. Gibbons, Director, Office of Science and Technology Policy, Executive Office of the President, Washington, DC 20506

880. B. Glaze, Director, Department of Environmental Sciences and Engineering, School of Public Health, Box 7400, 105 Rosen Avenue Hall (MNC), Chapel Hill, NC 27599

881. R. A. Goldstein, Ecological Studies Program, Electric Power Research Institute, 3412 Hillview Avenue, P.O. Box 10412, Palo Alto, CA 94303

882. J. R. Gosz, Biology Department, University of New Mexico, Albuquerque, NM 87131

883. P. E. Greeson, Assistant Regional Hydrologist, U.S. Geological Survey, R. B. Russell Federal Building, 75 Spring Street SW, Suite 772, Atlanta, GA 30303

884. S. Gronich, U.S. Department of Energy, CE-132, 5H-059, Forrestal Building, 1000 Independence Avenue SW, Washington, DC 20585

885. T. J. Gross, Environmental Sciences Division, Office of Health and Environmental Research, U.S. Depariment of Energy, ER-74, Washington, DC 20585

886. T. J. Gross, Office of Transportation Technologies, U.S. Department of Energy, CE-30, Forrestal Building, Washington, DC 20585

887. Y. Y. Haimes, Department of Systems Engineering, University of Virginia, Charlottesville, VA 22901

888. T. G. Hallam, Professor of Mathematics, Department of Mathematics, The University of Tennessee, 121 Ayers Hall, Knoxville, TN 37996-1300

889. T. E. Hamilton, Associate Deputy Chief, U.S. Department of Agriculture Forest Service, 14th Street SW, Washington, DC 20250

890. C. Hardin, Geography Department, 408 G\&G Building, The University of Tennessee, Knoxville, TN 37996-1420

891. L. Harris, USDA, U.S. Forest Service, Agricultural Research Service, BARC-W, Building 005, Room 236, Beltsville, MD 20705

892. M. H. Harris, Federal Building, Department of Energy, Oak Ridge, T\} 3 7 8 3 1

893. W. F. Harris, Director, Division of Biology, The University of Tennessee, M-303, Walters Life Sciences Building, Knoxville, Tennessee 37996-0830 
894. J. Harrison, Chief, Environmental Laboratory, Waterways Experiment Station, P.O. Box 631, Vicksburg, MS 39180

895. R. C. Harriss, Institute for the Study of Earth, Oceans, and Space, Science and Engineering Rescarch Building, University of New Hampshire, Durham, NH 03824

896. A. D. Hecht, Office of International Activities, U.S. Environmental Protection Agency, $401 \mathrm{M}$ Street SW, Washington, DC 20460

897. G. R. Hendrey, Brookhaven National Laboratory, Building 318, Upton, Long Island, NY 11973

898. G. D. Hertel, 5 Radnor Corporate Center, Suite 200, 100 Matsonfor Road, Radnor, PA 19087

899. J. E. Hobbie, The Ecosystems Center, Marine Biological Laboratory, Woods Hole, MA 02543

900. T. Hoekstra, Assistant Director for Research, North Central Forest Experiment Station, USFS, 1992 Folwell Avenue, St. Paul, MN 55108

901. J. S. Hoffman, Energy Policy Division, 432-W, PM-221, U.S. Environmental Protection Agency, 401 M Street NW, Washington, DC 20460

902. M. Holland, U.S. Environmental Protection Agency, USEPA/AREAC, Research Tringle Park, NC 27711

903. S. Horn, Geography Department, 408 G\&G Building, The University of Tennessee, Knoxville, TN 37996-1420

904. G. M. Hornberger, Professor, Department of Environmental Sciences, University of Virginia, Charlottesville, VA 22903

905. S. Hossein, Division of Nuclear Fuel Cycle and Waste Management, International Atomic Energy Agency, Wagramerstrasse 5, P.O. Box 100, A-1400, Vienna, AUSTRIA

906. J. W. Huckabee, Program Manager, Ecological Studies Program, Electric Power Research Institute, 3412 Hillview Avenue, P.O. Box 10412, Palo Alto, CA 94303

907. C. F. Ide, Director, Bioenvironmental Institute for Science, Engineering, and Public Policy, 604 Boggs Hall, Tulane University, New Orleans, LA 70118-5698

908. A. C. Janetos, NASA (Code SEL), 600 Independence Avenue SW, Washington, DC 20460

909. P. G. Jarvis, Department of Forestry and Natural Resources, University of Edinburgh, Edinburgh, EH9 3JU, Scotland, UNITED KINGDOM

910. B. D. Jimenez, Department of Pharmaceutical Science, School of Pharmacy, University of Puerto Rico, Medical Sciences Campus, GPO Box 5067, San Juan, PUERTO RICO 00936

911. J. Johansen, Department of Radioecology, Swedish University of Agricultural Sciences, Uppsala, SWEDEN

912. D. W. Johnson, Biological Sciences Center, Desert F.esearch Institute, P.O. Box 60220, Reno, NV 89506-0220

913. G. Y. Jordy, Director, Office of Program Analysis, Office of Energy Research, ER-30, G-226, U.S. Department of Energy, Washington, DC 20545

914. C. D. Jorgensen, Environmental Sciences Division, ER-74, Office of Health and Environmental Research, U.S. Department of Energy, Washington, DC 20585 
915. P. Kearl, Oak Ridge National Laboratory, Grand Junction Office, P.O. Box 2567, Grand Junction, CO 81502

916. H. Kibby, U.S. Environmental Protection Agency, Environmental Research Laboratory, 200 S.W. 35th Street, Corvallis, OR 97330

917. E. H. Kim, Assistant Professor, Kookmin University, College of Forestry, Department of Forest Resources, 861-1 Congnung-Dong, Songbuk-Ku, Seoul 136-702, REPUBLIC OF KOREA

918. E. S. Kim, Assistant Professor, Kookmin University, College of Forestry, Department of Forest Resources, 861-1 Chongnung-Dong, Songbuk-Ku, Seoul 136-702, REPUBLIC OF KOREA

919. V. Kishore, Professor and Chairman, Division of Basic Pharmaceutical Sciences, Xavier University of Louisiana, College of Pharmacy, 7325 Palmetto Street, New Orleans, LA 70125

920. M. Kleinrock, Environmental Compliance Division, EM-22, U.S. Department of Energy, Washington, DC 20585

921. N. E. Korte, Oak Ridge National Laboratory, Grand Junction Office, P.O. Box 2567, Grand Junction, CO 81502

922. S. L. Krugman, Director, USDA Forest Service, Timber Management Research, P.O. Box 2417, Washington, DC 20013

923. F. Kutz, U.S. Environmental Protection Agency, Office of Research and Development, RD-682, 401 M Street SW, Washington, DC 20460

924. A. Laase, Oak Ridge National Laboratory, Grand Junction Office, P.O. Box 2567, Grand Junction, CO 81502

925. R. T. Lackey, U.S. Environmental Protection Agency, Environmental Research Laboratory, 200 S.W. 35th Street, Corvallis, OR 97333

926. V. E. Lee, Program Coordinator, Office of Research, Tulane University, New Orleans, LA 70118-5645

927. J. Leggett, U.S. Environmental Protection Agency, 401 M Street SW, PM 221, Washington, DC 20460

928. S. A. Levin, Ecology and Systematics Department, Cornell University, Ithaca, NY 14850

929. Library, Bureau of Sport Fisheries and Wildlife, U.S. Department of the Interior, Washington, DC 20240

930. Library, Great Lakes Fishery Laboratory, U.S. Bureau of Sport Fisheries and Wildlife, Ann Arbor, MI 49904

931. Library, National Institute of Science Technology and Development Studies, New Delhi, INDIA 110012

932. Library, U.S. Department of the Interior, Fish and Wildlife Service, National Ecology Research Center, 4512 McMurray Avenue, Fort Collins, CO 80525-3400

933. G. E. Likens, Director, The New York Botanical Garden, Institute of Ecosystem Studies, The Mary Flagler Cary Arboretum, Box AB, Millbrook, NY 12545

934. R. D. Lindmark, Director, U.S. Forest Service, North Central Forest Experiment Station, 1992 Folwell Avenue, St. Paul, MN 55108

935. R. A. Linthurst, U.S. Environmental Protection Agency, MD-39, EPA/EMSL (Annex), Research Triangle Park, NC 27711 
936. J. Loney, Manager of Environmental Affairs, Resource Development, OCH ID 57E, Tennessee Valley Authority, Knoxville, TN 37902

937. R. R. Loose, U.S. Department of Energy, 1000 Independence Ave. SW, Room 5H-095 (CE-121), Office of Renewable Energy Technology, Washington, DC 20585

938. O. L. Loucks, Professor of Zoology, Department of Zoology, Biological Sciences Building, Miami University, Oxford, OH 45056

939. P. Lunn, U.S. Department of Energy, Environmental Sciences Division, Office of Health and Environmental Research, ER-74, Washington, DC 20585

940. W. Luth, ER-15, U.S. Department of Energy, G-357, Germantown, MD 20585

941. M. C. MacCracken, Office of the U.S. Global Change Research Program, 300 D Street SW, Suite 840, Washington, DC 20024

942. E. A. Marschall, Department of Zoology, North Carolina State University, Raleigh, NC 27695-7617

943. J. S. Mattice, Electric Power Research Institute, P.O. Box 10412, 3412 Hillview Avenue, Palo Alto, CA 94303

944. H. M. McCammon, Environmental Sciences Division, Office of Health and Environmental Research, Office of Energy Research, ER-74, U.S. Department of Energy, Washington, DC 20585

945. F. McCormick, Graduate Program in Ecology, The University of Tennessee, Knoxville, TN 37996

946. R. D. McCoy, Tennessee Department of Environment and Conservation, 761 Emory Valley Road, Oak Ridge, TN 37830-7072

947. T. V. McEvilly, Chairman, Department of Geology and Geophysics, University of California, Berkeley, CA 94720

948. K. McGinty, Office of Environmental Policy, Room 360, The Old Executive Office Building, Washington, DC 20501

949. A. David McKinney, Tennessee Department of Health and Environment, 1522 Cherokee Trail, Knoxville, TN 37920

950. R. I. McLean, Administrator, Radioecological Assessments, Power Plant Siting Program, Maryland Department of Natural Resources, Towes State Office Building, Annapolis, MD 21401

951. H. Y. McSween, Professor and Head, Department of Geological Sciences, The University of Tennessee, 306 G\&G Building, Knoxville TN 37996-1410

952. J. M. Melillo, The Ecosystems Center, Marine Biological Laboratory, Woods Hole, MA 02543

953. R. Menzel, Department of Agriculture, Water Quality and Watershed Research Laboratory, P.O. Box 1430, Durant, OK 74702

954. J. Messer, U.S. Environmental Protection Agency, MD-39, EPA/EMSI (Annex), Research Triangle Park, NC 27711

955. A. Miller, Director, Federal Agency Liaison Division, Office of Federal Activities (A-104), U.S. Environmental Protection Agency, Washington, DC 20460

956. C. P. Miller, University of Aberdeen, Scotland, Department of Forestry, Wood Supply Research Group, Street Machar Drive, Aberdeen AB9 2UD, UNITED KINGDOM 
957. H. G. Miller, The Macauley Institute for Soil Research, Craigiebuckler, Aberdeen AB9 2QJ, Scotland, UNITED KINGDOM

958. L. Miller, Office of Clean Coal Technology, U.S. Department of Energy, Forrestal Building, Washington, DC 20585

959. R. J. Millington, Division of Land Use Research, CSIRO, P.O. Box 109, Canberra City, ACT 2601 AUSTRALIA

960. F. J. Molz, Department of Civil Engineering, Auburn University, Auburn, AL 36830

961. J. Montgomery, Office of Federal Activities (A-104), U.S. Environmental Protection Agency, Washington, DC 20460

962. H. A. Mooney, Department of Biological Sciences, Stanford University, Stanford, CA 94305

963. B. Moore III, Complex Systems Research Center, Science and Engineering Building, College Road, University of New Hampshire, Durham, NH 03824

964. R. Moorer, U.S. Department of Energy, Office of Transportation Technology, CE-341, 1000 Independence Avenue, Washington, DC 20585

965. National Library of Medicine, TSD/Serial Records, Building 38, Room B1W-10, 8600 Rockville Pike, Bethesda, MD 20209

966. J. Nilsson, Statens Naturvardsverk (SNV), National Environmental Protection Board, Department of Research and Development, Box 1302, S-171 25 Solna, SWEDEN

967. S. C. Nodvin, National Park Service-CPSU, Department of Forestry, Wildlife, and Fisheries, P.O. Box 1071, The University of Tennessee, Knoxville, TN 37901-1071

968. K. Nuhfer, Westinghouse Environmental Management Company, 7400 Wiley Road, Fernald, OH 45030

969. S. E. O'Conner, Director of Environmental Programs, Professor of Chemistry, 7325 Palmetto Street, P.O. Box 45 B, New Orleans, LA 70125-1098

970. Office of Assistant Manager for Energy Research and Development, U.S. Department of Energy Oak Ridge Operations, P.O. Box 2001, Oak Ridge, TN 37831-8600

971. C. R. Olsen, 10101 Grosvenor Place, Apt. 116, Rockville, MD 20852

972. R. H. Olsen, Vice President for Research, University of Michigan, Medical Science Building II, \#5606, 1303 East Catherine Street, Ann Arbor, MI 48109

973. D. M. Olszyk, Statewide Air Pollution Research Laboratory, University of California, Riverside, CA 92521

974. W. S. Osburn, Jr., Environmental Sciences Division, Office of Health and Environmental Research, Office of Energy Research, MS-E201, EV-33, Room F-216, U.S. Department of Energy, Washington, DC 20545

975. D. G. Page, Room 2115, Federal Office Building, P.O. Box 2001, Oak Ridge, TN 37831

976. Dr. C. Papastefanou, Aristotle University of Thessaloniki, Nuclear Physics Department, Thessaloniki 540 \%6 GREECE

977. F. L. Parkrr, College of Engineering, Institute of Water Resources, Vanderbilt University, Nashville, TN 37325

978. D. F. Parkhurst, Indiana University, Bloomington, IN 47401 
979. W. J. Parton, Natural Resources Ecology Laboratory, Colorado State University, Fort Collins, CO 80523

980. A. Patrinos, Acting Director, Office of Health and Environmental Research, ER-74, U.S. Department of Energy, Washington, DC 20585

981. D. Peck, U.S. Geological Survey, Federal Building, Nashville, TN 37203

982. J. Peine, U.S. Department of the Interior, Uplands Field Research Laboratory, Twin Creeks Area, Great Smoky Mountains National Park, Gatlinburg, TN 37738

983. R. Pelletier, Office of Environmental Guidance, U.S. Department of Energy, EH-23, Washington, DC 20585

984. C. H. Pennington, Waterways Habitat and Monitoring Group, Waterways Experiment Station, P.O. Box 631, Vicksburg, MS 39180

985. R. Perhac, Electric Power Research Institute, P.O. Box 10412, Palo Alto, CA 94303

986. L. Petrakis, Chairman, Department of Applied Science, Brookhaven National Laboratory, Associated Universities, Inc., Upton, Long Island, NY 11973

987. C. W. Philpott, Station Director, Pacific Northwest Forest and Range Experiment Station, P.O. Box 3890, Portland, OR 97208

988. D. Piñero, Director, Center for Ecology, Universidad Nacional Autonoma de Mexico, Apartado Postal 20-364, 01000 MEXICO, D.F.

989. L. Pitelka, Electric Power Research Institute, P.O. Box 10412, Palo Alto, CA 94303

990. D. Porcella, Electric Power Research Institute, P.O. Box 10412, Palo Alto, CA 94303

991. S. Prestwich, EM-52, U.S. Department of Energy, Suite 400, 12800 Middlebrook Road, Germantown, MD 20874

992. F. Quinones, U.S. Geological Survey, 810 Broadway, Suite 500, Nashville, TN 37203

993. J. C. Randolph, Indiana University, Bloomington, IN 47401

994. G. D. Reed, Professor, Department of Civil Engineering, The University of Tennessee, 223 Perkins Hall, Knoxville, TN 37996-2010

995. C. A. Reilly, Director, Environmental Research Division, Argonne National Laboratory, 9700 Cass Avenue, Argonne, IL 60439

996. J. F. Reynolds, National Science Foundation, 1800 G Street NW, Washington, DC 20550

997. M. R. Riches, Acting Director, Environmental Sciences Division, Office of Health and Environmental Research, U.S. Department of Energy, ER-74, Washington, DC 20585

998. S. P. Riddle, Environmental Review Division, EW-91, Department of Energy, Oak Ridge Operations, P.O. Box 2001, Oak Ridge, TN 37831-8541

999. C. Riordan, U.S. Environmental Protection Agency, Environmental Processes and Effects Research, 401 M Street SW, RD-680, Washington, DC 20460

1000. P. G. Risser, President, Miami University, Oxford, OH 45056

1001. M. Roberts, Central Electricity Research Laboratories, Kelvin Avenue, Leatherhead, Surrey KT22 7SE, UNITED KINGDOM 
1002. D. Rodier, Office of Toxic Substances, Environmental Review Division, U.S. Environmental Protection Agency, 401 M Street SW, Washington, DC 20460

1003. W. H. Romme, Fort Lewis College, Durango, CO 81301

1004. H. Rosen, USDA/Forest Service, P.O. Box 96090 , Washington, DC 20090

1005. T. G. Rosswall, Executive Director, IGBP, IGBP Secretariat, Royal Swedish Academy of Sciences, S-10405 Stockholm, SWEDEN

1006. P. Roussopolis, Director, Southeastern Forest Experiment Station, U.S. Forest Service, P.O. Box 2680, Asheville, NC 28802

1007. M. R. Russell, The University of Tennessee, EERC, 327 S. Stadium Hall, Knoxville, TN 37996

1008. E. S. Rutherford, Chesapeake Biological Laboratory, Box 38, Solomons, MD 20688

1009. E. Rykiel, Jr., Department of Industrial Engineering, Texas A\& M University, College Station, TX 77843

1010. G. Saunders, Ecological Research Division, Office of Health and Environmental Research, Office of Energy Research, U.S. Department of Energy, Washington, DC 20545

1011. G. S. Sayler, The University of Tennessee, Center for Environmental Biotechnology, 10515 Research Drive, Knoxville, TN 37932

1012. R. Scott, Director, Office of Environmental Audit, EH-24, U.S. Department of Energy, 1000 Independence Avenue NW, Washington, DC 20585

1013. J. A. Sesco, Deputy Chief, Research, Forest Service-USDA, P.O. Box 96090, Washington, DC 20090-6090

1014. L. A. Shevenell, Nevada Bureau of Mines and Geology, MS-178, Reno, NV 89557-0088

1015. H. H. Shugart, Environmental Sciences Department, Clark Hall, University of Virginia, Charlottesville, VA 22903

1016. D. L. Shumway, Federal Energy Regulatory Commission, 825 North Capitol Street, Washington, DC 20426

1017. B. J. Shuter, Fisheries Research Section, Ontario Ministry of Natural Resources, Box 50000, Maple, Ontario L6A 1S9

1018. J. B. Smith, RCG/Hagler, Bailly, Inc., P.O. Drawer O, Boulder, CO 80306-1906

1019. M. H. Smith, Savannah River Ecology Laboratory, Drawer E, Aiken, SC 29801

1020. A. D. Solomon, U.S. Environmental Protection Agency, 200 SW 35th Street, Corvallis, OR 97333

1021. D. K. Solomon, Department of Geology and Geophysics, College of Mines and Earth Sciences, 717 WBB, Salt Lake City, UT 84112-1183

1022. C. Stalnaker, National Ecology Center, USFWS, 2627 Redwing Road, Fort Collins, CO 80526-2899

1023. A. D. Steinman, SFWMD, P.O. Box 24480, 3301 Gun Club Road, West Palm Beach, FL 33416

1024. B. R. Strain, Department of Botany, Duke University, Durham, NC 27708

1025. W. T. Swank, Coweeta Hydrologic Laboratory, Rt. 1, Box 216, Otto, NC 28763

1026. W. L. Templeton, Ecosystems Department, Battelle-Pacific Northwest Laboratory, ichland, WA 99352 
1027. The University of Tennessee Center for the Health Sciences Library, 800 Madison Avenue, Memphis, TN 38163

1028. W. A. Thomas, Director, Development \& Quality, Oak Ridge Institute for Science and Education, P.O. Box 117, Oak Ridge, TN 37830

1029. L. Thompson, Office of Environmental Compliance, EH-232, U.S. Department of Energy, Washington, DC 20585

1030. G. Tidwell, Administrator, Region IV, U.S. Environmental Protection Agency, 345 Courtland Street NE, Atlanta, GA 30365

1031. D. A. Tirpak, U.S. Environmental Protection Agency, Climate Change Division, 401 M Street SW, PM-221, Washington, DC 20460

1032. T. Traceski, Director, RCRA/CERCLA Division, Office of Environmental Guidance, EH-231, U.S. Department of Energy, Washington, DC 20858

1033. M. A. Travaglini, Federal Office Building, P.O. Box 2001, Oak Ridge, TN 37831

1034. B. Tschantz, Director, Water Resource Research Center, University of Tennessee, Knoxville, TN 37996

1035. J. H. Turnball, Electric Power Research Institute, Storage and Renewables Department, P.O. Box 10412, Palo Alto, CA 94303

1036. M. Unsworth, Director, Center for Analysis of Environmental Change, Oregon State University, 283 Weniger Hall, Corvallis, OR 97331-6511

1037. J. Vanderryn, Agency Director for Energy and Natural Resources, U.S. Agency for International Development, 1601 Kent Street, Washington, DC 20523-1811

1038. H. Van Miegroet, Utah State University, Department of Forest Resources, Logan, UT 84322-5215

1039. B. Vaughan, Office of University Relations, Battelle-Pacific Northwest Laboratory, Richland, WA 99352

1040. K. L. Von Damm, Department of Earth Sciences, University of New Hampshire, James Hall, Durham, NH 03824-3589

1041. F. H. Wagner, Ecology Center, Utah State University, Logan, UT 84322-5205

1042. A. Wallo, Director, Air, Water and Radiation Division, Office of Environmental Guidance, EH-232, U.S. Department of Energy, Washington, DC 20585

1043. D. J. Walukas, Director, Environmentally Conscious Manufacturing, National Center for Manufacturing Sciences, 900 Victors Way, Ann Arbor, MI 481081779

1044. W. L. Warnick, U.S. Department of Energy, Program Integration Analysis Division, Office of Energy Research, ER-32, G-226, Washington, DC 20545

1045. J. D. Weaver, USGS-WRD, 1013 N. Broadway, Knoxville, TN 37917

1046. C. Werner, Environmental and Energy Study Institute, $122 \mathrm{C}$ Street NW, Suite 700, Washington, DC 20001

1047. P. A. Werner, Director, Division of Biotic Systems and Resources, National Science Foundation, 1800 G Street NW, Washington, DC 20550

1048. D. C. White, 10515 Research Drive, Suite 300, Knoxville, TN 37932

1049. R. P. Whitfield, EM-40 U.S. Department of Energy, 100 Independence Avenue SW, Washington, DC 20585

1050. J. G. Wiener, Assistant Chief, Field Research Program, U.S. Department of the Interior, Fish and Wildlife Service, National Fisheries Contaminant Research Center, Route 1, Columbia, MO 65201 
1051. D. M. Wiffen, Technical Support Division, Office of Environmental Management, EM-35, U.S. Department of Energy, Washington, DC 20585

1052. T. M. L. Wigley, Professor, University Corporation of Atmosphere Research, OEIS, P.O. Box 3000, Boulder, CO 80307-3000

1053. R. E. Wildung, Associate Manager, Earth Sciences Department, Battelle-Pacific Northwest Laboratories, P.O. Box 999, Richland, WA 99352

1054. R. G. Wilhour, U.S. Environmental Protection Agency, Environmental Research Laboratory, Sabine Island, Gulf Breeze, FL 32561

1055. T. Williams, U.S. Department of Energy, Office of Environmental Analysis, EH-22, 1000 Independence Avenue SW, Washington, DC 20585

1056. G. V. Wilson, Department of Plant and Soil Science, The University of Tennessee Institute of Agriculture, 369 Ellington, Knoxville, TN 37901-1071

1057. D. Winstanley, Director, National Acid Precipitation Assessment Program, 722 Jackson Place, NW, Washington, DC 20506

1058. F. J. Wobber, Environmental Sciences Division, Office of Health and Environmental Research, ER-74, U.S. Department of Energy, Washington, DC 20585

1059. M. G. Wolman, The Johns Hopkins University, Department of Geography and Environmental Engineering, Baltimore, MD 21218

1060. R. Woodmansee, Natural Resources Ecology Laboratory, Colorado State University, Fort Collins, CO 80523

1061. G. M. Woodwell, Woods Hole Research Center, P.O. Box 296, Woods Hole, MA 02543

1062. K. S. Yearman, D\&R Office, Wausaukee, WI 54177

1063. M. Zeeman, Branch Chief, Office of Toxic Substances, Environmental Review Division, U.S. Environmental Protection Agency, 401 M Street SW, Washington, DC 20460

1064-1117. Given distribution as shown in DOE/OSTI-4500 under category UC-402, Environmental Sciences 

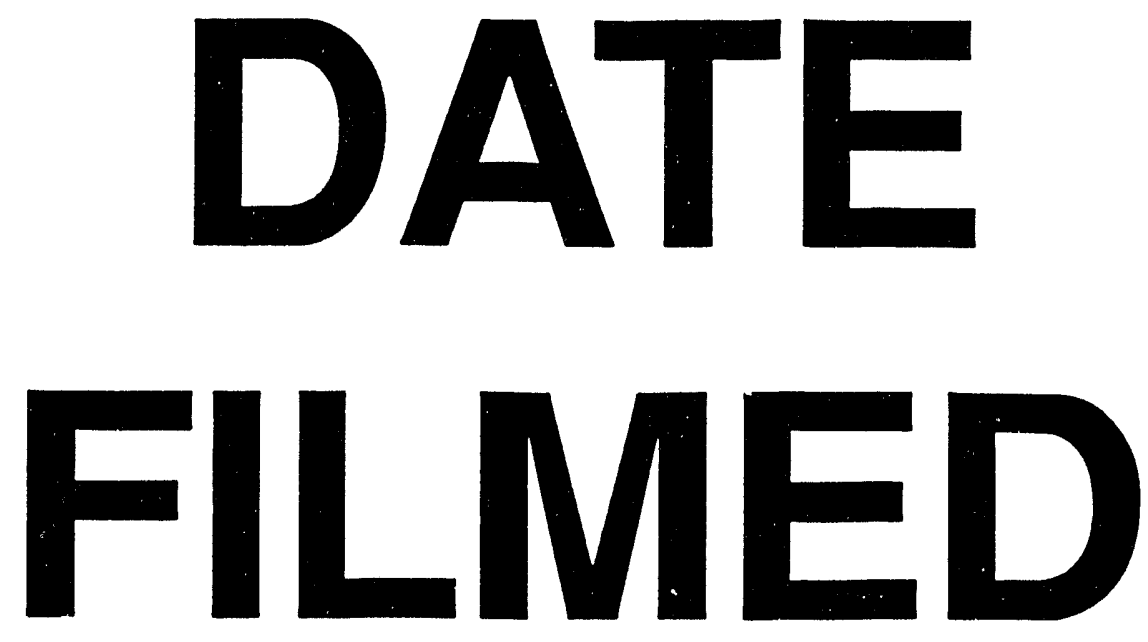

$8 / 25 / 94$
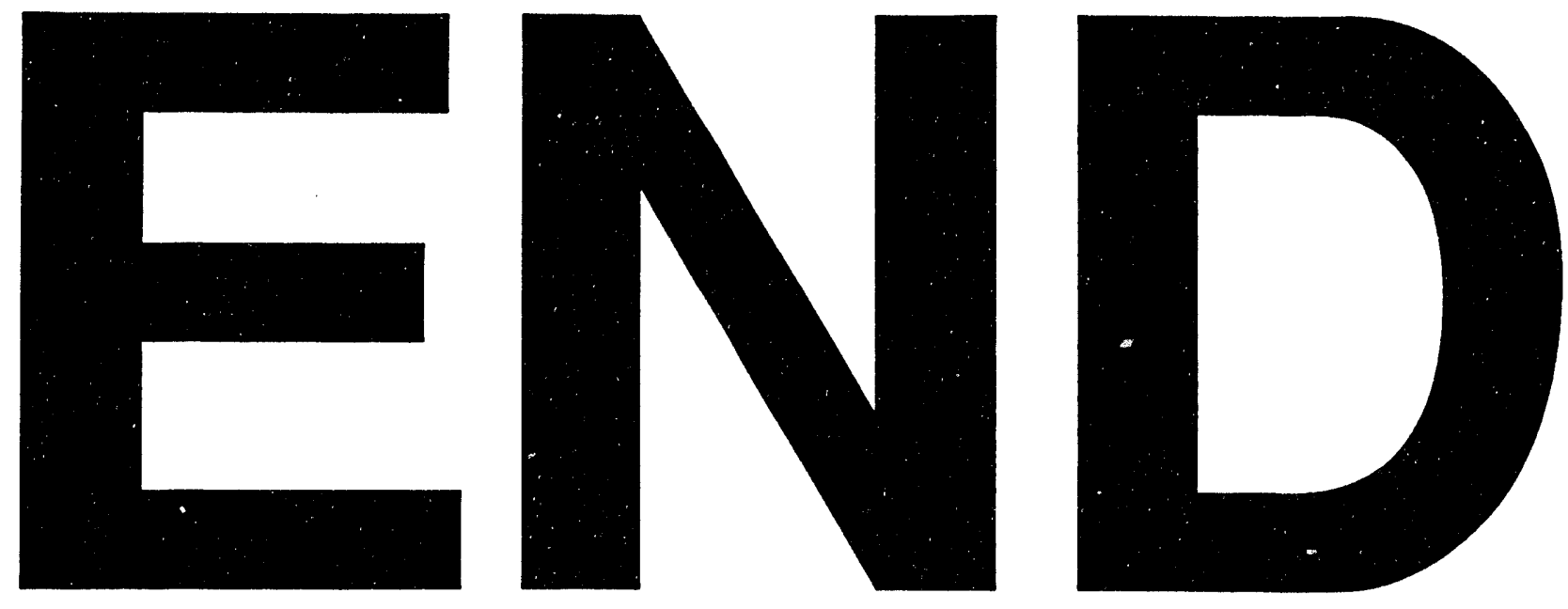


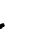

